\title{
Iminopyrrolidine Ligand Design and Novel Group Four Precursors for Chemical Vapour and Atomic Layer Deposition
}

\author{
by
}

Yamile Ana-Maria Wasslen

A thesis submitted to the Faculty of Graduate Studies and Research in partial fulfillment of the requirements for the degree of

Doctor of Philosophy

in

Inorganic Chemistry

Carleton University

Ottawa, Ontario

Canada

(C) 2010, Yamile Ana-Maria Wasslen 


$\begin{array}{ll}\begin{array}{l}\text { Library and Archives } \\ \text { Canada }\end{array} & \begin{array}{l}\text { Bibliotheque et } \\ \text { Archives Canada }\end{array} \\ \begin{array}{l}\text { Published Heritage } \\ \text { Branch }\end{array} & \begin{array}{l}\text { Direction du } \\ \text { Patrimoine de l'édition }\end{array} \\ \begin{array}{l}\text { 395 Wellington Street } \\ \text { Ottawa ON K1A ON4 } \\ \text { Canada }\end{array} & \begin{array}{l}395, \text { rue Wellington } \\ \text { Ottawa ON K1A ON4 } \\ \text { Canada }\end{array}\end{array}$

Your file Votre référence

ISBN: 978-0-494-70553-7

Our file Notre référence

ISBN: 978-0-494-70553-7

NOTICE:

AVIS:

The author has granted a nonexclusive license allowing Library and Archives Canada to reproduce, publish, archive, preserve, conserve, communicate to the public by telecommunication or on the Internet, loan, distribute and sell theses worldwide, for commercial or noncommercial purposes, in microform, paper, electronic and/or any other formats.

The author retains copyright ownership and moral rights in this thesis. Neither the thesis nor substantial extracts from it may be printed or otherwise reproduced without the author's permission.

L'auteur a accordé une licence non exclusive permettant à la Bibliothèque et Archives Canada de reproduire, publier, archiver, sauvegarder, conserver, transmettre au public par télécommunication ou par l'Internet, prêter, distribuer et vendre des thèses partout dans le monde, à des fins commerciales ou autres, sur support microforme, papier, électronique etou autres formats.

L'auteur conserve la propriété du droit d'auteur et des droits moraux qui protège cette thèse. $\mathrm{Ni}$ la thèse ni des extraits substantiels de celle-ci ne doivent être imprimés ou autrement reproduits sans son autorisation.
In compliance with the Canadian Privacy Act some supporting forms may have been removed from this thesis.

While these forms may be included in the document page count, their removal does not represent any loss of content from the thesis.
Conformément à la loi canadienne sur la protection de la vie privée, quelques formulaires secondaires ont été enlevés de cette thèse.

Bien que ces formulaires aient inclus dans la pagination, il n'y aura aucun contenu manquant.

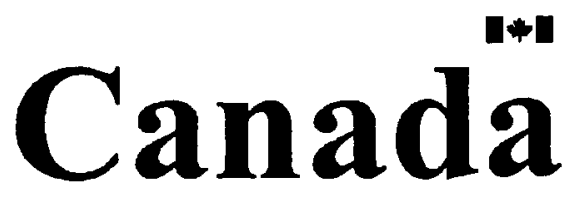




\begin{abstract}
Consistent downsizing of microelectronics due to Moore's law scaling of integrated circuits has pushed traditional design techniques to their micro-scale limitations. When approaching the nano-scale, the electrical properties of the widely used poly-silicon based metal-oxide-semiconductor field-effect transistor (MOSFET) change drastically and render the devices un-useable. For this reason, the development of new materials that maintain favourable electrical properties on a nano-scale, such as titanium, aluminum, and zirconium based metals, metal-nitrides and metal-oxides, have been of growing interest in research. Future circuit design will require an efficient means for controlled and uniform coating of ultra-thin films of next-generation microelectronic materials. Two interesting candidates for depositing thin films are atomic layer deposition (ALD) and chemical vapour deposition (CVD).

The ability to control the uniformity of thin films using ALD and CVD depends on locating effective precursors for deposition. An effective precursor should be thermally stable, volatile, chemically reactive and self-limiting. Compounds with guanidinate and amidinate ligands make promising precursors due to their facile tunability, their volatility and their self-limiting properties. In this work amidinate and guanidinate precursors for ALD and CVD are developed and characterized.

This work includes the synthesis of a novel iminopyrrolidine ligand and characterization to determine its potential as an ALD precursor ligand. The ligand showed thermal stability and a tunable melting point trend demonstrating potential as an effective ligand for ALD and CVD precursors. In addition, once the iminopyrrolidinate
\end{abstract}


ligand was reacted with aluminum and titanium species, tunable melting points were observed for the resulting metal containing precursor species, offering potential flexibility in ALD process design.

The synthesis and thermal chemistry of other novel heteroleptic titanium and zirconium species are also presented. The most promising precursors include the heteroleptic titanium +3 guanidinate and amidinate species for the deposition of $\mathrm{TiN} / \mathrm{TiO}_{2}$ films. One of the guanidinate species was chosen for an exposure experiment on high surface area silica to study and determine the precursor chemistry with respect to nucleation between titanium and the substrate. The novel heteroleptic zirconium species presented in this work demonstrated two different bonding arrangements within the guanidinate family. 


\section{Acknowledgements}

Firstly I would like to thank my supervisor, Dr. Seán Barry, for all the patience he showed me during my years in the lab. Thank you for the help you have given me during the writing of this thesis. I would like to thank the Barry group, past and present members, for the great times we had both in the lab and out. There were plenty of inspiring talks along with ample amounts of beer and laughs.

Thanks to everyone in the Steacie Building who has helped me along the way. Toni O'Neil and Keith Bourque for help with IR and NMR experiments. Peter Mosher for helping with TA organization and always giving me what I wanted. Susaritha Chandrabose and Tanya Rudd for helping me send off all my samples for further analysis. A special thanks to Susa for all the talks we had.

I would like to thank the girls from both Ottawa U and Carleton for the girl's nights out; book club included. I would like to take this opportunity to thank Claire Foottit and Kathy McGilvray, for being great friends. You girls were always there to lend a hand when needed and made gradschool less overwhelming. Thanks to my good friends Anahit and Phil for listening to all my complaints and the great talks we had.

Thank you to my family; mom (Ninfa), dad (Larry), and brothers (Nick and Karl) for being there for me since the beginning of this adventure. Your support and encouragement was appreciated and will always be remembered.

Lastly, I can not thank my husband, Jamie Gaudette, enough for being my central pillar. Your love, encouragement, understanding and eagerness to teach have made me strive to be a better person. 


\section{Table of Contents}

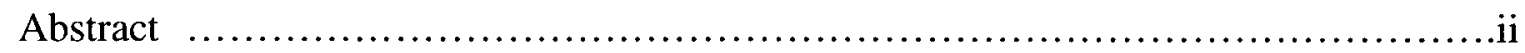

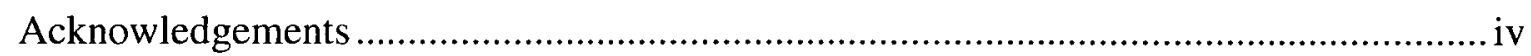

Table of Contents ..........................................................................................

List of Tables................................................................................................

List of Figures .............................................................................................

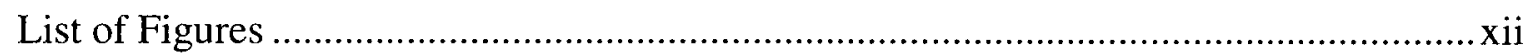

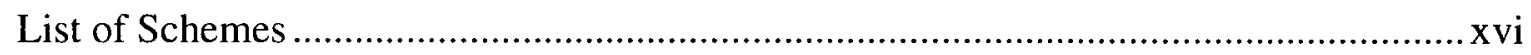

List of Appendices .....................................................................................

List of Abbreviations..................................................................................

List of Abbreviations....................................................................................... v viii

List of Publications .......................................................................................

\section{Chapter 1: Introduction}

Atomic Layer Deposition .................................................................. 1

$1.2 \quad$ Precursor Design .............................................................................. 7

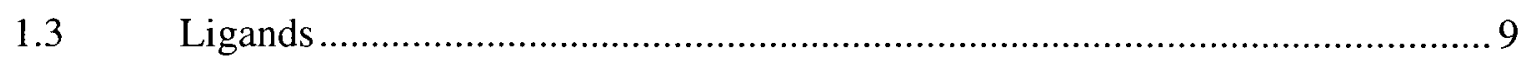

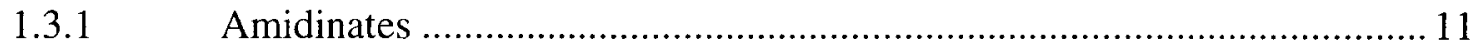

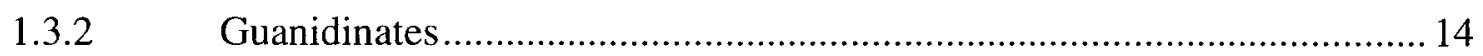

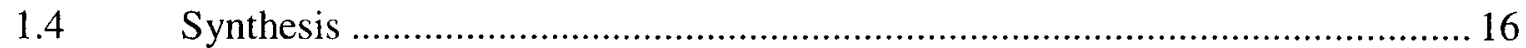

Thermal Characterization ................................................................... 19

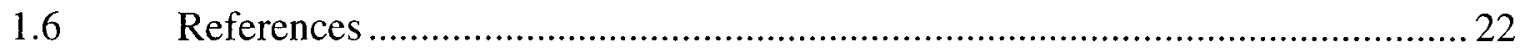




\section{Chapter 2: Iminopyrrolidine Ligand and Aluminum Complexes}

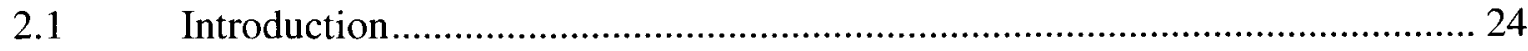

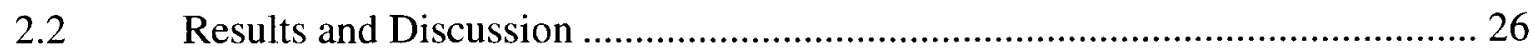

2.2.1 Ligand Synthesis and Thermolysis ........................................... 26

2.2.2 Syntheis of Heteroleptic Aluminum Species and Crystal Structure Data. 32

2.2.3 Thermolysis of Heteroleptic Organometallic Compounds ..................... 37

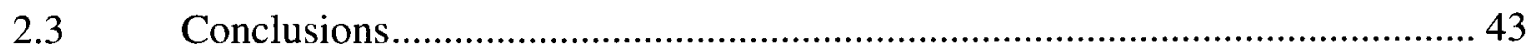

Methods and Materials................................................................. 44

2.4.1 N-propyl iminopyrrolidine, 1 ................................................. 45

2.4.2 Dimethyl aluminum n-propyl iminopyrrolidinate, 2 ......................... 46

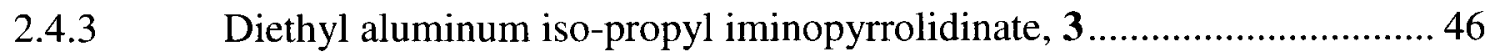

2.4.4 Diethyl aluminum n-propyl iminopyrrolidinate, 4.......................... 47

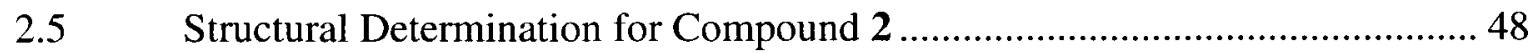

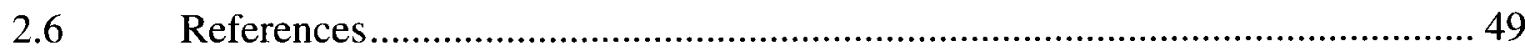

\section{Chapter 3: Heteroleptic Cyclopentadienyl Titanium (III) Guanidinates}

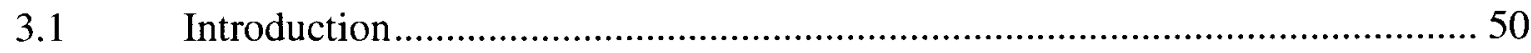

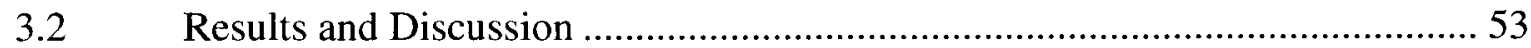

3.2.1 Synthesis and Crystal Structure Data.......................................... 53

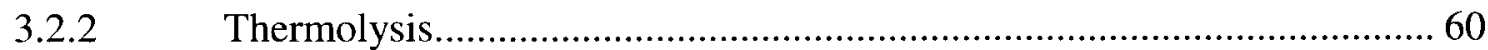

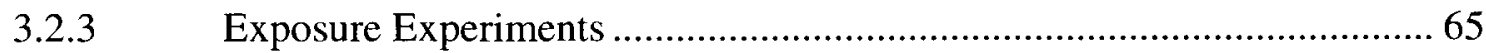

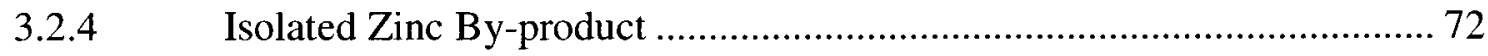

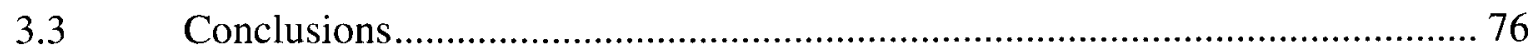

Methods and Materials.................................................................... 78 
3.4.2 Bis(cyclopentadienyl) titanium dimethylamide diisopropyl guanidinate, 6

3.4.3 Bis(cyclopentadienyl) titanium diethylamide diisopropyl guanidinate, 780

3.4.4 Bis(cyclopentadienyl) titanium tetrakis isopropyl guanidinate, 8 . 81

3.4.5 Bis(cyclopentadienyl) titanium t-butylamide diisopropyl guanidinate, 9. 81

3.5 Structural Determination for Compounds $\mathbf{5}, \mathbf{6}, \mathbf{8}, \mathbf{9}$, and $10 \ldots \ldots \ldots \ldots \ldots \ldots \ldots . . . \ldots 1$

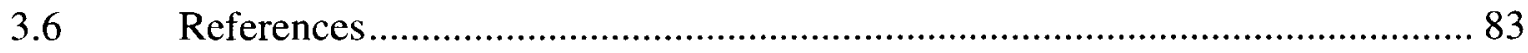

\section{Chapter 4: Heteroleptic Cyclopentadienyl Titanium (III) Amidinates}

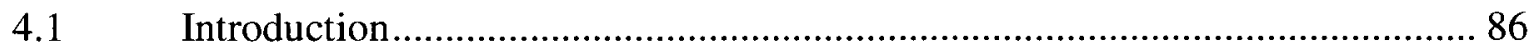

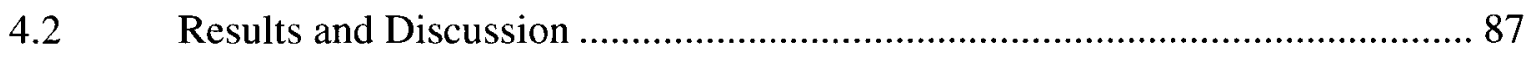

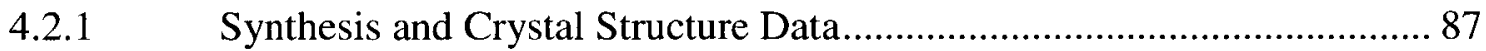

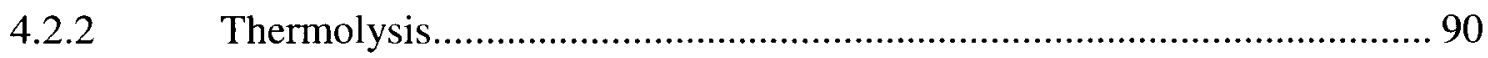

4.2.3 Preliminary ALD reactions ................................................... 94

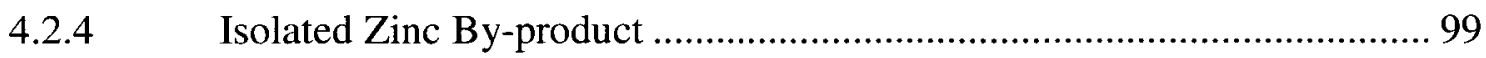

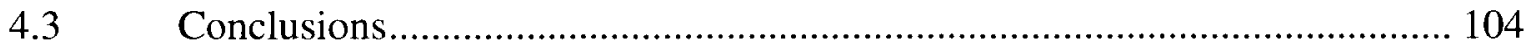

Methods and Materials.................................................................. 105

4.4.1 Bis(cyclopentadienyl) titanium acetamidinate, 11 ........................... 106

4.4.2 Bis(cyclopentadienyl) titanium ethyl amidinate, 12 ......................... 107

4.4.3 Bis(cyclopentadienyl) titanium iso-propyl iminopyrrolidinate, $13 \ldots \ldots .107$

4.4.4 Bis(cyclopentadienyl) titanium biscyclohexyl acetamidinate, 14 ........ 107

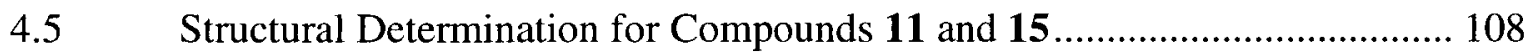

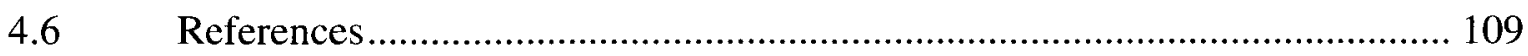




\section{Chapter 5: Homoleptic Titanium (III) Compounds}

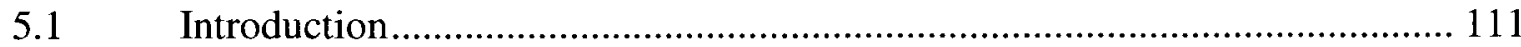

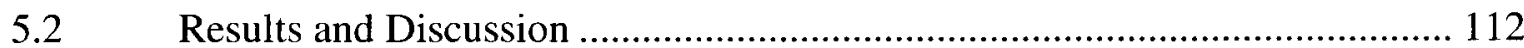

5.2.1 Synthesis and Crystal Structure Data................................................... 112

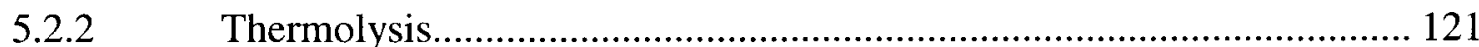

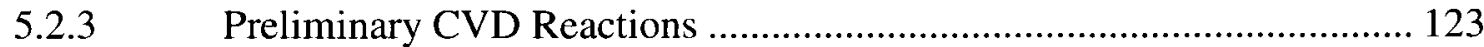

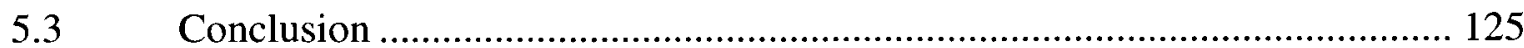

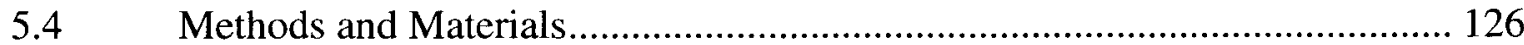

5.4.1 Tris(dimethylamide diisopropyl guanidinate) titanium, $\mathbf{1 6} \ldots \ldots \ldots \ldots \ldots \ldots . . .126$

5.4.2 Tris(triisopropyl guanidinate) titanium, 17 ..................................... 127

5.4.3 Bis(triisopropyl guanidinate) titanium chloride, 18 ……...................... 128

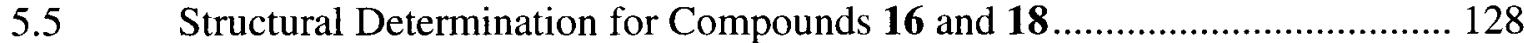

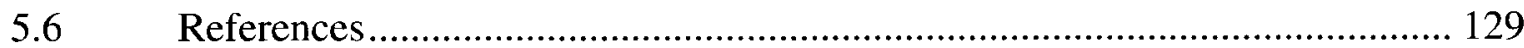

Chapter 6: Heteroleptic Amido Iminopyrrolidinato Titanium (IV) Complexes

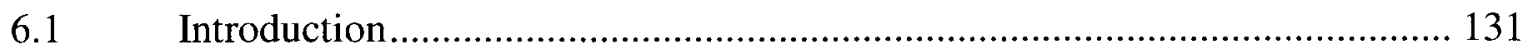

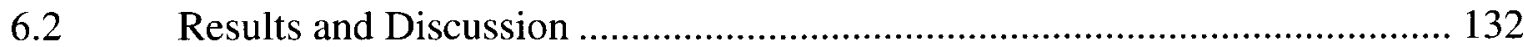

6.2.1 Synthesis and Crystal Structure Data................................................. 132

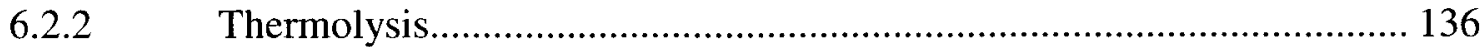

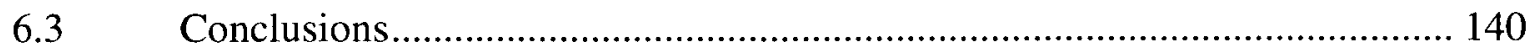

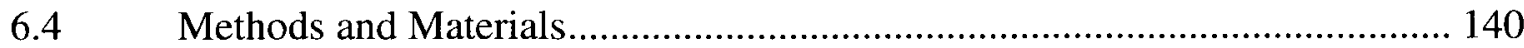

6.4.1 Bis(dimethyl amido) titanium bis(isopropyl iminopyrrolidinate), 19..... 141

6.4.2 Bis(dimethyl amido) titanium bis(sec-butyl iminopyrrolidinate), 20 ..... 141

6.4.3 Bis(dimethyl amido) titanium bis(tert-butyl iminopyrrolidinate), 21 .... 142 
6.5 Structural Determination for Compound 19

6.6 References.

\section{Chapter 7: Heteroleptic Zirconium Complexes}

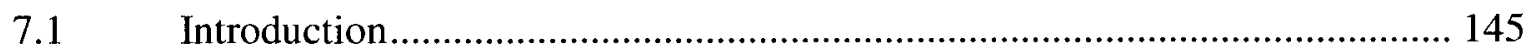

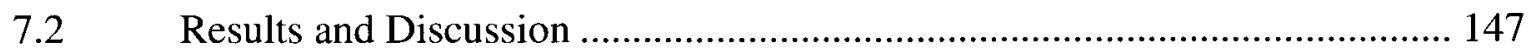

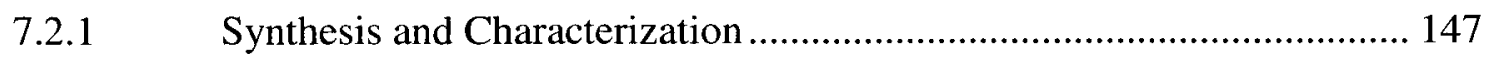

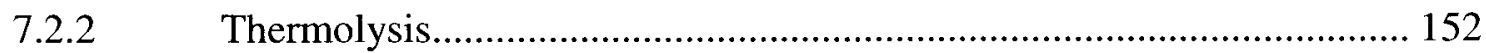

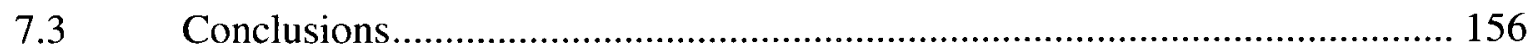

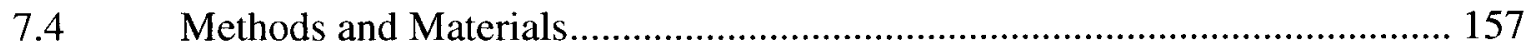

7.4.1 Bis(triisopropyl monoguanidinate) zirconium mono(dianionic triisopropyl

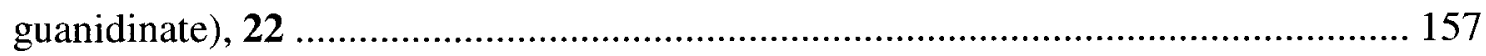

7.4.2 Bis(dimethylamide diisopropyl guanidinate) zirconium mono(dianionic

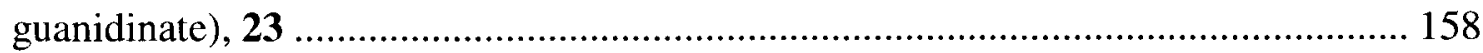

7.4.3 Bis(acetamidinate) zirconium mono(dianionic guanidinate), 24......... 159

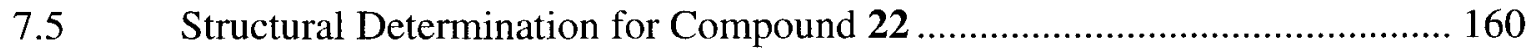

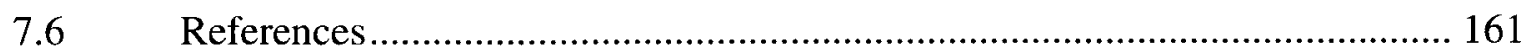

\section{Chapter 8: $\quad$ Future Work}

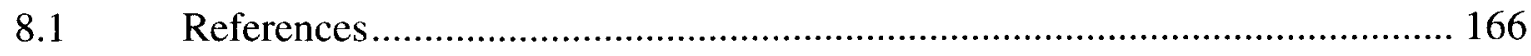




\section{List of Tables}

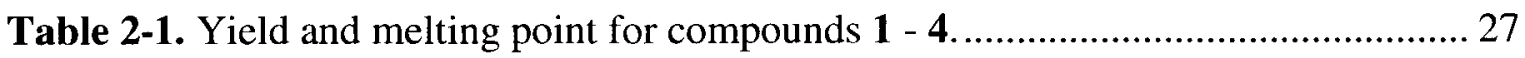

Table 2-2. Thermal parameters of iminopyrrolidine ligands. .................................... 29

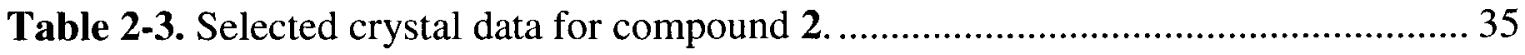

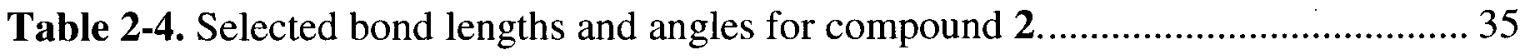

Table 2-5. Melting points for aluminum dimethyl iminopyrrolidinate complexes......... 38

Table 2-6. $\mathrm{R}^{2}$ value, rate constant and half-lives of heteroleptic aluminum complexes. . 43

Table 3-1. Guanidinate species and percent yield of compounds 5 - 9....................... 54

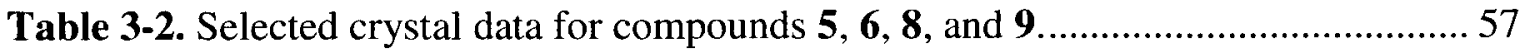

Table 3-3. Selected bond lengths and angles for compounds 5 and 6......................5 58

Table 3-4. Selected bond lengths and angles for compounds 8 and 9..................... 58

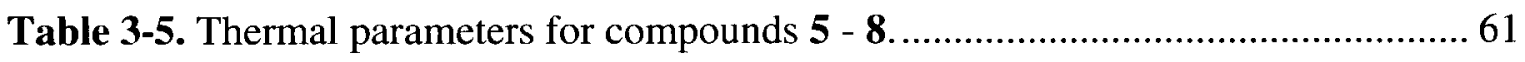

Table 3-6. Physical properties of high surface area substrates. .............................. 67

Table 3-7. Exposure experiment data for pre-heated silica at $350^{\circ} \mathrm{C}\left(\mathrm{SiO}_{2}-350\right)$ and

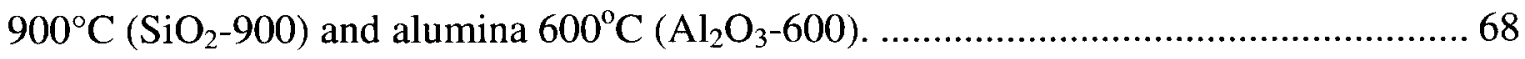

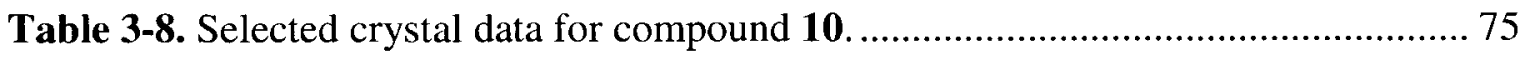

Table 3-9. Selected bond lengths and angles for compound 10........................... 76

Table 4-1. Selected crystal data for compound 11 ......................................... 90

Table 4-2. Selected bond lengths and angles for compound 11............................ 90

Table 4-3. Thermal parameters for compounds 11 - 14................................... 91

Table 4-4. Selected crystal data for compound 15........................................... 103

Table 4-5. Selected bond lengths and angles for compound 15............................ 104

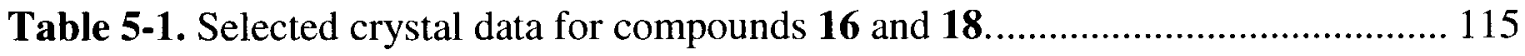


Table 5-2. Selected bond lengths and angles for compounds 16 and 18 .

Table 5-3. Yield and thermal parameters of compounds 16 - 18

Table 6-1. Yield and thermal parameters for compounds 19 - 21

132

Table 6-2. Selected crystal data for compound 19 135

Table 6-3. Selected bond lengths and angles for compound 19 136

Table 7-1. Percent yield and thermal data of compounds $22-24$ 148

Table 7-2. Selected crystal data for compound 22 151

Table 7-3. Selected bond lengths and angles for compound $\mathbf{2 2}$ 151 


\section{List of Figures}

Figure 1-1. Step-wise growth of $\mathrm{Al}_{2} \mathrm{O}_{3}$ film using $\mathrm{ALD}$............................................ 3

Figure 1-2. Saturation curve demonstrating a) ALD growth by self-limiting monolayer formation and b) continuous growth for a CVD process................................................ 4

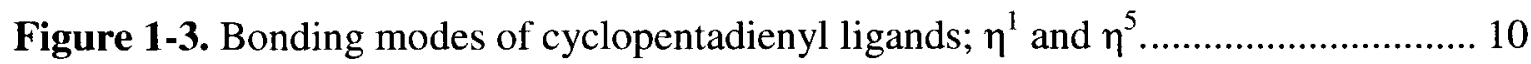

Figure 1-4. Resonance structure of a) amidinate and b) guanidinate ligands................. 10

Figure 1-5. Theoretical bonding modes of the amidinate ligand................................... 12

Figure 1-6. Resonance structure of amidinate ligands............................................... 13

Figure 1-7. Bonding modes of a) mono-substituted (four-coordinate) and b) trisubstituted (six-coordinate) amidinate species. ............................................................. 13

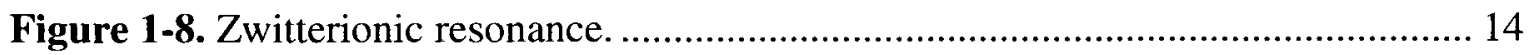

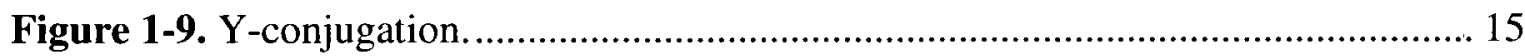

Figure 1-10. Bonding modes of a) mono-substituted (four-coordinate) and b) trisubstituted (six-coordinate) guanidinate species. ......................................................... 16

Figure 1-11. TG demonstrating a clean volatilization accompanied with a derivative

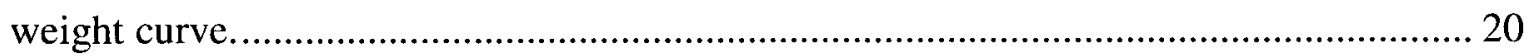

Figure 1-12. TG demonstrating an interrupted derivative weight curve and poor volatilization. 20

Figure 2-1. The similarity in chelating geometry of an amidinate, an iminopyrrolidinate and an aminooxazolidinate. 25

Figure 2-2. Differential scanning calorimetery of 1. 28

Figure 2-3. Thermal gravimetric analysis of iminopyrrolidine ligands. 30 
Figure 2-4. Differential weight curve for iminopyrrolidine ligands.

Figure 2-5. The single-crystal X-ray structure of 2. The thermal ellipsoids are shown at $50 \%$ probability and the hydrogen centres are omitted for clarity. 33

Figure 2-6. The single-crystal X-ray structure of 2 demonstrating chair conformation. The thermal ellipsoids are shown at 50\% probability; the hydrogen centres and both aluminum methyls are omitted for clarity. 34

Figure 2-7. Analogous aluminum amidinate precursors.................................................. 37

Figure 2-8. Thermal gravimetric analysis of 2.......................................................... 39

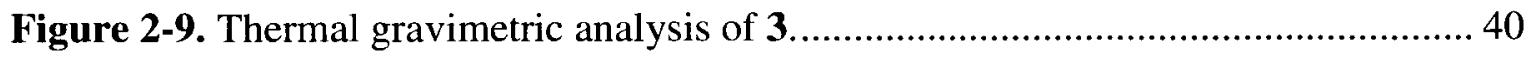

Figure 2-10. First order decomposition of the dimethyl and diethyl peak at $78^{\circ} \mathrm{C}$.......... 42

Figure 3-1. Heteroleptic titanium species.................................................................... 54

Figure 3-2. The single-crystal $X$-ray structure of (a) 5, (b) 6, and (c) 8. The thermal ellipsoids are shown at $50 \%$ probability and the hydrogen centres are omitted for clarity.

N.B.: Only one of two orientations of 6 is shown (see text).......................................... 55

Figure 3-3. Asymmetric coordination of guanidinate ligand........................................... 56

Figure 3-4. The single-crystal X-ray structure of 9. The thermal ellipsoids are shown at $50 \%$ probability and the hydrogen centres are omitted for clarity.................................. 57

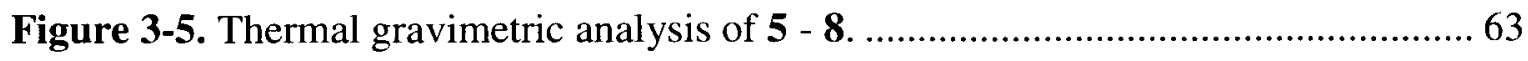

Figure 3-6. Differential weight curve for compounds 5 - 8........................................ 64

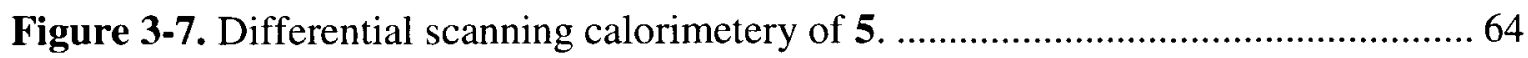

Figure 3-8. Hydroxyl group density as a function of temperature pre-treatment (adapted from Gunter). 66

Figure 3-9. Schematic of F-120 $\mathrm{ALCVD}^{\mathrm{TM}}$ reactor. 67 
Figure 3-10. Resulting colour change of $\mathrm{SiO}_{2}-350, \mathrm{SiO}_{2}-900$ and $\mathrm{Al}_{2} \mathrm{O}_{3}-600$ after

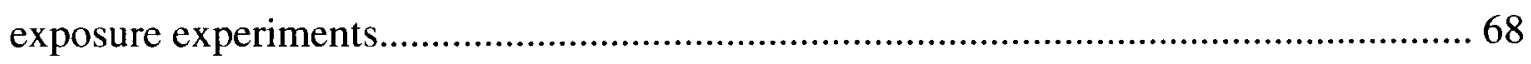

Figure 3-11. Solid state ${ }^{13} \mathrm{C}$ NMR of $\mathrm{SiO}_{2}-350$ depicting aromatic and aliphatic carbons. 69

Figure 3-12. Solid state ${ }^{13} \mathrm{C}$ NMR of $\mathrm{SiO}_{2}-900$ depicting aromatic carbons................. 70

Figure 3-13. Solid state ${ }^{13} \mathrm{C}$ NMR of $\mathrm{Al}_{2} \mathrm{O}_{3}-600$ depicting aromatic and aliphatic carbons.

Figure 3-14. The single-crystal $X$-ray structure of 10. The thermal ellipsoids are shown at $50 \%$ probability and the hydrogen centres are omitted for clarity. 74

Figure 3-15. The single-crystal $X$-ray structure of 10. The thermal ellipsoids are shown at $50 \%$ probability and the hydrogen centres are omitted for clarity. (a) demonstrating guanidinate twist across the $\mathrm{Cl} 1-\mathrm{Zn} 2-\mathrm{Zn} 1$ plane with one isopropyl moiety omitted for clarity, (b) looking down $\mathrm{Cl1}-\mathrm{Zn} 2-\mathrm{Zn} 1$ axis 75

Figure 4-1. Heteroleptic titanium amidinate species. .88

Figure 4-2. The single-crystal $X$-ray structure of 11. The thermal ellipsoids are shown at $50 \%$ probability and the hydrogen centres are omitted for clarity. .88

Figure 4-3. Thermal gravimetric analysis of 11 14....................................... 92

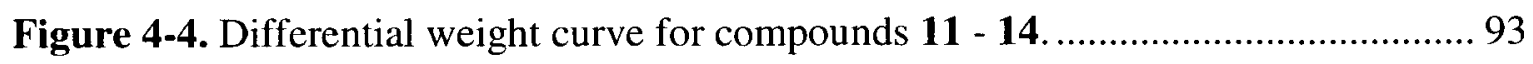

Figure 4-5. Schematic diagram of hot-walled ALD reactor. ................................ 95

Figure 4-6. SEM image showing the surface morphology of $\mathbf{S} 2$ deposited at $175^{\circ} \mathrm{C}$ over

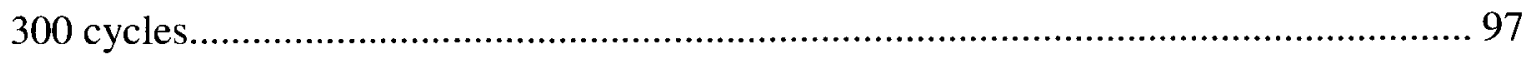

Figure 4-7. EDS spectrum of $\mathbf{S 2}$ deposited at $175^{\circ} \mathrm{C}$ over 300 cycles....................... 98 
Figure 4-8. The single-crystal X-ray structure of $\mathbf{1 5}$. The thermal ellipsoids are shown at $50 \%$ probability and the hydrogen centres are omitted for clarity 100

Figure 4-9. The single-crystal $X$-ray structure of 15 , looking down $Z n 2-Z n 1$ axis. The thermal ellipsoids are shown at 50\% probability; the hydrogen centres and all isopropyl groups are omitted for clarity

Figure 5-1. The single-crystal X-ray structure of 16. The thermal ellipsoids are shown at $50 \%$ probability and the hydrogen centres are omitted for clarity

114

Figure 5-2. The single-crystal X-ray structure of 18. The thermal ellipsoids are shown at $50 \%$ probability and the hydrogen centres are omitted for clarity

117

Figure 5-3. Five-coordinate structures of a) square-planar and b) trigonal-bipyramidal geometries. 118

Figure 5-4. Homoleptic titanium (III) species. 120

Figure 5-5. Thermal gravimetric analysis of $\mathbf{1 6}$. 122

Figure 6-1. The single-crystal X-ray structure of compound 19. The thermal ellipsoids are shown at $50 \%$ probability and the hydrogen centres are omitted for clarity. 134

Figure 6-2. Thermal gravimetric analysis of 19 - 21.

Figure 6-3. Differential weight curve for compounds 19 - 21 138

Figure 7-1. Heteroleptic zirconium species 148

Figure 7-2. The single crystal X-ray structure of compound 22. The thermal ellipsoids are shown at 50\% probability and the hydrogen centres are omitted for clarity. 150

Figure 7-3. Thermal gravimetric analysis of $22-\mathbf{2 4}$. 153

Figure 7-4. Differential weight curve for compounds 22 - 24. 154

Figure 7-5. Differential scanning calorimetery of $\mathbf{2 3}$. 155 


\section{List of Schemes}

Scheme 1-1. Insertion reaction of carbodiimide to metal alkyl or amido bond.

Scheme 1-2. Ligand exchange from a five-coordinate species to a four-coordinate species

Scheme 1-3. Alkane or amine elimination. 18

Scheme 1-4. Salt metathesis reaction. 19

Scheme 2-1. Deinsertion of CDI at elevated temperatures. 24

Scheme 2-2. Synthetic procedure for iminopyrrolidine ligands............................. 26

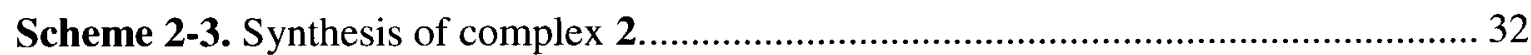

Scheme 2-4. Synthesis of $\mathrm{AlEt}_{2}$ iminopyrrolidinate complexes. ........................... 36

Scheme 2-5. Speculation of isomerization followed by dimerization of the ligand. ...... 41

Scheme 3-1. Lithium amide insertion over CDI bond. ..................................... 56

Scheme 6-1. Synthesis of heteroleptic titanium complexes. .................................. 133

Scheme 7-1. Deinsertion less likely to occur for dianionic ligands. ....................... 146 


\section{List of Appendices}

Appendix A: Crystallographic Data for Compounds 2, 5, 6, 8, 9, 10, 11, 15, 16, 18,

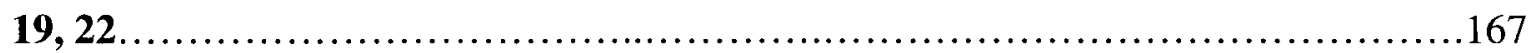

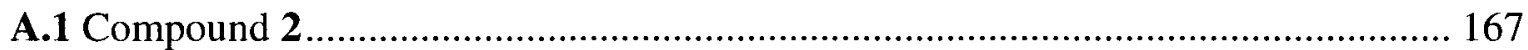

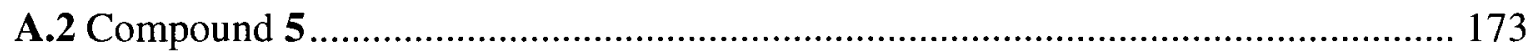

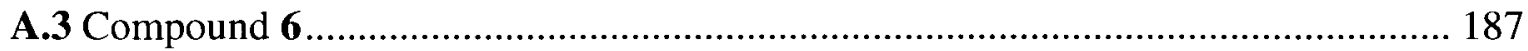

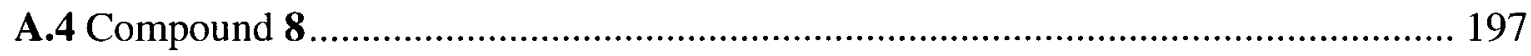

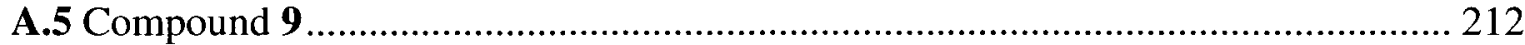

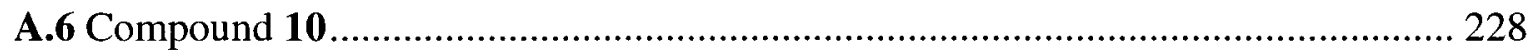

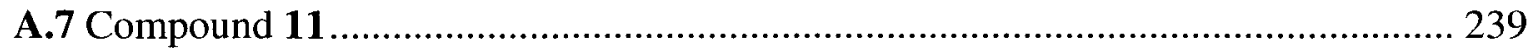

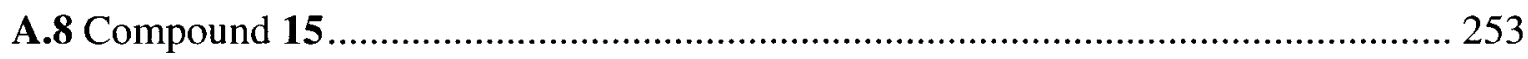

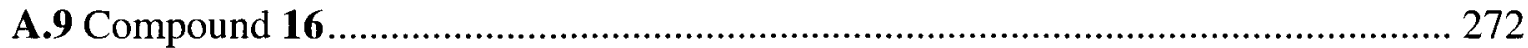

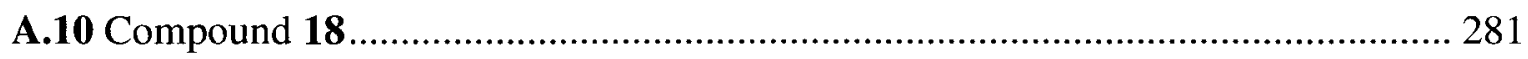

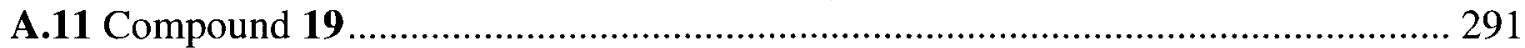

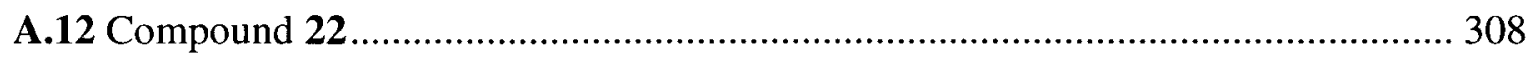




\section{List of Abbreviations}

ALD - Atomic Layer Deposition

$\mathrm{C}_{6} \mathrm{D}_{6}-$ Benzene

CDI - Carbodiimide

CMOS - Complimentary Metal-Oxide-Semiconductor

CVD - Chemical Vapour Deposition

DEPT - Distortionless Enhancement by Polarization Transfer

DFT - Density Functional Theory

dimdip - dimethylamide diisopropyl guanidinate

DSC - Differential Scanning Calorimetery

EDS - Electron Diffraction X-ray Spectroscopy

ibip - iso-butyl iminopyrrolidine

IC - Integrated Circuit

ip - iminopyrrolidine

ipip - iso-propyl iminopyrrolidine

MAS-NMR - Magic Angle Spinning Nuclear Magnetic Resonance

MOCVD - Metal Organic Chemical Vapour Deposition

MOSFET - Metal-Oxide-Semiconductor Field-Effect Transistors

MS - Mass Spectroscopy

nbip - n-butyl iminopyrrolidine

NMR - Nuclear Magnetic Resonance

npip - n-propyl iminopyrrolidine

PVD - Physical Vapour Deposition 
sbip - sec-butyl iminopyrrolidine

SEM - Scanning Electron Microscopy

SSP - Single Source Precursor

tbip - tert-butyl iminopyrrolidine

TEA - Triethyl aluminum

TG - Thermal Gravimetric

THF - Tetrahydrofuran

TMA - Trimethyl aluminum

TMS - Tetramethylsilane

tripyl - triisopropyl guanidinate

UHP - Ultra High Pure

VT NMR - Variable Temperature Nuclear Magnetic Resonance 


\section{List of Publications}

Yamile Ana-Maria Wasslen, Agnieszka Kurek, Paul A. Johnson, Taylor C. Pigeon, Wesley H. Monillas, Glenn P. A. Yap, Seán T. Barry; Heteroleptic Iminopyrrolidinates of Aluminum, Dalton Trans., 2010, DOI: 10.1039/C0DT00267D.

Yamile Ana-Maria Wasslen, Eva Tois, Suvi Haukka, Kevin A. Kreisel, Glenn P.A. Yap, Mathew D. Halls, Seán T. Barry; A Family of Heteroleptic Titanium Guanidinates: Synthesis, Thermolysis, and Surface Reactivity, Inorg. Chem, 2010, 49, 1976.

Yamile Ana-Maria Wasslen, Seán T. Barry, Antti Rahtu, Suvi Haukka; A Novel Titanium Precursor for Atomic Layer Deposition, U.S. patent, 2006 , No. 11/588,595. 


\section{Chapter 1: Introduction}

\subsection{Atomic Layer Deposition}

As nanotechnology becomes increasingly prevalent, the desire to make smaller scale architectures and thinner films is a mounting challenge. One method for developing thin films in a controlled manner can be accomplished using chemical vapour deposition techniques known as metal organic chemical vapour deposition (MOCVD) and atomic layer deposition (ALD). ${ }^{1}$ Both techniques involve gas-phase introduction of reactants and require a chemical change to occur at the deposition surface. MOCVD and ALD are close cousins for the fabrication of thin films. They differ in the way in which the precursor is handled, which greatly affects the surface chemistry of the process. MOCVD introduces both precursors into the reaction chamber simultaneously where they react at the substrate to form a thermodynamically determined film. ${ }^{2}$ ALD on the other hand has more control over the uniformity and the thickness of the film by introducing the precursors in intervals to the reaction chamber separated by purges to remove any volatile by-products. ${ }^{1,2}$ This process allows a monolayer of chemisorbed precursor with self-limiting behaviour to form at the substrate, which subsequently allows greater control of the film. Self-limiting monolayer formation occurs when the surface reactions are limited by the number of reactive surface sites and no further reactions occur on the surface once these sites are occupied. ${ }^{1,2}$ This complete monolayer saturation prevents continual growth of the film by inhibiting further reactions on the surface. ${ }^{1,2}$ 
The step-wise introduction of the precursors help to attain the control that is achieved during ALD. ${ }^{2}$ In the first step a metallic species for the desired target film is introduced to the reaction chamber and allowed to saturate the surface. During saturation, the metallic species chemisorbs to the surface via an anchoring ligand forming a new surface functional group and volatile by-products.

The second step is the removal of any unreacted metallic species and volatile byproducts through purging with an inert gas, evacuating the chamber or by a combination of the two.

In the third step the second precursor, commonly referred to as the reactant gas, is introduced to the reaction chamber where it reacts with the chemisorbed metallic species to form a monolayer of the target film.

The resulting volatile by-products, this time the protonated ligands from the metallic species, and any excess second precursor is removed through purging with an inert gas, evacuating the chamber or by a combination of the two. This is the fourth and final step of a binary ALD cycle. Typical monolayer thicknesses are measured in Angstroms ( $\AA$ ), varying anywhere from a fraction of an Angstrom to several Angstroms. ${ }^{1}$

An example of the step-wise growth of ALD is shown in Figure 1-1 using trimethyl aluminum (TMA) as the metallic precursor and water as the second precursor. The target film in this example is $\mathrm{Al}_{2} \mathrm{O}_{3}$. a) is the introduction of the organometallic precursor, b) is the removal of unused volatile species and by-products, c) the introduction of the second precursor and d) removal of unused volatile species and by-products. 

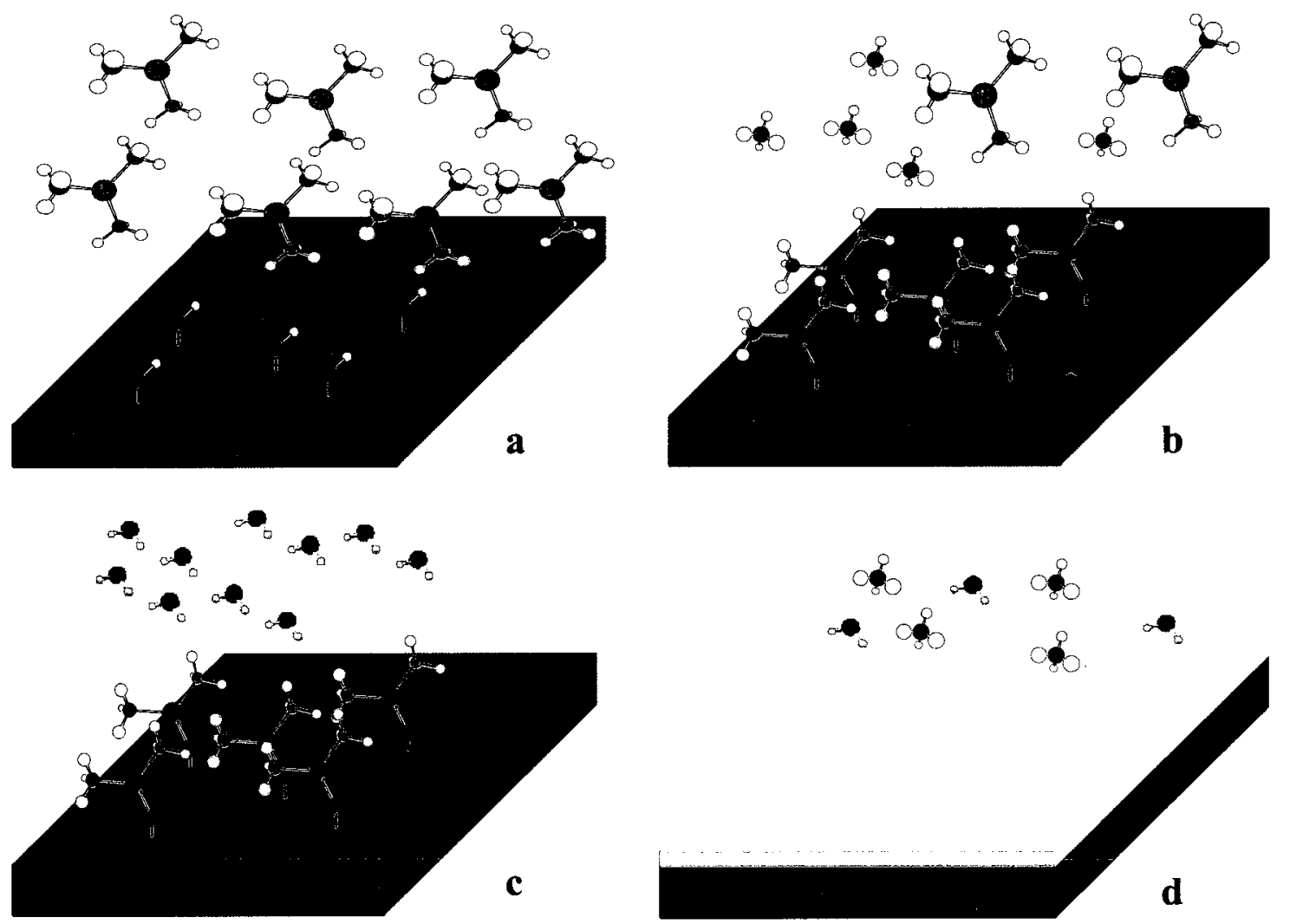

Figure 1-1. Step-wise growth of $\mathrm{Al}_{2} \mathrm{O}_{3}$ film using ALD.

These four steps are repeated until the desired thickness of the target film is achieved. In an ideal ALD process a full monolayer is formed after each cycle. ${ }^{3}$ In practice, however, due to steric hindrance caused by the precursor molecules, one cycle will usually produce only a partial monolayer. ${ }^{1 \mathrm{~d}}$ This does not decrease the atomic level control that an ALD process can achieve as film thickness is dependent on the number of deposition cycles. ${ }^{\text {ld }}$

There are two types of film growth that can occur through gas-phase reactions; continuous growth and self-limiting growth. One method of differentiating the type of growth that occurs during deposition is by collecting a saturation curve. ${ }^{4}$ A saturation 
curve is a plot of the film growth rate as a function of precursor concentration and can be seen in Figure 1-2.

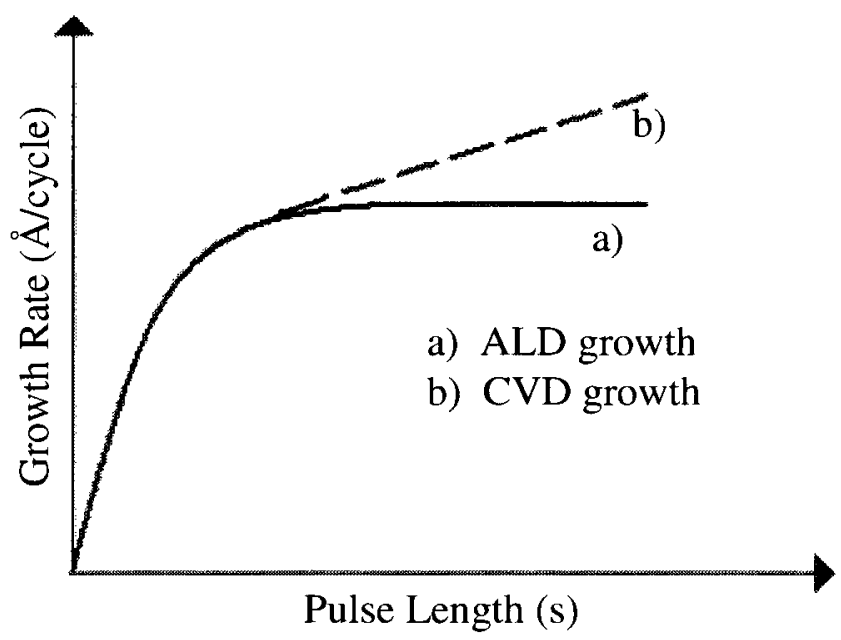

Figure 1-2. Saturation curve demonstrating a) ALD growth by self-limiting monolayer formation and $b$ ) continuous growth for a CVD process.

The precursor concentration can be determined by the pulse length, typically measured in seconds. When the pulse length is long, more precursor is introduced into the reaction chamber, thus increasing the exposure of the surface to the precursor. When self-limiting behaviour is reached (Figure 1-2a), all the surface sites have been fully saturated by a monolayer of precursor and no further reaction will occur on the surface, regardless of the amount of precursor introduced into the reaction chamber. ${ }^{4}$ At such a concentration the growth rate will reach a plateau as any further increase in precursor concentration will not affect the growth rate. In order for a process to be considered ALD, both precursors must exhibit self-limiting behaviour. This can be accomplished by collecting saturation curves for both precursors demonstrating a growth rate plateau with respect to precursor concentration. Saturation curves not only demonstrate the type of 
growth occurring during deposition but it is also a useful tool in optimizing growth conditions such that precursor waste and process times are kept to a minimum.

If self-limiting monolayer formation is not accomplished during deposition, continuous growth can be seen in the saturation curve (Figure 1-2b). In a continuous growth deposition, no plateau of the growth rate is reached and the growth rate will increase with increasing precursor concentration. This type of growth is a chemical vapour deposition (CVD) process: the precursor is decomposing upon chemisorption to the surface. ${ }^{4}$ The thickness of the film cannot be controlled through number of pulses as film thickness will increase with increasing precursor concentrations.

Many different types of films can be produced via ALD or CVD process such as metal oxides, metal nitrides and metal films, to name a few. Metal oxides typically use water as the second precursor; however ozone $e^{5}$, hydrogen peroxide ${ }^{4,6}$ and oxygen ${ }^{\text {ld }}$ have also been used when the reactivity of water has not been sufficient. ${ }^{7}$ Metal nitride films are typically deposited using metal halide and ammonia as the two precursors. ${ }^{2}$ Metal films can be deposited by ALD using either hydrogen reduction through thermal chemistry or enhanced by hydrogen plasma. ${ }^{8}$ The reactions that occur spontaneously at various temperatures are referred to as thermal ALD because films can be deposited through use of heat and without the aid of plasma assistance. However, for certain metallic films, thermal chemistry and hydrogen reduction is not reactive enough and so techniques such as plasma enhanced ALD can be used. Energetic species in the plasma can induce reactions that are otherwise not possible using thermal energy. Plasma sources can be used to produce hydrogen radicals that reduce the metal. ${ }^{2 \mathrm{~d}}$ 
ALD is not only limited to binary reaction sequences. Other types of films such as binary oxide films $\mathrm{Zr}_{\mathrm{x}} \mathrm{Ti}_{\mathrm{y}} \mathrm{O}_{\mathrm{z}},{ }^{9} \mathrm{GdScO}_{3}{ }^{10}$ and $\mathrm{SrTiO}_{3}{ }^{11}$ can be deposited using this technique. The deposition temperature (also known as reaction temperature) for a selflimiting ALD process is very important. It is at these optimal temperatures that thermal decomposition of the precursor does not occur, but monolayer growth is achieved. ${ }^{\text {ld }}$ This temperature is typically above the temperature of chemisorptions, but below the temperature of thermal decomposition.

Additionally, when depositing a multi component film it is very important to know the vapour phase thermal stability of the precursors. ${ }^{12}$ The reaction temperature of each precursor should overlap in such a manner that self-limiting growth is attained and condensation or insufficient precursor reactivity (reaction temperature too low) or decomposition or desorption of precursors (reaction temperature too high) does not occur. ${ }^{1}$ Desining processes with lower reaction temperatures for ALD and CVD processes is an ongoing challenge in this field of chemistry. The drive for lower temperature processes is an effort to reduce energy consumption and (in some cases) prevent crystallization of the target film. One method of achieving this is by synthesizing precursors that are highly volatile and chemically active at lower temperatures.

ALD is becoming an important technique for depositing thin films for a variety of applications. $^{1,2,4}$ The ability to control the deposition of thin films by an atomic layer stems from the stepwise addition of the precursors. However the design of the precursors also plays an important role in the uniform and controlled manner of this technique. ${ }^{8,13}$ In order for a precursor to be ideal for ALD it must follow certain criteria. ${ }^{3,4}$ 


\subsection{Precursor Design}

The first design criterion is the production of a volatile species. The precursor must have a high vapour pressure in order to reach the reaction chamber in the gaseous state as ALD is a gas-phase reaction. This characteristic can be achieved by coordinatively saturating the metal centre to prevent oligomerization from occurring and by keeping the molecular weight of the species to a minimum.

The second design criterion that compliments the first is to design a precursor with a low melting point. A distillable liquid precursor would be ideal; however low melting solids are not detrimental. ${ }^{4}$ Heating a low melting solid at an elevated temperature forces the solid to melt. Once the solid has melted, the surface area of the liquid would allow production of a reproducible amount of gaseous precursor to enter the reaction chamber as the surface area will constantly replenish itself. High melting solids do not have a surface area that can replenish itself; as the solid sublimes, the surface area of the solid decreases. A precursor with a reproducible vapour pressure would allow a constant concentration to enter the reaction chamber at each cycle of an ALD run. This in turn would help to ensure complete and uniform monolayer formation and will help to make ALD a more efficient process for thin film deposition. This can be achieved by introducing branching and asymmetry in the ligand in order to frustrate crystallization. ${ }^{14}$

Thermal stability is an important design criterion for two reasons. Firstly, since ALD is a gas-phase reaction and a high vapour pressure is essential, the precursor of choice may be heated for long periods of time to maintain an acceptable vapour pressure during deposition. The precursor must be able to withstand such treatment to ensure that the species introduced to the reaction chamber in the first pulse is the same as the species 
introduced in the last pulse. The second reason for thermal stability is to prevent thermal decomposition once in the gas-phase in order to obtain self-limiting film growth. Decomposition may occur during the deposition of a film without the reactant gas, (i.e. CVD-type growth). The rate of decomposition will increase exponentially with temperature as decomposition is thermally activated. Reaction chamber temperatures can range from room temperature to as high as $500^{\circ} \mathrm{C}^{15}$ and so a good precursor must be kinetically stable at these temperatures.

Chemical reactivity is another criterion for a good ALD precursor. The bonds being formed during deposition must be stronger than the bonds being broken within the precursor. $^{1 \mathrm{c}}$ Both precursors must be reactive towards each other and should react completely to reduce cycle time and impurity levels. ${ }^{4}$ The organometallic precursor must react with the surface functional groups of the substrate by chemisorption and remain bonded during purging periods. ${ }^{3}$ One way of achieving this is by including an anchor ligand on the metal precursor. An anchor ligand is a small monodentate ligand that can reach, and thus react, with the surface species resulting in the formation and evolution of a stable volatile by-product. An example of an anchor ligand would be a methyl group from a precursor such as TMA, which, once reacted to the surface hydroxyl species, would produce methane for aluminum oxide depositions.

The production of stable and volatile by-products when the metal precursor reacts with the surface functional groups and when the reducing precursor reacts with the chemisorbed metal precursor is a subset to the latter criterion. This ensures that the metal films contain fewer impurities as the by-products can be easily and efficiently removed during the purging or evacuation step. 
The most important criterion for ALD is self-limiting behaviour. ${ }^{1,2,3,4,8}$ This type of behaviour is accomplished by sterically protecting the metal centre through use of a ligand. This will prevent vapour phase molecules from reacting with the molecules chemisorbed to the surface as well as preventing the molecules from reacting with itself in the gas-phase. If this criterion is not met then continuous growth can occur as more than one monolayer can be deposited in each sequential pulse.

Meeting these simple criteria can afford a precursor that will help make the ALD process more efficient. In order to do so, the ligands of the metal precursor must be carefully considered.

\subsection{Ligands}

Previously, cyclopentadienyl groups have been used as ancillary ligands for ALD as they have been known to increase the deposition rates for certain films. ${ }^{16}$ Due to the reactive nature of these metallocene precursors, softer oxidizing precursors, such as water, are often used for oxide film deposition. The most common bonding arrangement of cyclopentadienyl to a metal ion is "side on", where all five carbon atoms are equidistant from the metal ion and are thought to participate in a $\pi$-bonding fashion. ${ }^{17}$ The other less common bonding arrangement of cyclopentadienyl ligand is through a single C-M bond where it is considered to participate in a $\sigma$-bonding mode (Figure 1-3). 

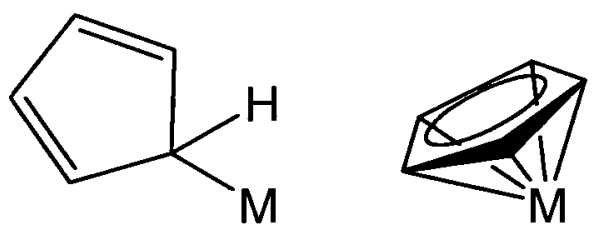

Figure 1-3. Bonding modes of cyclopentadienyl ligands; $\eta^{1}$ and $\eta^{5}$.

ALD precursors with cyclopentadienyl ligands are attractive, however their reactive nature and troublesome handling (they can be very pyrophoric and air-sensitive) make them undesirable. ${ }^{18}$ There have been many advances in organometallic chemistry to find alternative ancillary ligands to the cyclopentadienyl ligands. ${ }^{19}$ Amidinate and guanidinate ligands are of particular interest for many reasons, one being their wide range of commercially available starting materials - carbodiimides and lithiated alkyl and amido groups (Figure 1-4) as well as their versatile nature.

a)

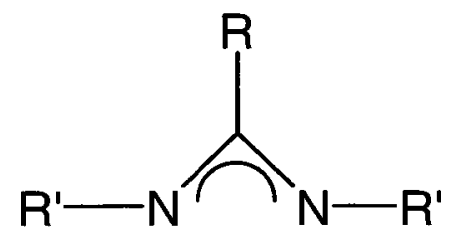

b)

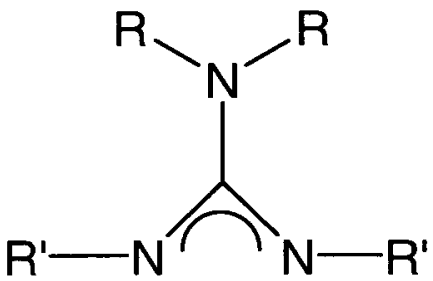

$$
\begin{gathered}
\mathrm{R}=\mathrm{H} \text { or alkyl } \\
\mathrm{R}^{\prime}=\text { alkyl }
\end{gathered}
$$

Figure 1-4. Resonance structure of a) amidinate and b) guanidinate ligands.

Amidinates and guanidinates are interesting $\mathrm{N}$-centred donor ligands in organometallic chemistry. They are especially important as they have been shown to behave similar to cyclopentadienyl ligands; their core angles and sterics are very similar. $^{20}$ They have an advantage over the latter ligands in that they are more versatile 
and their electronic and steric properties can be altered more readily by varying the substituents on the $\mathrm{N}$-atoms. ${ }^{21}$

\subsubsection{Amidinates}

Amidinate anions have been thoroughly studied in the past few decades. ${ }^{19}$ Their versatility makes them attractive ligands for ALD as they can be easily tuned to meet the specific criteria mentioned above. The nature of the ligand can vary depending on the steric bulk found on the $\mathrm{sp}^{2}$ hybridized carbon and the chelating nitrogens. Amidinates are named according to these substituents. An amidinate with $\mathrm{R}=\mathrm{H}$ is known as a formamidinate. Where $\mathrm{R}=\mathrm{Me}$ the ligand is known as an acetamidinate, $\mathrm{R}=\mathrm{Et}$ the ligand is named ethylamidinate and so on. There are theoretically eight ways in which they can bond to metal centres based on their electronic and spatial structures ${ }^{19 a}$ (Figure $1-5)$. 
a)<smiles>[R]N=C1C([R])N1[R]</smiles>

d)<smiles></smiles>

b)<smiles>[R7]N=C([R])N([R])[M]</smiles>

e)<smiles>[R]N=C1[M]([R])=NN1[R]</smiles>

c)<smiles>[R][Y14]1=C([R])N1[R7]</smiles>

f)<smiles></smiles>

g)<smiles></smiles>

h)<smiles>[R]N=C([R])[NH2+][3H]</smiles>

$$
\begin{gathered}
\mathrm{R}=\mathrm{H} \text { or alkyl } \\
\mathrm{R}^{\prime}=\text { alkyl } \\
\mathrm{M}=\text { metal } \\
\mathrm{An}=\text { anion }
\end{gathered}
$$

Figure 1-5. Theoretical bonding modes of the amidinate ligand.

Of these theoretical bonding modes, two have not been seen experimentally; A and E. The most commonly seen amidinate in ALD precursors is structure $\mathrm{C}$ and will be discussed further. The reason for its predominance is the stabilization of the metal centre through the resonance structure it possesses (Figure 1-6). In this mode, the fourmembered MNCN metallocycle introduces steric strain and can lead to a distortion in N$\mathrm{C}$ bond lengths and planarity of the ring. 
a)<smiles>[R]c1nn([R])n1[R]</smiles>

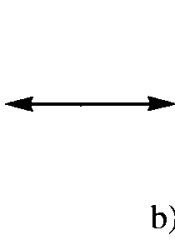

b)<smiles>[R]c1nn([R])n1[R]</smiles>

$\mathrm{R}=$ alkyl<smiles></smiles>

Figure 1-6. Resonance structure of amidinate ligands.

The degree of pyramidalization of the nitrogens is determined by the sum of all bond angles around the nitrogen atom. The closer this number is to $360^{\circ}$, the less pyramidalized the nitrogen atom and the closer the metallocycle geometry is to planar. The amidinate ligand has a net charge of -1 and thus can displace one monodentate ligand at a time to form mono-substituted (four-coordinate) to tri-substituted (six-coordinate) species (Figure 1-7). Their stabilization is limited compared to guanidinates as they do not have the ability to form a second resonance form like their guanidinate cousins.

a)<smiles>[R]C1N([R])[Y10]([R7])([R])N1[R]</smiles>

b)<smiles>[R]C1=NN([R])[N+]2(N1[R])N([R])C([R])N2[R]</smiles>

Figure 1-7. Bonding modes of a) mono-substituted (four-coordinate) and b) trisubstituted (six-coordinate) amidinate species. 


\subsubsection{Guanidinates}

Monoanionic guanidinate ligands have shown remarkable compatibility with a large range of metals in a variety of oxidation states. ${ }^{21}$ They differ from amidinates by the bonding of an amido group to the $\mathrm{sp}^{2}$ hybridized carbon. This bonding arrangement can lead to an extra electronic flexibility of the system due to a unique resonance form that can place a formal negative charge to both nitrogens, resulting in a zwitterionic resonance (Figure 1-8). This resonance form can only occur if the exocyclic nitrogen is in a position where its lone pair electron density can be donated to the central carbon atom. ${ }^{22}$ With this resonance form, guanidinates exceed the flexibility and $\pi$-donor ability of amidinates and allow them to bond to more electron deficient metals. It also increases their basicity as they are stronger donors, and for a given metal, replacement of an amidinate with a guanidinate would increase the electron density on the metal and reduce its oxidation potential. $^{21}$

a) $\mathrm{R}$<smiles>[R]N=C(N[R])N([R])[R]</smiles>

b)<smiles>[R]NC(N[O])=[N+]([R])[R]</smiles>
$\mathrm{R}=\mathrm{H}$ or alkyl
$\mathrm{R}^{\prime}=$ alkyl

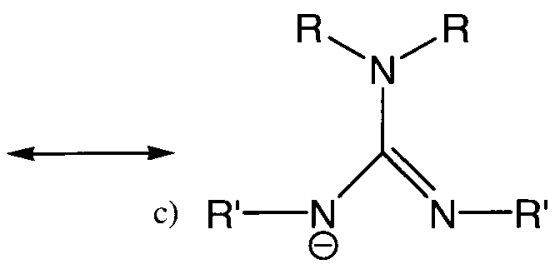

c) $\mathrm{R}^{\prime}-\mathrm{N}_{\Theta} \mathrm{N}-\mathrm{R}^{\prime}$

Figure 1-8. Zwitterionic resonance.

Dianionic guanidinate species can be synthesized by deprotonating the parent guanidine a second time in tetrahydrofuran (THF) at or below room temperature. This ligand is unique as it is isoelectronic with the carbonate anion and the trimethylenemethane dianions. ${ }^{21,23}$ Similar to the latter ligands, the dianionic guanidinate 
ligand can have a Y-conjugation occurring, where the $\pi$ delocalization of the lone pairs on the $\mathrm{sp}^{2}$ hybridized nitrogen are shared with the $\mathrm{sp}^{2}$ hybridized carbon centre as seen in Figure 1-9. ${ }^{23}$ There are fewer cases of the dianionic species than monoanionic guanidinate species found in literature. This may be attributed to the fact that these ligands have been known to form dimers with complicated bonding modes. ${ }^{24}$

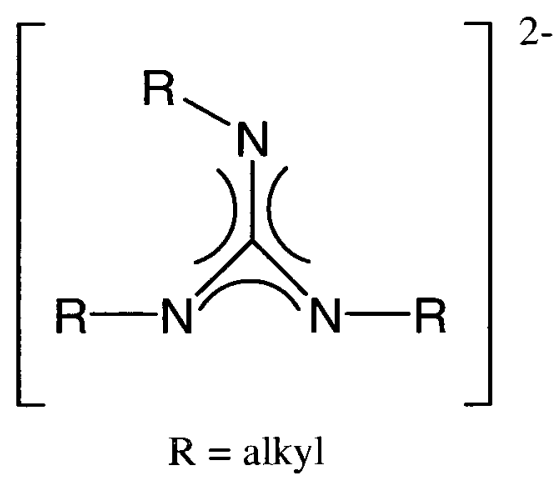

Figure 1-9. Y-conjugation.

Guanidinate anions are valuable ancillary ligands due to their steric and electronic flexibility, the variety of possible coordination modes, the availability of both monoanionic and dianionic forms and the ease with which they can be synthesized to bear many combinations of substituents. ${ }^{21}$ The monoanionic guanidinate has a net charge of -1 and can displace one to three monodentate ligands to form mono-substituted (fourcoordinate) to tri-substituted (six-coordinate) species. The dianionic guanidinate ligand has a net charge of -2 and can displace two monodentate ligands to form a monosubstituted (four-coordinate) species depending on the metal centre used. 
a)

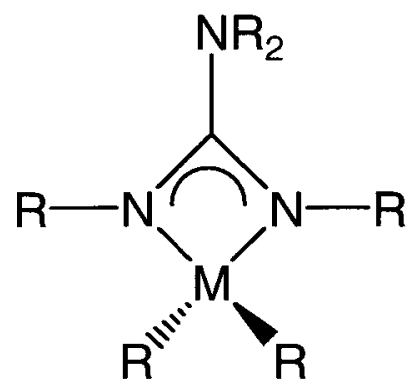

b)

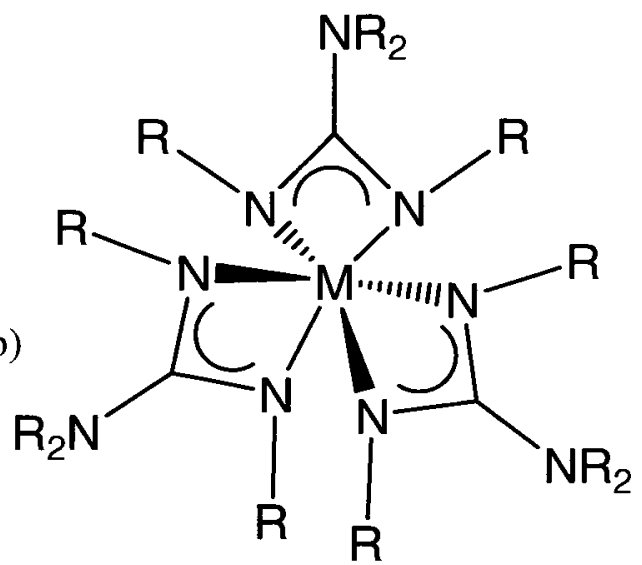

Figure 1-10. Bonding modes of a) mono-substituted (four-coordinate) and b) trisubstituted (six-coordinate) guanidinate species.

Each of the aforementioned ligands are volatile species when protonated, making their use in ALD and CVD attractive. The volatile by-products can be eliminated through purging or evacuation of the reaction chamber reducing the amount of impurities within the film.

\subsection{Synthesis}

There are several ways to synthesize metal complexes with amidinate and guanidinate ligands. The first synthetic method is an insertion reaction where an alkyl or amido group of an organometallic moiety (M-R) inserts into a $\mathrm{C}=\mathrm{N}$ double bond of a carbodiimide (CDI). These reactions proceed under fairly mild conditions and can produce mono, bis, or tris substituted amidinate and guanidinate derivatives in high yields. $^{25}$ CDI insertion reactions have been thoroughly studied and a mechanism was established using density functional theory (DFT) calculations. ${ }^{25 \mathrm{~d}}$ 
Scheme 1-1. Insertion reaction of carbodiimide to metal alkyl or amido bond.
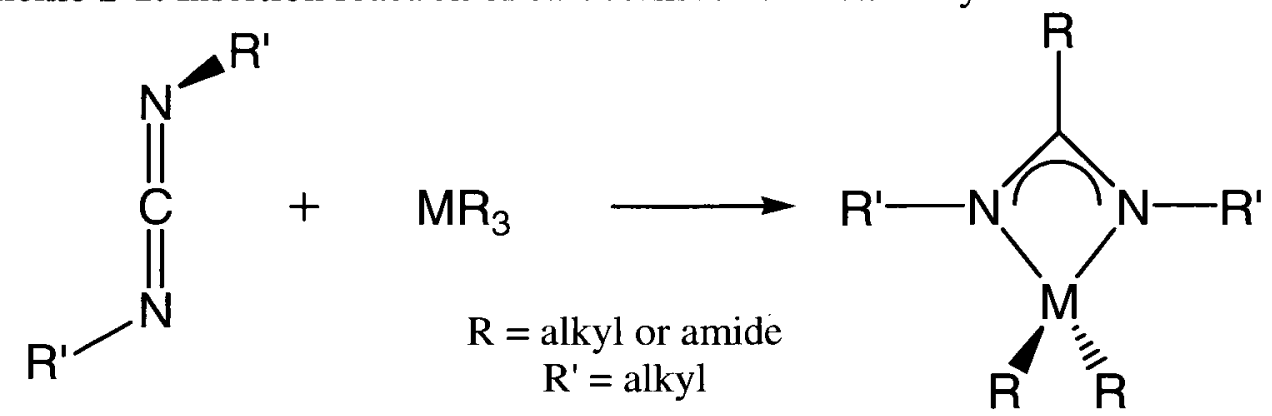

$\mathrm{CDI}$ insertion is an excellent synthetic pathway when the starting material contains only one type of ligand (homoleptic), however once there are different alkyls, amido or halogen ligands on the metal, CDI insertion can be problematic. Chang et al. have studied these systems and concluded that CDI insertion exhibits preferences over which ligand to insert depending on what type of CDI is used. One way to overcome such issues when synthesizing complexes that bear different ligands (heteroleptic) is by ligand exchange. Ligand exchange can occur between a six or five-coordinate metal species and a tri-substituted alkyl or amido homoleptic metal species (Scheme 1-2). This process was thoroughly studied using DFT calculations ${ }^{26}$ but will not be expanded upon as no exchange reactions were conducted throughout this work.

Scheme 1-2. Ligand exchange from a five-coordinate species to a four-coordinate species.

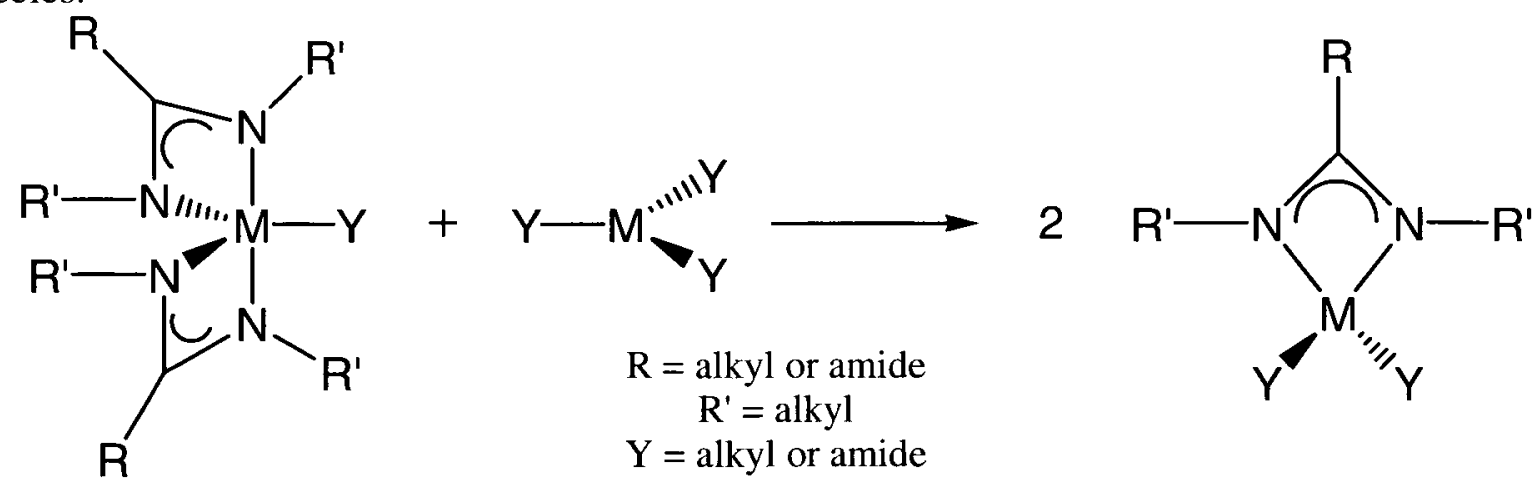


Another approach involves deprotonation of an amidine or guanidine by an alkyl or amido organometallic compound. ${ }^{19}$ This method also proceeds under fairly mild conditions and tends to produce high yields due to the thermodynamic sink of an evolving gas.

Scheme 1-3. Alkane or amine elimination.

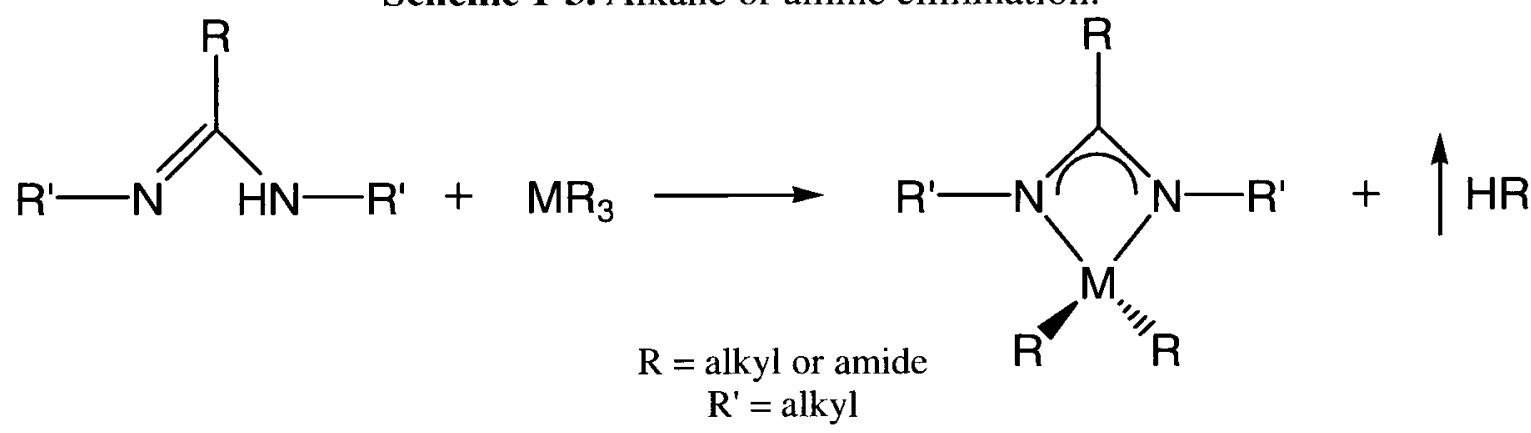

Alkane or amine elimination is an attractive method in synthesizing organometallic compounds as the production of by-products is minimal. This method was used in this work for the synthesis of heteroleptic aluminum and one set of heteroleptic titanium precursors.

The most popular method of amidinate and guanidinate synthesis in transition metal and main group complexes (and metal compound synthesis generally) is salt metathesis. ${ }^{19 a}$ This includes the reaction of anionic amidinate and guanidinate salts of alkali or alkaline-earth metals with halides of Group $3-15$ elements. The driving force of this reaction is the precipitation of insoluble salts, forcing the reaction to push to the right. 


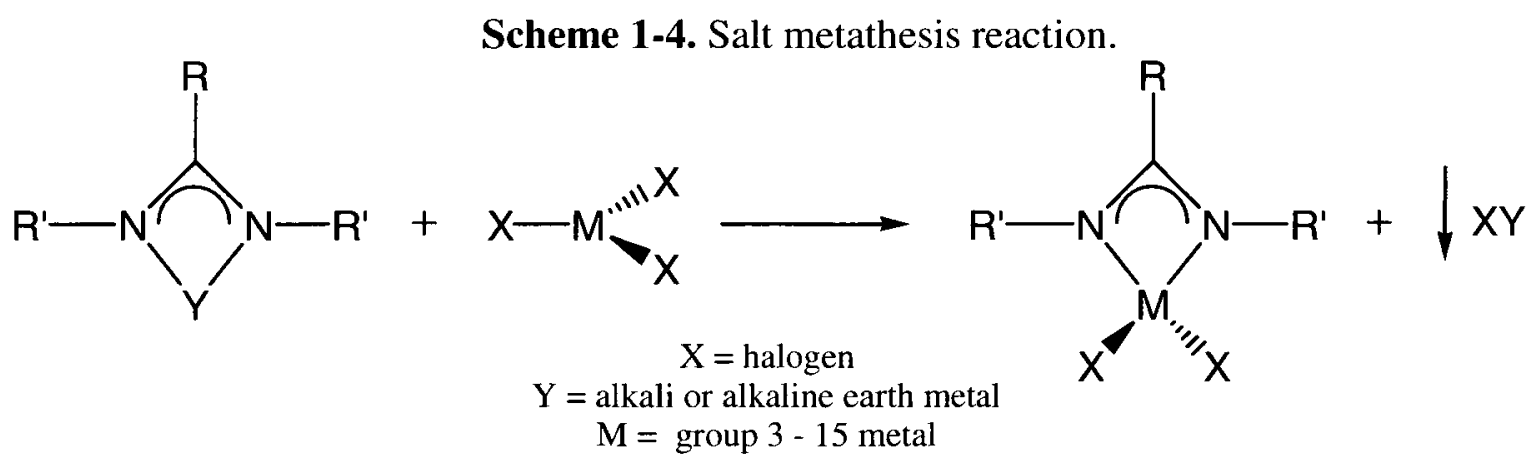

Four to six-coordinated amidinate and guanidinate species can be made using this synthetic pathway with overall decent yields. The majority of the compounds synthesized in this work were achieved through salt metathesis.

\subsection{Thermal Characterization}

One technique that is commonly used to determine the volatility of an ALD or CVD precursor is thermal gravimetric (TG) analysis. This technique measures weight changes in a material as a function of time or (most commonly) temperature under a controlled atmosphere. Such a technique can help to determine the thermal stability and volatility of a certain species. ${ }^{27}$ The slope and the temperature at which the compound begins to volatilize can help determine whether the species would be fit for ALD or CVD processes. When the slope is steep, has only one feature and results in a low residual mass $(<15 \%)$ (Figure 1-11), the species is considered to have high volatility and thermal stability as the thermolysis is considered to be clean. If the slope is gradual or interrupted the species is considered to have poor volatility as thermal degradation has occurred (Figure 1-12). 


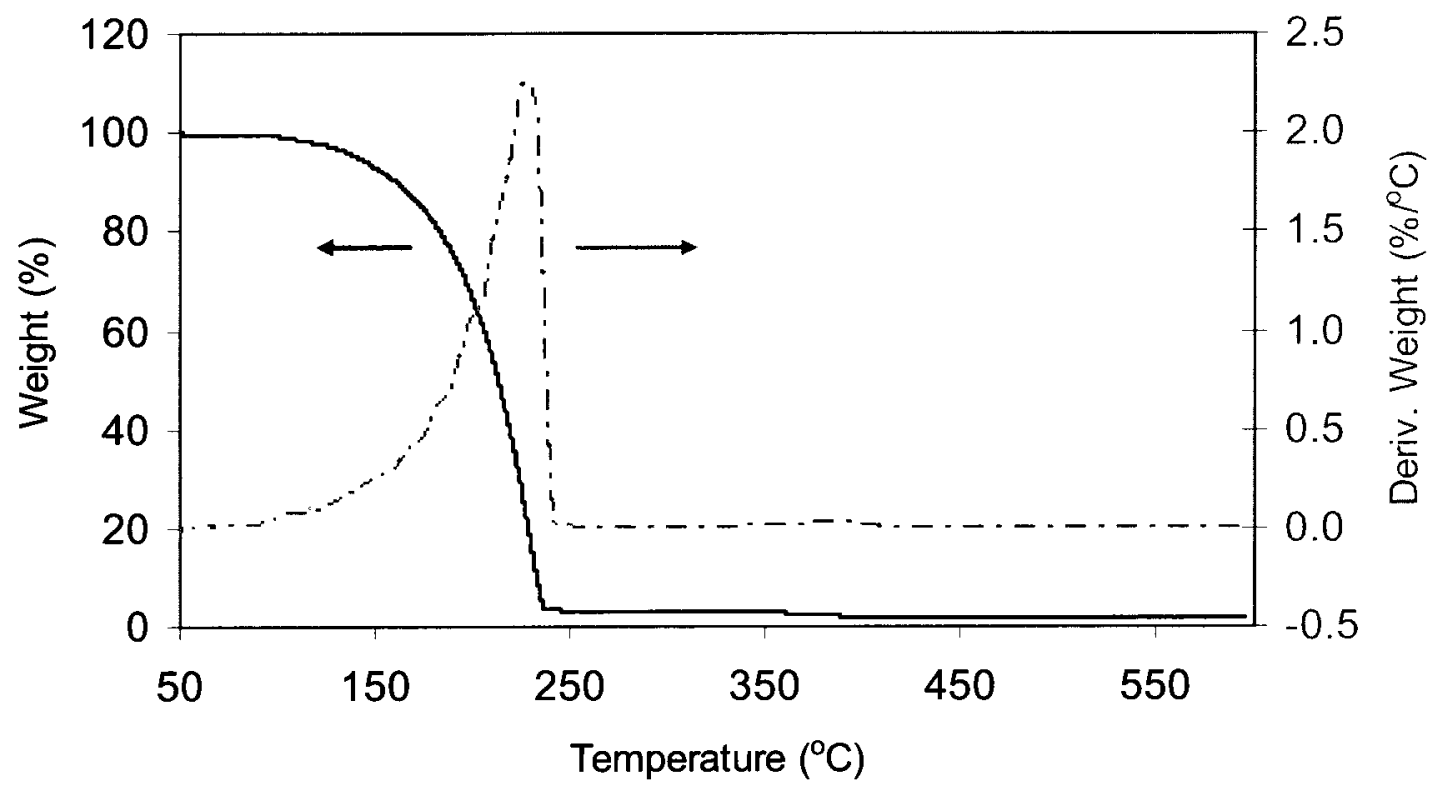

Figure 1-11. TG demonstrating a clean volatilization accompanied with a derivative weight curve.

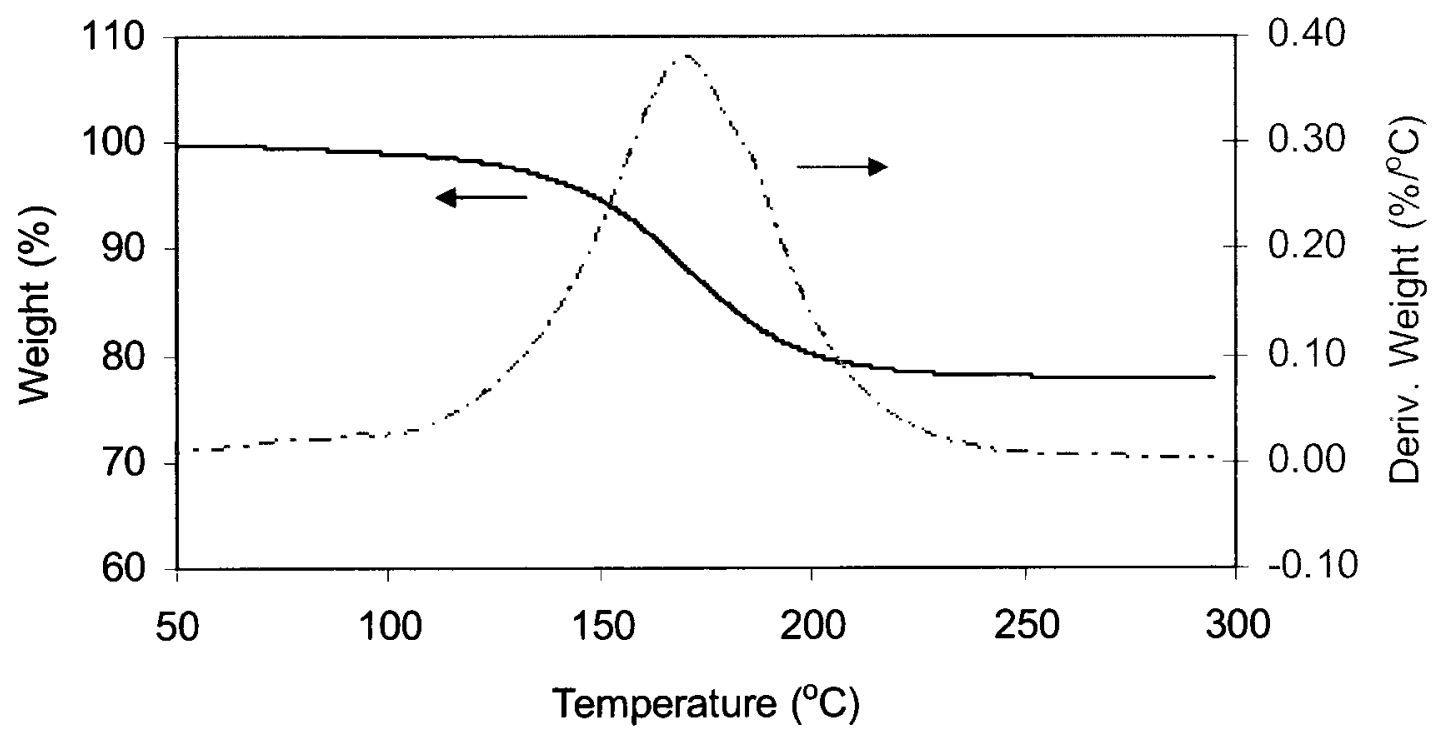

Figure 1-12. TG demonstrating an interrupted derivative weight curve and poor volatilization. 
A derivative weight curve is used to aid in the determination of clean thermolyses. A single asymmetric peak with a slow on-set and a quick drop-off after a maximum is reached demonstrates one thermal event has occurred and that clean volatilization was achieved (Figure 1-11). If the derivative weight percent shows several features or has a symmetric peak the species is considered to have most likely undergone thermal degradation (Figure 1-12).

The temperature at which volatilization begins is termed the on-set of volatility and is defined (somewhat arbitrarily) as 5\% weight loss. A desirable on-set of volatility for an ALD precursor would occur at low temperatures.

Another technique that is used simultaneously with TG is differential scanning calorimetery (DSC). DSC measures temperature and heat flow associated with the thermal transitions within a sample material. This is accomplished by measuring the difference in the amount of heat required to heat a sample and a reference as a function of temperature. This complementary technique measures endothermic or exothermic events which have no associated weight loss, such as melting, and can help to differentiate between events that do involve weight loss, such as thermal degradation. 


\subsection{References}

${ }^{1}$ (a) Jones, A.C., Aspinall, H.C., Chalker, P.R., Potter, R.J., Kukli, K., Rahtu, A., Ritala, M., Leskela, M.; J. Mater. Chem., 2004, 14, 3101. (b) Hausmann, D.M., Kim, E., Becker, J., Gordon, R.G.; Chem. Mater., 2002, 14, 4350. (c) George, S.M.; Chem. Rev., 2010, 110, 111. (d) Putkonen, M., Niinisto, L.;

Top. Organomet. Chem., 2005, 9, 125. (e) George, S.M., Ott, A.W., Klaus, J.W.; J. Phys. Chem., 1996, 100, 13121. (f) Ott, A.W., Klaus, J.W., Johnson, J.M., George, S.M.; Thin Solid Films, 1997, $292,135$. ${ }^{2}$ (a) Leskela, M., Ritala, M.; Angew. Chem. Int. Ed., 2003, 42, 5548. (b) Xie, Q., Jiang, Y.L., Detavernier, C., Deduytsche, D., Van Meirhaeghe, R.L., Ru, G.P., Li, B.Z., Qu, X.P.; J. Appl. Phys., 2007, 102, 083521. (c) Jogi, I., Pars, M., Aarik, A., Laan, M., Sundqvist, J., Oberbeck, L., Heitmann, J., Kukli, K.; Thin Solid Films, 2008, 516, 4855. (d) Maeng, W.J., Kim, H.; Electrochem. Solid-State Letters, 2006, 9, 6, G191.

${ }^{3}$ Kucheyev, S.O., Biener, J., Baumann, T.F., Wang, Y.M., Hamza, A.V., Li, Z., Lee, D.K., Gordon, R.G.; Langmuir, 2008, 24, 943.

${ }^{4}$ Niinisto, J., Kukli, K., Heikkila, M., Ritala, M., Leskela, M.; Adv. Eng. Mater., 2009, 11, 4, 223.

${ }^{5}$ Niinisto, J., Putkonen, M., Niinisto, L., Song, F., Williams, P., Heys, P.N., Odedra, R.; Chem. Mater., 2007, 19, 3319.

${ }^{6}$ Hatanpaa, T., Ihanus, J., Kansikas, J., Mutikainen, I., Ritala, M., Leskela, M.; Chem. Mater., 1999, $11,1846$.

${ }^{7}$ (a) Kukli, K., Ritala, M., Schuisky, M., Leskela, M, Sajavaara, T., Keinonen, J., Uustare, T., Harsta, A.; Chem. Vap. Deposition, 2000, 6, 303. (b) Ritala, M., Asikainen, T., Leskela, M.; Electrochem Solid State Lett, 1998, 1, 156.

${ }^{8}$ Leskela, M., Ritala, M.; Thin Solid Films., 2002, 409, 138.

${ }^{9}$ Rahtu, A., Ritala, M., Leskela, M.; Chem. Mater., 2001, 13, 1528.

${ }^{10}$ Kim, K.H., Farmer, D.B., Lehn, J.M., Rao, P.V., Gordon, R.G.; App. Phys. Lett., 2006, 89, 133512.

${ }^{11}$ Lee, M.K., Lee, H.C., Hsu, C.M.; Semicond. Sci. Tech., 2006, 21, 5, 604.

${ }^{12}$ Peck, J., Litwin, M.M., Meiere, S.H.; ECS Trans., 2006, 1, 10, 103. 
${ }^{13}$ (a) Kanjolia, R.K., Anthis, J., Odedra, R., Williams, P., Heys, P.N.; ECS Trans., 2008, 16, 4, 79. (b) Jones, A.C., Aspinall, H.C., Chalker, P.R.; Surf. Coat. Tech., 2007, 201, 9046.

${ }^{14}$ Li, Z., Barry, S.T., Gordon, R.G.; Inorg. Chem., 2005, 44, 1728.

${ }^{15}$ Pore, V., Kivela, T., Ritala, M., Leskela, M.; Dalton Trans., 2008, 45, 6467.

${ }^{16}$ Myllymaki, P., Nieminen, M., Niinisto, J., Putkonen, M., Kukli, K., Niinisto, L.; J. Mater. Chem., 2006, 16, 6, 563.

${ }^{17}$ Lawrance, G.A.; Introduction to Coordination Chemistry. Wiltshire, UK; John Wiley \& Sons, 2010. $37-38$.

${ }^{18}$ Vehkamaki, M., Hatanpaa, T., Hanninen, T., Ritala, M., Leskela, M.; Electrochem. Solid State Lett., $1999,2,504$

${ }^{19}$ (a) Kissounko, D.A., Zabalov, M.V., Brusova, G.P., Lemenovskii, D.A.; Russian Chem. Rev., 2006, 75(5), 351 - 374. (b) Bai, S.D., Guo, JP., Liu, D.S.; Dalton Trans., 2006, 2244-2250. (c) Barker, J, Kilner, M.; Coord. Chem. Rev., 1994, 133, 219. (d) Edelmann, F.T., Coord. Chem. Rev., 1994, 137, 403.

${ }^{20}$ Pang, X, Yao, Y., Wang, J., Sheng, H., Zhang, Y., Shen, Q., Chinese J. of Chem., 2005, 23, 1193

${ }^{21}$ Bailey, P.J., Pace, S.; Coord. Chem. Rev., 2001, 214, 91.

${ }^{22}$ Duncan, A.P., Mullins, S.M., Arnold, J., Bergman, R.G., Organomet, 2001, 20, 1808.

${ }^{23}$ Tin, M.K.T., Yap, G.P.A., Richeson, D.S., Inorg. Chem., 1998, 37, 6728 - 6730

${ }^{24}$ Unpublished results from Richeson, D.S.

${ }^{25}$ (a) Chang, C., Hsiung, C., Su, H., Srinivas, B., Chiang, M., Lee, G., Wang, Y.; Organometallics, 1998, 17, 1595. (b) Kenney, A.P., Yap, G.P.A., Richeson, D.S., Barry, S.T.; Inorg. Chem., 2005, 44, 2926. (c) Brazeau, A.L., Wang, Z., Rowley, C.N., Barry, S.T.; Inorg. Chem., 2006, 45, 2276. (d) Rowley, C.N., DiLabio, G.A., Barry, S.T.; Inorg. Chem., 2005, 44, 1983.

${ }^{26}$ (a) Brazeau, A.L., DeLabio, G.A., Kreisel, K.A., Yap, G.P.A., Barry, S.T.; Dalton Trans., 2007, 30, 3297. (b) Brazeau, A.L.; Theoretical and Experimental Investigation of Ligand Exchange in Amidinate and Guanidinate Ligand Systems and the Atomic Layer Deposition of Aluminum Oxide, M.Sc., 2007.

${ }^{27}$ Li, Z., Rahtu, A., Gordon, R.G., J. Electrochem. Soc., 2006, 153, 11, C787. 


\section{Chapter 2:}

\section{Iminopyrrolidine Ligand and Aluminum Complexes}

\subsection{Introduction}

Amidinates and guanidinates have been widely used as alternative ligands to cyclopentadienyl ligands in organometallic chemistry. ${ }^{1}$ These ligands have been used with many metals across the periodic table to make organometallic complexes for catalysis $^{2}$ as well as potential precursors for processes in material science and nanotechnology such as MOCVD and ALD. ${ }^{3}$

Amidinate and guanidinate anions of the general formula $\left[\mathrm{RC}\left(\mathrm{NR}^{\prime}\right)_{2}\right]^{-}$and $\left[\mathrm{R}_{2} \mathrm{NC}\left(\mathrm{NR}^{\prime}\right)_{2}\right]^{-}$respectively (where $\mathrm{R}=\mathrm{H}$ or alkyl and $\mathrm{R}^{\prime}=$ alkyl) are commonly found as ligands on precursors for ALD due to their tunable properties which allow control over volatility and melting point. ${ }^{4}$ The flexibility to change the steric and electronic properties of these ligands is highly attractive. However, mechanistic investigations of these ligands have revealed that deinsertion of CDI from the parent guanidinate or amidinate at elevated temperatures can occur (Scheme 2-1).

Scheme 2-1. Deinsertion of CDI at elevated temperatures.

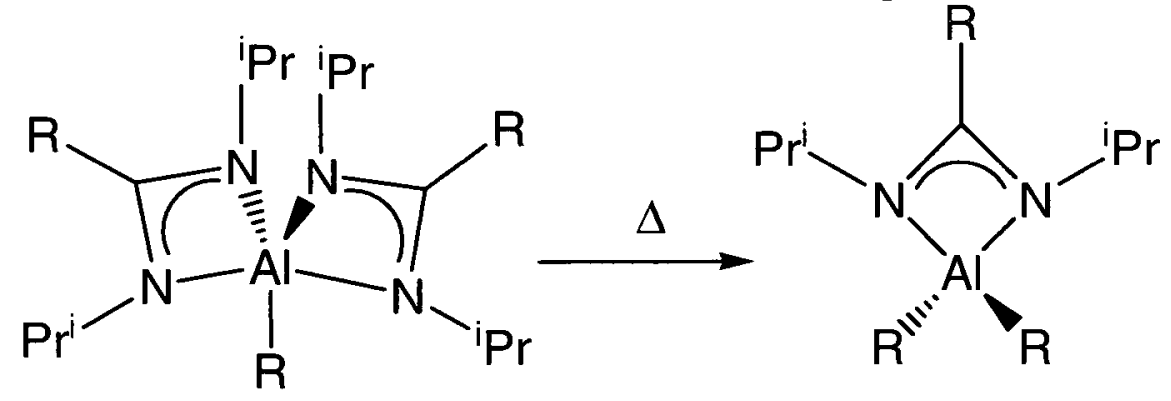<smiles>CCCPN=C=NP</smiles> 
Thus the search for a ligand that does not allow the deinsertion of CDI has led to a novel alternative; iminopyrrolidine. The iminopyrrolidinate ligand is monoanionic like its amidinate counterpart; however the $\mathrm{sp}^{2}$ carbon is tethered to one of the chelating nitrogens through a five membered ring (Figure 2-1). This type of structure would prevent CDI (Scheme 2-1) deinsertion because rearrangement to form CDI would be highly unfavourable. It is also viewed to be more stable than their oxazoline analogues as they are less likely to undergo ring opening decomposition. ${ }^{5}$
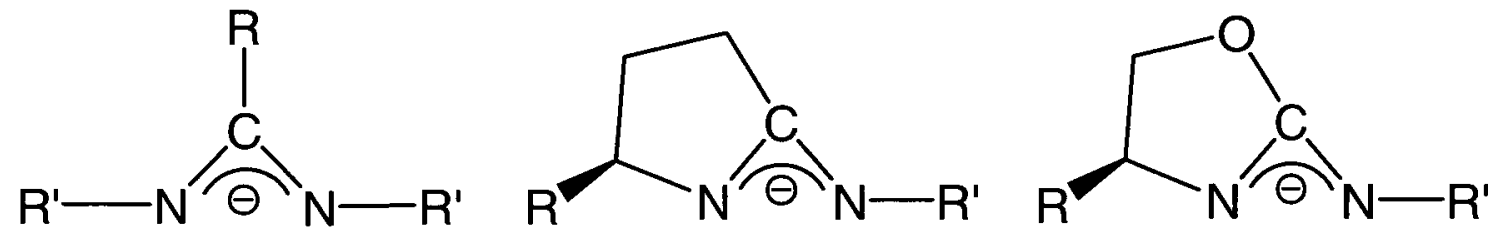

$$
\begin{gathered}
\mathrm{R}=\mathrm{H} \text { or alkyl } \\
\mathrm{R}^{\prime}=\text { alkyl }
\end{gathered}
$$

Figure 2-1. The similarity in chelating geometry of an amidinate, an iminopyrrolidinate and an aminooxazolidinate.

Iminopyrrolidinate based ligands, like amidinates, can be easily tuned to decrease melting point by increasing the length and controlling the branching of the alkyl chain bonded to the acyclic nitrogen. The asymmetry of the ligand is a desirable feature as it can increase volatility of organometallic complexes. This chapter will introduce a novel family of ligands and discuss their reactivity with TMA and triethyl aluminum (TEA) to make heteroleptic aluminum derivatives. Aluminum was used as an introductory metal as its chemistry is facile and well known. The thermal behaviour of the ligands and the aluminum compounds will also be examined. The advantage of these potential aluminum precursors would be the prevention of CDI deinsertion at elevated temperatures. 


\subsection{Results and Discussion}

\subsubsection{Ligand Synthesis and Thermolysis}

A straightforward synthetic route (Scheme 2-2) for iminopyrrolidines was achieved after Amanda Kenney and Agnieszka Kurek tweaked the experimental from two previously reported syntheses ${ }^{5,6}$ and each reported their advances in their theses. ${ }^{7,8}$ Due to the low boiling point of isopropyl amine, the butyl amine family and n-propyl amine were used in hopes to increase the yield of this ligand. Thus, the synthetic procedure will be discussed in detail.

Scheme 2-2. Synthetic procedure for iminopyrrolidine ligands.

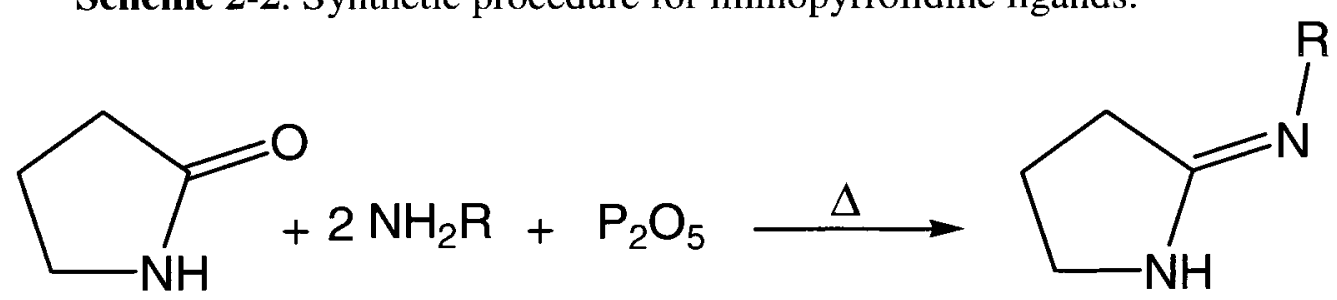

$$
\mathrm{R}=\text { propyl, iso-propyl, butyl, iso-butyl, sec-butyl, tert-butyl }
$$

The molar ratio of the amine was increased compared to the literature preparation due to high volatility issues. The amount of amine was doubled and mixed with the pyrrolidinone then added through a reflux condenser to neat $\mathrm{P}_{2} \mathrm{O}_{5}$. A longer reflux condenser was used to ensure that the amine would be contained during the reaction. Very importantly, the source of heat was changed from an oil bath to a sand bath. The sand bath proved to have less heat loss to the surroundings than the oil bath and so it was much easier to control and quicker to reach reflux temperatures. Keeping the time of heating short was crucial to improving the yield. 
Once the reaction time of 2 hours was reached, the reaction was allowed to cool to a glassy solid. Instead of using ice to dissolve the solid, ${ }^{6} 40 \mathrm{~mL}$ of distilled water was used with the aid of a heat gun. The strength of the base was increased to $6 \mathrm{M} \mathrm{NaOH}$ to avoid the introduction of too high a volume of water: iminopyrrolidines are soluble in water.

By simply implementing these changes we were able to achieve excellent yields of the purified ligands. The n-propyl iminopyrrolidine, 1, was sublimed under reduced pressure at $60^{\circ} \mathrm{C}$ to afford a colourless solid (Table 2-1).

Table 2-1. Yield and melting point for compounds 1 - 4.

\begin{tabular}{cccc}
\hline & Compound & $\begin{array}{c}\text { Yield } \\
(\mathbf{\%})\end{array}$ & $\begin{array}{c}\text { Melting Point } \\
\left({ }^{\mathbf{0}} \mathbf{C}\right)\end{array}$ \\
\hline \hline $\mathbf{1}$ & N-propyl iminopyrrolidine & 72 & $72-74$ \\
$\mathbf{2}$ & $\mathrm{AlMe}_{2}$ npip & 79 & $79-83$ \\
$\mathbf{3}$ & $\mathrm{AlEt}_{2}$ ipip & 70 & $120-124$ \\
$\mathbf{4}$ & $\mathrm{AlEt}_{2}$ npip & $72^{\mathrm{a}}$ & liquid \\
\hline${ }^{a}$ Crude yield & & &
\end{tabular}

The bench top melting point of the ligand 1 was comparable with the endothermic peak of the DSC results (Figure 2-2, Table 2-1). An endotherm at $79^{\circ} \mathrm{C}$ was achieved at a ramp rate of $10^{\circ} \mathrm{C} / \mathrm{min}$ as well as what may be a boiling point at $255^{\circ} \mathrm{C}$. The first endotherm was very close to the bench top melting point of $72-74^{\circ} \mathrm{C}$. Five other iminopyrrolidine ligands where synthesized, purified and studied in previous reports, with 1 completing the series of the propyl derivatives. ${ }^{7,8,10}$ Thermolysis studies demonstrated a melting point trend associated with the alkyl moiety on the ligand (Table 2-2). N-propyl iminopyrrolidine (npip, 1) has a lower melting point than its similar propyl iminopyrrolidine ligand; iso-propyl (ipip, 1.1), $74^{\circ} \mathrm{C}$ compared to $100^{\circ} \mathrm{C}$, respectively. The drop in melting point may be associated with the increase in the degree 
of freedom of the longer chain from the n-propyl moiety of 1 compared to the branched iso-propyl moiety of 1.1. This effect of lowering melting points was also evident when 1 was compared with the n-butyl iminopyrrolidine (nbip, 1.2), where the longer chain lowered the melting point by roughly $18^{\circ} \mathrm{C}$. The extra methyl group adds to the degree of freedom of 1.2 compared to 1 . As the branching increases, the degree of freedom decreases, from 1.2 to tert-butyl iminopyrrolidine (tbip, 1.5) increasing the melting point. Notably, there is a decrease in the melting point for sec-butyl iminopyrrolidine (sbip, 1.4). This can be attributed to the fact that there is asymmetric branching around the amine as well as the stereoisomer present due to the sec-butyl group.

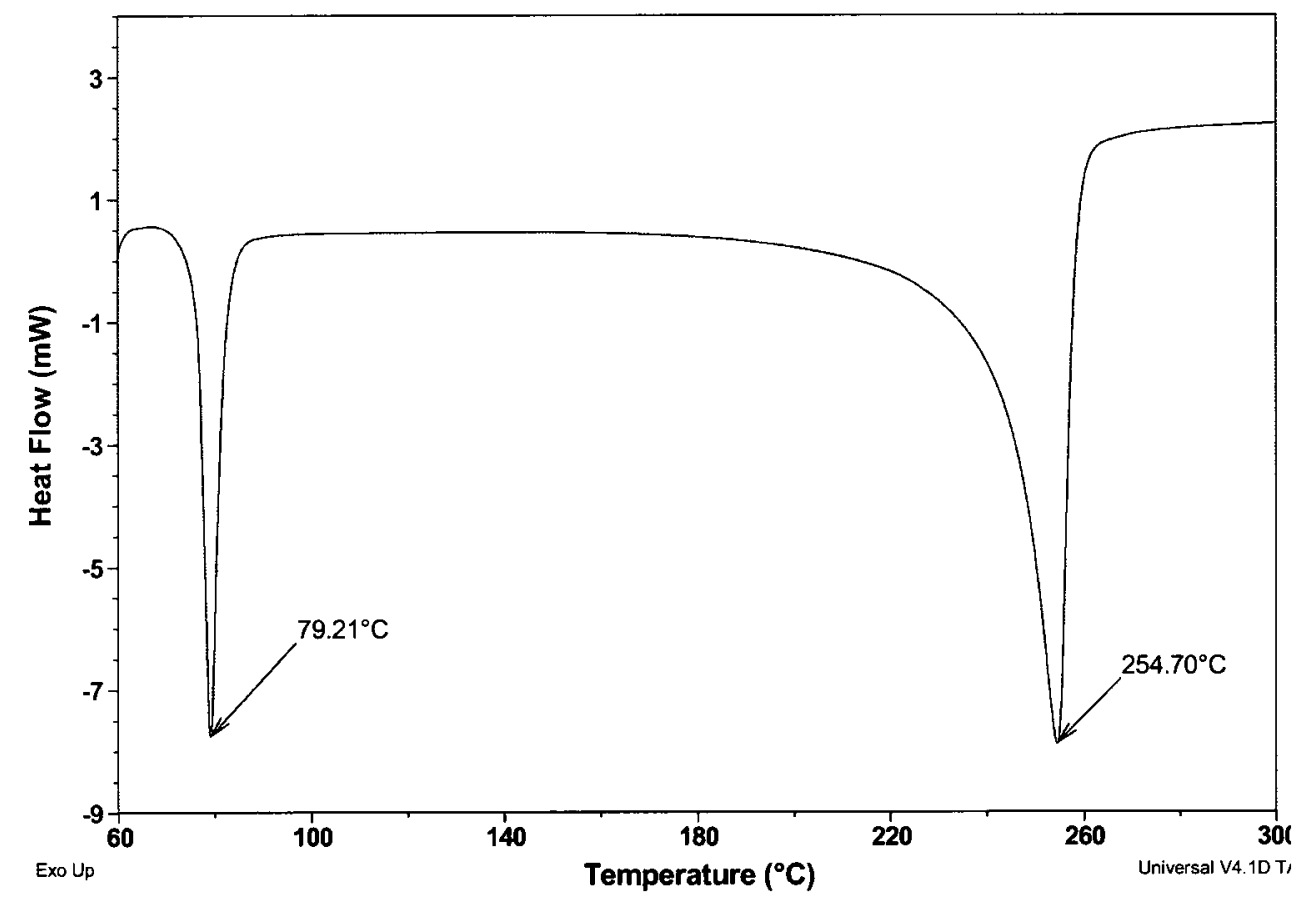

Figure 2-2. Differential scanning calorimetery of 1. 
Table 2-2. Thermal parameters of iminopyrrolidine ligands.

\begin{tabular}{cccc}
\hline Compound & $\mathbf{R}$ & Melting Point $\left({ }^{\mathbf{o}} \mathbf{C}\right)$ & $\begin{array}{c}\text { On-set of Volatility } \\
\left({ }^{\mathbf{0}} \mathbf{C}\right)^{\mathbf{a}}\end{array}$ \\
\hline $\mathbf{1}$ & N-propyl (npip) & $72-74$ & 84.91 \\
$\mathbf{1 . 1}$ & Iso-propyl (ipip) $^{b}$ & $99-100$ & 76.48 \\
$\mathbf{1 . 2}$ & N-butyl (nbip) $^{c}$ & $55-56$ & 95.30 \\
$\mathbf{1 . 3}$ & Iso-butyl (ibip) $^{c}$ & $102-103$ & 83.46 \\
$\mathbf{1 . 4}$ & Sec-butyl (sbip) $^{c}$ & $98-100$ & 75.51 \\
$\mathbf{1 . 5}$ & Tert-butyl (tbip) $^{c}$ & $108-110$ & 71.21 \\
\hline on-set of volatility was taken as 5\% mass loss, ${ }^{b}$ compound taken from reference [7] ${ }^{c}$ \\
compounds taken from reference [8].
\end{tabular}

Thermal gravimetric (TG) analyses of all six ligands were collected (Figure 2-3). Although 1.2 had the lowest melting point it is evident that it had the highest on-set of volatility, followed by 1 . The higher on-set of volatility suggests stronger hydrogen bonding between the molecules. This can be attributed to the lack of steric hindrance around the amide in the straight chained alkyl complexes. Even with a higher on-set of volatility compound $\mathbf{1}$ has a clean volatilization (only one feature in the TG), demonstrating that it did not decompose under heat. The residual mass of each ligand was zero, also indicating a clean thermolysis. The on-set of volatilization (i.e. $5 \%$ mass loss) for 1 occurred at $85^{\circ} \mathrm{C}$ and showed an uninterrupted weight loss to $0 \%$ residual mass. The differential curve for this weight loss (Figure 2-4) had the typical appearance of sublimation, an asymmetric curve with a slow on-set and a quick drop-off. 


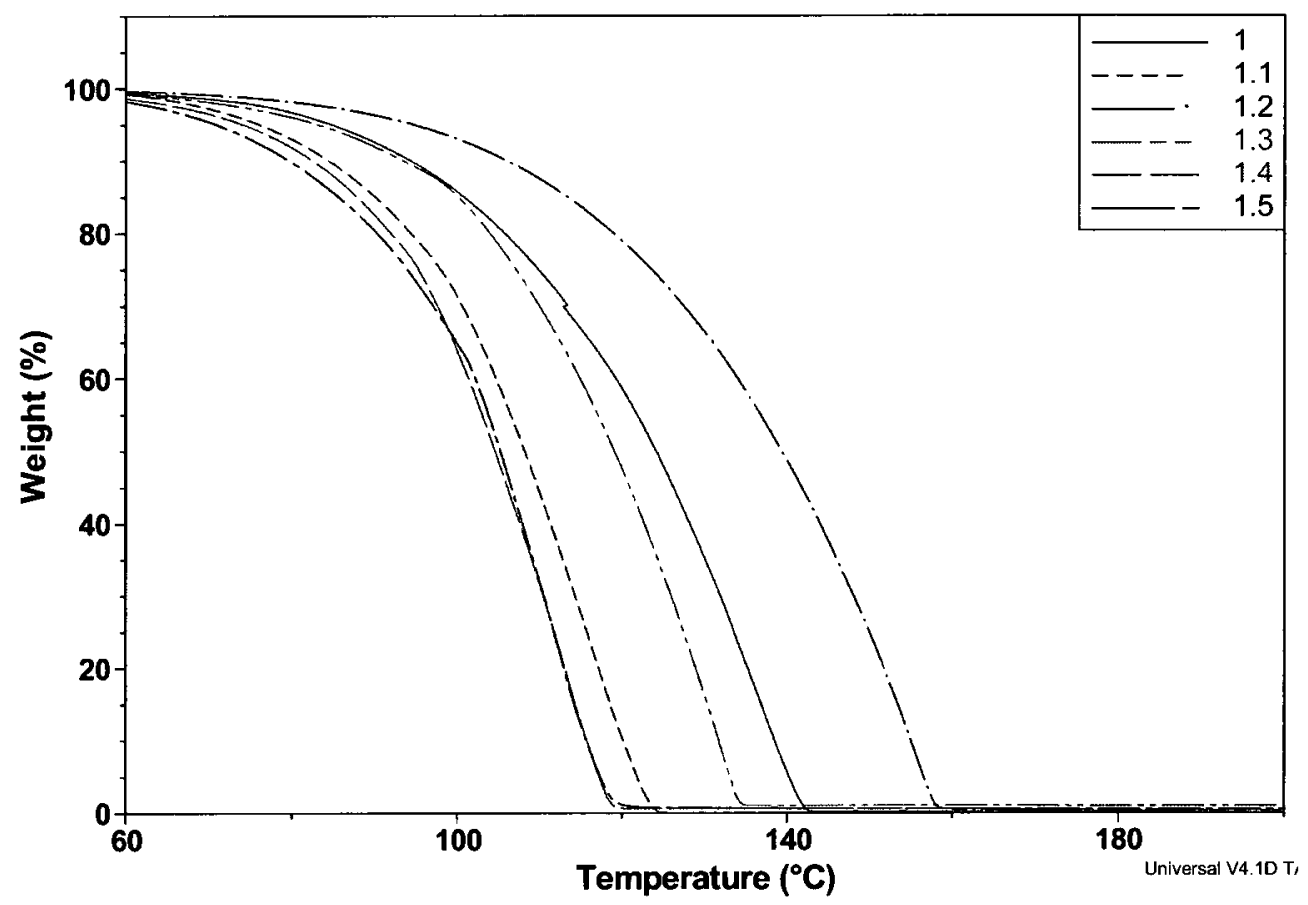

Figure 2-3. Thermal gravimetric analysis of iminopyrrolidine ligands.

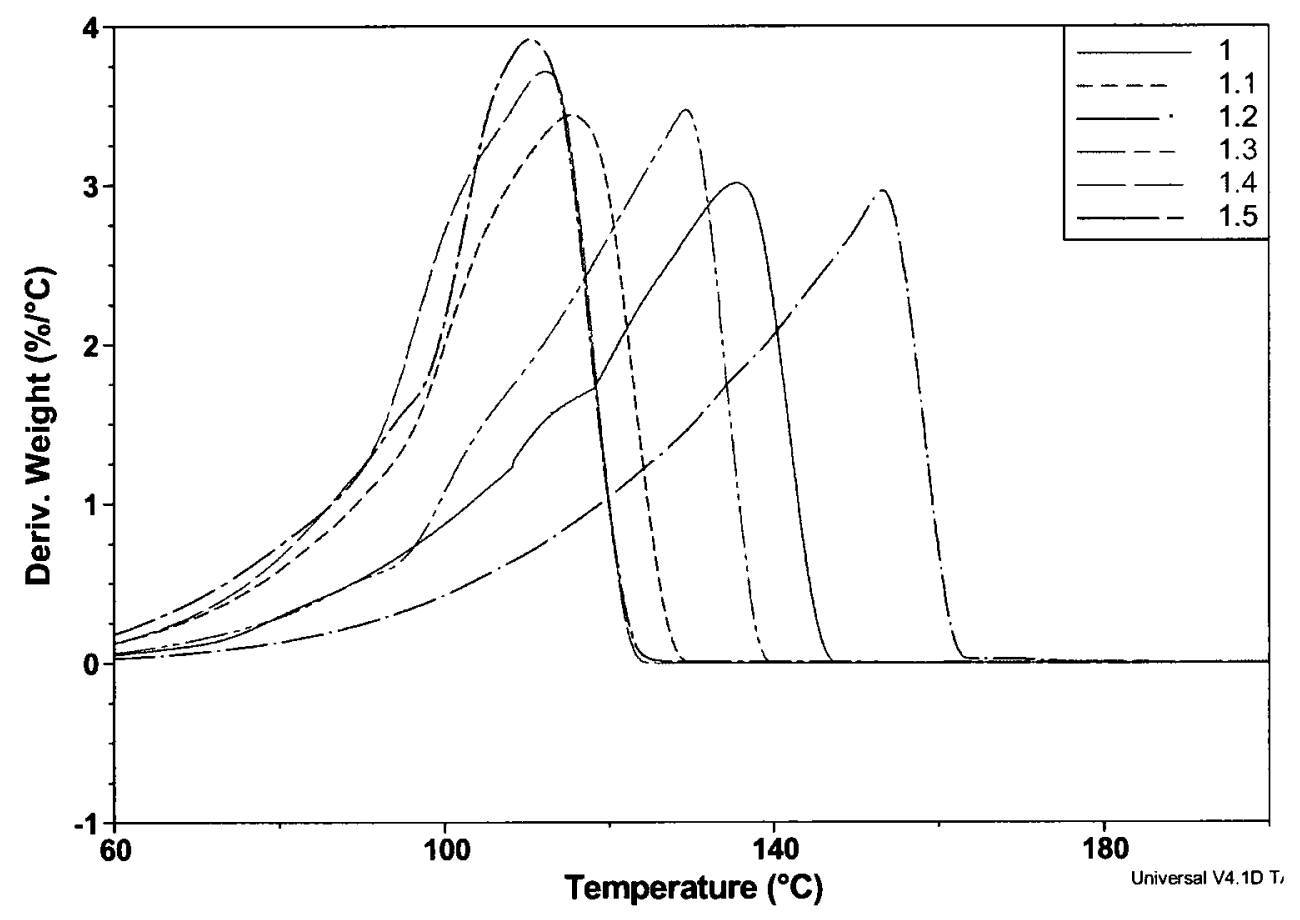

Figure 2-4. Differential weight curve for iminopyrrolidine ligands. 
A nuclear magnetic resonance (NMR) tube boil-up was performed on all six ligands since this thermolysis experiment was previously unreported for these compounds. ${ }^{10}$ Compounds 1 - 1.5 were dissolved in $0.25( \pm 6) \mathrm{mL}$ of $1 \% \mathrm{v} / \mathrm{v}$ tetramethylsilane (TMS) in benzene $\left(\mathrm{C}_{6} \mathrm{D}_{6}\right)$ solution in thick-walled NMR tubes under inert atmosphere. The tubes were immersed in liquid nitrogen and the glass tube was sealed under vacuum. Each tube was placed in a furnace at $125^{\circ} \mathrm{C}$ and the loss of the furthest methyl $\left(\mathrm{CH}_{3}\right)$ group peak of $\mathrm{R}$ was monitored relative to TMS using ${ }^{1} \mathrm{H}$ NMR. Decomposition began for ligands 1, 1.1, 1.2, and 1.3 after 6 days but did not progress further during the duration of the experiment. The decomposition of the ligands showed no production of CDI; however the formation of a small amount of the parent amine and a ring species was evident in each case. After 28 days at elevated temperatures ligands 1.4 and $\mathbf{1 . 5}$ showed no decomposition. This finding revealed that the ligand species $\mathbf{1}-\mathbf{1 . 3}$ thermolyses by loss of the parent amine was perhaps due to some impurities found within the NMR tube as there was no progression of the decomposition for the duration of the study. Subjecting these ligands to such aggressive conditions for an extended period of time without decomposition demonstrated that they may be excellent ligands for ALD processes. 


\subsubsection{Syntheis of Heteroleptic Aluminum Species and Crystal Structure Data}

TMA was used as the starting material for the synthesis of a heteroleptic aluminum complex containing 1 as the ligand. A one-to-one ligand-to-TMA mixture in hexanes at room temperature was used to synthesize the dimethyl aluminum iminopyrrolidinate complex 2 (Scheme 2-3). Methane elimination was the driving force of this reaction.

Scheme 2-3. Synthesis of complex 2.

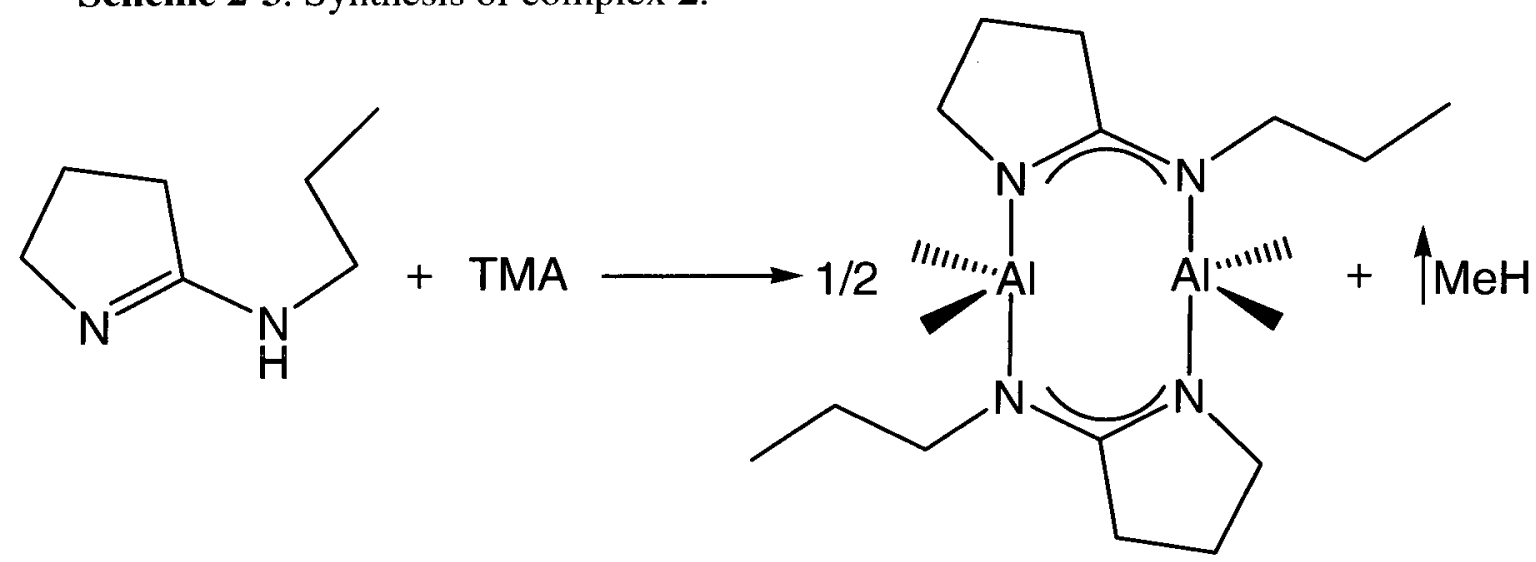

Compound 2 was a colourless solid and was purified by crystallization which produced cubic crystals of sufficient quality for a single crystal structure to be collected (Figure 2-5 and Figure 2-6, Table 2-3 and Table 2-4). The ${ }^{1} \mathrm{H}$ NMR for this compound was similar in its simplicity to the other bip/pip heteroleptic compounds ${ }^{7,8}$ suggesting a symmetric compound with no evidence of monomer - dimer equilibrium. 


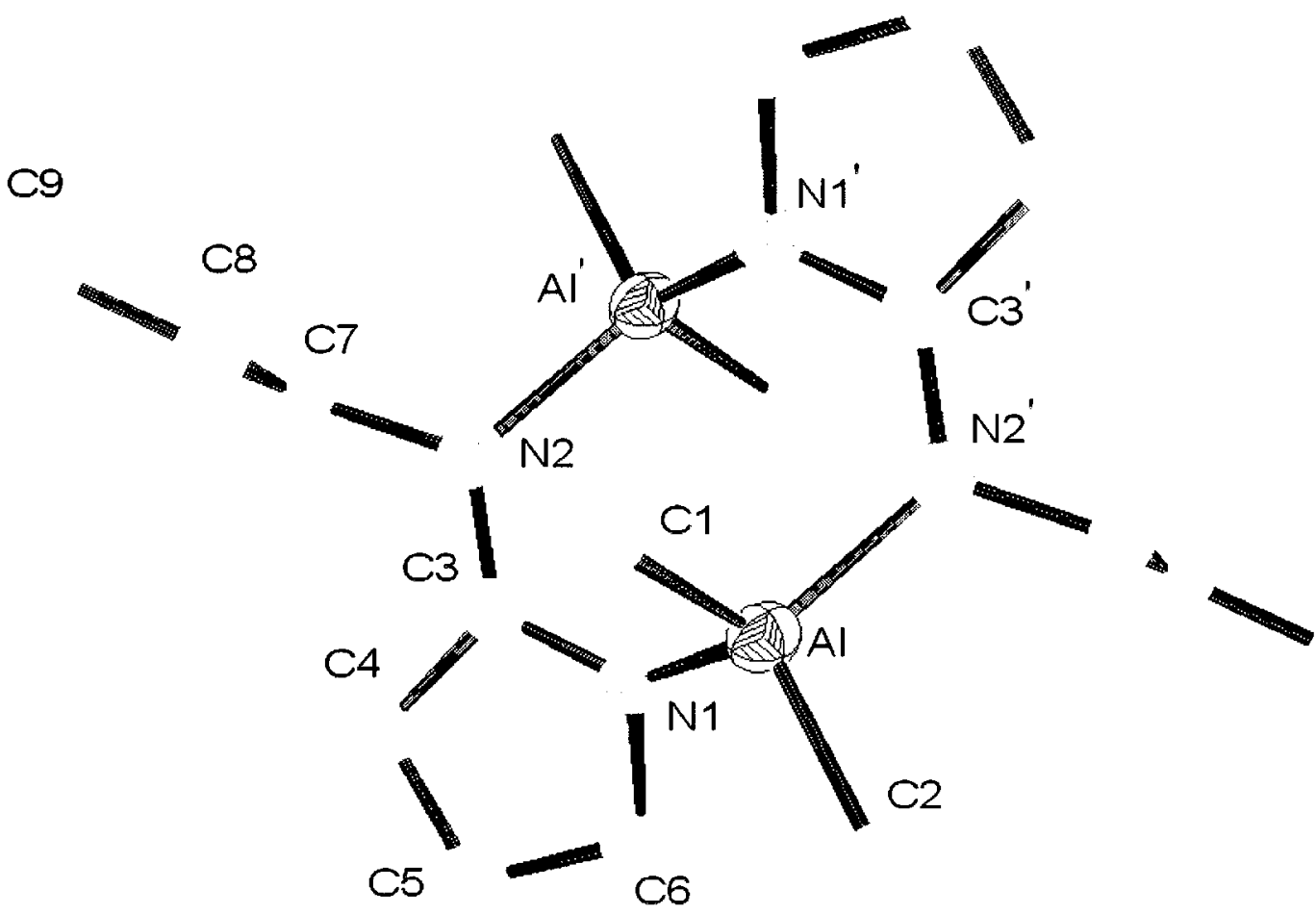

Figure 2-5. The single-crystal X-ray structure of 2. The thermal ellipsoids are shown at $50 \%$ probability and the hydrogen centres are omitted for clarity.

Compound 2 was symmetrical existing in a P-1 space group with an $\mathrm{S}_{2}$ symmetry axis and a centre of inversion residing at the molecular centre. The aluminum was in a distorted tetrahedral geometry with angles very close to ideal ranging from $105.7^{\circ}$ to $114.7^{\circ}$ with $\mathrm{C} 1-\mathrm{Al}-\mathrm{C} 2$ being the largest angle. It was evident from the crystal structure that the $\pi$-system was localized within the chelate ring as the N1-C3 and N2-C3 bonds were shorter at approximately $1.33 \AA$ than the N1-C6 and N2-C7 bonds at approximately $1.48 \AA$, respectively. The latter $\mathrm{C}-\mathrm{N}$ bonds were similar to ideal $\mathrm{C}-\mathrm{N}$ single bond lengths of $1.479 \AA .^{9}$ The quaternary carbon, C3, was planar with a sum of angles of $360^{\circ}$ indicating that it had an $\mathrm{sp}^{2}$ hybridization, allowing the remaining $\mathrm{p}$ orbital to participate in the $\pi$-system. The nitrogen centres $\mathrm{N} 1$ and $\mathrm{N} 2$ were close to planar with sums of 
angles at $355.5^{\circ}$ and $356.6^{\circ}$, respectively. The N1-Al-N2' angle was $113.5^{\circ}$ which was slightly larger than previously reported $\mathrm{Al}$ iminopyrrolidinate complexes. ${ }^{10}$ The pyrrole ring had a bite angle of $122.6^{\circ}$ which was the same as the previously reported $\mathrm{Al}$ complexes. The eight membered ring from the dimer structure had a chair conformation as seen from the side view in Figure 2-6.

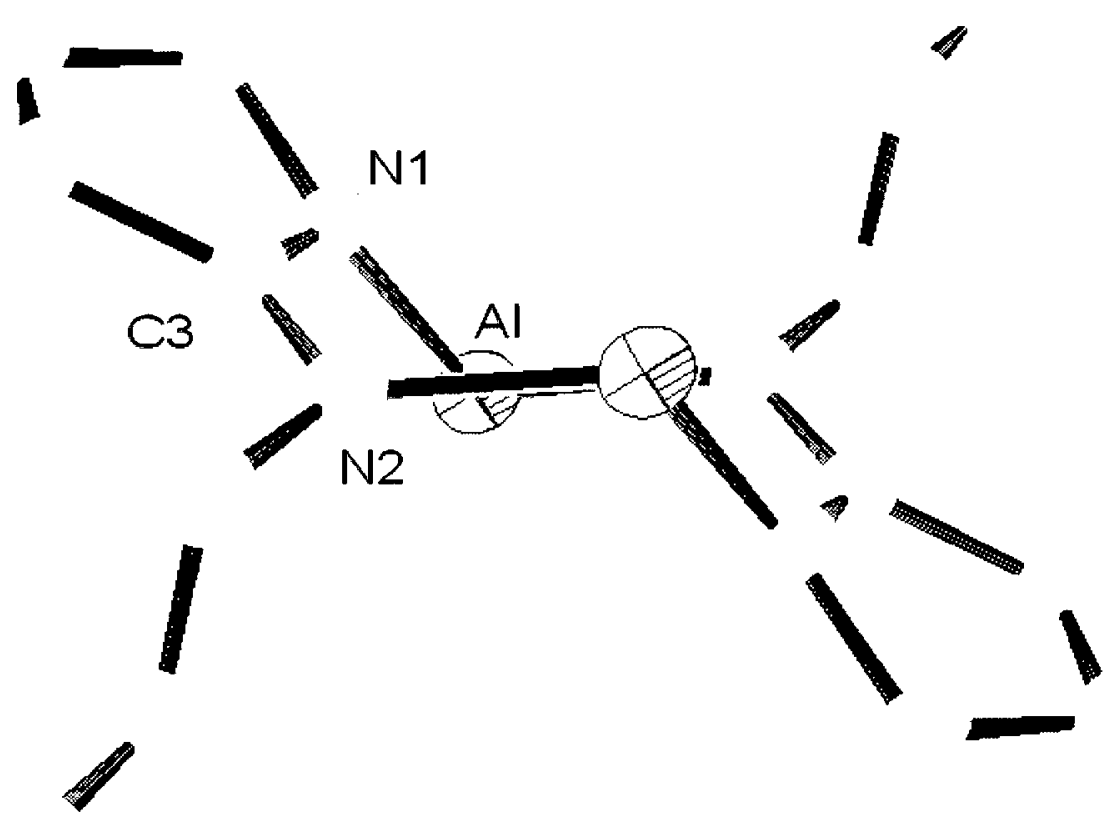

Figure 2-6. The single-crystal X-ray structure of 2 demonstrating chair conformation. The thermal ellipsoids are shown at 50\% probability; the hydrogen centres and both aluminum methyls are omitted for clarity. 
Table 2-3. Selected crystal data for compound 2.

\begin{tabular}{cc}
\hline & $\mathbf{2}$ \\
\hline \hline Empirical Formula & $\mathrm{C}_{18} \mathrm{H}_{38} \mathrm{AlN}_{2}$ \\
FW & 364.48 \\
Crystal System & Triclinic \\
Space Group & $\mathrm{P}-1$ \\
$a(\AA)$ & $8.243(3)$ \\
$b(\AA)$ & $8.424(3)$ \\
$c(\AA)$ & $8.511(3)$ \\
$\alpha(\mathrm{deg})$ & $94.333(5)$ \\
$\boldsymbol{\beta}(\mathrm{deg})$ & $92.335(5)$ \\
$\gamma(\mathrm{deg})$ & $108.428(5)$ \\
$\mathrm{V}\left(\AA^{3}\right)$ & $557.8(4)$ \\
$\mathrm{Z}$ & 1 \\
$\mathrm{D}_{\mathrm{c}}(\mathrm{kg} / \mathrm{L})$ & 1.085 \\
$\mu\left(\mathrm{mm}^{-1}\right)$ & 0.138 \\
$\mathrm{~T}(\mathrm{~K})$ & $200(2)$ \\
$\mathrm{R}, \mathrm{wR}$ & $0.0600,0.1665$ \\
Goodness-of-fit on $\mathrm{F}^{2}$ & 1.000 \\
\hline
\end{tabular}

Table 2-4. Selected bond lengths and angles for compound 2.

\begin{tabular}{|c|c|c|c|}
\hline \multicolumn{4}{|c|}{ Selected Bond Lengths $(\AA)$} \\
\hline $\mathrm{Al}-\mathrm{Cl}$ & $1.970(2)$ & N1-C6 & $1.483(2)$ \\
\hline $\mathrm{Al}-\mathrm{C} 2$ & $1.978(2)$ & C6-C5 & $1.495(3)$ \\
\hline $\mathrm{Al}-\mathrm{N} 1$ & $1.9219(16)$ & C5-C4 & $1.521(3)$ \\
\hline $\mathrm{N} 1-\mathrm{C} 3$ & $1.332(2)$ & $\mathrm{C} 4-\mathrm{C} 3$ & $1.520(2)$ \\
\hline $\mathrm{C} 3-\mathrm{N} 2$ & $1.326(2)$ & $\mathrm{C} 7-\mathrm{C} 8$ & $1.493(3)$ \\
\hline $\mathrm{N} 2-\mathrm{C} 7$ & $1.477(2)$ & $\mathrm{C} 8-\mathrm{C} 9$ & $1.518(4)$ \\
\hline $\mathrm{N} 2-\mathrm{Al}$ ' & $1.9285(17)$ & & \\
\hline \multicolumn{4}{|c|}{ Selected Bond Angles ( $\left.{ }^{\circ}\right)$} \\
\hline C1-Al-C2 & $114.73(9)$ & C3-N2-Al' & $120.95(12)$ \\
\hline $\mathrm{N} 2{ }^{\prime}-\mathrm{Al}-\mathrm{N} 1$ & $113.46(7)$ & $\mathrm{C} 7-\mathrm{N} 2-\mathrm{C} 3$ & $117.41(15)$ \\
\hline C1-Al-N1 & $108.53(8)$ & $\mathrm{N} 2-\mathrm{C} 3-\mathrm{C} 4$ & $125.32(16)$ \\
\hline C1-Al-N2' & $108.38(9)$ & $\mathrm{C} 3-\mathrm{C} 4-\mathrm{C} 5$ & $103.07(16)$ \\
\hline N1-Al-C2 & $105.67(8)$ & $\mathrm{C} 4-\mathrm{C} 5-\mathrm{C} 6$ & $105.48(18)$ \\
\hline $\mathrm{N} 2{ }^{\prime}-\mathrm{Al}-\mathrm{C} 2$ & $106.20(8)$ & C5-C6-N1 & $105.83(17)$ \\
\hline $\mathrm{Al}-\mathrm{N} 1-\mathrm{C} 3$ & $126.04(12)$ & C3-N1-C6 & $108.80(15)$ \\
\hline $\mathrm{N} 1-\mathrm{C} 3-\mathrm{N} 2$ & $122.62(16)$ & & \\
\hline \multicolumn{4}{|c|}{ Sum of Angles $\left(^{\circ}\right)$} \\
\hline N1 & 355.50 & $\mathrm{C} 3$ & 360 \\
\hline N2 & 356.56 & & \\
\hline
\end{tabular}


The n-propyl moiety of the iminopyrrolidine ligand was not large enough to prevent dimerization, so both iso-propyl and n-propyl ligands were reacted with TEA to try and force monomer formation through steric crowding by the aluminum alkyl groups. A oneto-one ligand-to-TEA reaction in hexanes at room temperature was used to synthesize the diethyl aluminum iminopyrrolidinate complexes (Scheme 2-4). Ethane elimination was the driving force of this reaction.

Scheme 2-4. Synthesis of $\mathrm{AlEt}_{2}$ iminopyrrolidinate complexes.

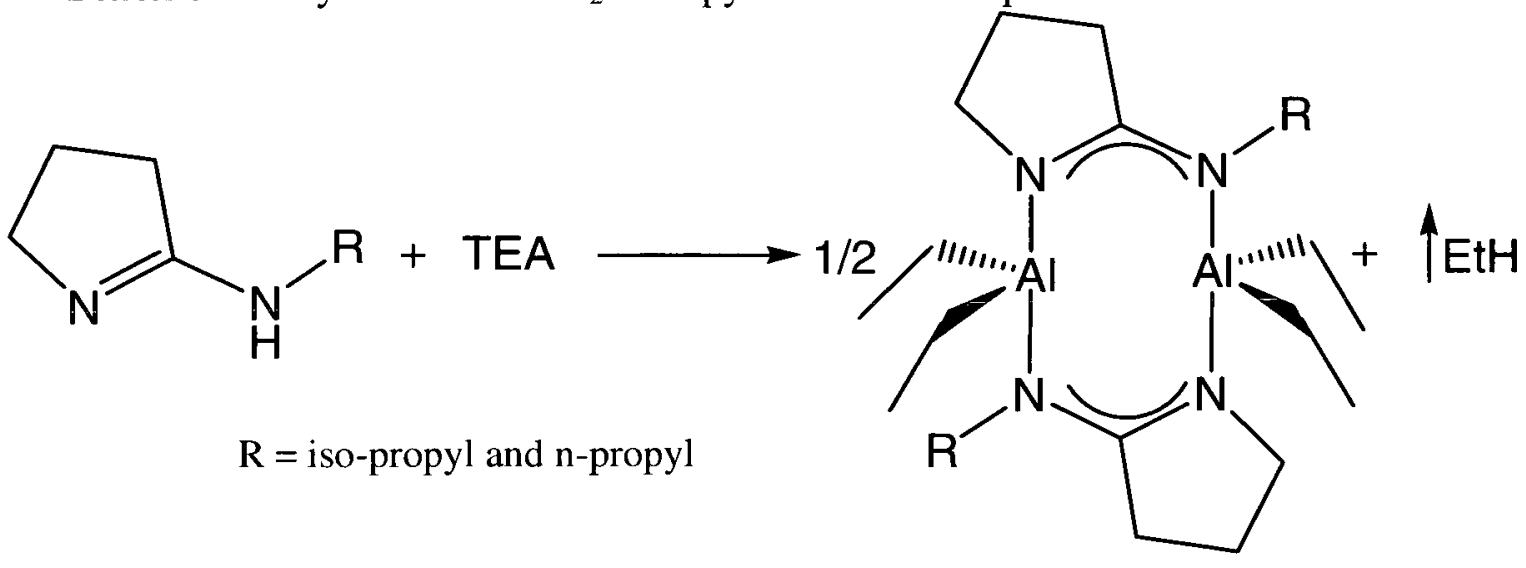

This reaction was also attempted with the sbip and tbip ligands ${ }^{8}$ and a crystal was collected from the sbip reaction demonstrating the formation of a dimer. Compound 3 formed a colourless solid in excellent yield (Table 2-1) and the diethyl aluminum npropyl iminopyrrolidinate, $\mathbf{4}$, formed a liquid. This liquid appeared to consist of several components according to the ${ }^{1} \mathrm{H}$ NMR, but the desired product was indeed present. Distillation at $86^{\circ} \mathrm{C}$ was attempted several times, however, no enhanced purity was seen by ${ }^{1} \mathrm{H}$ NMR. The reaction was repeated at lower temperatures $\left(-78^{\circ} \mathrm{C}\right)$ and the dissolved ligand was added dropwise. The ${ }^{1} \mathrm{H}$ NMR from these reactions were cleaner however, it was evident that there were still several by-products present. Distillation from these 
lower temperature reactions did not produce a purer compound. Further investigation of the purification of this compound is needed. If compound $\mathbf{4}$ is indeed a liquid, it would be very interesting to compare the thermolysis and the stability of this compound with an existing aluminum oxide precursor that was developed in our lab. ${ }^{11}$

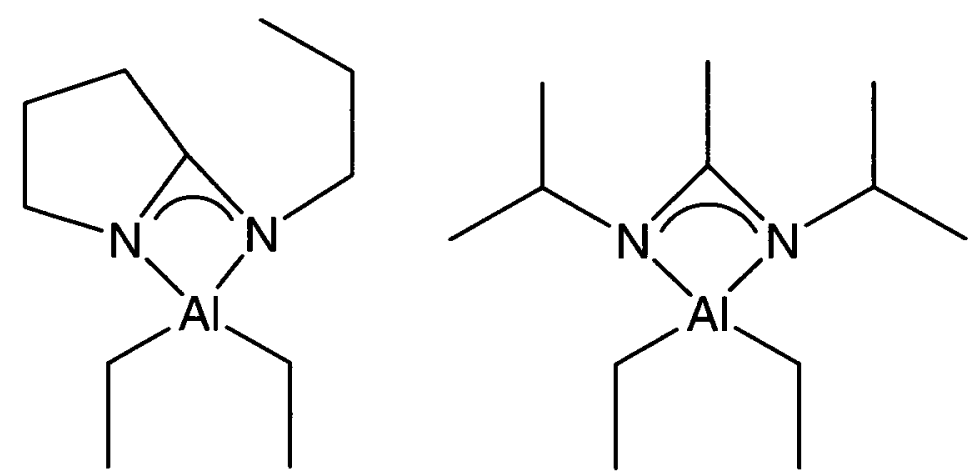

Figure 2-7. Analogous aluminum amidinate precursors.

This previously developed aluminum amidinate precursor is a colourless liquid that distils at $36^{\circ} \mathrm{C}$ at $85 \mathrm{mT}$ Torr with a yield of $77 \%$. The thermolysis of this compound has been thoroughly studied and an ALD process for $\mathrm{Al}_{2} \mathrm{O}_{3}$ films has been developed and is currently in use. Studying the thermolysis of the analogous amidinate ligand would provide a better understanding of how useful such a ligand would be for ALD processes.

\subsubsection{Thermolysis of Heteroleptic Organometallic Compounds}

The trend in the melting point of the ligands was reflected in the melting points of the heteroleptic aluminum complexes, as seen in Table 2-5. For instance, 2 (npipAlMe $)_{2}$ had a lower melting point than 2.1 (ipipAlMe ${ }_{2}$ ). As the length of the alkyl chain increased by

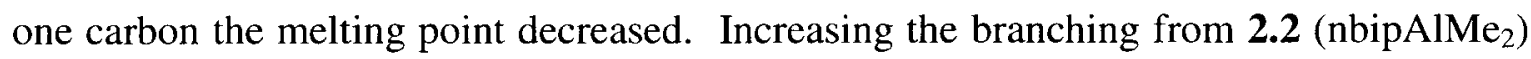


to 2.5 (tbipAlMe $_{2}$ increased the melting point with the exception of the stereocentre and asymmetry of $\mathbf{2 . 4}\left(\right.$ sbipAlMe$\left._{2}\right)$.

Table 2-5. Melting points for aluminum dimethyl iminopyrrolidinate complexes.

\begin{tabular}{ccc} 
Compound & $\mathbf{R}$ & $\begin{array}{c}\text { Melting Point } \\
\left({ }^{\mathbf{C}} \mathbf{C}\right)\end{array}$ \\
\hline $\mathbf{2}$ & N-propyl (npip) & $79-83$ \\
$\mathbf{2 . 1}$ & Iso-propyl (npip) $^{a}$ & $87-91$ \\
$\mathbf{2 . 2}$ & N-butyl (nbip) $^{b}$ & $68-70$ \\
$\mathbf{2 . 3}$ & Iso-butyl (ibip) $^{b}$ & $111-113$ \\
$\mathbf{2 . 4}$ & Sec-butyl (sbip) $^{b}$ & $62-65$ \\
$\mathbf{2 . 5}$ & Tert-butyl (tbip) $^{b}$ & $116-118$ \\
\hline${ }^{a}$ compound taken from reference [7], ${ }^{b}$ compounds taken from reference [8].
\end{tabular}

The TG analysis of the heteroleptic aluminum complex 2 can be seen in Figure 2-8. The TG had one major thermal event with two smaller events. The first small event occurred in the temperature range $60-98^{\circ} \mathrm{C}$ with a $1 \%$ weight loss which most likely corresponded to loss of incidental solvent. The second event occurred at temperature range $103-163^{\circ} \mathrm{C}$ a $5 \%$ weight loss which can be attributed to a slow thermal degradation of the compound. The major thermal event occurred at $167-315^{\circ} \mathrm{C}$ with a weight loss of $82 \%$. This feature had a shape that was characteristic of volatilization and was thought to be due to the volatilization of the decomposed aluminum complex. The curve was non-symmetrical in shape, which is commonly associated with the volatilization of a compound, where there is a slow on-set and a rapid drop-off when the maximum is reached. The final mass of 2 was approximately $8 \mathrm{mg}, 10 \%$ residual mass, most likely corresponding to the residual mass of a decomposed species. This is a reasonable residual mass for a vapour deposition precursor. Although there is no real need for additional aluminum-containing precursors for the deposition of traditional aluminum targets $\left(\mathrm{Al}_{2} \mathrm{O}_{3}\right.$ and $\left.\mathrm{AlN}\right)$, this does lend credibility to these ligands to fulfill a 
similar role as guanidinates and amidinates to aid in the volatility of other potential precursors.

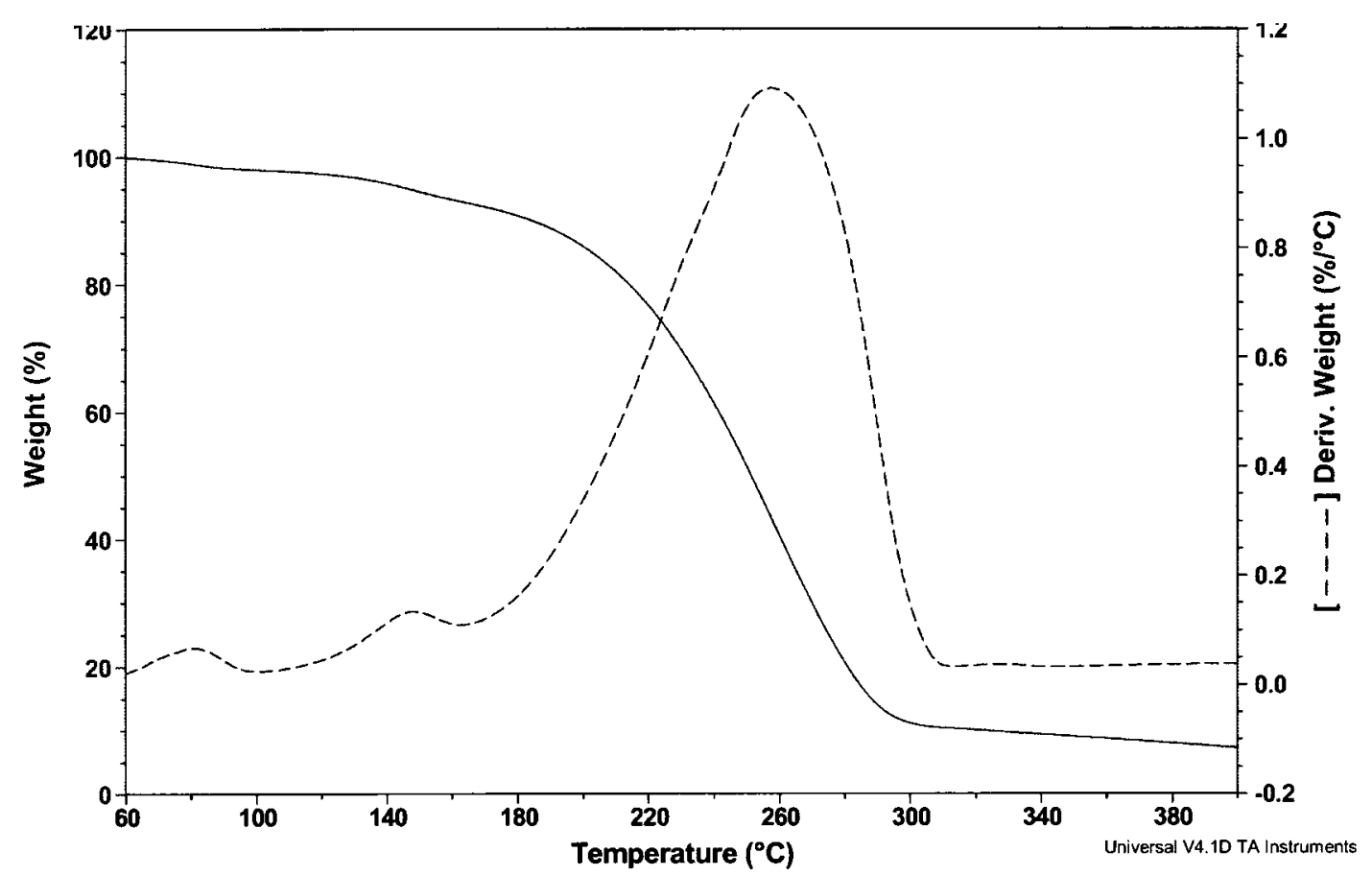

Figure 2-8. Thermal gravimetric analysis of 2.

The TG analysis of 3 had two thermal events (Figure 2-9). The on-set of volatility occurred at $109^{\circ} \mathrm{C}$ and the slope continued to $180^{\circ} \mathrm{C}$ with a weight loss $73 \%$. The second feature occurred at a temperature range of $180-280^{\circ} \mathrm{C}$ with a weight loss of $19 \%$. The major feature had a shape that was similar in character to volatilization and was thought to be due to the volatilization of the aluminum complex. The curve was non-symmetrical in shape, common to volatilization of a compound, with a slow on-set and a rapid dropoff when the maximum is reached. The second feature was characteristic of decomposition; a gradual on-set and drop-off. The residual mass of this complex was $1.8 \%$ which may correspond to residual decomposed material. 


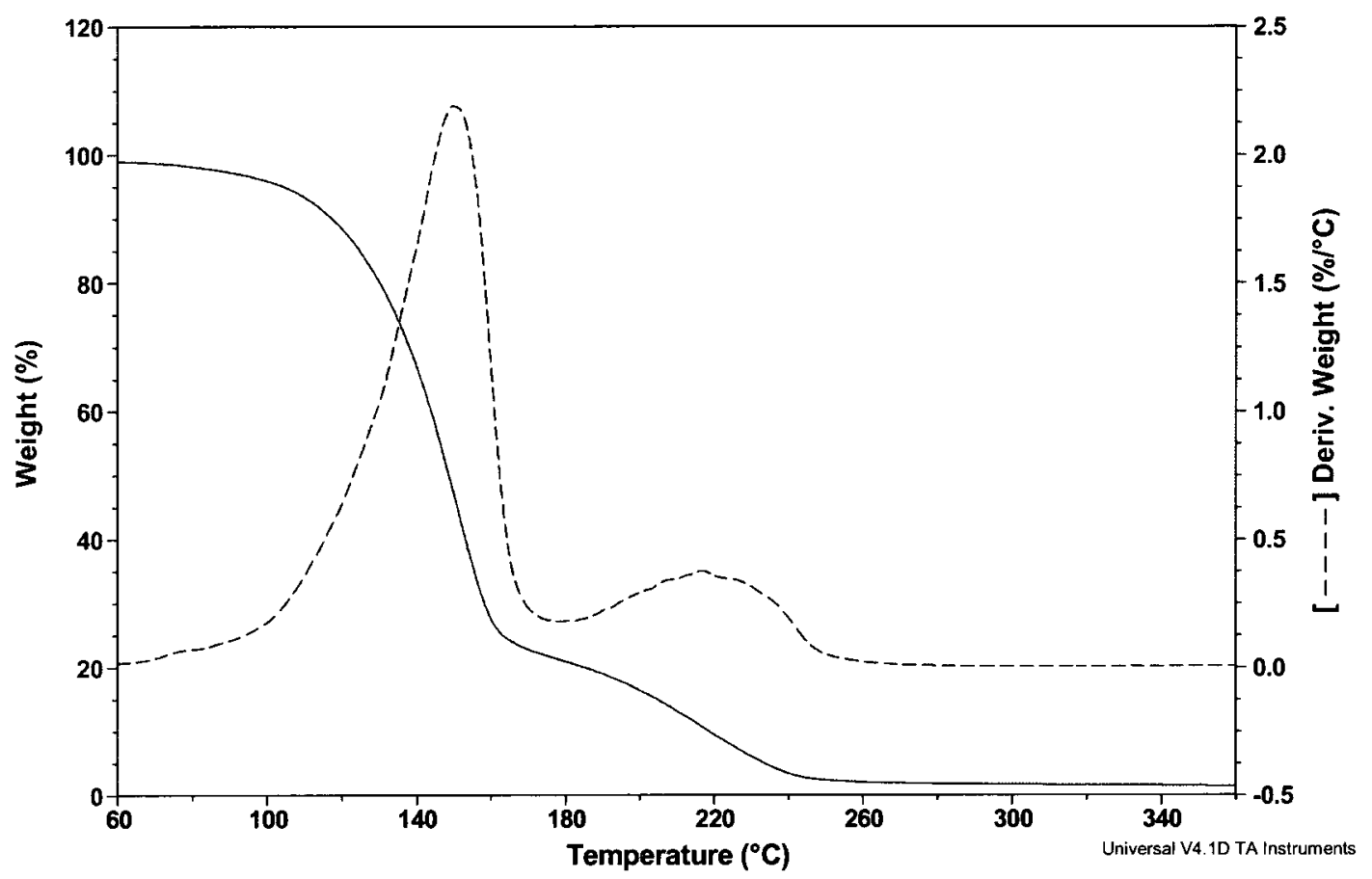

Figure 2-9. Thermal gravimetric analysis of 3.

A sealed NMR tube thermolysis experiment was conducted for two of the methyl derivatives 2 and 2.1 as well as the ethyl derivative 3 . They were dissolved in $0.35( \pm 6)$ $\mathrm{mL} 1 \% \mathrm{v} / \mathrm{v}$ TMS in $\mathrm{C}_{6} \mathrm{D}_{6}$ solution in thick-walled NMR tubes under inert atmosphere. The tubes were immersed in liquid nitrogen and the glass tube was sealed under vacuum. Each tube was placed in a furnace at $78^{\circ} \mathrm{C}$ and the decomposition of the dimethyl peak or the ethyl peak (as appropriate for the compound) was monitored relative to the TMS peak. Following the decomposition of these compounds, the ring feature designed to prevent CDI deinsertion had proven effective. No CDI peaks were seen by ${ }^{1} \mathrm{H}$ NMR and the ligands appeared to have stayed intact, possibly forming bis or tris iminopyrrolidinate aluminum species through the formation of a isomer from the iminopyrrolidinate ligand.

After 5 days at $78^{\circ} \mathrm{C}$, the ${ }^{1} \mathrm{H}$ NMR signals associated with compound 2 had shown the development of a new ligand environment with signals at $\delta 3.39,3.24(\mathrm{~m}, 4 \mathrm{H}$, 
$\left.\mathrm{NCH}_{2} \mathrm{CH}_{2} \mathrm{CH}_{2} \mathrm{C}\right), 3.00\left(\mathrm{~m}, 4 \mathrm{H}, \mathrm{CH}_{3} \mathrm{CH}_{2} \mathrm{CH}_{2} \mathrm{~N}\right), 1.96\left(\mathrm{~m}, 4 \mathrm{H}, \mathrm{NCH}_{2} \mathrm{CH}_{2} \mathrm{CH}_{2} \mathrm{C}\right), 1.42(\mathrm{~m}$, $4 \mathrm{H}, \mathrm{CH}_{3} \mathrm{CH}_{2} \mathrm{CH}_{2} \mathrm{~N}$ ), 1.29 (br. m, 4H, $\mathrm{NCH}_{2} \mathrm{CH}_{2} \mathrm{CH}_{2} \mathrm{C}$ ), 0.82 (dblt t, $6 \mathrm{H}, \mathrm{CH}_{3} \mathrm{CH}_{2} \mathrm{CH}_{2} \mathrm{~N}$ ), $0.15,-0.16,-1.01\left(\mathrm{~s}, 6 \mathrm{H}, \mathrm{Al}\left(\mathrm{CH}_{3}\right)_{2}\right)$. The change in the NMR suggests that a formation of a dimerised ligand occurred. It may be possible that the parent dimer molecule broke apart forming a monomer that could then easily isomerise during the thermolysis creating a new bonding mode to the aluminum.

Scheme 2-5. Speculation of isomerization followed by dimerization of the ligand.
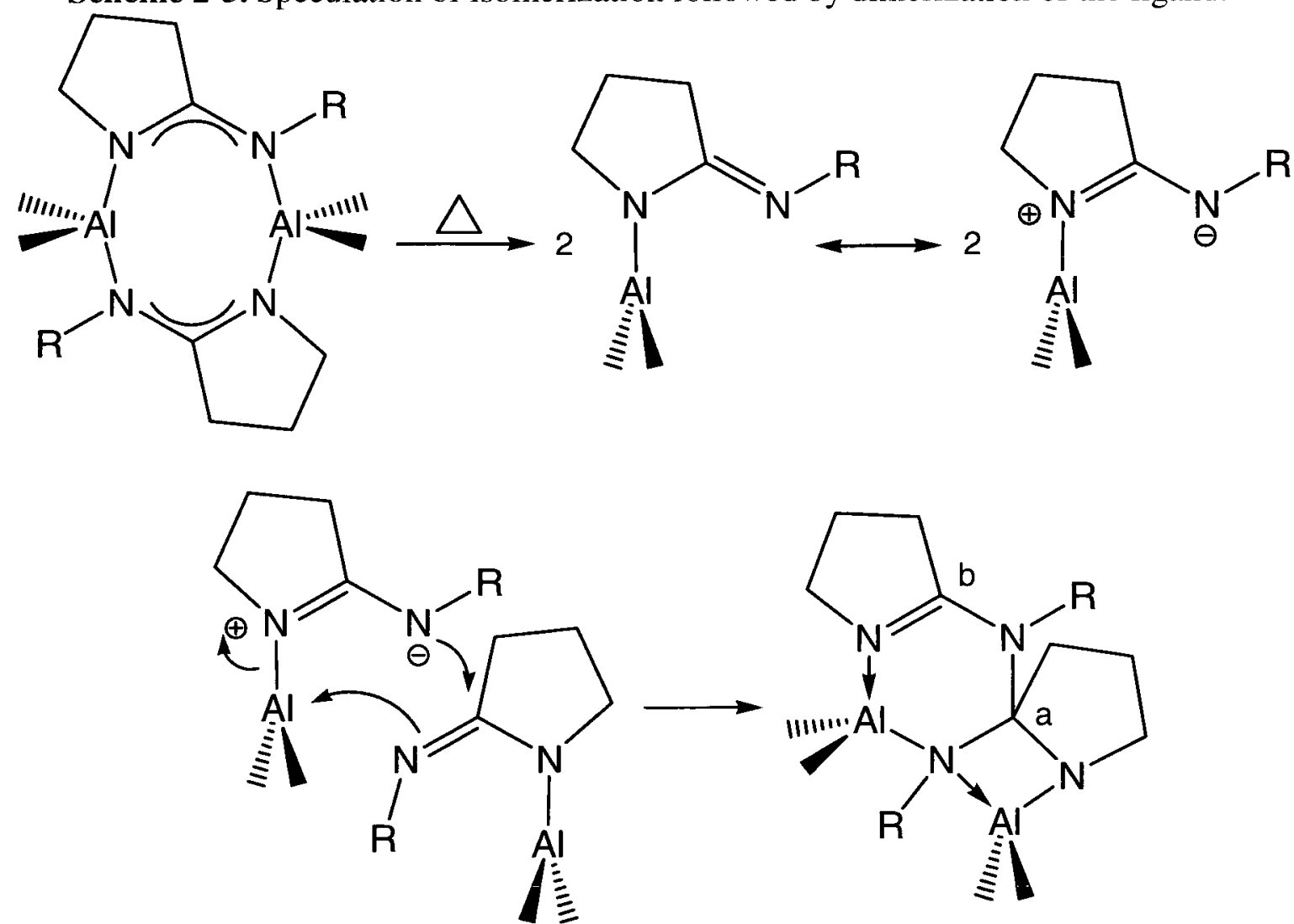

There were several shifts visible in the ${ }^{1} \mathrm{H}$ NMR that indicated the possibility that isomerization did indeed occur. The sextet of the n-propyl moiety of 2 showed a chemical shift from $1.39 \mathrm{ppm}$ to $1.42 \mathrm{ppm}$. Also the quintet of the pyrrole ring shifted 
from $1.32 \mathrm{ppm}$ to $1.29 \mathrm{ppm}$. The methyl signal from the aluminum at $-0.34 \mathrm{ppm}$ began to diminish and a new singlet grew in at $-0.16 \mathrm{ppm}$. The ${ }^{13} \mathrm{C}$ NMR also showed the development of new quaternary carbons at 179.7 and 179.5 ppm (labelled "a" and " $b$ " in Scheme 2-5). Neither peak represented the original quaternary carbon of 2 at $181.9 \mathrm{ppm}$. Additional NMR experiments such as DEPT-135 showed these carbons to be quaternary.

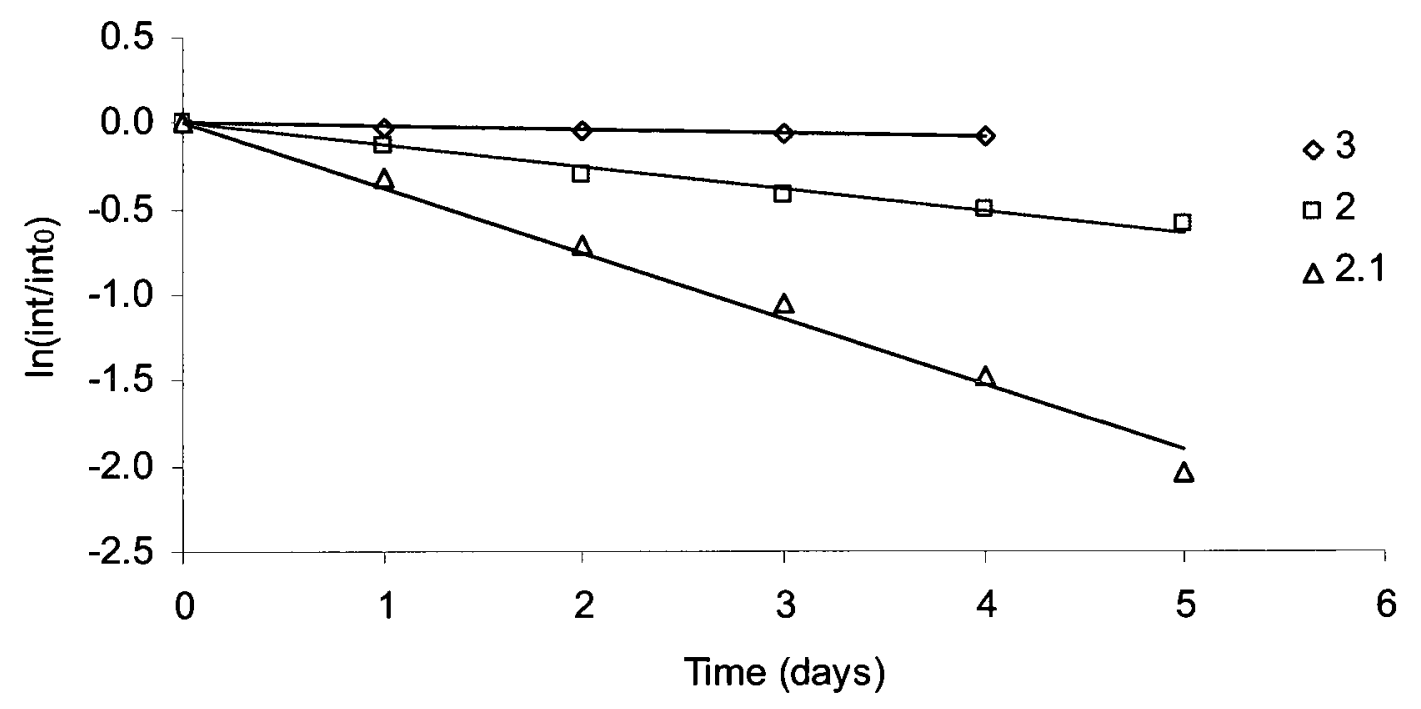

Figure 2-10. First order decomposition of the dimethyl and diethyl peak at $78^{\circ} \mathrm{C}$.

Compound 2.1 had shown almost complete transformation to the assumed dimerized species after 5 days at $78^{\circ} \mathrm{C}$. The ${ }^{1} \mathrm{H}$ NMR signal associated with the aluminum methyl for compound 2.1, had completely disappeared with the growth of a new methyl aluminum signal. A new ligand environment was also seen with signals at $\delta 3.46,3.09$ (m, 4H, $\left.\mathrm{N}\left(\mathrm{CH}_{2}\right)\left(\mathrm{CH}_{2}\right)\left(\mathrm{CH}_{2}\right) \mathrm{C}\right), 3.21$ (quin, 2H, $\left.\mathrm{NCH}\left(\mathrm{CH}_{3}\right)_{2}\right), 2.00,1.88(\mathrm{~m}, 4 \mathrm{H}$, $\left.\mathrm{N}\left(\mathrm{CH}_{2}\right)\left(\mathrm{CH}_{2}\right)\left(\mathrm{CH}_{2}\right) \mathrm{C}\right), \quad 1.31,1.23\left(\mathrm{~m}, \mathrm{~N}\left(\mathrm{CH}_{2}\right)\left(\mathrm{CH}_{2}\right)\left(\mathrm{CH}_{2}\right) \mathrm{C}\right), 1.28,1.11$ (d, 12H, $\left.\mathrm{NCH}\left(\mathrm{CH}_{3}\right)_{2}\right),-0.060,-1.027\left(\mathrm{~s}, 12 \mathrm{H}, \mathrm{Al}\left(\mathrm{CH}_{3}\right)_{2}\right)$. The ${ }^{13} \mathrm{C} \mathrm{NMR}$ of the thermal product 
supported the formation of an isomer as the quaternary carbon signal underwent a significant shift (from $179.0 \mathrm{ppm}$ to $177.9 \mathrm{ppm}$ in the thermal product) suggesting that the bonding environment had changed.

The ${ }^{1} \mathrm{H}$ NMR of compound 3 was very clean with the only change associated with the experiment - an increase in the noise of the base line. The ${ }^{13} \mathrm{C}$ NMR was also unchanged after 4 days.

From this study it was clear that the diethyl aluminum complex $\mathbf{3}$ was the most stable with a half-life of 21.7 days (Table 2-6). Each heteroleptic aluminum compound had a first order decomposition with respect to the loss of the dimethyl or diethyl group on the aluminum (Figure 2-10).

Table 2-6. $\mathrm{R}^{2}$ value, rate constant and half-lives of heteroleptic aluminum complexes.

\begin{tabular}{cccc}
\hline Compound & $\mathbf{R}^{2}$ value & $\mathbf{k}$ & $\boldsymbol{\tau}$ (days) \\
\hline \hline $\mathbf{2}$ & 0.982 & 0.123 & 5.6 \\
$\mathbf{2 . 1}$ & 0.975 & 0.449 & 1.5 \\
$\mathbf{3}$ & 0.9286 & 0.032 & 21.7 \\
\hline
\end{tabular}

\subsection{Conclusions}

A new iminopyrrolidine ligand was synthesized in good yield, $72 \%$. Low sublimation temperatures suggested volatility which was confirmed by DSC and TG analyses. These types of iminopyrrolidine ligands have proven to be more stable than their oxazoline analogues as ring opening decomposition ${ }^{5}$ did not occur as seen by ${ }^{1} \mathrm{H}$ NMR tube boil-ups.

Two novel heteroleptic aluminum complexes were synthesized and purified with great yields; 70 and $79 \%$, respectively. Some trends in melting points emerged reflecting 
that of the ligands. This suggests that thermal properties of the aluminum species may be controlled by variation of the R-group on the chelating ligand. Therefore, the synthesis of other organometallic compounds with these ligands may prove to be advantageous for ALD processes. Thermolyses of these heteroleptic compounds showed the stability of the ligands and were found to follow first order decomposition. The half-lives of the dimethyl aluminum complexes 2 and $\mathbf{2 . 1}$ were 5.6 and 1.5 days, respectively. The halflife of the diethyl aluminum complex, 3 , was higher at 21.7 days showing its stability to be higher than the dimethyl aluminum complexes.

\subsection{Methods and Materials}

All manipulations were performed in a nitrogen filled dry box unless otherwise specified. The chemicals: 2-pyrrolidinone, n-propyl amine, phosphorous pentoxide, TMA and TEA were purchased from Aldrich Chemical Company and used as received. All solvents used were reagent grade and purified from an MBraun Solvent Purifier System. Nuclear Magnetic Resonance was done on either a $300 \mathrm{MHz}$ Avance III or a 400MHz AMX Bruker. Mass spectra were obtained using the electron impact method on a VG ZAB-2HF triple-focusing spectrometer. Guelph Chemical Laboratories performed combustion analysis. Thermal gravimetric analyses were performed on a TA Instruments Q50 apparatus located in an MBraun Labmaster 130 Dry box under a nitrogen atmosphere. Differential Scanning Calorimetery was performed on a TA Instruments Q10 apparatus. Single crystal XRD was conducted on a Bruker-AXS APEX CCD Diffractometer located at Delaware University with the help of Glenn P. Yap. 


\subsubsection{N-propyl iminopyrrolidine, 1}

A mixture of 2-pyrrolidinone $(3.0 \mathrm{~g}, 35.2 \mathrm{mmol})$ and n-propyl amine $(4.4 \mathrm{~g}, 70.5$ mmol) was prepared in a $20 \mathrm{ml}$ vial in the dry box, capped and brought out of the dry box. This mixture was added $1 \mathrm{~mL}$ at a time through a reflux condenser to a $100 \mathrm{~mL}$ round bottom flask that contained neat phosphorous pentoxide $(5.0 \mathrm{~g}, 35.2 \mathrm{mmol})$. As the pyrrolidinone mixture reached the reaction flask, vapour began to rise up the reflux condenser. The reaction mixture was heated over one hour to $220^{\circ} \mathrm{C}$ and then refluxed with stirring for two hours in a sand bath. The reaction was cooled to room temperature and it became a hard glassy substance. $40 \mathrm{~mL}$ of distilled water was added to the flask and the compound dissolved with the aid of a heat gun. Using a Pasteur pipette $50 \mathrm{~mL}$ of $6 \mathrm{M}$ aqueous $\mathrm{NaOH}$ was added until a pH of 11 was obtained. The aqueous phase was extracted with $3 \times 70 \mathrm{~mL}$ of diethyl ether. Volatiles were removed under reduced pressure to afford a brown solid $(3.6 \mathrm{~g}, 28.5 \mathrm{mmol}, 81 \%)$. The brown solid sublimed at $60^{\circ} \mathrm{C}$ under reduced pressure to afford needle like white crystals $(3.2 \mathrm{~g}, 25.4 \mathrm{mmol}$, 72\%). mp $\left(72-74^{\circ} \mathrm{C}\right) .{ }^{1} \mathrm{H}$ NMR $\left(300 \mathrm{MHz}, \mathrm{C}_{6} \mathrm{D}_{6}\right): \delta 3.780\left(\mathrm{t}, 2 \mathrm{H}, \mathrm{NCH}_{2} \mathrm{CH}_{2} \mathrm{CH}_{2} \mathrm{C}\right)$, $3.44(\mathrm{~s}, 1 \mathrm{H}, \mathrm{NCNH}), 3.22\left(\mathrm{t}, 2 \mathrm{H}, \mathrm{CH}_{3} \mathrm{CH}_{2} \mathrm{CH}_{2} \mathrm{~N}\right), 1.92\left(\mathrm{t}, 2 \mathrm{H}, \mathrm{NCH}_{2} \mathrm{CH}_{2} \mathrm{CH}_{2} \mathrm{C}\right), 1.63$ (quintet, 2H, $\mathrm{NCH}_{2} \mathrm{CH}_{2} \mathrm{CH}_{2} \mathrm{C}$ ), 1.41 (sextet, 2H, $\mathrm{CH}_{3} \mathrm{CH}_{2} \mathrm{CH}_{2} \mathrm{~N}$ ), 0.77 (t, 3H, $\left.\mathrm{CH}_{3} \mathrm{CH}_{2} \mathrm{CH}_{2} \mathrm{~N}\right) .{ }^{13} \mathrm{C} \mathrm{NMR}\left(300 \mathrm{MHz}, \mathrm{C}_{6} \mathrm{D}_{6}\right): \delta 165.5(\mathrm{NCN}), 56.6\left(\mathrm{NCH}_{2} \mathrm{CH}_{2} \mathrm{CH}_{2} \mathrm{C}\right)$, $44.9\left(\mathrm{CH}_{3} \mathrm{CH}_{2} \mathrm{CH}_{2} \mathrm{~N}\right), 32.5\left(\mathrm{NCH}_{2} \mathrm{CH}_{2} \mathrm{CH}_{2} \mathrm{C}\right), 23.5\left(\mathrm{CH}_{3} \mathrm{CH}_{2} \mathrm{CH}_{2} \mathrm{~N}\right), 23.1\left(\mathrm{NCH}_{2} \mathrm{CH}-\right.$ ${ }_{2} \mathrm{CH}_{2} \mathrm{C}$ ), $11.4\left(\mathrm{CH}_{3} \mathrm{CH}_{2} \mathrm{CH}_{2} \mathrm{~N}\right)$. Mass spectral data (EI, $\left.\mathrm{m} / z\right)$ (rel. intensity, \%): 126.1 $\left(92.0, \mathrm{M}^{+}\right)$. Combustion analysis; found (calculated), C: 66.43 (66.62), H: 10.92 (11.18), $\mathrm{N}: 22.44$ (22.20). 


\subsubsection{Dimethyl aluminum n-propyl iminopyrrolidinate, 2}

N-propyl iminopyrrolidine $(1.5 \mathrm{~g}, 11.8 \mathrm{mmol})$ was suspended in approximately $40 \mathrm{ml}$ of hexanes and slowly added to a solution of TMA $(5.9 \mathrm{ml}, 12.5 \mathrm{mmol}, 2 \mathrm{M})$ dissolved in about $80 \mathrm{ml}$ of hexanes. The reaction was allowed to proceed for 18 hours at room temperature. Volatiles were removed under reduced pressure to afford a colourless solid. The solid was dissolved in about $8 \mathrm{~mL}$ of diethyl ether and allowed to recrystallize at $30^{\circ} \mathrm{C}$. Colourless cubic crystals were collected $(1.7 \mathrm{~g}, 9.3 \mathrm{mmol}, 79 \%) . \mathrm{mp}\left(79-83^{\circ} \mathrm{C}\right)$. ${ }^{1} \mathrm{H}$ NMR (300 MHz, $\left.\mathrm{C}_{6} \mathrm{D}_{6}\right): \delta 3.27\left(\mathrm{t}, 2 \mathrm{H}, \mathrm{NCH}_{2} \mathrm{CH}_{2} \mathrm{CH}_{2} \mathrm{C}\right), 3.05\left(\mathrm{t}, 2 \mathrm{H}, \mathrm{CH}_{3} \mathrm{CH}_{2} \mathrm{CH}_{2} \mathrm{~N}\right)$, 1.92 (t, 2H, $\mathrm{NCH}_{2} \mathrm{CH}_{2} \mathrm{CH}_{2} \mathrm{C}$ ), 1.39 (sextet, 2H, $\mathrm{CH}_{3} \mathrm{CH}_{2} \mathrm{CH}_{2} \mathrm{~N}$ ), 1.32 (quintet, 2H, $\left.\mathrm{NCH}_{2} \mathrm{CH}_{2} \mathrm{CH}_{2} \mathrm{C}\right), 0.77\left(\mathrm{t}, 3 \mathrm{H}, \mathrm{CH}_{3} \mathrm{CH}_{2} \mathrm{CH}_{2} \mathrm{~N}\right),-0.34\left(\mathrm{~s}, 6 \mathrm{H}, \mathrm{Al}\left(\mathrm{CH}_{3}\right)_{2}\right) . \quad{ }^{13} \mathrm{C} \mathrm{NMR}(300$ $\left.\mathrm{MHz}, \mathrm{C}_{6} \mathrm{D}_{6}\right): \delta 181.9(\mathrm{NCN}), 51.043\left(\mathrm{CH}_{3} \mathrm{CH}_{2} \mathrm{CH}_{2} \mathrm{~N}\right), 51.0\left(\mathrm{NCH}_{2} \mathrm{CH}_{2} \mathrm{CH}_{2} \mathrm{C}\right), 31.1$ $\left(\mathrm{NCH}_{2} \mathrm{CH}_{2} \mathrm{CH}_{2} \mathrm{C}\right), 25.8\left(\mathrm{CH}_{3} \mathrm{CH}_{2} \mathrm{CH}_{2} \mathrm{~N}\right), 21.8\left(\mathrm{NCH}_{2} \mathrm{CH}_{2} \mathrm{CH}_{2} \mathrm{C}\right), 11.5\left(\mathrm{CH}_{3} \mathrm{CH}_{2} \mathrm{CH}_{2} \mathrm{~N}\right)$. Mass spectral data $(\mathrm{EI}, \mathrm{m} / \mathrm{z})$ (rel. intensity, \%): $349.2\left(38.5,(\mathrm{M}-\mathrm{Me})^{+}\right)$. Combustion analysis; found (calculated), C: $59.15(59.31), \mathrm{H}: 10.80(10.51), \mathrm{N}: 15.33$ (15.37).

\subsubsection{Diethyl aluminum iso-propyl iminopyrrolidinate, 3}

Same reaction procedure as $\mathbf{2}$ was used substituting the previous aluminium complex with TEA (15.85 $\mathrm{ml}, 15.8 \mathrm{mmol}, 1 \mathrm{M})$ and the previous ip ligand with ipip $(1.99 \mathrm{~g}, 15.8$ mmol). The solution was clear and colourless. Volatiles were removed under reduced pressure to afford a colourless solid. The solid was dissolved in about $14 \mathrm{~mL}$ of diethyl ether and allowed to recrystallize at $-30^{\circ} \mathrm{C}$. Colourless cubic crystals were collected $(2.3$ $\mathrm{g}, 11.1 \mathrm{mmol}, 70 \%) . \operatorname{mp}\left(120-124^{\circ} \mathrm{C}\right) .{ }^{1} \mathrm{H}$ NMR $\left(300 \mathrm{MHz}, \mathrm{C}_{6} \mathrm{D}_{6}\right): \delta 3.35(\mathrm{~m}, 1 \mathrm{H}$, $\left.\mathrm{NCH}\left(\mathrm{CH}_{3}\right)_{2}\right), 3.25$ (t, 2H, $\mathrm{NCH}_{2} \mathrm{CH}_{2} \mathrm{CH}_{2} \mathrm{C}$ ), 2.06 (t, 2H, $\mathrm{NCH}_{2} \mathrm{CH}_{2} \mathrm{CH}_{2} \mathrm{C}$ ), 1.42 (quintet, 
$\left.2 \mathrm{H}, \mathrm{NCH}_{2} \mathrm{CH}_{2} \mathrm{CH}_{2} \mathrm{C}\right), 1.30\left(\mathrm{t}, 6 \mathrm{H}, \mathrm{Al}\left(\mathrm{CH}_{2} \mathrm{CH}_{3}\right)_{2}\right), 1.15$ (d, 6H, $\left.\mathrm{NCH}\left(\mathrm{CH}_{3}\right)_{2}\right), 0.24$ (q, 4H, $\left.\left.\mathrm{Al}\left(\mathrm{CH}_{2} \mathrm{CH}_{3}\right)_{2}\right) .{ }^{13} \mathrm{C} \mathrm{NMR}\left(300 \mathrm{MHz}, \mathrm{C}_{6} \mathrm{D}_{6}\right): \delta 181.5(\mathrm{NCN}), 50.1\left(\mathrm{NCH}_{2} \mathrm{CH}_{2} \mathrm{CH}_{2} \mathrm{C}\right)\right)$, $49.8\left(\mathrm{NCH}\left(\mathrm{CH}_{3}\right)_{2}\right), 32.5\left(\mathrm{NCH}_{2} \mathrm{CH}_{2} \mathrm{CH}_{2} \mathrm{C}\right), 23.1\left(\mathrm{NCH}\left(\mathrm{CH}_{3}\right)_{2}\right), 22.4\left(\mathrm{NCH}_{2} \mathrm{CH}_{2} \mathrm{CH}_{2} \mathrm{C}\right)$, $10.2\left(\mathrm{Al}\left(\mathrm{CH}_{2} \mathrm{CH}_{3}\right)_{2}\right), 1.2\left(\mathrm{Al}\left(\mathrm{CH}_{2} \mathrm{CH}_{3}\right)_{2}\right)$. Combustion analysis; found (calculated), $\mathrm{C}$ : 63.11 (62.82), H: 11.28 (11.02), N: 13.72 (13.32).

\subsubsection{Diethyl aluminum n-propyl iminopyrrolidinate, 4}

Same reaction procedure as $\mathbf{2}$ was used substituting the previous aluminium complex with TEA $(11.88 \mathrm{ml}, 11.8 \mathrm{mmol}, 1 \mathrm{M})$. The solution changed to clear yellow. Volatiles were removed under reduced pressure to afford a thick yellow wax. A distillation was attempted starting with an oil bath at $30^{\circ} \mathrm{C}$ and slowly increasing to $170^{\circ} \mathrm{C}$ throughout the day. At this point the vapour temperature increased to $86^{\circ} \mathrm{C}$ and $0.2 \mathrm{~g}(1.0 \mathrm{mmol}, 9 \%)$ clear colourless solution was obtained. ${ }^{1} \mathrm{H}$ NMR $\left(300 \mathrm{MHz}, \mathrm{C}_{6} \mathrm{D}_{6}\right): \delta 3.28(\mathrm{t}, 2 \mathrm{H}$, $\mathrm{NCH}_{2} \mathrm{CH}_{2} \mathrm{CH}_{2} \mathrm{C}$ ), $3.02\left(\mathrm{t}, 2 \mathrm{H}, \mathrm{CH}_{3} \mathrm{CH}_{2} \mathrm{CH}_{2} \mathrm{~N}\right), 2.06\left(\mathrm{t}, 2 \mathrm{H}, \mathrm{NCH}_{2} \mathrm{CH}_{2} \mathrm{CH}_{2} \mathrm{C}\right), 1.43(\mathrm{~m}$, $2 \mathrm{H}, \mathrm{CH}_{3} \mathrm{CH}_{2} \mathrm{CH}_{2} \mathrm{~N}$ and $\left.\mathrm{NCH}_{2} \mathrm{CH}_{2} \mathrm{CH}_{2} \mathrm{C}\right), 1.25\left(\mathrm{t}, 6 \mathrm{H}, \mathrm{Al}\left(\mathrm{CH}_{2} \mathrm{CH}_{3}\right)_{2}\right), 0.76(\mathrm{t}, 3 \mathrm{H}$, $\left.\mathrm{CH}_{3} \mathrm{CH}_{2} \mathrm{CH}_{2} \mathrm{~N}\right), 0.20\left(\mathrm{q}, 4 \mathrm{H}, \mathrm{Al}\left(\mathrm{CH}_{2} \mathrm{CH}_{3}\right)_{2}\right),{ }^{13} \mathrm{C} \mathrm{NMR}\left(400 \mathrm{MHz}, \mathrm{C}_{6} \mathrm{D}_{6}\right): \delta 180.4$ $(\mathrm{NCN}), 50.0\left(\mathrm{CH}_{3} \mathrm{CH}_{2} \mathrm{CH}_{2} \mathrm{~N}\right), 49.6\left(\mathrm{NCH}_{2} \mathrm{CH}_{2} \mathrm{CH}_{2} \mathrm{C}\right), 30.0\left(\mathrm{NCH}_{2} \mathrm{CH}_{2} \mathrm{CH}_{2} \mathrm{C}\right), 25.0$ $\left(\mathrm{CH}_{3} \mathrm{CH}_{2} \mathrm{CH}_{2} \mathrm{~N}\right), 22.2\left(\mathrm{NCH}_{2} \mathrm{CH}_{2} \mathrm{CH}_{2} \mathrm{C}\right), 11.1\left(\mathrm{CH}_{3} \mathrm{CH}_{2} \mathrm{CH}_{2} \mathrm{~N}\right), 9.45\left(\mathrm{Al}\left(\mathrm{CH}_{2} \mathrm{CH}_{3}\right)_{2}\right)$, $-0.9\left(\mathrm{Al}\left(\mathrm{CH}_{2} \mathrm{CH}_{3}\right)_{2}\right)$. 


\subsection{Structural Determination for Compound 2}

A suitable crystal was mounted with viscous oil on a plastic mesh and cooled to the data collection temperature. Unit cell parameters were determined using data frames from four different sections of the Ewald sphere. SADABS multi-scan absorption corrections were applied. No symmetry higher than triclinic was observed. Solution in the centrosymmetric space group option, P-1, yielded chemically reasonable and computationally stable results of refinement. The structure was solved using direct methods and refined with full matrix least squares procedures of $\mathrm{F}^{2}$ data. The dimeric molecule was located at an inversion centre. All hydrogen atoms were treated as idealized contributions and all non-hydrogen atoms were refined with anisotropic displacement coefficients. Atomic scattering factors are contained in the SHELXTL program library. 


\subsection{References}

${ }^{1}$ (a) Bai, SD; Guo, JP; Liu, DS, Dalton Trans., 2006, 2244-2250. (b) Barker, J., Kilner, M.; Coord Chem. Rev., 1994, 133, 219. (c) Edelmann, F.T., Coord. Chem. Rev., 1994, 137, 403. (d) Bailey, P.J., Pace, S.; Coord. Chem. Rev., 2001, 214, 91.

${ }^{2}$ (a) Edelmann, F.T., Chem. Soc. Rev., 2009, 38, 2253-2268. (b) Ong, TG.; Yap, G.P.A.; Richeson, D.S., J. Am. Chem. Soc., 2003, $125,8100$.

${ }^{3}$ (a) B. S. Lim, A. Rahtu, J.-S. Park and R. G. Gordon, Inorg. Chem.,2003, 42, 7951. (b) F. T.

Edelmann, Adv. Organomet. Chem., 2008, 57, 183. (c) B. S. Lim, A. Rahtu and R. G. Gordon, Nat. Mater., 2003, 2, 749 .

${ }^{4}$ Brazeau, A.L.; Wang, Z.; Rowley, C.N.; Barry, S.T., Inorg. Chem., 2006, 45, 2276.

${ }^{5}$ Ward, B.D.; Risler, H.; Weitershaus, K.; Bellemin-Laponnaz, S.; Wadepohl, H.; Gade, L.H. Inorg. Chem. 2006, 45, 7777-7787.

${ }^{6}$ Pederson, E. B. and Hansen, B. W. Acta Chemica Scandinavica B, 1980, 34, 369.

${ }^{7}$ Kenney, A; Design, Synthesis and Thermal Analysis of Group 11 and 13 ALD Precursosrs, M. Sc., 2007.

${ }^{8}$ Kurek, A; Synthesis, Characterization and Thermolysis of Novel Heteroleptic Aluminum Compounds, B.Sc., 2009.

${ }^{9}$ Macaulay, R., Burnelle, L.A., Sandorfy, C.; Theoret. Chim. Acta. (Ber.)., 1973, $29,1$.

${ }^{10}$ Wasslen, Y.A., Kurek, A., Johnson, P.A., Pigeon, T.C., Monillas, W.H., Yap, G.P.A., Barry, S.T., Dalton Trans., 2010, ASAP.

${ }^{11}$ Brazeau, A.L.; Theoretical and Experimental Investigation of Ligand Exchange in Amidinate and Guanidinate Ligand Systems and the Atomic Layer Deposition of Aluminum Oxide, M.Sc., 2007. 


\section{Chapter 3:}

\section{Heteroleptic Cyclopentadienyl Titanium (III) Guanidinates}

\subsection{Introduction}

Titanium-containing precursors used for the deposition of pure metal, nitride and oxide films have a variety of applications in microelectronics. Titanium as a metal can be used as an electrode in microelectronic devices. However, due to a high tendency towards oxidation, titanium itself is typically not used. Instead titanium-nitride (TiN) is often deposited as a capping layer. ${ }^{1}$ Some important examples of TiN in the microelectronic space include gate metals in metal-oxide-semiconductor field-effect transistors (MOSFETs) as well as metal electrodes in various capacitor applications. ${ }^{2}$ In these applications, extreme down-scaling of size of electronic components cannot be supported by traditional poly-silicon based techniques. ${ }^{3}$ When gate sizes approach $1 \mathrm{~nm}$ in thickness, thin-film metal gates such as $\mathrm{TiN}$ are required to obtain favourable electrical properties. ${ }^{4}$ In addition to applications in microelectronics, thin films of TiN have been used in solar cells, ${ }^{5}$ as hard and decorative coatings, and in optics. ${ }^{6}$ In addition to gate metals, down-scaling the size of electronics requires high-k dielectrics. ${ }^{7}$ To this end, there is an increasing interest in titanium oxide $\left(\mathrm{TiO}_{2}\right) .{ }^{8}$ Titanium oxide offers a high-k value $(80-110)^{9}$ and can be deposited either as the pure oxide, or in combination with other oxides to achieve desired properties. ${ }^{7,10}$ For instance, with strontium oxide it will form the ultra high-permittivity ternary material $\mathrm{SrTiO}_{3}$, with a $\mathrm{k}$ value that may exceed 300. 
Titanium based materials can be deposited by several known methods such as physical vapour deposition (PVD), ${ }^{11} \mathrm{CVD}^{12}$ and ALD. ${ }^{13}$ ALD for titanium based materials is promising because it offers control and scalability to a nanoscale. This chapter focuses on novel guanidinate precursors for the ALD of titanium based materials.

An ALD precursor should meet several design criteria: the compound should have a low molecular weight and the metal centre should be sterically congested. This promotes volatility as well as self-limiting behaviour when the chemisorbed monolayer is formed on the surface. The compound should be thermally stable to resist decomposition in the gas-phase and on the surface at process temperatures, yet be chemically reactive to allow formation of the target film.

A well known titanium precursor for $\mathrm{ALD}$ of $\mathrm{TiN}$ and $\mathrm{TiO}_{2}$ is $\mathrm{TiCl}_{4}$. It is highly volatile and thermally stable. However, $\mathrm{TiCl}_{4}$ cannot be used to deposit $\mathrm{TiN}$ layers near copper interconnects because of the formation of hydrogen chloride as a by-product, which etches the copper. ${ }^{14}$ Furthermore, $\mathrm{TiCl}_{4}$ can induce the formation of a very stable $\mathrm{SrCl}_{2}$ phase when employed in the deposition of $\mathrm{SrTiO}_{3}$ by $\mathrm{ALD}$, which contaminates the film and alters the electrical properties. Titanium alkyl amides have also been widely studied for the deposition of TiN via ALD. However, these precursors have low thermal stability and decompose above $150^{\circ} \mathrm{C}$ limiting their applications. ${ }^{15}$ Alkoxides have been used for $\mathrm{TiO}_{2}$ deposition but they too have low thermal stability, with a temperature limit of approximately $250^{\circ} \mathrm{C} .^{16}$ Despite the large number of titanium precursors available for ALD, there is need for development of thermally stable metal organic titanium precursors for both $\mathrm{TiN}$ and $\mathrm{TiO}_{2}$ deposition. 
Chapters 3 to 6 of this thesis introduces the synthesis of novel titanium (III) and titanium (IV) compounds that were synthesized to use as $\mathrm{TiN}$ or $\mathrm{TiO}_{2}$ precursors in ALD or CVD. This chapter introduces a new class of volatile and thermally stable titanium precursors for ALD: cyclopentadienyl titanium guanidinates; $\mathrm{Cp}_{2} \mathrm{Ti}\left(\mathrm{N}^{\mathrm{i}} \mathrm{Pr}\right)_{2} \mathrm{CNRR}$ ' (where $\mathrm{R}, \mathrm{R}^{\prime}=\mathrm{H}, \mathrm{Me},{ }^{\mathrm{i}} \mathrm{Pr}$ or ${ }^{\mathrm{t}} \mathrm{Bu}$ ). Guanidinate ligands were used in this chapter to increase the stability of the heteroleptic titanium precursors by increasing ligand saturation. ${ }^{17}$ The resonant structure of guanidinate ligands have been known to increase the stability of the compound (compared to metal alkyl amides) as well as prevent oligomerization of the organometallic species. ${ }^{18}$ They are also known for minimizing the amount of impurities found within deposited thin films; metal-nitrogen bonds within a precursor can help to eliminate potential halide and carbon contamination within the film. ${ }^{19}$ The advantage of these potential precursors is the increased stability the bidentate ligands offer compared to other monodentate cyclopentadienyl complexes. ${ }^{20}$

The volatility and thermal chemistry of these compounds will be discussed with the goal of assessing their suitability as ALD precursors. Finally, surface reactivity on high surface area silica will be shown for the selected candidate $\left[{ }^{\mathrm{i}} \operatorname{PrN}(\mathrm{H}) \mathrm{C}\left(\mathrm{N}^{\mathrm{i}} \mathrm{Pr}\right)_{2}\right] \mathrm{TiC} \mathrm{p}_{2}$ to determine how the precursor might dissociatively absorb to an oxide substrate. This experiment will give insight on how these types of metallic precursors react to form the first monolayer in an ALD process. High surface area silica is an ideal material for this experiment due to the abundance of surface hydroxyls, which in turn lead to a high enough concentration of surface species to use solid-state nuclear magnetic resonance to characterize the end result. 


\subsection{Results and Discussion}

\subsubsection{Synthesis and Crystal Structure Data}

Generally, $\mathrm{Ti}(\mathrm{III})$ compounds of the formulation (guan) $\mathrm{TiCp}_{2}$ (where guan is any guanidinate) can be made in very low yields from $\mathrm{Cp}_{2} \mathrm{TiCl}_{2}$ and a dianionic guanidinate at room temperature with stirring over night. An in situ reduction of the titanium centre and the reaction mixture resulted in several unidentifiable side products. This reaction is highlighted here by using the compound $\mathrm{Cp}_{2} \operatorname{Ti}\left[\left(\mathrm{N}^{i} \mathrm{Pr}\right)_{2} \mathrm{CN}(\mathrm{H})^{i} \mathrm{Pr}\right](5)$ as an example. When following equation 1 using $\operatorname{Li}_{2}\left({ }^{i} \operatorname{Pr}(\mathrm{N})_{3} \mathrm{C}\right)$ as a ligand, compound 5 was isolated in $15 \%$ yield, while the rational synthesis of 5 using $\left[\mathrm{Cp}_{2} \mathrm{TiCl}_{2}\right.$ (from reduction of $\mathrm{Cp}_{2} \mathrm{TiCl}_{2}$ and zinc dust, equations 2 and 3$)$ and $\operatorname{Li}\left({ }^{\mathrm{i}} \operatorname{PrN}\right)_{2} \mathrm{C}\left(\mathrm{N}(\mathrm{H})^{\mathrm{i}} \mathrm{Pr}\right)$ produced 5 in a $58 \%$ yield.

$\left.\mathrm{Cp}_{2} \mathrm{Ti}^{\left({ }^{(\mathrm{V})}\right)} \mathrm{Cl}_{2}+\mathrm{Li}_{2}\left({ }^{\mathrm{i}} \operatorname{Pr}(\mathrm{N})_{3} \mathrm{C}\right) \rightarrow \mathrm{Cp}_{2} \mathrm{Ti}^{(\mathrm{III})}{ }^{\mathrm{i}} \mathrm{PrN}\right)_{2} \mathrm{C}\left(\mathrm{N}(\mathrm{H})^{\mathrm{i}} \mathrm{Pr}\right)+$ unidentifiable products 1

$2 \mathrm{Cp}_{2} \mathrm{TiCl}_{2}+\mathrm{Zn}_{(\mathrm{s})} \rightarrow\left[\mathrm{Cp}_{2} \mathrm{Ti}^{(\mathrm{III})} \mathrm{Cl}_{2}+\mathrm{ZnCl}_{2}\right.$

$1 / 2\left[\mathrm{Cp}_{2} \mathrm{Ti}^{(\mathrm{III})} \mathrm{Cl}\right]_{2}+\mathrm{Li}\left({ }^{\mathrm{i}} \mathrm{PrN}\right)_{2} \mathrm{C}\left(\mathrm{N}(\mathrm{H})^{\mathrm{i}} \mathrm{Pr}\right) \rightarrow \mathrm{Cp}_{2} \mathrm{Ti}^{(\mathrm{III})}\left({ }^{\mathrm{i}} \mathrm{PrN}\right)_{2} \mathrm{C}\left(\mathrm{N}(\mathrm{H}){ }^{\mathrm{i}} \mathrm{Pr}\right)+\mathrm{xs} \mathrm{LiCl}$

In general, compounds 5 - 8 (Table 3-1, Figure 3-1 and Figure 3-2) were easily synthesized in moderate yields from the $\left[\mathrm{Cp}_{2} \mathrm{TiCl}\right]_{2}$ starting material and appropriate lithium guanidinate. It was found that the compounds formed slowly at room temperature with the starting titanium species changing from a characteristic yellowgreen to a solution ranging from grey-green to blue, depending on the guanidinate. In every case, blue crystals were isolated and this colour change was used to gauge the 
completeness of the reaction. Compounds $\mathbf{5}, \mathbf{6}$, and $\mathbf{8}$ produced crystals of sufficient quality for single crystal structures to be collected (Figure 3-1 and Table 3-1).

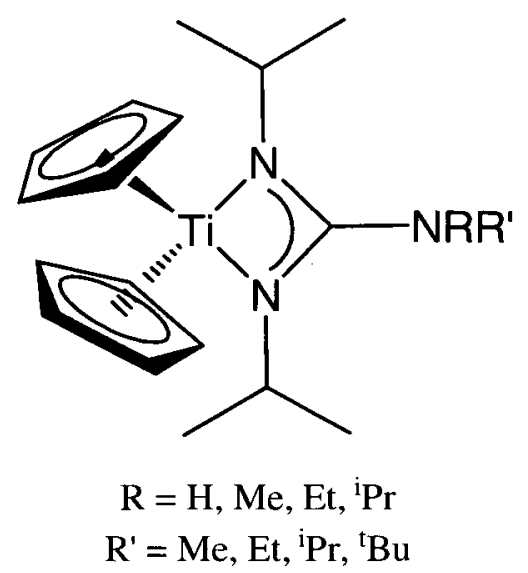

Figure 3-1. Heteroleptic titanium species.

Table 3-1. Guanidinate species and percent yield of compounds 5 - 9 .

\begin{tabular}{ccc}
\hline & $\begin{array}{c}\text { Compound } \\
\text { (Guanidinate) }\end{array}$ & $\begin{array}{c}\text { Percent } \\
\text { Yield (\%) }\end{array}$ \\
\hline \hline $\mathbf{5}$ & $\mathrm{Cp}$ Ti triisopropyl & 58 \\
$\mathbf{6}$ & $\mathrm{Cp}_{2} \mathrm{Ti}$ dimethyl diisopropyl & 39 \\
$\mathbf{7}$ & $\mathrm{Cp} \mathrm{p}_{2} \mathrm{Ti}$ diethyl diisopropyl & 40 \\
$\mathbf{8}$ & $\mathrm{Cp}$ Ti tetra isopropyl & 30 \\
$\mathbf{9}$ & $\mathrm{Cp}_{2} \mathrm{Ti}$ tert-butyl diisopropyl & 7 \\
\hline
\end{tabular}



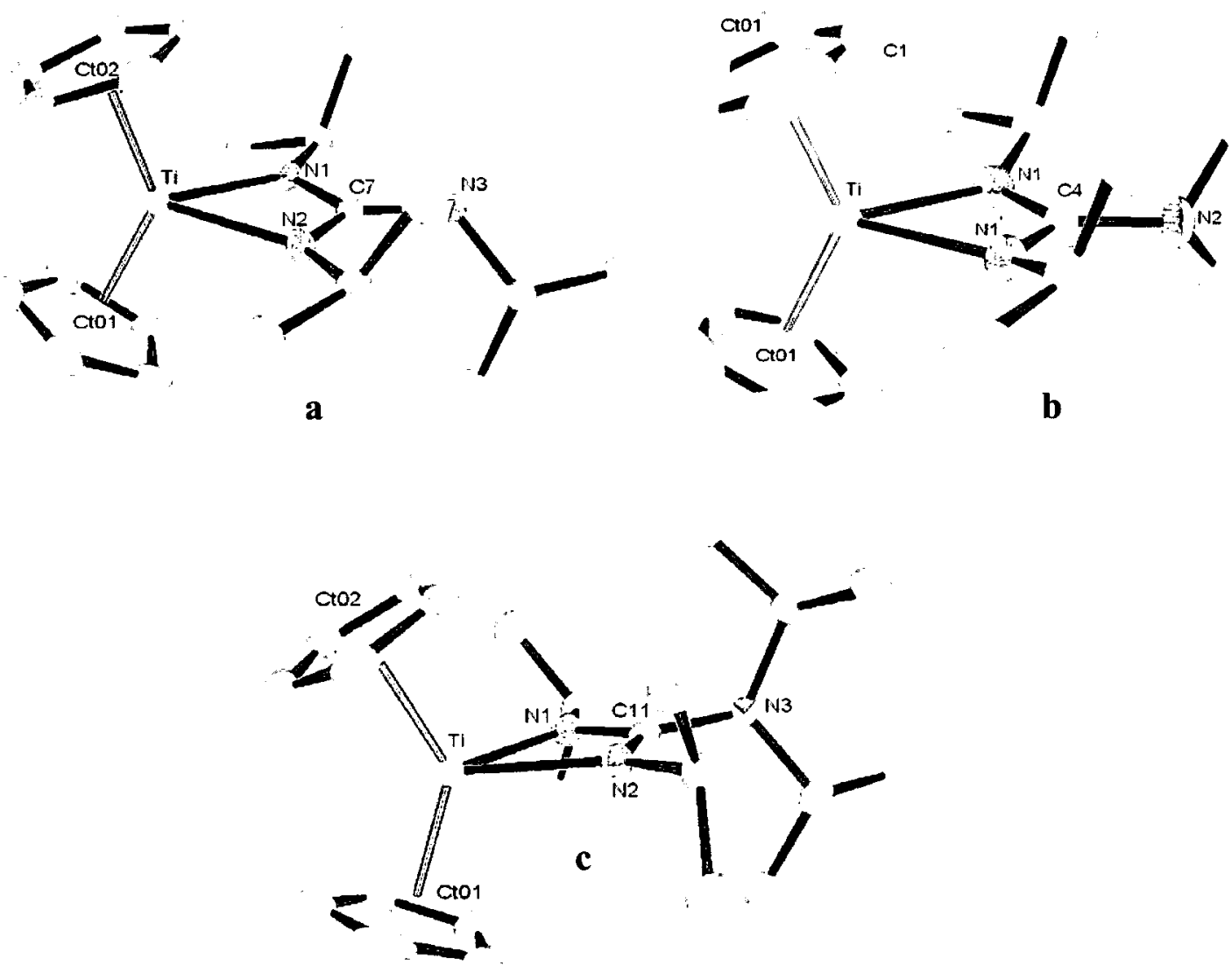

Figure 3-2. The single-crystal X-ray structure of (a) 5, (b) 6, and (c) 8. The thermal ellipsoids are shown at $50 \%$ probability and the hydrogen centres are omitted for clarity. N.B.: Only one of two orientations of 6 is shown (see text).

A fourth crystal structure was obtained: compound 9, bis(cyclopentadienyl) titanium (III) tert-butyl diisopropyl guanidinate (Figure 3-4, Table 3-2 and Table 3-4). The tertbutyl diisopropyl guanidinate ligand was prepared in a similar fashion as the other ligands used in this chapter: CDI insertion over a lithium-amido complex (Scheme 3-1). The organometallic compound was prepared similarly to the other compounds: a room temperature reaction with the addition of a lithiated guanidinate ligand. It was originally thought that the guanidinate ligand would bond to the titanium in a manner similar to the other guanidinate ligands: the isopropyl groups of the chelate nitrogens in the 
metallocycle and the tert-butyl moiety in the exocyclic position (Figure 3-3). However, the tert-butyl moiety was found in the chelate position forming an asymmetric guanidinate ligand (Figure 3-3 and Figure 3-4). A variety of by-products were isolated and - due to the paramagnetic nature of the solids - were unidentifiable by ${ }^{1} \mathrm{H}$ NMR. The synthesis was repeated several times both at room temperature and at lower temperatures in hopes to increase the yield. Even when the reaction was controlled at $-78^{\circ} \mathrm{C}$ no heteroleptic complexes were isolated and further thermolysis studies could not be conducted.

Scheme 3-1. Lithium amide insertion over CDI bond.<smiles>[R]N=C=N[R1]([R])=[W]</smiles><smiles>[R]N1[Al]N1[Y7]</smiles>

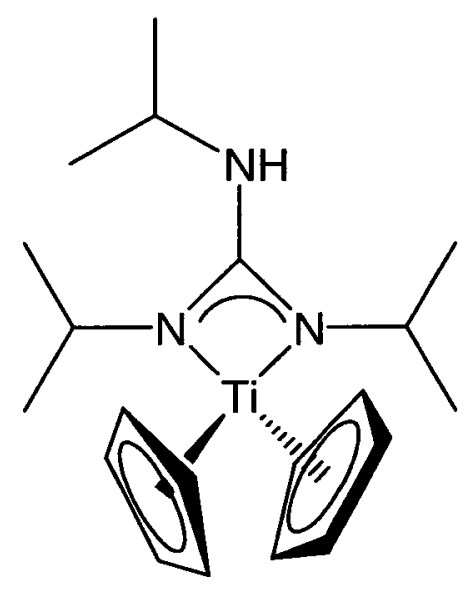

11

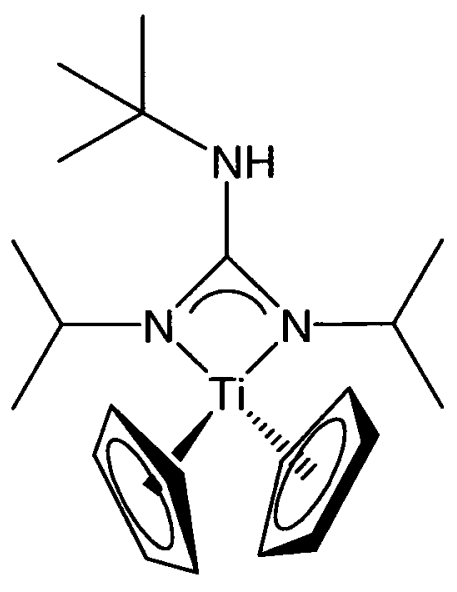

Proposed 15

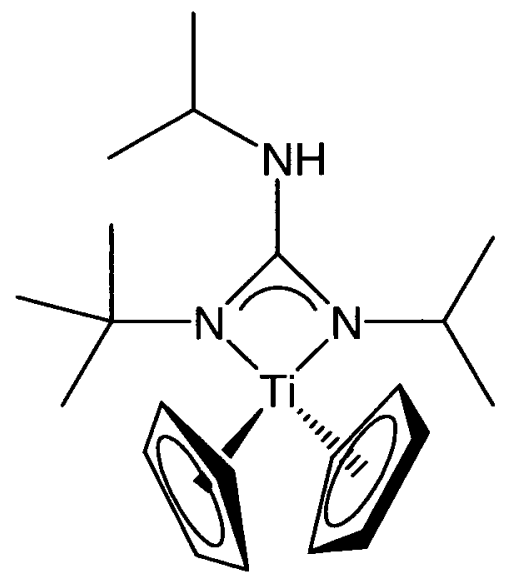

Collected $\mathbf{1 5}$

Figure 3-3. Asymmetric coordination of guanidinate ligand. 


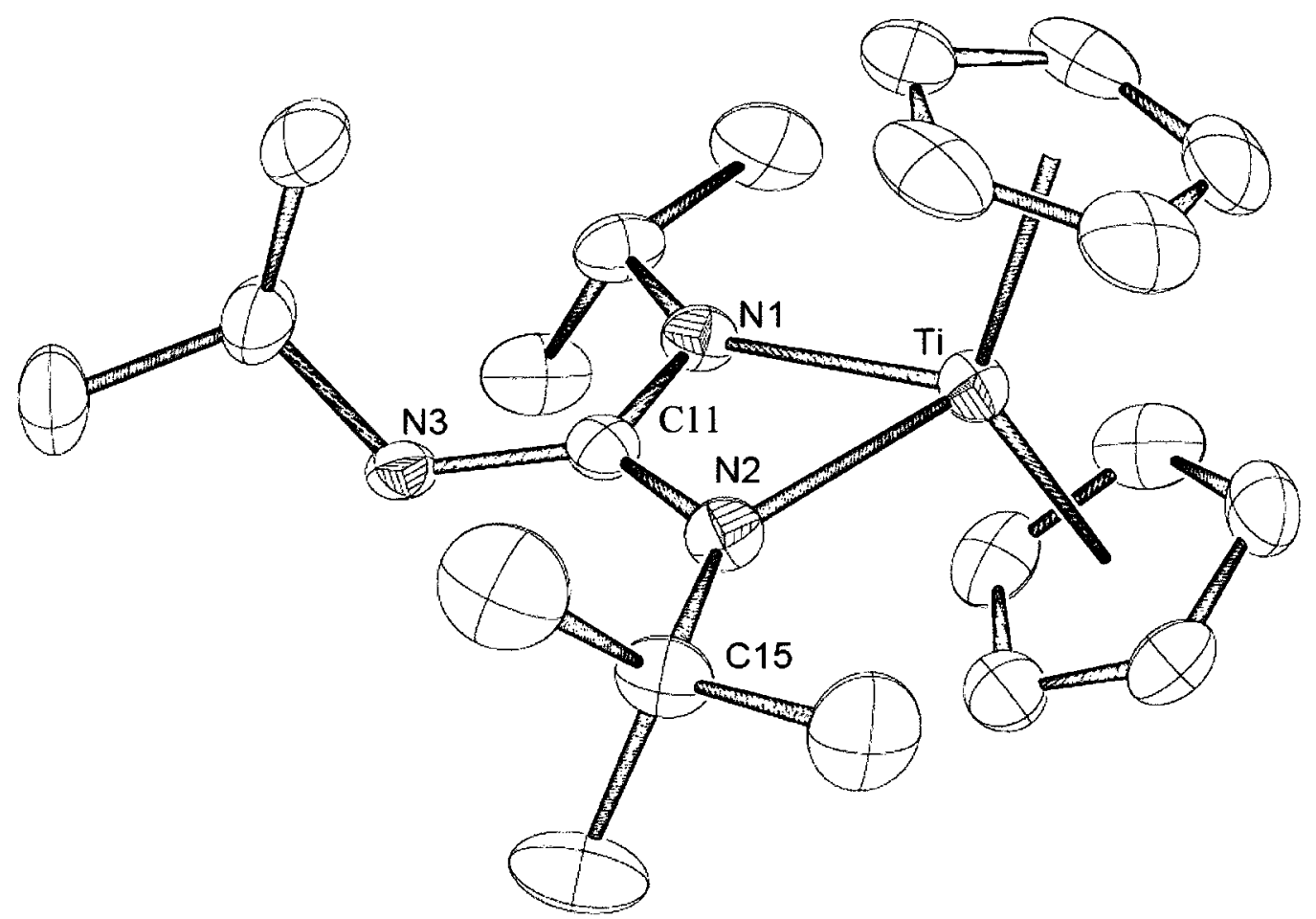

Figure 3-4. The single-crystal X-ray structure of 9. The thermal ellipsoids are shown at $50 \%$ probability and the hydrogen centres are omitted for clarity.

Table 3-2. Selected crystal data for compounds $5,6,8$, and 9.

\begin{tabular}{ccccc}
\hline & $\mathbf{5}$ & $\mathbf{6}$ & $\mathbf{8}$ & $\mathbf{9}$ \\
\hline Empirical Formula & $\mathrm{C}_{20} \mathrm{H}_{31} \mathrm{~N}_{3} \mathrm{Ti}$ & $\mathrm{C}_{19} \mathrm{H}_{30} \mathrm{~N}_{3} \mathrm{Ti}$ & $\mathrm{C}_{23} \mathrm{H}_{38} \mathrm{~N}_{3} \mathrm{Ti}$ & $\mathrm{C}_{21} \mathrm{H}_{34} \mathrm{~N}_{3} \mathrm{Ti}$ \\
FW & 361.38 & 348.36 & 404.46 & 376.41 \\
Crystal System & Monoclinic & Tetragonal & Monoclinic & Orthorhombic \\
Space Group & $\mathrm{P} 2_{1} / \mathrm{n}$ & $\mathrm{P} 4{ }_{2} / \mathrm{ncm}$ & $\mathrm{P} 21 / \mathrm{n}$ & Pbca \\
$A(\AA)$ & 14.870 & 8.1809 & 8.8431 & $10.6679(19)$ \\
$b(\AA)$ & 8.449 & 8.1809 & 29.036 & $14.750(3)$ \\
$c(\AA)$ & 16.922 & 28.121 & 9.0884 & $26.043(5)$ \\
$\alpha(\mathrm{deg})$ & 90 & 90 & 90 & 90 \\
$\beta(\mathrm{deg})$ & 111.68 & 90 & 110.82 & 90 \\
$\gamma(\mathrm{deg})$ & 90 & 90 & 90 & 90 \\
$\mathrm{~V}\left(\AA^{3}\right)$ & 1976 & 1882 & 2181 & $4097.8(13)$ \\
$Z$ & 4 & 4 & 4 & 8 \\
$\mathrm{D}_{\mathrm{c}}(\mathrm{kg} / \mathrm{L})$ & 1.215 & 1.229 & 1.232 & 1.220 \\
$\left.\mu(\mathrm{mm})^{-1}\right)$ & 0.439 & 0.458 & 0.405 & 0.426 \\
$\mathrm{~T}(\mathrm{~K})$ & $120(2)$ & $120(2)$ & $120(2)$ & $120(2)$ \\
$\mathrm{R}$ & 0.0666 & 0.0792 & 0.0555 & 0.0576 \\
wR & 0.1379 & 0.2128 & 0.1159 & 0.1427 \\
$\mathrm{~F}^{2}$ & 1.015 & 1.055 & 1.068 & 1.075 \\
\hline
\end{tabular}


Table 3-3. Selected bond lengths and angles for compounds 5 and 6 .

\begin{tabular}{|c|c|c|c|c|c|}
\hline \multicolumn{4}{|c|}{$\mathrm{C}_{20} \mathrm{H}_{31} \mathrm{~N}_{3} \mathrm{Ti}(\mathbf{5})$} & \multicolumn{2}{|c|}{$\mathrm{C}_{19} \mathrm{H}_{30} \mathrm{~N}_{3} \mathrm{Ti}(6)$} \\
\hline \multicolumn{6}{|c|}{ Selected Bond Lengths $(\AA)$} \\
\hline Ti-N1 & $2.154(2)$ & N3-C7 & $1.405(3)$ & Ti-N1 & $2.172(3)$ \\
\hline Ti-N2 & $2.147(2)$ & $\mathrm{Ti}-\mathrm{Ct} 01$ & 1.743 & $\mathrm{~N} 1-\mathrm{C} 4$ & $1.335(4)$ \\
\hline $\mathrm{N} 1-\mathrm{C} 7$ & $1.339(3)$ & Ti-Ct02 & 1.751 & $\mathrm{~N} 2-\mathrm{C} 4$ & $1.409(6)$ \\
\hline $\mathrm{N} 2-\mathrm{C} 7$ & $1.341(3)$ & & & $\mathrm{Ti}-\mathrm{Ct}$ & 1.723 \\
\hline \multicolumn{6}{|c|}{ Selected Bond Angles ( ${ }^{\circ}$ ) } \\
\hline N1-Ti-N2 & 61.81(7) & $\mathrm{N} 1-\mathrm{C} 7-\mathrm{N} 2$ & $111.07(18)$ & N1-Ti-N1' & $61.58(14)$ \\
\hline Ct01-Ti-N1 & 110.14 & $\mathrm{~N} 1-\mathrm{C} 7-\mathrm{N} 3$ & $122.4(2)$ & Ct01-Ti-N1 & 111.4 \\
\hline $\mathrm{Ct} 02-\mathrm{Ti}-\mathrm{N} 2$ & 108.35 & $\mathrm{~N} 2-\mathrm{C} 7-\mathrm{N} 3$ & $126.54(19)$ & N1-C4-N1' & $112.7(4)$ \\
\hline Ct01-Ti-Ct02 & 133.24 & & & N1-C4-N3 & $123.6(2)$ \\
\hline & & & & Ct01-Ti-Ct01, & 129.67 \\
\hline \multicolumn{6}{|c|}{ Sum of Angles $\left(^{\circ}\right)$} \\
\hline $\mathrm{N} 1$ & 360 & $\mathrm{~N} 2$ & 359 & N1 & 356 \\
\hline & & & & $\mathrm{N} 2$ & 360 \\
\hline
\end{tabular}

Table 3-4. Selected bond lengths and angles for compounds 8 and 9.

\begin{tabular}{|c|c|c|c|}
\hline \multicolumn{2}{|c|}{$\mathrm{C}_{23} \mathrm{H}_{38} \mathrm{~N}_{3} \mathrm{Ti}(\mathrm{8})$} & \multicolumn{2}{|c|}{$\mathrm{C}_{21} \mathrm{H}_{34} \mathrm{~N}_{3} \mathrm{Ti}(\mathbf{9})$} \\
\hline \multicolumn{4}{|c|}{ Selected Bond Lengths $(\AA)$} \\
\hline Ti-N1 & $2.1710(17)$ & Ti-N1 & $2.136(2)$ \\
\hline Ti-N2 & $2.1730(17)$ & Ti-N2 & $2.145(2)$ \\
\hline N1-C11 & $1.326(3)$ & N1-C11 & $1.333(3)$ \\
\hline $\mathrm{N} 2-\mathrm{C} 11$ & $1.328(3)$ & $\mathrm{N} 2-\mathrm{C} 11$ & $1.328(3)$ \\
\hline $\mathrm{N} 3-\mathrm{C} 11$ & $1.433(3)$ & N3-C11 & $1.402(4)$ \\
\hline Ti-Ct01 & 1.737 & $\mathrm{~N} 2-\mathrm{C} 15$ & $1.477(3)$ \\
\hline $\mathrm{Ti}-\mathrm{Ct} 02$ & 1.741 & Ti-Ct01 & 2.093 \\
\hline & & Ti-Ct02 & 2.099 \\
\hline \multicolumn{4}{|c|}{ Selected Bond Angles $\left({ }^{\circ}\right)$} \\
\hline N1-Ti-N2 & $60.91(6)$ & N1-Ti-N2 & $61.66(8)$ \\
\hline Ct01-Ti-N1 & 109.5 & Ct01-Ti-N1 & 108.5 \\
\hline $\mathrm{Ct} 02-\mathrm{Ti}-\mathrm{N} 2$ & 109.5 & Ct02-Ti-N2 & 109.1 \\
\hline $\mathrm{Ct} 01-\mathrm{Ti}-\mathrm{Ct} 02$ & 133.45 & $\mathrm{Ct} 01-\mathrm{Ti}-\mathrm{Ct} 02$ & 134.5 \\
\hline $\mathrm{N} 1-\mathrm{C} 11-\mathrm{N} 2$ & $112.14(17)$ & $\mathrm{N} 1-\mathrm{C} 11-\mathrm{N} 2$ & $111.0(2)$ \\
\hline $\mathrm{N} 1-\mathrm{C} 11-\mathrm{N} 3$ & $121.82(17)$ & N1-C11-N3 & $122.5(4)$ \\
\hline $\mathrm{N} 2-\mathrm{C} 11-\mathrm{N} 3$ & $126.04(18)$ & $\mathrm{N} 2-\mathrm{C} 11-\mathrm{N} 3$ & $126.5(2)$ \\
\hline \multicolumn{4}{|c|}{ Sum of Angles $\left(^{\circ}\right)$} \\
\hline N1 & 360 & N1 & 360 \\
\hline N2 & 360 & $\mathrm{~N} 2$ & 360 \\
\hline N3 & 354 & & \\
\hline
\end{tabular}

For compounds 5,6 and $\mathbf{8}$, the titanium was in a four-coordinate distorted tetrahedral environment, considering the centroids of the cyclopentadienyl rings. Not surprisingly, 
the angle between the centroids was much larger than ideal $\left(130-133^{\circ}\right)$ and the bite angle of the guanidinate was correspondingly smaller $\left(61.0-61.8^{\circ}\right)$. The centroidtitanium-nitrogen angles were closer to ideal for $5\left(108.4^{\circ}\right.$ and $\left.109.8^{\circ}\right)$ and $\mathbf{8}\left(109.5^{\circ}\right)$ and somewhat distorted for $6\left(111.4^{\circ}\right)$. The guanidinate ring was very close to planar in each case with torsion angles ranging from $0-1.3^{\circ}$. As is typical for guanidinates, the exocyclic amido moieties were rotated from the plane of the guanidinate ring in all cases. However, $\pi$-overlap follows a $\cos ^{2} \theta$ relationship for twisted systems like this, thus the exocyclic group participated significantly in the delocalized $\pi$-bonding of the guanidinate. $^{21}$ In every structure, the $\mathrm{C}-\mathrm{N}$ bond to the exocyclic amide was longer than the $\mathrm{C}-\mathrm{N}$ bonds to the chelate nitrogens. This indicated a higher contribution to the $\pi$ system from the metallocycle nitrogens compared to the exocyclic nitrogen. This can be seen in the sum of angles around the chelate nitrogens on $\mathbf{5}$ and 8 (N1 at $360^{\circ}$ and $\mathrm{N} 2$ at $359^{\circ}$ for $5,360^{\circ}$ for 8 ), whose planarity indicated an $\mathrm{sp}^{2}$ hybridization and thus participation in the $\pi$-system. Interestingly, compound 6 was defined by two planes of symmetry: one in the $\mathrm{C} 1-\mathrm{Ti}-\mathrm{C} 4$ plane and one in the Ti-N1-C4 plane. This gave rise to two orientations of the isopropyl groups where they bend $14^{\circ}$ above or below the Ti-N1C4 plane $50 \%$ of the time. Likewise, the exocyclic amido group tilts $36^{\circ}$ in either direction out of the $\mathrm{C} 1-\mathrm{Ti}-\mathrm{C} 4$ plane $50 \%$ of the time. This symmetry is likely enforced by the crystal's $\mathrm{P} 4_{2} / \mathrm{ncm}$ space group and forces the chelating nitrogen out of planarity.

In these structures, the bond lengths to the centroids were somewhat shorter than a typical four-coordinate $\mathrm{Cp}$-titanium compound $\left(\mathrm{Cp}_{2} \mathrm{Ti}(\mathrm{NSO})_{2}\right.$ reported by Roesky et al., $\mathrm{Cp}-\mathrm{Ti}=2.06 \AA) .^{22}$ The bond lengths were longer than those of the starting material $\left[\mathrm{Cp}_{2} \mathrm{TiCl}_{2}{ }_{2}^{23}\right.$ at a range of $1.72-1.75 \AA$ compared to $1.31-1.38 \AA$. The $\mathrm{Cp}$-Ti-Cp angle 
was similar to the starting material $\left[\mathrm{Cp}_{2} \mathrm{TiCl}\right]_{2}$ at a range of $129.7-133.4^{\circ}(\mathrm{Cp}-\mathrm{Ti}-\mathrm{Cp}=$ $\left.131.2-133.4^{\circ}\right)^{23}$ The Ti-N bond lengths were slightly longer than a typical bonding distance for a monoanionic guanidinate at titanium ${ }^{24}$ at a range of $2.14-2.17 \AA$ compared to $2.09-2.11 \AA .^{24}$ The lengths fell within range reported by Hagadorn and Arnold for their prototypical titanium (III) amidinate $(2.05-2.16 \AA) .{ }^{25}$

Complex 9 was also a four-coordinate distorted tetrahedron. The Ti-N bond lengths differed due to the sterically hindering t-butyl species found on one side of the ligand; Ti$\mathrm{N} 1$ at $2.136 \AA$ and Ti-N2 at $2.145 \AA$ (Figure $3-4$ ). The bite angle of the guanidinate was found to be $61.6^{\circ}$ with a corresponding centroid-titanium-centroid angle of $134.5^{\circ}$. The guanidinate ring deviated slightly from planarity with a torsion angle of $3.1^{\circ}$. The exocyclic amido species was found to be rotated from the Ti-N2-C11 plane of the guanidinate ring by $53.7^{\circ}$ showing partial participation in the delocalized $\pi$-bonding of the metallocycle. Similar to the other titanium (III) structures, the C-N bond to the

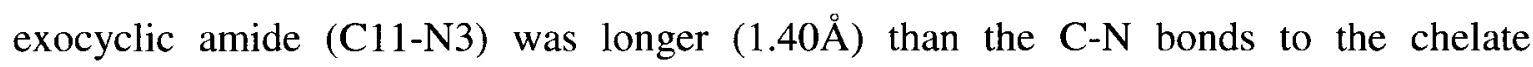
nitrogens (N1-C11 and N2-C11) at 1.33 contribution to the $\pi$-system from the chelate ring nitrogens compared to the exocyclic amide. The participation of the metallocycle nitrogens in the $\pi$-system was complimented by the sum of angles around the chelate nitrogens (N1 and $\mathrm{N} 2)$ at $360^{\circ}$.

\subsubsection{Thermolysis}

Thermal data for compound 9 was not studied due to difficulty in reproducing the ligand and the complex. The melting points for compounds $5-\mathbf{8}$ fell in a wide range, from $147^{\circ} \mathrm{C}$ for 5 to decomposition at $>180^{\circ} \mathrm{C}$ for 8 . TG analyses showed all compounds 
to decompose with small residual masses and similar on-sets of volatility (Figure 3-5, Table 3-5). The thermal data showed no clear predominant candidate as an ALD precursor from these compounds, so compound $\mathbf{5}$ was selected due to its higher yield, lower melting point and generally less problematic synthesis.

Thermal analyses was undertaken for compounds $\mathbf{5}$ - 8. For compound $\mathbf{5}$ there was a small initial weight loss in the TG of $<1 \%$ (highlighted in the derivative curve,Figure 3-6) that was due to residual solvent in the sample. The on-set of volatilization (i.e. 5\% mass loss) occurred at $149^{\circ} \mathrm{C}$ and showed an uninterrupted weight loss to $10.5 \%$ of the original mass. The differential curve (Figure 3-6) for this weight loss had the typical appearance of sublimation; a slow on-set and a quick drop-off with an additional small feature centred at $155^{\circ} \mathrm{C}$. This interruption in the otherwise smooth volatilization corresponded to the melting point of the sample and was likely caused by a change in surface area upon melting. From the residual mass, after volatilization, there was a second weight loss of approximately $5 \%$. This could be the volatilization of an impurity that was present in $\mathbf{5}$ but the more likely explanation is a subsequent thermal decomposition of the remaining mass.

Table 3-5. Thermal parameters for compounds 5 - 8 .

\begin{tabular}{lcccc}
\hline & Exocyclic Amido & $\begin{array}{c}\text { Melting point } \\
\left({ }^{\circ} \mathrm{C}\right)\end{array}$ & $\begin{array}{c}\text { On-set of Volatility } \\
\left({ }^{\circ} \mathrm{C}\right)\end{array}$ & $\begin{array}{c}\text { Residual Mass } \\
(\%)\end{array}$ \\
\hline $\mathbf{5}$ & $\mathrm{R}={ }^{\mathrm{i}} \mathrm{Pr}, \mathrm{R}^{\prime}=\mathrm{H}$ & $147-150$ & 149 & 10.5 \\
$\mathbf{6}$ & $\mathrm{R}=\mathrm{R}^{\prime}=\mathrm{Me}$ & $163-165$ & 127 & 0.0 \\
7 & $\mathrm{R}=\mathrm{R}^{\prime}=\mathrm{Et}$ & $155-157$ & 142 & 12.8 \\
$\mathbf{8}$ & $\mathrm{R}=\mathrm{R}^{\prime}={ }^{\mathrm{i}} \mathrm{Pr}$ & Decomposes & 168 & 1.3 \\
\hline 'on-set of volatility was taken as 5\% mass loss & &
\end{tabular}


The TG for compound $\mathbf{6}$ showed one thermal event that occurred at a temperature range of $127-382^{\circ} \mathrm{C}$ with a residual mass of $0 \%$. The derivative weight curve (Figure 3-6) displayed characteristic volatility as there was no interruption in the curve. This demonstrated that the compound had a clean volatilization with no decomposition occurred throughout the experiment.

The derivative weight curve (Figure 3-6) for compound 7 showed three minor thermal events ranging from $142-168^{\circ} \mathrm{C}, 168-185^{\circ} \mathrm{C}$ and $185-292^{\circ} \mathrm{C}$. The three events were considered to be caused by thermal degradation of the compound as the derivative weight curve (Figure 3-6) was symmetric. The curve demonstrated a gradual on-set and drop-off once the maximum was reached. The final residual mass of this compound was $12.8 \%$. The results of this experiment lead to the conclusion that this compound would not be an ideal candidate for ALD processes.

Compound 8 had one thermal event that occurred at the temperature range of 168 $340^{\circ} \mathrm{C}$ with a residual mass of $1.3 \%$. The derivative weight curve (Figure 3-6) demonstrated characteristic volatilization as the curve had a slow on-set and quick dropoff without interruption.

The DSC data for compound 5 suggested that the volatilization occurred while the material was in the liquid state. An initial endotherm at $152.5^{\circ} \mathrm{C}$ corresponded to the melting point of $\mathbf{5}$ as corroborated by bench-top methods. The second broad endotherm corresponded to the major weight loss in the TG and can thus be assigned to the volatilization of the compound. Although the on-set of volatilization was at a relatively high temperature with respect to ALD process temperatures, the lack of thermal 
decomposition during the volatilization event suggested that this material could be used as a vapour precursor.

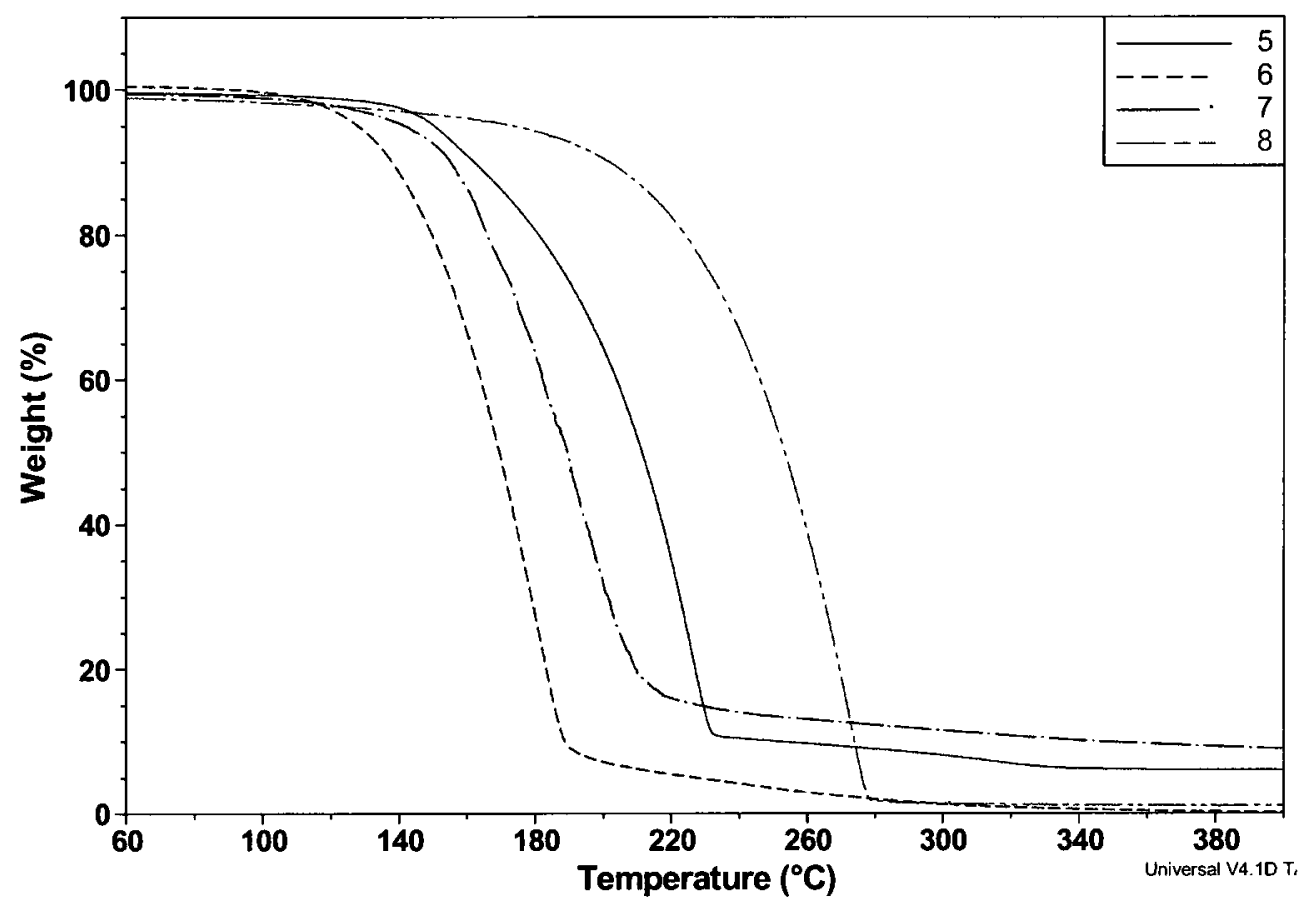

Figure 3-5. Thermal gravimetric analysis of 5 - 8. 


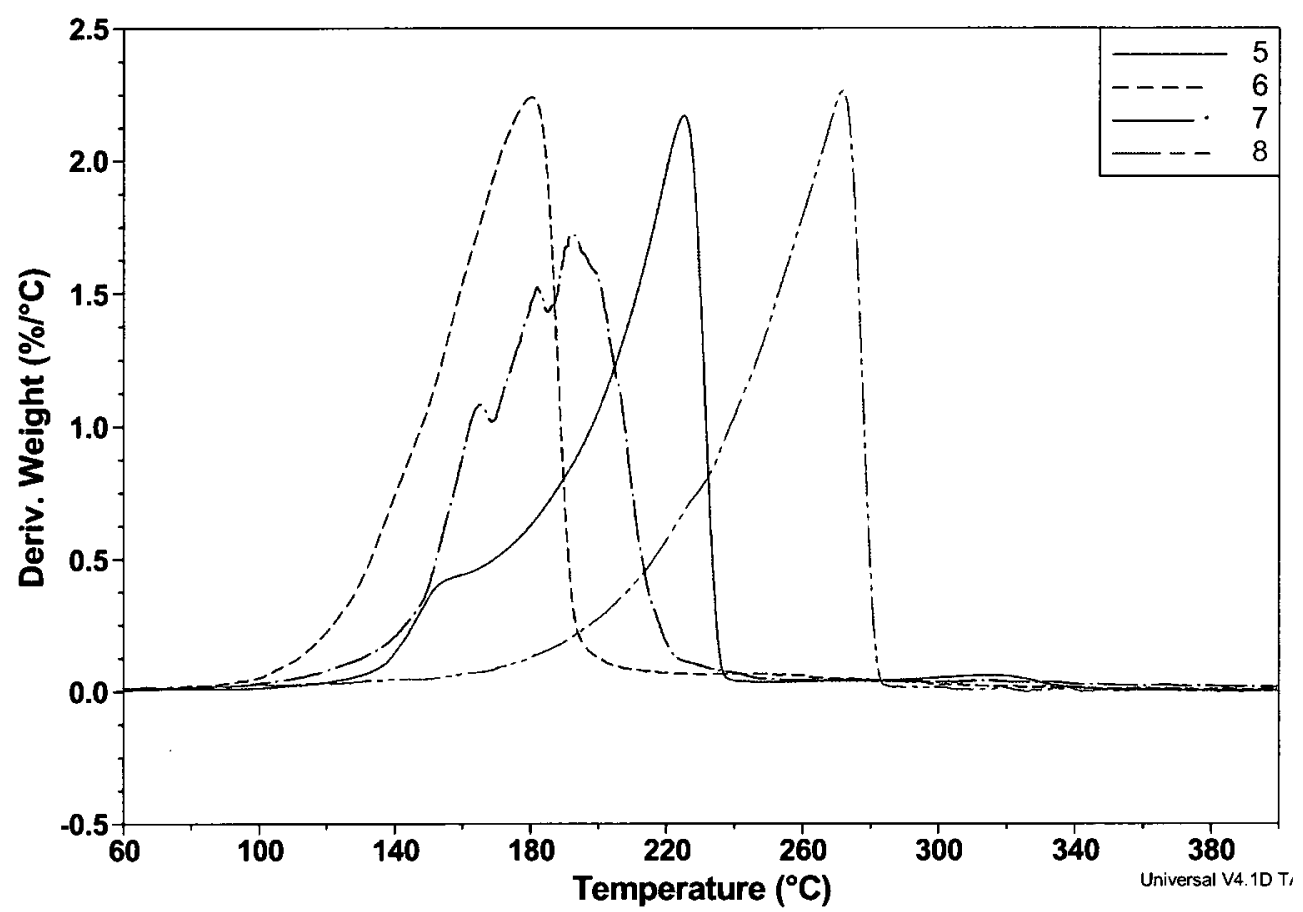

Figure 3-6. Differential weight curve for compounds 5 - 8.

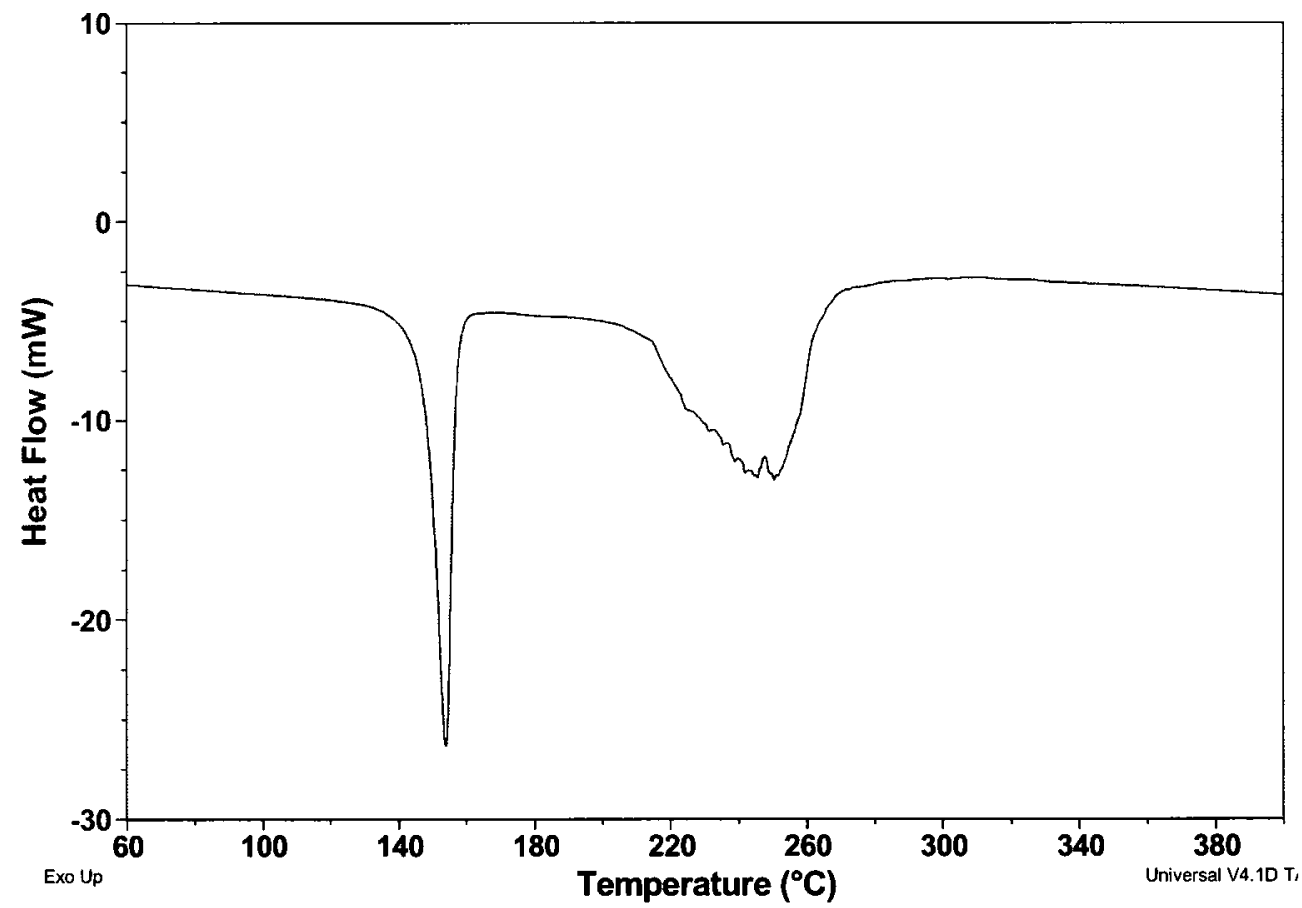

Figure 3-7. Differential scanning calorimetery of 5. 
In potential ALD growth of TiN films using $\mathbf{5}$ as a precursor, the initial nucleation pathway would involve nucleation on the interfacial oxide layer of a silicon substrate creating a bound titanium complex. High surface area silica is the most often used material support for metallocene catalysts ${ }^{26}$ and is a useful model to lend insight into the nucleation products at the interfacial oxide layer. High surface area silica is an ideal material for investigating the surface reactivity of $\mathbf{5}$ due to the abundance of surface hydroxyls, which in turn, leads to a high enough concentration of surface species to use traditional characterization techniques such as elemental analysis and solid-state nuclear magnetic resonance.

\subsubsection{Exposure Experiments}

Upon reactive exposure of the silica to a gas-phase metal precursor the number of product surface species is directed by details of the surface structure. Pre-heating the substrate decreases the density of surface hydroxyl sites ${ }^{27}$ limiting the coordination number of the bound product complex (Figure 3-8). Previous experimental work by Leskelä and co-workers $^{28}$ using NMR and elemental analysis demonstrated that the silica surface bonding mode of a zirconocene precursor depended on the level of substrate preheating. 


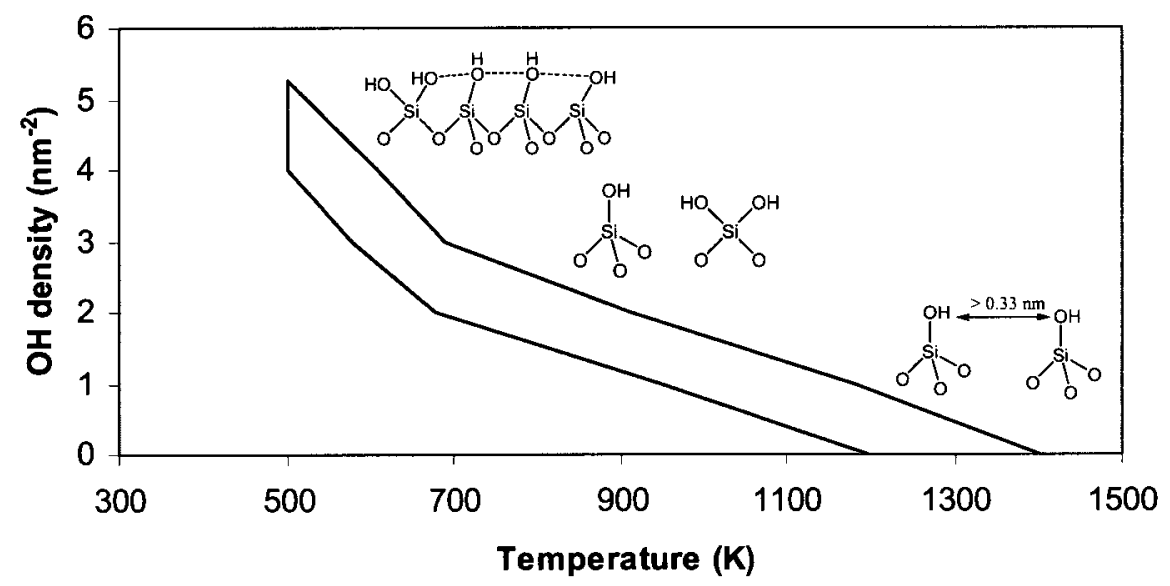

Figure 3-8. Hydroxyl group density as a function of temperature pre-treatment (adapted from Gunter $^{29}$ ).

Each exposure experiment was preformed on a commercial F-120 ALCVD ${ }^{\mathrm{TM}}$ reactor manufactured by ASM Microchemistry Ltd. (Figure 3-9). The reactor was equipped with a reaction chamber for processing porous materials. In the test exposures, 3 to $5 \mathrm{~g}$ of porous high surface area $\mathrm{SiO}_{2}$ and $\mathrm{Al}_{2} \mathrm{O}_{3}$ powder (Table 3-6) were heat treated in a muffle furnace for $16 \mathrm{~h}$ at 350,950 and $600^{\circ} \mathrm{C}$, respectively, to control the number of surface hydroxyl groups. These were subsequently used as substrates. Before the introduction of the titanium precursor to the surface, the substrates were further preheated in the reaction chamber at the reaction temperatures for 3 to $5 \mathrm{~h}$ to remove any possible moisture adsorbed to the surface during storage. After pre-treatment, the titanium precursor was vaporized and transported with the help of nitrogen flow through the silica particles where it reacted. Just one exposure of the precursor was carried out per test on the oxide surface. The precursor amount was varied from $1.8 \mathrm{~g}$ to $2.0 \mathrm{~g}$ and the reaction time was 4 hours to ensure surface saturation. After the reaction, the reaction chamber was purged with nitrogen. The samples were handled inertly by storing them in a glove box. 


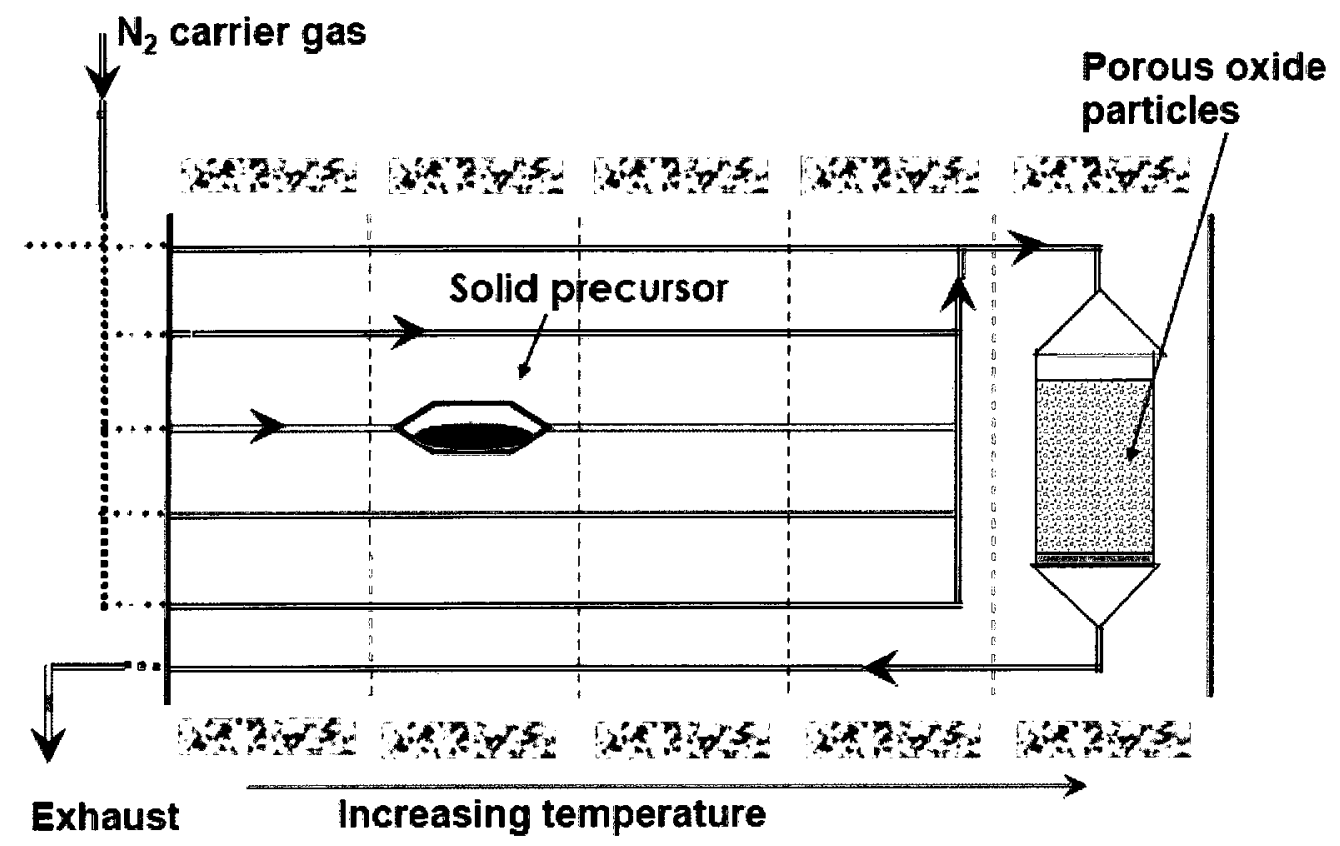

Figure 3-9. Schematic of F-120 ALCVD ${ }^{\mathrm{TM}}$ reactor.

Table 3-6. Physical properties of high surface area substrates.

\begin{tabular}{cccccc}
\hline Oxide & Type & $\begin{array}{c}\text { Surface area } \\
\left(\mathrm{m}^{2} / \mathrm{g}\right)\end{array}$ & $\begin{array}{c}\text { Pore volume } \\
\left(\mathrm{cm}^{3} / \mathrm{g}\right)\end{array}$ & $\begin{array}{c}\text { Pore size } \\
(\mathrm{nm})\end{array}$ & $\begin{array}{c}\text { Mean particle } \\
\text { diameter }(\mu \mathrm{m})\end{array}$ \\
\hline \hline $\mathrm{SiO}_{2}$ & $\begin{array}{c}\text { INEOS silicas } \\
\text { EP10X }\end{array}$ & 300 & 1.8 & 24 & 100 \\
$\mathrm{Al}_{2} \mathrm{O}_{3}$ & $\begin{array}{c}\text { Akzo Nobel } \\
\text { Alumina 000-1.5E }\end{array}$ & $180-195$ & 0.5 & 10 & $1600-1800$ \\
\hline
\end{tabular}

High surface area silica was pre-treated at two different temperatures: $350^{\circ} \mathrm{C}$ and $900^{\circ} \mathrm{C}$ and alumina extrudate pre-treated to $600^{\circ} \mathrm{C}$, labelled $\mathrm{SiO}_{2}-350, \mathrm{SiO}_{2}-900$ and $\mathrm{Al}_{2} \mathrm{O}_{3}-600$, respectively. In order to optimize the surface exposure experiment $\mathrm{SiO}_{2}-350$ was exposed to the titanium precursor in $\mathrm{N}_{2}$ carrier gas for 5 hours using $0.4-1.0 \mathrm{~g}$ of compound 5 at a variety of reaction temperatures. In these cases the precursor was completely volatilized from the bubbler. It was determined that $240^{\circ} \mathrm{C}$ was the optimal reaction temperature for the exposure experiments based on the latter exposure experiment results obtained by ASM Microchemistry Ltd. When the reactions were 
repeated at $240^{\circ} \mathrm{C}$ using an excess of precursor with substrates pre-heated at either $350^{\circ} \mathrm{C}$ or $900^{\circ} \mathrm{C}$, complete saturation was visually evident from the complete change in colour of the silica (Figure 3-10, Table 3-7). However, for the alumina substrate pre-treated to $600^{\circ} \mathrm{C}$, only partial saturation was achieved (Figure 3-10) as demonstrated by the patchy colour change.
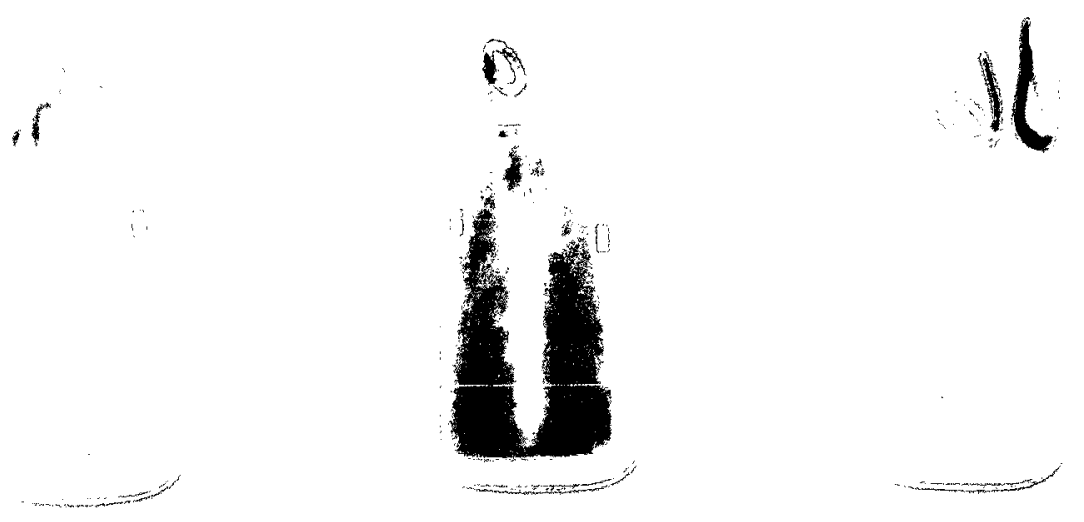

Figure 3-10. Resulting colour change of $\mathrm{SiO}_{2}-350, \mathrm{SiO}_{2}-900$ and $\mathrm{Al}_{2} \mathrm{O}_{3}-600$ after exposure experiments.

Table 3-7. Exposure experiment data for pre-heated silica at $350^{\circ} \mathrm{C}\left(\mathrm{SiO}_{2}-350\right)$ and $900^{\circ} \mathrm{C}\left(\mathrm{SiO}_{2}-900\right)$ and alumina $600^{\circ} \mathrm{C}\left(\mathrm{Al}_{2} \mathrm{O}_{3}-600\right)$.

\begin{tabular}{cccc} 
Substrate & $\begin{array}{c}\text { Reaction Temperature } \\
\left({ }^{\circ} \mathrm{C}\right)\end{array}$ & $\begin{array}{c}\text { Ti Density } \\
(\text { at·nm }\end{array}$ & C/Ti ratio \\
\hline \hline $\mathrm{SiO}_{2}-350$ & 180 & 0.53 & 8.8 \\
$\mathrm{SiO}_{2}-350$ & 210 & 0.31 & 7.45 \\
$\mathrm{SiO}_{2}-350$ & 240 & 0.25 & 8.0 \\
$\mathrm{SiO}_{2}-350$ & 270 & 0.71 & 6.8 \\
$\mathrm{SiO}_{2}-350$ & 300 & 0.54 & 5.0 \\
$\mathrm{SiO}_{2}-350$ & 330 & 0.72 & 4.9 \\
\hline $\mathrm{SiO}_{2}-350$ & 240 & 1.47 & 6.6 \\
$\mathrm{SiO}_{2}-900$ & 240 & 1.02 & 7.0 \\
$\mathrm{Al}_{2} \mathrm{O}_{3}-600$ & 240 & 1.67 & 8.4 \\
\hline
\end{tabular}


$\mathrm{SiO}_{2}-350$ turned uniformly bright orange, a colour that persisted on air exposure. Solid state magic angle spinning (MAS) NMR showed two ${ }^{13} \mathrm{C}$ resonances: a broad complex peak in the aliphatic region centred at $23.8 \mathrm{ppm}$ and a broad peak in the aromatic region at $\mathbf{1} 15.3 \mathrm{ppm}$ (Figure $3-11$ ). Elemental analysis yielded a C/Ti ratio of 6.6. This suggested that 5 may have decomposed on the $\mathrm{SiO}_{2}-350$ silica surface to yield both a guanidinate containing as well as a $\mathrm{Cp}$ containing surface species, suggesting that the surface enthalpies for equations a) and b) are similar.

$$
\mathrm{Cp}_{2} \mathrm{TiGuan}+2 \mathrm{SiO}_{2} / \mathrm{OH} \rightarrow \mathrm{SiO}_{2} /(\mathrm{O})_{2} \mathrm{TiGuan}+2 \mathrm{CpH}
$$

$$
\mathrm{Cp}_{2} \mathrm{TiGuan}+2 \mathrm{SiO}_{2} / \mathrm{OH} \rightarrow \mathrm{SiO}_{2} /(\mathrm{O})_{2} \mathrm{TiCp}+\mathrm{CpH}+\mathrm{GuanH}
$$

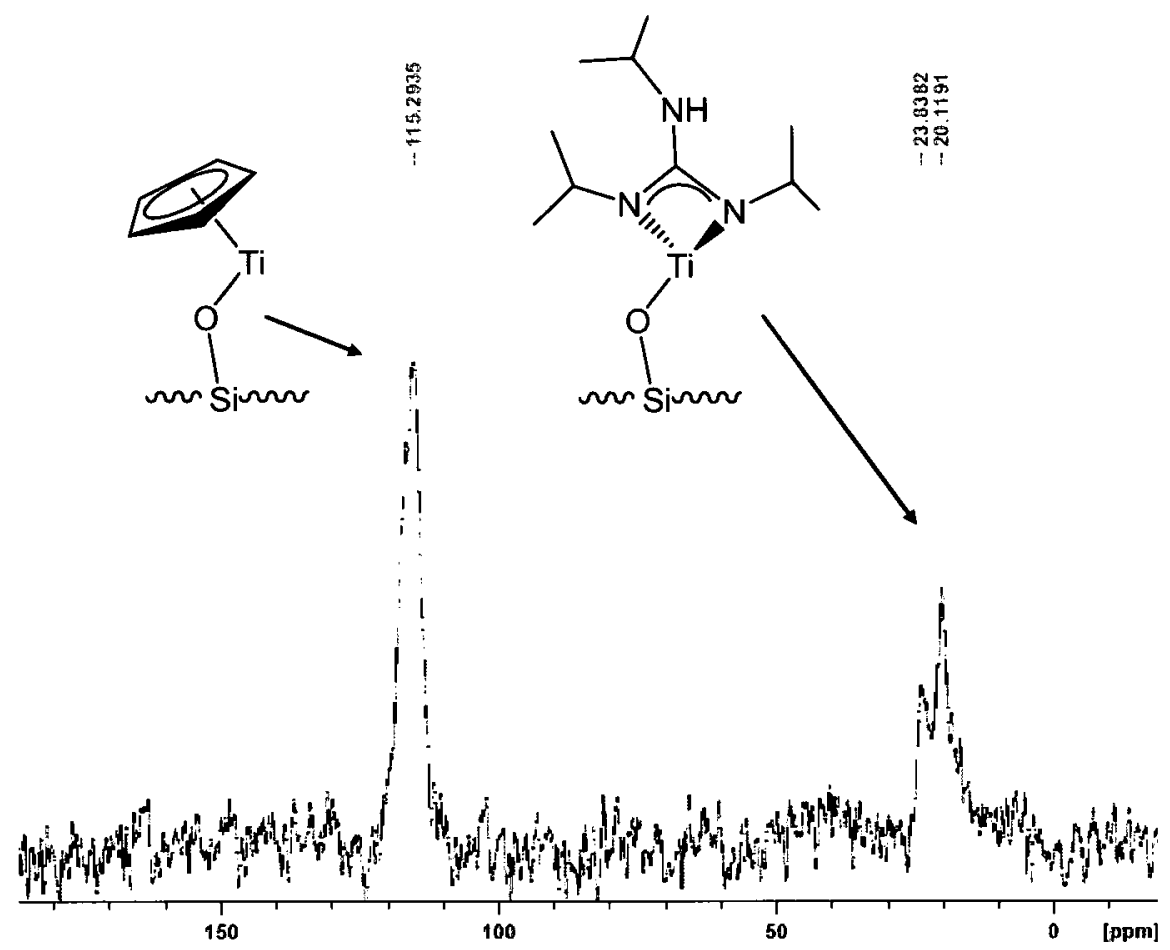

Figure 3-11. Solid state ${ }^{13} \mathrm{C}$ NMR of $\mathrm{SiO}_{2}-350$ depicting aromatic and aliphatic carbons. 
The lower pre-treatment temperature resulted in a larger hydroxyl density located on the surface causing the silica to be somewhat acidic. ${ }^{29}$ The acidity may have allowed the hydroxyl groups to participate in hydrogen bonding with the exocyclic nitrogen of the guanidinate, resulting in a stabilized guanidinate-titanium species.

$\mathrm{SiO}_{2}-900$ was uniformly dark orange-brown (Figure 3-10) and this colour faded to light yellow when the silica was exposed to atmosphere after several hours. Solid state ${ }^{13}$ C-MAS NMR showed one resonance at $115.0 \mathrm{ppm}$ (Figure 3-12), in the aromatic region, as well as a $\mathrm{C} / \mathrm{Ti}$ ratio of 7.0. This suggested a mixture containing one to two cyclopentadienyl titanium surface complexes remained. With higher pre-treatment temperature the surface had less hydroxyl density. The lack of hydroxyl groups present on the surface decreased the chance for hydrogen bonding thus the guanidinate-titanium species could not be preserved during the reaction.

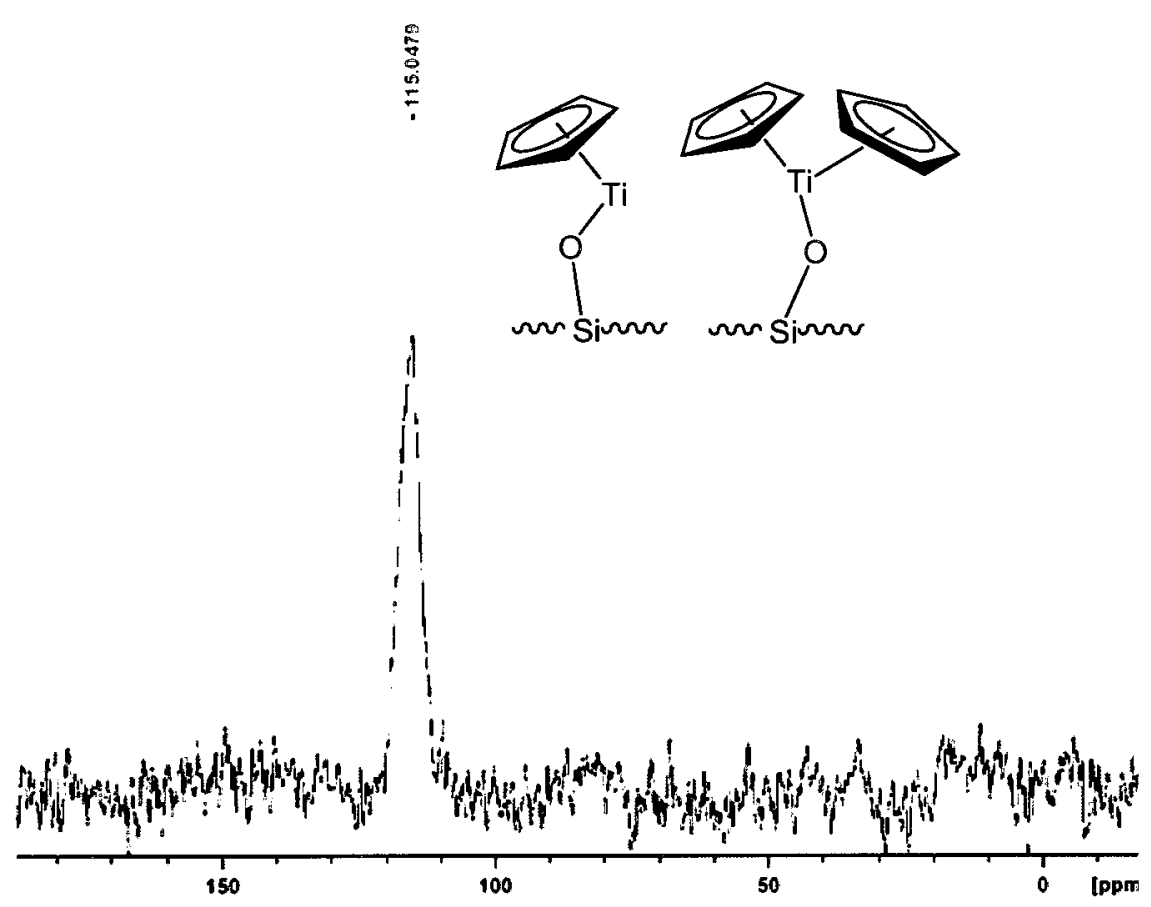

Figure 3-12. Solid state ${ }^{13} \mathrm{C}$ NMR of $\mathrm{SiO}_{2}-900$ depicting aromatic carbons. 
$\mathrm{Al}_{2} \mathrm{O}_{3}-600$ was not fully saturated demonstrated by the patchy brown colour (Figure 3-10). Solid state ${ }^{13} \mathrm{C}$-MAS NMR showed the presence of both aliphatic and aromatic resonances at 22.5 and $114.9 \mathrm{ppm}$, respectively (Figure 3-13). The C/Ti ratio was found to be 8.4 suggesting a possible mixture of one guanidinate-titanium species to one or two cyclopentadienyl containing titanium species. It can be speculated that hydrogen bonding also occurred as the pre-treatment temperature resulted in a higher concentration of hydroxyl density on the alumina as in the $\mathrm{SiO}_{2}-350$ example.

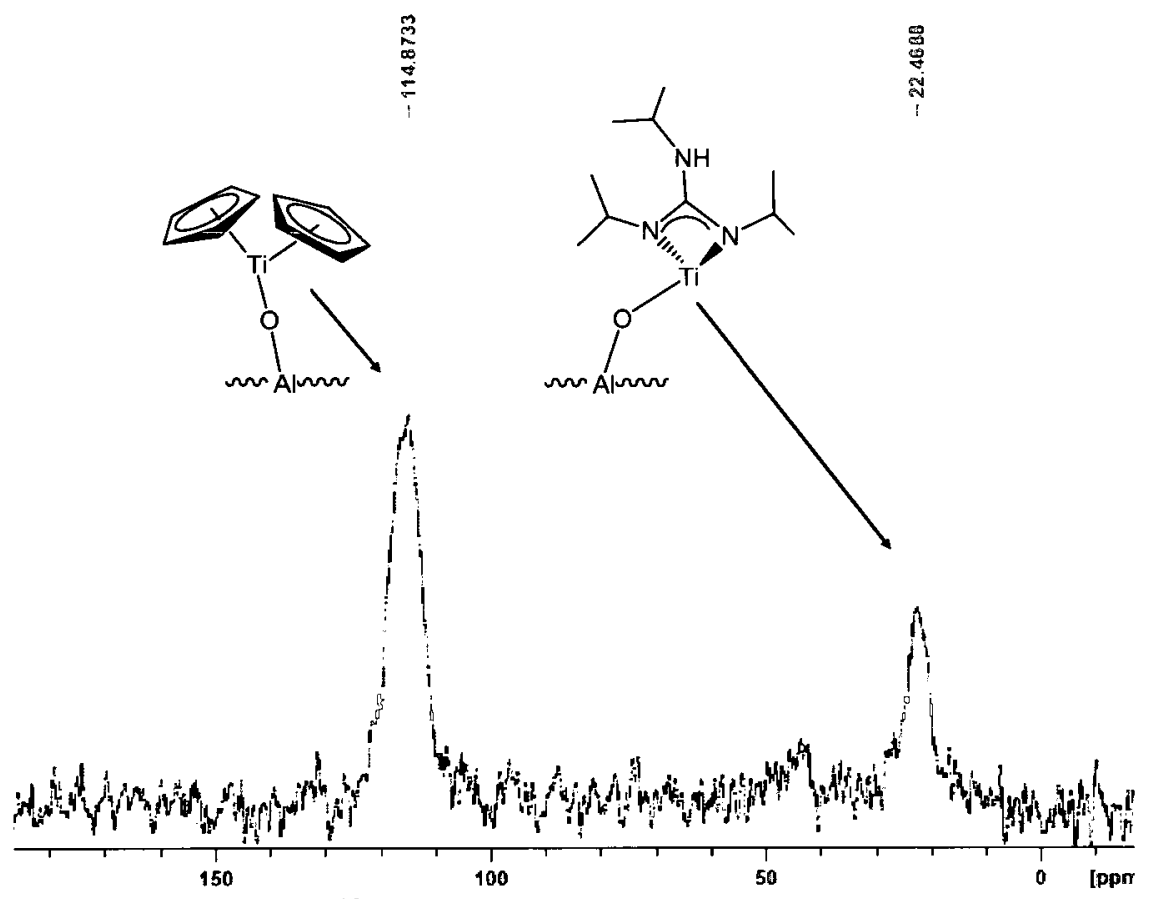

Figure 3-13. Solid state ${ }^{13} \mathrm{C}$ NMR of $\mathrm{Al}_{2} \mathrm{O}_{3}-600$ depicting aromatic and aliphatic carbons.

One interesting observation from these exposure experiments was that the titanium species found on the surface of the silica and alumina was likely in an oxidation state of +4. This can be seen by the characteristic colour of +4 oxidation state titanium species (orange/red) as well as the diamagnetic ${ }^{13} \mathrm{C}$ NMR signals. No special experiments were 
conducted while collecting the solid state MAS NMRs, which would have been an issue if the samples were paramagnetic. It was evident that the bound species were very stable as it took several hours for a colour change to occur when the coated silica was exposed to air. These observations would explain the inertness this monolayer showed while attempting ALD reactions with both ammonia and water as the second precursor.

\subsubsection{Isolated Zinc By-product}

The reduction of $\mathrm{Cp}_{2} \mathrm{TiCl}_{2}$ with zinc dust produced in situ $\mathrm{ZnCl}_{2}$. It was difficult to remove the $\mathrm{ZnCl}_{2}$ from solution, even though it has been reported that $\left[\mathrm{Cp}_{2} \mathrm{TiCl}\right]_{2}-\mathrm{ZnCl}_{2}$ is less soluble in polar solvents, such as ether. ${ }^{30}$ When the $\left[\mathrm{Cp}_{2} \mathrm{TiCl}\right]_{2}$ dimer crystallized out of solution, some $\mathrm{ZnCl}_{2}$ precipitated out as well forming the less soluble $\left[\mathrm{Cp}_{2} \mathrm{TiCl}_{2^{-}}\right.$ $\mathrm{ZnCl}_{2}$ species. Purification of the parent titanium species would have increased the yield of the cyclopentadienyl guanidinate species, however, this was experimentally difficult to achieve, thus the $\mathrm{Ti}^{+3}$ species was used in situ. When further reaction of the $\left[\mathrm{Cp} \mathrm{TiCl}_{2}\right.$ $\mathrm{ZnCl}_{2}$ species with lithiated triisopropyl guanidinate (tripyl) ligand was undertaken, a zinc guanidinate dimer was produced. Crystals of this compound (10) were isolated as colourless needles. The dimer contained two zinc centres with three tripyl ligands bound to them in a Chinese lantern fashion and a lone chlorine bound to one zinc (Figure 3-14, Table 3-8 and Table 3-9). The rational synthesis of this compound was further studied by a co-worker. $^{31}$

Compound 10 had two zincs in two different coordination environments. Zn1 was three coordinate with a trigonal planar geometry with respect to the nitrogens. The sum of angles around $\mathrm{Zn} 1$ in the nitrogen plane was $359.8^{\circ}$ indicating planarity at the bottom 
half of the dimer. The distance to $\mathrm{Zn} 2$ was almost at a right angle with respect to the nitrogen- $\mathrm{Zn}$ plane at an average of $88.6^{\circ}$, respectively. The angles of the three nitrogens around $\mathrm{Zn} 1$ were very close to ideal at $119.4^{\circ}, 120.0^{\circ}$ and $120.4^{\circ}$, respectively. $\mathrm{Zn} 2$ on the other hand was four coordinate in a slightly distorted tetrahedral geometry. The tetrahedral angles around $\mathrm{Zn} 2$ were very close to ideal at $110.2^{\circ}, 110.4^{\circ}, 112.6^{\circ}$ and $107.3^{\circ}$, respectively. The Zn2-Cl1 bond length was $2.29 \AA$, which was found to be similar to previously reported $\mathrm{Zn}-\mathrm{Cl}$ bonds of length $2.22 \AA{ }^{32}$ The $\mathrm{Zn} 1-\mathrm{Zn} 2$ distance of $2.71 \AA$ was longer than a previously reported $\mathrm{Zn}-\mathrm{Zn}$ bond at $2.33 \AA \AA^{33}$ The $\mathrm{Zn} 1-\mathrm{N} 2$, N4, and N8 bond lengths were all smaller than the $\mathrm{Zn} 2-\mathrm{N} 1, \mathrm{~N} 5$, and N7 at an average of $1.93 \AA$ compared to an average of $2.04 \AA$, respectively. Lengthening of the $\mathrm{Zn} 2-\mathrm{N}$ bonds may be caused by the steric bulk or the electron donating nature of the chlorine atom.

Each guanidinate bite angle was similar at $119.2^{\circ}$, respectively, which was quite large and unsurprisingly attributed to the dimer structure. The sum of angles around the chelate nitrogens, N1, N2, N4, N5, N7 and N8 were all very close to $360^{\circ}$ deviating by $<0.50^{\circ}$ indicating very good planarity around the nitrogens. The $\mathrm{C}-\mathrm{N}$ bond lengths of the chelate nitrogens $(\mathrm{N} 1, \mathrm{~N} 2, \mathrm{~N} 4, \mathrm{~N} 5, \mathrm{~N} 7$, and $\mathrm{N} 8)$ to the quaternary carbons $(\mathrm{C} 3, \mathrm{C} 4, \mathrm{C} 10)$ were also very similar and shorter than an ideal single C-N bond length $(1.479 \AA)^{34}$ at $1.33-1.35 \AA$. The shortened bond lengths demonstrated the participation of the chelate nitrogens to the $\pi$-system. The quaternary carbons $(\mathrm{C} 3, \mathrm{C} 4, \mathrm{C} 10)$ and exocyclic nitrogens (N3, N6, and N9) bond lengths were longer at 1.38 to $1.40 \AA$, respectively, however still shorter than an ideal single $\mathrm{C}-\mathrm{N}$ bond. ${ }^{34}$ This demonstrated that the exocyclic nitrogens were somewhat involved in the extended $\pi$-bonding of the guanidinate ring. The steric bulk of the isopropyl groups caused the guanidinate ligands to twist above and below the 
C11-Zn2-Zn1 plane (Figure 3-15a). The twist forced the chelate nitrogens to be above and below the plane with the quaternary carbon in the Cl1-Zn2-Zn1 plane. The twisting of the guanidinate ligands allowed $\mathrm{C}_{3}$ symmetry of the compound to occur as seen when looking at the complex through the Cl1-Zn2-Zn1 axis (Figure 3-15b).

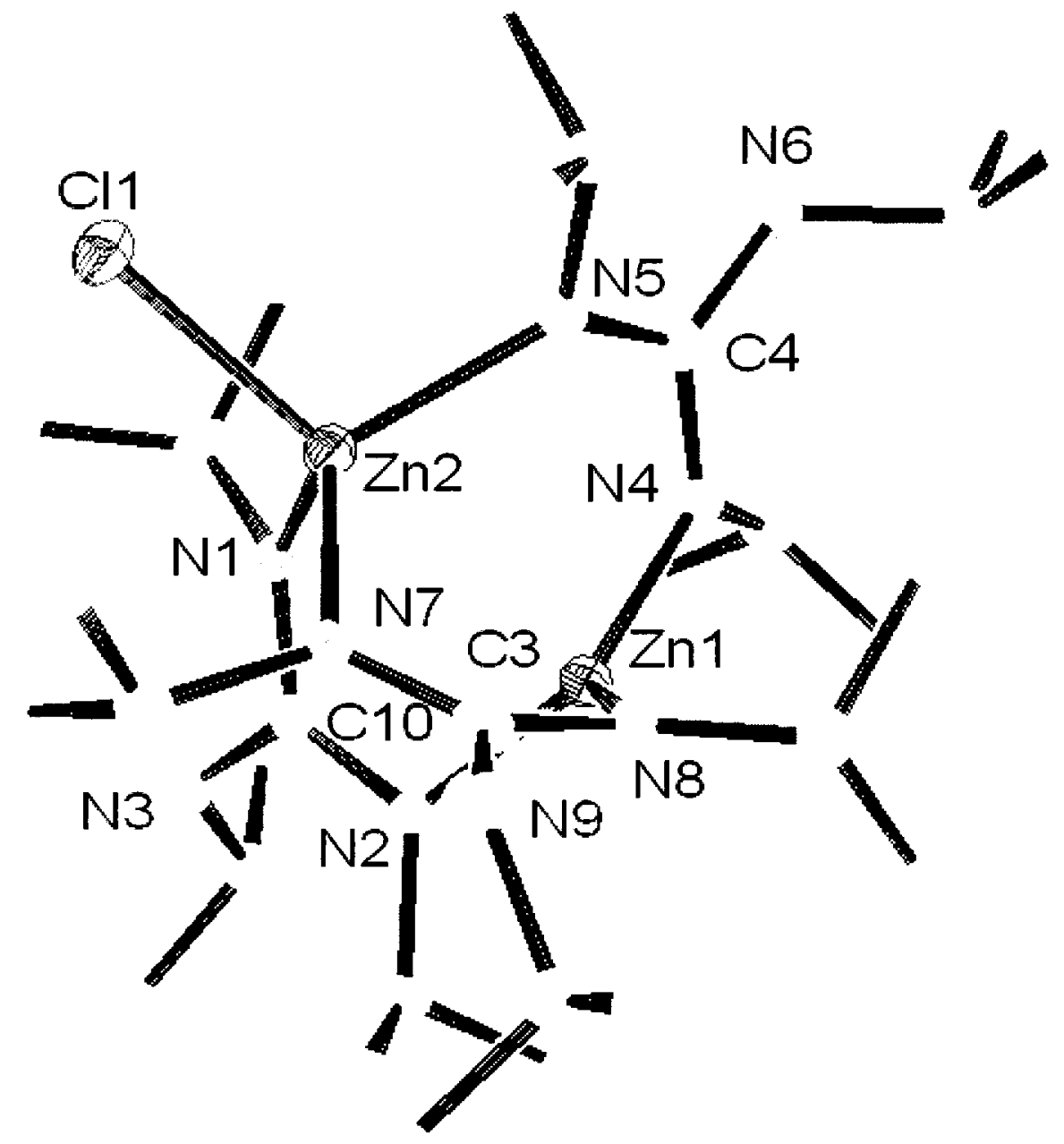

Figure 3-14. The single-crystal $X$-ray structure of 10. The thermal ellipsoids are shown at $50 \%$ probability and the hydrogen centres are omitted for clarity. 


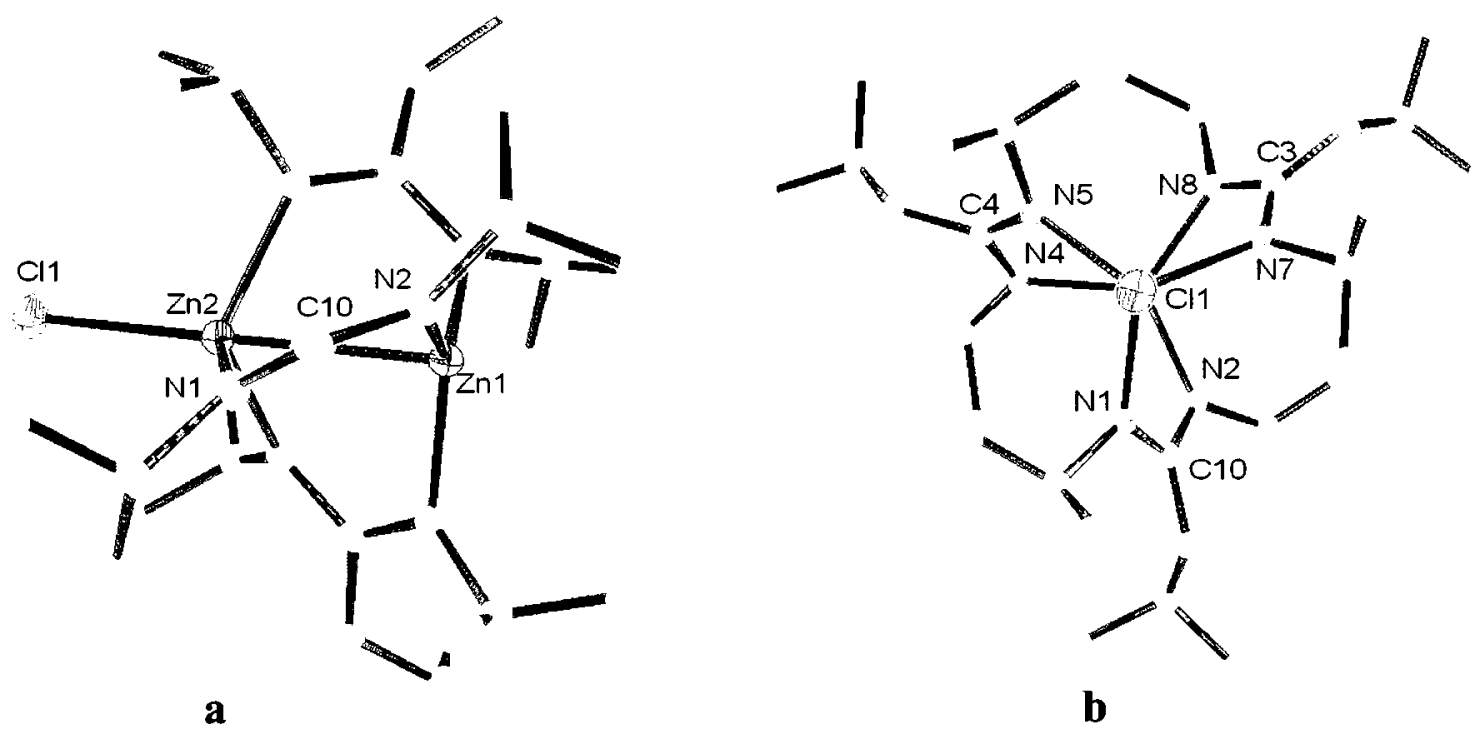

Figure 3-15. The single-crystal X-ray structure of 10. The thermal ellipsoids are shown at $50 \%$ probability and the hydrogen centres are omitted for clarity. (a) demonstrating guanidinate twist across the Cl1-Zn2-Zn1 plane with one isopropyl moiety omitted for clarity, (b) looking down $\mathrm{Cl1}-\mathrm{Zn} 2-\mathrm{Zn} 1$ axis.

Table 3-8. Selected crystal data for compound 10.

\begin{tabular}{cc}
\hline & $\mathbf{1 0}$ \\
\hline \hline Empirical Formula & $\mathrm{C}_{30} \mathrm{H}_{66} \mathrm{~N}_{9} \mathrm{ClZn}_{2}$ \\
FW & 719.11 \\
Crystal System & Monoclinic \\
Space Group & $\mathrm{P} 2{ }_{1} / \mathrm{c}$ \\
$a(\AA)$ & $10.725(3)$ \\
$b(\AA)$ & $34.697(10)$ \\
$c(\AA)$ & $10.581(3)$ \\
$a(\mathrm{Ceg})$ & 90 \\
$\beta(\mathrm{deg})$ & $104.206(4)$ \\
$\gamma(\mathrm{deg})$ & 90 \\
$\mathrm{~V}\left(\AA^{3}\right)$ & $3816.8(18)$ \\
$\mathrm{Z}$ & 4 \\
$\mathrm{D}_{\mathrm{c}}(\mathrm{kg} / \mathrm{L})$ & 1.251 \\
$\mu\left(\mathrm{mm}{ }^{-1}\right)$ & 1.358 \\
$\mathrm{~T}(\mathrm{~K})$ & $120(2)$ \\
$\mathrm{R}, \mathrm{wR}$ & $0.0614,0.1135$ \\
Goodness-of-fit on $\mathrm{F}^{2}$ & 1.029 \\
\hline
\end{tabular}


Table 3-9. Selected bond lengths and angles for compound 10.

\begin{tabular}{|c|c|c|c|}
\hline \multicolumn{4}{|c|}{ Selected Bond Lengths and Distances $(\stackrel{\AA}{A})$} \\
\hline Cl1-Zn2 & $2.2876(8)$ & N3-C10 & $1.385(3)$ \\
\hline N1-Zn2 & $2.040(2)$ & $\mathrm{N} 4-\mathrm{C} 4$ & $1.336(3)$ \\
\hline N5-Zn2 & $2.038(2)$ & $\mathrm{N} 5-\mathrm{C} 4$ & $1.347(3)$ \\
\hline N7-Zn2 & $2.054(2)$ & N6-C4 & $1.384(3)$ \\
\hline N2-Zn1 & $1.932(2)$ & N7-C3 & $1.337(3)$ \\
\hline N4-Zn1 & $1.928(2)$ & N8-C3 & $1.333(3)$ \\
\hline N8-Zn1 & $1.931(2)$ & N9-C3 & $1.394(3)$ \\
\hline $\mathrm{N} 1-\mathrm{C} 10$ & $1.338(3)$ & $\mathrm{Zn} 1-\mathrm{Zn} 2$ & $2.7093(6)$ \\
\hline $\mathrm{N} 2-\mathrm{C} 10$ & $1.334(3)$ & & \\
\hline \multicolumn{4}{|c|}{ Selected Bond Angles $\left(^{\circ}\right)$} \\
\hline N1-Zn2-N5 & $110.22(8)$ & N7-C3-N8 & 119.4(2) \\
\hline $\mathrm{N} 1-\mathrm{Zn} 2-\mathrm{N} 7$ & $110.36(8)$ & $\mathrm{Zn2-N1-C10}$ & $125.48(16)$ \\
\hline N5-Zn2-N7 & $112.64(8)$ & C10-N2-Zn1 & $113.39(16)$ \\
\hline $\mathrm{N} 2-\mathrm{Zn} 1-\mathrm{N} 4$ & $119.42(8)$ & Zn1-N4-C4 & $114.21(15)$ \\
\hline N2-Zn1-N8 & $119.96(8)$ & C4-N5-Zn2 & $125.12(16)$ \\
\hline N4-Zn1-N8 & $120.45(8)$ & $\mathrm{Zn2-N7-C3}$ & $125.01(16)$ \\
\hline N1-C10-N2 & $119.2(2)$ & C3-N8-Zn1 & $113.38(16)$ \\
\hline N4-C4-N5 & $119.0(2)$ & & \\
\hline \multicolumn{4}{|c|}{ Sum of Angles $\left(^{\circ}\right)$} \\
\hline N1 & 359.81 & N5 & 359.90 \\
\hline $\mathrm{N} 2$ & 359.50 & N7 & 359.88 \\
\hline N4 & 359.37 & N8 & 359.63 \\
\hline $\mathrm{Zn} 1$ & 359.83 & $\mathrm{Zn} 2$ & 333.21 \\
\hline
\end{tabular}

\subsection{Conclusions}

This chapter presented the synthesis, structural characterization and thermolysis of new monomeric heteroleptic titanium (III) gas-phase precursors of type $\mathrm{Cp}_{2} \operatorname{Ti}\left[\left(\mathrm{N}^{\mathrm{i}} \mathrm{Pr}\right)_{2} \mathrm{CNRR}\right.$ '] where $\mathrm{R}=\mathrm{H}, \mathrm{Me}$, Et or ${ }^{\mathrm{i}} \mathrm{Pr}$ and $\mathrm{R}^{\prime}=\mathrm{Me}, \mathrm{Et},{ }^{\mathrm{i}} \mathrm{Pr}$ or ${ }^{\mathrm{t}} \mathrm{Bu}$. Compounds 5 to 9 were synthesized using salt metathesis at room temperature after reducing the parent $\mathrm{Cp}_{2} \mathrm{TiCl}_{2}$ complex with zinc dust. Five crystal structures were obtained; four for the heteroleptic titanium (III) complexes and one for a zinc by-product. Melting points and TG analyses were obtained for complexes 5 to 8 which fell in a wide 
range, from $147^{\circ} \mathrm{C}$ for 5 to decomposition at $>180^{\circ} \mathrm{C}$ for 8 . Each TG analysis produced a smooth volatilization curve with low residual mass.

Compound 5 was used to study the interfacial oxide layer of a silicon substrate through an exposure experiment. High surface area silica and alumina extrudate were the substrate of choice and were pre-treated at different temperatures. The resultant exposed silica and alumina were then studied further using solid state ${ }^{13} \mathrm{C}-\mathrm{MAS}$ NMR and elemental analysis to observe how the complex bound to the nucleation sites.

Both pre-treated silica were fully saturated as demonstrated by complete colour change. The alumina extrudate was only partially saturated as a patchy colour change occurred. The $\mathrm{C} / \mathrm{Ti}$ ratio for $\mathrm{SiO}_{2}-350$ was 6.6 and the ${ }^{13} \mathrm{C}$ NMR showed the presence of both aliphatic and aromatic carbons. It was concluded that the acidity of $\mathrm{Si}-350$ allowed for hydrogen bonding to occur between the hydroxyl groups present on the surface and the exocyclic nitrogen allowing the guanidinate ligand to be preserved during the exposure. The $\mathrm{C} / \mathrm{Ti}$ ratio for $\mathrm{SiO}_{2}-900$ was 7.0 and the ${ }^{13} \mathrm{C}$ NMR demonstrated solely aromatic carbons. It was concluded that with less hydroxyl species present the guanidinate ligand could not be stabilized through hydrogen bonding. The partially saturated $\mathrm{Al}_{2} \mathrm{O}_{3}-600$ had a $\mathrm{C} / \mathrm{Ti}$ ratio of 8.4 and the ${ }^{13} \mathrm{C}$ NMR had both aliphatic and aromatic carbons present. With the lower pre-treatment temperature the extrudate surface acidity allowed for stabilization of the guanidinate species.

From the exposure experiments it was noted that the titanium species did not maintain the oxidation state of +3 but instead was oxidized to +4 . This was determined by both the colour of the exposed surface and the clear solid state ${ }^{13} \mathrm{C}-\mathrm{MAS}$ NMR. This result was a little off-putting as it would be very advantageous to have a Ti(III) precursor for 
ALD applications of TiN film deposition. Conserving oxidation state would allow for more facile ALD reactions as no oxidation or reduction would be necessary to obtain the desired TiN film.

\subsection{Methods and Materials}

All reactions were performed in a nitrogen-filled dry box, unless otherwise stated. The bis(cyclopentadienyl)titanium (IV) dichloride was purchased from Strem Chemicals and used as received. All solvents used were reagent grade purified from an MBraun Solvent Purifier System. The chemicals: diisopropyl amine, diethyl amine, tert-butyl amine, isopropyl amine, lithium dimethyl amide, 1,3-diisopropyl carbodiimide and zinc dust were purchased from Aldrich Chemical Company and used as received. Preparation of N,N',N' - triisopropyl guanidinate followed a literature procedure. ${ }^{35}$ Preparation of $\left[\mathrm{Cp}_{2} \mathrm{TiCl}\right]_{2}$ followed literature procedure. ${ }^{30}$ Mass spectra were obtained using electron impact on a VG ZAB-2HF triple-focusing spectrometer. Thermal gravimetric analysis was performed on a TA Instruments Q50 apparatus located in an MBraun Labmaster 130 Dry box under a nitrogen atmosphere. Differential scanning calorimetery analysis was performed on a TA Instruments Q10 apparatus. Guelph Chemical Laboratories performed combustion analysis. Single crystal XRD was conducted on a Bruker-AXS APEX CCD Diffractometer located at Delaware University with the help of Glenn P. Yap. 


\subsubsection{Synthesis of $\mathrm{Cp}_{2} \mathrm{Ti}\left[{ }^{\mathrm{i}} \operatorname{PrN}(\mathrm{H}) \mathrm{C}\left({ }^{\mathrm{i}} \mathrm{PrN}\right)_{2}\right](5)$ from $\mathrm{Cp}_{2} \mathrm{TiCl}_{2}$}

In a $60 \mathrm{~mL}$ round bottom flask $4.20 \mathrm{~g}(16.9 \mathrm{mmol})$ of bis(cyclopentadienyl)titanium (IV) dichloride was allowed to stir in $40 \mathrm{~mL}$ of diethyl ether. $3.33 \mathrm{~g}(16.9 \mathrm{mmol})$ of dianionic ligand was slowly added to the red solution. The solution changed from bright red to a dark maroon, almost brown colour and was left to stir over night. The resulting blue solution was then filtered and placed in the freezer and allowed to sit for 24 hours. $0.916 \mathrm{~g}(2.53 \mathrm{mmol}, 15 \%$ yield) dark blue needle like crystals of 1 were collected. Combustion analysis: found (calculated). C: $65.97(66.29), \mathrm{H}: 9.21(8.90), \mathrm{N}: 11.52$ (11.59). Mass Spectral data: $248\left(\mathrm{M}^{+}\right)$.

\subsubsection{Synthesis of $\mathrm{Cp}_{2} \mathrm{Ti}\left[{ }^{\mathrm{i}} \operatorname{PrN}(\mathrm{H}) \mathrm{C}\left({ }^{\mathrm{i}} \operatorname{PrN}\right)_{2}\right](5)$ from $\left[\mathrm{Cp}_{2} \mathrm{TiCl}\right]_{2}$}

$2.82 \mathrm{~g}(10 \mathrm{mmol})$ of $\left[\mathrm{Cp}_{2} \mathrm{TiCl}\right]_{2}$ was placed in a $60 \mathrm{~mL}$ round bottom flask and dissolved in ether. To this solution, an in situ solution of $\operatorname{Li}\left({ }^{\mathrm{i}} \operatorname{PrN}\right)_{2} \mathrm{C}\left(\mathrm{N}(\mathrm{H}){ }^{\mathrm{i}} \operatorname{Pr}\right)(1.92 \mathrm{~g}, 10$ mmol) was slowly added. As the reaction proceeded, the solution changed from light green to dark blue. The reaction was allowed to stir overnight. It was then filtered to remove $\mathrm{LiCl}$, evacuated to dryness and redissolved in approximately $10 \mathrm{~mL}$ of diethyl ether, then placed in a freezer at $-30{ }^{\circ} \mathrm{C}$ overnight. Thick dark blue needle-like crystals were collected ( $58 \%$ yield, $1.76 \mathrm{~g}, 4.9 \mathrm{mmol}$ ). Combustion analysis; found (calculated). C: 65.87 (66.29), H: 9.23 (8.90), N: 11.65 (11.59). Mass Spectral data: $248\left(\mathrm{M}^{+}\right)$. 


\subsubsection{Bis(cyclopentadienyl) titanium dimethylamide diisopropyl guanidinate,} 6

Same reaction procedure as $\mathbf{5}$ from $\left[\mathrm{Cp}_{2} \mathrm{TiCl}\right]_{2}$ was used substituting the previous guanidinato ligand with $\left[\mathrm{Me}_{2} \mathrm{NC}\left(\mathrm{N}^{i} \mathrm{Pr}\right)_{2}\right] \mathrm{Li}(0.44 \mathrm{~g}, 2.48 \mathrm{mmol})$. The reaction was allowed to stir overnight at room temperature. The resulting baby blue solution was then filtered, evacuated to dryness, redissolved in approximately $5 \mathrm{~mL}$ of diethyl ether and placed into a freezer at $-30^{\circ} \mathrm{C}$. After 16 hours in the freezer, $0.34 \mathrm{~g}(0.98 \mathrm{mmol})$ of a baby blue solid was collected resulting in $39 \%$ yield. Mass spectral data $(\mathrm{EI}, \mathrm{m} / \mathrm{z})(\mathrm{rel}$. intensity, \%): 348, (37.3, $\left.\mathrm{M}^{+}\right)$. Combustion analysis; found (calculated). C: 65.85 (65.51), H: $9.00(8.68), \mathrm{N}: 11.64$ (12.06).

\subsubsection{Bis(cyclopentadienyl) titanium diethylamide diisopropyl guanidinate, 7}

Same reaction procedure as 5 from $\left[\mathrm{Cp}_{2} \mathrm{TiCl}\right]_{2}$ was used substituting the previous guanidinato ligand with $\left[\mathrm{Et}_{2} \mathrm{NC}\left(\mathrm{N}^{i} \mathrm{Pr}\right)_{2}\right] \mathrm{Li}(0.72 \mathrm{~g}, 3.50 \mathrm{mmol})$. The reaction was allowed to stir overnight at room temperature. The light blue solution was then filtered to remove $\mathrm{LiCl}$, evacuated to dryness, redissolved in approximately $5 \mathrm{~mL}$ of diethyl ether and placed into a freezer at $-30^{\circ} \mathrm{C}$. The next morning $0.53 \mathrm{~g}(1.4 \mathrm{mmol})$ of a dark blue solid was collected resulting in $40 \%$ yield. Mass spectral data (EI, $m / z)$ (rel. intensity, \%): 376.2, $\left(100, \mathrm{M}^{+}\right)$. Combustion analysis; found (calculated). C: 67.20 (67.01); H: 9.33 (9.11); N: $11.00(11.16)$. 


\subsubsection{Bis(cyclopentadienyl) titanium tetrakis isopropyl guanidinate, 8}

Same reaction procedure as $\mathbf{5}$ from $\left[\mathrm{Cp}_{2} \mathrm{TiCl}\right]_{2}$ was used substituting the previous guanidinato ligand with $\left[{ }^{i} \mathrm{Pr}_{2} \mathrm{NC}\left(\mathrm{N}^{i} \mathrm{Pr}\right)_{2}\right] \mathrm{Li}(4.14 \mathrm{~g}, 17.8 \mathrm{mmol})$. The solution changed to a dark army green colour. The reaction was allowed to stir overnight at room temperature. The resulting green solution was then filtered to remove $\mathrm{LiCl}$. The blue mother liquor was evacuated to dryness, redissolved in diethyl ether and placed into a freezer at $-30^{\circ} \mathrm{C}$. Blue crystals were collected $(2.12 \mathrm{~g}, 5.24 \mathrm{mmol})$ yielding $30 \%$. Mass spectral data (EI, $m / z)$ (rel. intensity, \%): 404.3, $\left(100, \mathrm{M}^{+}\right)$. Combustion analysis; found (calculated). C: 68.40 (68.30), H: $9.56(9.47), \mathrm{N}: 10.35(10.39)$.

\subsubsection{Bis(cyclopentadienyl) titanium t-butylamide diisopropyl guanidinate, 9}

Same reaction procedure as $\mathbf{5}$ from $\left[\mathrm{Cp}_{2} \mathrm{TiCl}\right]_{2}$ was used substituting the previous guanidinato ligand with $\left[{ }^{t} \mathrm{BuN}(\mathrm{H}) \mathrm{C}\left(\mathrm{N}^{i} \mathrm{Pr}\right)_{2}\right] \mathrm{Li}(1.71 \mathrm{~g}, 8.0 \mathrm{mmol})$. The reaction was allowed to stir overnight at room temperature. The midnight blue solution was then filtered to remove $\mathrm{LiCl}$, evacuated to dryness, redissolved in diethyl ether and placed into a freezer at $-30^{\circ} \mathrm{C}$. Baby blue crystals were collected, $0.21 \mathrm{~g}(0.56 \mathrm{mmol})$ resulting in 7 $\%$ yield.

\subsection{Structural Determination for Compounds 5, 6, 8, 9, and 10}

Suitable crystals were mounted with viscous oil on a plastic mesh and cooled to the data collection temperature. Unit cell parameters were determined using data frames from four different sections of the Ewald sphere. SADABS multi-scan absorption 
corrections were applied. No symmetry higher than monoclinic was observed for compounds 5, 8 and 10. Compound 6 showed no higher symmetry than tetragonal and compound 9 showed no higher symmetry than orthorhombic. Solution in the space group option, $\mathrm{P} 2{ }_{1} / \mathrm{n}$, yielded chemically reasonable and computationally stable results of refinement for compounds 5 and 8 , and $P 2{ }_{1} / c$ for 10 . For compounds 6 and 9 space group option $\mathrm{P}_{2} / \mathrm{ncm}$ and Pbca yielded chemically reasonable and computationally stable results of refinement. The structures were solved using direct methods and refined with full matrix least squares procedures of $\mathrm{F}^{2}$ data. All hydrogen atoms were treated as idealized contributions and all non-hydrogen atoms were refined with anisotropic displacement coefficients. Atomic scattering factors are contained in the SHELXTL program library. 


\subsection{References}

${ }^{1}$ Grigorov, G.I., Grigorov, K.G., Stayanova, M., Vignes, J.L., Langeron, J.P., Denjaean, P.; Appl. Phys. A, 1993, 57, 195.

${ }^{2}$ Shimizu, M., Shiosaki, T.; Mater. Res. Soc. Symp. Proc., 1995, 361, 295.

${ }^{3}$ George, S.M.; Chem. Rev., 2010, 110, 111 .

${ }^{4}$ Leskela, M., Ritala, M.; Angew. Chem, Int. Ed., 2003, 42, 5548.

${ }^{5}$ Granquist C.G.; Sol. Energy Mater. Sol. Cells, 2007, 91, 1529, and references therein.

${ }^{6}$ Perry, A.J., Georgson, M., Sproul, W.D.; Thin Solid Films, 1988, 157, 255.

${ }^{7}$ Niinisto, J., Kukli, K., Heikkila, M., Ritala, M., Leskela, M.; Adv. Eng. Mater., 2009, 11, 4, 223.

${ }^{8}$ (a) Aarik, J., Aidla, A., Uustare, T., Kukli, K., Sammelselg, V., Ritala, M., Leskela, M.; Appl. Surf.

Sci., 2002, 193, 277. (b) Sbai, N., Perriere, J., Gallas, B., Millon, E., Seiler, W., Bernard, M.C.; J.

Appl. Phys., 2008, 104, 033529. (c) Kukli, K., Ritala, M., Schuisky, M., Leskela, M., Sajavaara, T.,

Keinonen, J., Uustare, T., Harsta, A.; Chem. Vap. Deposition, 2000, 6, 303.

${ }^{9}$ (a) Green, M.L., Gusev, E.P., Degraeve, R., Garfunkel, E.L.; J. Appl. Phys., 2001, 90, 5, 2057. (b)

Lide, D.R., Handbook of Chemistry and Physics. Ed. 77, CRC Press, New York, 1996, pp 12-40. (c)

Wilk, G.D., Wallace, R.M., Anthony, J.M.; J. Appl. Phys., 2001, 89, 10, 5243.

${ }^{10}$ Lee, M.K., Lee, H.C., Hsu, C.M.; Semicond. Sci. Tech., 2006, 21, 5, 604.

${ }^{11}$ Wang, S., Raaijmakers, I., Burrows, B., Suthar, S., Redkar, S., Kim, K.; J. Appl. Phys., 1990, 68, 5176.

${ }^{12}$ Choy, K.L.; Prog. Mater. Sci., 2003, 48, 57, and references therein.

${ }^{13}$ a) Tiznado, H., Menno Bouman, M., Kang, B-C., Lee, I., Zaera F.; J. Mol. Catal. A: Chem. 2008, 281, 35. b) Kim, J., Hong, H., Oh, K., Lee, C.; Appl. Surf. Sci., 2003, 210, 231. c) Ritala, M., Leskelä, M., Rauhala, E., Haussalo, P.; J. Electrochem. Soc., 1995, 142, 2731.

${ }^{14}$ Elers, K.E., Blomberg, T., Peussa, M., Aitchison, B., Haukka, S., Marcus S.; Chem. Vap. Deposition 2006, 12, 13 .

${ }^{15}$ Elama, J.W., Schuiskya, M., Fergusona, J.D., George S.M.; Thin Solid Films 2003, 436, 145. 
${ }^{16}$ a) Pore, V., Rahtu, A., Leskela, M., Ritala, M., Sajavaara D., Keinonen, J.; Chem. Vap. Depos., 2004, 10, 143. b) Aktar, M.K., Pratsinis S.E., Mastrangelo, S.V.R.; J. Mater. Res. 1994, 9, 1241. c) Evans, P., Pemble, M.E., Sheel, D.W.; Chem.Mater., 2006, 18, 5750. d) Kim, B.H., Lee, J.Y., Choa, Y.H., Higuchi M., Mizutani, N.; Mater. Sci. Eng., B, 2004, 107, 289.

${ }^{17}$ Eleter, M., Daniele, S., Brize, V., Dubourdieu, C., Lachaud, C., Blasco, N., Pinchart, A.; ECS Trans, 2009, 25 (8 EuroCVD 17), 151.

${ }^{18}$ Milanov, A., Bhakta, R., Baunemann, A., Becker, H.W., Thomas, R., Erhart, P., Winter, M., Devi, A.; Inorg. Chem., 2006, 45, 26, 11008.

${ }^{19} \mathrm{PCT} / \mathrm{US} 2007 / 015847$, (2007-7-12), Ma, Ce and Wang, Qing Min, Atomic layer deposition precursors comprising mixed, sterically hindered ligands that include at least one metal-nitrogen bond.

${ }^{20}$ Myllymaki, P., Nieminen, M., Niinisto, J., Putkonen, M., Kukli, K., Niinisto, L.; J. Mater. Chem., 2006, 16, 6, 563 .

${ }^{21}$ DiLabio, G.A., Litwinienko, G., Shuquiong, L.S., Pratt, D.A., Ingold, K.U.; J. Phys. Chem. A, 2002, $106,11719$.

${ }^{22}$ Plenio, H., Roesky, H.W., Noltemeyer, M., Sheldrick G.M.; J. Chem. Soc., Chem. Commun., 1987, 1483.

${ }^{23}$ Jungst, R., Sekutowski, D., Davis, J., Luly, M., Stucky, G.; Inorg. Chem., 1977, 16, 1645.

${ }^{24}$ Ong, T.G., Yap, G.P.A., Richeson, D.S.; J. Am. Chem. Soc., 2003, 125, 8100.

${ }^{25}$ Hagadorn, J.R., Arnold, J.; Organomet., 1998, 17, 1355.

${ }^{26}$ Fink G., Steinmetz B., Zechlin J., Przybyla C., Tesche B.; Chem. Rev., 2000, 100, 1377.

${ }^{27}$ Serp, P., Feurer, R., Kalck, P.; Chem. Rev., 2002, 102, 3085-3128.

${ }^{28}$ Kröger-Laukkanen, M., Peussa, M., Leskelä, M., Niinistö, L.; Appl. Surf. Sci,. 2001, 183, 290.

${ }^{29}$ Gunter, P.L.J., Niemantsverdriet, W.J.H., Ribiero, F.H., Somorjai, G.A.; Catal. Rev-Sci. Eng, 1997, 39,77 .

${ }^{30}$ Green, M. L. H.; Lucas, C. R. J. Chem. Soc. Dalton 1972, 1000.

${ }^{31}$ Whitehorne, T.J.J., Synthesis, Structure and Thermochemistry of Selected Group 11 and 12 Metals, M. Sc., 2009. 
${ }^{32}$ Barwick, M., Abu-Izneid, T., Novak, I., Kovac, B.; Chem. Phys. Letters, 2008, 460, 79-81.

${ }^{33}$ Rio, D., Galindo, A., Resa, I., Carmona, E.; Angew. Chem. Int. Ed., 2005, 44, 1244.

${ }^{34}$ Macaulay, R., Burnelle, L.A., Sandorfy, C.; Theoret. Chim. Acta. (Ber.)., 1973, $29,1$.

${ }^{35}$ Aeilts, S.L., Coles, M.P., Swenson, D.C., and Jordan, R.F., Organomet., 1998, 17(15), 3265. 


\section{Chapter 4:}

\section{Heteroleptic Cyclopentadienyl Titanium (III) Amidinates}

\subsection{Introduction}

It was found that the bis(cyclopentadienyl) titanium (III) guanidinate complexes ${ }^{1}$ reported in Chapter 3 were not as reactive as were expected for thin film deposition, thus the amidinate analogues were synthesized and tested for their thermal reactivity. It has been reported that guanidinate anions are stronger donors (more basic) than amidinate anions since the lone pair on the exocyclic amido group can donate into the ligand system, thus increasing the electron-density of the metal. ${ }^{2}$ Replacement of a guanidinate by an amidinate ion could increase the reactivity of the metal by reducing the electrondensity on the metal centre. ${ }^{3}$ Multidentate ligands, such as amidinates, have allowed researchers to produce volatile monomeric complexes of Group 2 metals, ${ }^{4}$ transition metals ${ }^{5}$ and lanthanides. ${ }^{6}$ The advantage to using bidentate ligands as opposed to monodentate ligands (such as alkylamido species) is that oligomerization can be suppressed. Amidinates have the ability to shield the metal centre from inter-molecular interactions. ${ }^{5}$ Aditionally, introducing the bidentate amidinate ligand to these cyclopentadienyl titanium species might increase the stability - making them easier to handle. As heteroleptic cyclopentadienyl complexes that have monodentate ligands within the complex are known to be highly reactive towards air and moisture, thus harder to handle. ${ }^{7}$ 
Four heteroleptic titanium amidinate precursors were synthesized and their thermal properties were studied. Thermolyses of these compounds were encouraging by TG analysis and DSC. The amidinate analogue ligand ip ${ }^{8}$ was included in these studies to compare the thermal stability of the four compounds.

\subsection{Results and Discussion}

\subsubsection{Synthesis and Crystal Structure Data}

Four heteroleptic titanium (III) compounds were synthesized in reasonable yields from the $\left[\mathrm{Cp}_{2} \mathrm{TiCl}\right]_{2}$ starting material and appropriate lithium amidinate (Figure 4-1 and Figure 4-2). It was found that the compounds formed slowly at room temperature, with the starting titanium species changing from a characteristic yellow-green to a solution ranging from light blue to dark blue, depending on the amidinate used. In the case of compounds 11, 12, and 14 the solution was removed under vacuum; the blue solid was redissolved in diethyl ether and placed in the freezer to promote crystallization. Blue crystals were isolated and further characterization was undertaken. Compound $\mathbf{1 3}$ formed green plate-like crystals after volatiles were removed under vacuum. The solid was redissolved in a minimal amount of diethyl ether and placed in the freezer for purification. Compound $\mathbf{1 1}$ produced crystals of sufficient quality for a single crystal structure to be collected (Figure 4-2, Table 4-1 and Table 4-2). 

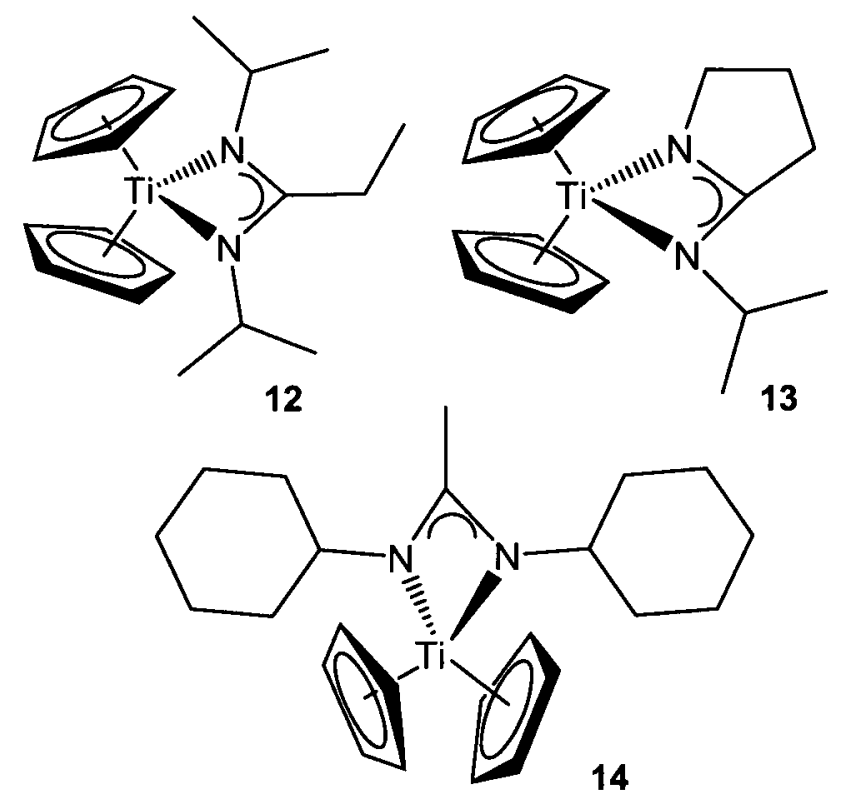

Figure 4-1. Heteroleptic titanium amidinate species.

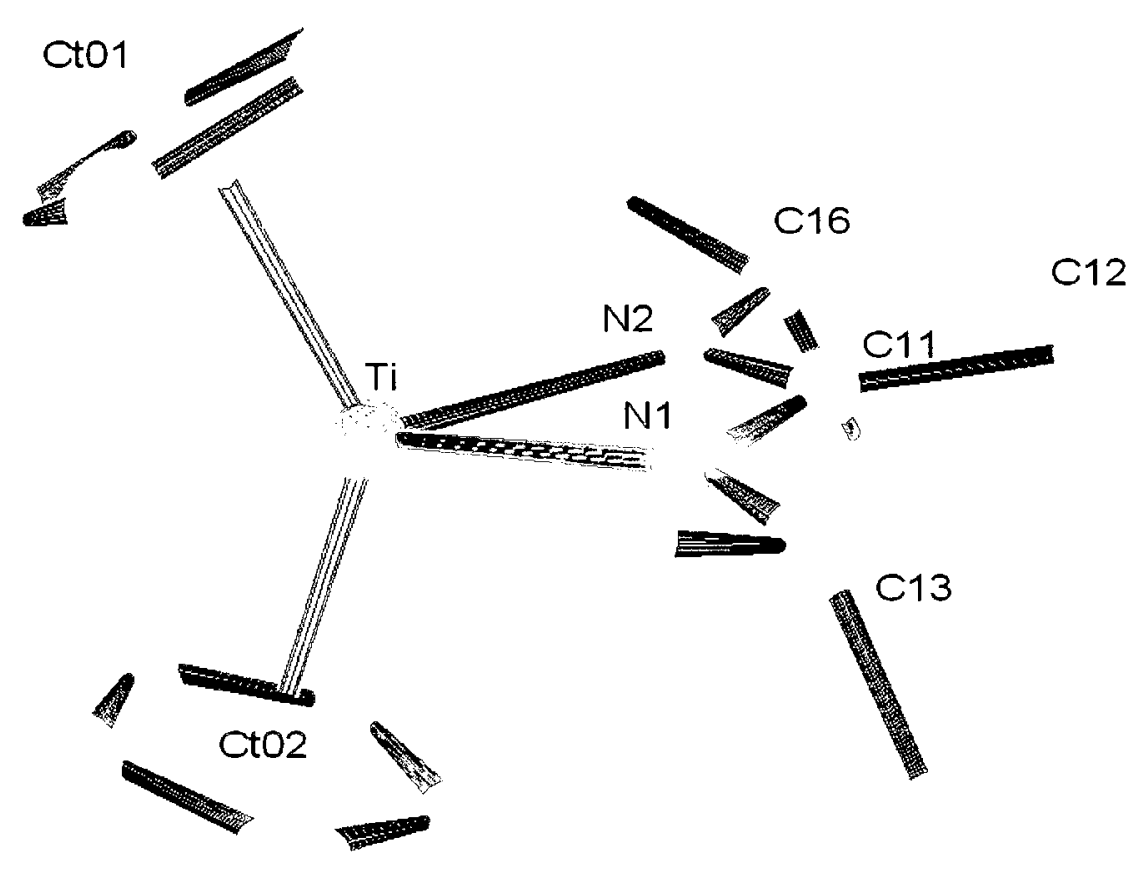

Figure 4-2. The single-crystal X-ray structure of 11. The thermal ellipsoids are shown at $50 \%$ probability and the hydrogen centres are omitted for clarity. 
Compound 11 was a four coordinate distorted tetrahedral considering the centroids of the cyclopentadienyl rings with an acetamidinate bite angle of $61.5^{\circ}$. The amidinate bite angle fell within range of the titanium guanidinate bite angles. ${ }^{1}$ The centroid angle was correspondingly larger than ideal at $134^{\circ}$ similar to the previously reported titanium guanidinate complexes. ${ }^{1} \quad$ The centroid-metal-nitrogen angles were closer to ideal tetrahedral angles at $110.7^{\circ}$ and $108.7^{\circ}$, respectively. The acetamidinate ring was very close to planar with a torsion angle of only $1.1^{\circ}$ across the metallocycle. The titaniumcentroid bond lengths were much smaller than a previously reported bis(cyclopentadienyl) bis(thionyl)imide titanium (IV) complex $(\mathrm{Cp}-\mathrm{Ti}=2.06 \AA)^{9,10}$ and similar in length to compounds $\mathbf{8 , 9}$, and $\mathbf{1 1}$ from Chapter $3(\mathrm{Ct0} 1-\mathrm{Ti}=1.74$ and $\mathrm{Ct} 02-\mathrm{Ti}$ $=1.73 \AA$ ). Due to the short centroid bond lengths the titanium-nitrogen bond lengths were longer than reported acetamidinate complexes $^{11}(\mathrm{Ti}-\mathrm{N} 1=2.146$ and $\mathrm{Ti}-\mathrm{N} 2=2.152$ $\AA$ ). Interestingly, the methyls of both isopropyl groups point in the same direction, angled toward the metal centre unlike compounds $\mathbf{8 , 9}$, and $\mathbf{1 1}$ from Chapter 3 . The exocyclic carbon (C12) was slightly out of plane from the chelate ring (Ti-N1-C11) by $2.7^{\circ}$, correspondingly $\mathrm{C} 13$ is $3^{\circ}$ and $\mathrm{C} 16$ is $1.6^{\circ}$ out of plane.

The carbon-nitrogen bonds of the chelate ring (N1-C11 and C11-N2) were shorter at $1.33 \AA$ than the carbon-nitrogen bonds of the exocyclic isopropyl moieties (N1-C13 and N2-C16) at $1.46 \AA$, respectively. The bond length and the sum of angles around the chelate nitrogens ( $\mathrm{N} 1$ and $\mathrm{N} 2$ both at $360^{\circ}$ ) and the sum of angles around the $\mathrm{sp}^{2}$ carbon $\left(\mathrm{C} 11\right.$ at $\left.360^{\circ}\right)$ corroborated with the planarity of the system indicating an $\mathrm{sp}^{2}$ hybridization, and thus participation in the $\pi$-system. 
Table 4-1. Selected crystal data for compound 11.

\begin{tabular}{cc}
\hline & $\mathbf{1 1}$ \\
\hline Empirical Formula & $\mathrm{C}_{18} \mathrm{H}_{27} \mathrm{~N}_{2} \mathrm{Ti}$ \\
$\mathrm{FW}$ & 319.32 \\
Crystal System & Monoclinic \\
Space Group & $\mathrm{Cc}$ \\
$a(\AA)$ & $9.5692(14)$ \\
$b(\AA)$ & $15.311(2)$ \\
$c(\AA)$ & $11.7080(17)$ \\
$\alpha(\mathrm{deg})$ & 90 \\
$\beta(\mathrm{deg})$ & $91.569(2)$ \\
$\gamma(\mathrm{deg})$ & 90 \\
$\mathrm{~V}\left(\AA^{3}\right)$ & $1714.7(4)$ \\
$\mathrm{Z}$ & 4 \\
$\mathrm{D}_{\mathrm{c}}(\mathrm{kg} / \mathrm{L})$ & 1.237 \\
$\mu\left(\mathrm{mm}{ }^{-1}\right)$ & 0.495 \\
$\mathrm{~T}\left({ }^{\circ} \mathrm{C}\right)$ & $120(2)$ \\
$\mathrm{R}, \mathrm{wR}$ & $0.0477,0.0893$ \\
Goodness-of-fit on $\mathrm{F}^{2}$ & 1.028 \\
\hline
\end{tabular}

Table 4-2. Selected bond lengths and angles for compound 11 .

\begin{tabular}{cccc}
\hline \multicolumn{5}{c}{ Selected Bond Lengths $(\dot{\boldsymbol{A}})$} \\
\hline Ti-N1 & $2.1459(19)$ & $\mathrm{C} 11-\mathrm{C} 12$ \\
Ti-N2 & $2.1517(18)$ & $\mathrm{N} 2-\mathrm{C} 11$ & $1.502(3)$ \\
N1-C11 & $1.329(3)$ & $\mathrm{N} 2-\mathrm{C} 16$ & $1.327(3)$ \\
N1-C13 & $1.455(3)$ & $1.462(3)$ \\
\hline \multicolumn{4}{c}{ Selected Bond Angles $\left(^{\circ}\right)$} \\
\hline Ct01-Ti-Ct02 & 134.23 & N1-C11-N2 & $111.64(19)$ \\
Ct01-Ti-N1 & 108.74 & Ti-N1-C11 & $93.51(13)$ \\
Ct02-Ti-N2 & 110.72 & C11-N2-Ti & $93.32(14)$ \\
N1-Ti-N2 & $61.51(7)$ & Sum of Angles $\left(^{\circ}\right)$ \\
\hline \multicolumn{5}{c}{$\mathrm{N} 2$} \\
\hline \multicolumn{5}{c}{ N1 }
\end{tabular}

\subsubsection{Thermolysis}

The melting points of these compounds fell in a wide range, from $65^{\circ} \mathrm{C}$ for 11 to $181^{\circ} \mathrm{C}$ for 14. TG analysis showed all compounds to decompose with low residual masses with a wide range of on-sets of volatility (Figure 4-3, Table 4-3). Compound 11 
had the second highest on-set of volatilization at $141^{\circ} \mathrm{C}$. The curve was characteristic of volatilization with the asymmetric curve due to a slow weight loss until the maximum of the curve was reached at which point the compound had completely volatized away. The TG showed one major thermal event in the derivative weight curve (Figure 4-4) that occurred at a temperature range of $141-270^{\circ} \mathrm{C}$ with a residual mass of $3 \%$. The TG demonstrated that 11 may be a good candidate for ALD or CVD. This would be a great finding as the acetamidinate ligand is very easy to synthesize and thus the production of large amounts of the titanium precursor would be possible.

Compound 12 had the lowest on-set of volatilization at $118^{\circ} \mathrm{C}$. The TG showed one major thermal event that occurred from $118-249^{\circ} \mathrm{C}$. This major thermal event had a shape that was characteristic of volatilization. The derivative curve (Figure 4-4) was non-symmetrical in shape which is commonly associated with the volatilization of a compound, where there is a slow on-set and a rapid drop-off when the maximum is reached. A residual mass of $6 \%$ was achieved. Such a low residual mass could be attributed to the complete volatilization of the titanium species.

Table 4-3. Thermal parameters for compounds 11 - 14.

\begin{tabular}{|c|c|c|c|c|c|}
\hline & Compound & $\begin{array}{c}\text { Percent } \\
\text { Yield (\%) } \\
\end{array}$ & $\begin{array}{c}\text { Melting } \\
\left.\text { Point ( }{ }^{\circ} \mathrm{C}\right) \\
\end{array}$ & $\begin{array}{c}\text { Onset of } \\
\text { Volatility }{ }^{1}(\mathrm{C}) \\
\end{array}$ & $\begin{array}{r}\text { Residual } \\
\text { Mass (\%) } \\
\end{array}$ \\
\hline 11 & $\begin{array}{c}\mathrm{Cp}_{2} \mathrm{Ti} \\
\text { acetamidinate }\end{array}$ & 43 & $65-66.5$ & 140.55 & 3.0 \\
\hline 12 & $\begin{array}{l}\mathrm{Cp}_{2} \mathrm{Ti} \text { ethyl } \\
\text { amidinate }\end{array}$ & 36 & $99-104$ & 117.88 & 5.5 \\
\hline 13 & $\begin{array}{l}\mathrm{Cp}_{2} \mathrm{Ti} \text { iso-propyl } \\
\text { iminopyrrolidinate }\end{array}$ & 42 & $111-115$ & 126.91 & 6.0 \\
\hline 14 & $\begin{array}{c}\mathrm{Cp}_{2} \mathrm{Ti} \text { dicyclohexyl } \\
\text { acetamidinate }\end{array}$ & 26 & $179-181$ & 187.89 & 2.8 \\
\hline
\end{tabular}


Compound 13 was found to have the second lowest on-set of volatilization at $127^{\circ} \mathrm{C}$. The derivative weight curve (Figure 4-4) had a non-symmetrical shape which is commonly associated with the volatilization of a compound, a slow on-set and a rapid drop-off when the maximum is reached. The TG had one major thermal event that occurred from $127-230^{\circ} \mathrm{C}$ with a residual mass of $6 \%$. The TG was very clean and indicated that this compound has potential as a CVD or ALD candidate as complete volatilization occurred. However the synthesis of this compound is a little more tedious than compounds 11,12 , and 14 because the ipip ligand synthesis is somewhat longer.

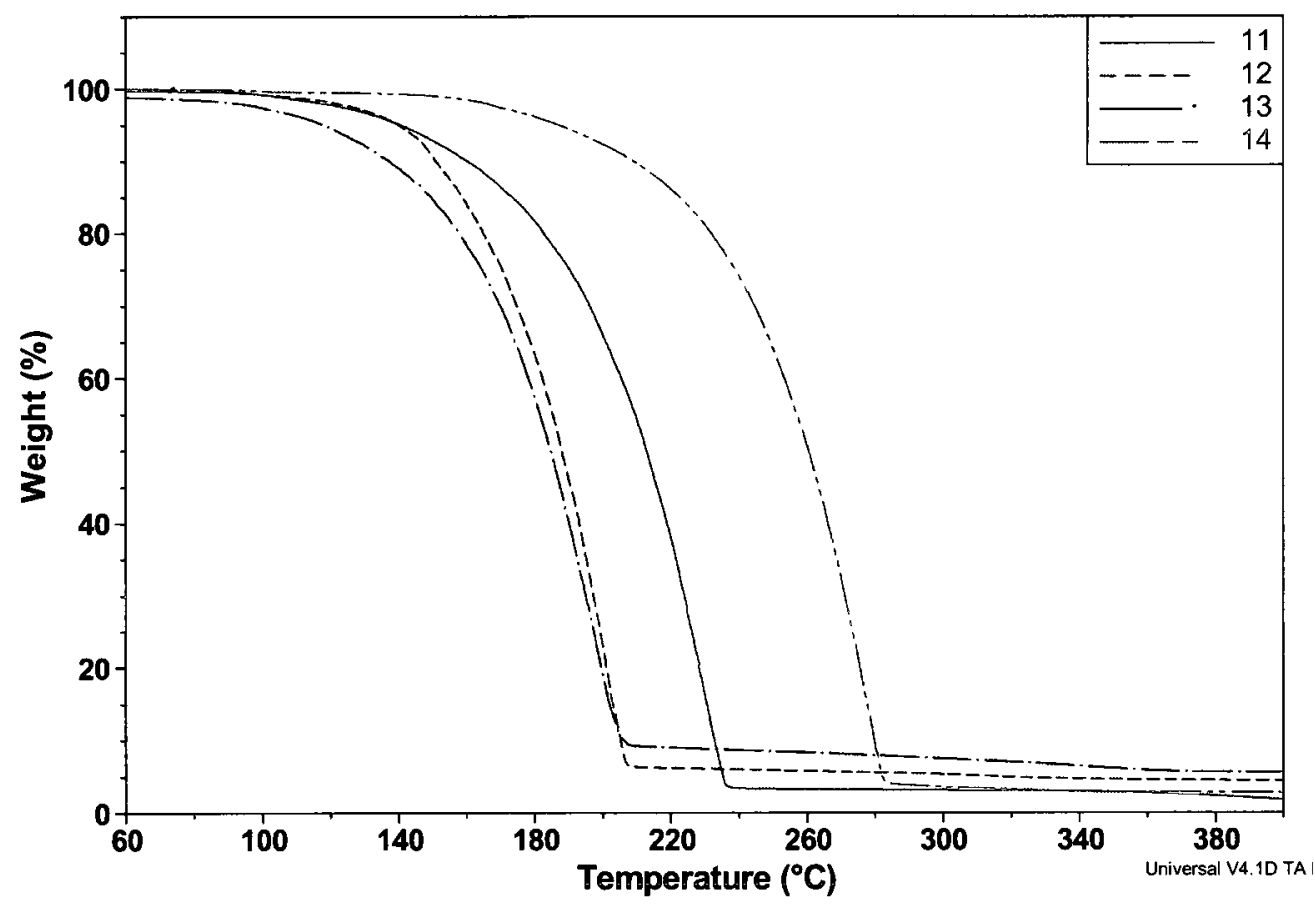

Figure 4-3. Thermal gravimetric analysis of $11-14$. 


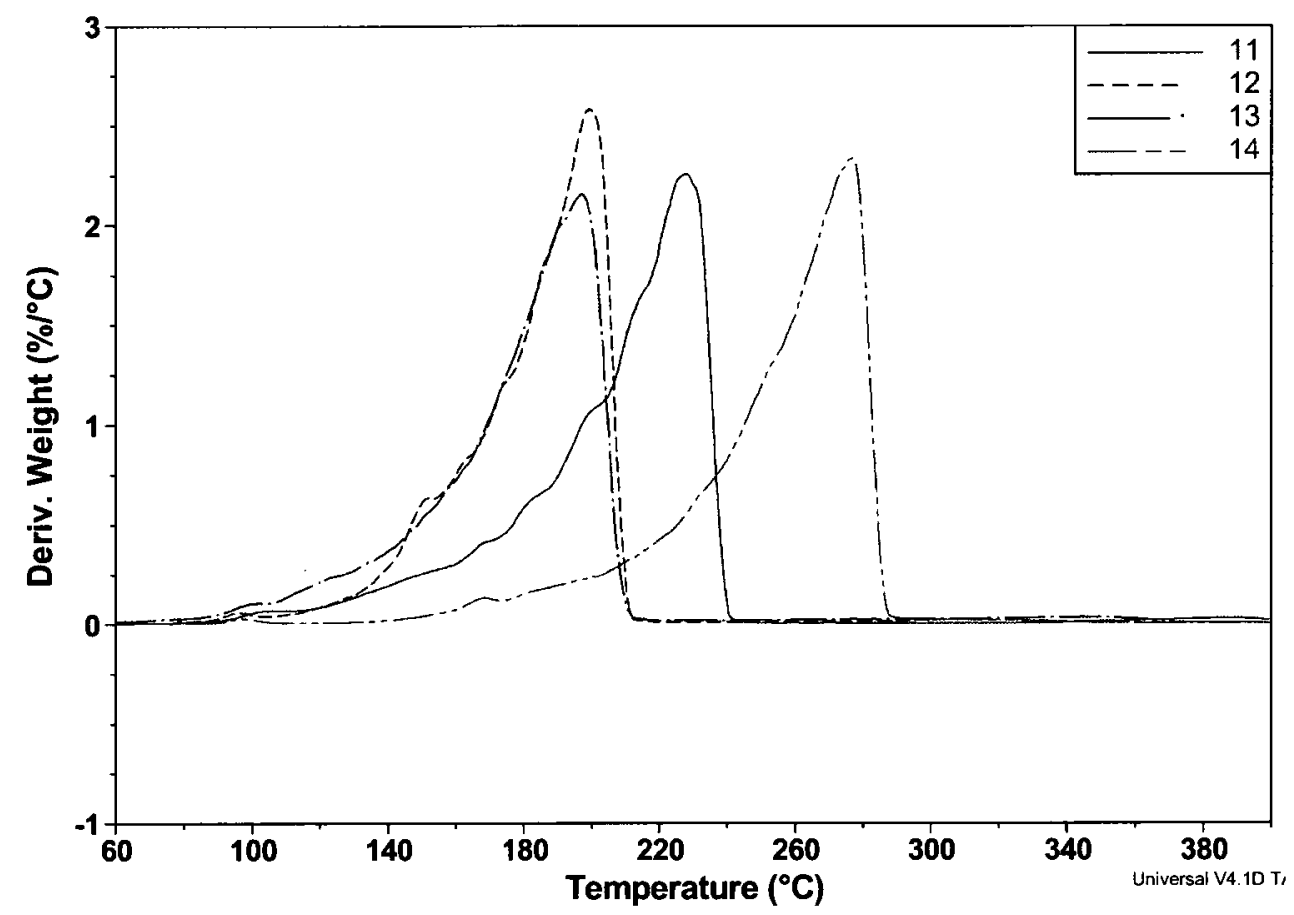

Figure 4-4. Differential weight curve for compounds 11 - 14.

The thermal data for compound $\mathbf{1 4}$ showed that it would be less likely a candidate for ALD or CVD of the four compounds discussed as it had the highest on-set of volatilization at $188^{\circ} \mathrm{C}$ and melting point at $181^{\circ} \mathrm{C}$. The $\mathrm{TG}$ had one thermal feature as seen in the derivative weight curve (Figure 4-4). The thermal event occurred at a temperature range of $188-297^{\circ} \mathrm{C}$ with a weight loss of $92 \%$ resulting in a residual mass of $3 \%$. The low yielding residual mass and the uninterrupted volatilization curve demonstrated that this compound had a clean volatilization. The large on-set of volatility may be attributed to the large molecular mass of the compound as it possesses cyclohexyl groups on the chelating nitrogens rather than iso-propyl groups as compounds $\mathbf{1 1}$ and $\mathbf{1 2 .}$

An NMR tube boil up was performed on each compound. They were each dissolved in $0.25( \pm 6) \mathrm{mL}$ of $1 \% \mathrm{v} / \mathrm{v}$ TMS in $\mathrm{C}_{6} \mathrm{D}_{6}$ solution in thick-walled NMR tubes under inert atmosphere. The tubes were immersed in liquid $\mathrm{N}_{2}$ and the glass tube was sealed under 
vacuum. Each tube was placed in a furnace at $125^{\circ} \mathrm{C}$ and the decomposition of peaks was monitored to observe CDI growth. It was clear that CDI deinsertion did not occur for compounds 11, 13, and 14 under these extreme conditions as no CDI peaks were observed by ${ }^{1} \mathrm{H}$ NMR. This was not a surprise for compound $\mathbf{1 3}$ as it contained a ligand that was synthesized to prevent CDI deinsertion. As no CDI deinsertion occurred for compounds 11 and $\mathbf{1 4}$ their thermal stability in solution was demonstrated to be a success. After seven days there was a metallic precipitate that collected at the bottom of the NMR tubes for each compound.

By contrast, after three days at $125^{\circ} \mathrm{C}$ compound 12 showed the presence of $\mathrm{CDI}$ by

${ }^{1} \mathrm{H}$ NMR as well as a precipitation at the bottom of the NMR tube. The presence of CDI was not a surprise as it has been known to deinsert from amidinate or guanidinate ligands at elevated temperatures. ${ }^{12}$ It may be possible that the deinsertion occurred on the titanium species leaving behind an alkyl group instead of forming the parent amidine and subsequently deinserting CDI, as there were a broad peaks growing in that region of the NMR throughout the experiment.

\subsubsection{Preliminary ALD reactions}

An attempt at depositing $\mathrm{TiO}_{2}$ films was undertaken using compound $\mathbf{1 1}$ as the metallic precursor and water as the second precursor. Compound 11 was chosen for two reasons; the thermolysis studies done on this compound showed it to be stable and the synthesis of this compound was easiest. A starting mass of $0.9 \mathrm{~g}$ of $\mathrm{Cp} \mathrm{p}_{2} \mathrm{Ti}\left[\mathrm{MeC}\left(\mathrm{N}^{i} \mathrm{Pr}\right)_{2}\right]$ was placed in the bubbler and a $\mathrm{N}_{2}$ flow of $20 \mathrm{sccm}$ was used. The substrates used were mechanical grade $\mathrm{N}$-doped $\mathrm{Si}(100)$ with a resistance of $1-10 \Omega$ and a native $\mathrm{SiO}_{2}$ layer. 
The deposition apparatus used was a hot-walled ALD reactor (Angstrom Engineering Inc.) consisting of an automated valve array of five pneumatic valves (Figure 4-5).

The reaction chamber was a stainless steel tube with a 1 inch diameter encased in a furnace which leads to a vacuum pump. Bubbler 1 was independently heated and connected to the reactor by a manual valve. Bubbler 2 was held at room temperature. Ultra high pure nitrogen (UHP, 5.0) was used as the carrier and purging gas. The base pressure of the reactor was less than $1 \times 10^{-3}$ Torr and the typical operating pressure was in the range of 0.08 to 0.09 Torr.

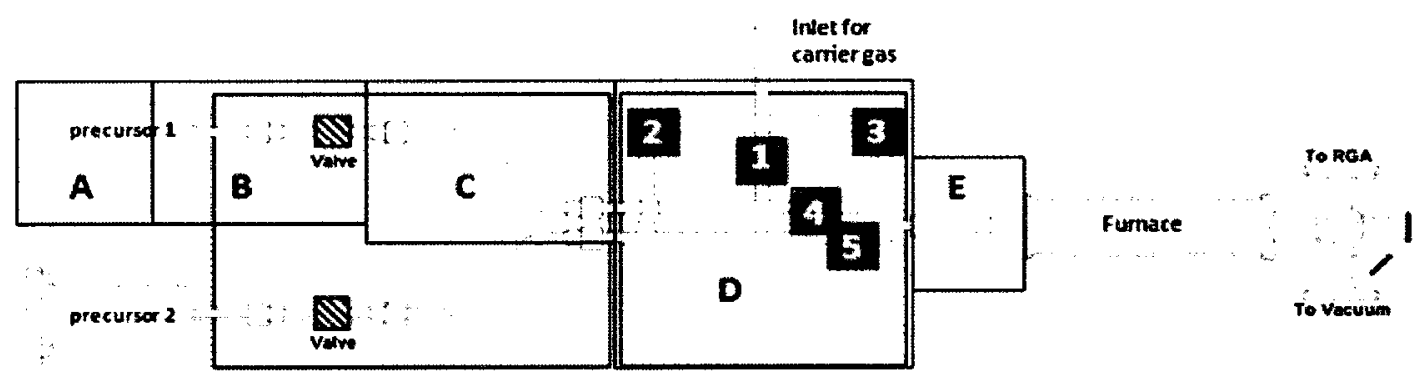

Figure 4-5. Schematic diagram of hot-walled ALD reactor.

The $\mathrm{Si}(100)$ substrates were fractured from three inch diameter wafers into strips of $1 \mathrm{~cm}$ by use of a diamond tipped glass cutter. The edges were scored with the cutter and broken by hand along the scored line. The substrates were cleaned and prepared by an $\mathrm{HF}$ dip and $\mathrm{UV} / \mathrm{O}_{3}$ method that a previous student had reported in her thesis. ${ }^{13}$ The pulse sequence for one cycle in the ALD deposition experiment was:

1. $5.0 \mathrm{~s} \mathrm{~N}_{2}$, evacuate for $5.0 \mathrm{~s}$

2. $5.0 \mathrm{~s}$ fill $\mathrm{Cp}_{2} \mathrm{Ti}\left[\mathrm{MeC}\left(\mathrm{N}^{i} \mathrm{Pr}\right)_{2}\right]$ bubbler with $\mathrm{N}_{2}, 0.5 \mathrm{~s}$ evacuate

3. $5.0 \mathrm{~s} \mathrm{Cp}_{2} \mathrm{Ti}\left[\mathrm{MeC}\left(\mathrm{N}^{i} \mathrm{Pr}\right)_{2}\right], 0.5 \mathrm{~s}$ evacuate

4. $5.0 \mathrm{~s} \mathrm{~N}_{2}, 5.0 \mathrm{~s}$ evacuate

5. $5.0 \mathrm{~s}$ fill $\mathrm{H}_{2} \mathrm{O}$ bubbler with $\mathrm{N}_{2}, 0.5 \mathrm{~s}$ evacuate

6. $3.0 \mathrm{~s} \mathrm{H}_{2} \mathrm{O}, 10.0 \mathrm{~s}$ evacuate 
The first experiment was conducted for 300 cycles with bubbler 1 set to $100^{\circ} \mathrm{C}$ with a gradual temperature gradient throughout the reactor to prevent condensation of the precursor. The precursor delivery line was set to $110^{\circ} \mathrm{C}$, the valve array was set to $120^{\circ} \mathrm{C}$, line $\mathrm{E}$ (Figure $4-5$ ) was set to $130^{\circ} \mathrm{C}$ and the furnace was set to $200^{\circ} \mathrm{C}$. The slides were placed on a stainless steel holder and placed at the centre of the furnace, where the temperature of the furnace was more precisely controlled. The slides retrieved from this experiment (S1) did not show any deposition.

The furnace temperature for the second experiment was decreased to $175^{\circ} \mathrm{C}$ because from the TG it was thought that perhaps at $200^{\circ} \mathrm{C}$ decomposition of the precursor was occurring in the reaction chamber. The slides from this experiment (S2) appeared dusty, as though a thermalization occurred in the gas phase and compound snowed onto the slide.

The third experiment used the same temperatures and parameters as the second experiment with the only exception being an increase in the cycles; from 300 to 1000 . These slides (S3) again appeared to have undergone no deposition.

The composition of the surface of $\mathbf{S} 2$ and $\mathbf{S 3}$ was analyzed by energy dispersive x-ray spectroscopy (EDS) (Cameca Camebox) that was concomitant with the scanning electron microscope (SEM) (Joel 840). This experimental technique removes an electron from the inner shell of an atom by means of an electron or photon beam. This in effect, leaves an empty space which is then filled with an electron from an outer shell, higher in energy, which releases the excess energy as a characteristic X-ray. This technique can be used to characterize composition as the spectral lines of the $\mathrm{X}$-ray are specific to an element. The dusty film S2 had some copper particles scattered throughout with a small amount of 
titanium present (Figure 4-6). The residual copper (from a different ALD experiment) that was present in the reactor was thermalized and snowed out onto the substrate. The $\mathrm{K}$ energies of copper, titanium, oxygen and silicon are $8.982 \mathrm{keV}, 4.966 \mathrm{keV}, 0.532 \mathrm{keV}$ and $1.838 \mathrm{keV}$, respectively. ${ }^{14}$

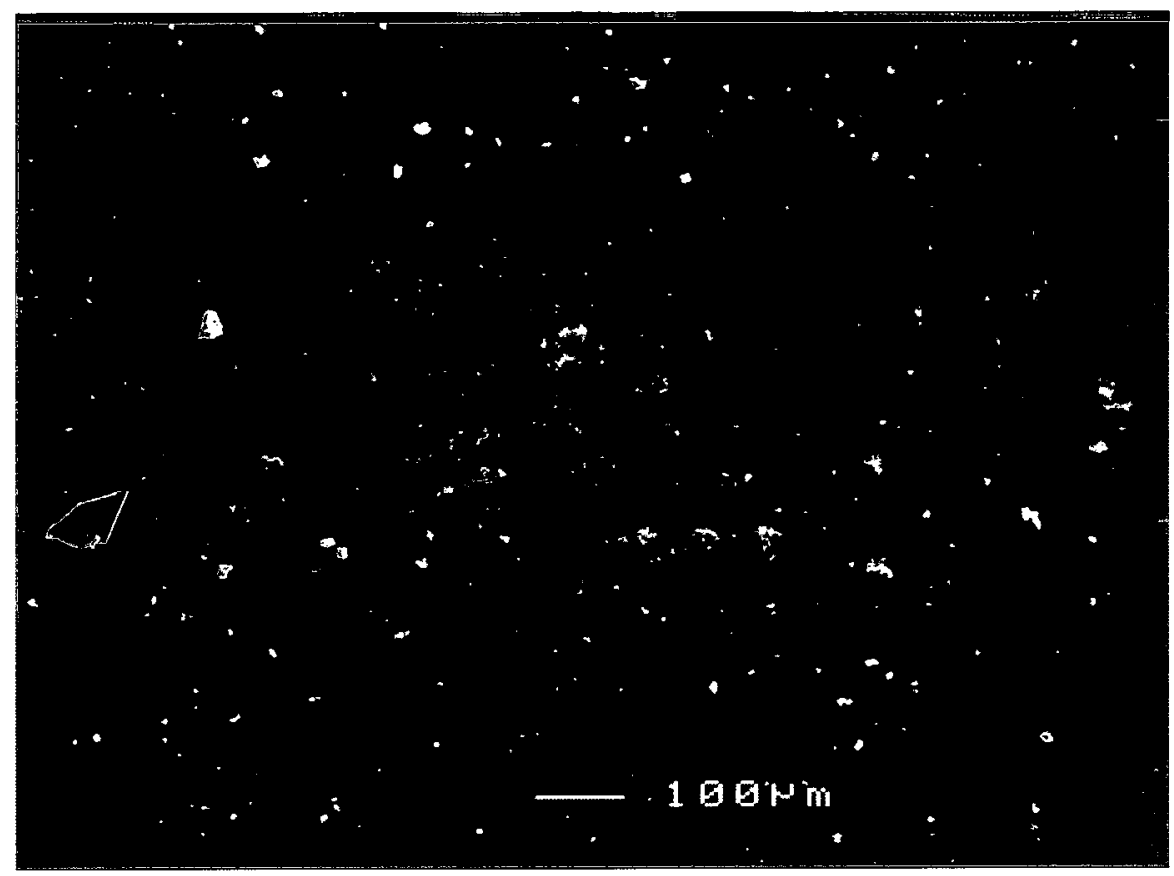

Figure 4-6. SEM image showing the surface morphology of $\mathbf{S 2}$ deposited at $175^{\circ} \mathrm{C}$ over 300 cycles.

The composition of $\mathbf{S 3}$ showed no titanium present and consisted solely of silicon and oxygen. 


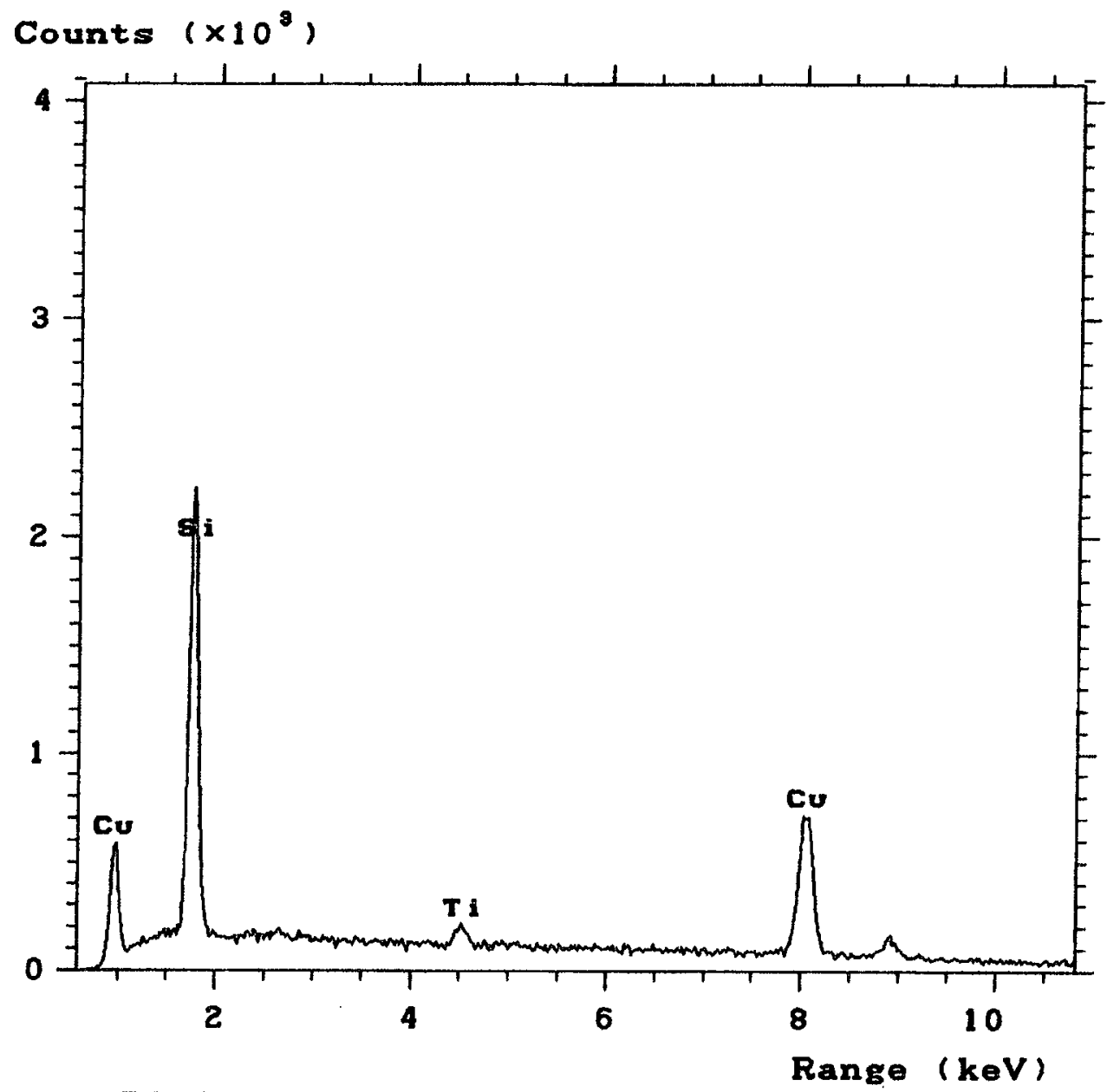

ywD 13 f

Figure 4-7. EDS spectrum of $\mathbf{S 2}$ deposited at $175^{\circ} \mathrm{C}$ over 300 cycles.

After the attempt at ALD was completed, the precursor vial was weighed and a mass of $0.4 \mathrm{~g}$ of $\mathrm{Cp}_{2} \mathrm{Ti}\left[\mathrm{MeC}\left(\mathrm{N}^{i} \mathrm{Pr}\right)_{2}\right]$ was collected demonstrating a $55 \%$ weight loss. The material appeared to have melted as it had conformed to the shape of the vial. The substance was analyzed by MS and the parent peak was observed. From this it can be deduced that the problem with these failed experiments was not due to volatility and thermal stability but perhaps with reactivity of the compound to the substrate, reactivity of the compound to water, or transportation of the volatilized species. As seen in Chapter 3 , the titanium species bound to the high surface area silica were very stable. Water may 
not have been a strong enough oxidizer to promote $\mathrm{TiO}_{2}$ film growth. Acquiring optimized parameters for deposition experiments is very tedious and time consuming. With only one ALD reactor time was very limited thus optimization experiments were unable to be performed. As well, the lab is not equipped to handle stronger oxidizing agents as they require proper ventilation throughout the experiment.

\subsubsection{Isolated Zinc By-product}

The reduction of $\mathrm{Cp}_{2} \mathrm{TiCl}_{2}$ with zinc dust produced in situ $\mathrm{ZnCl}_{2}$. It was difficult to entirely remove the $\mathrm{ZnCl}_{2}$ from solution, so when the $\left[\mathrm{Cp}_{2} \mathrm{TiCl}\right]_{2}$ dimer crystallized out of solution, $\mathrm{ZnCl}_{2}$ precipitated as well. Since the $\mathrm{Ti}^{+3}$ species was used in situ, further reaction of the $\left[\mathrm{Cp}_{2} \mathrm{TiCl}\right]_{2}-\mathrm{ZnCl}_{2}$ species with lithiated acetamidinate ligand produced a zinc amidinate dimer. Colourless cubic crystals of compound $\mathbf{1 5}$ were isolated and single crystal XRD was undertaken. The dimeric species contained two zinc centres with three acetamidinate ligands and one chlorine atom (Figure 4-8, Table 4-4 and Table 4-5). Interestingly the amidinate ligands had three different bonding arrangements; one bridged, one shared chelate and one normally chelating amidinate. 


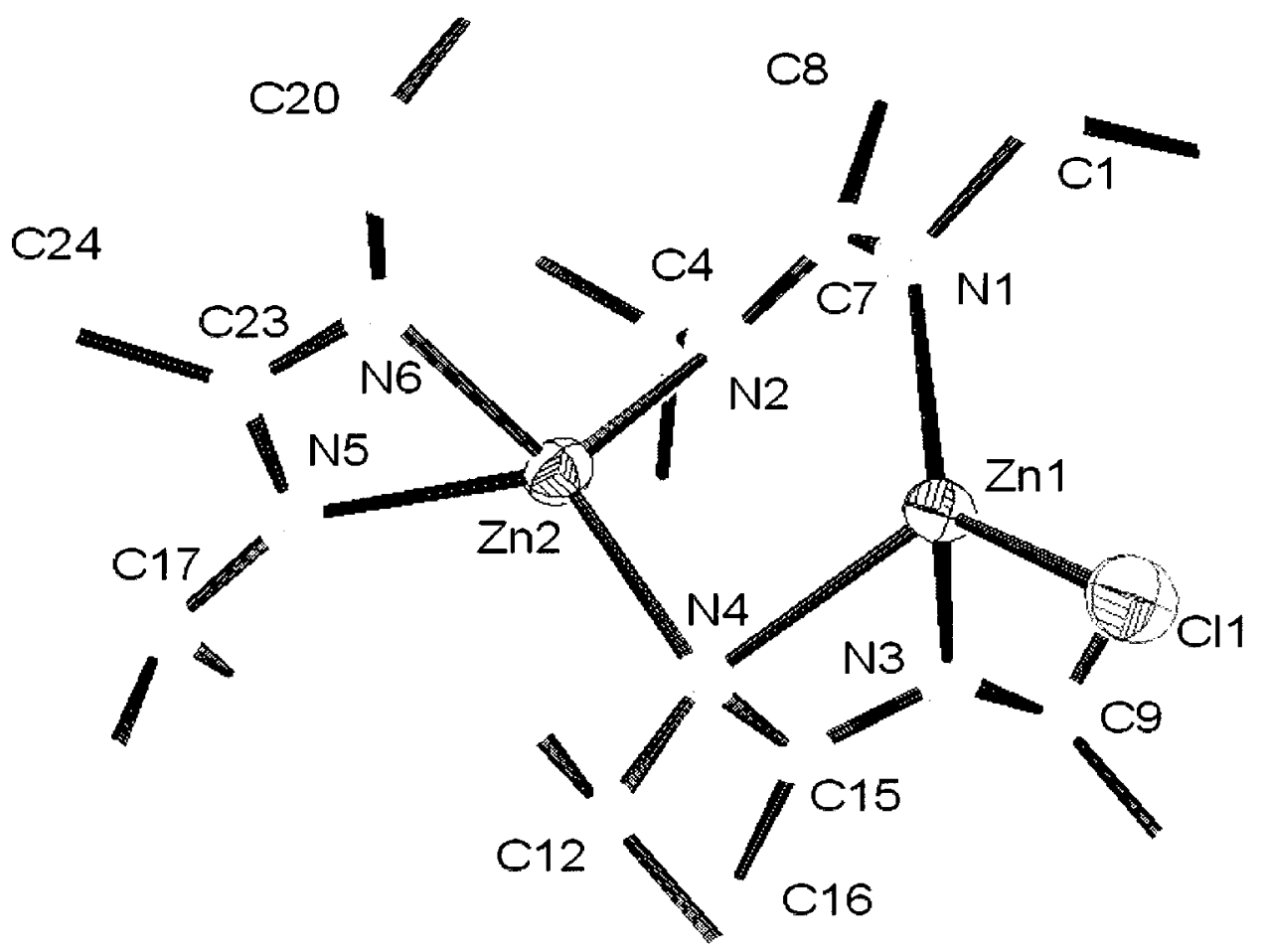

Figure 4-8. The single-crystal X-ray structure of 15 . The thermal ellipsoids are shown at $50 \%$ probability and the hydrogen centres are omitted for clarity.

Both $\mathrm{Zn} 1$ and $\mathrm{Zn} 2$ were found in distorted tetrahedral geometries. The angles around $\mathrm{Zn} 1$ ranged from $64.5^{\circ}$ to $122.5^{\circ}$ with the smallest angle corresponding to the bite angle of the N3, N4 amidinate ring and the largest angle corresponding to the Cl1-Zn1-N1 angle. The $\mathrm{C} 11-\mathrm{Zn} 1$ bond length was $2.21 \AA$ which was similar to previously reported $\mathrm{Zn}$ $\mathrm{Cl}$ bond lengths at $2.22 \AA^{15}$ The nitrogen- $\mathrm{Znl}$ bond lengths varied from 1.98 to $2.15 \AA$, with Zn1-N1 being the shortest and Zn1-N4 the longest. The lengthening of the Zn1-N4 bond length could be a result of the $\mu, \eta^{2}: \eta^{1}$-coordination mode of the second amidinate ligand where $\mathrm{Zn1-N4}$ was a dative bond.

The bridging N1, N2 amidinate had a bite angle of $119.9^{\circ}$ which was very similar to a previously reported guanidinate $\mathrm{Zn}$ complex ${ }^{16}\left(119.3^{\circ}\right)$ and a little smaller than another 
amidinate $\mathrm{Zn}$ complex ${ }^{17}\left(120.8^{\circ}\right)$. The $\mathrm{C}-\mathrm{N}$ bond lengths of the chelate nitrogens ( $\mathrm{N} 1$ and N2) to the quaternary carbon $\mathrm{C} 7$ were shorter than an ideal single $\mathrm{C}-\mathrm{N}$ bond length $(1.479 \AA),{ }^{18}$ at 1.35 and $1.32 \AA$, respectively. The shortening of the bond lengths demonstrated the participation of the chelate nitrogens and $\mathrm{sp}^{2}$ carbon in the $\pi$-system. The sum of angles around the chelate nitrogens ( $\mathrm{N} 1$ and $\mathrm{N} 2$ ) were found to be $355.4^{\circ}$ and $357.4^{\circ}$, showing partial pyramidalization of the nitrogens. The quaternary carbon $\mathrm{C} 7 \mathrm{had}$ a sum of angles of $360^{\circ}$. The bond length from C7-C8 was $1.52 \AA$, which is similar to CC single bond lengths of $1.54 \AA$.

The N3, N4 amidinate had a complicated $\mu, \eta^{2}: \eta^{1}$-coordination mode. The bite angle was $113.0^{\circ}$ (N3-Zn1-N4) which was comparable to other shared amidinate bite angles ${ }^{16}$ on zinc at $112.2^{\circ}$. The $\mathrm{Zn} 1-\mathrm{N} 4-\mathrm{Zn} 2$ angle was found to be $92.2^{\circ}$ with a $\mathrm{Zn} 2-\mathrm{N} 4$ bond length of $2.04 \AA$ similar to a previously reported complex ${ }^{16}$ at $2.10 \AA$. The $\mathrm{C}-\mathrm{N}$ bond lengths of the chelate nitrogens ( $\mathrm{N} 3$ and $\mathrm{N} 4)$ to the quaternary carbon $\mathrm{C} 15$ were shorter than ideal single $\mathrm{C}-\mathrm{N}$ bond lengths $(1.479 \AA)^{18}$ at 1.29 and $1.40 \AA$, respectively. Interestingly, the N4-C15 bond length was much longer than the N3-C15 bond length. The sum of angles around $\mathrm{N} 3$ and $\mathrm{N} 4$ were $360^{\circ}$ and $332.7^{\circ}$, respectively. The bond length and the sum of angles around N4 make it clear that it was not participating fully in the $\pi$-system. The lone pair of $\mathrm{N} 4$ was involved in the $\mathrm{Zn} 2-\mathrm{N} 4$ bond thus making the N4C15 bond longer than the N3-C15 bond. The bond length of N3-C15 was very similar to the bond lengths of imines at $1.28 \AA .^{18}$ The quaternary carbon $\mathrm{C} 15$ had a sum of angles of $360^{\circ}$ demonstrating the participation in the resonance structure. The bond length of $\mathrm{C} 15-$ C16 was a little shorter than $\mathrm{C} 7-\mathrm{C} 8$ at $1.51 \AA$. 
$\mathrm{Zn} 2$ was in a distorted tetrahedral arrangement with angles ranging from $64.8^{\circ}$ to $126.2^{\circ}$ with the smallest angle corresponding to the bite angle of the amidinate ring and the largest angle corresponding to the N4-Zn2-N6 angle. The $\mathrm{N}-\mathrm{Zn} 2$ bond lengths varied from 2.00 to $2.09 \AA$ with $\mathrm{Zn} 2-\mathrm{N} 2$ being the shortest and Zn2-N5 the longest.

The normally chelating amidinate (N5, N6) had a ligand angle of $113.3^{\circ}$ which was very similar to previously reported zinc amidinate complex ${ }^{17}$ at $113.0^{\circ}$. The C-N bond lengths of the chelate nitrogens (N5 and N6) to the quaternary carbon C23 were shorter than an ideal single $\mathrm{C}-\mathrm{N}$ bond length $(1.479 \AA)^{18}$ at 1.33 and $1.31 \AA$, respectively. The shortening of the bond lengths demonstrated the participation of the chelate nitrogens and $\mathrm{sp}^{2}$ carbon to the $\pi$-system. The sum of angles around N5 and N6 were both $360^{\circ}$ as well as the sum of angles around the quaternary carbon C23. The shortening of the bond lengths and the sum of angles corroborated the participation of the chelate nitrogens and $\mathrm{sp}^{2}$ carbon to the $\pi$-system. The bond length of $\mathrm{C} 23-\mathrm{C} 24$ was $1.52 \AA$ which was similar to C-C single bond lengths of $1.54 \AA$. 


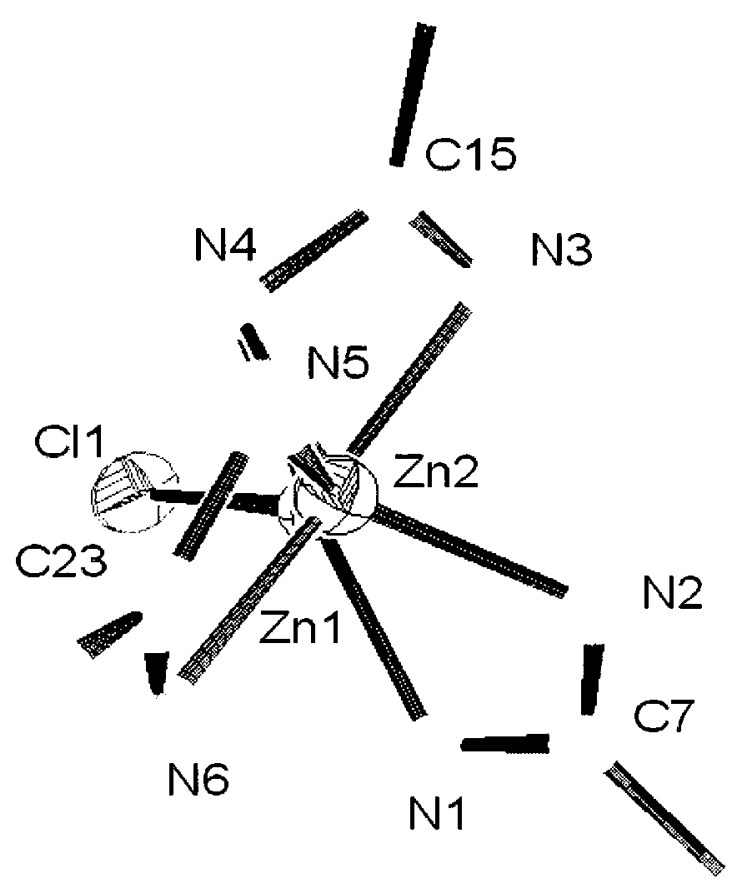

Figure 4-9. The single-crystal $\mathrm{X}$-ray structure of 15, looking down $\mathrm{Zn} 2-\mathrm{Zn} 1$ axis. The thermal ellipsoids are shown at 50\% probability; the hydrogen centres and all isopropyl groups are omitted for clarity.

Table 4-4. Selected crystal data for compound 15.

\begin{tabular}{cc}
\hline & $\mathbf{1 5}$ \\
\hline Empirical Formula & $\mathrm{C}_{24} \mathrm{H}_{51} \mathrm{~N}_{6} \mathrm{ClZn}_{2}$ \\
FW & 589.90 \\
Crystal System & Monoclinic \\
Space Group & $\mathrm{P}_{1}$ \\
$a(\AA)$ & $10.028(4)$ \\
$b(\AA)$ & $10.595(4)$ \\
$c(\AA)$ & $29.245(11)$ \\
$\alpha(\mathrm{deg})$ & 90 \\
$\beta(\mathrm{deg})$ & $96.308(6)$ \\
$\gamma(\mathrm{deg})$ & 90 \\
$\mathrm{~V}\left(\AA^{3}\right)$ & $3088(2)$ \\
$\mathrm{Z}$ & 4 \\
$\mathrm{D}_{\mathrm{c}}(\mathrm{kg} / \mathrm{L})$ & 1.269 \\
$\mu\left(\mathrm{mm}^{-1}\right)$ & 1.661 \\
$\mathrm{~T}(\mathrm{~K})$ & $120(2)$ \\
$\mathrm{R}, \mathrm{wR}$ & $0.0319,0.0685$ \\
Goodness-of-fit on $\mathrm{F}^{2}$ & 1.037 \\
\hline
\end{tabular}


Table 4-5. Selected bond lengths and angles for compound 15.

\begin{tabular}{|c|c|c|c|}
\hline \multicolumn{4}{|c|}{ Selected Bond Lengths and Distances $(\stackrel{\AA}{A})$} \\
\hline $\mathrm{Zn} 1-\mathrm{Cl} 1$ & $2.2125(9)$ & N3-C9 & $1.467(2)$ \\
\hline $\mathrm{Zn} 1-\mathrm{N} 1$ & $1.9754(17)$ & N3-C15 & $1.291(2)$ \\
\hline $\mathrm{Zn} 1-\mathrm{N} 3$ & $2.0556(16)$ & $\mathrm{N} 4-\mathrm{C} 12$ & $1.477(2)$ \\
\hline Zn1-N4 & $2.1485(17)$ & N4-C15 & $1.401(2)$ \\
\hline $\mathrm{Zn} 2-\mathrm{N} 2$ & $2.0014(18)$ & N5-C17 & $1.467(3)$ \\
\hline Zn2-N4 & $2.0412(16)$ & N5-C23 & $1.329(3)$ \\
\hline Zn2-N5 & $2.0866(18)$ & $\mathrm{N} 6-\mathrm{C} 20$ & $1.469(3)$ \\
\hline Zn2-N6 & $2.0323(19)$ & N6-C23 & $1.312(3)$ \\
\hline $\mathrm{N} 1-\mathrm{Cl}$ & $1.490(3)$ & $\mathrm{C} 7-\mathrm{C} 8$ & $1.523(3)$ \\
\hline $\mathrm{N} 1-\mathrm{C} 7$ & $1.346(3)$ & $\mathrm{C} 15-\mathrm{C} 16$ & $1.507(3)$ \\
\hline $\mathrm{N} 2-\mathrm{C} 4$ & $1.480(3)$ & $\mathrm{C} 23-\mathrm{C} 24$ & $1.518(3)$ \\
\hline $\mathrm{N} 2-\mathrm{C} 7$ & $1.317(3)$ & $\mathrm{Zn} 1-\mathrm{Zn} 2$ & $3.0201(7)$ \\
\hline \multicolumn{4}{|c|}{ Selected Bond Angles $\left(^{\circ}\right)$} \\
\hline N1-Zn1-N3 & $112.51(7)$ & N1-C7-N2 & $119.94(19)$ \\
\hline $\mathrm{N} 1-\mathrm{Zn} 1-\mathrm{N} 4$ & $116.15(7)$ & $\mathrm{C} 7-\mathrm{N} 2-\mathrm{Zn} 2$ & $119.14(13)$ \\
\hline N3-Zn1-N4 & $64.51(6)$ & Zn1-N3-C15 & $94.59(11)$ \\
\hline $\mathrm{Zn} 1-\mathrm{N} 4-\mathrm{Zn} 2$ & $92.21(6)$ & $\mathrm{N} 3-\mathrm{C} 15-\mathrm{N} 4$ & $112.95(16)$ \\
\hline $\mathrm{N} 2-\mathrm{Zn} 2-\mathrm{N} 4$ & $106.43(7)$ & C15-N4-Zn1 & $87.51(11)$ \\
\hline N2-Zn2-N6 & $113.15(7)$ & $\mathrm{C} 15-\mathrm{N} 4-\mathrm{Zn} 2$ & $109.80(12)$ \\
\hline N4-Zn2-N5 & $117.03(7)$ & $\mathrm{Zn} 2-\mathrm{N} 5-\mathrm{C} 23$ & $89.54(13)$ \\
\hline N5-Zn2-N6 & $64.76(8)$ & $\mathrm{N} 5-\mathrm{C} 23-\mathrm{N} 6$ & $113.27(19)$ \\
\hline Zn1-N1-C7 & $118.13(14)$ & C23-N6-Zn2 & 92.41(14) \\
\hline \multicolumn{4}{|c|}{ Sum of Angles $\left(^{\circ}\right)$} \\
\hline N1 & 355.35 & N6 & 360 \\
\hline $\mathrm{N} 2$ & 357.41 & $\mathrm{C} 7$ & 360 \\
\hline N3 & 360 & $\mathrm{C} 15$ & 360 \\
\hline $\mathrm{N} 4$ & 332.68 & $\mathrm{C} 23$ & 360 \\
\hline N5 & 360 & & \\
\hline
\end{tabular}

\subsection{Conclusions}

This work presented the synthesis, structural characterization, and thermolysis of new monomeric heteroleptic titanium (III) gas-phase amidinate precursors. Two crystal structures were obtained; one of the heteroleptic titanium (III) complexes and one zinc by-product. Preliminary thermolyses (TG and melting points) of the new precursors showed good volatility and thermal stability satisfying important requirements for 
application as a titanium-containing precursor for chemical deposition techniques such as ALD. Further thermal investigations were conducted for each compound using sealed NMR tubes to study the decomposition of the compounds using ${ }^{1} \mathrm{H}$ NMR. It was found that compounds $11, \mathbf{1 3}$, and 14 were thermally stable at $125^{\circ} \mathrm{C}$ for 7 days, after which a grey metallic precipitate was observed in the NMR tubes. Compound 12 was not as stable at elevated temperatures as CDI peaks were observed by ${ }^{1} \mathrm{H}$ NMR after three days as well as precipitation of a black solid out of solution.

Preliminary film deposition was attempted with compound $\mathbf{1 1}$ as the metallic precursor and water as the second precursor. Titanium was observed on S2 however a film was not deposited. The titanium species was volatilizing and may have entered the reaction chamber, however the reactivity of the second precursor may have deterred film deposition from occurring. Further tests should be conducted on this species to determine whether it could be used in ALD applications.

\subsection{Methods and Materials}

All manipulations were performed in a nitrogen filled drybox unless otherwise stated. The chemicals: methyl lithium, ethyl lithium, 1,3-diisopropyl carbodiimide, 1,3dicyclohexyl carbodiimide, 2-pyrrolidinone, isopropyl amine, phosphorous pentoxide and zinc dust were purchased from Aldrich Chemical Company and used as received. Bis(cyclopentadienyl) titanium dichloride was purchased from StremChemicals and used without further purification. All solvents used were reagent grade purified from an MBraun Solvent Purifier System. The monoanionic ligand synthesis of $\left[\mathrm{MeC}\left(\mathrm{N}^{i} \mathrm{Pr}\right)_{2}\right] \mathrm{Li}$, 
$\left[\mathrm{MeC}(\mathrm{NCy})_{2}\right] \mathrm{Li}$ and $\left[\mathrm{EtC}\left(\mathrm{N}^{i} \mathrm{Pr}\right)_{2}\right] \mathrm{Li}$ followed literature procedures. ${ }^{19}$ Iminopyrrolidine synthesis followed literature procedure. ${ }^{8}$ The iminopyrrolidinate $\left[\mathrm{N}\left(\mathrm{CH}_{2}\right)_{3} \mathrm{C}\left(\mathrm{N}^{i} \mathrm{Pr}\right)\right] \mathrm{Li}$ synthesis followed Aeilts et. al. procedure for monoanionic ligands. ${ }^{19}$ The bis(cyclopentadienyl) titanium dichloride complex was reduced following literature procedure. ${ }^{20}$ Mass spectra were obtained using the electron impact method on a VG ZAB-2HF triple-focusing spectrometer. Guelph Chemical Laboratories performed combustion analysis. TG analysis was performed on a TA Instruments Q50 apparatus located within a Labmaster 130 Dry box. Differential Scanning Calorimetry was performed on a DSC Instruments Q10 apparatus. Single crystal XRD was conducted on a Bruker-AXS APEX CCD Diffractometer located at Delaware University with the help of Glenn P. Yap.

\subsubsection{Bis(cyclopentadienyl) titanium acetamidinate, 11}

In a $60 \mathrm{~mL}$ round bottom flask $2.62 \mathrm{~g}(12.2 \mathrm{mmol})$ of $\left[\mathrm{Cp}_{2} \mathrm{TiCl}\right]_{2}$ was allowed to dissolve in about $30 \mathrm{~mL}$ of diethyl ether for about $10 \mathrm{~min}$. An in situ solution of $\left[\mathrm{MeC}\left(\mathrm{N}^{i} \mathrm{Pr}\right)_{2}\right] \operatorname{Li}(1.82 \mathrm{~g}, 12.2 \mathrm{mmol})$ in diethyl ether was slowly added to the yellowish green titanium solution. The reaction was allowed to stir overnight at room temperature. The light blue solution was filtered, evacuated to dryness, redissolved in approximately $10 \mathrm{~mL}$ of diethyl ether and placed into a freezer at $-30^{\circ} \mathrm{C} .1 .13 \mathrm{~g}(3.5 \mathrm{mmol})$ of light blue solid was collected resulting in $43 \%$ yield. mp $65-66.5^{\circ} \mathrm{C} .{ }^{1} \mathrm{H}$ NMR $\left(300 \mathrm{MHz}, \mathrm{C}_{6} \mathrm{D}_{6}\right)$ :

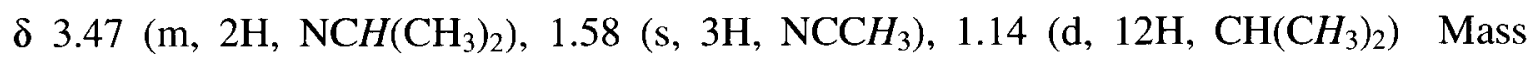
spectral data $(\mathrm{EI}, \mathrm{m} / \mathrm{z})$ (rel. intensity, \%): $319.2\left(\mathrm{M}^{+}, 100\right)$. Elemental analysis (calculated) experimental; C: (67.71), 67.60; H: (8.52), 8.21; N: (8.77), 8.57. 


\subsubsection{Bis(cyclopentadienyl) titanium ethyl amidinate, 12}

Same reaction procedure as $\mathbf{1 1}$ was used substituting the previous amidinato ligand with $\left[\mathrm{EtC}\left(\mathrm{N}^{i} \mathrm{Pr}\right)_{2}\right] \mathrm{Li}(0.568 \mathrm{~g}, 3.5 \mathrm{mmol})$. The reaction was allowed to stir overnight at room temperature. The blue solution was then filtered to remove $\mathrm{LiCl}$, evacuated to dryness with a $65 \%$ crude yield, redissolved in approximately $5 \mathrm{~mL}$ diethyl ether and placed into a freezer at $-30^{\circ} \mathrm{C} . \quad 0.42 \mathrm{~g}(1.26 \mathrm{mmol})$ of a baby blue solid was collected resulting in a $36 \%$ yield. $\mathrm{mp} 99-104^{\circ} \mathrm{C}$. Mass spectral data (EI, $\mathrm{m} / \mathrm{z}$ ) (rel. intensity, \%): $333.2\left(\mathrm{M}^{+}, 21.7\right)$. Elemental analysis (calculated) experimental; $\mathrm{C}:(68.46), 68.13 ; \mathrm{H}$ : (8.77), 8.39; N: (8.40), 7.94 .

\subsubsection{Bis(cyclopentadienyl) titanium iso-propyl iminopyrrolidinate, 13}

Same reaction procedure as $\mathbf{1 1}$ was used substituting the previous amidinato ligand with $\left[\mathrm{N}\left(\mathrm{CH}_{2}\right)_{3} \mathrm{C}\left(\mathrm{N}^{i} \mathrm{Pr}\right)\right] \mathrm{Li}(0.416 \mathrm{~g}, 3.5 \mathrm{mmol})$. The reaction was allowed to stir overnight at room temperature. The green solution was then filtered, evacuated to dryness, redissolved in approximately $5 \mathrm{~mL}$ of diethyl ether and placed into a freezer at $30^{\circ} \mathrm{C}$. $0.4 \mathrm{~g}(1.3 \mathrm{mmol})$ of a light green solid was collected resulting in a $42 \%$ yield. mp $111-115^{\circ} \mathrm{C}$. Mass spectral data (EI, $\left.m / z\right)$ (rel. intensity, \%): $303.1\left(\mathrm{M}^{+}, 18.7\right)$. Elemental analysis (calculated) experimental; C: (67.33), 66.97; H: (7.64), 7.38; N: (9.24) 8.85.

\subsubsection{Bis(cyclopentadienyl) titanium biscyclohexyl acetamidinate, 14}

Same reaction procedure as $\mathbf{1 1}$ was used substituting the previous amidinato ligand with $\left[\mathrm{MeC}(\mathrm{NCy})_{2}\right] \mathrm{Li}(0.80 \mathrm{~g}, 3.5 \mathrm{mmol})$. The reaction was allowed to stir overnight at 
room temperature. The light blue solution was then filtered, evacuated to dryness, redissolved in approximately $5 \mathrm{~mL}$ of diethyl ether and placed into a freezer at $-30^{\circ} \mathrm{C}$. $0.311 \mathrm{~g}(0.90 \mathrm{mmol})$ of a blue solid was collected resulting in a $26 \%$ yield. $\mathrm{mp} 179$ $181^{\circ} \mathrm{C}$. Mass spectral data (EI, $\left.m / z\right)$ (rel. intensity, \%): $399.2\left(\mathrm{M}^{+}, 100\right)$.

\subsection{Structural Determination for Compounds 11 and 15}

Suitable crystals were mounted with viscous oil on a plastic mesh and cooled to the data collection temperature. Unit cell parameters were determined using data frames from four different sections of the Ewald sphere. SADABS multi-scan absorption corrections were applied. No symmetry higher than monoclinic was observed for compounds 11 and 15. Solution in the space group option, Cc and P2, yielded chemically reasonable and computationally stable results of refinement for compounds $\mathbf{1 1}$ and 15. The structures were solved using direct methods and refined with full matrix least squares procedures of $\mathrm{F}^{2}$ data. All hydrogen atoms were treated as idealized contributions and all non-hydrogen atoms were refined with anisotropic displacement coefficients. Atomic scattering factors are contained in the SHELXTL program library. 


\subsection{References}

${ }^{1}$ Wasslen, Y.A., Tois, E., Haukka, S., Kreisel, K.A., Yap, G.P.A., Halls, M.D., Barry, S.T.; Inorg.

Chem, 2010, 49, 1976.

${ }^{2}$ Milanov, A., Bhakta, R., Baunemann, A., Becker, H.W., Thomas, R., Erhart, P., Winter, M., Devi, A.; Inorg. Chem., 2006, 45, 26, 11008.

${ }^{3}$ Bailey, P.J., Pace, S.; Coord. Chem. Rev., 2001, 214, 91.

${ }^{4}$ Neumayer, D.A., Belot, J.A., Feezel, R.L., Reedy, C., Stern, C.L., Marks, T.J.; Inorg. Chem., 1998, 5625 .

${ }^{5}$ Jones, A.C., Aspinall, H.C., Chalker, P.R.; Surf. Coat. Tech., 2007, 201, 9046.

${ }^{6}$ Edelmann, F.T.; Chem. Soc. Rev., 2009, 38, 8, 2253.

${ }^{7}$ Myllymaki, P., Nieminen, M., Niinisto, J., Putkonen, M., Kukli, K., Niinisto, L.; J. Mater. Chem., 2006, 16, 6, 563 .

${ }^{8}$ Wasslen, Y.A., Kurek, A., Johnson, P.A., Pigeon, T.C., Monillas, W.H., Yap, G.P.A., Barry, S.T., Dalton Trans., 2010, ASAP.

${ }^{9}$ Plenio, H.; Roesky, H. W.; Noltemeyer, M.; Sheldrick, G.M.; J. Chem. Soc., Chem. Commun., 1987, 1483.

${ }^{10}$ Koterwas, L.A.; Fettinger, J.C.; Sita, L.R.; Organometallics, 18, 20, 1999, 4183.

${ }^{11}$ Hagadorn, J. R.; Arnold, J. Organometallics 1998, 17, 1355.

${ }^{12}$ Rowley, C.N.; DiLabio, G.A.; Barry, S.T. Inorg.Chem. 2005, 44, 1983.

${ }^{13}$ Brazeau, A.L.; Theoretical and Experimental Investigations of Ligand Exchange in Amidinate and Guanidinate Ligand Systems and the Atomic Layer Deposition of Aluminum Oxide, M.Sc., 2007.

${ }^{14}$ Lide, D.R., Handbook of Chemistry and Physics. Ed. 77, CRC Press, New York, 1996, pp 12-40.

${ }^{15}$ Barwick, M., Abu-Izneid, T., Novak, I., Kovac, B.; Chem. Phys. Letters, 2008, 460, 79-81.

${ }^{16}$ Coles, M.P., Hitchcock, P.B.; Eur. J. Inorg. Chem., 2004, 13, 2662-2672.

${ }^{17}$ Nimitsiriwat, N., Gibson, V.C., Marshall, E.L., Takolpuckdee, P., Tomov, A.K., White, A.J.P., Williams, D.J., Elsegood, M.R.J., Dale, S.H.; Inorg. Chem., 2007, 46, 9988-9997. 
${ }^{18}$ Macaulay, R., Burnelle, L.A., Sandorfy, C.; Theoret. Chim. Acta. (Ber.)., 1973, $29,1$.

${ }^{19}$ Aeilts, S.L., Coles, M.P., Swenson, D.C., and Jordan, R.F., Organomet, 1998, 17(15), 3265.

${ }^{20}$ Green, M.L.H. and Lucas, C.R. J.C.S. Dalton, 1972, 1000. 


\section{Chapter 5: Homoleptic Titanium (III) Compounds}

\subsection{Introduction}

One issue that continues to arise in transition metal nitride film deposition is the lack of reactivity the commonly used nitrogen source ammonia $\left(\mathrm{NH}_{3}\right)$ has. Finding a suitable reducing agent to reduce titanium metal to the +3 oxidation state is a constant challenge. One method of avoiding such an issue is by developing a single source precursor (SSP) that contains both titanium and nitrogen in a single molecule. ${ }^{1}$ The search for SSPs for TiN films began in the mid seventies. ${ }^{2}$ The majority of these compounds, however, have been volatile homoleptic tetrakis(dialkylamido) titanium complexes in the +4 oxidation state. $^{3,4}$ Other heteroleptic bis(dialkylamido) titanium species have been studied in SSP process by Carmalt et. al. and Winters et. al., these compounds, however, contained chlorine. $^{5,6}$ Synthesizing a SSP that is chlorine free would be advantageous in improving the halide contamination of the deposited TiN film. To the best of our knowledge, the development of SSPs consisting of titanium in the +3 oxidation state has no been reported. It would be advantageous to synthesize a +3 oxidation state titanium SSP for TiN thin film deposition so that the surface reduction of the titanium would be unnecessary within the reaction chamber.

It has been reported that tetrakis(dialkylamido) titanium complexes under go thermal decomposition at elevated temperatures and prolonged evacuation leaving behind high carbon impurities. ${ }^{4}$ As most CVD and ALD processes are conducted under such 
environments, a compound that thermally decomposes with high impurities is highly undesirable.

It was predicted that by fully saturating the titanium centre with bulky bidentate ligands, such as guanidinates, the vapour phase thermal stability may increase. This chapter focuses on the synthesis of homoleptic titanium (III) guanidinate compounds, their thermolysis and their reactivity towards N-doped $\mathrm{Si}(100)$ films.

\subsection{Results and Discussion}

\subsubsection{Synthesis and Crystal Structure Data}

Two homoleptic titanium (III) guanidinate species were synthesized in low yields from the $\mathrm{TiCl}_{3}$ 3THF starting material and the appropriate lithiated guanidinate. It was found that the compounds formed slowly at room temperature with the starting titanium species changing from a characteristic yellow-green to a solution ranging from dark green to brown, depending on the lithiated guanidinate used. In every case, the solution was removed under vacuum, the solid was redissolved in diethyl ether and placed in the freezer to promote crystallization. Dark green, red and black crystals were isolated, and further characterization was undertaken. Compounds $\mathbf{1 6}$ and $\mathbf{1 8}$ produced crystals of sufficient quality for a single crystal structure to be collected (Figure 5-1 and Figure 5-2, Table 5-1 and Table 5-2).

$$
\begin{gathered}
\mathrm{TiCl}_{3} \cdot 3 \mathrm{THF}+3 \mathrm{Li}\left[\mathrm{RC}\left(\mathrm{N}^{i} \mathrm{Pr}\right)_{2}\right] \rightarrow \mathrm{Ti}\left[\mathrm{RC}\left(\mathrm{N}^{i} \mathrm{Pr}\right)_{2}\right]_{3}+3 \mathrm{LiCl} \\
\text { where } \mathrm{R}=\mathrm{NMe}_{2} \text { or } \mathrm{NH}^{i} \mathrm{Pr}
\end{gathered}
$$


The salt metathesis reaction for compound $\mathbf{1 6}$ was a success and the compound was characterized by MS, NMR and XRD with a crystallized yield of 59\%. The reaction was a ratio of one $\mathrm{TiCl}_{3} 3 \mathrm{THF}$ to three lithiated dimethylamide diisopropyl guanidinate (dimdip). The ligand was made two hours prior to the reaction and used in situ. The reaction was carried out overnight at room temperature. The collected crystal structure was very symmetric with an I-43d space group. Compound $\mathbf{1 6}$ was a six coordinate distorted octahedral considering the arrangement of the dimdip ligands. The bite angle of the ligand was $62.4^{\circ}$ which was slightly larger than previously reported heteroleptic titanium (III) guanidinate species at $61.6^{\circ} .^{7}$ The increase in bite angle may be due to the fact that this compound is homoleptic and there is no competition between the electronic and steric properties of a single type of ligand ${ }^{8}$ as there would be if there were two different ligands present. The ligand angle (N1-C7-N2) was $112.8^{\circ}$ which was the same as the previously reported heteroleptic dimdip species. ${ }^{7}$ 


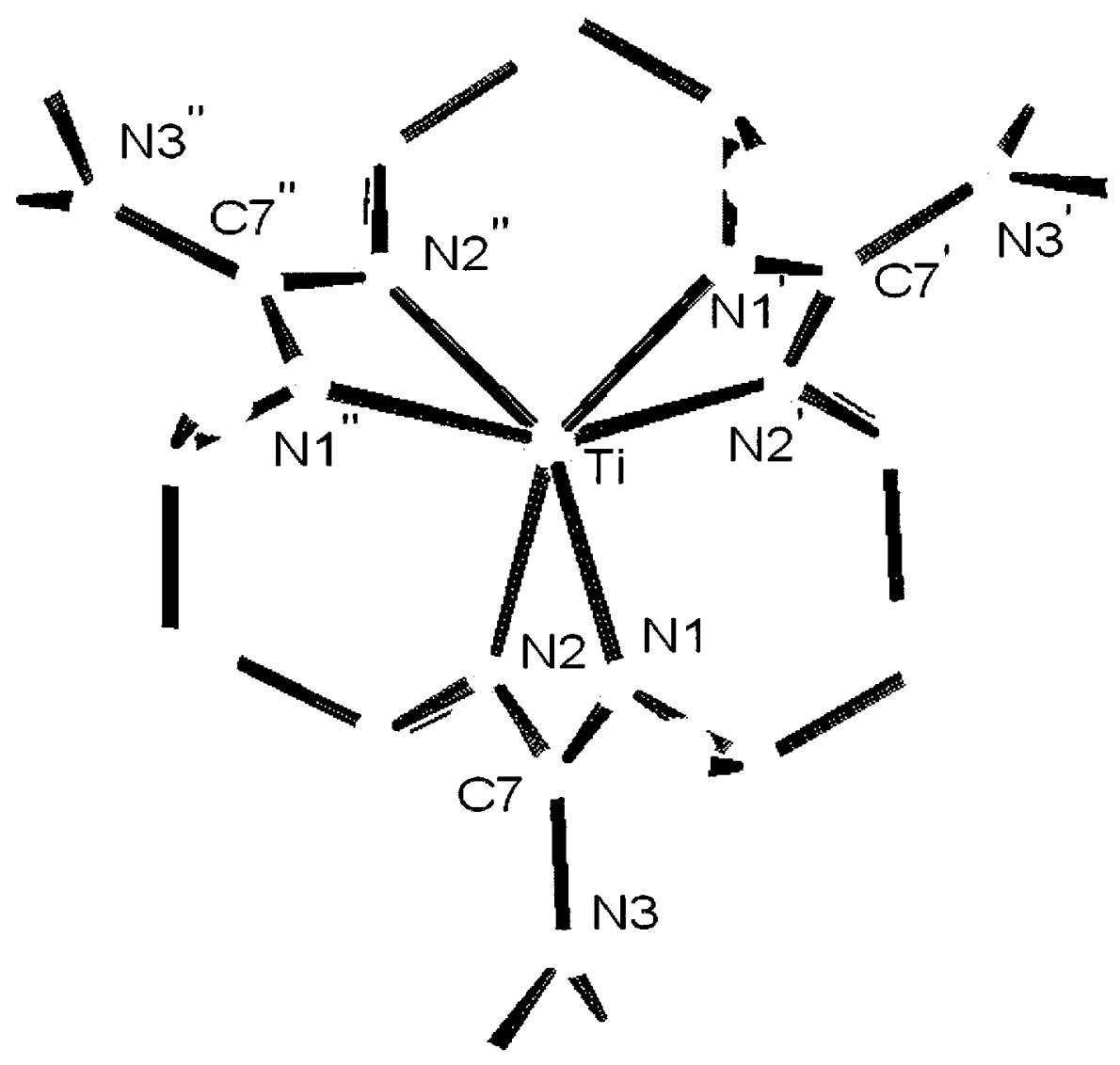

Figure 5-1. The single-crystal X-ray structure of 16. The thermal ellipsoids are shown at $50 \%$ probability and the hydrogen centres are omitted for clarity.

The titanium-nitrogen bond lengths of compound $\mathbf{1 6}$ were slightly smaller than previously reported heteroleptic guanidinate complexes ${ }^{7}$ at $2.14 \AA$ as compared to $2.17 \AA$. This may also be attributed to the fact that $\mathbf{1 6}$ was a homoleptic species (as described above). The $\mathrm{C}-\mathrm{N}$ bond lengths within the $\mathrm{CN}_{3}$ core of the coordinated ligand were found to contain the $\pi$-system within the metallocycle with carbon-nitrogen bond lengths of $1.33 \AA$ for both N1-C7 and N2-C7. The bond length of the exocyclic nitrogen was found to be longer at $1.40 \AA$, however, it was still shorter than single C-N bond lengths. ${ }^{9,10}$ The shorter than single $\mathrm{C}-\mathrm{N}$ bond lengths of the exocyclic moiety led to the inclination that 
the exocyclic nitrogen was participating slightly in the $\pi$-system of the ring. A torsion angle of $41.7^{\circ}$ was found for $(\mathrm{C} 8-\mathrm{N} 3-\mathrm{C} 7-\mathrm{N} 2)$ with a sum of angles around $\mathrm{N} 3$ of $357.8^{\circ}$. These results gave validation to the inclination that $\mathrm{N} 3$ was participating in the $\pi$-system. The guanidinate ring was planar with a torsion angle of $0.0^{\circ}$.

Table 5-1. Selected crystal data for compounds 16 and 18.

\begin{tabular}{ccc}
\hline & $\mathbf{1 6}$ & $\mathbf{1 8}$ \\
\hline \hline Empirical Formula & $\mathrm{C}_{27} \mathrm{H}_{60} \mathrm{~N}_{9} \mathrm{Ti}$ & $\mathrm{C}_{20} \mathrm{H}_{44} \mathrm{~N}_{6} \mathrm{ClTi}$ \\
FW & 558.74 & 451.96 \\
Crystal System & Cubic & Monoclinic \\
Space Group & $\mathrm{I}-43 \mathrm{~d}$ & $\mathrm{P} 2_{1} / \mathrm{c}$ \\
$a(\AA)$ & $23.739(4)$ & $9.6420(11)$ \\
$b(\AA)$ & $23.739(4)$ & $14.1909(17)$ \\
$c(\AA)$ & $23.739(4)$ & $19.236(2)$ \\
$\alpha(\mathrm{deg})$ & 90.00 & 90.00 \\
$\beta(\mathrm{deg})$ & 90.00 & $99.354(2)$ \\
$\gamma(\mathrm{deg})$ & 90.00 & 90.00 \\
$\mathrm{~V}\left(\AA^{3}\right)$ & $13378(4)$ & $2597.0(5)$ \\
$\mathrm{Z}$ & 16 & 4 \\
$\mathrm{D}_{\mathrm{c}}\left(\mathrm{Mg} / \mathrm{m}^{-3}\right)$ & 4912 & 1.156 \\
$\mu\left(\mathrm{mm}{ }^{-1}\right)$ & 0.285 & 0.449 \\
$\mathrm{~T}(\mathrm{~K})$ & $120(2)$ & $120(2)$ \\
$\mathrm{R}, \mathrm{wR}$ & $0.0327,0.0810$ & $0.1011,0.1338$ \\
Goodness-of-fit on $\mathrm{F}^{2}$ & 1.013 & 1.050 \\
\hline
\end{tabular}


Table 5-2. Selected bond lengths and angles for compounds 16 and 18.

\begin{tabular}{|c|c|c|c|c|c|}
\hline \multicolumn{2}{|c|}{$\mathrm{C}_{27} \mathrm{H}_{60} \mathrm{~N}_{9} \mathrm{Ti}(\mathbf{1 6})$} & \multicolumn{4}{|c|}{$\mathrm{C}_{20} \mathrm{H}_{44} \mathrm{~N}_{6} \mathrm{ClTi}$ (18) } \\
\hline \multicolumn{6}{|c|}{ Selected Bond Lengths $(\AA)$} \\
\hline $\mathrm{N} 1-\mathrm{Ti}$ & $2.1424(12)$ & $\mathrm{N} 1-\mathrm{Ti}$ & $2.147(2)$ & N4-Ti & $2.027(2)$ \\
\hline N1-C7 & $1.335(2)$ & $\mathrm{N} 2-\mathrm{Ti}$ & $2.037(2)$ & N5-Ti & $2.117(2)$ \\
\hline $\mathrm{N} 2-\mathrm{Ti}$ & $2.1432(13)$ & $\mathrm{N} 1-\mathrm{C} 1$ & $1.323(3)$ & $\mathrm{N} 4-\mathrm{C} 11$ & $1.355(3)$ \\
\hline $\mathrm{N} 2-\mathrm{C} 7$ & $1.3303(19)$ & $\mathrm{N} 2-\mathrm{C} 1$ & $1.368(3)$ & N5-C11 & $1.336(3)$ \\
\hline N3-C7 & $1.4055(18)$ & $\mathrm{N} 3-\mathrm{C} 1$ & $1.365(3)$ & N6-C11 & $1.362(3)$ \\
\hline & & $\mathrm{Ti}-\mathrm{Cl}$ & $2.3326(8)$ & & \\
\hline \multicolumn{6}{|c|}{ Selected Bond Angles $\left({ }^{\circ}\right)$} \\
\hline N1-Ti-N2 & $62.35(5)$ & $\mathrm{N} 1-\mathrm{C} 1-\mathrm{N} 2$ & $111.2(2)$ & N4-Ti-N5 & $64.58(8)$ \\
\hline N1-C7-N2 & $112.70(12)$ & N1-Ti-N2 & $64.07(8)$ & $\mathrm{N} 4-\mathrm{C} 11-\mathrm{N} 5$ & $110.8(2)$ \\
\hline Ti-N1-C7 & $92.42(8)$ & Ti-N1-C1 & $90.59(15)$ & Ti-N4-C11 & $93.91(15)$ \\
\hline $\mathrm{Ti}-\mathrm{N} 2-\mathrm{C} 7$ & $92.52(9)$ & $\mathrm{Ti}-\mathrm{N} 2-\mathrm{C} 1$ & $94.08(15)$ & Ti-N5-C11 & $90.53(15)$ \\
\hline \multicolumn{6}{|c|}{ Sum of Angles $\left(^{\circ}\right)$} \\
\hline N1 & 356.88 & N1 & 355.22 & $\mathrm{~N} 4$ & 358.27 \\
\hline $\mathrm{N} 2$ & 356.83 & $\mathrm{~N} 2$ & 355.32 & N5 & 356.68 \\
\hline N3 & 357.75 & & & & \\
\hline
\end{tabular}

Compound 18 was isolated from the salt metathesis reaction of a miscalculation for compound 17. A ratio of one $\mathrm{TiCl}_{3} 3 \mathrm{THF}$ to two lithiated tripyl was used rather than the intended one to three equivalents.

\section{$\mathrm{TiCl}_{3} 3 \mathrm{THF}+2 \mathrm{Li}\left[{ }^{i} \operatorname{PrHNC}\left(\mathrm{N}^{i} \mathrm{Pr}\right)_{2}\right] \rightarrow \operatorname{Ti}\left[{ }^{i} \operatorname{PrHNC}\left(\mathrm{N}^{i} \mathrm{Pr}\right)_{2}\right]_{2} \mathrm{Cl}+2 \mathrm{LiCl}$}

Brownish-red rectangular crystals were isolated, which were different from any other crystals isolated from these types of reactions. $\mathrm{A}^{1} \mathrm{H}$ NMR was taken to see if the product was oxidized to a +4 oxidation state. The NMR was not clear as the peaks were broad indicating that the compound may still be paramagnetic; +3 oxidation state. Due to the puzzling NMR and colour of the crystals, qualitative tests for lithium and chloride were performed. The compound was dissolved in dilute nitric acid solution and a flame test was conducted. If lithium were present in the compound a bright magenta colour would 
have appeared when introduced to the flame of a propane torch. This test was negative; no lithium was present in the isolated crystal. Next, three drops of silver nitrate were introduced to the solution and cloudy white precipitate formed immediately, indicating the presence of a halide by silver halide precipitation. With these tests it was considered that perhaps a bis(tripyl) titanium(III) mono chloride compound was synthesized. The crystal was sent for structural determination after a parent peak for the bis compound was seen by MS. A rational synthesis was performed in an attempt to increase the yield. From a rational synthesis, $0.3 \mathrm{~g}$ of brownish-red crystals were obtained ( $24 \%$ yield).

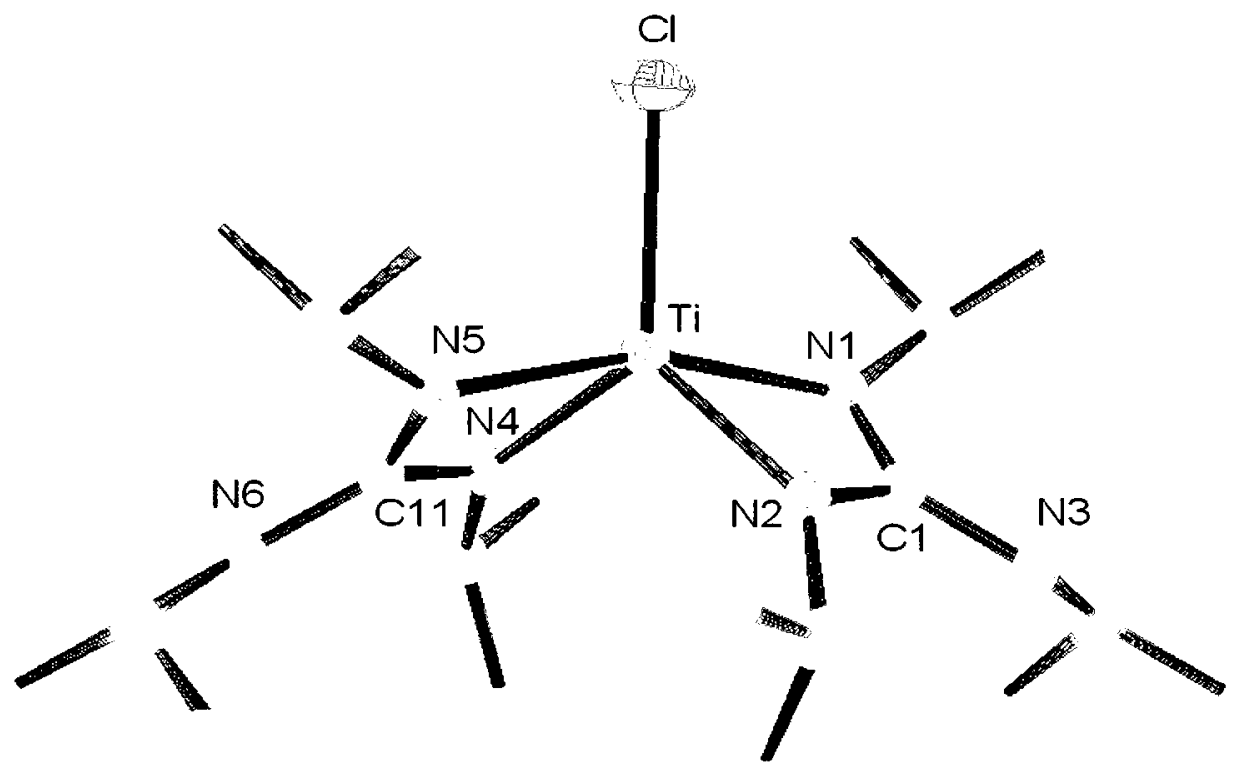

Figure 5-2. The single-crystal $X$-ray structure of 18 . The thermal ellipsoids are shown at $50 \%$ probability and the hydrogen centres are omitted for clarity.

There are two possible geometries for a five-coordinate species, trigonal-bipyramidal or square-pyramidal. Addison et al. suggested a geometric parameter, $\tau$, that can be used to distinguish which geometry is dominant. ${ }^{11}$ For square-pyramidal systems $\alpha=\beta=180^{\circ}$ 
where $\alpha$ is the DME angle and $\beta$ is the BMC angle with $A$ as the axial ligand (Figure 5-3). In most square-pyramidal systems $M$ is slightly displaced out of the BDCE plane, shifted towards $\mathrm{A}$, this forces $\alpha=\beta<180^{\circ}$. For perfectly trigonal-bipyramidal systems $\alpha$ and $\beta$ angles differ with $\alpha=120^{\circ}$ and $\beta=180^{\circ}$. Thus the parameter $\tau$ is defined as equation 1:

$$
\tau=\frac{(\beta-\alpha)}{60}, \text { where } 0 \leq \tau \leq 1
$$

A square-pyramidal $C_{4 v}$ geometry has a value of 0 and trigonal-bipyramidal $D_{3 h}$ geometry has a value of 1 .

a)

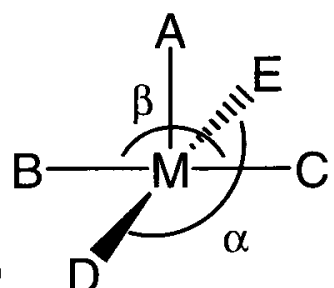

b)

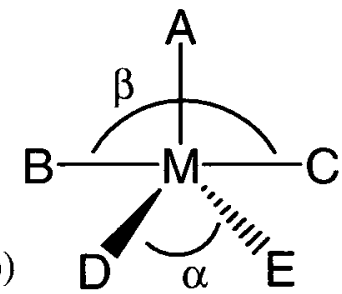

Figure 5-3. Five-coordinate structures of a) square-planar and b) trigonal-bipyramidal geometries.

Compound 18 showed titanium to be in a five coordinate system that had $\alpha=111.3^{\circ}$ and $\beta=161.2^{\circ}$ giving a $\tau$ value of 0.83 . With this high value it can be concluded that 18 was distinguishably more trigonal-bipyramidal in shape. The Ti-Cl bond length was $2.33 \AA$ which was similar to previously reported titanocene monochloride species at $2.36 \AA^{12}$ and monochloride bis(amidinate) Ti(III) species $\left(2.33 \AA\right.$ ) by Hagadorn et. al. ${ }^{13}$ The chlorine-titanium-nitrogen angles ranged from $98.8^{\circ}$ to $125.9^{\circ}$ with $\mathrm{Cl}-\mathrm{Ti}-\mathrm{N} 1$ being the smallest and $\mathrm{Cl}-\mathrm{Ti}-\mathrm{N} 2$ being the largest angle. Interestingly, the Cl-Ti-N5 angle was smaller than the Cl-Ti-N4 at almost the same values as for $\mathrm{N} 1$ and $\mathrm{N} 2$ at $100.0^{\circ}$ and $122.8^{\circ}$, respectively. This difference in angles can be associated with the propeller like 
structure the guanidinate ligands formed. This gave the structure a $\mathrm{P} 2{ }_{1} / \mathrm{c}$ space group with a $\mathrm{C}_{2}$ symmetry on the Cl-Ti axis. The bite angle of the tripyl ligands were $64.1^{\circ}$ and $64.7^{\circ}$, respectively. The angles were much larger than previously reported tripyl heteroleptic species at $61.8^{\circ 7}$ and similar to Hagadorn's monochloride species at $64.3^{\circ}$ and $65.5^{\circ} .{ }^{13}$ The ligand angles (N1-C1-N2 and N4-C11-N5) were $111.2^{\circ}$ and $110.3^{\circ}$ which were similar to the previously reported tripyl heteroleptic species at $111.1^{0}$.

The titanium-nitrogen bond lengths of compound 18 ranged from 2.03 to $2.15 \AA$, with Ti-N4 being the shortest and Ti-N1 the longest bonds. Similarly the bond lengths mimic the Cl-Ti-N angles. The shortening of the $\mathrm{N} 2$ and $\mathrm{N} 4$ bond lengths was caused by their position in the equatorial plane.

The C-N bond lengths of both ligands were all relatively short at $1.32 \AA$ for $\mathrm{N} 1-\mathrm{C} 1$ and $1.37 \AA$ for $\mathrm{N} 2-\mathrm{C} 1$ with the exocyclic N3-C1 at $1.36 \AA .^{14}$ Similarly N4-C11 was $1.36 \AA$, N5-C11 was $1.34 \AA$ and the exocyclic N6-C11 was $1.36 \AA$. The shorter bond lengths led to the inclination that all three nitrogens were participating in the $\pi$-system of the ligand. The torsion angles within the guanidinate ring were $2.1^{\circ}$ and $4.2^{\circ}$, far from planar. The iso-propyl groups on the exocyclic amido moieties of both ligands were rotated from the plane of the guanidinate ring by $30^{\circ}$ for N2-C1-N3-C8 and $24^{\circ}$ for N4C11-N6-C18. However, $\pi$-overlap is known to follow a $\cos ^{2} \theta$ relationship for twisted systems and with the lengths of the $\mathrm{C}-\mathrm{N}$ bonds it was clear that the exocyclic groups participated significantly in the delocalized $\pi$-bonding of the guanidinate. ${ }^{15}$ 


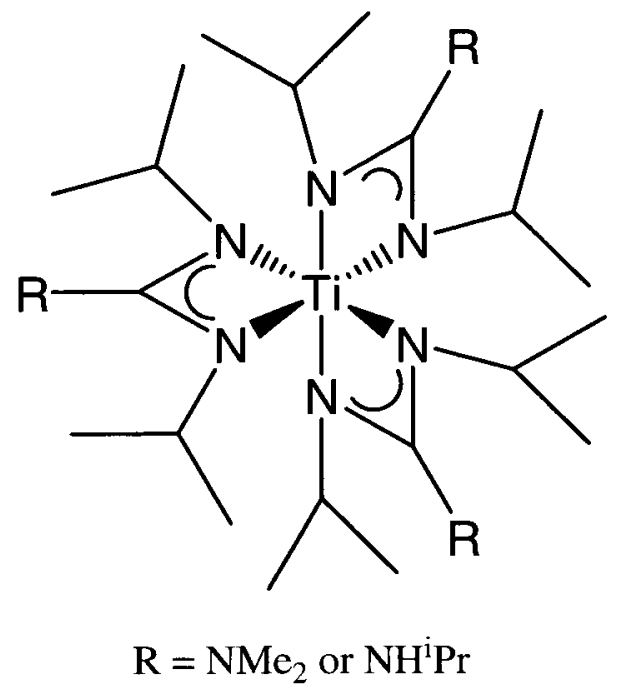

Figure 5-4. Homoleptic titanium (III) species.

Similarly, the synthesis of compound $\mathbf{1 7}$ was attempted at room temperature and solids were allowed to precipitate out of solution in the freezer; $-30^{\circ} \mathrm{C}$. The black needle like crystals were not easily isolated; they began to melt as the temperature began to approach room temperature.

\section{$\left.\mathrm{TiCl}_{3} 3 \mathrm{THF}+3 \mathrm{Li}\left[{ }^{i} \operatorname{PrHNC}\left(\mathrm{N}^{i} \mathrm{Pr}\right)_{2}\right] \rightarrow \mathrm{Ti}^{i} \operatorname{PrHNC}\left(\mathrm{N}^{i} \operatorname{Pr}\right)_{2}\right]_{3}+3 \mathrm{LiCl}$}

This reaction was repeated several times at room temperature to attempt to collect the low melting solid previously seen. However, the colour of the solution (black) and the lack of precipitate led to believe that there were competing reactions, possibly $\beta$-hydride elimination from a guanidinate ligand occurring during synthesis. The reaction was attempted at lower temperatures outside the dry box, using Schlenk techniques. The lithiated tripyl was added slowly at $-78^{\circ} \mathrm{C}$ over the period of an hour. The reaction was allowed to stir at low temperatures and slowly warm up to room temperature. The reaction was executed with careful control producing the same black solution. Volatiles 
were removed under vacuum and the black paste was redissolved in minimal diethyl ether, filtered to remove any insoluble products and placed in the freezer for a long period of time. No solids were ever isolated.

\subsubsection{Thermolysis}

Only one melting point was obtained from the two paramagnetic homoleptic titanium precursors. TG analysis showed compound $\mathbf{1 6}$ to decompose with large residual mass and relatively low on-set of volatility (Figure 5-5 and Table 5-3). Compound 16 was found to have an on-set of volatility of $98^{\circ} \mathrm{C}$. From the derivative weight curve it was clear that three thermal events occurred. These thermal events occurred at temperature ranges of $97.9-124.4^{\circ} \mathrm{C}, 124.4-163.3^{\circ} \mathrm{C}$ and $163.3-232.8^{\circ} \mathrm{C}$ which can be attributed to a slow thermal degradation of the compound. The residual mass was high, $15.1 \%$ at $232.8^{\circ} \mathrm{C}$, which most likely corresponded to the mass of a decomposed species. The TG curve was not characteristic of volatilization as it had a very slow and gradual slope. The derivative weight curve did not show the characteristic asymmetry of a slow on-set and quick drop-off. The rather gradual drop-off led to believe that decomposition was occurring within the TG pan. It was suspected that one of the thermal events was the deinsertion of CDI and so an NMR tube boil-up experiment was performed.

Table 5-3. Yield and thermal parameters of compounds 16 - 18.

\begin{tabular}{ccccc}
\hline Compound & $\mathbf{R}$ & $\begin{array}{c}\text { Percent Yield } \\
(\mathbf{\%})\end{array}$ & $\begin{array}{c}\text { Melting Point } \\
\left({ }^{\circ} \mathbf{C}\right)\end{array}$ & $\begin{array}{c}\text { On-set of } \\
\text { Volatility }\left({ }^{\circ} \mathbf{C}\right)^{a}\end{array}$ \\
\hline \hline $\mathbf{1 6}$ & $\mathrm{NMe}_{2}$ & 59 & $211-213$ & 98 \\
$\mathbf{1 7}$ & $\mathrm{NH}^{i} \mathrm{Pr}$ & N/A & Low melting & N/A \\
$\mathbf{1 8}$ & $\mathrm{NH}^{i} \mathrm{Pr}$ & 24 & solid & N/A \\
\hline
\end{tabular}

\footnotetext{
${ }^{a}$ on-set of volatility was taken as $5 \%$ mass loss
} 


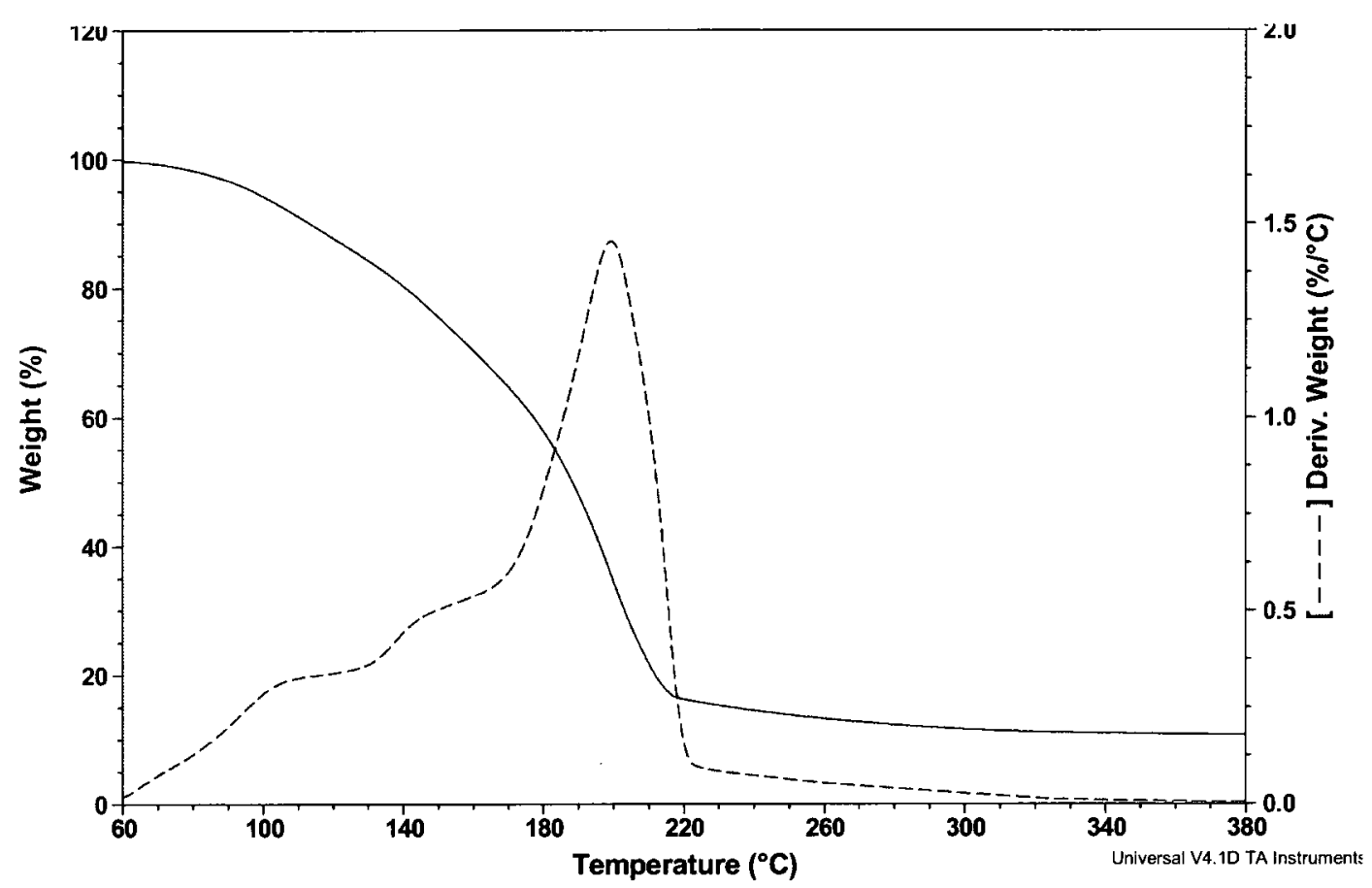

Figure 5-5. Thermal gravimetric analysis of 16.

The complex was dissolved in $0.25( \pm 6) \mathrm{mL}$ of $\mathrm{C}_{6} \mathrm{D}_{6}$ solution in a thick-walled NMR tube under inert atmosphere. The tube was immersed in liquid $\mathrm{N}_{2}$ and the glass tube was sealed under vacuum. The tube was placed in a furnace starting at $50^{\circ} \mathrm{C}$ and the temperature increased to $160^{\circ} \mathrm{C}$ over several days to observe possible CDI growth. On the third day at a temperature of $70^{\circ} \mathrm{C}$ compound 16 demonstrated the presence of CDI by ${ }^{1} \mathrm{H}$ NMR. The characteristic multiplet and doublet at 3.33 and $1.04 \mathrm{ppm}$ was first observed at $70^{\circ} \mathrm{C}$ and the intensity increased as the temperature increased for the duration of the experiment. The presence of CDI was not a surprise as it has been known to deinsert from amidinate or guanidinate ligands at elevated temperatures. ${ }^{16}$ 


\subsubsection{Preliminary CVD Reactions}

Even though compound 16 did not seem like the ideal candidate for ALD from the thermolysis studies, it was thought that it could be a suitable candidate for CVD of TiN films. Titanium nitride films have been produced by a single source method for over a decade using different alkyl amines and hydrazine-derived nitrogen sources. ${ }^{4,5,17}$ However, to this date there have not been TiN films deposited from guanidinate titanium (III) complexes. Thus it would be interesting to see if this tris(dimdip) guanidinate complex can be used as a SSP to deposit TiN thin films. The compound was sublimed at $110^{\circ} \mathrm{C}$ and used as the pure form. The same $\mathrm{N}$-doped $\mathrm{Si}(100)$ substrates, cleaning procedures for the substrates, and ALD reactor were used as in Chapter 4 (Figure 4-5) with the exception of the pulse sequence used.

The pulse sequence of this experiment was:

1. 5.0 s fill $\mathrm{Ti}\left[\mathrm{Me}_{2} \mathrm{NC}\left(\mathrm{N}^{\mathrm{i}} \mathrm{Pr}\right)_{2}\right]_{3}$ bubbler with $\mathrm{N}_{2}$

2. $5.0 \mathrm{~s} \mathrm{Ti}\left[\mathrm{Me}_{2} \mathrm{NC}\left(\mathrm{N}^{\mathrm{i}} \mathrm{Pr}\right)_{2}\right]_{3}$ introduction to reaction chamber

3. $10.0 \mathrm{~s}$ evacuation

This cycle was repeated 1000 times. The starting mass of the titanium precursor was $0.9 \mathrm{~g}$.

All the temperatures within the reactor varied throughout the experiment as no film was observed after each run. The first experiment conducted had the bubbler set to $85^{\circ} \mathrm{C}$ with a gradual temperature gradient throughout the reactor to prevent condensation of the precursor within the reactor. Line $\mathrm{C}$ (Figure 4-5) was set to $95^{\circ} \mathrm{C}$, the valve array system and line $\mathrm{E}$ were set to $105^{\circ} \mathrm{C}$ and the furnace was set to $300^{\circ} \mathrm{C}$. The slides were placed on a stainless steel holder and positioned at the centre of the furnace where the temperature 
of the furnace was seen to be more precise. After the first experiment was finished, the slides (S4 and S4.1) were taken out of the furnace with no observable change.

The temperature was increased by $15^{\circ} \mathrm{C}$ throughout the system for the second deposition experiment. The pulse sequence, the furnace temperature and the placement of the slides remained the same with the only change being the addition of a glass substrate. The new substrate was cleaned using the same method as the $\mathrm{Si}(100)$ substrate. The Si(100) slide (S5) and the glass slide (S5.1) had undergone minimal change as evidence of contamination from the apparatus occurred and no obvious TiN was formed.

Increasing the temperature throughout the system by an extra $30^{\circ} \mathrm{C}$ with the furnace temperature constant produced no obvious films. The bare $\operatorname{Si}(100)$ substrates (S6) and the results from the previous two depositions (S4 and S5) were taken to get the surface composition analyzed.

The lack of titanium on all three slides (S4, S5, and S6) was confirmed using an EDS (Cameca Camebox) that was concomitant with the SEM (Joel 840). The energies of oxygen and silicon at $0.532 \mathrm{keV}$ and $1.839 \mathrm{keV}$, respectively ${ }^{9 \mathrm{~b}}$ were the only signals observed.

When the bubbler was taken off the reactor and the vial with the titanium precursor weighed, a loss of $0.17 \mathrm{~g}$ was observed. The titanium precursor was no longer a dark green material but a black material. It appeared as though the material had melted as it conformed to the shape of the vial. The material was analyzed by MS and no parent peak was observed. The small weight loss throughout the experiment could have been associated with thermal decomposition. The deposition experiments performed were merely preliminary. A substantial amount of time and dedication would be necessary in 
order to achieve a proper film; however this compound demonstrated that it was not an excellent candidate for such extensive studies as it was not volatile and its thermal stability was limited.

\subsection{Conclusion}

This work presented the synthesis, structural characterization and thermolysis of new monomeric homoleptic titanium (III) complexes in low yields. Two crystal structures were obtained; one for the tris(dimdip) titanium species $\mathbf{1 6}$ along with a serendipitous bis(tripyl) titanium mono chloride structure 18. Preliminary thermolyses (TG) of compound 16 demonstrated that it decomposed slowly as the temperature increased. Further thermal investigations were conducted using a sealed NMR tube to study the decomposition of the compounds using ${ }^{1} \mathrm{H}$ NMR. It was found that $\mathbf{1 6}$ was not stable at elevated temperatures in solution as CDI peaks were observed by ${ }^{1} \mathrm{H}$ NMR after 3 days of the study, demonstrating CDI deinsertion. It was thought that $\mathbf{1 6}$ could decompose to make TiN films by means of a single source thus CVD was attempted. The results of the CVD experiments demonstrated that this compound showed poor volatility and thermal stability. These important requirements for CVD precursors were not satisfied and thus 16 would not be a likely titanium-containing precursor for chemical vapour deposition techniques. 


\subsection{Methods and Materials}

All manipulations were performed in a nitrogen filled dry box, unless otherwise specified. The chemicals: isopropyl amine, lithium dimethyl amide, methyl lithium, 1,3diisopropyl carbodiimide and titanium (III) chloride tetrahydrofuran complex (1:3) were purchased from Aldrich Chemical Company and used as received. All solvents used were reagent grade purified from an MBraun Solvent Purifier System. The monoanionic ligand synthesis of $\left[\mathrm{Me}_{2} \mathrm{NC}\left(\mathrm{N}^{i} \mathrm{Pr}\right)_{2}\right] \mathrm{Li}$ and $\left[{ }^{i} \operatorname{PrHNC}\left(\mathrm{N}^{i} \mathrm{Pr}\right)_{2}\right] \mathrm{Li}$ followed literature procedures. ${ }^{18}$ Nuclear Magnetic Resonance was done on a 300MHz Avance III. Mass spectra were obtained using the electron impact method on a VG ZAB-2HF triplefocusing spectrometer. Thermogravimetric analysis was performed on a TA Instruments Q50 apparatus located within a Labmaster 130 Dry box. Differential Scanning Calorimetery was performed on a DSC Instruments Q10 apparatus. Single crystal XRD was conducted on a Bruker-AXS APEX CCD Diffractometer located at Delaware University with the help of Glenn P. Yap.

\subsubsection{Tris(dimethylamide diisopropyl guanidinate) titanium, 16}

In a $60 \mathrm{~mL}$ round bottom flask, $0.50 \mathrm{~g}(1.35 \mathrm{mmol})$ of titanium (III) chloride tetrahydrofuran complex (1:3) was weighed and then suspended in $20 \mathrm{~mL}$ of diethyl ether. While this mixture was stirring at room temperature $0.72 \mathrm{~g}(4.05 \mathrm{mmol})$ of dimdip was added drop-wise. The ligand was made 2 hours prior to the reaction and was then added in situ. The suspended mixture was an opaque yellowish-green solution and as the ligand was added drop-wise the solution changed from an opaque yellowish-green to an army green colour. The reaction was allowed to stir at room temperature for 16 hours, 
after which it was filtered to remove any $\mathrm{LiCl}$ that precipitated out. The green solution was evacuated to dryness in vacuo and then redissolved in about $1 \mathrm{~mL}$ of diethyl ether and placed in the freezer. After 1 hour dark green crystals precipitated out of solution. The crystals were allowed to grow over night in the freezer after which, $0.44 \mathrm{~g}(0.80$ mmol) were collected in the morning. This resulted in a 59\% yield. A melting point of $211-213^{\circ} \mathrm{C}$ was observed. The crystals were dissolved in deuterated benzene to take an NMR, however since the complex was paramagnetic, no clear spectra was collected. Mass spectral data $(\mathrm{EI}, \mathrm{m} / \mathrm{z})\left(\right.$ rel. intensity, \%): $558\left(\mathrm{M}^{+}, 19\right)$.

\subsubsection{Tris(triisopropyl guanidinate) titanium, 17}

The same reaction procedure as $\mathbf{1 6}$ was used substituting the previous guanidinate with triisopropyl guanidinate. The opaque black solution was evacuated to dryness in vacuo and then redissolved in about $3 \mathrm{~mL}$ of diethyl ether and placed in the freezer. Black needle like crystals were obtained after 16 hours. The crystals began to melt as the temperature approached room temperature while trying to isolate them on a kim wipe. The reaction was repeated at $-78^{\circ} \mathrm{C}$ using solid $\mathrm{CO}_{2}$ and acetone mixture. The lithiated guanidinate was slowly added through the use of an air free funnel. The reaction was allowed to proceed for 16 hours with an over pressure of nitrogen. Volatiles were removed under reduced pressure to afford a black paste. The black paste was dissolved in a minimal amount of diethyl ether, filtered to remove any insoluble substances and placed in the freezer. No solids were isolated. 


\subsubsection{Bis(triisopropyl guanidinate) titanium chloride, 18}

The same reaction procedure as $\mathbf{1 6}$ was used substituting the previous guanidinate with triisopropyl guanidinate and a decreased equivalence of the ligand. Ratios were $1.00 \mathrm{~g}(2.70 \mathrm{mmol})$ of titanium to $1.03 \mathrm{~g}(5.40 \mathrm{mmol})$ of lithiated ligand. Volatiles were removed and the remaining brownish-red solid was dissolved in a minimal amount of diethyl ether and placed in the freezer overnight. $0.3 \mathrm{~g}(0.66 \mathrm{mmol}, 24 \%$ yield $)$ of brownish-red crystals were isolated from the first batch of crystallization. Mass spectral data (EI, $m / z)\left(\right.$ rel. intensity, \%): $451\left(\mathrm{M}^{+}, 25\right)$.

\subsection{Structural Determination for Compounds 16 and 18}

Suitable crystals were mounted with viscous oil on a plastic mesh and cooled to the data collection temperature. Unit cell parameters were determined using data frames from four different sections of the Ewald sphere. SADABS multi-scan absorption corrections were applied. No symmetry higher than cubic was observed for compound 16 and monoclinic for compound 18. Solution in the space group option, I-43d, yielded chemically reasonable and computationally stable results of refinement for $\mathbf{1 6}$ and the centrosymmetric space group option $\mathrm{P} 2{ }_{1} / \mathrm{c}$ for 18 . The structures were solved using direct methods and refined with full matrix least squares procedures of $\mathrm{F}^{2}$ data. All hydrogen atoms were treated as idealized contributions and all non-hydrogen atoms were refined with anisotropic displacement coefficients. Atomic scattering factors are contained in the SHELXTL program library. 


\subsection{References}

${ }^{1}$ Ritch, J.S., Chivers, T., Afzaal, M., O'Brien, P.; Chem. Soc. Rev., 2007, 36, 1622.

${ }^{2}$ Sugiyama, K., Pac, S., Takahashi, Y., Motojima, S.; J. Electro-chem. Soc., 1975, 122, 1545.

${ }^{3}$ Fix, R., Gordon, R.G., Hoffman, D.M.; Chem. Mater., 1990, 2, 235. Winter, C.H., Sheridan, P.H., Lewkebandara, T.S., Heeg, M.J., Proscia, J.W.; J. Am. Chem. Soc., 1992, 114, 3, 1095.

${ }^{4}$ Beaudoin, M., Scott, S.L., Organomet., 2001, 20, 2, 237.

${ }^{5}$ Carmalt, C.J., Newport, A.C., Parkin, I.P., White, A.J.P., Williams, D.J.; J. Chem. Soc., Dalton Trans., 2002, 4055.

${ }^{6}$ Winter, C.H., Sheridan, P.H., Lewkebandara, T.S., Heeg, M.J., Proscia, J.W.;

J. Am. Chem. Soc., 1992, 114, 3, 1095.

${ }^{7}$ Wasslen, Y.A., Tois, E., Haukka, S., Kreisel, K.A., Yap, G.P.A., Halls, M.D., Barry, S.T.; Inorg. Chem, 2010, 49, 1976.

${ }^{8}$ Alonso, P.J., Falvello, L.R., Fornies, J., Garcia-Monforte, M.A., Menjon, B.; Angew. Chem. Int. Ed., 2004, 43, 5225 .

${ }^{9}$ Ong, T.G., Yap, G.P.A., Richeson, D.S.; J. Am. Chem. Soc., 2003, 125, 8100.

${ }^{10}$ Macaulay, R., Burnelle, L.A., Sandorfy, C.; Theoret. Chim. Acta. (Ber.)., 1973, $29,1$.

${ }^{11}$ Addison, A.W., Nageswara Rao, T., Reedijk, J., van Rijn, J., Verschoor, G.C.; J. Chem. Soc .Dalton

Trans., 1984, 1349.

${ }^{12}$ Lukesova, L., Horacek, M., Stepnicka, P., Fejfarova, K., Gyepes, R., Cisarova, I., Kubista, J., Mack, K.; J. Organomet. Chem., 2002, 663, 134.

${ }^{13}$ Hagadorn, J. R.; Arnold, J. Organometallics 1998, 17, 1355.

${ }^{14}$ Bailey, P.J., Pace, S.; Coord. Chem. Rev., 2001, 214, 91.

${ }^{15}$ DiLabio, G. A.; Litwinienko, G.; Shuquiong, L. S.; Pratt, D. A.; Ingold, K. U. J. Phys. Chem. A, 2002, 106, 11719.

${ }^{16}$ Brazeau, A.L.; Wang, Z.; Rowley, C.N.; Barry, S.T., Inorg. Chem., 2006, 45, 2276.

${ }^{17}$ (a) Scheper, J.T., McKarns, P.J., Lewkebandara, T.S., Winter, C.H.; Mater. Sci. Semiconduct. 
Processing, 1999, 2, 149. (b) Wu, M.; J.Alloys Comp., 2009, 486, 1-2, 223.

${ }^{18}$ Aeilts, S.L., Coles, M.P., Swenson, D.C., and Jordan, R.F., Organomet, 1998, 17(15), 3265. 


\section{Chapter 6:}

\section{Heteroleptic Amido Iminopyrrolidinato Titanium (IV) Complexes}

\subsection{Introduction}

The reactivity of an organometallic compound is controlled to a large extent by the ancillary ligands bound to it. Amidinates and guanidinates have proven to be versatile supporting ligands in organometallic and coordination chemistry. ${ }^{1} \quad$ They have found use in many fields of chemistry including catalysis ${ }^{2}$ and film deposition ${ }^{3}$. Iminopyrrolidinato ligands have been synthesized and used as spectator ligands for titanium half sandwich complexes which are known to be pre-catalysts for the inter- and intramolecular hydroamination of alkynes. ${ }^{4}$

Interestingly iminopyrrolidinate ligands have not been studied in thin film deposition as of yet. There are similarities between amidinates and iminopyrrolidinates that make them an interesting avenue to explore. Both ligands are bidentate (capable of protecting the metal centre), highly volatile when protonated (great for reducing impurities within deposited films), and are versatile (the steric and electronic properties can be easily tuned). The ip ligands introduced in Chapter 2 have demonstrated an advantage over amidinates; a predictable melting point trend can be reached by altering the R-group. The ligand melting point trend can be carried through once introduced to a metal centre. This valuable quality can be very useful in the synthesis of precursors for thin film 
deposition. This chapter introduces the synthesis of three heteroleptic titanium (IV) compounds along with their preliminary thermolyses.

\subsection{Results and Discussion}

\subsubsection{Synthesis and Crystal Structure Data}

Three heteroleptic amido iminopyrrolidinate titanium (IV) complexes were synthesized and isolated in reasonable yields (Table 6-1) from $\mathrm{Ti}\left(\mathrm{NMe}_{2}\right)_{4}$ and appropriate iminopyrrolidine starting materials. It was found that the compounds formed rather quickly (within four hours) at room temperature or at $-20^{\circ} \mathrm{C}$; with the starting titanium species changing from a characteristic yellow solution to an orange/red solution. For each compound the volatiles were removed under vacuum; the orange/red solid was redissolved in diethyl ether and placed in the freezer to promote crystallization. Red crystals were isolated for each compound. Compound 19 produced crystals of sufficient quality for a single crystal structure to be collected (Figure 6-1, Table 6-2 and Table 6-3).

Table 6-1. Yield and thermal parameters for compounds 19 - 21.

\begin{tabular}{lcccc}
\hline R & $\begin{array}{c}\text { Percent Yield } \\
(\mathbf{\%})\end{array}$ & $\begin{array}{c}\text { Melting Point } \\
(\mathbf{O} \mathbf{C})\end{array}$ & $\begin{array}{c}\text { Residual } \\
\text { Mass (\%) }\end{array}$ \\
\hline \hline $\mathbf{1 9}$ & ipip & 87 & $130-132$ & 16.5 \\
$\mathbf{2 0}$ & sbip & 43 & $112-114$ & 14.1 \\
$\mathbf{2 1}$ & tbip & 81 & Decomposed $>120$ & 17.5 \\
\hline
\end{tabular}

Amine elimination was the driving force for these reactions (Scheme 6-1). An interesting result occurred while attempting to produce mono and tris ipip titanium complexes. Appropriate stoichiometric amounts of ipip (i.e. 1 or 3 equivalents) were 
added to the starting titanium species and let to react overnight. The resultant pink solid was dissolved in minimal amounts of pentane and was then filtered to remove any insoluble solids. The resultant red solution was placed in the freezer and crystals of compound 19 were isolated from both reactions, demonstrating a thermodynamic preference for a bis-iminopyrrolidinate titanium species. This interesting result has occurred in the synthesis of similar iminopyrrolidinate titanium (IV) complexes by Gade et al. ${ }^{5}$

Scheme 6-1. Synthesis of heteroleptic titanium complexes.

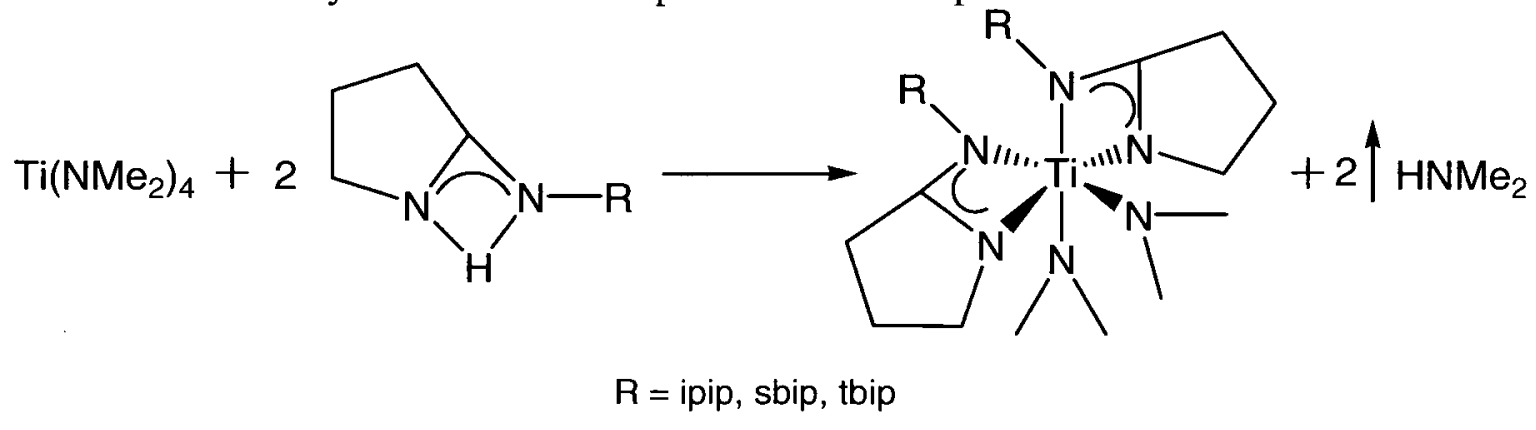

A similar result occurred during the synthesis of compound 21, when an excess amount of tbip ligand was added to the reaction. The resulting ${ }^{1} H$ NMR showed the presence of the desired $\mathbf{2 1}$ along with excess tbip. The sample was placed in a sublimation apparatus and the ligand was removed under low temperature sublimation, $45^{\circ} \mathrm{C}$. Pure thip was isolated on the cold finger of the sublimation apparatus and pure $\mathbf{2 1}$ was left unsublimed.

The reaction for compound $\mathbf{2 0}$ was done at lower temperatures to prevent possible formation of a racemic mixture and was deemed to be a success as the NMRs were clean and the melting point was sharp. The ${ }^{1} \mathrm{H}$ and ${ }^{13} \mathrm{C}$ NMR of compounds 19 and 21 were 
similar in their simplicity. The ${ }^{1} \mathrm{H}$ and ${ }^{13} \mathrm{C}$ NMR for compound 20 was a little more complicated as the stereocentre of the sbip ligand was evident.

Compound 19 was a six coordinate titanium species in a distorted octahedral geometry. It had a P-1 space group with a $\mathrm{C}_{2}$ symmetry which explains the simplicity of the ${ }^{1} \mathrm{H}$ NMRs. The ip ligands were found cis to each other as was seen in other similar structures from Gade et al. ${ }^{5}$ The bite angle for the ipip ligands were $61.9^{\circ}$ for N1-Ti-N2 and $62.1^{\circ}$ for $\mathrm{N} 3-\mathrm{Ti}-\mathrm{N} 4$. These angles were a slightly larger than previously reported iminopyrrolidinate titanium structures ranging from $61.1^{\circ}$ and $61.8^{\circ} .5$ The amido angle (N5-Ti-N6) was thus slightly smaller at $96.2^{\circ}$ than the reported structures with angles of $97.4^{\circ}$ and $101.1^{\circ}$. The ipip-titanium metallocycle was close to planar at $0.7^{\circ}$ for $\mathrm{Ti}-\mathrm{N} 1-$ C4-N2 and $3.4^{\circ}$ for Ti-N3-C11-N4.

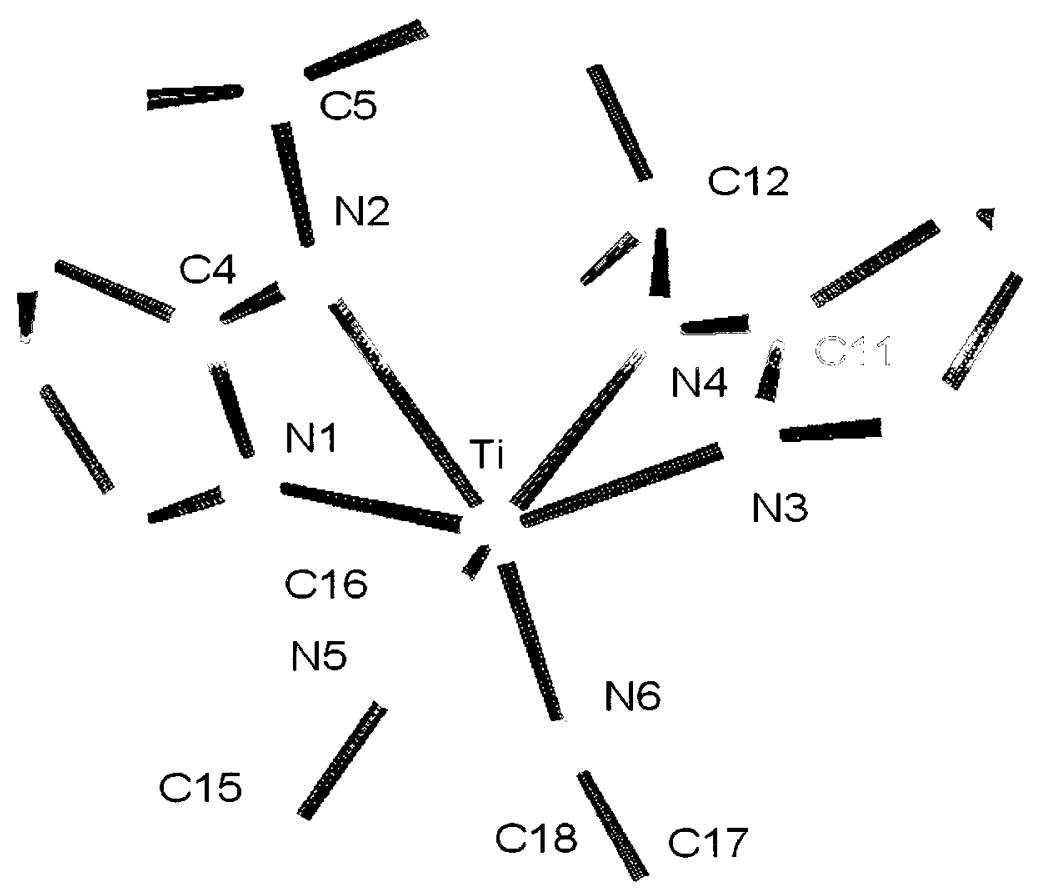

Figure 6-1. The single-crystal X-ray structure of compound 19. The thermal ellipsoids are shown at $50 \%$ probability and the hydrogen centres are omitted for clarity. 
The Ti-N bonds varied from $1.92-2.27 \AA$, with both amido (Ti-N5 and Ti-N6) lengths being the shortest at $1.92 \AA$. The nitrogens trans to the amido species (N2 and N4) were the longest distances at 2.27 and $2.22 \AA$. The lengthening of these bonds may be caused by the participation of the lone pair from the amido nitrogens to the titanium forcing the Ti-N bond lengths trans to the amido species to elongate.

The C-N bonds within the chelate ring showed participation in the $\pi$-system as their bond lengths were much shorter, ranging from $1.30-1.34 \AA$ compared to the $\mathrm{C}-\mathrm{N}$ distance on the exocyclic nitrogen $\mathrm{N} 2-\mathrm{C} 5$ and $\mathrm{N} 4-\mathrm{C} 12$ at 1.48 and $1.46 \AA$. The $\mathrm{C}-\mathrm{N}$ lengths of the amido species were within range of single $\mathrm{C}-\mathrm{N}$ distances of $1.479 \AA$ and were nearly indistinguishable at values ranging from $1.44-1.45 \AA$. These distances demonstrated that $\mathrm{N} 1, \mathrm{~N} 2, \mathrm{~N} 3$ and $\mathrm{N} 4$ were all participating in the $\pi$-system with $\mathrm{C} 4$ and C11; the distances were within C-N resonance bond lengths given by Allen et al. ${ }^{6}$

Table 6-2. Selected crystal data for compound 19.

\begin{tabular}{cc}
\hline Empirical Formula & $\mathrm{C}_{18} \mathrm{H}_{38} \mathrm{~N}_{6} \mathrm{Ti}$ \\
\hline \hline $\mathrm{FW}$ & 386.44 \\
Crystal System & Triclinic \\
Space Group & $\mathrm{P}-1$ \\
$a(\AA)$ & $8.732(2)$ \\
$b(\AA)$ & $16.114(4)$ \\
$c(\AA)$ & $17.358(4)$ \\
$\alpha(\mathrm{deg})$ & $63.344(3)$ \\
$\beta(\mathrm{deg})$ & $83.829(4)$ \\
$\gamma(\mathrm{deg})$ & $83.848(4)$ \\
$\mathrm{V}\left(\AA^{3}\right)$ & $2165.4(9)$ \\
$\mathrm{Z}$ & 4 \\
$\mathrm{D}_{\mathrm{c}}(\mathrm{kg} / \mathrm{L})$ & 1.185 \\
$\left.\mu(\mathrm{mm})^{-1}\right)$ & 0.408 \\
$\mathrm{~T}(\mathrm{~K})$ & $200(2)$ \\
$\mathrm{R}, \mathrm{wR}$ & $0.0668,0.1336$ \\
Goodness-of-fit on $\mathrm{F}^{2}$ & 1.021 \\
\hline
\end{tabular}


The sum of angles around the nitrogens were very close to planar $(\mathrm{N} 1, \mathrm{~N} 2$, and $\mathrm{N} 3=$ $360^{\circ}$ and $\mathrm{N} 4=358^{\circ}$ ). The sum of angles around $\mathrm{C} 4$ and $\mathrm{C} 11$ were $360^{\circ}$ also demonstrating planarity and thus participation in the $\pi$-system. The sum of angles around the amido nitrogens N5 and N6 were also $360^{\circ}$ demonstrating the participation of the lone pairs of the nitrogens to the titanium species.

Table 6-3. Selected bond lengths and angles for compound 19.

\begin{tabular}{|c|c|c|c|}
\hline \multicolumn{4}{|c|}{ Selected Bond Lengths $(\stackrel{\AA}{A})$} \\
\hline Ti-N1 & $2.0735(17)$ & $\mathrm{N} 2-\mathrm{C} 5$ & $1.457(2)$ \\
\hline Ti-N2 & $2.2682(17)$ & $\mathrm{N} 3-\mathrm{C} 11$ & $1.335(3)$ \\
\hline Ti-N3 & $2.0766(17)$ & $\mathrm{N} 4-\mathrm{C} 11$ & $1.304(3)$ \\
\hline Ti-N4 & $2.2243(17)$ & $\mathrm{N} 4-\mathrm{C} 12$ & $1.463(2)$ \\
\hline Ti-N5 & $1.9194(17)$ & $\mathrm{N} 5-\mathrm{C} 15$ & $1.448(3)$ \\
\hline Ti-N6 & $1.9204(17)$ & $\mathrm{N} 5-\mathrm{C} 16$ & $1.445(3)$ \\
\hline $\mathrm{N} 1-\mathrm{C} 4$ & $1.344(2)$ & N6-C17 & $1.453(3)$ \\
\hline $\mathrm{N} 2-\mathrm{C} 4$ & $1.301(2)$ & N6-C18 & $1.453(3)$ \\
\hline \multicolumn{4}{|c|}{ Selected Bond Angles $\left(^{\circ}\right)$} \\
\hline N1-Ti-N2 & $61.91(6)$ & N3-C11-N4 & $114.86(17)$ \\
\hline N3-Ti-N4 & $62.17(6)$ & Ti-N3-C11 & $94.24(12)$ \\
\hline N5-Ti-N6 & $96.25(8)$ & Ti-N4-C11 & $88.59(12)$ \\
\hline $\mathrm{N} 1-\mathrm{C} 4-\mathrm{N} 2$ & $115.72(17)$ & Ti-N4-C12 & $148.46(14)$ \\
\hline Ti-N1-C4 & $94.87(11)$ & $\mathrm{C} 11-\mathrm{N} 4-\mathrm{C} 12$ & $121.42(17)$ \\
\hline Ti-N2-C4 & $87.49(12)$ & $\mathrm{C} 15-\mathrm{N} 5-\mathrm{C} 16$ & $111.27(18)$ \\
\hline Ti-N2-C5 & $151.78(13)$ & $\mathrm{C} 17-\mathrm{N} 6-\mathrm{C} 18$ & $110.68(18)$ \\
\hline $\mathrm{C} 4-\mathrm{N} 2-\mathrm{C} 5$ & $120.70(17)$ & & \\
\hline \multicolumn{4}{|c|}{ Sum of Angles ( $\left(^{\circ}\right)$} \\
\hline N1 & 359.88 & $\mathrm{~N} 4$ & 358.47 \\
\hline $\mathrm{N} 2$ & 359.97 & N5 & 359.79 \\
\hline N3 & 359.96 & N6 & 359.87 \\
\hline
\end{tabular}

\subsubsection{Thermolysis}

Preliminary thermolyses (TGs) were conducted on each compound. Unfortunately, each experiment showed complicated and incomplete thermolysis as seen in Figure 6-2. 
Compound 19 had two thermal events. The first event occurred at a temperature range of $151-193^{\circ} \mathrm{C}$. This event may have been the thermal decomposition of the starting material into a compound that was more volatile, as the second thermal event had a characteristic volatilization curve as seen by the derivative weight curve (Figure 6-3). The second thermal event occurred at a range of $193-350^{\circ} \mathrm{C}$ resulting in a residual mass of $16 \%$. With a rather high residual mass and a complicated volatilization curve this compound would not be a good candidate for either CVD or ALD.

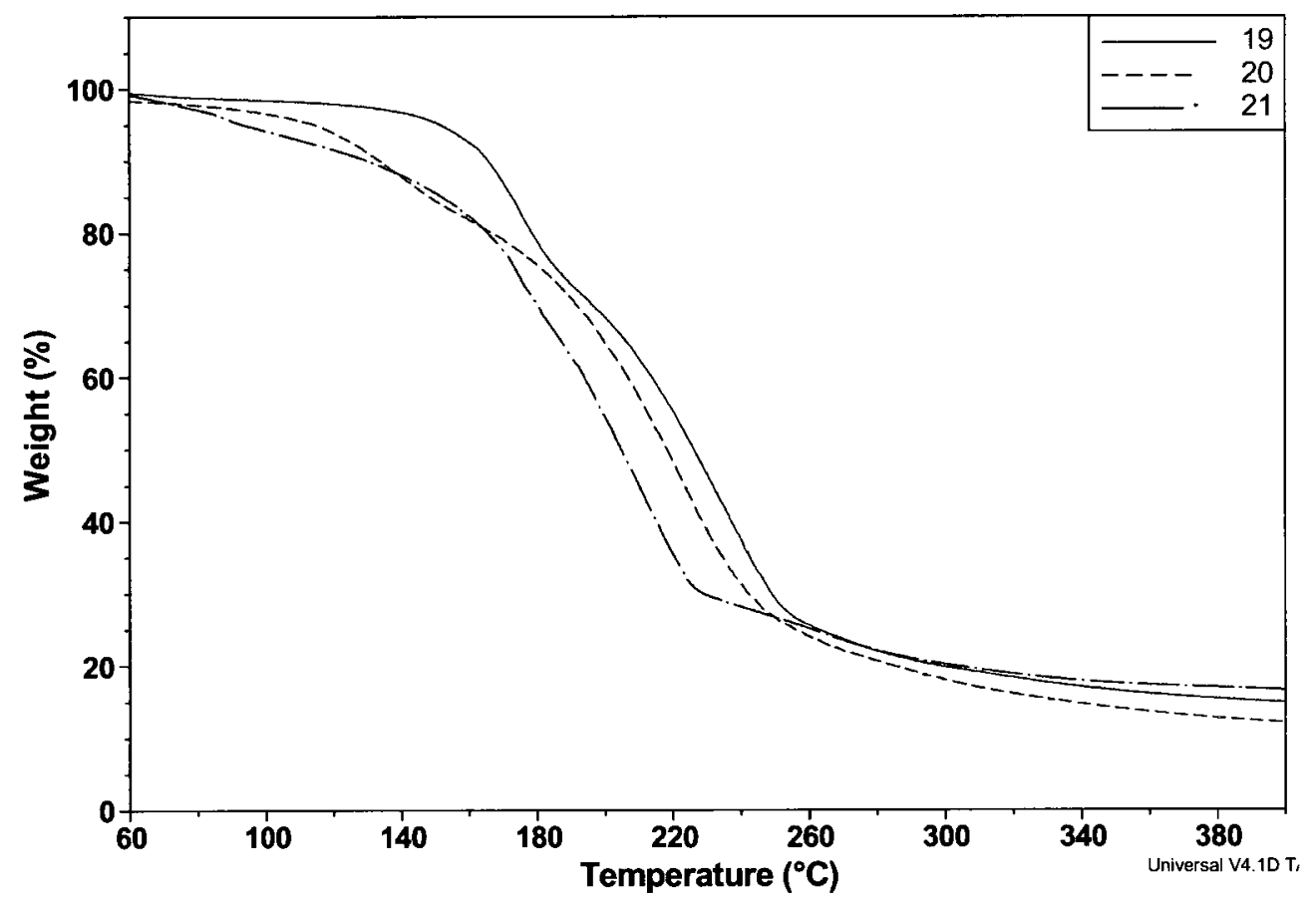

Figure 6-2. Thermal gravimetric analysis of 19 - 21. 


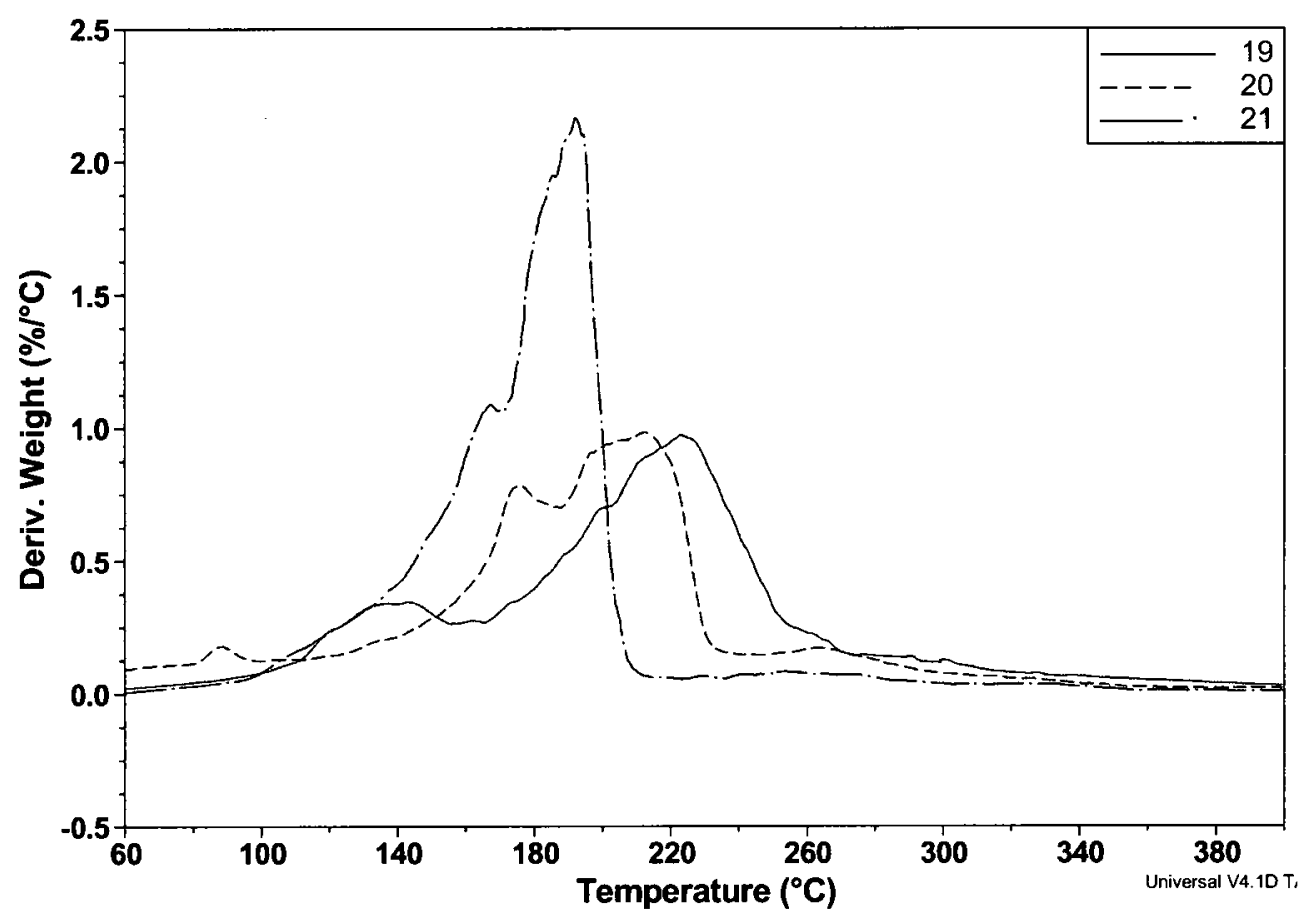

Figure 6-3. Differential weight curve for compounds 19 - 21.

Compound 20 had an on-set of volatility of $122^{\circ} \mathrm{C}$ and two thermal events observed in the derivative weight curve (Figure 6-3). The first thermal event occurred at a temperature range of $122-162^{\circ} \mathrm{C}$. This event was characteristic of decomposition as the derivative weight curve (Figure 6-3) was broad and very symmetrical. The second thermal event occurred at a range of $162-350^{\circ} \mathrm{C}$ and showed a characteristic volatilization curve of the thermalized material, as it had an asymmetric peak demonstrating a slow on-set and a quick drop-off as the thermalized species volatilized off the pan. The residual mass for compound 20 was a little lower at $14 \%$, resulting from a thermalized species volatilizing away and leaving behind a decomposed product.

Compound 21 had an on-set of volatility of $92^{\circ} \mathrm{C}$ and a complicated TG with three thermal events. The first feature occurred at a temperature range of $92-187^{\circ} \mathrm{C}$, the second feature occurred at $187-244^{\circ} \mathrm{C}$ and the third event occurred at $244-377^{\circ} \mathrm{C}$. Each 
of these events were observed as thermal decompositions as neither of the events had a derivative weight curve (Figure 6-3) characteristic of volatilization.

An NMR tube boil up was performed on compound 19 to discern the nature of the thermolysis. The complex was dissolved in $0.25( \pm 6) \mathrm{mL}$ of $\mathrm{C}_{6} \mathrm{D}_{6}$ solution in a thickwalled NMR tube under inert atmosphere. The tube was immersed in liquid $\mathrm{N}_{2}$ and the glass tube was sealed under vacuum. The tube was placed in a furnace at $58^{\circ} \mathrm{C}$ to observe the stability of the complex. At this temperature a new amido peak was observed at 3.33 ppm as well as a new isopropyl doublet at $1.042 \mathrm{ppm}$ along with new ring environments. The new peaks present may be attributed to a loss of symmetry, indicating a change in the geometry of the complex from cis to trans. After 2 days the temperature was increased to $94^{\circ} \mathrm{C}$ which increased the intensity of the amido singlet and the isopropyl doublet. This result along with the complicated TG demonstrated that 19 would not be a suitable compound for thin film deposition.

In Chapter 2, the iminopyrrolidine ligands were found to import their melting point trend to the heteroleptic aluminum family (Table 2-5). It was thought that the introduction of these ligands to titanium species would help to control thermal properties such as melting points by varying the R-group. This trend was arguably visible within the heteroleptic titanium species synthesized in this chapter as the ipip complex had a melting point of $130-132^{\circ} \mathrm{C}$, the sbip complex had a melting point of $112-114^{\circ} \mathrm{C}$ and the tbip complex decomposed at $>120^{\circ} \mathrm{C}$. The ligands as well as the aluminum complexes demonstrated a dip in the melting point trend for sbip as it had a stereocentre and the tbip ligand had the highest melting point as seen in Table 2-2 and Table 2-5 in Chapter 2. 


\subsection{Conclusions}

Three heteroleptic amido iminopyrrolidinate titanium (IV) complexes were synthesized in relatively high yields ranging from 50 to $87 \%$. Compound 19 was isolated as red needle like crystals with a triclinic crystal system and a P-1 space group. The melting point trend present in the iminopyrrolidine ligands was visible within the heteroleptic titanium complexes. Preliminary thermolyses (TGs) were conducted on all three compounds and resulted in complicated stepwise thermal decomposition. Unfortunately these heteroleptic compounds would find no use in thin film deposition techniques; however they may find use in other branches of chemistry such as catalysis.

\subsection{Methods and Materials}

All manipulations were performed in a nitrogen filled drybox unless otherwise stated. The chemicals: 2-pyrrolidinone, phosphorous pentoxide, isopropyl amine, sec-butyl amine, tert-butyl amine, lithium dimethyl amide and titanium tetrachloride were purchased from Aldrich Chemical Company and used as received. All solvents used were reagent grade purified from an MBraun Solvent Purifier System. All iminopyrrolidine ligands were synthesized following literature procedures. ${ }^{7}$ Mass spectra were obtained using the electron impact method on a VG ZAB-2HF triple-focusing spectrometer. Thermal gravimetric analysis was performed on a TA Instruments Q50 apparatus located within a Labmaster 130 Dry box. Differential Scanning Calorimetry was performed on a DSC Instruments Q10 apparatus. Nuclear Magnetic Resonance was done on $300 \mathrm{MHz}$ Avance III or $400 \mathrm{MHz}$ AMX Bruker. Single crystal XRD was 
conducted on a Bruker-AXS APEX CCD Diffractometer located at Delaware University with the help of Glenn P. Yap.

\subsubsection{Bis(dimethyl amido) titanium bis(isopropyl iminopyrrolidinate), 19}

Both isopropyl iminopyrrolidine $(0.93 \mathrm{~g}, 7.4 \mathrm{mmol})$ and $\mathrm{Ti}\left(\mathrm{NMe}_{2}\right)_{4}(0.83 \mathrm{~g}, 3.7$ mmol) were dissolved in $20 \mathrm{~mL}$ diethyl ether. The dissolved ligand was added dropwise to the yellow Ti solution, as the reaction preceded the solution changed to a dark red colour. The reaction was allowed to stir overnight at room temperature. Volatiles were removed under reduced pressure to afford a red solid $(1.24 \mathrm{~g}, 3.21 \mathrm{mmol}, 87 \%)$. The red solid was dissolved in minimal diethyl ether and placed in the freezer to afford needle like red crystals $(1.10 \mathrm{~g}, 2.85 \mathrm{mmol}, 77 \%)$. mp $130-132^{\circ} \mathrm{C} .{ }^{1} \mathrm{H}$ NMR $\left(300 \mathrm{MHz}, \mathrm{C}_{6} \mathrm{D}_{6}\right)$ :

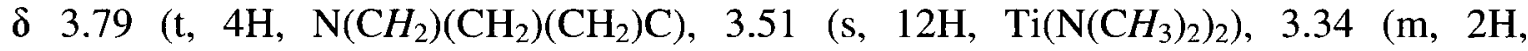
$\left.\mathrm{NCH}\left(\mathrm{CH}_{3}\right)_{2}\right), 1.99\left(\mathrm{t}, 4 \mathrm{H}, \mathrm{N}\left(\mathrm{CH}_{2}\right)\left(\mathrm{CH}_{2}\right)\left(\mathrm{CH}_{2}\right) \mathrm{C}\right), 1.63\left(\mathrm{~m}, 4 \mathrm{H}, \mathrm{N}\left(\mathrm{CH}_{2}\right)\left(\mathrm{CH}_{2}\right)\left(\mathrm{CH}_{2}\right) \mathrm{C}\right)$, $1.16\left(\mathrm{~d}, 12 \mathrm{H}, \mathrm{NCH}\left(\mathrm{CH}_{3}\right)_{2}\right) .{ }^{13} \mathrm{C}$ NMR $\left(300 \mathrm{MHz}, \mathrm{C}_{6} \mathrm{D}_{6}\right): \delta 176.7(\mathrm{NCN}), 52.3$ $\left(\mathrm{N}\left(\mathrm{CH}_{2}\right)\left(\mathrm{CH}_{2}\right)\left(\mathrm{CH}_{2}\right) \mathrm{C}\right), \quad 50.8 \quad\left(\mathrm{NCH}\left(\mathrm{CH}_{3}\right)_{2}\right), \quad 47.5 \quad\left(\mathrm{Ti}\left(\mathrm{N}\left(\mathrm{CH}_{3}\right)_{2}\right)_{2}\right), \quad 26.6$ $\left(\mathrm{N}\left(\mathrm{CH}_{2}\right)\left(\mathrm{CH}_{2}\right)\left(\mathrm{CH}_{2}\right) \mathrm{C}\right), 25.3\left(\mathrm{NCH}\left(\mathrm{CH}_{3}\right)_{2}\right), 23.9\left(\mathrm{~N}\left(\mathrm{CH}_{2}\right)\left(\mathrm{CH}_{2}\right)\left(\mathrm{CH}_{2}\right) \mathrm{C}\right)$. Mass spectral data $(\mathrm{EI}, m / z)\left(\right.$ rel. intensity, \%): $386.40\left(\left(\mathrm{M}-\mathrm{NMe}_{2}\right)^{+}, 66\right)$.

\subsubsection{Bis(dimethyl amido) titanium bis(sec-butyl iminopyrrolidinate), 20}

Suspended $0.56 \mathrm{~g}(2.52 \mathrm{mmol})$ of $\mathrm{Ti}\left(\mathrm{NMe}_{2}\right)_{4}$ in $60 \mathrm{~mL}$ ether in a $250 \mathrm{~mL}$ Schlenk flask. Cooled the reaction flask to $-78^{\circ} \mathrm{C}$ using an acetone $/ \mathrm{CO}_{2(\mathrm{~s})}$ bath. Sec-butyl iminopyrrolidine $(0.71 \mathrm{~g}, 5.04 \mathrm{mmol})$ was dissolved in $20 \mathrm{~mL}$ ether. The dissolved 
ligand was slowly added to the cooled titanium mixture by use of two $10 \mathrm{~mL}$ syringes. The reaction was stirred at low temperatures for 2 hours and then allowed to slowly reach room temperature for an additional 2 hours. After 4 hours of reaction time, volatiles were removed under reduced pressure to afford a red solid $(0.453 \mathrm{~g}, 1.09 \mathrm{mmol}, 43 \%)$. $\mathrm{mp}$ 112 - 114. ${ }^{1} \mathrm{H}$ NMR $\left(400 \mathrm{MHz}, \mathrm{C}_{6} \mathrm{D}_{6}\right): \delta 3.87\left(\mathrm{t}, 4 \mathrm{H}, \mathrm{N}\left(\mathrm{CH}_{2}\right)\left(\mathrm{CH}_{2}\right)\left(\mathrm{CH}_{2}\right) \mathrm{C}\right), 3.61(\mathrm{~s}$, $\left.12 \mathrm{H}, \quad \mathrm{Ti}\left(\mathrm{N}\left(\mathrm{CH}_{3}\right)_{2}\right)_{2}\right), \quad 3.14 \quad\left(\mathrm{~m}, \quad 2 \mathrm{H}, \quad \mathrm{NCH}\left(\mathrm{CH}_{3}\right)\left(\mathrm{CH}_{2} \mathrm{CH}_{3}\right)\right), \quad 2.14 \quad(\mathrm{t}, \quad 4 \mathrm{H}$, $\left.\mathrm{N}\left(\mathrm{CH}_{2}\right)\left(\mathrm{CH}_{2}\right)\left(\mathrm{CH}_{2}\right) \mathrm{C}\right), \quad 1.76 \quad\left(\mathrm{~m}, \quad 4 \mathrm{H}, \quad \mathrm{N}\left(\mathrm{CH}_{2}\right)\left(\mathrm{CH}_{2}\right)\left(\mathrm{CH}_{2}\right) \mathrm{C}\right), \quad 1.68 \quad(\mathrm{~m}, \quad 4 \mathrm{H}$, $\left.\mathrm{NCH}\left(\mathrm{CH}_{3}\right)\left(\mathrm{CH}_{2} \mathrm{CH}_{3}\right)\right), \quad 1.26\left(\mathrm{dd}, \quad 6 \mathrm{H}, \quad \mathrm{NCH}\left(\mathrm{CH}_{3}\right)\left(\mathrm{CH}_{2} \mathrm{CH}_{3}\right)\right), \quad 1.02 \quad(\mathrm{dt}, \quad 6 \mathrm{H}$, $\begin{array}{llllllllll}\left.\mathrm{NCH}\left(\mathrm{CH}_{3}\right)\left(\mathrm{CH}_{2} \mathrm{CH}_{3}\right)\right) . & { }^{13} \mathrm{C} & \mathrm{NMR} & (300 & \mathrm{MHz}, & \left.\mathrm{C}_{6} \mathrm{D}_{6}\right): & \delta & 177.3 & (\mathrm{NCN}), & 57.6\end{array}$ $\left(\mathrm{NCH}\left(\mathrm{CH}_{3}\right)\left(\mathrm{CH}_{2} \mathrm{CH}_{3}\right)\right), \quad 52.5 \quad\left(\mathrm{~N}\left(\mathrm{CH}_{2}\right)\left(\mathrm{CH}_{2}\right)\left(\mathrm{CH}_{2}\right) \mathrm{C}\right), \quad 46.5 \quad\left(\mathrm{Ti}\left(\mathrm{N}\left(\mathrm{CH}_{3}\right)_{2}\right)_{2}\right), \quad 32.8$ $\left(\mathrm{NCH}\left(\mathrm{CH}_{3}\right)\left(\mathrm{CH}_{2} \mathrm{CH}_{3}\right)\right), 27.1\left(\mathrm{~N}\left(\mathrm{CH}_{2}\right)\left(\mathrm{CH}_{2}\right)\left(\mathrm{CH}_{2}\right) \mathrm{C}\right), 23.8\left(\mathrm{~N}\left(\mathrm{CH}_{2}\right)\left(\mathrm{CH}_{2}\right)\left(\mathrm{CH}_{2}\right) \mathrm{C}\right), 22.7$ $\left.\left(\mathrm{NCH}\left(\mathrm{CH}_{3}\right)\left(\mathrm{CH}_{2} \mathrm{CH}_{3}\right)\right), 11.8\left(\mathrm{NCH}\left(\mathrm{CH}_{3}\right)\left(\mathrm{CH}_{2} \mathrm{CH}_{3}\right)\right)\right)$. Mass spectral data (EI, $\left.\mathrm{m} / z\right)$ (rel. intensity, \%): $370.3\left(\left(\mathrm{M}-\mathrm{NMe}_{2}\right)^{+}, 100\right)$.

\subsubsection{Bis(dimethyl amido) titanium bis(tert-butyl iminopyrrolidinate), 21}

Same reaction procedure as $\mathbf{1 9}$ was used substituting the previous iminopyrrolidine with t-butyl iminopyrrolidine $(0.50 \mathrm{~g}, 3.56 \mathrm{mmol})$. Volatiles were removed under reduced pressure to afford a red solid $(0.60 \mathrm{~g}, 1.45 \mathrm{mmol}, 81 \%)$. Decomposed $>120^{\circ} \mathrm{C}$. ${ }^{1} \mathrm{H}$ NMR $\left(300 \mathrm{MHz}, \mathrm{C}_{6} \mathrm{D}_{6}\right): \delta 3.753\left(\mathrm{t}, 4 \mathrm{H}, \mathrm{N}\left(\mathrm{CH}_{2}\right)\left(\mathrm{CH}_{2}\right)\left(\mathrm{CH}_{2}\right) \mathrm{C}\right), 3.45(\mathrm{~s}, 12 \mathrm{H}$, $\mathrm{Ti}\left(\mathrm{NC}\left(\mathrm{CH}_{3}\right)_{2}\right), 2.06\left(\mathrm{t}, 4 \mathrm{H}, \mathrm{N}\left(\mathrm{CH}_{2}\right)\left(\mathrm{CH}_{2}\right)\left(\mathrm{CH}_{2}\right) \mathrm{C}\right), 1.62\left(\mathrm{~m}, 4 \mathrm{H}, \mathrm{N}\left(\mathrm{CH}_{2}\right)\left(\mathrm{CH}_{2}\right)\left(\mathrm{CH}_{2}\right) \mathrm{C}\right)$, $1.27\left(\mathrm{~s}, 18 \mathrm{H}, \mathrm{N}\left(\mathrm{CH}_{3}\right)_{3}\right) .{ }^{13} \mathrm{C} \mathrm{NMR}\left(300 \mathrm{MHz}, \mathrm{C}_{6} \mathrm{D}_{6}\right): \delta 175.4(\mathrm{NCN}), 152.1\left(\mathrm{NC}\left(\mathrm{CH}_{3}\right)_{3}\right)$ $50.9 \quad\left(\mathrm{~N}\left(\mathrm{CH}_{2}\right)\left(\mathrm{CH}_{2}\right)\left(\mathrm{CH}_{2}\right) \mathrm{C}\right), \quad 47.2 \quad\left(\mathrm{Ti}\left(\mathrm{N}\left(\mathrm{CH}_{3}\right)_{2}\right)_{2}\right), \quad 31.5 \quad\left(\mathrm{NC}\left(\mathrm{CH}_{3}\right)_{3}\right), \quad 30.4$ 
$\left(\mathrm{N}\left(\mathrm{CH}_{2}\right)\left(\mathrm{CH}_{2}\right)\left(\mathrm{CH}_{2}\right) \mathrm{C}\right), 23.5\left(\mathrm{~N}\left(\mathrm{CH}_{2}\right)\left(\mathrm{CH}_{2}\right)\left(\mathrm{CH}_{2}\right) \mathrm{C}\right.$. Mass spectral data $(\mathrm{EI}, \mathrm{m} / \mathrm{z})$ (rel. intensity, \%): $414.45\left(\left(\mathrm{M}-\mathrm{NMe}_{2}\right)^{+}, 100\right)$.

\subsection{Structural Determination for Compound 19}

A suitable crystal was mounted with viscous oil on a plastic mesh and cooled to the data collection temperature. Unit cell parameters were determined using data frames from four different sections of the Ewald sphere. SADABS multi-scan absorption corrections were applied. No symmetry higher than triclinic was observed. Solution in the centrosymmetric space group option, P-1, yielded chemically reasonable and computationally stable results of refinement. The structures were solved using direct methods and refined with full matrix least squares procedures of $F^{2}$ data. All hydrogen atoms were treated as idealized contributions and all non-hydrogen atoms were refined with anisotropic displacement coefficients. Atomic scattering factors are contained in the SHELXTL program library. 


\subsection{References}

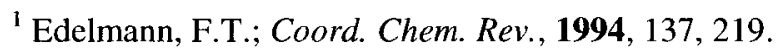

${ }^{2}$ Duncan, A.P., Mullins, S.M., Arnold, J., Bergman, R.G., Organomet, 2001, 20, 1808 - 1819.

3 (a) B. S. Lim, A. Rahtu, J.-S. Park and R. G. Gordon, Inorg. Chem.,2003, 42, 7951. (b) F. T.

Edelmann, Adv. Organomet. Chem., 2008, 57, 183. (c) B. S. Lim, A. Rahtu and R. G. Gordon, Nat. Mater., 2003, 2, 749.

${ }^{4}$ (a) Weitershaus, K., Ward, B.D., Kubiak, R., Muller, C., Wadepohl, H., Doye, S., Gade, L.H.; Dalton Trans., 2009, 4586. (b) Weitershaus, K., Wadepohl, H., Gade, L.H.; Organometallics, 2009, 28, 12 , 3381. (c) Weitershaus, K., Fillol, J.L., Wadepohl, H., Gade, L.H.; Organometallics, 2009, 28, 16, 4747.

${ }^{5}$ Ward, B.D., Risler, H., Weitershaus, K., Bellemin-Laponnaz, S., Wadepohl, H., Gade, L.H.; Inorg. Chem., 2006, 45, 7777 .

${ }^{6}$ Allen, F.H., Kennard, O., Watson, D.G., Brammer, L., Orpen, A.G., Taylor, R.; J. Chem. Soc. Perkin Trans. $I I, 1987, \mathrm{~S} 1$.

${ }^{7}$ Wasslen, Y.A., Kurek, A., Johnson, P.A., Pigeon, T.C., Monillas, W.H., Yap, G.P.A., Barry, S.T.; Dalton Trans., 2010, ASAP. 


\section{Chapter 7: Heteroleptic Zirconium Complexes}

\subsection{Introduction}

Group 4 guanidinate and amidinate compounds have been used in studies of polymerization reactions such as homogeneous Ziegler - Natta catalysis ${ }^{1}$ as well as in advanced techniques for growth of high quality thin films; CVD and ALD. ${ }^{2}$ Zirconium oxide thin films are of interest in thin film applications because they have excellent thermal, chemical and mechanical stability, as well as interesting optical and dielectric properties. This interesting group 4 metal oxide has an effective dielectric constant $\mathrm{k}=$ $22^{3}$, is thermodynamically stable on silicon, ${ }^{4}$ and has a band gap that ranges from $5-7$ $\mathrm{eV}^{5}$ Due to the downscaling of microelectronics silicon dioxide thin films are unable to cope as their dielectric constant is so low; 3.9. ${ }^{6}$ Zirconium oxide thin films are attracting attention as possible high-k gate oxide dielectrics in complementary metal-oxide semiconductor (CMOS) devices. $^{2}$

Zirconium oxide thin films have been deposited using a variety of precursors such as inorganic salts of $\mathrm{ZrCl}_{4}$ and $\mathrm{Zr}\left(\mathrm{NO}_{3}\right)_{4}$, as well as organometallic zirconium alkoxides $\left(\mathrm{Zr}(\mathrm{OR})_{4}\right)$ where $\mathrm{R}={ }^{\mathrm{i}} \operatorname{Pr}$ or ${ }^{\mathrm{t}} \mathrm{Bu} \cdot{ }^{2 \mathrm{a}}$ These precursors have some disadvantages associated with them, such as chlorine contamination for $\mathrm{ZrCl}_{4}$ and the zirconium alkoxides have tendencies to oligomerize. Zirconium amides have also been studied for thin film deposition however they have proven to be very reactive towards air and moisture and thus are difficult to handle. ${ }^{2}$ Bidentate ligands such as amidinates and guanidinates have 
proven to be more stable as they coordinatively saturate the metal complex. Guanidinates also offer another mode of stabilization by allowing zwitterionic resonance to occur.

It is important for applications such as CVD and ALD that the precursors are thermally stable and easy to handle allowing for much research in the development of organometallic precursors. Amidinates and guanidinates are of interest for these processes mainly due to their versatility but also because they can minimize impurities that are found in thin films produced by other precursors, such as those containing halogens. A drawback of monoanionic guanidinates (and amidinates), however, is their ability to deinsert carbodiimide upon heating (Scheme 2-1). ${ }^{7}$ Indeed, many guanidinate syntheses rely on carbodiimide insertion as a synthetic mechanism, ${ }^{8}$ however it has recently been shown to be reversible for group 13 metals. ${ }^{7}$

There are fewer examples of complexes containing dianionic guanidinates than the previously mentioned monoanionic guanidinates. ${ }^{9}$ Dianionic guanidinates of the type $\left[\mathrm{RN}=\mathrm{C}(\mathrm{NR})_{2}\right]^{-}$(where $\mathrm{R}$ and $\mathrm{R}^{\prime}$ = alkyl) are chelating ligands that have the ability to fulfill the same favourable characteristics of monoanionic guanidinates, however, deinsertion is far less favourable due to the necessary formation of a metal imide when carbodiimide is expelled (Scheme 7-1).

Scheme 7-1. Deinsertion less likely to occur for dianionic ligands.

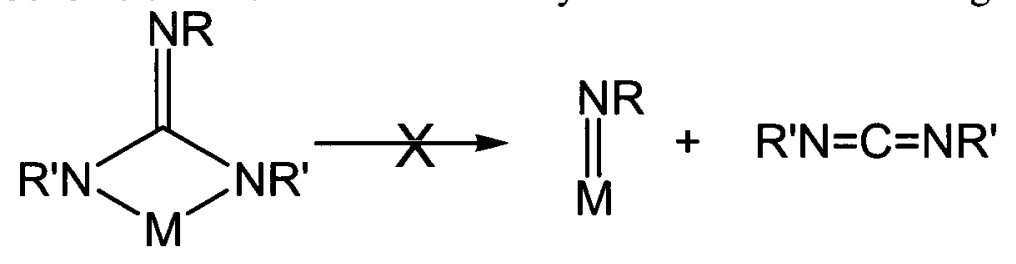


This chapter will focus on the synthesis, characterization, and thermolysis of novel heteroleptic zirconium species using a mixture of guanidinate and amidinate ligands. Synthesizing heteroleptic zirconium species with solely bidentate ligands may help improve the stability of the species, as amides are known to be highly reactive towards air and moisture. ${ }^{10}$ Formation of a monomer would be ideal for ALD and CVD purposes as the molecular weight would be less; potentially allowing for a more volatile species. Dianionic guanidinates have been found to produce dimers when reacted to hafnium and zirconium species. ${ }^{11}$ For this reason, the monoanionic ligands were reacted with the metal centre before reaction with the dianionic ligand. This was done in attempts to break the dimer; the process was found to be successful.

\subsection{Results and Discussion}

\subsubsection{Synthesis and Characterization}

Three heteroleptic zirconium compounds were synthesized in low yields (Table 7-1) from sequential salt metathesis reactions starting with $\mathrm{ZrCl}_{4}$, appropriate amidinate or guanidinate ligands and lithiated dianionic guanidinate species. It was found that the compounds formed slowly at room temperature with the reaction changing from colourless to yellow. In every case, the volatiles were removed under vacuum; the yellow solid was redissolved in diethyl ether and placed in the freezer to promote crystallization. Colourless crystals were isolated and further characterization was undertaken. Compound 22 produced crystals of sufficient quality for a single crystal structure to be collected (Figure 7-2, Table 7-2 and Table 7-3). 


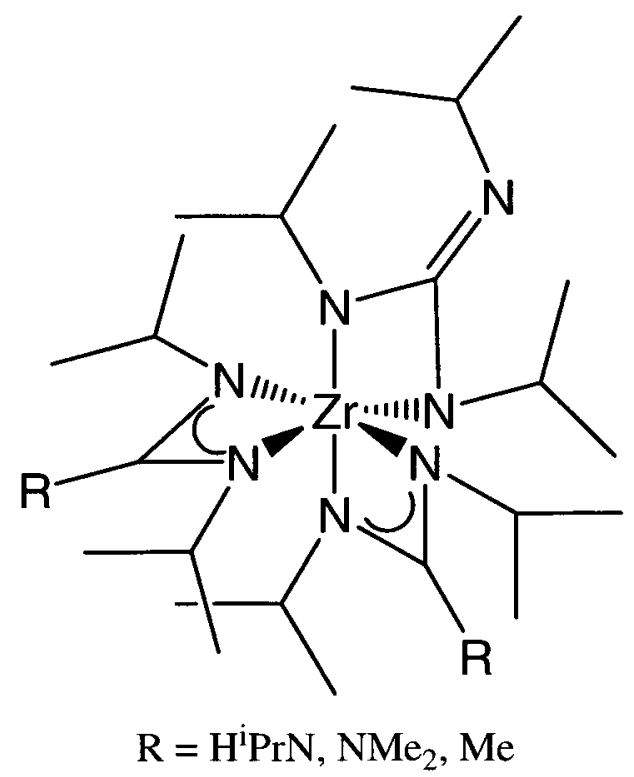

Figure 7-1. Heteroleptic zirconium species.

Table 7-1. Percent yield and thermal data of compounds 22 - 24 .

\begin{tabular}{cccc}
\hline & $\mathbf{R}$ & $\begin{array}{c}\text { Percent Yield } \\
(\boldsymbol{\%})\end{array}$ & $\begin{array}{c}\text { Melting Point } \\
\left({ }^{\mathbf{0}} \mathbf{C}\right)\end{array}$ \\
\hline \hline $\mathbf{2 2}$ & $\mathrm{H}^{i} \mathrm{PrN}$ & 35 & 96 \\
$\mathbf{2 3}$ & $\mathrm{NMe}_{2}$ & 25 & 126 \\
$\mathbf{2 4}$ & $\mathrm{Me}$ & $\mathbf{5 2}$ & 113 \\
\hline
\end{tabular}

The ${ }^{1} \mathrm{H}$ NMR for these compounds were difficult to interpret. Due to the fluxional behaviour of monoanionic guanidinate and amidinate ligands and their ability to move about the metal centre within the time frame of the experiment, the NMRs were very complicated. A variety of isopropyl environments were observed along with the corresponding multiplets. A variable temperature (VT) NMR was undertaken for compound 24 to slow down the fluxionalization. Coalescence did not occur in the ${ }^{1} \mathrm{H}$ NMR as the solvent used $\left(\mathrm{C}_{6} \mathrm{D}_{6}\right)$ could not reach the necessary low temperatures. It would have been advantageous to repeat this experiment with deuterated toluene $\left(\mathrm{C}_{7} \mathrm{D}_{8}\right)$ to observe the change in NMR through a larger temperature range. 
Compound 22 crystallized in a Ccca space group showing $C_{2}$ symmetry by ${ }^{1} \mathrm{H}$ NMR. The zirconium atom was found in a distorted octahedral position due to the strain introduced by the bite angles of the chelate rings at $61.5^{\circ}$ for the dianionic ligand (N4-Zr$\mathrm{N} 5)$ and $60.7^{\circ}$ for the monoanionic ligands (N1-Zr-N2 and N7-Zr-N8). The bite angles for the monoanionic ligands were slightly larger than in a similar compound reported by Richeson et. al. at $59.3^{\circ}$ and $59.4^{\circ}$, respectively. ${ }^{12}$ This can be attributed to a lower steric demand of the dianionic ligand compared to the two benzyl groups in the above reference. The bite angle of the dianionic ligand was only slightly larger than that of the monoanionic ligands. The N-C-N angles were similar, ranging from $108.0-111.3^{\circ}$; the shortest angle being for the dianionic ligand (N4-C14-N6) at $108.0^{\circ}$ as a compensation for the slightly larger bite angle. These were smaller than previously reported complexes. $^{12}$

The sum of angles around the central carbon of the $\mathrm{CN}_{3}$ core for each guanidinate ( $\mathrm{C} 4, \mathrm{C} 14$, and $\mathrm{C} 24$ ) totalled $360.0^{\circ}$ indicating delocalization of the $\pi$-system within the guanidinate. The sum of angles of the chelating nitrogens ranged from nearly planar at $360.0^{\circ}$ for $\mathrm{N} 7$ to far from planar at $352.0^{\circ}$ for $\mathrm{N} 1$. The guanidinate ring for each ligand had a torsion angle that ranged from $6.2^{\circ}$ for the dianionic ligand (Zr-N4-C14-N5) to $7.0^{\circ}$ for Zr-N1-C4-N2, showing partial participation of all three ligands in the $\pi$-system.

The nitrogen-zirconium bond lengths ranged from 2.17 to $2.23 \AA$ with $\mathrm{Zr}$-N4 being the shortest and $\mathrm{Zr}-\mathrm{N} 2$ being the longest; which fell within range of previously reported zirconium guanidinate structures. ${ }^{12}$ Interestingly, the dianionic guanidinate had the shortest $\mathrm{Zr}-\mathrm{N}$ bond lengths at 2.17 and 2.19 $(\mathrm{Zr}-\mathrm{N} 4$ and $\mathrm{Zr}-\mathrm{N} 5)$. The shorter Zr-N bond 
lengths for the dianionic ligand may be attributed to the higher $\pi$-donor properties it possesses.

Although the monoanionic and dianionic ligands were only differentiated in connectivity by the presence of a proton, they can easily be distinguished by the comparison of the $\mathrm{C}-\mathrm{N}$ bond lengths within the $\mathrm{CN}_{3}$ core of the coordinated ligand (Table 7-3).

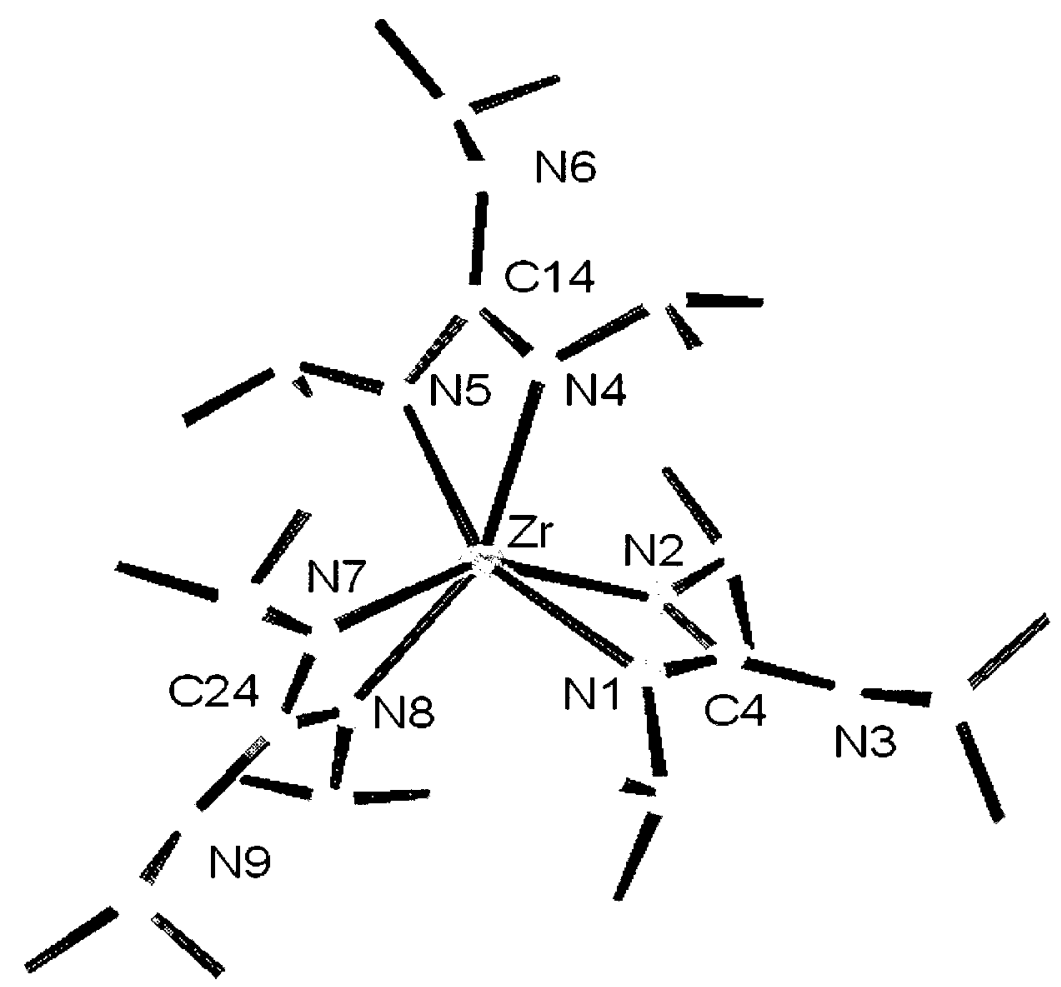

Figure 7-2. The single crystal X-ray structure of compound 22 . The thermal ellipsoids are shown at $50 \%$ probability and the hydrogen centres are omitted for clarity. 
Table 7-2. Selected crystal data for compound 22.

\begin{tabular}{cc}
\hline Empirical Formula & $\mathrm{C}_{30} \mathrm{H}_{65} \mathrm{~N}_{9} \mathrm{Zr}$ \\
\hline FW & 643.13 \\
Crystal System & Orthorhombic \\
Space Group & $\mathrm{Ccca}$ \\
$\mathrm{a}(\AA)$ & $26.876(3)$ \\
$\mathrm{b}(\AA)$ & $35.647(5)$ \\
$\mathrm{c}(\AA)$ & $15.144(2)$ \\
$\alpha(\mathrm{deg})$ & 90 \\
$\beta(\mathrm{deg})$ & 90 \\
$\gamma(\mathrm{deg})$ & 90 \\
$\mathrm{~V}\left(\AA^{3}\right)$ & $145088(3)$ \\
$\mathrm{Z}$ & 16 \\
$\mathrm{D}_{\mathrm{c}}(\mathrm{kg} / \mathrm{L})$ & 1.178 \\
$\mu(\mathrm{mm})$ & 0.334 \\
$\mathrm{~T}(\mathrm{~K})$ & $120(2)$ \\
$\mathrm{R}, \mathrm{wR}$ & $0.0473,0.1135$ \\
Goodness-of-fit on $\mathrm{F}^{2}$ & 1.063 \\
\hline
\end{tabular}

Table 7-3. Selected bond lengths and angles for compound 22.

\begin{tabular}{|c|c|c|c|}
\hline \multicolumn{4}{|c|}{ Selected Bond Lengths $(\AA)$} \\
\hline Zr-N1 & $2.2134(15)$ & N3-C4 & $1.346(2)$ \\
\hline $\mathrm{Zr}-\mathrm{N} 2$ & $2.2260(13)$ & $\mathrm{N} 4-\mathrm{C} 14$ & $1.383(2)$ \\
\hline $\mathrm{Zr}-\mathrm{N} 4$ & $2.1711(14)$ & $\mathrm{N} 5-\mathrm{C} 14$ & $1.370(2)$ \\
\hline Zr-N5 & $2.1871(15)$ & N6-C14 & $1.326(2)$ \\
\hline $\mathrm{Zr}-\mathrm{N} 7$ & $2.1925(15$ & $\mathrm{N} 7-\mathrm{C} 24$ & $1.358(2)$ \\
\hline Zr-N8 & $2.2246(15)$ & $\mathrm{N} 8-\mathrm{C} 24$ & $1.361(2)$ \\
\hline $\mathrm{N} 1-\mathrm{C} 4$ & $1.358(2)$ & N9-C24 & $1.353(2)$ \\
\hline $\mathrm{N} 2-\mathrm{C} 4$ & $1.358(2)$ & & \\
\hline \multicolumn{4}{|c|}{ Selected Bond Angles $\left(^{\circ}\right)$} \\
\hline $\mathrm{N} 1-\mathrm{Zr}-\mathrm{N} 2$ & $60.71(5)$ & $\mathrm{Zr}-\mathrm{N} 8-\mathrm{C} 24$ & $93.55(11)$ \\
\hline $\mathrm{N} 7-\mathrm{Zr}-\mathrm{N} 8$ & $60.65(6)$ & $\mathrm{Zr}-\mathrm{N} 4-\mathrm{C} 14$ & $95.21(10)$ \\
\hline $\mathrm{N} 4-\mathrm{Zr}-\mathrm{N} 5$ & $61.47(5)$ & $\mathrm{Zr}-\mathrm{N} 5-\mathrm{C} 14$ & $94.88(10)$ \\
\hline Zr-N1-C4 & $93.96(10)$ & $\mathrm{N} 1-\mathrm{C} 4-\mathrm{N} 2$ & $111.38(15)$ \\
\hline $\mathrm{Zr}-\mathrm{N} 2-\mathrm{C} 4$ & $93.40(10)$ & $\mathrm{N} 7-\mathrm{C} 24-\mathrm{N} 8$ & $110.20(15)$ \\
\hline Zr-N7-C24 & $95.06(11)$ & N4-C14-N5 & $107.99(14)$ \\
\hline \multicolumn{4}{|c|}{ Sum of Angles $\left(^{\circ}\right)$} \\
\hline N1 & 351.6 & C14 & 360 \\
\hline $\mathrm{N} 2$ & 355.76 & N7 & 359.55 \\
\hline $\mathrm{C} 4$ & 360 & N8 & 357.87 \\
\hline $\mathrm{N} 4$ & 352.7 & $\mathrm{C} 24$ & 360 \\
\hline N5 & 357.28 & & \\
\hline
\end{tabular}


The exocyclic amide moieties on all three ligands were participating in the $\pi$-system to a certain extent as the $\mathrm{C}-\mathrm{N}$ bond lengths are shorter than typical $\mathrm{C}-\mathrm{N}$ single bond lengths of $1.479 \AA$ and longer than $\mathrm{C}=\mathrm{N}$ double bond lengths at $1.29-1.30 \AA^{13}$ The exocyclic nitrogen bond length of the dianionic guanidinate (N6-C14) was slightly smaller at $1.32 \AA$ than for the two monoanionic guanidinate exocyclic C-N lengths (N3$\mathrm{C} 4$ and $\mathrm{N} 9-\mathrm{C} 24)$ at $1.35 \AA$, respectively. The $\mathrm{C}-\mathrm{N}$ bond lengths within the chelate rings showed the opposite trend. The C-N bonds were longer in the dianionic ligand at $1.38 \AA$ for $\mathrm{N} 4-\mathrm{C} 14$ and $\mathrm{N} 5-\mathrm{C} 14$, respectively, due to the deficiency of the $\pi$-system within the metallocycle. The monoanionic guanidinate $\mathrm{C}$-N bonds were shorter at $1.36 \AA$ for N1C4, N2-C4, N7-C24 and N8-C24. The lengths of the C-N bonds within the $\mathrm{CN}_{3}$ core of the monoanionic ligands were nearly indistinguishable indicating considerable delocalization of the nitrogen lone pair into the ligand $\pi$-system. From these results it can be concluded that the majority of the $\pi$-system for the dianionic ligand was localized at the exocyclic nitrogen while the monoanionic ligands displayed even distribution of the $\pi$-system throughout the $\mathrm{CN}_{3}$ core. ${ }^{14}$

\subsubsection{Thermolysis}

No bench top melting point was collected for compound $\mathbf{2 3}$ as the sticky nature made it difficult to collect the sample at the bottom of the capillary tube. However, a DSC was collected at a ramp rate of $10^{\circ} \mathrm{C} / \mathrm{min}$ and three endothermic peaks were observed (Figure 7-5). The first endotherm was at $126^{\circ} \mathrm{C}$ (associated with melting). The second endotherm observed at $264^{\circ} \mathrm{C}$ was thought to be associated with volatilization of a thermalized zirconium species and the third endotherm at $352^{\circ} \mathrm{C}$ was thought to be 
decomposition given the complicated TG. TG analysis showed compound 23 to decompose with a large residual mass of $28 \%$ (Figure 7-3). There were 3 thermal events present in the TG demonstrated by the derivative weight curve (Figure 7-4). The first event corresponded to $1 \%$ weight loss which was most likely due to loss of incidental solvent. The second thermal event was the major feature which occurred at a temperature range of $130-279^{\circ} \mathrm{C}$. This feature had the characteristic shape of volatilization; a slower on-set and a rapid drop-off. The volatilization of a thermalized zirconium species was apparent in this temperature range and a third thermal event occurred from $279-376^{\circ} \mathrm{C}$ indicative of decomposition. The residual mass was considered to be relatively high for a vapour deposition precursor.

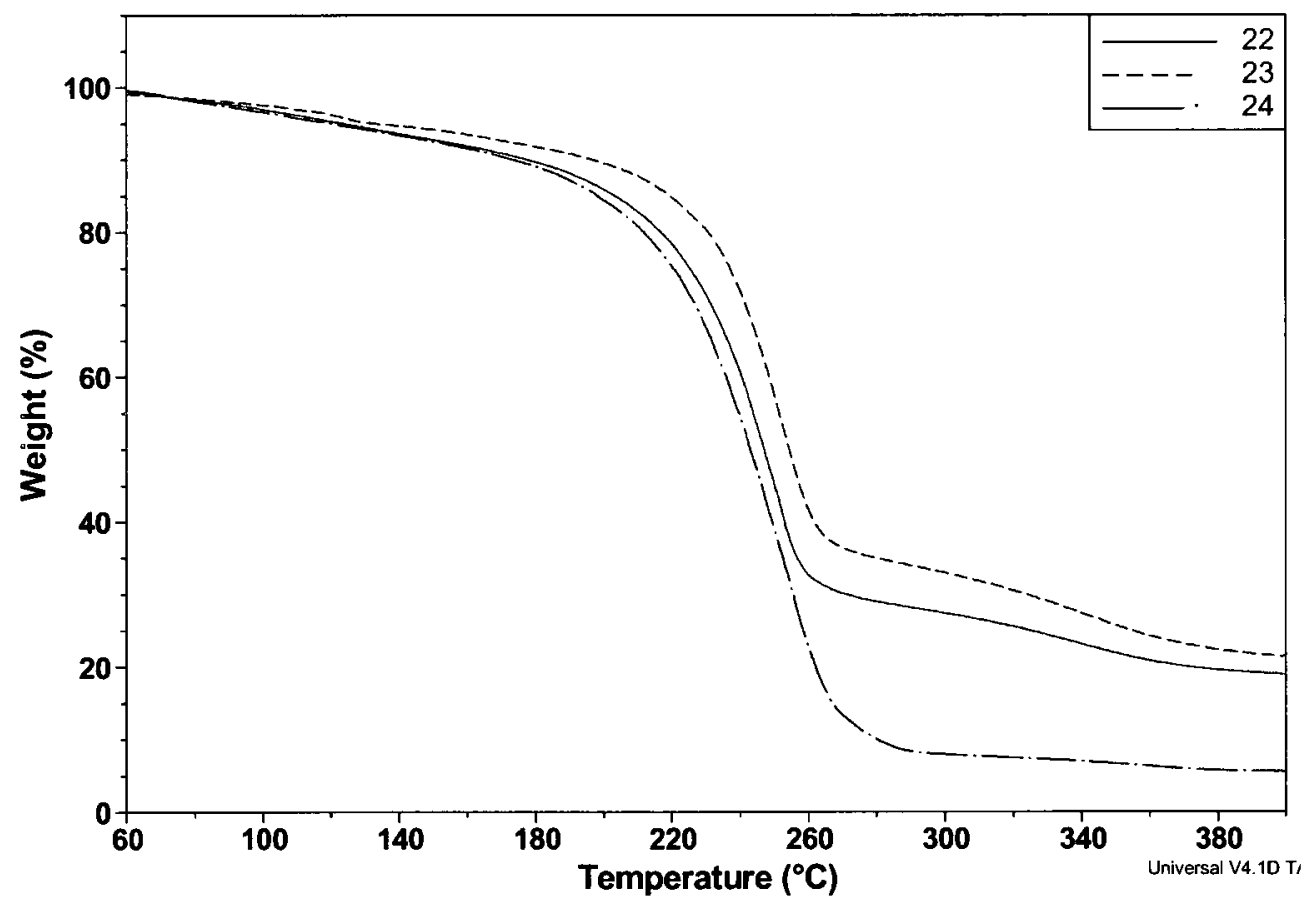

Figure 7-3. Thermal gravimetric analysis of $22-24$. 


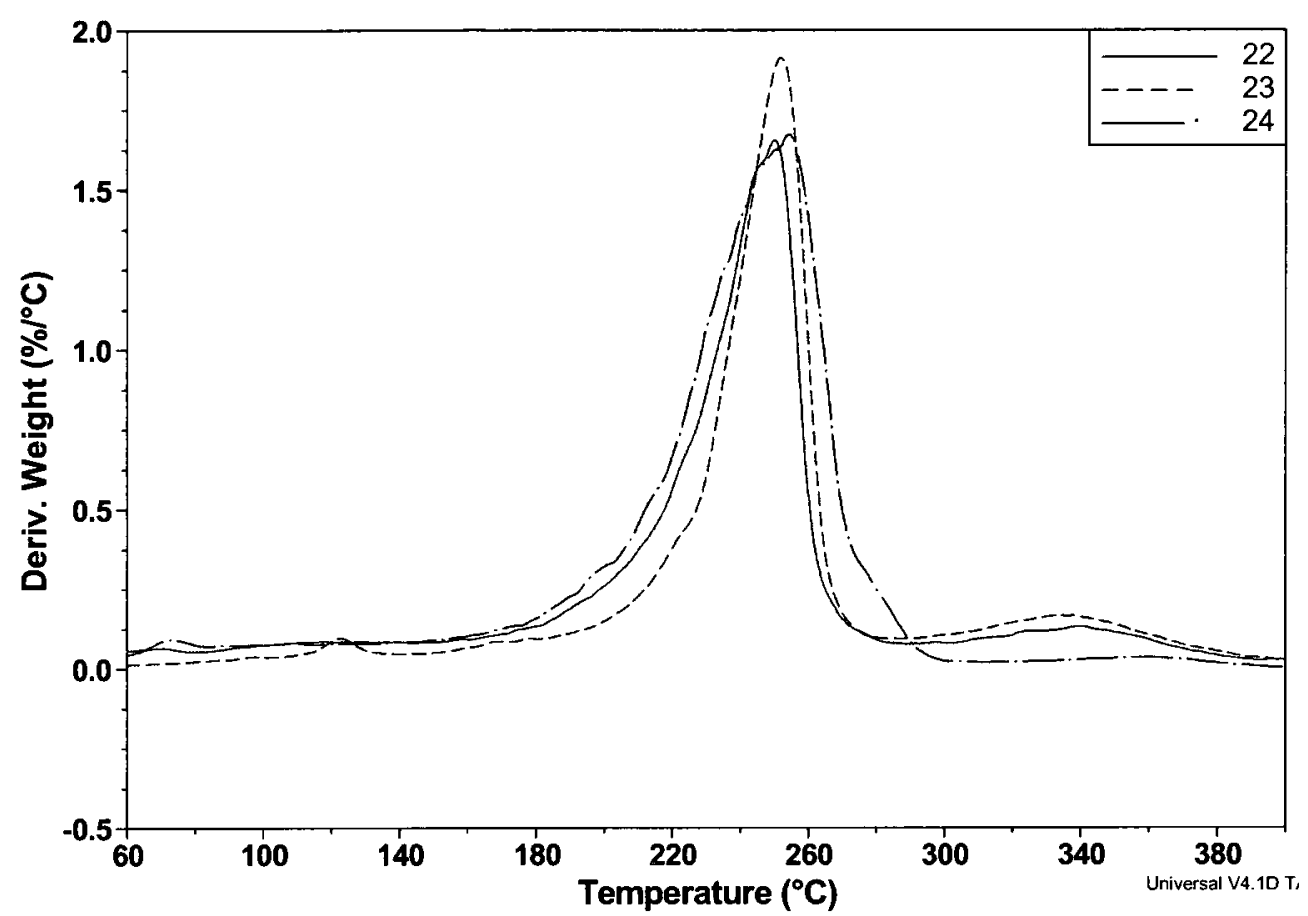

Figure 7-4. Differential weight curve for compounds 22 - 24.

Compound 22 had a melting point of $95-96^{\circ} \mathrm{C}$ conducted on a bench top melting point apparatus. There were two major thermal events present as seen by the derivative weight curve (Figure 7-4). The first thermal event occurred at a temperature range of 126 $-285^{\circ} \mathrm{C}$ which was the major feature. It had the characteristic shape of volatilization, an asymmetric curve with a slow on-set and a quick drop-off. The second thermal event was observed at a temperaturen range of $285-392^{\circ} \mathrm{C}$ which was considered to be decomposition. The complicated TG curve and residual mass of $18.6 \%$ demonstrated that this compound decomposed leaving behind several non-volatile contaminates which is an undesirable characteristic for vapour deposition precursors. 


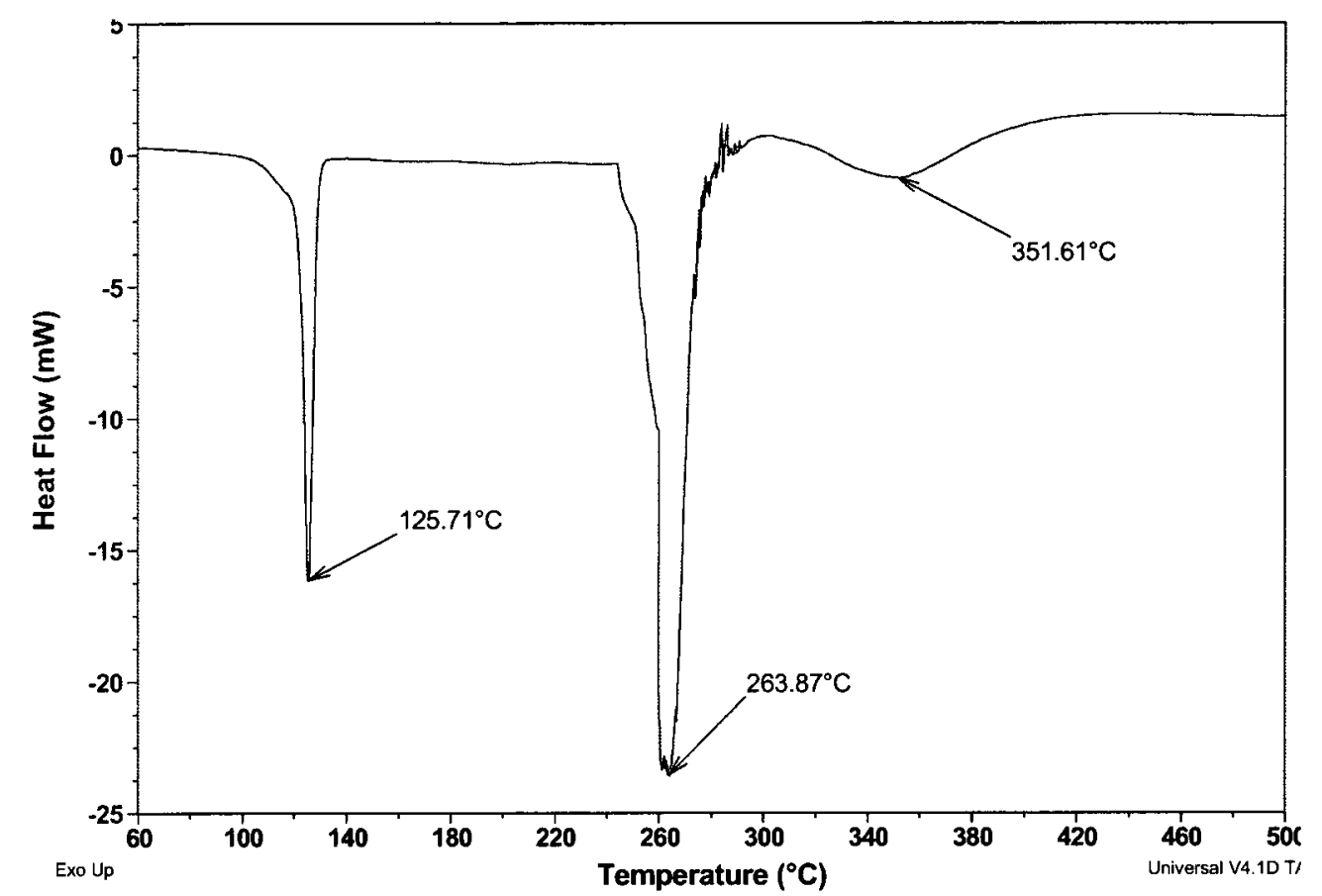

Figure 7-5. Differential scanning calorimetery of 23.

Compound 24 had a melting point of $110-113^{\circ} \mathrm{C}$ collected on a bench top melting point apparatus. The TG showed one major thermal event that ranged from $122-301^{\circ} \mathrm{C}$ with a residual mass of $7.6 \%$. Thermal degradation was observed at the beginning of this experiment as shown by the initial gradual slope.

All three heteroleptic zirconium species had complicated TG curves resulting in high residual masses, with the exception of the residual mass of 24 . These results are undesirable when designing precursors for thin film deposition procedures; thus these complexes would not be considered as candidates for such procedures.

An NMR tube boil up was performed on compound 23. The complex was dissolved in $0.25( \pm 6) \mathrm{mL}$ of $\mathrm{C}_{6} \mathrm{D}_{6}$ solution in a thick-walled NMR tube under inert atmosphere. The tube was immersed in liquid $\mathrm{N}_{2}$ and the glass tube was sealed under vacuum. The tube was placed in a furnace at $100^{\circ} \mathrm{C}$ to observe possible $\mathrm{CDI}$ growth. On the third day 
compound 23 demonstrated the presence of CDI by ${ }^{1} \mathrm{H}$ NMR. The characteristic multiplet and doublet at 3.33 and $1.04 \mathrm{ppm}$ was observed and the intensity increased for the duration of the experiment. The presence of CDI was not a surprise as it has been known to deinsert from amidinate or guanidinate ligands at elevated temperatures. ${ }^{7}$

\subsection{Conclusions}

This work presented the synthesis and thermolysis of three new heteroleptic zirconium complexes in reasonable to low yields. The ${ }^{1} \mathrm{H}$ NMRs collected were complicated in that many isopropyl environments were present and seemed to be fluxuating during the time frame of the experiment as the peaks were somewhat broad. One crystal structure was obtained for compound $\mathbf{2 3}$ displaying a Ccca space group. The crystal structure was novel as both monoanionic and dianionic guanidinates were present and were distinguishable through $\mathrm{C}-\mathrm{N}$ bond lengths found within the $\mathrm{CN}_{3}$ core of the ligand. Preliminary thermolysis experiments such as TG were performed on all three compounds and they displayed complicated volatilization. The compounds synthesized in this chapter would not be good candidates for chemical vapour deposition techniques such as CVD or ALD as they were found to be thermally unstable. However, the isolation of a heteroleptic zirconium single crystal consisting of both monoanionic and dianionic guanidinate ligands was an interesting find. 


\subsection{Methods and Materials}

All manipulations were performed in a nitrogen-filled drybox. The chemicals: isopropyl amine, zirconium tetrachloride, methyl lithium, lithium dimethyl amide and 1,3-diisopropyl carbodiimide were purchased from Aldrich Chemical Company and used as received. All solvents used were reagent grade purified from an MBraun Solvent Purifier System. The monoanionic ligand synthesis of $\left[\mathrm{H}^{i} \operatorname{PrNC}\left(\mathrm{N}^{i} \mathrm{Pr}\right)_{2}\right] \mathrm{Li}$, $\left[\mathrm{Me}_{2} \mathrm{NC}\left(\mathrm{N}^{i} \mathrm{Pr}\right)_{2}\right] \mathrm{Li}$ and $\left[\mathrm{MeC}\left(\mathrm{N}^{i} \mathrm{Pr}\right)_{2}\right] \mathrm{Li}$ followed literature procedures. ${ }^{15}$ Dianionic ligand synthesis of $\left[{ }^{i} \mathrm{PrN}=\mathrm{C}\left(\mathrm{N}^{i} \mathrm{Pr}\right)_{2}\right] \mathrm{Li}_{2}$ followed literature procedures. ${ }^{16}{ }^{1} \mathrm{H}$ and ${ }^{13} \mathrm{C}$ NMR spectra were collected on a Bruker $300 \mathrm{MHz}$ or a Bruker $400 \mathrm{MHz}$ spectrometer using the residual protons in the deuterated solvent for reference. Mass spectra were obtained using the electron impact method on a VG ZAB-2HF triple-focusing spectrometer. Thermal gravimetric analyses were performed on a TA Instruments Q50 apparatus located within a Labmaster 130 Dry box. Differential Scanning Calorimetery was performed on a DSC Instruments Q10 apparatus. Single crystal XRD was conducted on a Bruker-AXS APEX CCD Diffractometer located at Delaware University with the help of Glenn P. Yap.

\subsubsection{Bis(triisopropyl monoguanidinate) zirconium mono(dianionic triisopropyl guanidinate), 22}

In a $60 \mathrm{~mL}$ round bottom flask $3.57 \mathrm{~g}$ of $\left[\mathrm{H}^{i} \operatorname{PrNC}\left(\mathrm{N}^{i} \operatorname{Pr}\right)_{2}\right]_{2} \mathrm{ZrCl}_{2}(6.7 \mathrm{mmol})$ was mixed with $40 \mathrm{~mL}$ of ether and allowed to stir for $10 \mathrm{~min}$. $1.33 \mathrm{~g}$ of $\left[{ }^{i} \operatorname{PrNC}\left(\mathrm{N}^{i} \mathrm{Pr}\right)_{2}\right] \mathrm{Li}_{2}$ $(6.7 \mathrm{mmol})$ was slowly added to the solution while stirring over $10 \mathrm{~min}$, the solution 
turned a beige colour. The reaction was allowed to stir over night at room temperature. The flask was then evacuated to dryness revealing a light brown powder and then redissolved in ether to separate the $\mathrm{LiCl}$ formed and the desired product. The mixture was then filtered and the brown mother liquor was evacuated to brown viscous oil and redissolved in ether and placed in the freezer at $-30^{\circ} \mathrm{C}$. The crystallized yield was found to be $35 \%$. ${ }^{1} \mathrm{H}$ NMR $\left(300 \mathrm{MHz}, \mathrm{C}_{6} \mathrm{D}_{6}\right): \delta 4.26\left(\mathrm{sept}, 2 \mathrm{H},\left(\mathrm{CH}_{3}\right)_{2} \mathrm{HCN}=\mathrm{C}\left[\mathrm{NCH}\left(\mathrm{CH}_{3}\right)_{2}\right]_{2}\right)$, 3.88 (sept, $\left.\quad 1 \mathrm{H}, \quad\left(\mathrm{CH}_{3}\right)_{2} \mathrm{HCN}=\mathrm{C}\left[\mathrm{NCH}\left(\mathrm{CH}_{3}\right)_{2}\right]_{2}\right), \quad 3.34 \quad\left(\right.$ sept, $\quad 2 \mathrm{H}, \quad\left(\mathrm{CH}_{3}\right)_{2} \mathrm{HCNC}-$ $\left.\left[\mathrm{NCH}\left(\mathrm{CH}_{3}\right)_{2}\right]_{2}\right), \quad 3.06 \quad\left(\mathrm{~m}, \quad 4 \mathrm{H}, \quad\left(\mathrm{CH}_{3}\right)_{2} \mathrm{HCNC}-\left[\mathrm{NCH}\left(\mathrm{CH}_{3}\right)_{2}\right]_{2}\right), \quad 1.30 \quad(\mathrm{~d}, \quad 12 \mathrm{H}$, $\left.\left(\mathrm{CH}_{3}\right)_{2} \mathrm{HCN}=\mathrm{C}\left[\mathrm{NCH}\left(\mathrm{CH}_{3}\right)_{2}\right]_{2}\right), 1.10\left(\mathrm{~d}, 12 \mathrm{H},\left(\mathrm{CH}_{3}\right)_{2} \mathrm{HCNC}-\left[\mathrm{NCH}\left(\mathrm{CH}_{3}\right)_{2}\right]_{2}\right), 1.02(\mathrm{~d}, 6 \mathrm{H}$, $\left.\left(\mathrm{CH}_{3}\right)_{2} \mathrm{HCN}=\mathrm{C}\left[\mathrm{NCH}\left(\mathrm{CH}_{3}\right)_{2}\right]_{2}\right), 0.83\left(\mathrm{~d}, 24 \mathrm{H},\left(\mathrm{CH}_{3}\right)_{2} \mathrm{HCNC}-\left[\mathrm{NCH}\left(\mathrm{CH}_{3}\right)_{2}\right]_{2}\right)$.

\subsubsection{Bis(dimethylamide diisopropyl guanidinate) zirconium mono(dianionic guanidinate), 23}

In a $100 \mathrm{~mL}$ round bottom flask $7.00 \mathrm{~g}$ of $\left[(\mathrm{Me})_{2} \mathrm{NC}\left(\mathrm{N}^{i} \mathrm{Pr}\right)_{2}\right]_{2} \mathrm{ZrCl}_{2}(13.9 \mathrm{mmol})$ was mixed with $60 \mathrm{~mL}$ of ether and allowed to stir for $10 \mathrm{~min} .2 .75 \mathrm{~g}$ of $\left[{ }^{i} \mathrm{PrNC}\left(\mathrm{N}^{i} \mathrm{Pr}\right)_{2}\right] \mathrm{Li}_{2}$ (13.9 mmol) was slowly added to the solution while stirring over $10 \mathrm{~min}$, the solution turned a pale orange colour. The reaction was allowed to stir over night at room temperature. The flask was then evacuated to dryness revealing a pale orange powder and then redissolved in tetrahydrofuran (THF) to separate the $\mathrm{LiCl}$ from the desired product. The mixture was then filtered and the orange mother liquor was evacuated to dryness. The crude yield was found to be $58 \%$ from $4.95 \mathrm{~g}$ collected after filtering. From crystallization $2.12 \mathrm{~g}$ was collected a $25 \%$ yield. ${ }^{1} \mathrm{H}$ NMR $\left(300 \mathrm{MHz}, \mathrm{C}_{6} \mathrm{D}_{6}\right): \delta$ 4.58 (sept, $\left.2 \mathrm{H}, \quad\left(\mathrm{CH}_{3}\right)_{2} \mathrm{HCN}=\mathrm{C}\left[\mathrm{NCH}\left(\mathrm{CH}_{3}\right)_{2}\right]_{2}\right), \quad 4.39 \quad\left(\mathrm{~m}, \quad 1 \mathrm{H}, \quad\left(\mathrm{CH}_{3}\right)_{2} \mathrm{HCN}=\mathrm{C}-\right.$ 
$\left.\left[\mathrm{NCH}\left(\mathrm{CH}_{3}\right)_{2}\right]_{2}\right), \quad 3.45 \quad\left(\mathrm{~m}, \quad 4 \mathrm{H}, \quad\left(\mathrm{CH}_{3}\right)_{2} \mathrm{NC}\left[\mathrm{NCH}\left(\mathrm{CH}_{3}\right)_{2}\right]_{2}\right), \quad 2.37 \quad(\mathrm{~s}, \quad 12 \mathrm{H}$, $\left.\left(\mathrm{CH}_{3}\right)_{2} \mathrm{NC}\left[\mathrm{NCH}\left(\mathrm{CH}_{3}\right)_{2}\right]_{2}\right), 1.58\left(\mathrm{~d}, 12 \mathrm{H},\left(\mathrm{CH}_{3}\right)_{2} \mathrm{HCN}=\mathrm{C}\left[\mathrm{NCH}\left(\mathrm{CH}_{3}\right)_{2}\right]_{2}\right), 1.55(\mathrm{~d}, 6 \mathrm{H}$, $\left.\mathrm{NCH}\left(\mathrm{CH}_{3}\right)_{2}\right), 1.41$ (d, 6H, $\left.\mathrm{NCH}\left(\mathrm{CH}_{3}\right)_{2}\right), 1.32$ (d, 6H, $\left.\mathrm{NCH}\left(\mathrm{CH}_{3}\right)_{2}\right), 1.29$ (d, 6H, $\left.\mathrm{NCH}\left(\mathrm{CH}_{3}\right)_{2}\right), 1.03\left(\mathrm{~d}, 6 \mathrm{H}, \mathrm{NCH}\left(\mathrm{CH}_{3}\right)_{2}\right)$. Mass spectrum (EI, m/z) (rel. intensity, \%): $615,\left(6.0, \mathrm{M}^{+}\right)$

\subsubsection{Bis(acetamidinate) zirconium mono(dianionic guanidinate), 24}

In a $100 \mathrm{~mL}$ round bottom flask $1.38 \mathrm{~g}$ of $\left[\mathrm{MeC}\left(\mathrm{N}^{i} \mathrm{Pr}\right)_{2}\right]_{2} \mathrm{ZrCl}_{2}(3.1 \mathrm{mmol})$ was mixed with $40 \mathrm{~mL}$ of diethyl ether and allowed to stir for $10 \mathrm{~min} .0 .67 \mathrm{~g}$ of $\left[{ }^{i} \operatorname{PrNC}\left(\mathrm{N}^{i} \operatorname{Pr}\right)_{2}\right] \mathrm{Li}_{2}$ (3.1 mmol) was used in situ and was slowly added to the suspended solution while stirring at room temperature. The colour changed from a white solution to an iridescent yellow solution, the reaction was allowed to stir over night. The flask was then evacuated to dryness revealing a vibrant yellow powder and then redissolved in about 20 $\mathrm{mL}$ of tetrahydrofuran (THF) to separate the $\mathrm{LiCl}$ from the desired product. The mixture was then filtered and the yellow mother liqueur was evacuated to dryness to reveal $1.38 \mathrm{~g}$ of a yellow amorphous powder. The crude yield was found to be $72 \%$. The yellow powder was dissolved in about $10 \mathrm{~mL}$ of diethyl ether and placed in the freezer overnight. The resultant colourless powder was filtered and weighed at $1.0 \mathrm{~g}$, a percent yield of 52\%. ${ }^{1} \mathrm{H}$ NMR $\left(300 \mathrm{MHz}, \mathrm{C}_{6} \mathrm{D}_{6}\right): \delta 4.47\left(\mathrm{~m}, 1 \mathrm{H}, \mathrm{NCH}\left(\mathrm{CH}_{3}\right)_{2}\right), 4.44(\mathrm{~m}, 1 \mathrm{H}$, $\left.\mathrm{NCH}\left(\mathrm{CH}_{3}\right)_{2}\right), 4.30\left(\mathrm{~m}, 1 \mathrm{H}, \mathrm{NCH}\left(\mathrm{CH}_{3}\right)_{2}\right), 3.57\left(\mathrm{~m}, 2 \mathrm{H}, \mathrm{NCH}\left(\mathrm{CH}_{3}\right)_{2}\right), 3.24(\mathrm{~m}, 2 \mathrm{H}$, $\left.\mathrm{NCH}\left(\mathrm{CH}_{3}\right)_{2}\right), 1.57$ (d, 6H, $\left.\mathrm{NCH}\left(\mathrm{CH}_{3}\right)_{2}\right), 1.52\left(\mathrm{~s}, 6 \mathrm{H}, \mathrm{CCH}_{3}\right), 1.46$ (d, 6H, $\left.\mathrm{NCH}\left(\mathrm{CH}_{3}\right)_{2}\right)$, $1.33\left(\mathrm{~m}, 18 \mathrm{H}, \mathrm{NCH}\left(\mathrm{CH}_{3}\right)_{2}\right), 1.32\left(\mathrm{~d}, 6 \mathrm{H}, \mathrm{NCH}\left(\mathrm{CH}_{3}\right)_{2}\right), 1.20\left(\mathrm{~d}, 6 \mathrm{H}, \mathrm{NCH}\left(\mathrm{CH}_{3}\right)_{2}\right), 1.15$ (d, 6H, $\left.\mathrm{NCH}\left(\mathrm{CH}_{3}\right)_{2}\right)$. 


\subsection{Structural Determination for Compound 22}

A suitable crystal was mounted with viscous oil on a plastic mesh and cooled to the data collection temperature. Unit cell parameters were determined using data frames from four different sections of the Ewald sphere. SADABS multi-scan absorption corrections were applied. No symmetry higher than orthorhombic was observed. Solution in the centrosymmetric space group option, Ccca, yielded chemically reasonable and computationally stable results of refinement. The structure was solved using direct methods and refined with full matrix least squares procedures of F2 data. All hydrogen atoms were treated as idealized contributions and all non-hydrogen atoms were refined with anisotropic displacement coefficients. Atomic scattering factors are contained in the SHELXTL program library. 


\subsection{References}

${ }^{1}$ Duncan, A.P., Mullins, S.M., Arnold, J., Bergman, R.G., Organomet, 2001, 20, 1808 - 1819.

${ }^{2}$ (a) Devi, A., Bhakta, R., Milanov, A., Hellwig, M., Berraca, D., Tondello, E., Thomas, R., Ehrhart, P., Winter, M., Fischer, R., Dalton Trans., 2007, 1671 -1676. (b) Milanov, A. P., Bhakta, R., Winter,

M., Klaus Merzb, K., Devia, A.; Acta Cryst., 2005, C61, m370.

${ }^{3}$ Green, M.L., Gusev, E.P., Degraeve, R., Garfunkel, E.L.; J. Appl. Phys., 2001, 90, 5, 2057.

${ }^{4}$ Hausmann, D.M., Kim, E., Becker, J., Gordon, R.G.; Chem. Mater., 2002, 14, 4350.

${ }^{5}$ Balog, M., Schieber, M., Michman, M., Patai, S.; Thin Solid Films, 1972, 47, 109.

${ }^{6}$ Gray, Paul R., Hurst, Paul J., Lewis, Stephen H., and Meyer, Robert G.; Analysis and Design of Analog Integrated Circuits $5^{\text {th }}$ Ed. New York, Wiley, 2009, 40.

${ }^{7}$ Rowley, C.N.; DiLabio, G.A.; Barry, S.T. Inorg.Chem. 2005, 44, 1983.

${ }^{8}$ (a) Kissounko, D.A., Zabalov, M.V., Brusova, G.P., Lemenovskii, D.A.; Russian Chem. Rev., 2006, 75(5), 351 - 374. (b) Baker, J., Kilner, M.; Coord. Chem. Rev., 1994, 133, 219. (c) Edelmann, F.T.;

Coord. Chem. Rev., 1994, 137, 403.

${ }^{9}$ Bailey, P.J., Pace, S.; Coord. Chem. Rev., 2001, $214,91$.

${ }^{10}$ Milanov, A., Bhakta, R., Baunemann, A., Becker, H.W., Thomas, R., Erhart, P., Winter, M., Devi, A.; Inorg. Chem., 2006, 45, 26, 11008.

${ }^{11}$ Unpublished results from Richeson, D.S.

${ }^{12}$ Bazinet, P., Wood, D., Yap, G. P. A., Richeson, D. S.; Inorg. Chem., 2003, 42, 6225

${ }^{13}$ Macaulay, R., Burnelle, L.A., Sandorfy, C.; Theoret. Chim. Acta. (Ber.)., 1973, $29,1$.

${ }^{14}$ The partial $\pi$-bonding character of the exocyclic amide in guanidinate ligands is a common feature. See, for example: Kenney, A. P., Yap, G. P. A., Richeson, D. S., Barry, S. T.; Inorg. Chem., 2005 , 44 , 2926.

${ }^{15}$ Aeilts, S.L., Coles, M.P., Swenson, D.C., Jordan, R.F.; Organomet, 1998, 17(15), 3265.

${ }^{16}$ Thirupathi, N., Yap, G. P. A., Richeson, D. S.; Chem. Commun., 1999, 2483. 


\section{Chapter 8: $\quad$ Future Work}

This thesis presented the synthesis, characterization, and thermolysis of twenty one heteroleptic organometallic compounds, two homoleptic titanium (III) complexes, and one new ligand. A large portion of the work focused on the synthesis of novel ancillary ligands for potential use in ALD and CVD processes (Chapter 2). The "ip" ligands were engineered to prevent CDI deinsertion (Scheme 2-1 and Figure 2-1) and the melting point could be tuned by simply altering the R-group of the exocyclic nitrogen (Table 2-2). It was found that the longer and the less branched the alkyl group, the lower the melting point.

Three heteroleptic aluminum species were synthesized (Chapter 2), out of which, only one was not fully purified. Repeating this reaction in a more controlled manner (perhaps at lower temperatures) may allow the isolation of pure diethyl aluminum "npip". Alkyl elimination was the sole synthetic method that was attempted throughout this work. One may attempt the salt metathesis synthetic route to see if this would produce purer results. Once isolated in good yields, further studies, such as sealed NMR tube boil-ups as well as TG and DSC analysis should be conducted and the results compared to the analogous diethyl aluminum amidinate species (Figure 2-7). If suitable, ALD should be attempted with this species as well.

DFT calculations should be conducted to help discover the isomerization of these dimers in solution (Scheme 2-5). This would help to discern the decomposition pathway of the organometallic species and the thermolysis of the "ip" ligands could then be compared more thoroughly to the thermolysis of amidinates and guanidinates. This will 
help to design and engineer optimal precursors for both ALD and CVD processes. Since the melting points of these ligands can be tuned by simply changing the R-group of the exocyclic nitrogen, and the melting point trend can be carried through when reacted to a metal centre (Table 2-5), these ligands should be used with many different metals and analyzed for ALD purposes. This presents the opportunity for a great deal of future work in synthetic inorganic chemistry, resulting in many novel compounds.

Five heteroleptic titanium (III) guanidinate species were synthesized in this work (Figure 3-1 and Table 3-1). Only one species was studied for the surface reactivity with high surface area silica. It would be very interesting to see if changing the $\mathrm{R}$ groups of the exocyclic position of the guanidinate ligand would change the absorption of the titanium species onto the oxide substrate. Perhaps compound $\mathbf{5}$ (which has a proton on the exocyclic nitrogen) would have a different bonding arrangement than compounds 6 , 7, or $\mathbf{8}$, as they each have a bulkier exocyclic nitrogen (Figure 3-1). Hydrogen bonding might be suppressed by the bulkier species; thus the guanidinate ligand may not be stabilized upon exposure to high surface area silica - no matter the surface hydroxyl concentration (Figure 3-8 and Figure 3-11). Further exposure experiments can be conducted to fully understand the chemisorption of this family of heteroleptic titanium species.

An extremely stable monomer was produced during the exposure experiments of compound 5 (Chapter 3), as indicated by the lengthy oxidation that took place when exposed to air. ALD was attempted with $\mathrm{NH}_{3}$, however, no film was produced. It would be beneficial to either attempt ALD with a stronger reductant or use plasma or radical enhanced ALD to make the desired TiN films. 
Four heteroleptic titanium (III) amidinate complexes were synthesized throughout this work (Figure 4-1). Their thermolysis was also studied with promising results (Table 4-3). Conducting exposure experiments is the next step for this family of heteroleptic titanium species. It would be interesting to see if the adsorption of these species would be similar to their guanidinate analogues. Without the exocyclic nitrogen for $\mathrm{H}$-bonding stabilization with surface hydroxyl species, would the amidinate ligands be able to withstand the elevated temperatures of the exposure experiment?

ALD was attempted with $\mathrm{H}_{2} \mathrm{O}$ as the reducing precursor and the acetamidinate titanium species as the metallic precursor; however, no film was produced (Figure 4-6). $\mathrm{TiO}_{2}$ film deposition could be repeated with a stronger reductant such as ozone or hydrogen peroxide. A TiN film deposition could also be attempted with compound $\mathbf{1 1}$ and $\mathrm{NH}_{3}$, as the reactivity of this compound might be higher than the guanidinate analogue.

Three heteroleptic titanium (IV) species were synthesized within this work (Scheme 6-1 and Table 6-1). Their synthesis was successful; however, their thermolysis was not. The poor stability of these compounds may be due to the monodentate amido ligands. Perhaps the stability of these compounds could be increased if a bulkier ligand, such as cyclopentadienyl, was used in place of the small monodentate amido ligand. The synthesis of a bisguanidinate or bisamidinate with two "ip" ligands, [(guan $)_{2} \operatorname{Ti}(\mathrm{ip})_{2}$ ] or [(amid $\left.)_{2} \mathrm{Ti}(\mathrm{ip})_{2}\right]$, would also be interesting to study. The bidentate nature of the amidinate and guanidinate ligand could help increase the thermal stability.

Another interesting branch of chemistry that could be explored concerning this family of titanium (III) and titanium (IV) heteroleptic species is catalysis. Previously, 
$\left[\mathrm{Cp}_{2} \mathrm{TiCl}\right]_{2}$ has been employed as a catalyst for the intermolecular addition of epoxides to activated olefins. ${ }^{1}$ The titanium (III) species was used as a transition-metal-centred radical that instigates homolysis of an epoxide $\mathrm{C}-\mathrm{O}$ bond. ${ }^{2}$ A second equivalent of Ti(III) scavenged the resulting radical from solution preventing further additions from occurring. ${ }^{1}$

Many metallocene transition-metal complexes have been used in polymerization of 1alkenes. ${ }^{3}$ Metallocene titanium species were found to undergo reduction when used as soluble Ziegler - Natta catalysts. ${ }^{4}$ Catalysts based on metal complexes with multidentate ligands, such as guanidinates and amidinates, have also been studied. ${ }^{5}$ The fluxional behaviour of these bidentate ligands allows a vacant site at the metal centre to be exposed where insertion of a $\mathrm{C}=\mathrm{C}$ can occur. ${ }^{6}$ It would be interesting to see if this combination of ligands (cyclopentadienyl with guanidinate or amidinate) and the +3 oxidation state can be used as a catalyst for olefin polymerization.

Iminopyrrolidinate ligands have been used as spectator ligands for titanium complexes as pre-catalysts for inter- and intramolecular hydroamination of alkynes. ${ }^{7}$ The "ip" ligands that were synthesized and studied in this work, which are less bulky than previous "ip" ligands, have not been used in such catalysis and so this may be an area to explore in future work of such compounds. 


\subsection{References}

${ }^{1}$ Rajanbabu, T.V., Nugent, W.A.; J. Am. Chem. Soc., 1989, 111, 4525.

${ }^{2}$ Nugent, W.A., Rajanbabu, T.V.; J. Am. Chem. Soc., 1988, 110, 8561.

${ }^{3}$ Hoff, R.E. and Mather, R.T., Handbook of Transition Metal Polymerization Catalysts, Wiley and Sons, New Jersey, 2010, 1-29.

${ }^{4}$ Waters, J.A, Mortimer, G.A.; J. Organomet. Chem., 1974, 77, 231.

${ }^{5}$ Duncan, A.P., Mullins, S.M., Arnold, J., Bergmann, R.G.; Organomet., 2001, 20, 1808.

${ }^{6}$ Liu, S.R., Li, B.X., Liu, J.Y., Li, Y.S.; Polymer, 2010, 51, 9, 1921.

${ }^{7}$ (a) Weitershaus, K., Ward, B.D., Kubiak, R., Muller, C., Wadepohl, H., Doye, S., Gade, L.H.; Dalton Trans., 2009, 4586. (b) Weitershaus, K., Wadepohl, H., Gade, L.H.; Organometallics, 2009, 28, 12 , 3381. (c) Weitershaus, K., Fillol, J.L., Wadepohl, H., Gade, L.H.; Organometallics, 2009, 28, 16 , 4747. 


\section{Appendix A: Crystallographic Data for Compounds 2, 5, 6, 8, $9,10,11,15,16,18,19,22$.}

\section{A.1 Compound 2}

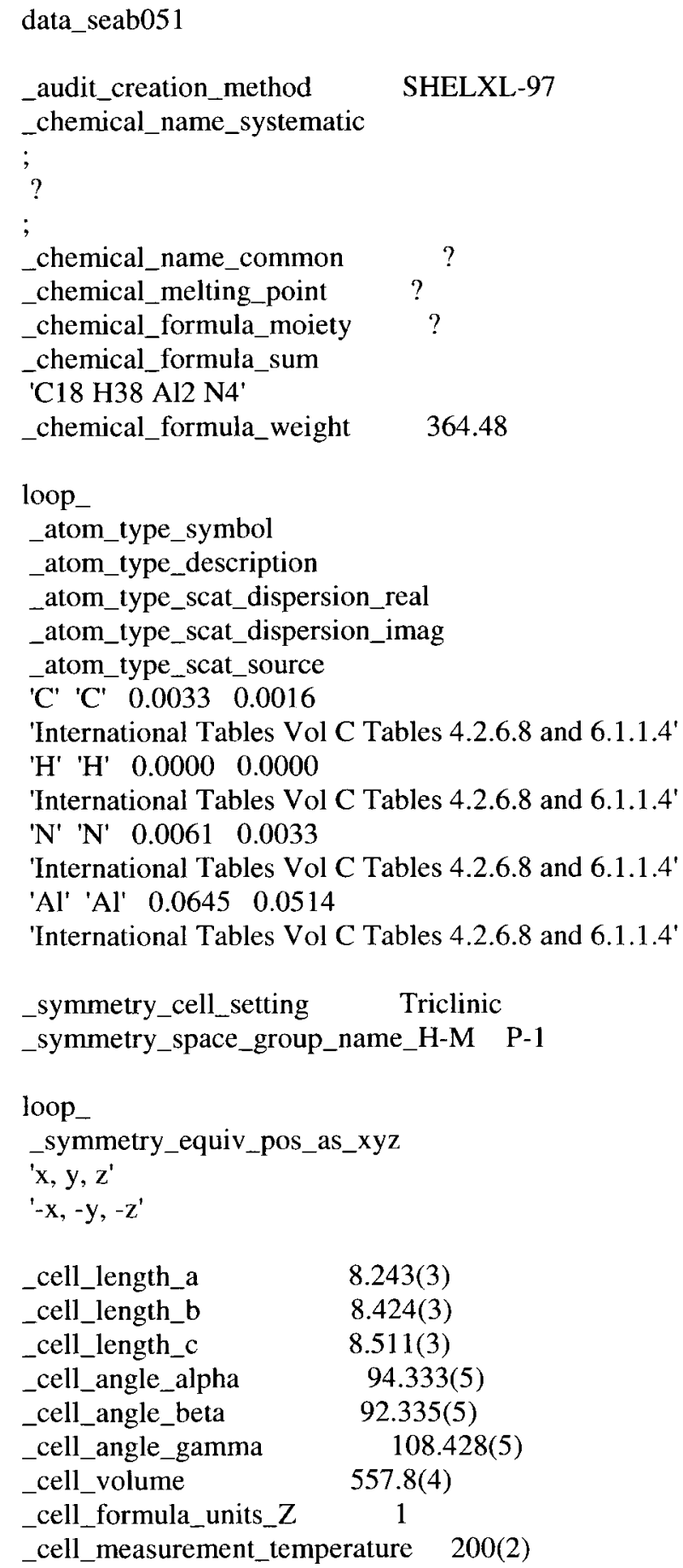




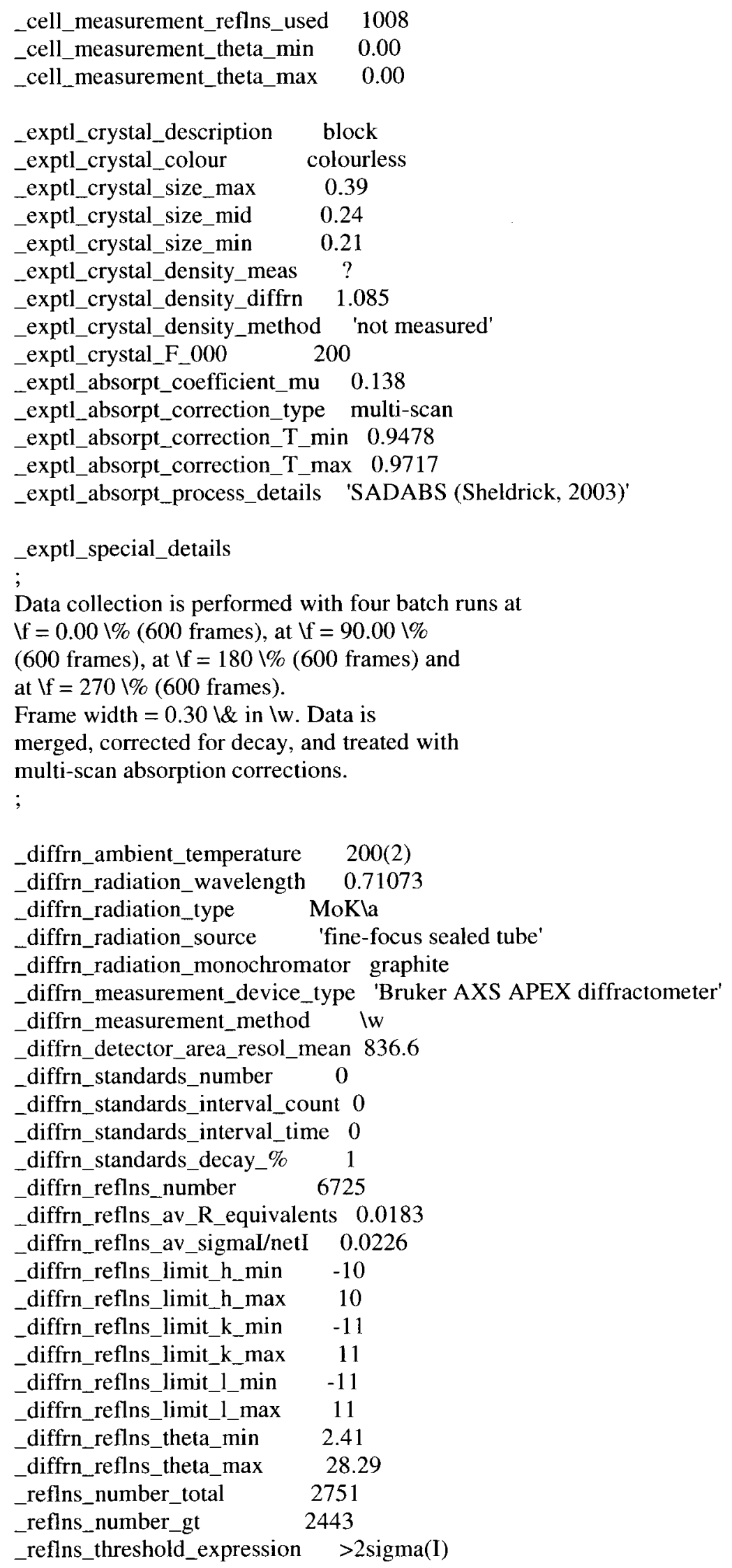


_computing_data_collection _computing_cell_refinement _computing_data_reduction _computing_structure_solution

_computing_structure_refinement 'SHELXL-97 (Sheldrick, 1997)'

_computing_molecular_graphics 'SHELXTL (Sheldrick, 2001)'

_computing_publication_material 'SHELXTL (Sheldrick, 2001)'

_refine_special_details

;

Refinement of $\mathrm{F}^{\wedge} 2^{\wedge}$ against ALL reflections. The weighted $\mathrm{R}$-factor $w R$ and goodness of fit $S$ are based on $F^{\wedge} 2^{\wedge}$, conventional $R$-factors $R$ are based on $F$, with $F$ set to zero for negative $\mathrm{F}^{\wedge} 2^{\wedge}$. The threshold expression of $\mathrm{F}^{\wedge} 2^{\wedge}>2 \operatorname{sigma}\left(\mathrm{F}^{\wedge} 2^{\wedge}\right)$ is used only for calculating $\mathrm{R}$-factors $(\mathrm{gt})$ etc. and is not relevant to the choice of reflections for refinement. R-factors based on $\mathrm{F}^{\wedge} 2^{\wedge}$ are statistically about twice as large as those based on F, and Rfactors based on ALL data will be even larger.

;

_refine_ls_structure_factor_coef Fsqd

_refine_ls_matrix_type full

_refine_ls_weighting_scheme calc

_refine_ls_weighting_details

'calc $\mathrm{w}=1 /\left[\mathrm{|s} \mathrm{s}^{\wedge} 2^{\wedge}\left(\mathrm{Fo}^{\wedge} 2^{\wedge}\right)+(0.1011 \mathrm{P})^{\wedge} 2^{\wedge}+0.2531 \mathrm{P}\right]$ where $\mathrm{P}=\left(\mathrm{Fo}^{\wedge} 2^{\wedge}+2 \mathrm{Fc}^{\wedge} 2^{\wedge}\right) / 3^{\prime}$

_atom_sites_solution_primary direct

_atom_sites_solution_secondary difmap

_atom_sites_solution_hydrogens geom

_refine_ls_hydrogen_treatment constr

refine_ls_extinction_method none

_refine_ls_extinction_coef ?

_refine_ls_number_reflns 2751

_refine_ls_number_parameters 112

_refine_ls_number_restraints 0

_refine_ls_R_factor_all $\quad 0.0600$

_refine_ls_R_factor_gt $\quad 0.0548$

_refine_ls_wR_factor_ref $\quad 0.1665$

_refine_ls_wR_factor_gt $\quad 0.1602$

refine_ls_goodness_of_fit_ref 1.000

_refine_ls_restrained_S_all 1.000

_refine_ls_shift/su_max $\quad 0.001$

_refine_ls_shift/su_mean $\quad 0.000$

loop_

_atom_site_label

_atom_site_type_symbol

_atom_site_fract_x

_atom_site_fract_y

atom_site_fract_z

_atom_site_U_iso_or_equiv

_atom_site_adp_type

_atom_site_occupancy

_atom_site_symmetry_multiplicity

_atom_site_calc_flag

_atom_site_refinement_flags

_atom_site_disorder_assembly 
_atom_site_disorder_group

Al Al 0.27594(6) 0.41705(6) 0.43543(6) 0.03427(19) Uani $11 \mathrm{~d} \ldots$

$\mathrm{N} 1 \mathrm{~N} 0.42026(19) 0.28615(18) 0.37441$ (18) $0.0367(3)$ Uani $11 \mathrm{~d}$. .

$\mathrm{N} 2 \mathrm{~N} 0.68207(18) 0.49081(18) 0.34675(18)$ 0.0362(3) Uani $11 \mathrm{~d} \ldots$

C1 C 0.3159(3) 0.6044(3) 0.3010(2) 0.0450(4) Uani $11 \mathrm{~d}$. . .

H1 A H 0.43930 .66380 .30210 .068 Uiso 11 calc R . .

H1B H 0.25750 .68230 .34150 .068 Uiso 11 calc $R$. .

H1C H 0.27090 .56030 .19260 .068 Uiso 11 calc R . .

C2 C 0.0394(2) 0.2580(3) 0.4150(3) 0.0469(5) Uani $11 \mathrm{~d} \ldots$ H2A H 0.02860 .17350 .49050 .070 Uiso 11 calc R. . H2B H 0.01390 .20230 .30740 .070 Uiso 11 calc $R$. . $\mathrm{H} 2 \mathrm{C} \mathrm{H}-0.04140 .31940 .43720 .070$ Uiso 11 calc $\mathrm{R}$. .

C3 C 0.5673(2) 0.3413(2) 0.3053(2) 0.0357(4) Uani $11 \mathrm{~d}$...

C4 C 0.5897(3) 0.2094(3) 0.1838(2) 0.0463(5) Uani $11 \mathrm{~d} \ldots$

H4A H 0.69250 .17820 .21240 .056 Uiso 11 calc R. .

H4B H 0.59950 .24990 .07730 .056 Uiso 11 calc R. .

C5 C 0.4266(4) 0.0620(3) 0.1904(4) 0.0714(8) Uani 11 d . .

H5A H 0.34810 .05070 .09600 .086 Uiso 11 calc R . .

H5B H $0.4534-0.04400 .19570 .086$ Uiso 11 calc $R$. .

C6 C 0.3472(3) 0.1016(2) 0.3368(3) 0.0482(5) Uani $11 \mathrm{~d}$. .

H6A H 0.22100 .06740 .31850 .058 Uiso 11 calc R . .

H6B H 0.37540 .04210 .42460 .058 Uiso 11 calc R . .

C7 C 0.8166(2) 0.5562(3) 0.2369(2) 0.0437(4) Uani $11 \mathrm{~d}$. .

H7A H 0.82390 .46180 .16400 .052 Uiso 11 calc R . .

H7B H 0.92850 .60530 .29810 .052 Uiso 11 calc $R$. .

C8 C 0.7834(3) 0.6865(4) 0.1427(3) 0.0693(7) Uani $11 \mathrm{~d}$. .

H8B H 0.76300 .77520 .21470 .083 Uiso 11 calc R . .

$\mathrm{H} 8 \mathrm{C} \mathrm{H} 0.67910 .63460 .07110 .083$ Uiso 11 calc R . .

C9 C 0.9345(4) 0.7645(5) 0.0463(4) 0.0891(10) Uani $11 \mathrm{~d}$...

H9C H $0.91720 .8599-0.00310 .134$ Uiso 11 calc R . .

H9D H $0.94380 .6804-0.03590 .134$ Uiso 11 calc $R$. .

H9A H 1.04000 .80360 .11550 .134 Uiso 11 calc R .

loop_

_atom_site_aniso_label
_atom_site_aniso_U_11
_atom_site_aniso_U_22
_atom_site_aniso_U_33
-atom_site_aniso_U_23
_atom_site_aniso_U_13
-atom_site_aniso_U_12

Al $0.0282(3) 0.0327(3) 0.0414(3) 0.0025(2) 0.0038(2) 0.0091(2)$

$\mathrm{N} 10.0343(7) 0.0295(7) 0.0448(8)-0.0013(6) 0.0035(6) 0.0091(6)$

$\mathrm{N} 20.0319(7) 0.0352(7) 0.0425(8) 0.0022(6) 0.0076(6) 0.0119(6)$

C1 $0.0397(9) 0.0445(10) 0.0538(11) 0.0121(8) 0.0047(8) 0.0157(8)$

C2 $0.0320(9) 0.0475(11) 0.0566(11) 0.0033(9) 0.0019(8) 0.0066(8)$

C3 0.0357(8) $0.0366(8) 0.0378(8) 0.0003(7) 0.0014(6) 0.0168(7)$

C4 0.0460(10) $0.0457(10) 0.0484(10)-0.0078(8) 0.0055(8) 0.0187(8)$

C5 $0.0805(18) 0.0446(12) 0.0806(18)-0.0144(11) 0.0273(14) 0.0102(12)$

C6 0.0475(11) 0.0309(9) 0.0623(12) $-0.0033(8) 0.0062(9) 0.0088(8)$

C7 0.0368(9) 0.0463(10) 0.0472(10) 0.0023(8) 0.0111(7) 0.0116(8)

C8 0.0545(13) 0.0847(18) 0.0753(17) 0.0371(14) 0.0184(12) 0.0232(13)

C9 0.081(2) 0.103(3) 0.080(2) 0.0428(18) 0.0242(16) 0.0150(18)

_geom_special_details

; 
All esds (except the esd in the dihedral angle between two 1.s. planes) are estimated using the full covariance matrix. The cell esds are taken into account individually in the estimation of esds in distances, angles and torsion angles; correlations between esds in cell parameters are only used when they are defined by crystal symmetry. An approximate (isotropic) treatment of cell esds is used for estimating esds involving 1.s. planes.

\section{;}

loop

_geom_bond_atom_site_label_1

_geom_bond_atom_site_label_2

_geom_bond_distance

_geom_bond_site_symmetry_2

_geom_bond_publ_flag

Al N1 1.9219(16) . ?

Al N2 1.9285(17) 2_666?

Al C1 1.970(2) . ?

Al C2 1.978(2) . ?

N1 C3 1.332(2) .?

N1 C6 1.483(2) .?

N2 C3 1.326(2).?

N2 C7 1.477(2) .?

$\mathrm{N} 2 \mathrm{Al} 1.9286(17) 2 \_666$ ?

C3 C4 1.520(2) . ?

C4 C5 1.521(3) . ?

C5 C6 1.495(3) . ?

C7 C8 1.493(3) . ?

C8 C9 1.518(4) . ?

loop

_geom_angle_atom_site_label_1

_geom_angle_atom_site_label_2

_geom_angle_atom_site_label_3

_geom_angle

_geom_angle_site_symmetry_1

_geom_angle_site_symmetry_3

_geom_angle_publ_flag

N1 Al N2 113.46(7) . 2_666?

$\mathrm{N} 1 \mathrm{Al} \mathrm{C} 1$ 108.53(8) . . ?

N2 Al C1 108.38(9) 2_666 . ?

$\mathrm{N} 1 \mathrm{Al} \mathrm{C} 2$ 105.67(8) ..?

$\mathrm{N} 2 \mathrm{Al} \mathrm{C} 2$ 106.20(8) 2_666 . ?

$\mathrm{C} 1 \mathrm{Al} \mathrm{C} 2$ 114.73(9) .. ?

C3 N1 C6 108.80(15) . . ?

C3 N1 Al 126.04(12) . . ?

C6 N1 Al 120.66(12) . . ?

C3 N2 C7 117.41(15) . . ?

C3 N2 Al 120.95(12) . 2_666?

C7 N2 Al 118.20(12) . 2_666?

N2 C3 N1 122.62(16) ..?

N2 C3 C4 125.32(16) . . ?

N1 C3 C4 111.96(16) . . ?

C3 C4 C5 103.07(16) . . ?

C6 C5 C4 105.48(18) . . ?

N1 C6 C5 105.83(17) ..?

N2 C7 C8 112.67(17) . . ? 
C7 C8 C9 110.7(2) . . ?

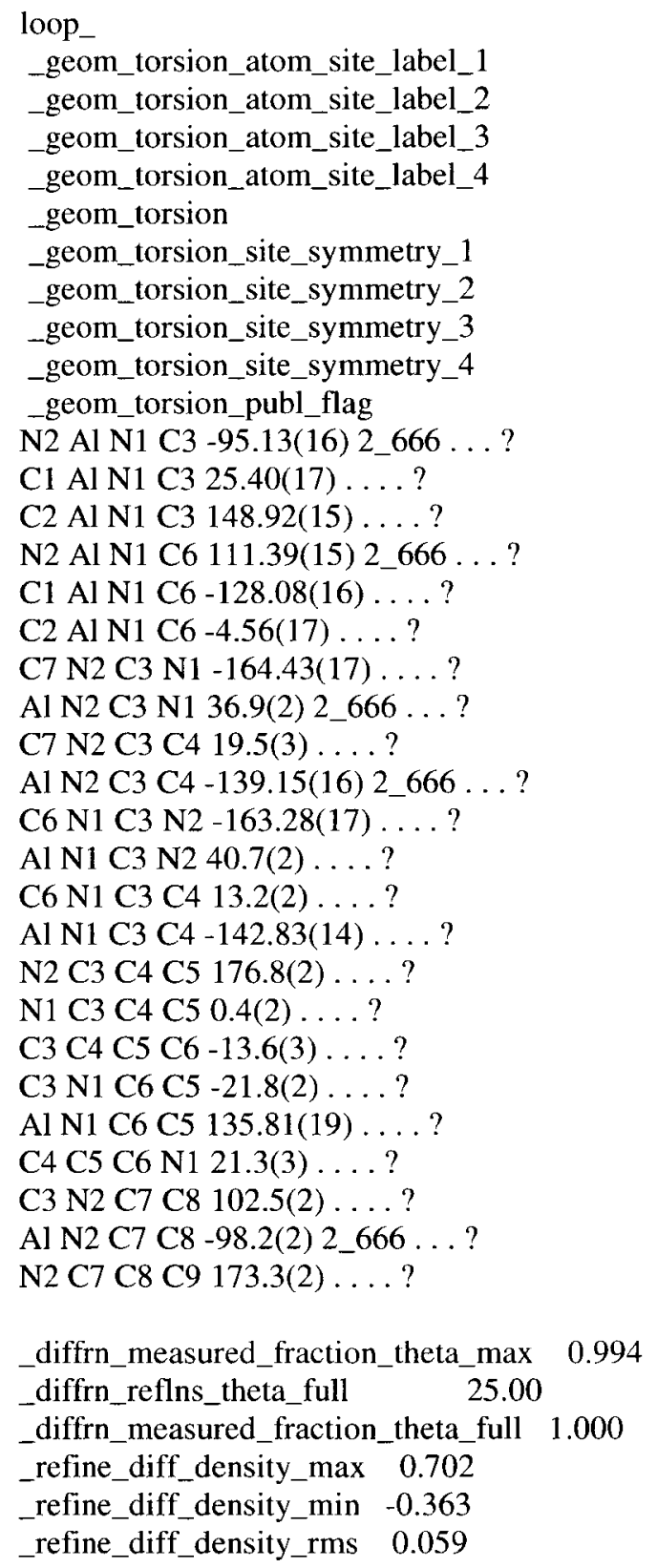




\section{A.2 Compound 5}

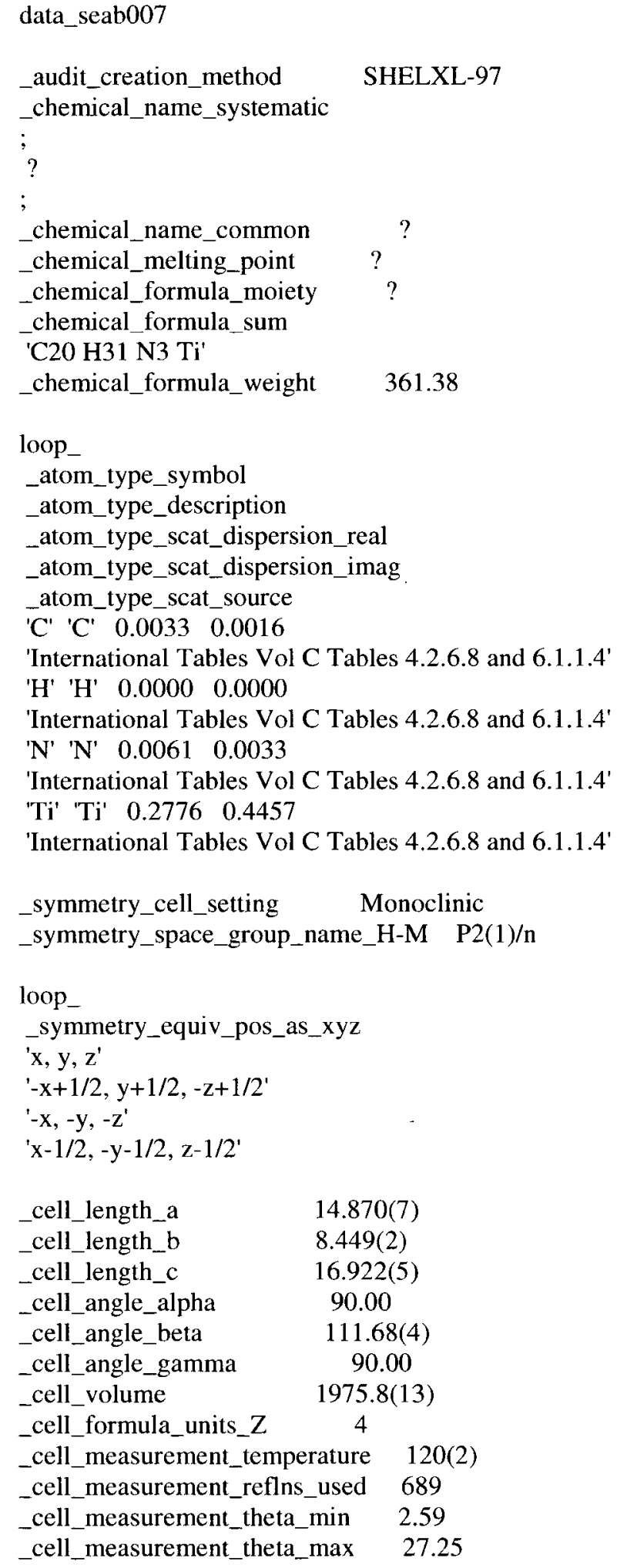




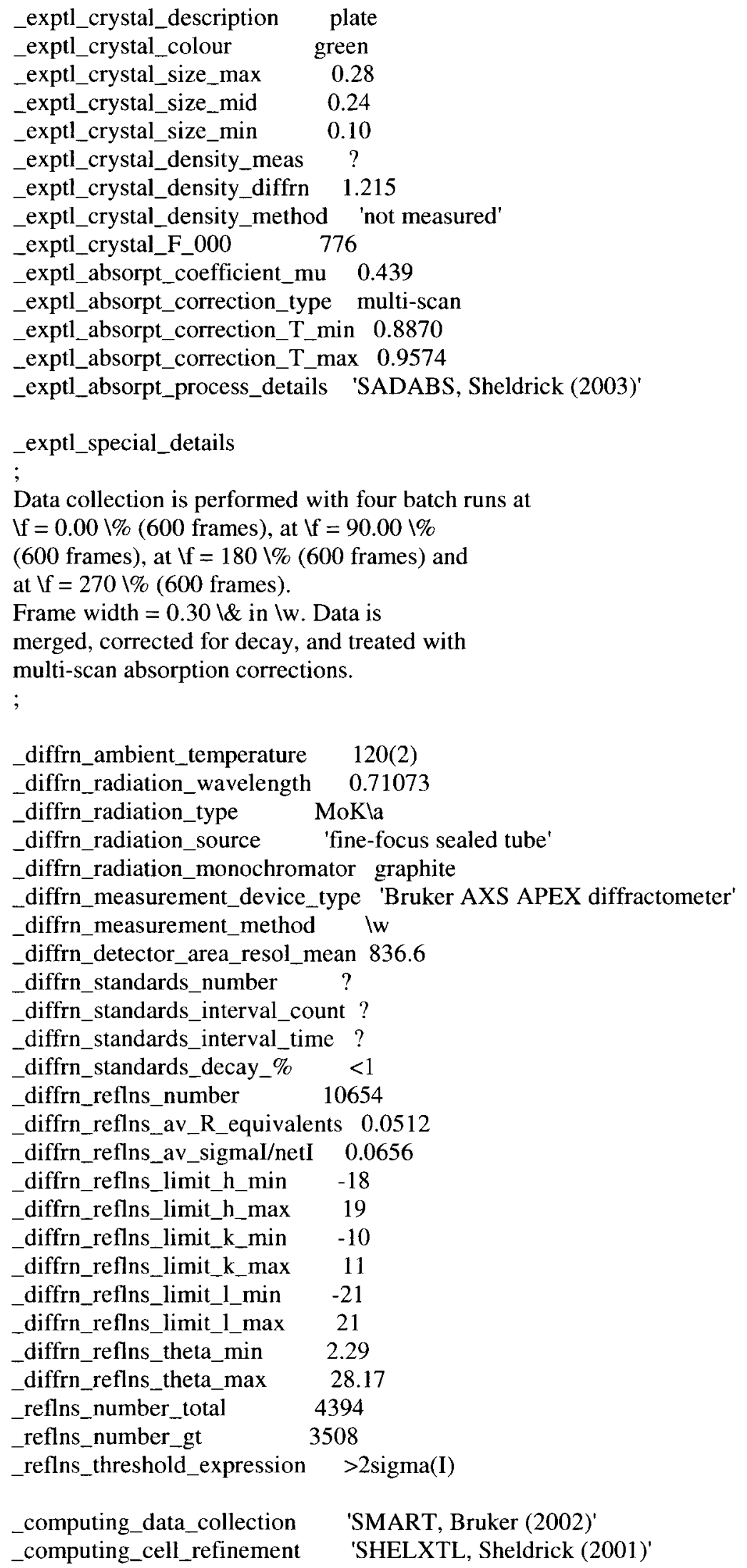


_computing_data_reduction 'SHELXTL, Sheldrick (2001)'

_computing_structure_solution～'SHELXS-97 (Sheldrick, 1990)'

_computing_structure_refinement 'SHELXL-97 (Sheldrick, 1997)'

_computing_molecular_graphics 'SHELXTL, Sheldrick (2001)'

_computing_publication_material 'SHELXTL, Sheldrick (2001)'

_refine_special_details

;

Refinement of $F^{\wedge} 2^{\wedge}$ against ALL reflections. The weighted $R$-factor $w R$ and goodness of fit $\mathrm{S}$ are based on $\mathrm{F}^{\wedge} 2^{\wedge}$, conventional $\mathrm{R}$-factors $\mathrm{R}$ are based on $F$, with $F$ set to zero for negative $F^{\wedge} 2^{\wedge}$. The threshold expression of $\mathrm{F}^{\wedge} 2^{\wedge}>2 \operatorname{sigma}\left(\mathrm{F}^{\wedge} 2^{\wedge}\right)$ is used only for calculating $\mathrm{R}$-factors $(\mathrm{gt}) \mathrm{etc}$. and is not relevant to the choice of reflections for refinement. R-factors based on $\mathrm{F}^{\wedge} 2^{\wedge}$ are statistically about twice as large as those based on F, and $\mathrm{R}$ factors based on ALL data will be even larger.

;

_refine_ls_structure_factor_coef Fsqd

_refine_ls_matrix_type full

_refine_ls_weighting_scheme calc

_refine_ls_weighting_details

'calc $\mathrm{w}=1 /\left[\mathrm{Is}^{\wedge} 2^{\wedge}\left(\mathrm{Fo}^{\wedge} 2^{\wedge}\right)+(0.0665 \mathrm{P})^{\wedge} 2^{\wedge}+0.8038 \mathrm{P}\right]$ where $\mathrm{P}=\left(\mathrm{Fo}^{\wedge} 2^{\wedge}+2 \mathrm{Fc}^{\wedge} 2^{\wedge}\right) / 3^{\prime}$

atom_sites_solution_primary direct

_atom_sites_solution_secondary difmap

_atom_sites_solution_hydrogens geom

_refine_ls_hydrogen_treatment constr

_refine_ls_extinction_method none

_refine_ls_extinction_coef ?

_refine_ls_number_reflns 4394

_refine_ls_number_parameters 223

_refine_ls_number_restraints 0

_refine_ls_R_factor_all $\quad 0.0666$

_refine_ls_R_factor_gt $\quad 0.0505$

_refine_ls_wR_factor_ref $\quad 0.1379$

_refine_Is_wR_factor_gt $\quad 0.1256$

_refine_ls_goodness_of_fit_ref 1.015

_refine_Is_restrained_S_all $\mathbf{1 . 0 1 5}$

_refine_ls_shift/su_max $\quad 0.001$

_refine_ls_shift/su_mean $\quad 0.000$

loop

_atom_site_label

_atom_site_type_symbol

_atom_site_fract_x

_atom_site_fract_y

_atom_site_fract_z

_atom_site_U_iso_or_equiv

_atom_site_adp_type

_atom_site_occupancy

_atom_site_symmetry_multiplicity

_atom_site_calc_flag

_atom_site_refinement_flags

_atom_site_disorder_assembly

_atom_site_disorder_group

Ti Ti - $0.05957(3) 0.93433(5) 0.23392(2) 0.01588(14)$ Uani $11 \mathrm{~d} \ldots$

N1 N 0.04935(12) 0.8675(2) $0.35398(11) 0.0164(4)$ Uani $11 \mathrm{~d} \ldots$ 
$\mathrm{N} 2 \mathrm{~N} 0.08344(12) 1.0296(2) 0.26650(11) 0.0170(4)$ Uani $11 \mathrm{~d} \ldots$ $\mathrm{N} 3 \mathrm{~N} 0.21500(12) 0.9526(2) 0.39855(12) 0.0182(4)$ Uani $11 \mathrm{~d} \ldots$ C1 C 0.06682(15) 0.7737(3) 0.43089(14) 0.0194(5) Uani $11 \mathrm{~d} \ldots$ H1A H 0.11270 .83350 .48040 .023 Uiso 11 calc R . . C2 C -0.02759(17) 0.7496(3) 0.44553(16) 0.0272(6) Uani $11 \mathrm{~d} \ldots$ H2A H -0.05170 .85210 .45630 .041 Uiso 11 calc R . . H2B H -0.01600 .68020 .49470 .041 Uiso 11 calc R . . H2C H -0.07570 .70100 .39500 .041 Uiso 11 calc R . C3 C 0.11217(18) 0.6128(3) 0.42626(16) 0.0271(5) Uani $11 \mathrm{~d}$. . H3A H 0.17260 .62890 .41660 .041 Uiso 11 calc $R$. . H3B H 0.06710 .55090 .37930 .041 Uiso 11 calc $R$. . H3C H 0.12580 .55580 .47990 .041 Uiso 11 calc R . . C4 C 0.14194(15) 1.1202(3) 0.22935(14) 0.0193(5) Uani $11 \mathrm{~d} .$. H4A H 0.17981 .20050 .27220 .023 Uiso 11 calc R . . C5 C 0.07515(18) 1.2092(3) 0.15059(16) 0.0307(6) Uani $11 \mathrm{~d} \ldots$ H5A H 0.03671 .28670 .16760 .046 Uiso 11 calc R . . H5B H 0.03181 .13370 .11040 .046 Uiso 11 calc R . H5C H 0.11421 .26390 .12340 .046 Uiso 11 calc R . . C6 C 0.21348(17) 1.0167(3) 0.20760(17) 0.0304(6) Uani $11 \mathrm{~d} \ldots$ H6A H 0.25350 .95770 .25830 .046 Uiso 11 calc R . . H6B H 0.25501 .08360 .18810 .046 Uiso 11 calc $R$. . H6C H 0.17790 .94220 .16250 .046 Uiso 11 calc R . . C7 C 0.11854(14) 0.9526(3) 0.34095(14) 0.0154(4) Uani $11 \mathrm{~d}$. . . C8 C 0.27399(16) 1.0981(3) 0.42402(15) 0.0224(5) Uani $11 \mathrm{~d} \ldots$ H8A H 0.28901 .13460 .37400 .027 Uiso 11 calc R . . C9 C 0.22065(18) 1.2317(3) 0.44863(17) 0.0336(6) Uani $11 \mathrm{~d} \ldots$ H9A H 0.16021 .25460 .40100 .050 Uiso 11 calc R . . H9B H 0.26141 .32660 .46250 .050 Uiso 11 calc R. . H9C H 0.20601 .19970 .49820 .050 Uiso 11 calc R . . C10 C 0.36903(16) 1.0577(3) 0.49481(15) 0.0242(5) Uani $11 \mathrm{~d} \ldots$ H10A H 0.40120 .97250 .47600 .036 Uiso 11 calc $R$. . H10B H 0.35661 .02290 .54510 .036 Uiso 11 calc R. . H10C H 0.41081 .15140 .50910 .036 Uiso 11 calc R . . C11 C -0.00570(17) 0.6971(3) 0.18609(16) 0.0272(6) Uani $11 \mathrm{~d} \ldots$ H1 1A H 0.05870 .64530 .21450 .033 Uiso 11 calc R . . C12 C -0.02940(17) 0.8045(3) 0.11765(16) 0.0277(6) Uani $11 \mathrm{~d}$... H12A H 0.01550 .84290 .09000 .033 Uiso 11 calc R. . C13 C -0.12961(17) 0.8343(3) 0.08917(15) 0.0267(5) Uani $11 \mathrm{~d} \ldots$ H13A H -0.1681 0.8973 0.0378 0.032 Uiso 11 calc R .

C14 C -0.16774(16) 0.7432(3) 0.13933(15) 0.0251(5) Uani $11 \mathrm{~d} \ldots$ H14A H -0.23800 .73080 .12920 .030 Uiso 11 calc R . .

C15 C -0.09161(17) 0.6585(3) 0.19959(16) 0.0252(5) Uani $11 \mathrm{~d} \ldots$ H15A H -0.09850 .57440 .23860 .030 Uiso 11 calc R . .

C16 C -0.14879(17) 1.1771(3) 0.18990(17) 0.0304(6) Uani $11 \mathrm{~d} \ldots$ H16A H -0.1540 1.2413 0.1387 0.037 Uiso 11 calc R . .

C17 C -0.21428(17) 1.0594(3) 0.19371(19) 0.0336(7) Uani $11 \mathrm{~d} \ldots$ H17A H -0.2741 1.0263 0.1454 0.040 Uiso 11 calc R . .

C18 C -0.18760(17) 1.0093(3) 0.27927(19) 0.0332(6) Uani $11 \mathrm{~d} \ldots$ H18A H -0.22550 .93670 .30190 .040 Uiso 11 calc R . .

C19 C -0.10689(18) 1.1023(3) 0.32835(17) 0.0287(6) Uani $11 \mathrm{~d} \ldots$ H19A H - 0.07631 .10270 .39180 .034 Uiso 11 calc R . C20 C -0.08357(17) $1.2043(3)$ 0.27400(17) 0.0277(6) Uani $11 \mathrm{~d} \ldots$ H20A H -0.03301 .28900 .29210 .033 Uiso 11 calc R .

loop_

_atom_site_aniso_label 


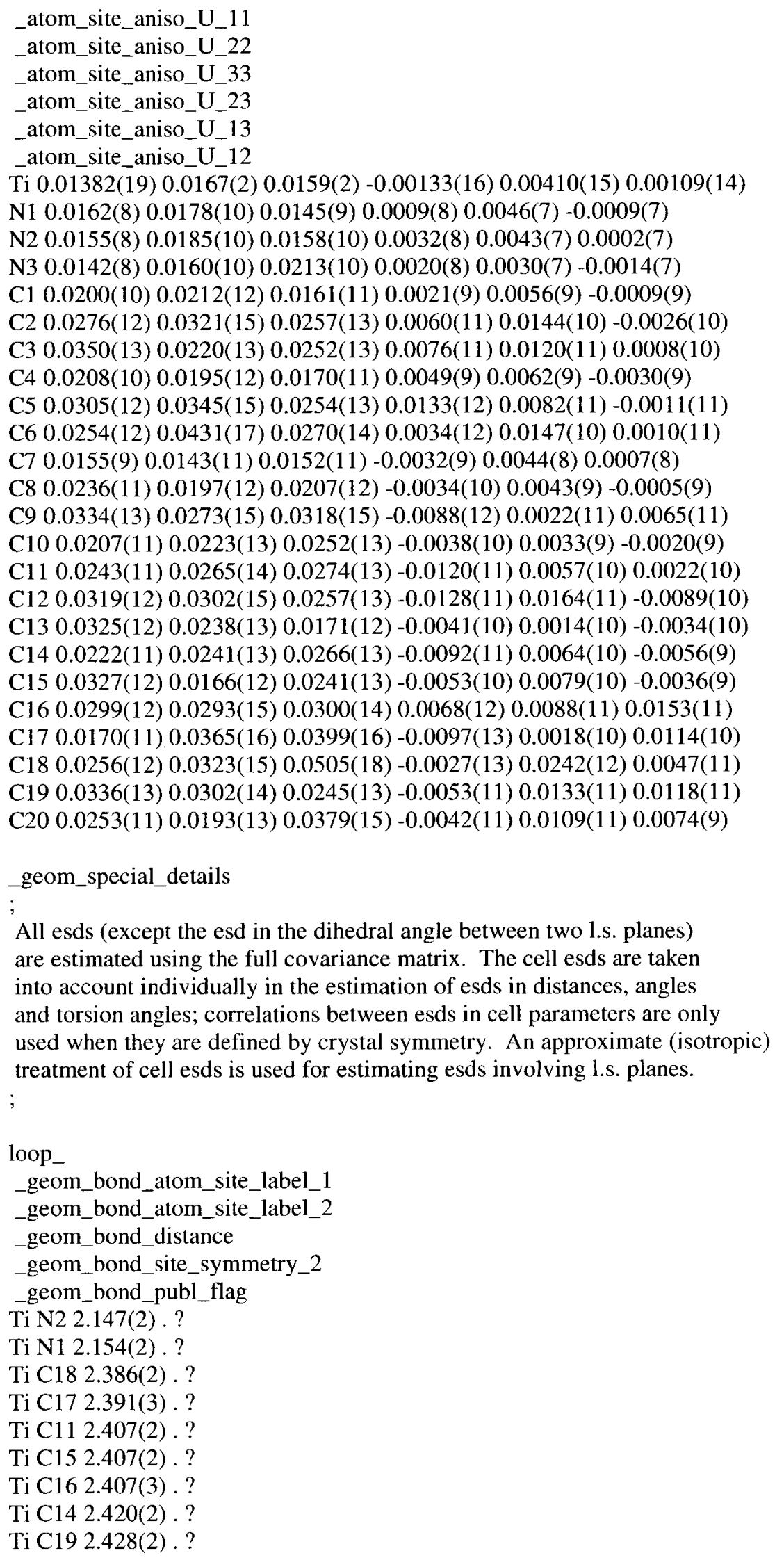


Ti C13 2.432(3) . ?

Ti C12 2.435(2) . ?

Ti C20 2.443(2) . ?

N1 C7 1.339(3).?

N1 C1 1.463(3) .?

N2 C7 1.340(3) . ?

N2 C4 1.464(3). ?

N3 C7 1.405(3) . ?

N3 C8 1.479(3).?

C1 C2 1.527(3) .?

C1 C3 1.532(3) . ?

C4 C6 1.524(3) . ?

C4 C5 1.533(3) .?

$\mathrm{C} 8 \mathrm{C} 10$ 1.516(3) . ?

C8 C9 1.523(3) . ?

C11 C12 1.410(4) . ?

C11 C15 1.416(3) . ?

C12 C13 1.409(3) . ?

C13 C14 1.411(4) ?

C14 C15 1.407(3) . ?

C16 C17 1.410(4) . ?

C16 C20 1.414(4) . ?

C17 C18 1.417(4) . ?

C18 C19 1.418(4) . ?

C19 C20 1.394(4) . ?

loop

_geom_angle_atom_site_label_1

_geom_angle_atom_site_label_2

_geom_angle_atom_site_label_3

_geom_angle

_geom_angle_site_symmetry_1

_geom_angle_site_symmetry_3

_geom_angle_publ_flag

N2 Ti N1 61.81(7) ..?

N2 Ti C18 130.57(9) .. ?

N1 Ti C18 100.23(9) . . ?

N2 Ti C17 131.69(9) . . ?

N1 Ti C17 133.92(9)..?

C18 Ti C17 34.52(10) . . ?

N2 Ti C11 88.70(8) .. ?

$\mathrm{N} 1 \mathrm{Ti} \mathrm{C} 1182.60(8) \ldots$ ?

C18 Ti C11 137.17(9) . . ?

C17 Ti C11 132.63(9) . . ?

N2 Ti C15 120.94(8) .. ?

N1 Ti C15 89.23(8) .. ?

C18 Ti C15 102.96(9) . . ?

C17 Ti C15 105.99(9) . . ?

C11 Ti C15 34.23(8) . . ?

N2 Ti C16 98.07(9) ..?

N1 Ti C16 130.69(8) ..?

C18 Ti C16 57.27(10) . .?

C17 Ti C16 34.18(9) ..?

C11 Ti C16 145.04(9) . . ?

C15 Ti C16 135.51(9) . . ?

N2 Ti C14 140.67(8) . . ? 
N1 Ti C14 122.24(8) . . ?

C18 Ti C14 88.59(9) . . ?

C17 Ti C14 76.83(9) . . ?

C11 Ti C14 56.24(8) . . ?

C15 Ti C14 33.91(8) . . ?

C16 Ti C14 102.02(9) . .?

N2 Ti C19 96.45(9) . . ?

N1 Ti C19 80.35(8) .. ?

C18 Ti C19 34.26(9) .. ?

C17 Ti C19 56.39(9) .. ?

C11 Ti C19 157.16(9) . . ?

C15 Ti C19 130.20(9) . . ?

C16 Ti C19 56.27(9) . . ?

C14 Ti C19 122.83(9) . . ?

N2 Ti C13 113.83(8) . . ?

N1 Ti C13 138.76(8) ..?

C18 Ti C13 108.69(10) . . ?

C17 Ti C13 81.83(10) . . ?

C11 Ti C13 56.20(9) . . ?

C15 Ti C13 56.45(9) .. ?

C16 Ti C13 90.14(9) . . ?

C14 Ti C13 33.80(8) . . ?

C19 Ti C13 138.22(9) . . ?

$\mathrm{N} 2$ Ti C12 85.16(8) .. ?

N1 Ti C12 110.20(8) . . ?

C18 Ti C12 141.86(9) . . ?

C17 Ti C12 114.48(10) .. ?

C11 Ti C12 33.85(9) . . ?

C15 Ti C12 56.48(9) .. ?

C16 Ti C12 112.26(9) . . ?

C14 Ti C12 55.99(8) ..?

C19 Ti C12 168.53(9) . . ?

C13 Ti C12 33.66(8) . . ?

N2 Ti C20 79.11(8) . . ?

N1 Ti C20 96.84(8) . .?

C18 Ti C20 56.45(9) .. ?

C17 Ti C20 56.11(9) .. ?

C11 Ti C20 166.33(9) . . ?

C15 Ti C20 159.22(8) . . ?

C16 Ti C20 33.89(9).. ?

C14 Ti C20 132.62(8) . . ?

C19 Ti C20 33.27(9) . . ?

C13 Ti C20 123.50(9) . . ?

C12 Ti C20 137.25(9) . . ?

C7 N1 C1 122.89(18) ...?

C7 N1 Ti 93.41(14) . .?

C1 N1 Ti 143.69(14)..?

C7 N2 C4 124.80(18) ..?

C7 N2 Ti 93.69(13) . . ?

C4 N2 Ti 140.85(14) ..?

C7 N3 C8 123.05(18) . . ?

N1 C1 C2 110.19(18) . . ?

N1 C1 C3 111.83(19) . . ?

C2 C1 C3 109.77(19) . . ?

N2 C4 C6 112.5(2) ..?

$\mathrm{N} 2 \mathrm{C} 4 \mathrm{C} 5109.45(18) \ldots$ ? 
C6 C4 C5 110.9(2) . ?

N1 C7 N2 111.07(18) ..?

N1 C7 N3 122.4(2) ..?

N2 C7 N3 126.54(19) . .?

N1 C7 Ti 55.69(11) . ?

N2 C7 Ti 55.39(11)..?

N3 C7 Ti 176.57(15) . . ?

N3 C8 C10 108.80(19) . . ?

N3 C8 C9 112.5(2) .. ?

C10 C8 C9 112.2(2) .. ?

C12 C11 C15 108.3(2) . . ?

C12 C11 Ti 74.17(15)..?

C15 C11 Ti 72.88(14) . . ?

C13 C12 C11 107.9(2) . ? ?

C13 C12 Ti 73.05(14) ..?

C11 C12 Ti 71.98(14) ..?

C12 C13 C14 107.8(2) . . ?

C12 C13 Ti 73.28(14) . . ?

C14 C13 Ti 72.62(14) ..?

C15 C14 C13 108.6(2) .. ?

C15 C14 Ti 72.54(14)..?

C13 C14 Ti 73.58(14) . . ?

C14 C15 C11 107.3(2) . ?

C14 C15 Ti 73.55(14) ..?

C11 C15 Ti 72.89(14) .. ?

C17 C16 C20 107.3(2) . . ?

C17 C16 Ti 72.29(15) .. ?

C20 C16 Ti 74.47(14)..?

C16 C17 C18 108.7(2) . . ?

C16 C17 Ti 73.53(14) . .?

C18 C17 Ti 72.56(14) . . ?

C17 C18 C19 106.8(2) . ?

C17 C18 Ti 72.92(14) . . ?

C19 C18 Ti 74.48(14) . .?

C20 C19 C18 108.6(2) . . ?

C20 C19 Ti 73.98(14) ..?

C18 C19 Ti 71.26(14) . .?

$\mathrm{C} 19 \mathrm{C} 20 \mathrm{C} 16$ 108.6(2) . . ?

C19 C20 Ti 72.75(14) ..?

C16 C20 Ti 71.64(14) . .?

loop

_geom_torsion_atom_site_label_1

_geom_torsion_atom_site_label_2

_geom_torsion_atom_site_label_3

_geom_torsion_atom_site_label_4

_geom_torsion

_geom_torsion_site_symmetry_1

_geom_torsion_site_symmetry_2

_geom_torsion_site_symmetry_3

_geom_torsion_site_symmetry_4

_geom_torsion_publ_flag

N2 Ti N1 C7 $-0.88(12) \ldots$ ?

C18 Ti N1 C7 -131.65(14) ....?

C17 Ti N1 C7 $-122.99(15) \ldots$ ?

C11 Ti N1 C7 91.63(14) ....? 
C15 Ti N1 C7 125.31(14) ... . ?

C16 Ti N1 C7 -76.36(16) ....?

C14 Ti N1 C7 133.51(13) ....?

C19 Ti N1 C7 -103.61(15) ....?

C13 Ti N1 C7 93.94(17) ....?

C12 Ti N1 C7 71.71(15) ....?

C20 Ti N1 C7 -74.61(14)....?

N2 Ti N1 C1 179.4(3) ....?

C18 Ti N1 C1 48.6(3) .... ?

C17 Ti N1 C1 57.3(3) ....?

C11 Ti N1 C1 -88.1(3)....?

C15 Ti N1 C1 -54.4(3) ... . ?

C16 Ti N1 C1 103.9(3).... ?

C14 Ti N1 C1 $-46.2(3) \ldots$ ?

C19 Ti N1 C1 76.7(3) ....?

C13 Ti N1 C1 $-85.8(3) \ldots$ ?

C12 Ti N1 C1 -108.0(2) ... . ?

C20 Ti N1 C1 105.7(3) ....?

N1 Ti N2 C7 0.88(12) ...?

C18 Ti N2 C7 79.71(17) ....?

C17 Ti N2 C7 126.09(15) ....?

C11 Ti N2 C7 $-81.42(14) \ldots$ ?

C15 Ti N2 C7 -69.31(15) ....?

C16 Ti N2 C7 133.03(14) ... . ?

C14 Ti N2 C7 -106.64(16) ....?

C19 Ti N2 C7 76.28(14)....?

C13 Ti N2 C7 -133.23(13) ....?

C12 Ti N2 C7 -115.13(14) ....?

C20 Ti N2 C7 104.80(14)....?

N1 Ti N2 C4 170.9(3) ....?

C18 Ti N2 C4 -110.3(2) ... . ?

C17 Ti N2 C4 -63.9(3) ....?

C11 Ti N2 C4 88.6(2) ... . ?

C15 Ti N2 C4 100.7(2)....?

C16 Ti N2 C4 -57.0(2) ... . ?

C14 Ti N2 C4 63.4(3) .... ?

C19 Ti N2 C4 -113.7(2) ... ?

C13 Ti N2 C4 36.8(3) ... . ?

C12 Ti N2 C4 54.9(2) ... ?

$\mathrm{C} 20 \mathrm{Ti}$ N2 C4 -85.2(2) ... ? ?

C7 N1 C1 C2 156.0(2) ....?

Ti N1 C1 C2 -24.4(3) ... . ?

C7 N1 C1 C3 $-81.7(3) \ldots$ ?

Ti N1 C1 C3 98.0(3) ....?

C7 N2 C4 C6 63.9(3) ....?

Ti N2 C4 C6 -103.9(2) ....?

C7 N2 C4 C5 -172.3(2) ... . ?

Ti N2 C4 C5 19.9(3)....?

C1 N1 C7 N2 -178.88(19) ....?

Ti N1 C7 N2 1.33(18) ....?

C1 N1 C7 N3 3.2(3) ....?

Ti N1 C7 N3 -176.62(18) ....?

C1 N1 C7 Ti 179.8(2) ....?

C4 N2 C7 N1 -173.7(2) . . . ?

Ti N2 C7 N1 -1.33(19) ....?

C4 N2 C7 N3 4.2(4) ....? 
Ti N2 C7 N3 176.51(19) ....?

C4 N2 C7 Ti-172.3(2) ....?

C8 N3 C7 N1 -136.8(2) ... . ?

C8 N3 C7 N2 45.6(3) ....?

C8 N3 C7 Ti 169(3) .... ?

$\mathrm{N} 2 \mathrm{TiC} 7 \mathrm{~N} 1178.5(2) \ldots$ ?

C18 Ti C7 N1 57.41(16) ... . ?

C17 Ti C7 N1 91.86(19) ... . ?

C11 Ti C7 N1 $-84.79(14) \ldots$ ?

C15 Ti C7 N1 -58.35(15) ....?

C16 Ti C7 N1 123.53(14) .... ?

C14 Ti C7 N1 -69.79(18)....?

C19 Ti C7 N1 73.43(14) ....?

C13 Ti C7 N1 -117.84(15) ....?

C12 Ti C7 N1 -115.76(14) ....?

C20 Ti C7 N1 106.70(14)....?

N1 Ti C7 N2 -178.5(2)....?

C18 Ti C7 N2 -121.09(15)... . ?

C17 Ti C7 N2 -86.64(19) ... . ?

C11 Ti C7 N2 96.71(14) ... . ?

C15 Ti C7 N2 123.15(14) ....?

C16 Ti C7 N2 -54.97(16) ... . ?

C14 Ti C7 N2 111.71(16) ... ?

C19 Ti C7 N2 -105.07(14)...? ?

C13 Ti C7 N2 63.67(17) ... . ?

C12 Ti C7 N2 65.75(14) ... . ?

C20 Ti C7 N2 -71.79(14) ... ?

N2 Ti C7 N3 -125(3) ...? ?

N1 Ti C7 N3 56(3) ....?

C18 Ti C7 N3 114(3) ... ?

C17 Ti C7 N3 148(3) ....?

C11 Ti C7 N3 -29(3) ... . ?

C15 Ti C7 N3 -2(3) ....?

C16 Ti C7 N3 180(100) ....?

C14 Ti C7 N3 -14(3) ....?

C19 Ti C7 N3 130(3) .... ?

C13 Ti C7 N3 -62(3).... ?

C12 Ti C7 N3 -59(3)....?

C20 Ti C7 N3 163(3) ....?

C7 N3 C8 C10 172.8(2) . . . ?

C7 N3 C8 C9 47.8(3) ... ?

N2 Ti C11 C12 -83.23(14) ... ?

N1 Ti C11 C12 -144.97(14) ... . ?

C18 Ti C11 C12 117.95(17) ....?

C17 Ti C11 C12 68.82(19) .... ?

C15 Ti C11 C12 115.4(2) ....?

C16 Ti C11 C12 19.0(2) ....?

C14 Ti C11 C12 77.81(15)....?

C19 Ti C11 C12 173.1(2) ....?

C13 Ti C11 C12 36.86(13) ... . ?

C20 Ti C11 C12 -56.5(4)....?

N2 Ti C11 C15 161.35(15) ... . ?

N1 Ti C11 C15 99.61(15) . ... ?

C18 Ti C11 C15 2.5(2) ....?

C17 Ti C11 C15 -46.6(2) ... ? ?

C16 Ti C11 C15 -96.4(2) ... . ? 
C14 Ti C11 C15 -37.61(14) ....?

C19 Ti C11 C15 57.7(3) ... . ?

C13 Ti C11 C15 -78.55(16) ....?

C12 Ti C11 C15-115.4(2) ....?

C20 Ti C11 C15-171.9(3) ... . ?

$\mathrm{C} 15 \mathrm{C} 11 \mathrm{C} 12 \mathrm{C} 13$ 0.7(3) ....?

Ti C11 C12 C13 -64.71(17) ... . ?

C15 C11 C12 Ti 65.41(17) ... . ?

N2 Ti C12 C13 -149.16(16) ....?

N1 Ti C12 C13 153.27(15) ....?

$\mathrm{C} 18 \mathrm{TiC} 12 \mathrm{C} 13$ 12.5(2) ... ?

C17 Ti C12 C13 -15.14(18) ....?

$\mathrm{C} 11 \mathrm{Ti} \mathrm{C12}$ C13 115.9(2) ....?

C15 Ti C12 C13 78.39(16) ... . ?

C16 Ti C12 C13 -52.41(17) ... . ?

C14 Ti C12 C13 37.32(15)....?

C19 Ti C12 C13-50.6(5) ....?

C20 Ti C12 C13-80.94(18) ... ? ?

N2 Ti C12 C11 94.91(14) ... . ?

N1 Ti C12 C11 37.34(15) ....?

C18 Ti C12 C11-103.46(19) ... . ?

C17 Ti C12 C11 -131.08(15) ... . ?

C15 Ti C12 C11 -37.54(14) ....?

C16 Ti C12 C11 -168.34(14) ....?

C14 Ti C12 C11 -78.61(15) ....?

C19 Ti C12 C11 -166.5(4) ....?

C13 Ti C12 C11 -115.9(2)....?

$\mathrm{C} 20 \mathrm{Ti} \mathrm{C} 12 \mathrm{C} 11$ 163.13(14) ... ?

C11 C12 C13 C14 -0.9(3) ....?

Ti C12 C13 C14 -64.90(17) . . . ? ?

C11 C12 C13 Ti 64.00(17) ....?

N2 Ti C13 C12 33.94(17) ... . ?

N1 Ti C13 C12 -39.8(2) ....?

C18 Ti C13 C12 -171.91(15) ... . ?

C17 Ti C13 C12 166.10(17) ....?

C11 Ti C13 C12 -37.07(15) .... ?

C15 Ti C13 C12 -78.48(16) ....? ?

C16 Ti C13 C12 132.83(16) ....?

C14 Ti C13 C12 -115.4(2) ... . ?

C19 Ti C13 C12 166.67(16) ... . ?

C20 Ti C13 C12 126.50(15) ....?

N2 Ti C13 C14 149.34(14) ... ?

N1 Ti C13 C14 75.58(18) ....?

C18 Ti C13 C14 -56.51(17) ... . ?

C17 Ti C13 C14 -78.50(16) ... . ?

C11 Ti C13 C14 78.33(16) ... ? ?

C15 Ti C13 C14 36.92(14) ....?

C16 Ti C13 C14-111.77(15) ... . ?

C19 Ti C13 C14 -77.93(19) ... . ?

C12 Ti C13 C14 115.4(2) ... . ?

C20 Ti C13 C14-118.10(15) ... . ?

C12 C13 C14 C15 0.8(3) ....?

Ti C13 C14 C15 -64.58(17) . . . ?

C12 C13 C14 Ti 65.34(17) ... ? ?

N2 Ti C14 C15 68.80(19) ... . ?

N1 Ti C14 C15 -14.81(17) ....? 
C18 Ti C14 C15-116.02(16) ... . ?

C17 Ti C14 C15-148.81(16) ....?

C11 Ti C14 C15 37.97(14) ....?

C16 Ti C14 C15-172.09(15) ... . ?

C19 Ti C14 C15 -114.65(15) ....?

C13 Ti C14 C15 116.2(2) ... . ?

C12 Ti C14 C15 79.03(16) ....?

C20 Ti C14 C15 -155.32(14) ... . ?

N2 Ti C14 C13 -47.4(2) ... ?

N1 Ti C14 C13 -130.99(14) ... . ?

C18 Ti C14 C13 127.79(16) ... . ?

C17 Ti C14 C13 95.01(16) ... ? ?

C11 Ti C14 C13-78.21(16) ... . ?

C15 Ti C14 C13 -116.2(2) ....?

C16 Ti C14 C13 71.72(16) ....?

C19 Ti C14 C13 129.16(15) . . . ? ?

C12 Ti C14 C13 -37.16(14) ... . ?

C20 Ti C14 C13 88.50(17) ... . ?

C13 C14 C15 C11 -0.3(3) ... . ?

Ti C14 C15 C11 -65.58(17) ... . ?

C13 C14 C15 Ti 65.25(17) .... ?

C12 C11 C15 C14 -0.2(3) ... ? ?

Ti C11 C15 C14 66.02(17) ....?

C12 C11 C15 Ti -66.26(18) ... ? ?

N2 Ti C15 C14 -136.46(14) ... . ?

N1 Ti C15 C14 167.52(14) ....?

C18 Ti C15 C14 67.20(16) .... ?

C17 Ti C15 C14 31.64(17) . . . ? ?

C11 Ti C15 C14-114.6(2) .... ?

C16 Ti C15 C14 11.1(2) ... ?

C19 Ti C15 C14 90.87(17) ... . ?

C13 Ti C15 C14 -36.80(14) ... . ?

C12 Ti C15 C14 -77.46(16) ... . ?

C20 Ti C15 C14 60.0(3) ....?

N2 Ti C15 C11 -21.88(18) ... ?

N1 Ti C15 C11 -77.91(15) ....?

C18 Ti C15 C11 -178.23(15) ... . ?

C17 Ti C15 C11 146.22(15) ... . ?

C16 Ti C15 C11 125.64(16) ... . ?

C14 Ti C15 C11 114.6(2) ... . ?

C19 Ti C15 C11 -154.56(15) . . . ?

C13 Ti C15 C11 77.77(16) ... . ?

C12 Ti C15 C11 37.12(14) ....?

C20 Ti C15 C11 174.6(2) ... ? ?

N2 $\mathrm{Ti} \mathrm{C16} \mathrm{C17-170.76(16) \ldots .?}$

N1 Ti C16 C17-111.24(17) ... ?

C18 Ti C16 C17 -37.15(16) ....?

C11 Ti C16 C17 89.9(2) ... ?

C15 Ti C16 C17 37.0(2) ...? ?

C14 Ti C16 C17 43.25(18) ... . ?

C19 Ti C16 C17 -78.37(18) ... . ?

C13 Ti C16 C17 75.14(17) ... . ?

C12 Ti C16 C17 101.19(17) ... . ?

C20 Ti C16 C17-114.4(2) ... ? ?

N2 Ti C16 C20 -56.40(16) ....?

N1 Ti C16 C20 3.1(2) ....? 


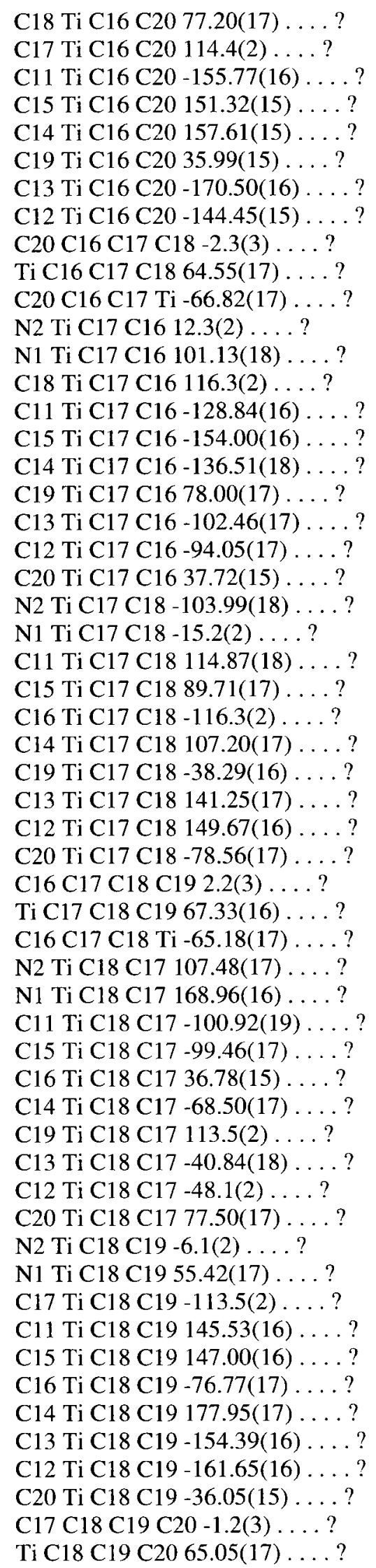


C17 C18 C19 Ti -66.27(16).... ?

N2 Ti C19 C20 58.74(15) ... ? ?

N1 Ti C19 C20 118.65(15) ....?

C18 Ti C19 C20-116.6(2) .... ?

C17 Ti C19 C20 -78.03(16) ... . ?

C11 Ti C19 C20 160.85(19) ... . ?

C15 Ti C19 C20 -160.65(14) ... . ?

C16 Ti C19 C20 -36.67(14) .... ?

C14 Ti C19 C20-119.05(15) ... . ?

C13 Ti C19 C20 -78.71(19) .... ?

C12 Ti C19 C20 -38.7(5) ....?

N2 Ti C19 C18 175.37(16) ... ?

N1 Ti C19 C18 -124.73(17) ... . ?

C17 Ti C19 C18 38.59(16) ....?

C11 Ti C19 C18-82.5(3)....?

C15 Ti C19 C18 -44.0(2) ... ? ?

C16 Ti C19 C18 79.95(18) ... ?

C14 Ti C19 C18 -2.4(2) ....?

C13 Ti C19 C18 37.9(2) ....?

C12 Ti C19 C18 77.9(5) ... . ?

C20 Ti C19 C18 116.6(2) ... . ?

C18 C19 C20 C16 -0.2(3) ... ? ?

Ti C19 C20 C16 63.12(17) ... . ?

C18 C19 C20 Ti -63.30(17) ....?

C17 C16 C20 C19 1.5(3) ... . ?

Ti C16 C20 C19 -63.84(17) ... . ?

C17 C16 C20 Ti 65.34(17) ....?

N2 Ti C20 C19-120.11(16) ... . ?

$\mathrm{N} 1 \mathrm{Ti} \mathrm{C} 20 \mathrm{C} 19-60.61(15) \ldots$. . ?

C18 Ti C20 C19 37.15(15) ....?

C17 Ti C20 C19 78.94(17) ....?

C11 Ti C20 C19-147.4(3).... ?

C15 Ti C20 C19 45.5(3) ....?

C16 Ti C20 C19 117.0(2) ....?

C14 Ti C20 C19 86.59(18) ....?

C13 Ti C20 C19 128.42(15) ... . ?

C12 Ti C20 C19 169.44(14) ... . ?

N2 Ti C20 C16 122.88(16) ....?

N1 Ti C20 C16 -177.62(15) ....?

C18 Ti C20 C16 -79.86(17) ....?

C17 Ti C20 C16 -38.06(16) ... . ?

C11 Ti C20 C16 95.6(4) ....?

C15 Ti C20 C16-71.5(3) ... ?

C14 Ti C20 C16 -30.4(2) ... . ?

C19 Ti C20 C16-117.0(2) ... ?

C13 Ti C20 C16 11.41(19)....?

C12 Ti C20 C16 52.4(2) ... . ?

diffrn_measured_fraction_theta_max 0.906

_diffrn_reflns_theta_full 25.00

_diffrn_measured_fraction_theta_full 0.994

_refine_diff_density_max 0.799

_refine_diff_density_min -0.337

_refine_diff_density_rms 0.076 


\section{A.3 Compound 6}

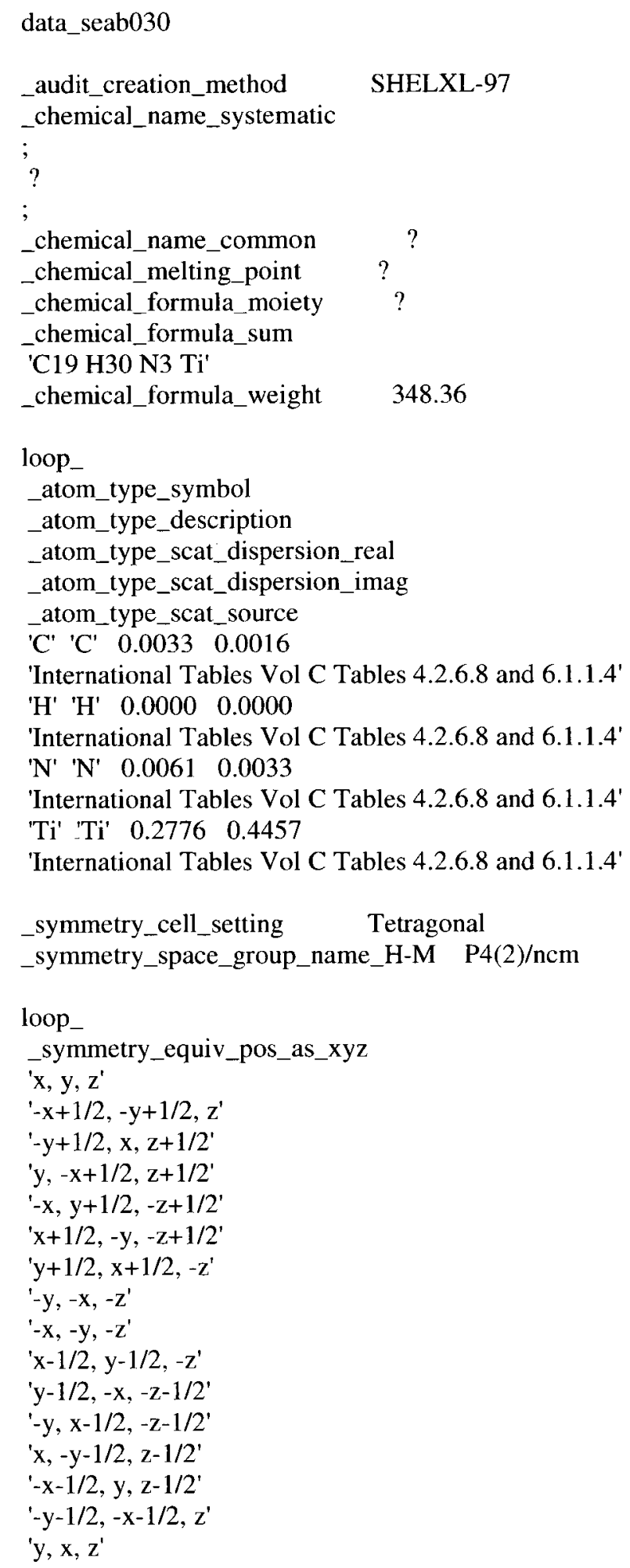




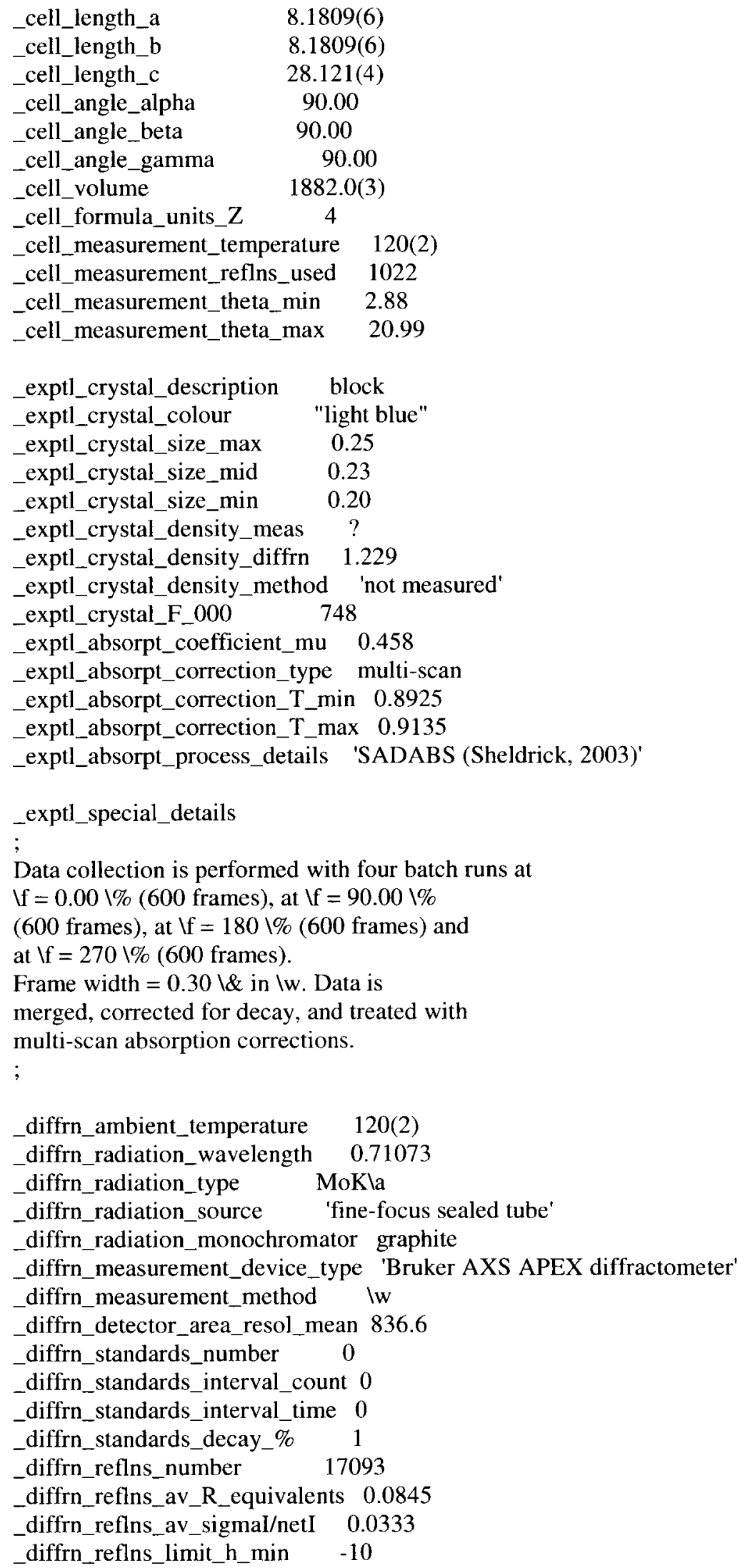




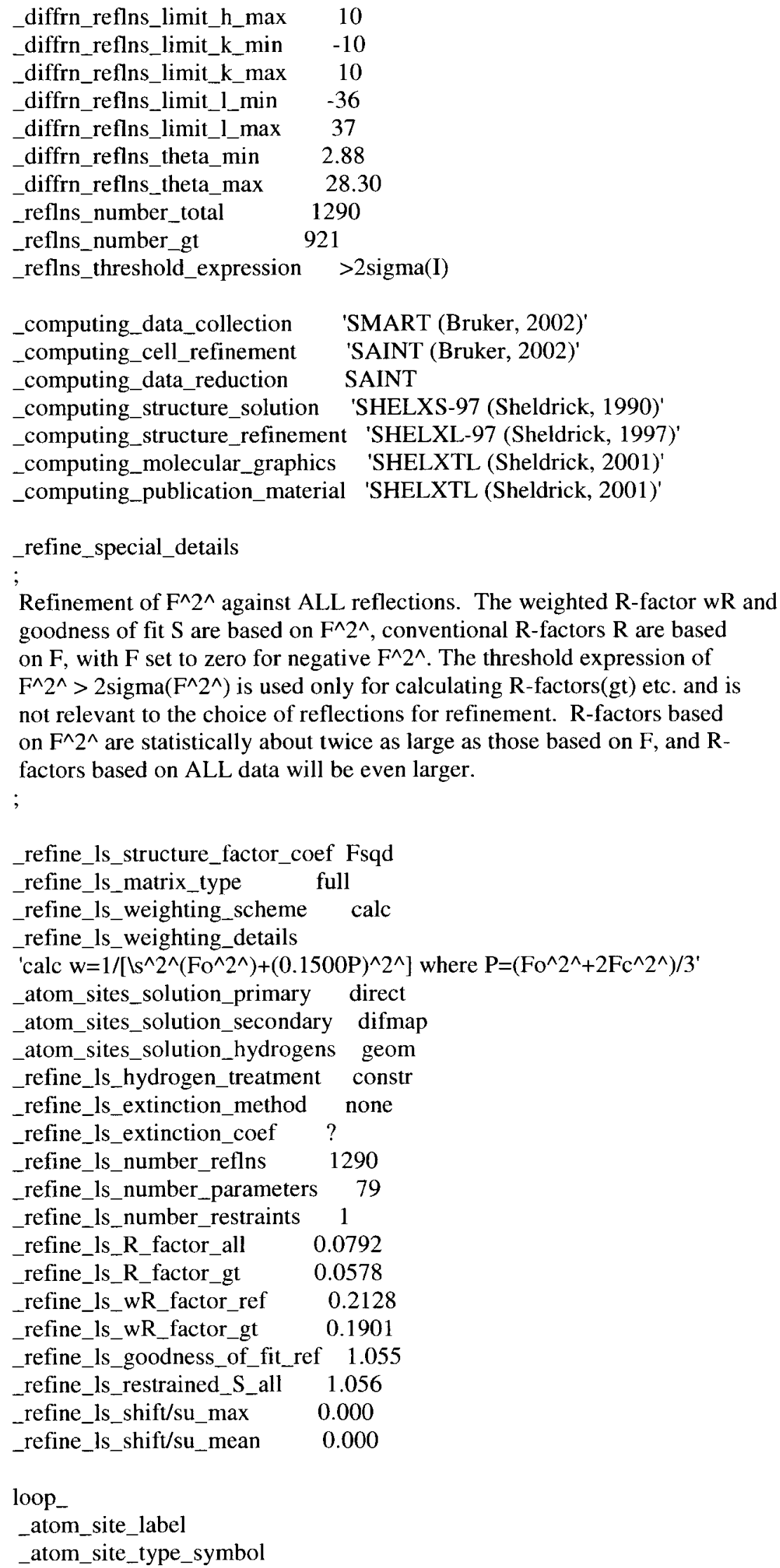




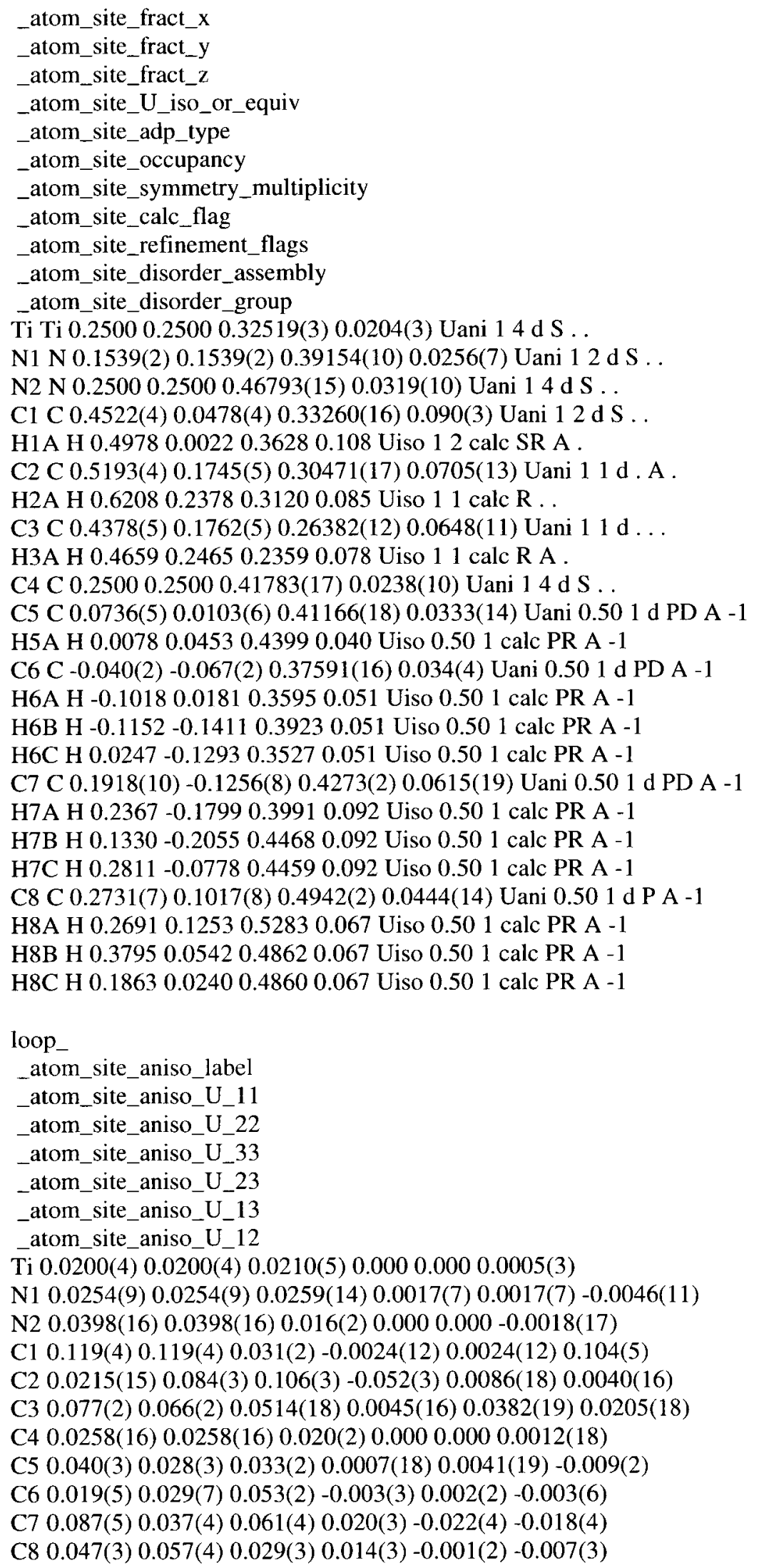


_geom_special_details

All esds (except the esd in the dihedral angle between two l.s. planes) are estimated using the full covariance matrix. The cell esds are taken into account individually in the estimation of esds in distances, angles and torsion angles; correlations between esds in cell parameters are only used when they are defined by crystal symmetry. An approximate (isotropic) treatment of cell esds is used for estimating esds involving l.s. planes.

loop_

_geom_bond_atom_site_label_1 _geom_bond_atom_site_label_2

_geom_bond_distance

_geom_bond_site_symmetry_2

_geom_bond_publ_flag

Ti N1 2.172(3) . ?

Ti N1 2.172(3) 2 ?

Ti C1 2.348(4) . ?

Ti C1 2.348(4) 2 ?

Ti C2 2.360(3) 15_665?

Ti C2 2.360(3) 2 ?

Ti C2 2.360(3) 16 ?

Ti C2 2.360(3) . ?

Ti C3 2.388(3) 15_665 ?

Ti C3 2.388(3) 2 ?

Ti C3 2.388(3) . ?

Ti C3 2.388(3) 16 ?

N1 C4 1.335(4). ?

N1 C5 $1.460(5) 16$ ?

N1 C5 1.460(5).?

N2 C4 1.409(6). ?

$\mathrm{N} 2 \mathrm{C} 81.433(6) 16$ ?

N2 C8 1.433(6) 15_665?

N2 C8 1.433(6) 2 ?

N2 C8 1.433(6). ?

C1 C2 1.411(5) 15_665?

C1 C2 1.411(5).?

C2 C3 1.330(6) . ?

C3 C3 1.319(9) 15_665?

C4 N1 1.335(4) 2 ?

C5 C6 1.507(7) . ?

C5 C7 1.537(8) . ?

loop_

_geom_angle_atom_site_label_1

_geom_angle_atom_site_label_2

_geom_angle_atom_site_label_3

_geom_angle

_geom_angle_site_symmetry_1

_geom_angle_site_symmetry_3

_geom_angle_publ_flag

N1 Ti N1 61.58(14) . 2 ?

N1 Ti C1 85.63(9) . . ?

N1 Ti C1 85.63(9) 2 .?

N1 Ti C1 85.63(9). 2 ? 
N1 Ti C1 85.63(9) 22 ?

C1 Ti C1 169.8(2). 2 ?

N1 Ti C2 88.07(10) . 15_665?

N1 Ti C2 116.93(13) 2 15_665?

C1 Ti C2 34.87(13). 15_665 ?

C1 Ti C2 149.74(13) 2 15_665?

N1 Ti C2 88.07(10). 2 ?

N1 Ti C2 116.93(13) 22 ?

C1 Ti C2 149.74(13) . 2 ?

$\mathrm{C} 1 \mathrm{Ti}$ C2 34.87(13) 22 ?

C2 Ti C2 115.4(2) 15_6652 ?

N1 Ti C2 116.93(13). 16 ?

N1 Ti C2 88.07(10) 216 ?

C1 Ti C2 149.73(13) . 16 ?

C1 Ti C2 34.87(13) 216 ?

C2 Ti C2 151.8(2) 15_665 16 ?

$\mathrm{C} 2 \mathrm{TiC} 256.7(2) 216$ ?

N1 Ti C2 116.93(13) ..?

N1 Ti C2 88.07(10) 2 . ?

C1 Ti C2 34.87(13) . .?

C1 Ti C2 149.73(13) 2 . ?

C2 Ti C2 56.7(2) 15_665.?

C2 Ti C2 151.8(2) 2.?

C2 Ti C2 115.4(2) 16.?

N1 Ti C3 118.65(12). 15_665 ?

N1 Ti C3 139.65(9) 2 15_665?

C1 Ti C3 55.45(13). 15_665?

C1 Ti C3 134.05(14) 2 15_665?

C2 Ti C3 32.52(14) 15_665 15_665 ?

C2 Ti C3 103.19(17) 2 15_665?

C2 Ti C3 119.38(17) $1615 \_665$ ?

C2 Ti C3 54.49(13). 15_665?

N1 Ti C3 118.65(12). 2 ?

N1 Ti C3 139.65(9) 22 ?

C1 Ti C3 134.05(14). 2 ?

C1 Ti C3 55.45(13) 22 ?

C2 Ti C3 103.19(17) 15_665 2 ?

$\mathrm{C} 2 \mathrm{Ti} \mathrm{C} 332.52(14) 22$ ?

C2 Ti C3 54.49(13) 162 ?

C2 Ti C3 119.38(17) . 2 ?

C3 Ti C3 78.65(18) 15_6652?

N1 Ti C3 139.65(9) . .?

N1 Ti C3 118.65(12) 2.?

C1 Ti C3 55.45(13) ..?

C1 Ti C3 134.05(14) 2 . ?

C2 Ti C3 54.49(13) 15_665.?

C2 Ti C3 119.38(17) 2.?

C2 Ti C3 103.19(17) 16.?

C2 Ti C3 32.51(14) .. ?

C3 Ti C3 32.1(2) 15_665.?

C3 Ti C3 87.5(2) 2 . ?

N1 Ti C3 139.65(9) . 16 ?

N1 Ti C3 118.65(12) 216 ?

C1 Ti C3 134.05(14). 16 ?

C1 Ti C3 55.45(13) 216 ?

C2 Ti C3 119.38(17) 15_665 16 ? 
C2 Ti C3 54.49(13) 216 ?

C2 Ti C3 32.52(14) 1616 ?

C2 Ti C3 103.19(17). 16 ?

C3 Ti C3 87.5(2) 15_665 16 ?

C3 Ti C3 32.1(2) 216 ?

C3 Ti C3 78.65(18) . 16 ?

C4 N1 C5 121.6(3). 16 ?

C4 N1 C5 121.6(3) .. ?

C5 N1 C5 29.1(4) 16.?

C4 N1 Ti 92.8(2)..?

C5 N1 Ti 141.9(2) 16.?

C5 N1 Ti 141.9(2)..?

C4 N2 C8 121.0(3) . 16 ?

C4 N2 C8 121.0(3) . 15_665?

C8 N2 C8 118.0(6) 16 15_665?

$\mathrm{C} 4 \mathrm{~N} 2 \mathrm{C} 8121.0(3) .2$ ?

C8 N2 C8 60.8(5) 162 ?

C8 N2 C8 87.6(5) 15_665 2 ?

C4 N2 C8 121.0(3) ..?

C8 N2 C8 87.6(5) 16 .?

C8 N2 C8 60.8(5) 15_665.?

$\mathrm{C} 8 \mathrm{~N} 2 \mathrm{C} 8118.0(6) 2$.?

C2 C1 C2 105.3(4) 15_665 . ?

C2 C1 Ti 73.0(2) 15_665 .?

$\mathrm{C} 2 \mathrm{C} 1 \mathrm{Ti} 73.0(2) \ldots$ ?

C3 C2 C1 107.0(3) . .?

C3 C2 Ti 74.9(2) .. ?

$\mathrm{C} 1 \mathrm{C} 2 \mathrm{Ti} 72.1(2) \ldots$ ?

C3 C3 C2 110.3(3) 15_665.?

C3 C3 Ti 73.97(11) 15_665.?

C2 C3 Ti 72.56(19) .. ?

N1 C4 N1 112.7(4) 2 . ?

N1 C4 N2 123.6(2) 2 .?

N1 C4 N2 123.6(2) . .?

N1 C4 Ti 56.4(2) 2.?

N1 C4 Ti 56.4(2) ..?

N2 C4 Ti $180.0 \ldots$ ?

N1 C5 C6 110.9(5) . .?

N1 C5 C7 114.2(4)..?

C6 C5 C7 105.8(10) . ?

loop_

_geom_torsion_atom_site_label_1 _geom_torsion_atom_site_label_2 geom_torsion_atom_site_label_3 geom_torsion_atom_site_label_4 geom_torsion geom_torsion_site_symmetry_1 _geom_torsion_site_symmetry_2 _geom_torsion_site_symmetry_3 _geom_torsion_site_symmetry_4 _geom_torsion_publ_flag

N1 Ti N1 C4 $0.02 \ldots$ ?

C1 Ti N1 C4 87.39(6) ....?

C1 Ti N1 C4 -87.39(6) $2 \ldots$ ?

C2 Ti N1 C4 122.23(13) 15_665 ... ? 


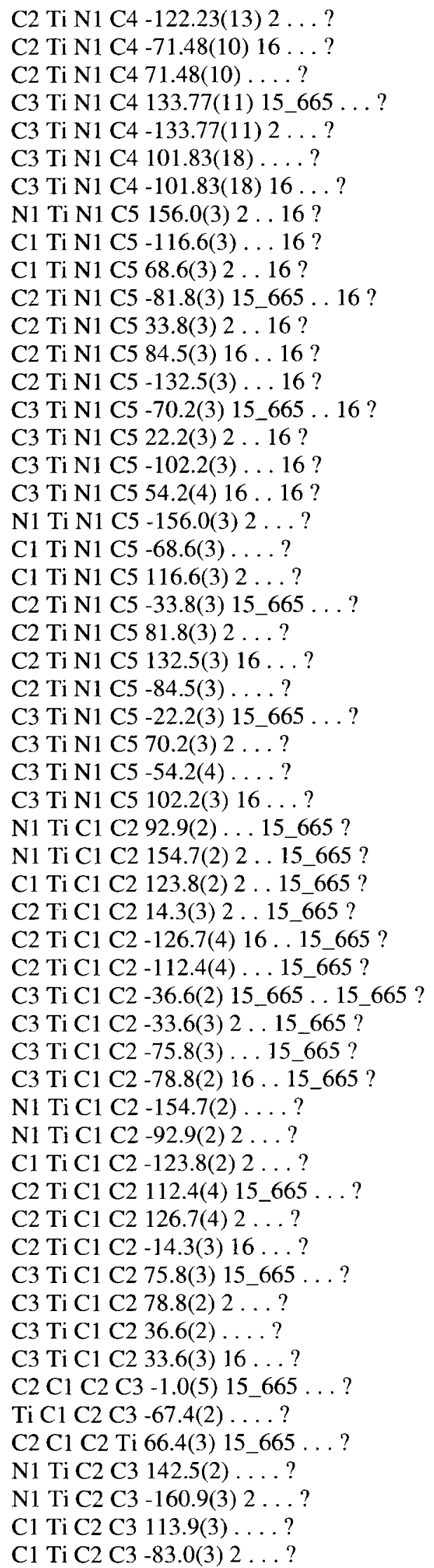




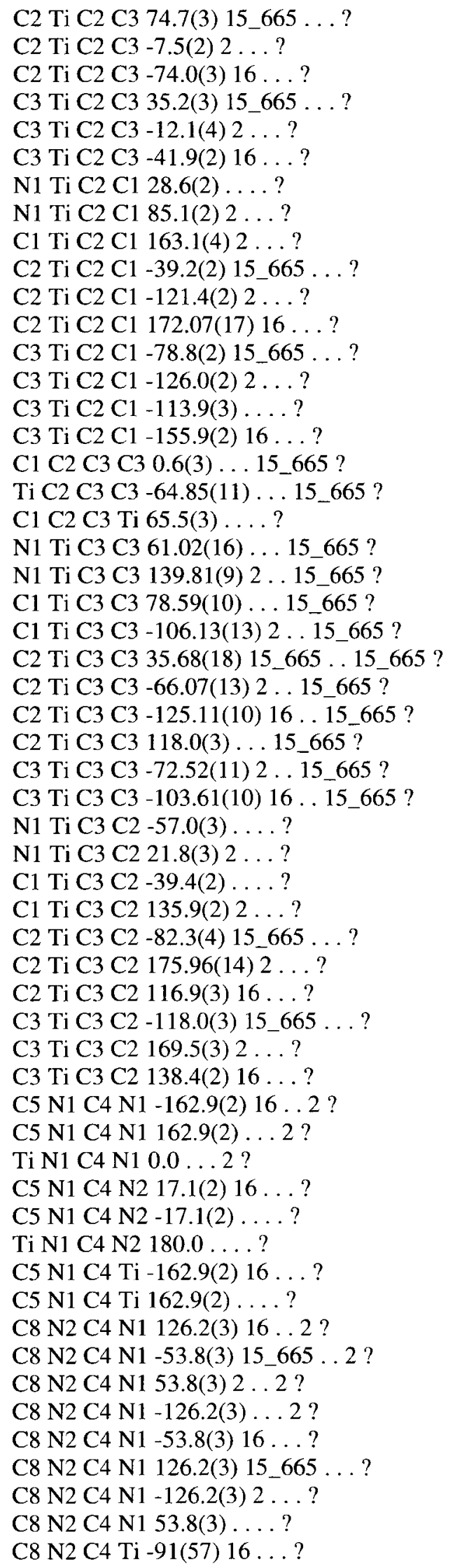


C8 N2 C4 Ti 89(54) 15_665 . . . ?

C8 N2 C4 Ti-164(100) $2 \ldots$ ?

C8 N2 C4 Ti 16(54) ....?

N1 Ti C4 N1 $180.0 \ldots 2$ ?

C1 Ti C4 N1 90.0 . . 2?

C1 Ti C4 N1 -90.02 . 2 ?

C2 Ti C4 N1 119.34(11) 15_665 .. 2?

C2 Ti C4 N1-119.34(11) 2.. 2 ?

C2 Ti C4 N1 -60.66(11) 16 .. 2?

C2 Ti C4 N1 60.66(11)... 2 ?

C3 Ti C4 N1 113.54(15) 15_665...2?

C3 Ti C4 N1 -113.54(15) 2 .. 2 ?

C3 Ti C4 N1 66.46(15) ...2?

C3 Ti C4 N1 -66.46(15) 16 . . 2 ?

$\mathrm{N} 1 \mathrm{TiC} 4 \mathrm{~N} 1180.02 \ldots$ ?

C1 Ti C4 N1 $-90.0 \ldots$ ?

C1 Ti C4 N1 90.02 ...?

C2 Ti C4 N1 -60.66(11) 15_665 ...?

C2 Ti C4 N1 60.66(11) $2 \ldots$ ?

C2 Ti C4 N1 119.34(11) $16 \ldots$ ?

C2 Ti C4 N1 -119.34(11) ....?

C3 Ti C4 N1 -66.46(15) 15_665 ...?

C3 Ti C4 N1 66.46(15) $2 \ldots$ ?

C3 Ti C4 N1 -113.54(15) ....?

C3 Ti C4 N1 113.54(15) 16 ...?

N1 Ti C4 N2 38(87) ....?

N1 Ti C4 N2 -142(100) $2 \ldots$ ?

$\mathrm{C} 1 \mathrm{TiC} 4 \mathrm{~N} 2-52(87) \ldots$ ?

C1 Ti C4 N2 128(100) $2 \ldots$ ?

C2 Ti C4 N2 -23(87) 15_665 ...?

C2 Ti C4 N2 98(100) $2 \ldots$ ?

$\mathrm{C} 2 \mathrm{Ti} \mathrm{C} 4 \mathrm{~N} 2$ 157(100) $16 \ldots$ ?

C2 Ti C4 N2 -82(87) ....?

C3 Ti C4 N2 -29(87) 15_665 . . . ?

C3 Ti C4 N2 104(100) $2 \ldots$ ?

C3 Ti C4 N2 -76(87) ....?

C3 Ti C4 N2 151(100) 16 . . ?

C4 N1 C5 C6 174.7(10) ....?

C5 N1 C5 C6 75.5(10) $16 \ldots$ ?

Ti N1 C5 C6 $-33.8(11) \ldots$ ?

C4 N1 C5 C7 -65.9(5) ....?

C5 N1 C5 C7 -165.1(4) 16 ...?

Ti N1 C5 C7 85.6(5) . . . . ?

_diffrn_measured_fraction_theta_max 0.999

diffrn_reflns theta_full 25.00

diffrn_measured_fraction_theta_full 0.999

_refine_diff_density_max 0.635

_refine_diff_density_min -0.326

_refine_diff_density_rms 0.078 


\section{A.4 Compound 8}

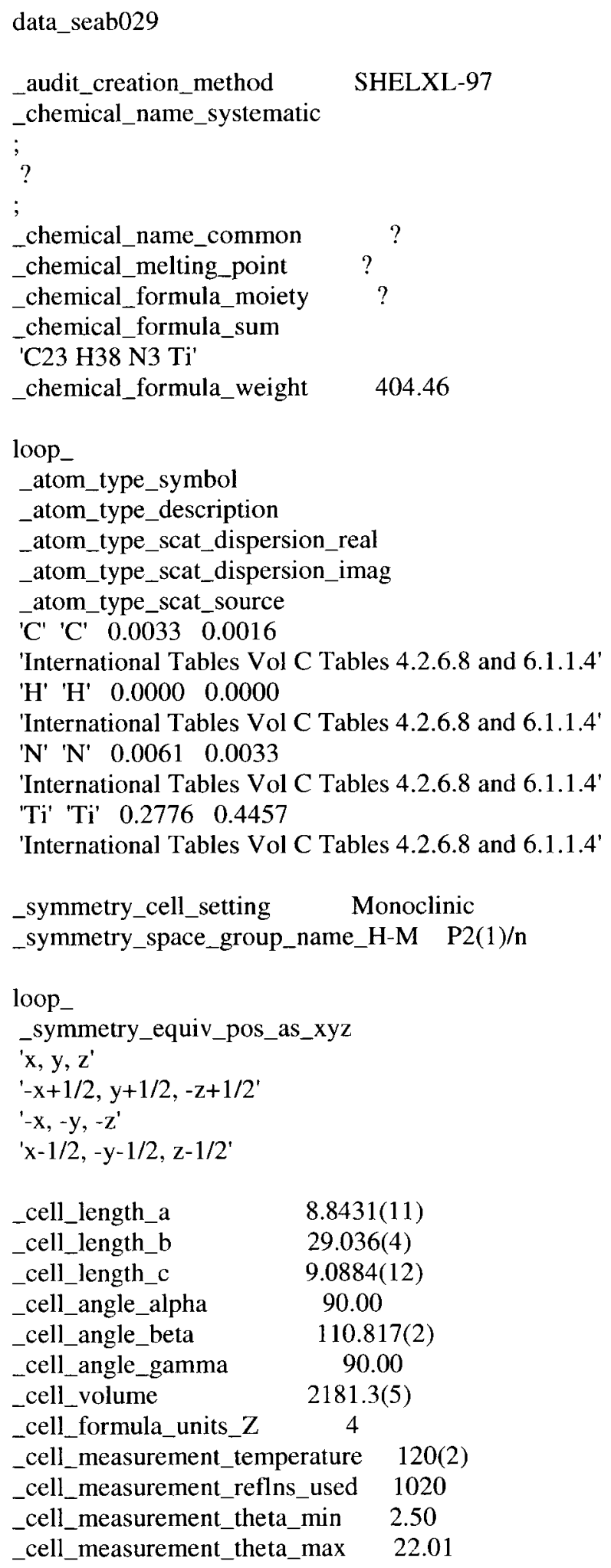




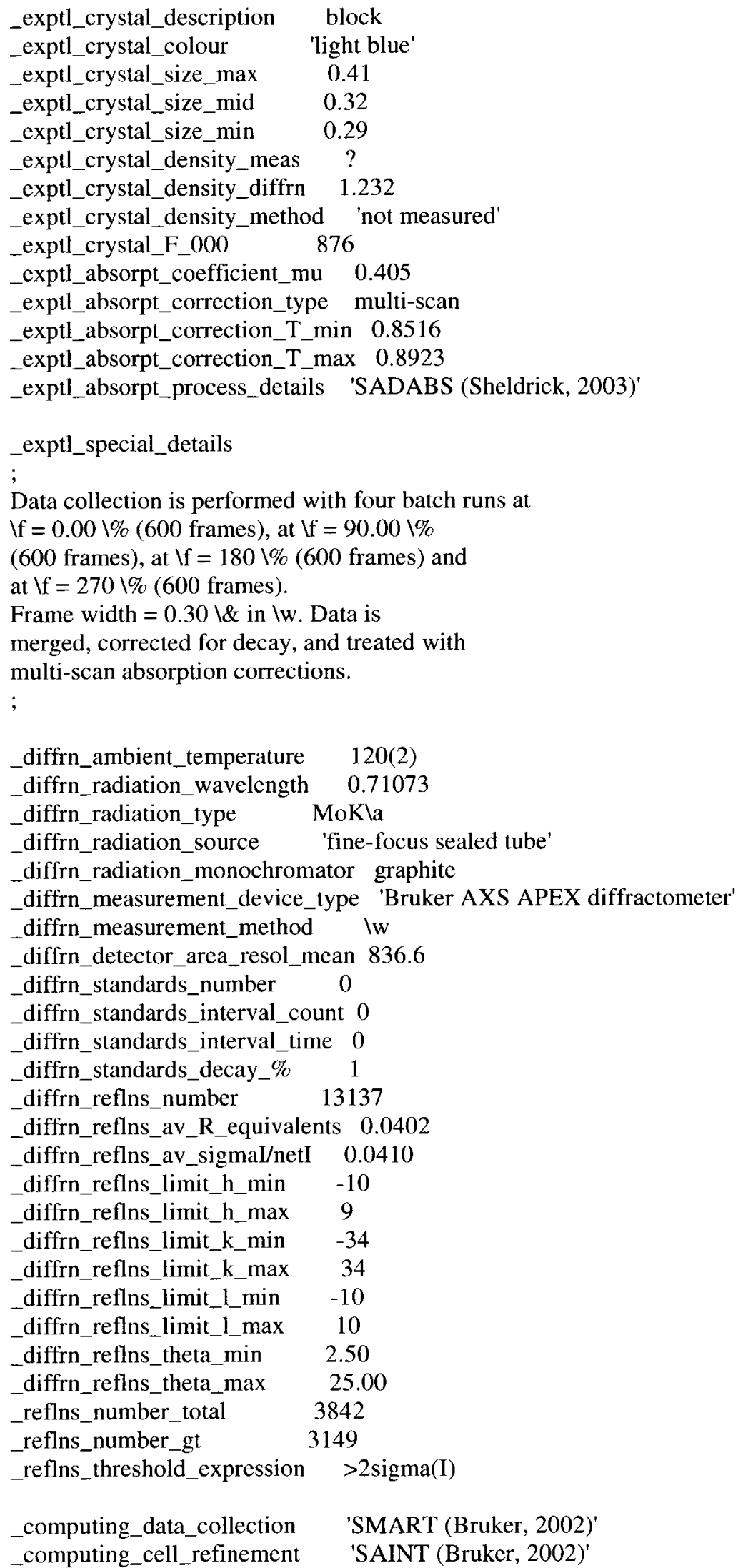


_computing_data_reduction SAINT

_computing_structure_solution 'SHELXS-97 (Sheldrick, 1990)'

_computing_structure_refinement 'SHELXL-97 (Sheldrick, 1997)'

_computing_molecular_graphics 'SHELXTL (Sheldrick, 2001)'

_computing_publication_material 'SHELXTL (Sheldrick, 2001)'

_refine_special_details

;

Refinement of $F^{\wedge} 2^{\wedge}$ against ALL reflections. The weighted $R$-factor $w R$ and goodness of fit $S$ are based on $\mathrm{F}^{\wedge} 2^{\wedge}$, conventional $\mathrm{R}$-factors $\mathrm{R}$ are based on $F$, with $F$ set to zero for negative $F^{\wedge} 2^{\wedge}$. The threshold expression of $\mathrm{F}^{\wedge} 2^{\wedge}>2 \operatorname{sigma}\left(\mathrm{F}^{\wedge} 2^{\wedge}\right)$ is used only for calculating R-factors(gt) etc. and is not relevant to the choice of reflections for refinement. R-factors based on $\mathrm{F}^{\wedge} 2^{\wedge}$ are statistically about twice as large as those based on F, and Rfactors based on ALL data will be even larger. ;

_refine_ls_structure_factor_coef Fsqd

_refine_Is_matrix_type full

_refine_ls_weighting_scheme calc

_refine_ls_weighting_details

'calc $\mathrm{w}=1 /\left[\mathrm{I \textrm {s } ^ { \wedge }} 2^{\wedge}\left(\mathrm{Fo}^{\wedge} 2^{\wedge}\right)+(0.0655 \mathrm{P})^{\wedge} 2^{\wedge}+0.2947 \mathrm{P}\right]$ where $\mathrm{P}=\left(\mathrm{Fo}^{\wedge} 2^{\wedge}+2 \mathrm{Fc}^{\wedge} 2^{\wedge}\right) / 3^{\prime}$

_atom_sites_solution_primary direct

_atom_sites_solution_secondary difmap

_atom_sites_solution_hydrogens geom

_refine_Is_hydrogen_treatment constr

_refine_ls_extinction_method none

_refine_ls_extinction_coef ?

_refine_ls_number_reflns 3842

_refine_ls_number_parameters 252

refine_ls_number_restraints 0

_refine_ls_R_factor_all $\quad 0.0555$

_refine_ls_R_factor_gt $\quad 0.0424$

_refine_ls_wR_factor_ref $\quad 0.1159$

_refine_ls_wR_factor_gt 0.1064

_refine_ls_goodness_of_fit_ref 1.068

_refine_ls_restrained_S_all 1.068

_refine_ls_shift/su_max $\quad 0.000$

_refine_ls_shift/su_mean $\quad 0.000$

loop_

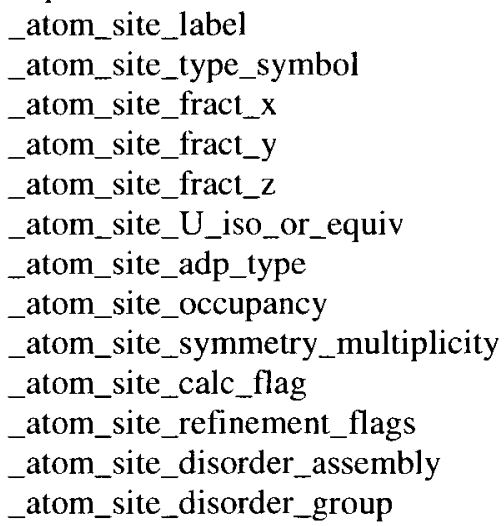

Ti Ti $0.12773(5) 0.157315(12) 0.01650(4) 0.01866(15)$ Uani $11 \mathrm{~d} \ldots$

$\mathrm{N} 1 \mathrm{~N} 0.1141(2) 0.14794(6) 0.24844(19) 0.0184(4)$ Uani $11 \mathrm{~d} \ldots$ 
$\mathrm{N} 2 \mathrm{~N} 0.2567(2) 0.10017(5) 0.16147(19) 0.0183(4)$ Uani $11 \mathrm{~d} \ldots$ $\mathrm{N} 3 \mathrm{~N} 0.2473(2) 0.08643(5) 0.42522(19) 0.0187(4)$ Uani $11 \mathrm{~d} \ldots$ C1 C 0.3210(3) 0.19269(9) -0.0775(3) 0.0405(7) Uani $11 \mathrm{~d} \ldots$ H1A H $0.35880 .1803-0.16120 .049$ Uiso 11 calc R . . C2 C 0.1954(3) 0.22434(8) -0.0994(3) 0.0370(6) Uani $11 \mathrm{~d}$. . H2A H $0.12750 .2382-0.20230 .044$ Uiso 11 calc R . . C3 C 0.1935(3) 0.23713(8) 0.0461(3) 0.0351(6) Uani $11 \mathrm{~d}$. . . H3A H 0.12480 .26200 .06590 .042 Uiso 11 calc R . . C4 C 0.3195(3) 0.21457(8) 0.1605(3) 0.0314(6) Uani $11 \mathrm{~d}$... H4A H 0.35460 .22010 .27640 .038 Uiso 11 calc R . . C5 C 0.3999(3) 0.18728(8) 0.0868(3) 0.0353(6) Uani $11 \mathrm{~d} \ldots$ H5A H 0.50220 .16980 .14010 .042 Uiso 11 calc R . . C6 C -0.1515(3) 0.16766(8) -0.1342(3) 0.0307(6) Uani $11 \mathrm{~d}$. . H6A H - $0.21920 .1946-0.12730 .037$ Uiso 11 calc R . . C7 C -0.0725(3) 0.16262(8) -0.2418(3) 0.0307(6) Uani $11 \mathrm{~d} \ldots$ H7A H - $0.07310 .1856-0.32410 .037$ Uiso 11 calc R . . C8 C -0.0086(3) 0.11777(8) -0.2273(3) 0.0302(6) Uani $11 \mathrm{~d}$. . H8A H $0.04400 .1034-0.29690 .036$ Uiso 11 calc R . . C9 C -0.0537(3) 0.09494(8) -0.1132(3) 0.0299(6) Uani $11 \mathrm{~d} \ldots$ H9A H -0.0356 0.0616 -0.0856 0.036 Uiso 11 calc R . . C10 C -0.1417(3) 0.12521(8) -0.0567(3) 0.0297(6) Uani $11 \mathrm{~d} \ldots$ H10A H -0.19840 .11720 .01750 .036 Uiso 11 calc R . .

C11 C 0.2072(2) 0.11076(7) 0.2792(2) 0.0172(4) Uani $11 \mathrm{~d} \ldots$ C12 C 0.0473(3) 0.16793(7) 0.3603(2) 0.0232(5) Uani $11 \mathrm{~d} \ldots$ H12A H 0.07120 .14650 .45190 .028 Uiso 11 calc R . . C13 C -0.1356(3) 0.17395(9) 0.2867(3) 0.0326(6) Uani $11 \mathrm{~d} \ldots$ H13A H -0.1866 0.1439 0.2537 0.049 Uiso 11 calc R . H13B H - 0.16150 .19420 .19480 .049 Uiso 11 calc $R$. . H13C H -0.1762 0.1876 0.3641 0.049 Uiso 11 calc R . . C14 C 0.1226(3) 0.21490(8) 0.4218(3) 0.0340(6) Uani $11 \mathrm{~d} \ldots$ H14A H 0.24010 .21160 .47210 .051 Uiso 11 calc R. . H14B H 0.07750 .22660 .49870 .051 Uiso 11 calc R. . H14C H 0.09820 .23660 .33380 .051 Uiso 11 calc R . . C15 C 0.3599(3) 0.06023(7) 0.1660(2) 0.0207(5) Uani $11 \mathrm{~d} \ldots$ H15A H 0.37810 .04350 .26700 .025 Uiso 11 calc R.. C16 C 0.5249(3) 0.07455(8) 0.1629(3) 0.0292(5) Uani $11 . \mathrm{d} \ldots$ H16A H 0.57930 .09450 .25330 .044 Uiso 11 calc R. . H16B H 0.51040 .09130 .06530 .044 Uiso 11 calc R. . H16C H 0.59090 .04700 .16830 .044 Uiso 11 calc R . . C17 C 0.2788(3) 0.02696(7) 0.0313(3) 0.0288(5) Uani $11 \mathrm{~d} \ldots$ H17A H 0.17800 .01550 .03990 .043 Uiso 11 calc R . H17B H 0.35150 .00100 .03690 .043 Uiso 11 calc R . . $\mathrm{H} 17 \mathrm{C} \mathrm{H} 0.25470 .0430-0.06930 .043$ Uiso 11 calc $\mathrm{R}$. . C18 C 0.1508(3) 0.04533(7) 0.4325(2) 0.0212(5) Uani $11 \mathrm{~d} \ldots$ H18A H 0.13740 .04610 .53720 .025 Uiso 11 calc R . C19 C -0.0180(3) 0.04758(8) 0.3081(3) 0.0317(6) Uani $11 \mathrm{~d} \ldots$ H19A H -0.0748 0.0747 0.3269 0.048 Uiso 11 calc R. . H19B H - 0.07810 .01970 .31360 .048 Uiso 11 calc R . . H19C H - 0.00990 .04990 .20350 .048 Uiso 11 calc R. . C20 C 0.2282(3) $-0.00125(7) 0.4213$ (3) $0.0302(5)$ Uani $11 \mathrm{~d} \ldots$ H20A H $0.3415-0.00130 .49220 .045$ Uiso 11 calc R . . H20B H $0.2229-0.00620 .31290 .045$ Uiso 11 calc R . . H20C H $0.1695-0.02600 .45150 .045$ Uiso 11 calc R . . C21 C 0.4171(3) 0.08803(8) 0.5326(2) 0.0263(5) Uani $11 \mathrm{~d} \ldots$ H21 A H 0.47950 .06450 .49730 .032 Uiso 11 calc R . . C22 C 0.4913(3) 0.13486(8) 0.5294(3) 0.0313(6) Uani $11 \mathrm{~d} \ldots$ 
H22A H 0.47780 .14280 .42070 .047 Uiso 11 calc R . . H22B H 0.60680 .13400 .59350 .047 Uiso 11 calc R . . H22C H 0.43740 .15800 .57190 .047 Uiso 11 calc R . . C23 C 0.4316(3) 0.07672(8) 0.7006(3) 0.0312(6) Uani $11 \mathrm{~d} \ldots$ H23A H 0.39700 .04490 .70560 .047 Uiso 11 calc R . . H23B H 0.36290 .09770 .73370 .047 Uiso 11 calc R . . H23C H 0.54440 .08030 .77080 .047 Uiso 11 calc R . .

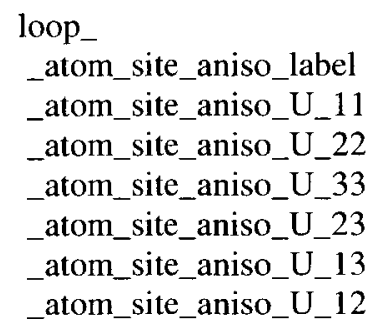

loop_

_geom_bond_atom_site_label_1 
_geom_bond_atom_site_label_2 _geom_bond_distance

_geom_bond_site_symmetry_2

_geom_bond_publ_flag

Ti N1 2.1710(17) . ?

Ti N2 2.1730(17) . ?

Ti C6 2.379(2) . ?

Ti C3 2.381(2) . ?

Ti C2 2.388(2) . ?

Ti C7 2.391(2). ?

Ti C1 2.397(2) . ?

Ti C4 2.403(2) . ?

Ti C8 2.405(2) . ?

Ti C10 2.421(2) . ?

Ti C5 2.422(2). ?

Ti C9 2.429(2) . ?

N1 C11 1.326(3). ?

N1 C12 1.465(3).?

N2 C11 1.328(3). ?

N2 C15 1.467(3) . ?

N3 C11 1.433(3). ?

$\mathrm{N} 3 \mathrm{C} 21$ 1.473(3) . ?

N3 C18 1.482(3).?

C1 C2 1.400(4).?

C1 C5 1.415(4).?

C2 C3 1.379(4).?

C3 C4 1.388(3) . ?

C4 C5 1.385(4).?

C6 C7 1.397(3). ?

C6 C10 1.407(3). ?

C7 C8 1.407(3) .?

C8 C9 1.403(3) . ?

C9 C10 1.388(3). ?

C12 C13 1.525(3).?

C12 C14 1.533(3) . ?

C15 C17 1.523(3) . ?

C15 C16 1.527(3). ?

C18 C19 1.521(3).?

C18 C20 1.535(3).?

C21 C22 1.515(3).?

C21 C23 1.522(3).?

loop_

_geom_angle_atom_site_label_1 _geom_angle_atom_site_label_2

_geom_angle_atom_site_label_3

_geom_angle

_geom_angle_site_symmetry_1

_geom_angle_site_symmetry_3

_geom_angle_publ_flag

N1 Ti N2 60.91(6) . . ?

N1 Ti C6 99.80(8) . . ?

N2 Ti C6 131.25(7) . . ?

N1 Ti C3 96.21(8) . . ?

N2 Ti C3 128.33(8) . . ?

C6 Ti C3 95.97(9) . . ? 
N1 Ti C2 129.75(8) . . ?

N2 Ti C2 136.87(8) .. ?

C6 Ti C2 90.85(9) . . ?

C3 Ti C2 33.61(9) . . ?

N1 Ti C7 133.18(8) .. ?

$\mathrm{N} 2$ Ti C7 133.67(7) ..?

C6 Ti C7 34.07(8) . . ?

C3 Ti C7 96.55(8) . . ?

$\mathrm{C} 2 \mathrm{Ti} \mathrm{C} 7$ 74.26(8) . . ?

N1 Ti C1 133.84(8) . . ?

N2 Ti C1 104.84(9) . . ?

C6 Ti C1 117.81(9) .. ?

C3 Ti C1 56.40(9) . . ?

C2 Ti C1 34.04(9) . . ?

C7 Ti C1 89.74(9) . . ?

N1 Ti C4 80.21(7) . . ?

N2 Ti C4 94.66(7) .. ?

C6 Ti C4 127.83(8) .. ?

C3 Ti C4 33.74(8) . . ?

C2 Ti C4 55.76(8)..?

C7 Ti C4 128.55(8) .. ?

C1 Ti C4 56.15(8) .. ?

N1 Ti C8 130.70(7) . . ?

$\mathrm{N} 2 \mathrm{Ti}$ C8 100.22(7). . ?

C6 Ti C8 56.76(8). . ?

C3 Ti C8 126.23(9) .. ?

C2 Ti C8 96.02(8). . ?

C7 Ti C8 34.11(8) . . ?

C1 Ti C8 93.66(9). . ?

C4 Ti C8 149.07(8) . . ?

N1 Ti C10 80.20(7) . .?

N2 Ti C10 97.24(8) . . ?

C6 Ti C10 34.07(8) . . ?

C3 Ti C10 125.65(9) .. ?

C2 Ti C10 124.68(8) . . ?

C7 Ti C10 56.08(8) . . ?

C1 Ti C10 145.47(9) . . ?

C4 Ti C10 148.33(8) . . ?

C8 Ti C10 55.99(8) . . ?

N1 Ti C5 100.47(8) . .?

N2 Ti C5 81.72(7) .. ?

C6 Ti C5 146.87(8) .. ?

C3 Ti C5 55.98(9) . . ?

C2 Ti C5 56.10(8) . . ?

C7 Ti C5 123.76(9) . . ?

C1 Ti C5 34.14(9) . . ?

C4 Ti C5 33.37(8)...?

C8 Ti C5 122.73(9) .. ?

C10 Ti C5 178.23(9) .. ?

N1 Ti C9 97.05(7) . . ?

N2 Ti C9 80.73(7) . . ?

C6 Ti C9 56.17(8) .. ?

C3 Ti C9 150.83(8) . . ?

C2 Ti C9 128.28(8) . . ?

C7 Ti C9 55.97(8) .. ?

C1 Ti C9 125.33(8)...? 
C4 Ti C9 175.37(8) .. ?

C8 Ti C9 33.73(8) . . ?

C10 Ti C9 33.25(8) .. ?

C5 Ti C9 145.00(9) .. ?

C11 N1 C12 123.36(17) . . ?

C11 N1 Ti 93.55(12). .?

C12 N1 Ti 143.07(13) . .?

C11 N2 C15 122.71(16) . . ?

C11 N2 Ti 93.39(12)..?

C15 N2 Ti 143.88(13) . .?

C11 N3 C21 117.19(16) . . ?

C11 N3 C18 118.80(16) . . ?

C21 N3 C18 117.60(16) . . ?

C2 C1 C5 106.9(2) . . ?

C2 C1 Ti 72.64(13) .. ?

C5 C1 Ti 73.88(14) ..?

C3 C2 C1 108.7(2) . . ?

C3 C2 Ti 72.92(13) .. ?

C1 C2 Ti 73.33(13) . .?

C2 C3 C4 108.1(2) ..?

C2 C3 Ti 73.47(13) . . ?

C4 C3 Ti 73.99(13) . . ?

C3 C4 C5 108.7(2) . . ?

C3 C4 Ti 72.27(13) . . ?

C5 C4 Ti 74.05(13) . . ?

C4 C5 C1 107.6(2) . .?

$\mathrm{C} 4 \mathrm{C} 5 \mathrm{Ti} 72.58(13) \ldots$ ?

C1 C5 Ti 71.97(14)..?

C7 C6 C10 107.5(2) . . ?

C7 C6 Ti 73.45(14) .. ?

C10 C6 Ti 74.61(13) . . ?

C6 C7 C8 108.4(2) ..?

C6 C7 Ti 72.48(13) .. ?

C8 C7 Ti 73.49(13) . . ?

C9 C8 C7 107.3(2) ..?

C9 C8 Ti 74.08(12) .. ?

C7 C8 Ti 72.40(12)..?

C10 C9 C8 108.6(2)..?

C10 C9 Ti 73.05(13) . . ?

C8 C9 Ti 72.19(12) ..?

C9 C10 C6 108.2(2) . . ?

C9 C10 Ti 73.70(13) . . ?

C6 C10 Ti 71.32(13) . . ?

N1 C11 N2 112.14(17) .. ?

N1 C11 N3 121.82(17) . . ?

N2 C11 N3 126.04(18) ..?

N1 C11 Ti 56.02(10) . .?

N2 C11 Ti 56.12(10) . ? ?

N3 C11 Ti 177.84(15) . . ?

N1 C12 C13 111.54(17) . .?

N1 C12 C14 112.07(18) . .?

C13 C12 C14 108.26(19) . . ?

N2 C15 C17 111.62(17) . . ?

N2 C15 C16 111.90(17) . ?

C17 C15 C16 109.76(17) ..?

N3 C18 C19 111.13(17) . .? 
N3 C18 C20 115.43(18) . ? C19 C18 C20 109.34(18) . . ? N3 C21 C22 111.25(18) . ? N3 C21 C23 111.15(18) . . ? C22 C21 C23 109.30(18) .. ?

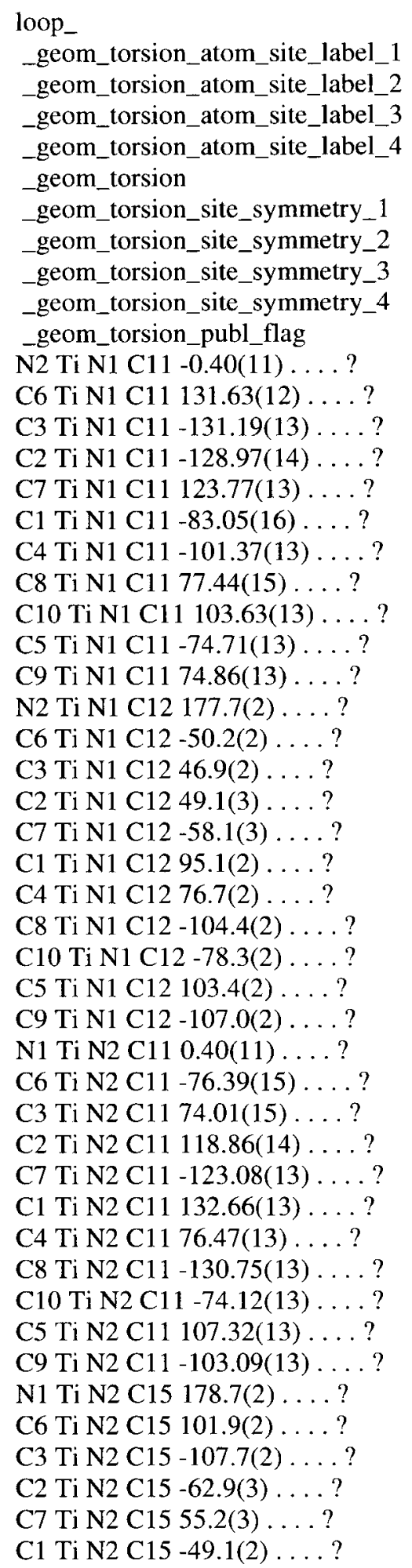


C4 Ti N2 C15-105.3(2) ...?

$\mathrm{C} 8 \mathrm{Ti} \mathrm{N} 2 \mathrm{C} 1547.5(2) \ldots$ ?

C10 Ti N2 C15 104.1(2)....?

C5 Ti N2 C15 -74.4(2) ... . ?

C9 Ti N2 C15 75.2(2) ....?

N1 Ti C1 C2 -99.34(17) ... . ?

N2 Ti C1 C2 $-163.06(14) \ldots$ ?

C6 Ti C1 C2 41.31(17)....?

C3 Ti C1 C2 $-36.60(14) \ldots$ ?

C7 Ti C1 C2 61.45(15) ....?

C4 Ti Cl C2 -77.44(15) ....?

C8 Ti C1 C2 95.35(15)....?

C10 Ti C1 C2 69.0(2) ....?

C5 Ti C1 C2 -114.1(2) ... . ?

C9 Ti Cl C2 107.89(15) .... ?

N1 Ti C1 C5 14.7(2) ....?

N2 Ti C1 C5 $-48.99(15) \ldots$ ?

C6 Ti C1 C5 155.38(14)....?

C3 Ti C1 C5 77.46(15) ... . ?

C2 Ti C1 C5 114.1(2)....?

C7 Ti C1 C5 175.51(15).... ?

C4 Ti C1 C5 36.62(14).... ?

C8 Ti C1 C5 -150.58(15).... ?

C10 Ti C1 C5 -176.95(15) ... . ?

C9 Ti C1 C5 $-138.05(14) \ldots$ ?

$\mathrm{C} 5 \mathrm{C} 1 \mathrm{C} 2 \mathrm{C} 3-1.6(3) \ldots$ ?

Ti C1 C2 C3 64.86(17) ....?

C5 C1 C2 Ti -66.48(16) ....?

$\mathrm{N} 1 \mathrm{Ti} \mathrm{C} 2 \mathrm{C} 3-4.0(2) \ldots$ ?

$\mathrm{N} 2 \mathrm{Ti} \mathrm{C} 2 \mathrm{C} 3-91.87(18) \ldots$. . ?

C6 Ti C2 C3 99.53(16) .... ?

C7 Ti C2 C3 129.67(17) ....?

$\mathrm{C} 1 \mathrm{Ti} \mathrm{C} 2 \mathrm{C} 3-116.2(2) \ldots$ ?

C4 Ti C2 C3 -37.51(15) ... . ?

C8 Ti C2 C3 156.19(16) ....?

C10 Ti C2 C3 103.84(16).... ?

C5 Ti C2 C3 -78.07(17) .... ?

C9 Ti C2 C3 145.30(15) ....?

N1 Ti C2 C1 112.21(16) . . . ?

N2 Ti C2 C1 24.3(2) ....?

C6 Ti C2 C1 -144.27(15) .... ?

C3 Ti C2 C1 116.2(2) ... . ?

C7 Ti C2 C1 -114.13(16) ... . ?

$\mathrm{C} 4 \mathrm{TiC}$ C2 $178.69(16) \ldots$ ?

C8 Ti C2 C1 -87.61(15) ....?

C10 Ti C2 C1 -139.95(14).... ?

C5 Ti C2 C1 38.13(15) ... . ?

C9 Ti C2 C1 $-98.50(16) \ldots$ ?

$\mathrm{C} 1 \mathrm{C} 2 \mathrm{C} 3 \mathrm{C} 41.3(3) \ldots$ ?

$\mathrm{Ti} \mathrm{C} 2 \mathrm{C} 3 \mathrm{C} 466.44(16) \ldots$. . ?

C1 C2 C3 Ti $-65.13(16) \ldots$ ?

N1 Ti C3 C2 176.91(15) ... . ?

N2 Ti C3 C2 119.42(15) ....?

C6 Ti C3 C2 $-82.51(16) \ldots$. . ?

C7 Ti C3 C2 $-48.23(17) \ldots$ ?

C1 Ti C3 C2 37.08(15) ....? 


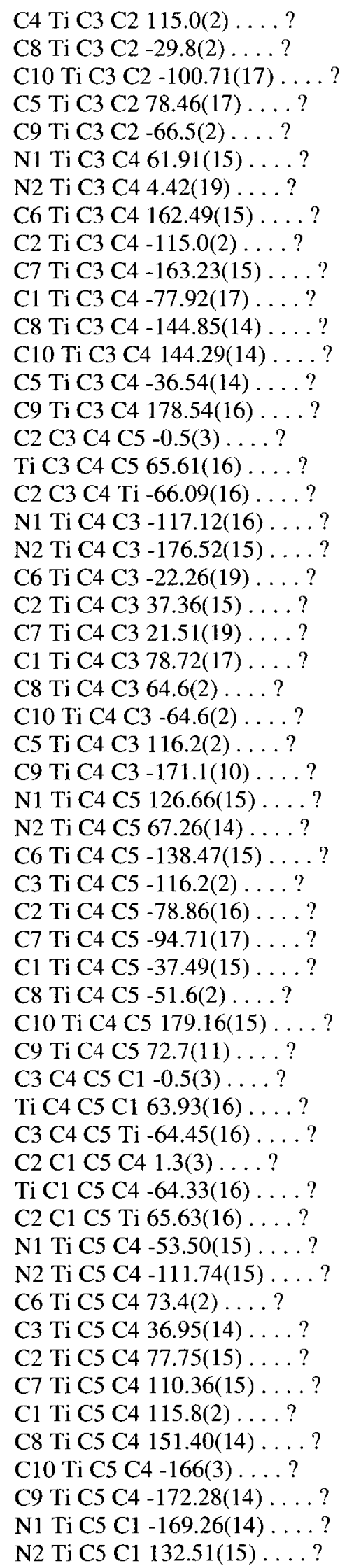


C6 Ti C5 C1 $-42.4(2) \ldots$ ?

C3 Ti C5 C1 $-78.80(16) \ldots$ ?

C2 Ti C5 C1 -38.00(14) ....?

C7 Ti C5 C1 -5.40(18) ....?

C4 Ti C5 C1 -115.8(2) ... . ?

C8 Ti C5 C1 35.64(18) .... ?

C10 Ti C5 C1 79(3) ... . ?

C9 Ti C5 C1 72.0(2) ....?

N1 Ti C6 C7 $-169.75(13) \ldots$ ?

N2 Ti C6 C7 -110.05(14) ... ?

C3 Ti C6 C7 92.88(14).... ?

C2 Ti C6 C7 59.59(14)....?

C1 Ti C6 C7 37.90(16) ....?

C4 Ti C6 C7 105.09(15) .... ?

C8 Ti C6 C7 -37.06(13) .... ?

C10 Ti C6 C7 -114.1(2) ....?

C5 Ti C6 C7 63.2(2) ....?

C9 Ti C6 C7 -77.79(15) ... ? ?

N1 Ti C6 C10 -55.68(14) ....?

N2 Ti C6 C10 4.02(18) ....?

C3 Ti C6 C10-153.05(14) ... . ?

C2 Ti C6 C10 173.66(15) ....?

C7 Ti C6 C10 114.1(2) ....?

C1 Ti C6 C10 151.97(14).... ?

C4 Ti C6 C10-140.84(14) ... . ?

C8 Ti C6 C10 77.01(15) ....?

C5 Ti C6 C10 177.30(16) .... ?

C9 Ti C6 C10 36.28(13) .... ?

C10 C6 C7 C8 -2.2(3) ... ? ?

Ti C6 C7 C8 65.23(16) ... . ?

C10 C6 C7 Ti-67.40(16) ....?

N1 Ti C7 C6 13.92(18).... ?

N2 Ti C7 C6 102.45(15) ... . ?

C3 Ti C7 C6 $-90.97(15) \ldots$ ?

C2 Ti C7 C6-116.37(15) .... ?

C1 Ti C7 C6-147.09(15) .... ?

C4 Ti C7 C6 -102.80(15) .... ?

C8 Ti C7 C6 116.0(2) ... . ?

C10 Ti C7 C6 38.06(13) ....?

C5 Ti C7 C6 -144.06(14) .... . ?

C9 Ti C7 C6 78.42(15) ....?

N1 Ti C7 C8 $-102.08(15) \ldots$ ?

N2 Ti C7 C8 $-13.55(19) \ldots$ ?

C6 Ti C7 C8 -116.0(2) ....?

C3 Ti C7 C8 153.03(15) ... ?

C2 Ti C7 C8 127.64(16) ....?

C1 Ti C7 C8 96.92(15) ....?

C4 Ti C7 C8 141.20(14) ....?

C10 Ti C7 C8 $-77.94(15) \ldots$ ?

C5 Ti C7 C8 99.95(15) ....?

C9 Ti C7 C8 $-37.58(14) \ldots$ ?

C6 C7 C8 C9 1.9(3) ... ?

Ti C7 C8 C9 66.43(15) .... ?

C6 C7 C8 Ti-64.58(16) ....?

N1 Ti C8 C9 $-4.62(18) \ldots$. . ?

N2 Ti C8 C9 55.61(15) ... . ? 
C6 Ti C8 C9 -77.46(15) ....?

C3 Ti C8 C9 -148.43(14) .... ?

C2 Ti C8 C9 -164.51(15) .... ?

C7 Ti C8 C9 $-114.5(2) \ldots$ ?

C1 Ti C8 C9 161.41(15) ... . ?

C4 Ti C8 C9 173.10(16) ....?

C10 Ti C8 C9 $-36.27(13) \ldots$. . ?

C5 Ti C8 C9 142.28(14) ....?

N1 Ti C8 C7 109.85(15) ... . ?

N2 Ti C8 C7 170.09(14) ... ?

C6 Ti C8 C7 37.02(14) ....?

C3 Ti C8 C7 $-33.95(18) \ldots$ ?

C2 Ti C8 C7 $-50.04(15) \ldots$ ?

C1 Ti C8 C7 -84.12(15) ... ? ?

C4 Ti C8 C7 -72.4(2) ....?

C10 Ti C8 C7 78.21(15) ... . ?

C5 Ti C8 C7 $-103.25(15) \ldots$ ?

C9 Ti C8 C7 114.5(2) ....?

C7 C8 C9 C10 -0.8(2) .... ?

Ti C8 C9 C10 64.48(15) ... . ?

C7 C8 C9 Ti -65.30(15) .... ?

N1 Ti C9 C10 59.90(14) . . . ? ?

N2 Ti C9 C10 118.80(14) ... . ?

C6 Ti C9 C10 -37.20(13) .... ? ?

C3 Ti C9 C10 -56.5(2) .... ?

C2 Ti C9 C10 -96.80(16) .... ?

C7 Ti C9 C10 -78.56(15) .... ?

C1 Ti C9 C10-139.52(15) .... ?

C4 Ti C9 C10 113.4(10) ... . ?

C8 Ti C9 C10 -116.6(2) .... ?

C5 Ti C9 C10 179.62(15) ....?

N1 Ti C9 C8 176.47(14) ... . ?

N2 Ti C9 C8 -124.63(15) ....?

C6 Ti C9 C8 79.37(15).... ?

C3 Ti C9 C8 60.0(2) ....?

C2 Ti C9 C8 19.77(19) ... . ?

C7 Ti C9 C8 38.01(14) .... ?

C1 Ti C9 C8 $-22.95(18) \ldots$ ?

C4 Ti C9 C8 $-130.1(10) \ldots$ ?

C10 Ti C9 C8 116.6(2) ... . ?

C5 Ti C9 C8 -63.8(2) ... . ?

C8 C9 C10 C6 $-0.5(2) \ldots$ ?

Ti C9 C10 C6 63.40(15) ... . ?

C8 C9 C10 Ti -63.92(15) ... . ?

C7 C6 C10 C9 1.7(3) ....?

Ti C6 C10 C9 $-64.96(15) \ldots$. . ?

C7 C6 C10 Ti 66.62(16) ... . ?

N1 Ti C10 C9 $-119.39(14) \ldots$ ?

N2 Ti C10 C9 $-60.67(14) \ldots$ ?

C6 Ti C10 C9 116.3(2).... ?

C3 Ti C10 C9 149.98(14) ... . ?

C2 Ti C10 C9 108.57(15)....?

C7 Ti C10 C9 78.23(15) ....?

C1 Ti C10 C9 69.1(2) ....?

C4 Ti C10 C9 -171.89(14) ....?

C8 Ti C10 C9 36.81(13) .... ? 


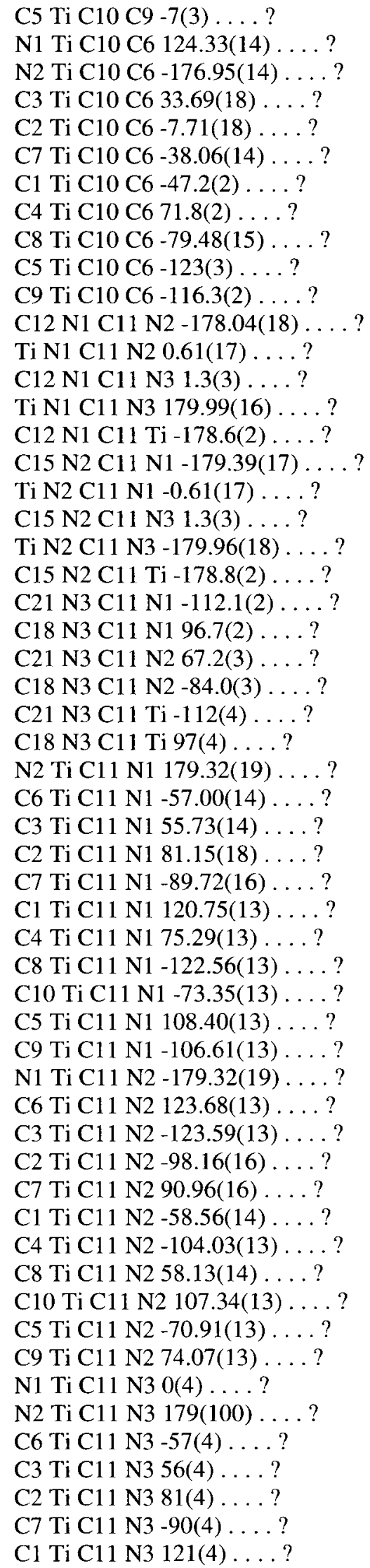


C4 Ti C11 N3 75(4) ... . ?

C8 Ti C11 N3-123(4)....?

C10 Ti C11 N3-73(4)....?

C5 Ti C11 N3 108(4) ... . ?

C9 Ti C11 N3-107(4) ....?

C11 N1 C12 C13 -126.9(2) ....?

Ti N1 C12 C13 55.4(3) ... ?

C11 N1 C12 C14 111.5(2) ...?

Ti N1 C12 C14 -66.2(3) ... ? ?

C11 N2 C15 C17 120.7(2) ... ?

Ti N2 C15 C17 -57.3(3) ... ?

C11 N2 C15 C16-115.9(2) ....?

Ti N2 C15 C16 66.2(3) ....?

C11 N3 C18 C19-25.4(2) ....?

C21 N3 C18 C19-176.53(18) ....?

C11 N3 C18 C20 99.8(2) ....?

C21 N3 C18 C20 -51.3(2) ... . ?

C11 N3 C21 C22 37.2(2) ....?

C18 N3 C21 C22 -171.15(18)....?

C11 N3 C21 C23 159.30(18) ....?

C18 N3 C21 C23 -49.1(2) ... . ?

diffrn_measured_fraction_theta_max 1.000

diffrn_reflns_theta_full 25.00

_diffrn_measured_fraction_theta_full 1.000

_refine_diff_density_max 0.390

_refine_diff_density_min -0.226

_refine_diff_density_rms 0.058 


\section{A.5 Compound 9}

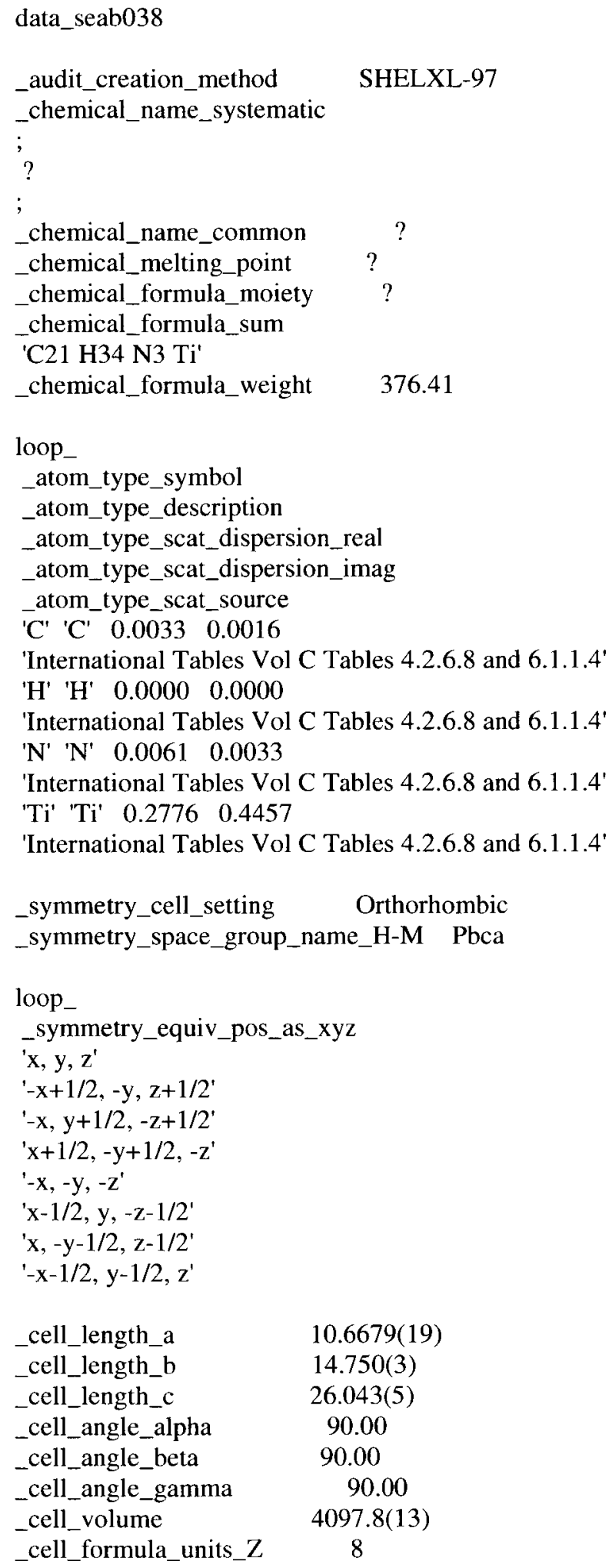


$\begin{array}{ll}\text { _cell_measurement_temperature } & 120(2) \\ \text { _cell_measurement_reflns_used } & 968 \\ \text { _cell_measurement_theta_min } & 2.47 \\ \text { _cell_measurement_theta_max } & 26.38\end{array}$

_exptl_crystal_description block

_exptl_crystal_colour blue

_exptl_crystal_size_max 0.21

_exptl_crystal_size_mid $\quad 0.20$

_exptl_crystal_size_min 0.19

_exptl_crystal_density_meas ?

_exptl_crystal_density_diffrn 1.220

_exptl_crystal_density_method 'not measured'

_exptl_crystal_F_000 1624

_exptl_absorpt_coefficient_mu 0.426

_exptl_absorpt_correction_type multi-scan

_exptl_absorpt_correction_T_min 0.9155

_exptl_absorpt_correction_T_max 0.9242

_exptl_absorpt_process_details 'SADABS (Sheldrick, 2003)'

_exptl_special_details

;

Data collection is performed with four batch runs at

If $=0.00 \backslash \%$ (600 frames), at $\backslash f=90.00 \backslash \%$

(600 frames), at $\backslash \mathrm{f}=180 \backslash \%$ (600 frames) and

at $\backslash f=270 \backslash \%$ ( 600 frames $)$.

Frame width $=0.30 \mathrm{l} \&$ in Iw. Data is

merged, corrected for decay, and treated with

multi-scan absorption corrections.

;

_diffrn_ambient_temperature 120(2)

_diffrn_radiation_wavelength $\quad 0.71073$

_diffrn_radiation_type MoKla

_diffrn_radiation_source 'fine-focus sealed tube'

_diffrn_radiation_monochromator graphite

_diffrn_measurement_device_type 'Bruker AXS APEX diffractometer'

_diffrn_measurement_method Iw

_diffrn_detector_area_resol_mean 836.6

_diffrn_standards_number 0

_diffrn_standards_interval_count 0

_diffrn_standards_interval_time 0

_diffrn_standards_decay_\% 1

_diffrn_reflns_number 27607

_diffrn_reflns_av_R_equivalents 0.0462

_diffrn_reflns_av_sigmaI/netl 0.0274

_diffrn_reflns_limit_h_min -12

_diffrn_reflns_limit_h_max 12

_diffrn_reflns_limit_k_min $\quad-17$

_diffrn_reflns_limit_k_max 17

_diffrn_reflns_limit_l_min $\quad-30$

_diffrn_reflns_limit_I_max 30

_diffrn_reflns_theta_min 2.47

_diffrn_reflns_theta_max $\quad 25.00$

_reflns_number_total 3612

_reflns_number_gt 3028 
_reflns_threshold_expression >2sigma(I)

_computing_data_collection

'SMART (Bruker, 2002)'

_computing_cell_refinement

'SAINT (Bruker, 2002)'

_computing_data_reduction

SAINT

_computing_structure_solution 'SHELXS-97 (Sheldrick, 1990)'

_computing_structure_refinement 'SHELXL-97 (Sheldrick, 1997)'

_computing_molecular_graphics 'SHELXTL (Sheldrick, 2001)'

_computing_publication_material 'SHELXTL (Sheldrick, 2001)'

_refine_special_details

;

Refinement of $\mathrm{F}^{\wedge} 2^{\wedge}$ against ALL reflections. The weighted $\mathrm{R}$-factor $w \mathrm{R}$ and goodness of fit $\mathrm{S}$ are based on $\mathrm{F}^{\wedge} 2^{\wedge}$, conventional $\mathrm{R}$-factors $\mathrm{R}$ are based on $\mathrm{F}$, with $\mathrm{F}$ set to zero for negative $\mathrm{F}^{\wedge} 2^{\wedge}$. The threshold expression of $\mathrm{F}^{\wedge} 2^{\wedge}>2 \operatorname{sigma}\left(\mathrm{F}^{\wedge} 2^{\wedge}\right)$ is used only for calculating $\mathrm{R}$-factors $(\mathrm{gt})$ etc. and is not relevant to the choice of reflections for refinement. R-factors based on $\mathrm{F}^{\wedge} 2^{\wedge}$ are statistically about twice as large as those based on F, and Rfactors based on ALL data will be even larger.

;

_refine_ls_structure_factor_coef Fsqd

_refine_ls_matrix_type full

_refine_ls_weighting_scheme calc

_refine_1s_weighting_details

'calc $\mathrm{w}=1 /\left[\backslash \mathrm{s}^{\wedge} 2^{\wedge}\left(\mathrm{Fo}^{\wedge} 2^{\wedge}\right)+(0.0747 \mathrm{P})^{\wedge} 2^{\wedge}+3.9698 \mathrm{P}\right]$ where $\mathrm{P}=\left(\mathrm{Fo}^{\wedge} 2^{\wedge}+2 \mathrm{Fc}^{\wedge} 2^{\wedge}\right) / 3^{\prime}$

_atom_sites_solution_primary direct

_atom_sites_solution_secondary difmap

_atom_sites_solution_hydrogens geom

_refine_ls_hydrogen_treatment constr

_refine_ls_extinction_method none

_refine_ls_extinction_coef ?

_refine_ls_number_reflns 3612

_refine_ls_number_parameters 248

_refine_ls_number_restraints 20

_refine_ls_R_factor_all $\quad 0.0576$

_refine_ls_R_factor_gt $\quad 0.0486$

_refine_ls_wR_factor_ref 0.1427

_refine_ls_wR_factor_gt 0.1338

_refine_ls_goodness_of_fit_ref 1.075

_refine_ls_restrained_S_all 1.075

_refine_ls_shift/su_max $\quad 0.000$

_refine_ls_shift/su_mean $\quad 0.000$

loop

_atom_site_label

_atom_site_type_symbol

_atom_site_fract_x

_atom_site_fract_y

_atom_site_fract_z

_atom_site_U_iso_or_equiv

_atom_site_adp_type

_atom_site_occupancy

_atom_site_symmetry_multiplicity

_atom_site_calc_flag

_atom_site_refinement_flags 
_atom_site_disorder_assembly

_atom_site_disorder_group

Ti Ti 0.61588(4) 0.14118(3) 0.644759(16) 0.02433(18) Uani $11 \mathrm{~d}$. A.

N1 N 0.4765(2) 0.13621(13) 0.58594(8) 0.0260(5) Uani $11 \mathrm{~d} D$ A .

N2 N 0.4825(2) $0.03242(14) 0.64622(7) 0.0255(5)$ Uani $11 \mathrm{~d} \mathrm{D} \mathrm{A} \mathrm{.}$

C1 C 0.4789(3) 0.1979(2) 0.71169(13) 0.0504(9) Uani $11 \mathrm{~d} \ldots$

H1A H 0.40410 .16570 .72590 .060 Uiso 11 calc R . .

C2 C 0.4771(3) 0.2619(2) 0.67256(12) 0.0446(8) Uani $11 \mathrm{~d} \ldots$

H2A H 0.40080 .28350 .65390 .054 Uiso 11 calc R . .

C3 C 0.5971(3) 0.2981(2) 0.66814(12) 0.0462(8) Uani $11 \mathrm{~d}$. .

H3B H 0.62130 .35090 .64620 .055 Uiso 11 calc R . .

C4 C 0.6722(3) 0.2572(2) 0.70516(12) 0.0487(8) Uani $11 \mathrm{~d} \ldots$

H4A H 0.75970 .27570 .71410 .058 Uiso 11 calc R . .

C5 C 0.6007(4) 0.1941(2) 0.73167(12) 0.0514(9) Uani $11 \mathrm{~d} \ldots$

H5A H 0.62740 .16000 .76300 .062 Uiso 11 calc $R$. .

C6 C 0.7450(3) 0.0910(2) 0.57368(11) 0.0439(8) Uani $11 \mathrm{~d} \ldots$

H6A H 0.71850 .08760 .53690 .053 Uiso 11 calc R . .

C7 C 0.8046(3) 0.1655(2) 0.59740(14) 0.0502(9) Uani $11 \mathrm{~d}$. .

H7A H 0.82990 .22320 .58020 .060 Uiso 11 calc R . .

C8 C 0.8399(3) 0.1378(2) 0.64680(12) 0.0436(8) Uani $11 \mathrm{~d} \ldots$

H8A H 0.89450 .17260 .67100 .052 Uiso 11 calc R . .

C9 C 0.7999(3) 0.0489(2) 0.65345(11) 0.0393(7) Uani $11 \mathrm{~d} \ldots$

H9A H 0.82000 .00960 .68360 .047 Uiso 11 calc R . .

C10 C 0.7424(3) 0.0199(2) 0.60875(11) 0.0386(7) Uani $11 \mathrm{~d} \ldots$

H10A H $0.7131-0.04320 .60150 .046$ Uiso 11 calc R . .

C11 C 0.4210(2) 0.06286(16) 0.60535(9) 0.0241(5) Uani $11 \mathrm{~d} \mathrm{D} \mathrm{.}$

C12 C 0.4403(3) 0.18213(18) 0.53852(10) 0.0348(6) Uani $11 \mathrm{~d} \ldots$

H12A H 0.35210 .20410 .54230 .042 Uiso 11 calc R A .

C13 C 0.5259(4) 0.2646(2) 0.53057(13) 0.0548(9) Uani $11 \mathrm{~d}$. A .

H13A H 0.52430 .30260 .56140 .082 Uiso 11 calc R . .

H13B H 0.49620 .29980 .50110 .082 Uiso 11 calc R . .

H13C H 0.61180 .24390 .52420 .082 Uiso 11 calc R . .

C14 C 0.4473(4) 0.1216(2) 0.49142(11) 0.0495(8) Uani $11 \mathrm{~d}$. A .

H14A H 0.39520 .06770 .49680 .074 Uiso 11 calc $R$. .

H14B H 0.53440 .10300 .48570 .074 Uiso 11 calc R . .

H14C H 0.41690 .15500 .46140 .074 Uiso 11 calc R . .

C15 C 0.4453(3) -0.04584(17) 0.67815(10) 0.0317(6) Uani $11 \mathrm{~d} \ldots$

C16 C 0.3131(4) -0.0382(3) 0.70128(14) 0.0617(10) Uani $11 \mathrm{~d}$. A .

H16A H 0.30250 .02190 .71680 .093 Uiso 11 calc R . .

H16B H $0.3020-0.08490 .72770 .093$ Uiso 11 calc R . .

H16C H $0.2505-0.04660 .67420 .093$ Uiso 11 calc R . .

C17 C 0.4577(4) -0.1357(2) 0.64922(12) 0.0519(9) Uani $11 \mathrm{~d}$. A .

H17A H $0.5444-0.14320 .63740 .078$ Uiso 11 calc R . .

H17B H $0.4012-0.13560 .61950 .078$ Uiso 11 calc R . .

H17C H $0.4355-0.18590 .67210 .078$ Uiso 11 calc R . .

C18 C 0.5331(3) -0.0491(2) 0.72431(12) 0.0521(9) Uani $11 \mathrm{~d}$. A .

H18A H $0.6201-0.05210 .71240 .078$ Uiso 11 calc R . .

H18B H $0.5141-0.10290 .74500 .078$ Uiso 11 calc R . .

H18C H 0.52140 .00550 .74520 .078 Uiso 11 calc R . .

N3 N 0.3132(3) 0.0246(2) 0.58347(11) 0.0240(7) Uani 0.824(4) $1 \mathrm{~d}$ PD A 1

H3A H $0.3163-0.03340 .57590 .029$ Uiso 0.824(4) 1 calc PR A 1

C19 C 0.1971(3) 0.0715(3) 0.57217(15) 0.0406(9) Uani 0.824(4) $1 \mathrm{~d}$ PD A 1

H19A H 0.20860 .10320 .53860 .049 Uiso 0.824(4) 1 calc PR A 1

C20 C 0.1659(4) 0.1434(3) 0.61187(16) 0.0449(10) Uani 0.824(4) 1 d PD A 1

H20A H 0.23930 .18220 .61740 .067 Uiso $0.824(4) 1$ calc PR A 1

H20B H 0.14260 .11410 .64420 .067 Uiso $0.824(4) 1$ calc PR A 1 
H20C H 0.09580 .18040 .59960 .067 Uiso 0.824(4) 1 calc PR A 1 C21 C 0.0920(4) 0.0034(3) 0.5653(2) 0.0555(13) Uani 0.824(4) 1 d PD A 1 H21 A H $0.1142-0.03940 .53800 .083$ Uiso 0.824(4) 1 calc PR A 1 H21B H 0.01470 .03530 .55600 .083 Uiso 0.824(4) 1 calc PR A 1 H21C H $0.0792-0.02980 .59750 .083$ Uiso 0.824(4) 1 calc PR A 1 N3' N 0.3209(12) 0.0040(11) 0.5944(6) 0.0240(7) Uani 0.176(4) $1 \mathrm{~d}$ PD A 2 H3A H $0.3402-0.04800 .57980 .029$ Uiso 0.176(4) 1 calc PR A 2 C19' C 0.1926(13) 0.0196(12) 0.6044(5) 0.0406(9) Uani 0.176(4) $1 \mathrm{~d}$ PD A 2 H19B H $0.1581-0.03810 .61890 .049$ Uiso 0.176(4) 1 calc PR A 2 C20' C 0.1733(16) 0.0924(12) 0.6451(6) 0.0449(10) Uani 0.176(4) $1 \mathrm{~d}$ PD A 2 H20D H 0.1106 0.0717 0.6700 0.067 Uiso 0.176(4) 1 calc PR A 2 H20E H 0.14410 .14830 .62880 .067 Uiso 0.176(4) 1 calc PR A 2 H20F H 0.25270 .10390 .66280 .067 Uiso 0.176(4) 1 calc PR A 2 C21' C 0.1209(18) 0.0382(16) 0.5550(7) 0.0555(13) Uani 0.176(4) $1 \mathrm{~d}$ PD A 2 H21D H $0.0919-0.01930 .54030 .083$ Uiso 0.176(4) 1 calc PR A 2 H21E H 0.17620 .06880 .53040 .083 Uiso 0.176(4) 1 calc PR A 2 H21F H 0.04860 .07700 .56240 .083 Uiso 0.176(4) 1 calc PR A 2

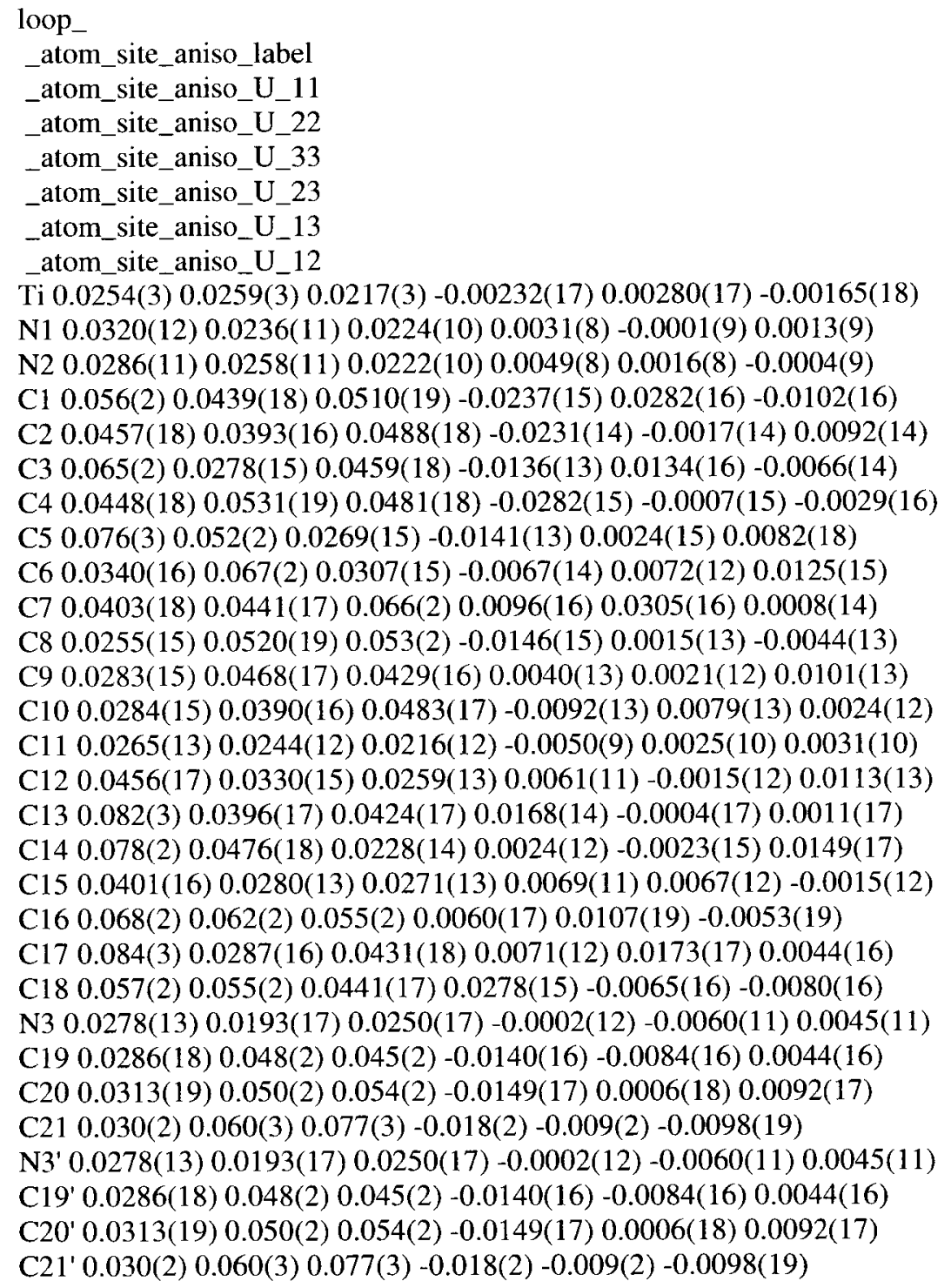




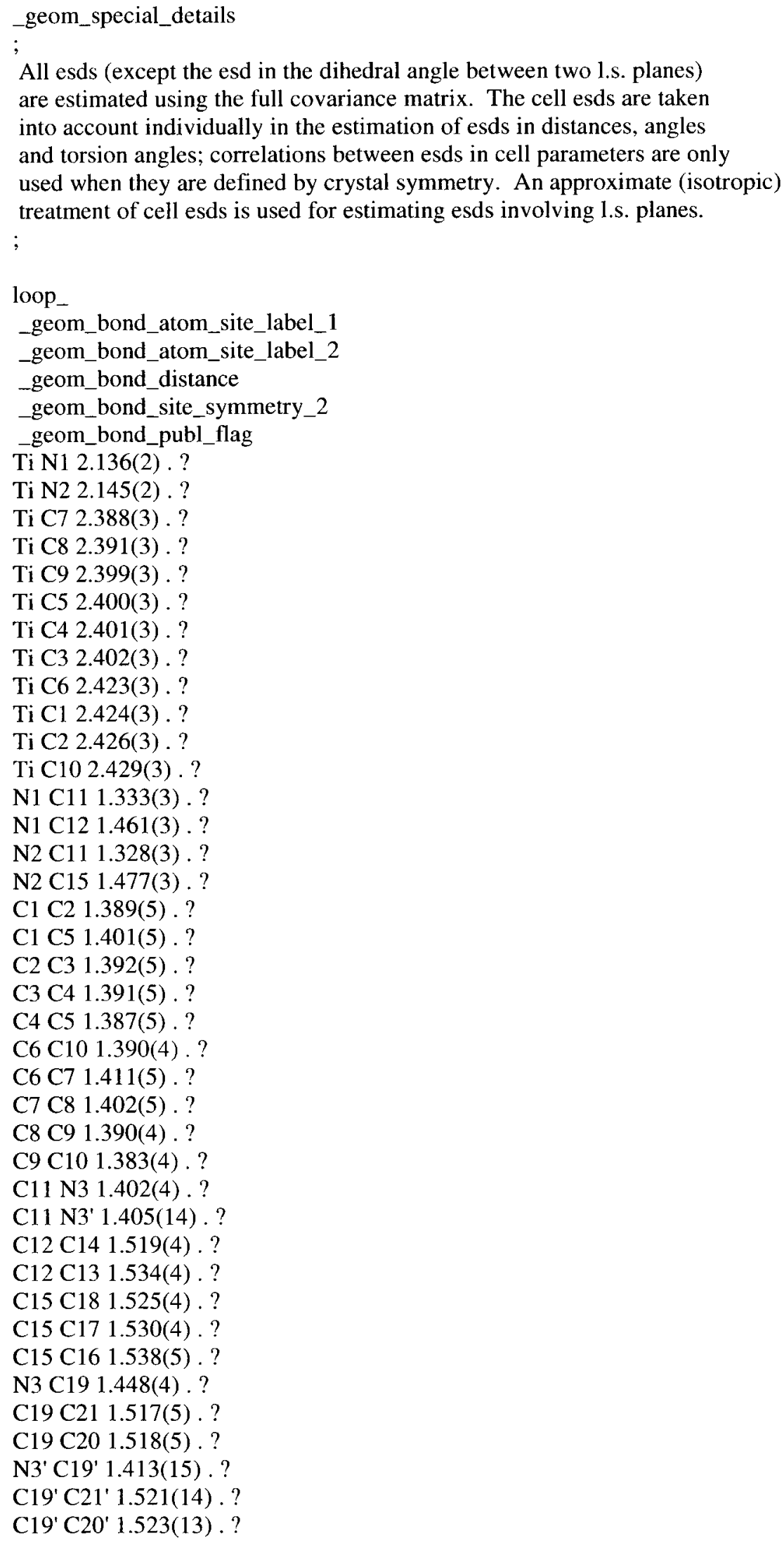




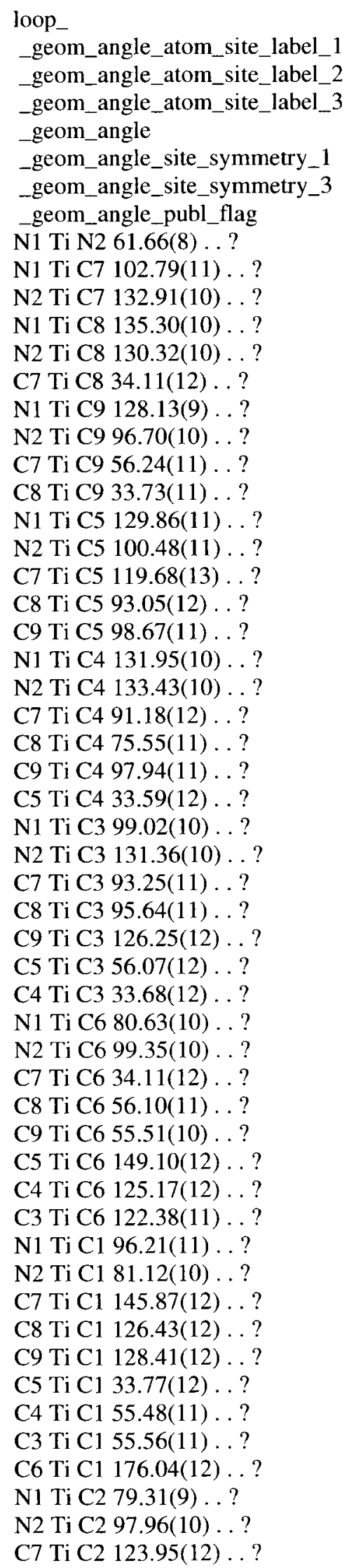


C8 Ti C2 128.24(11) . . ?

C9 Ti C2 152.56(11). . ?

C5 Ti C2 55.86(12) . .?

C4 Ti C2 55.54(11)..?

C3 Ti C2 33.51(11)..?

C6 Ti C2 143.03(12) . . ?

C1 Ti C2 33.28(11) . . ?

N1 Ti C10 94.85(9) . . ?

$\mathrm{N} 2 \mathrm{Ti} \mathrm{C} 10$ 79.92(9) .. ?

C7 Ti C10 56.13(11). . ?

C8 Ti C10 55.78(10) . . ?

C9 Ti C10 33.29(10) . . ?

C5 Ti C10 129.88(11).. ?

C4 Ti C10 129.70(11)..?

C3 Ti C10 148.63(11) . . ?

C6 Ti C10 33.30(10) . . ?

C1 Ti C10 150.12(11)..?

C2 Ti C10 174.07(11)..?

C11 N1 C12 125.4(2) . . ?

C11 N1 Ti 93.75(15)..?

C12 N1 Ti 140.78(18)..?

C11 N2 C15 125.6(2) . . ?

C11 N2 Ti 93.48(15) . .?

C15 N2 Ti 140.60(17) . . ?

C2 C1 C5 108.3(3) .. ?

C2 C1 Ti 73.47(17) . . ?

C5 C1 Ti 72.18(17) . .?

C1 C2 C3 107.9(3)..?

$\mathrm{C} 1 \mathrm{C} 2 \mathrm{Ti} 73.25(17) \ldots$ ?

C3 C2 Ti 72.28(17) . . ?

C4 C3 C2 107.8(3) .. ?

$\mathrm{C} 4 \mathrm{C} 3 \mathrm{Ti} 73.12(17) \ldots$ ?

$\mathrm{C} 2 \mathrm{C} 3 \mathrm{Ti}$ 74.21(17) . . ?

C5 C4 C3 108.6(3) .. ?

$\mathrm{C} 5 \mathrm{C} 4 \mathrm{Ti} 73.16(17) \ldots$ ?

C3 C4 Ti 73.20(17) . . ?

C4 C5 C1 107.3(3) .. ?

C4 C5 Ti 73.25(17) . . ?

C1 C5 Ti 74.05(17) . . ?

C10 C6 C7 108.0(3) . . ?

C10 C6 Ti 73.56(16) . . ?

C7 C6 Ti 71.56(16) . . ?

C8 C7 C6 107.2(3) . .?

C8 C7 Ti 73.08(18) . . ?

C6 C7 Ti 74.33(17) . . ?

C9 C8 C7 107.9(3) . . ?

C9 C8 Ti 73.46(17) .. ?

C7 C8 Ti 72.81(18) . . ?

C10 C9 C8 108.8(3) . . ?

C10 C9 Ti 74.53(17) . . ?

C8 C9 Ti 72.81(18) . . ?

C9 C10 C6 108.1(3) . . ?

C9 C10 Ti 72.19(17) . . ?

C6 C10 Ti 73.14(17) . . ?

$\mathrm{N} 2 \mathrm{C} 11 \mathrm{~N} 1111.0(2) \ldots$ ?

N2 C1 1 N3 126.5(2) ..? 
N1 C11 N3 122.5(2) . .?

N2 C11 N3' 109.2(7) . . ?

N1 C11 N3' 139.7(7) . .?

N3 C11 N3' 17.4(7) . .?

N2 C11 Ti 55.74(13) .. ?

N1 C11 Ti 55.35(13) . . ?

N3 C11 Ti 177.2(2) . . ?

N3' C11 Ti 164.9(7) . . ?

N1 C12 C14 113.4(2) . . ?

N1 C12 C13 108.9(2) . . ?

C14 C12 C13 109.1(3) . . ?

N2 C15 C18 107.7(2) ..?

N2 C15 C17 112.1(2) ..?

C18 C15 C17 107.9(3) ..?

N2 C15 C16 114.1(2) ..?

C18 C15 C16 104.9(2) ..?

C17 C15 C16 109.6(3) . . ?

C11 N3 C19 126.3(3) .. ?

N3 C19 C21 109.9(3) .. ?

N3 C19 C20 112.5(3) ..?

C21 C19 C20 112.4(3) . . ?

C11 N3' C19' 126.7(12) . . ?

N3' C19' C21' 111.1(12) . . ?

N3' C19' C20' 112.0(11) . . ?

C21' C19' C20' 113.2(13) . . ?

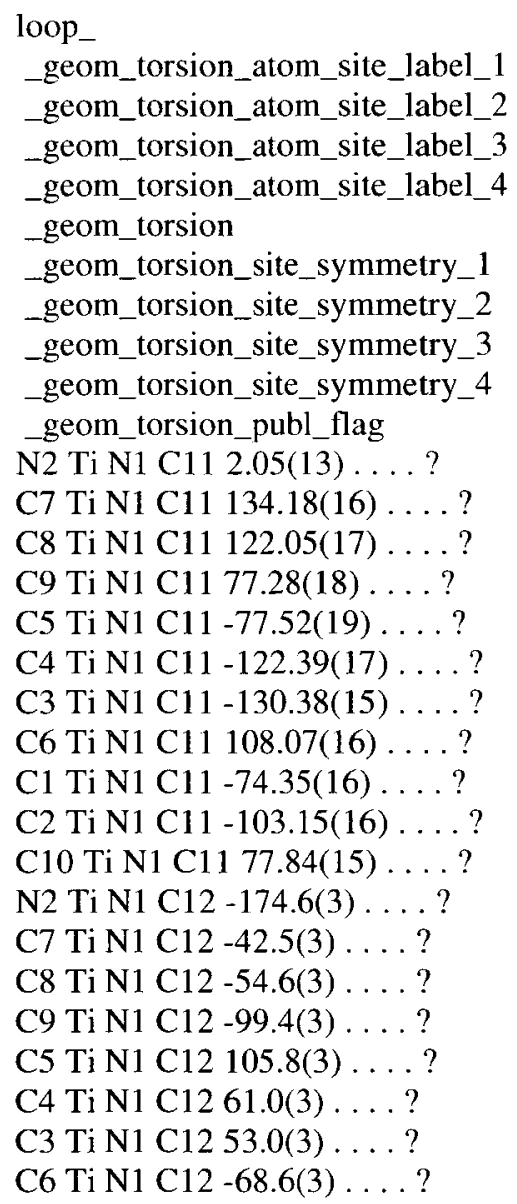


C1 Ti N1 C12 109.0(3) ... . ?

C2 TiN1 C12 80.2(3) ....?

C10 Ti N1 C12 -98.8(3) ... ?

N1 Ti N2 C11 -2.05(13) ....?

C7 Ti N2 C11 -83.0(2) ....?

C8 Ti N2 C11 -129.03(16) ... . ?

C9 Ti N2 C11 -132.07(15) ....?

C5 Ti N2 C11 127.80(16) ....?

C4 Ti N2 C11 120.31(17) ... . ?

C3 Ti N2 C11 74.20(19) ....?

C6 Ti N2 C11 -76.02(16) ... . ?

C1 Ti N2 C11 100.00(17) ....?

C2 Ti N2 C11 71.19(16) ....?

C10 Ti N2 C11 -103.20(15) ....?

N1 Ti N2 C15 -175.6(3) ...? ?

C7 Ti N2 C15 103.5(3)....?

C8 Ti N2 C15 57.4(3) ....?

C9 Ti N2 C15 54.4(3) ....?

C5 Ti N2 C15 -45.8(3) ....?

C4 Ti N2 C15 -53.3(3) ....?

C3 Ti N2 C15 -99.4(3) ....?

C6 Ti N2 C15 110.4(3) ....?

$\mathrm{C} 1 \mathrm{Ti}$ N2 C15 -73.6(3)....?

C2 Ti N2 C15 -102.4(3) ....?

C10 Ti N2 C15 83.2(3) ....?

N1 Ti C1 C2 -59.6(2) ....?

N2 $\mathrm{Ti} \mathrm{C} 1 \mathrm{C} 2-119.6(2) \ldots$ ?

C7 Ti C1 C2 64.3(3) .... ?

C8 Ti C1 C2 106.1(2) ... . ?

C9 Ti C1 C2 148.88(19) ....?

C5 Ti C1 C2 116.0(3)....?

$\mathrm{C} 4 \mathrm{Ti} \mathrm{C} 1 \mathrm{C} 278.2(2) \ldots$ ?

C3 Ti C1 C2 37.09(19) ... . ?

C6 Ti C1 C2 $-22.5(17) \ldots$ ?

C10 Ti C1 C2 -170.7(2)....?

N1 Ti C1 C5 -175.6(2) ....?

N2 Ti C1 C5 124.4(2) ....?

C7 Ti Cl C5 -51.7(3) ... . ?

C8 Ti C1 C5 $-9.9(3) \ldots$ ?

C9 Ti C1 C5 32.9(3) ....?

C4 Ti C1 C5 $-37.8(2) \ldots$ ?

C3 Ti C1 C5 $-78.9(2) \ldots$. . ?

C6 Ti C1 C5 -138.6(16) .... ?

$\mathrm{C} 2 \mathrm{Ti} \mathrm{C} 1 \mathrm{C} 5-116.0(3) \ldots$ ?

C10 Ti C1 C5 73.3(3) ....?

$\mathrm{C} 5 \mathrm{C} 1 \mathrm{C} 2 \mathrm{C} 3-0.2(3) \ldots$ ?

Ti C1 C2 C3 -64.4(2) . . . ?

C5 C1 C2 Ti 64.3(2) ....?

N1 Ti C2 C1 119.2(2) ... . ?

N2 Ti C2 C1 60.2(2) ....?

C7 Ti C2 C1 -142.5(2) ... . ?

C8 Ti C2 C1 $-100.2(2) \ldots$ ?

C9 Ti C2 C1 -61.5(3) ... . ?

$\mathrm{C} 5 \mathrm{Ti} \mathrm{C} 2 \mathrm{Cl}-37.1(2) \ldots$ ?

C4 TiC2 C1 -78.1(2)....?

C3 Ti C2 C1 -115.7(3) ... ? 


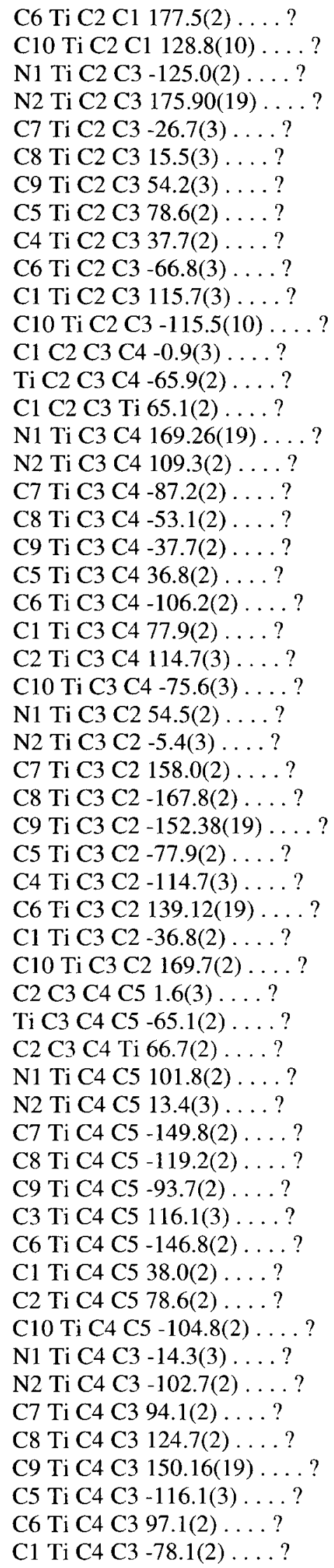




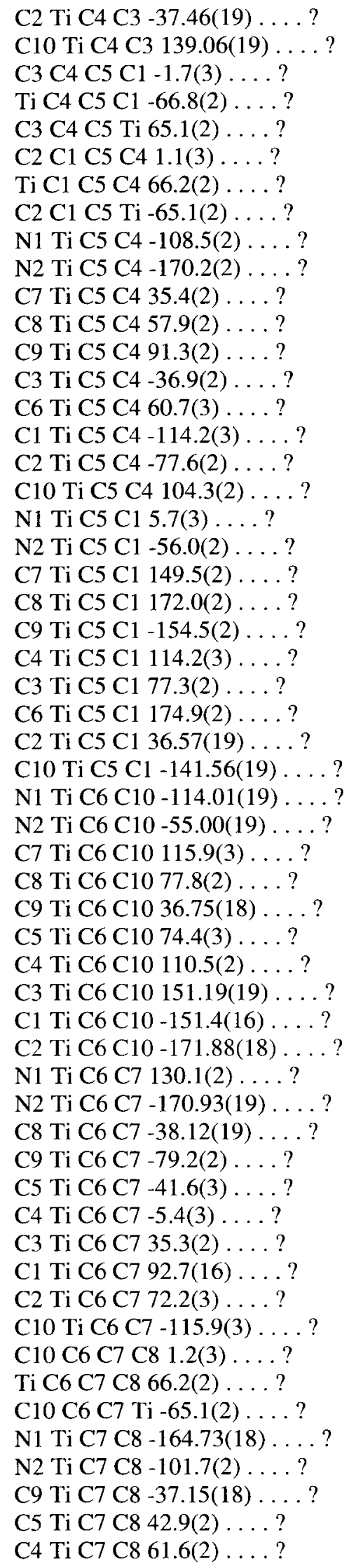


C3 Ti C7 C8 95.3(2) ... . ?

C6 Ti C7 C8 -114.0(3) ....?

C1 Ti C7 C8 73.1(3) ....?

C2 Ti C7 C8 109.7(2) ....?

C10 Ti C7 C8 $-77.5(2) \ldots$ ?

N1 Ti C7 C6 $-50.7(2) \ldots$ ?

N2 Ti C7 C6 12.3(3) ....?

C8 Ti C7 C6 114.0(3) ....?

C9 Ti C7 C6 76.8(2) ....?

C5 Ti C7 C6 156.91(19) ....?

C4 Ti C7 C6 175.6(2) ....?

C3 Ti C7 C6 -150.8(2) .... ?

C1 Ti C7 C6 -172.9(2)....?

C2 Ti C7 C6-136.36(19) ... . ?

C10 Ti C7 C6 36.50(18) .... ?

C6 C7 C8 C9 $-1.5(3) \ldots$ ?

Ti C7 C8 C9 65.6(2) ... ?

C6 C7 C8 Ti-67.1(2)....?

N1 Ti C8 C9 -93.9(2) ....?

N2 Ti C8 C9 $-5.4(2) \ldots$ ?

C7 Ti C8 C9 -115.3(3).... ?

C5 Ti C8 C9 101.07(19) ....?

C4 Ti C8 C9 130.0(2) ....?

C3 Ti C8 C9 157.25(18) ... . ?

C6 Ti C8 C9 -77.16(19) ....?

C1 Ti C8 C9 106.6(2) ....?

C2 Ti C8 C9 148.73(18) ... . ?

C10 Ti C8 C9 -36.69(17) .... ?

N1 Ti C8 C7 21.4(2) ... . ?

N2 Ti C8 C7 109.8(2) ... ?

C9 Ti C8 C7 115.3(3) .... ?

C5 Ti C8 C7 -143.7(2) ... . ?

C4 Ti C8 C7 -114.7(2) ... ?

C3 Ti C8 C7 $-87.5(2) \ldots$ ?

C6 Ti C8 C7 38.12(19) ... . ?

C1 Ti C8 C7 -138.2(2) ....?

C2 Ti C8 C7 $-96.0(2) \ldots$ ?

C10 Ti C8 C7 78.6(2) ... . ?

C7 C8 C9 C10 1.2(3) .... ?

Ti C8 C9 C10 66.4(2) . . . ?

C7 C8 C9 Ti -65.2(2) . . . ?

N1 Ti C9 C10 1.0(2) . . . ?

N2 Ti C9 C10 59.99(18) ....?

C7 Ti C9 C10 - 78.3(2) .... ?

C8 Ti C9 C10-115.8(3) ....?

C5 Ti C9 C10 161.71(19) ... . ?

C4 Ti C9 C10-164.34(19) ... . ?

C3 Ti C9 C10-144.33(18) ... . ?

C6 Ti C9 C10 -36.77(18) ... . ?

C1 Ti C9 C10 143.95(18).... ?

C2 Ti C9 C10-178.1(2) ....?

N1 Ti C9 C8 116.85(18) ... ?

N2 Ti C9 C8 175.83(18) ... ?

C7 Ti C9 C8 37.58(19) .... ?

C5 Ti C9 C8 $-82.4(2) \ldots$ ?

C4 Ti C9 C8 $-48.5(2) \ldots$ ? 
C3 Ti C9 C8 -28.5(2) ... ?

C6 Ti C9 C8 79.1(2) ....?

C1 Ti C9 C8 -100.2(2) ... . ?

$\mathrm{C} 2 \mathrm{Ti}$ C9 C8 -62.2(3).... ?

C10 Ti C9 C8 115.8(3) ... . ?

C8 C9 C10 C6 -0.5(3) ... . ?

Ti C9 C10 C6 64.8(2) ....?

C8 C9 C10 Ti -65.3(2) .... ?

C7 C6 C10 C9 -0.4(3) ... . ?

Ti C6 C10 C9 $-64.2(2) \ldots$. . ?

C7 C6 C10 Ti 63.7(2) .... ?

N1 Ti C10 C9 $-179.20(18) \ldots$ ?

N2 Ti C10 C9 -119.13(18)....?

C7 Ti C10 C9 78.6(2) ... . ?

C8 Ti C10 C9 37.18(18) ... . ?

C5 Ti C10 C9 -23.8(2) ....?

C4 Ti C10 C9 20.3(2) ... . ?

C3 Ti C10 C9 64.6(3) ....?

C6 Ti C10 C9 116.0(3) ... . ?

C1 Ti C10 C9 -67.8(3)....?

C2 Ti C10 C9 171.3(10) ... . ?

N1 Ti C10 C6 64.76(19) ....?

N2 Ti C10 C6 124.82(19) . . . ? ?

C7 Ti C10 C6 $-37.40(19) \ldots$ ?

C8 Ti C10 C6 -78.9(2) ....?

C9 Ti C10 C6 -116.0(3) ... . ?

C5 Ti C10 C6 -139.9(2) .... ?

C4 Ti C10 C6 $-95.7(2) \ldots$ ?

C3 Ti C10 C6 -51.4(3) .... ?

C1 Ti C10 C6 176.2(2) ....?

C2 Ti C10 C6 55.3(11) ....?

C15 N2 C11 N1 178.1(2)...?

Ti N2 C11 N1 3.1(2) ... . ?

C15 N2 C11 N3 -3.0(4) ...? ?

Ti N2 C11 N3 -178.0(2) . . . ?

C15 N2 C11 N3' -5.3(7) ... . ?

Ti N2 C11 N3' 179.8(6) ....?

C15 N2 C11 Ti 175.0(3) ... ?

C12 N1 C11 N2 174.3(2)...?

Ti N1 C11 N2 -3.1(2) ...?

C12 N1 C11 N3 -4.7(4)...?

Ti N1 C11 N3 177.9(2) ... ?

C12 N1 C11 N3' $-0.8(10) \ldots$ ?

Ti N1 C11 N3' -178.2(9) ....?

C12 N1 C11 Ti 177.4(3)....?

N1 Ti C11 N2 176.5(2) ....?

C7 Ti C11 N2 120.35(16) ....?

C8 Ti C11 N2 82.2(2) ...?

C9 Ti C11 N2 55.23(17) ... . ?

C5 Ti C11 N2 $-61.35(18) \ldots$ ?

C4 Ti C11 N2 -93.4(2) ... . ?

C3 Ti C11 N2 -125.43(16) ... . ?

C6 Ti C11 N2 106.74(16) ... . ?

C1 Ti C11 N2 -76.90(16) ... . ?

C2 Ti C11 N2 -110.22(16) ... . ?

C10 Ti C11 N2 73.56(16) ....? 
$\mathrm{N} 2 \mathrm{Ti}$ C11 N1 $-176.5(2) \ldots$ ?

C7 Ti C11 N1 -56.13(18) ... . ?

C8 Ti C11 N1 -94.3(2) ... ?

C9 Ti C11 N1-121.25(16) ... . ?

C5 Ti C11 N1 122.17(16) ... . ?

C4 TiC11 N1 90.1(2) ... ?

C3 Ti C11 N1 58.09(17) ....?

C6 Ti C11 N1 -69.75(16) ....?

C1 Ti C11 N1 106.62(16) ... . ?

C2 Ti C11 N1 73.30(16) ....?

C10 Ti C11 N1 -102.92(16) ....?

N1 Ti C11 N3 -39(4) ... ?

N2 Ti C11 N3 144(4) ... . ?

C7 Ti C11 N3 -95(4).... ?

C8 Ti C11 N3-133(4) ... . ?

C9 Ti C11 N3-160(4) ....?

C5 Ti C11 N3 83(4) ....?

C4 Ti C11 N3 51(4) ... . ?

C3 Ti C11 N3 19(4)....?

C6 Ti C11 N3-109(4).... ?

C1 TiC11 N3 67(4) ....?

C2 Ti C11 N3 34(4) ....?

C10 Ti C11 N3-142(4) ....?

N1 Ti C11 N3' 176(2) ....?

N2 Ti C11 N3' -1(2) ....?

C7 Ti C11 N3' 120(2) ....?

C8 Ti C11 N3' 81(2) ... . ?

C9 Ti Cl1 N3' 54(2) ... . ?

C5 Ti C11 N3'-62(2) ... . ?

C4 Ti C11 N3' -94(2) ... . ?

C3 Ti C11 N3'-126(2) .... ?

C6 Ti C11 N3' 106(2) ....?

C1 Ti C11 N3' -78(2)....?

C2 Ti C11 N3'-111(2) ... ? ?

C10 Ti C11 N3' 73(2) ... . ?

C11 N1 C12 C14 -59.6(4)....?

Ti N1 C12 C14 116.3(3) ... . ?

C11 N1 C12 C13 178.7(2) ...? ?

Ti N1 C12 C13 -5.4(4) ...? ?

C11 N2 C15 C18-173.1(2) ....?

Ti N2 C15 C18 -1.0(4) ....?

C11 N2 C15 C17 68.3(3) ....?

Ti N2 C15 C17-119.6(3) ...?

C11 N2 C15 C16 -57.1(3) ... ?

Ti N2 C15 C16 115.0(3) . . . ?

N2 C11 N3 C19 127.5(3) ... ?

N1 C11 N3 C19 $-53.7(4) \ldots$ ?

N3' C11 N3 C19 135(2) ....?

Ti C11 N3 C19-16(4) ....?

C11 N3 C19 C21 -161.8(3) ... . ?

C11 N3 C19 C20 -35.8(5) .... ?

N2 C11 N3' C19' 104.5(15) ... . ?

N1 C11 N3' C19' -80.3(18) .... ?

N3 C11 N3' C19' -69(2) ... ? ?

Ti C11 N3' C19' 105(2) ....?

C11 N3' C19' C21' 107.6(18) ... . ? 
C11 N3' C19' C20' -20(2) ....?

_diffrn_measured_fraction_theta_max 0.999

_diffrn_reflns_theta_full 25.00

_diffrn_measured_fraction_theta_full 0.999

_refine_diff_density_max 0.793

_refine_diff_density_min -0.578

_refine_diff_density_rms 0.065 


\section{A.6 Compound 10}

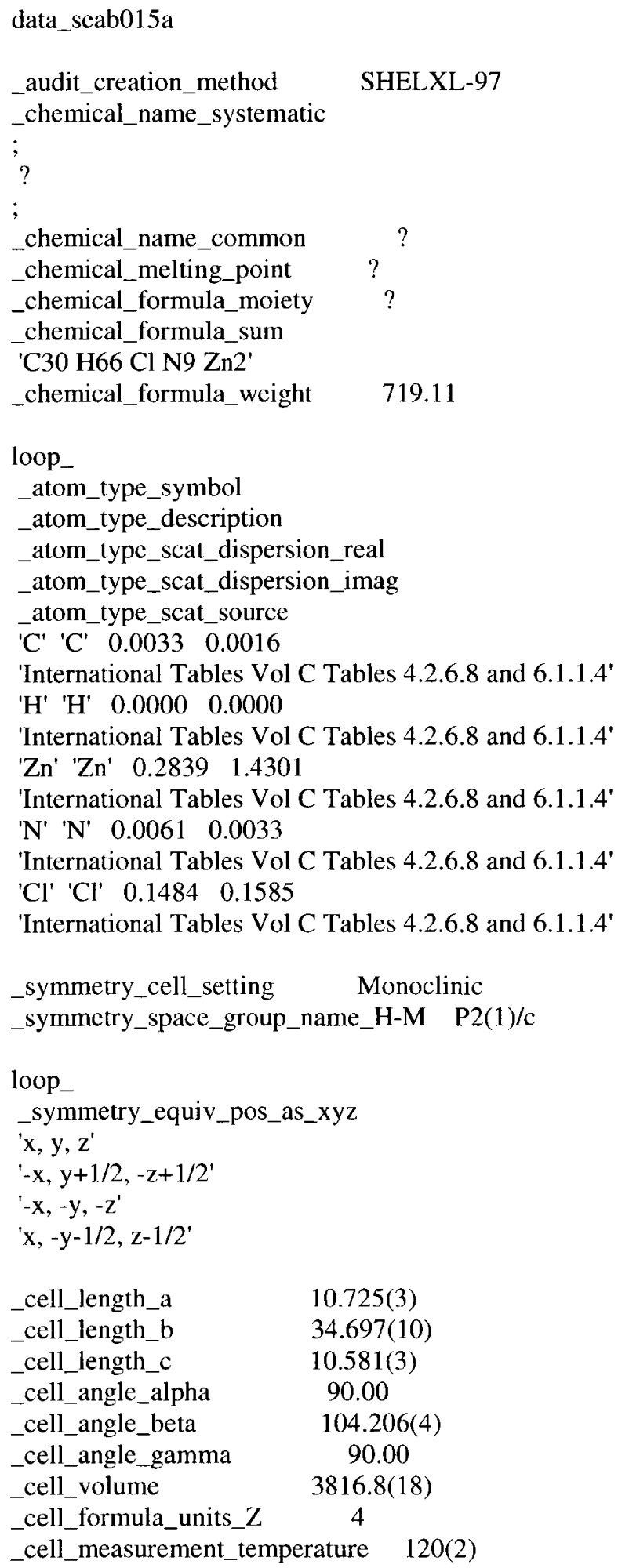




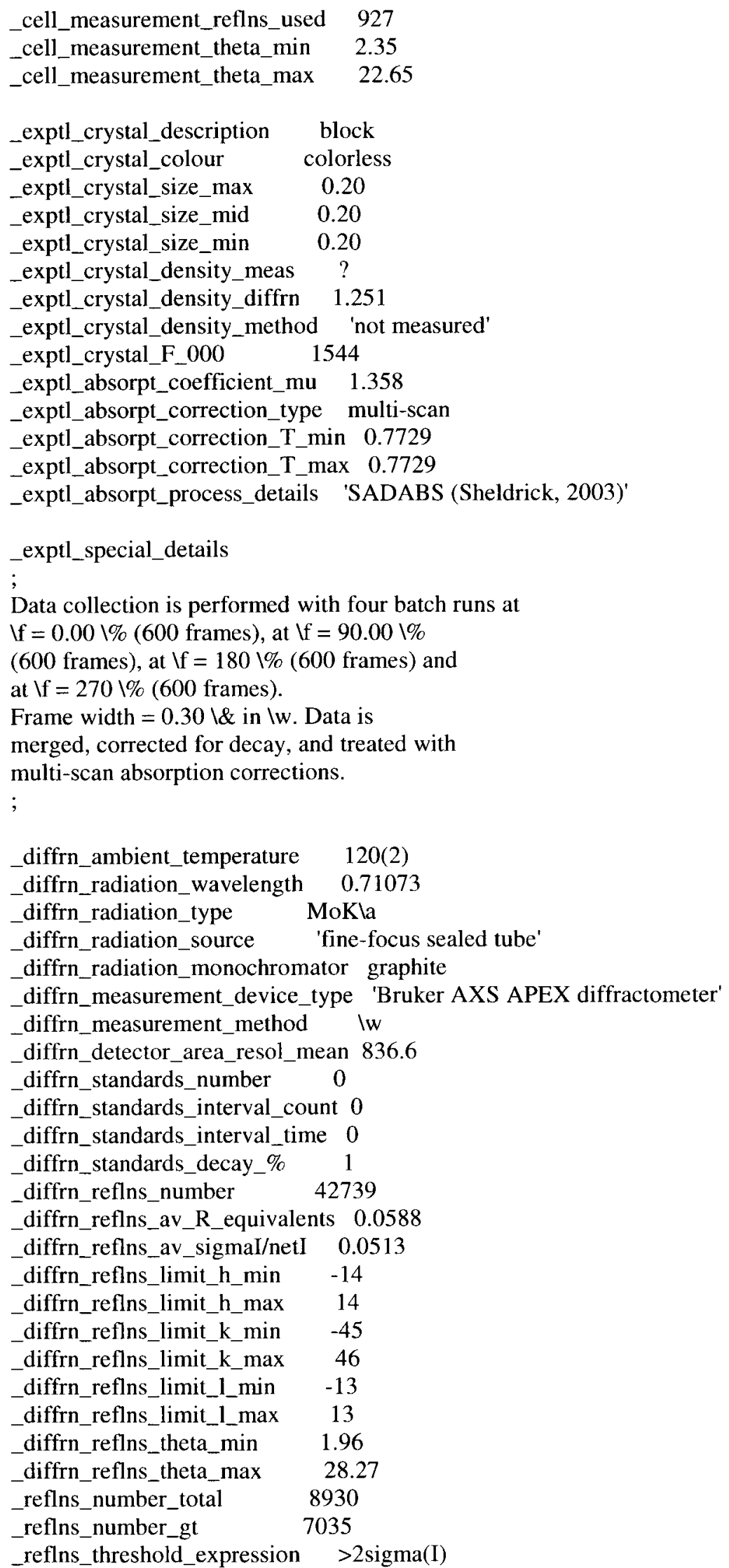


_computing_data_collection _computing_cell_refinement _computing_data_reduction _computing_structure_solution _computing_structure_refinement _computing_molecular_graphics _computing_publication_material

_refine_special_details

;

Refinement of $\mathrm{F}^{\wedge} 2^{\wedge}$ against ALL reflections. The weighted R-factor wR and goodness of fit $\mathrm{S}$ are based on $\mathrm{F}^{\wedge} 2^{\wedge}$, conventional $\mathrm{R}$-factors $\mathrm{R}$ are based on $F$, with $F$ set to zero for negative $\mathrm{F}^{\wedge} 2^{\wedge}$. The threshold expression of $\mathrm{F}^{\wedge} 2^{\wedge}>2 \operatorname{sigma}\left(\mathrm{F}^{\wedge} 2^{\wedge}\right)$ is used only for calculating $\mathrm{R}$-factors $(\mathrm{gt})$ etc. and is not relevant to the choice of reflections for refinement. R-factors based on $\mathrm{F}^{\wedge} 2^{\wedge}$ are statistically about twice as large as those based on $\mathrm{F}$, and $\mathrm{R}$ factors based on ALL data will be even larger.

;

_refine_ls_structure_factor_coef Fsqd

_refine_ls_matrix_type full

_refine_ls_weighting_scheme calc

_refine_ls_weighting_details

'calc $\mathrm{w}=1 /\left[\backslash \mathrm{s}^{\wedge} 2^{\wedge}\left(\mathrm{Fo}^{\wedge} 2^{\wedge}\right)+(0.0650 \mathrm{P})^{\wedge} 2^{\wedge}\right]$ where $\mathrm{P}=\left(\mathrm{Fo}^{\wedge} 2^{\wedge}+2 \mathrm{Fc}^{\wedge} 2^{\wedge}\right) / 3^{\prime}$

_atom_sites_solution_primary direct

_atom_sites_solution_secondary difmap

_atom_sites_solution_hydrogens geom

_refine_ls_hydrogen_treatment constr

refine_ls_extinction_method none

refine_ls_extinction_coef ?

_refine_ls_number_reflns 8930

_refine_ls_number_parameters 379

_refine_ls_number_restraints 0

_refine_ls_R_factor_all $\quad 0.0614$

_refine_ls_R_factor_gt $\quad 0.0432$

_refine_ls_wR_factor_ref $\quad 0.1135$

_refine_ls_wR_factor_gt 0.1054

_refine_ls_goodness_of_fit_ref 1.029

_refine_ls_restrained_S_all 1.029

_refine_ls_shift/su_max $\quad 0.001$

_refine_ls_shift/su_mean $\quad 0.000$

loop_

_atom_site_label

_atom_site_type_symbol

_atom_site_fract_x

_atom_site_fract_y

_atom_site_fract_z

_atom_site_U_iso_or_equiv

_atom_site_adp_type

_atom_site_occupancy

_atom_site_symmetry_multiplicity

_atom_site_calc_flag

_atom_site_refinement_flags

_atom_site_disorder_assembly
'SAINT (Bruker, 2002)'

SAINT

'SHELXL-97 (Sheldrick, 1997)'

'SHELXTL (Sheldrick, 2001)'

HELXTL
MART (Bruker, 2002)' 79 
_atom_site_disorder_group Zn1 Zn 0.33436(3) $0.110438(8) 0.56252(3) 0.01716(9)$ Uani $11 \mathrm{~d} \ldots$ Zn2 Zn 0.18693(3) 0.135638(8) 0.72014(3) 0.01754(9) Uani $11 \mathrm{~d} \ldots$ $\mathrm{Cl} 1 \mathrm{Cl} 0.06074(6) 0.156300(19) 0.85239(6) 0.02667(15)$ Uani $11 \mathrm{~d} \ldots$ N1 N 0.09965(19) 0.15140(6) 0.53366(19) 0.0182(4) Uani $11 \mathrm{~d} \ldots$ $\mathrm{N} 2 \mathrm{~N} 0.17971(18) 0.10327(5) 0.42560(19) 0.0172(4)$ Uani $11 \mathrm{~d} \ldots$ N3 N-0.01690(19) 0.13270(6) 0.32254(19) 0.0202(4) Uani $11 \mathrm{~d} \ldots$ H3A H - 0.09390 .13100 .33740 .024 Uiso 11 calc R . .

N4 N 0.41927(19) 0.15983(6) 0.58221(19) 0.0183(4) Uani $11 \mathrm{~d} \ldots$ N5 N 0.36186(19) 0.16172(6) 0.77892(19) 0.0180(4) Uani $11 \mathrm{~d} \ldots$ N6 N 0.50770(19) 0.20820(6) 0.7351(2) 0.0198(4) Uani $11 \mathrm{~d} \ldots$ H6B H 0.47370 .22860 .76300 .024 Uiso 11 calc $R$. . N7 N 0.19854(18) 0.07665(6) 0.73547(19) 0.0179(4) Uani $11 \mathrm{~d} \ldots$ N8 N 0.39520(19) 0.06961(6) 0.68636(19) 0.0187(4) Uani $11 \mathrm{~d} \ldots$ N9 N 0.3214(2) $0.02032(6) 0.8042(2) 0.0232(5)$ Uani $11 \mathrm{~d} \ldots$ H9D H 0.30810 .01910 .88300 .028 Uiso 11 calc $R$. . C1 C -0.0374(2) 0.07384(8) 0.6605(3) 0.0289(6) Uani 11 d . . . H1A H - 0.02760 .07460 .57090 .043 Uiso 11 calc R . H1B H -0.0481 0.1001 0.6900 0.043 Uiso 11 calc R. H1C H -0.11330 .05850 .66370 .043 Uiso 11 calc R . . C2 C $0.0337(3) 0.18950(7) 0.5146(3) 0.0246(6)$ Uani $11 \mathrm{~d} \ldots$ H2A H 0.02440 .19730 .42170 .029 Uiso 11 calc R . .

C3 C 0.3050(2) 0.05594(7) 0.7414(2) 0.0192(5) Uani $11 \mathrm{~d} \ldots$ C4 C 0.4301(2) 0.17624(7) 0.6987(2) 0.0177(5) Uani $11 \mathrm{~d}$. . . C5 C 0.6752(3) 0.25109(8) 0.6969(3) 0.0345(7) Uani $11 \mathrm{~d} \ldots$ H5A H 0.61700 .25890 .61420 .052 Uiso 11 calc R . . H5B H 0.76430 .25210 .68880 .052 Uiso 11 calc R.. H5C H 0.66500 .26860 .76620 .052 Uiso 11 calc R . . C6 C 0.1551(2) 0.06990(7) 0.3377(2) 0.0218(5) Uani $11 \mathrm{~d} \ldots$ H6A H 0.07070 .07360 .27290 .026 Uiso 11 calc R . . C7 C 0.5304(2) 0.05766(7) 0.7281(3) 0.0236(5) Uani $11 \mathrm{~d} \ldots$ H7A H 0.53710 .03500 .78770 .028 Uiso 11 calc $R$. . C8 C 0.0692(3) 0.05453(8) 0.8907(3) 0.0352(7) Uani $11 \mathrm{~d} \ldots$ H8A H 0.14670 .04290 .94640 .053 Uiso 11 calc R . . H8B H -0.00610 .03910 .89530 .053 Uiso 11 calc R . H8C H 0.05910 .08080 .92080 .053 Uiso 11 calc R . C9 C 0.2426(3) $-0.03877(8) 0.6797(3) 0.0330(7)$ Uani $11 \mathrm{~d} \ldots$ H9A H $0.1879-0.02310 .61080 .050$ Uiso 11 calc $R$. . H9B H $0.1937-0.04640 .74270 .050$ Uiso 11 calc R . H9C H $0.2708-0.06190 .64120 .050$ Uiso 11 calc R . . C10 C 0.0886(2) 0.12928(7) 0.4279(2) $0.0184(5)$ Uani $11 \mathrm{~d} \ldots$ C11 C 0.6433(2) 0.21021(7) 0.7302(2) 0.0222(5) Uani 11 d . . H11A H 0.65570 .19270 .65920 .027 Uiso 11 calc R . . C12 C 0.3305(3) $0.18889(8) 0.3653(2) 0.0275(6)$ Uani $11 \mathrm{~d} \ldots$ H12A H 0.27220 .20490 .40120 .041 Uiso 11 calc R. . H12B H 0.28760 .16470 .33260 .041 Uiso 11 calc R. . H12C H 0.35400 .20270 .29360 .041 Uiso 11 calc R. . C13 C 0.2607(3) 0.06662(8) 0.2654(3) 0.0314(6) Uani $11 \mathrm{~d} \ldots$ H13A H 0.26290 .09020 .21480 .047 Uiso 11 calc R. . H13B H 0.24360 .04440 .20640 .047 Uiso 11 calc R . . H13C H 0.34380 .06320 .32830 .047 Uiso 11 calc R . . C14 C 0.6145(2) $0.09005(8) 0.7997(3) 0.0288(6)$ Uani $11 \mathrm{~d} \ldots$ H14A H 0.58450 .09750 .87650 .043 Uiso 11 calc R. . H14B H 0.60940 .11230 .74150 .043 Uiso 11 calc R. . H14C H 0.70390 .08120 .82720 .043 Uiso 11 calc R. . C15 C 0.5784(3) 0.04612(9) 0.6100(3) 0.0356(7) Uani $11 \mathrm{~d} \ldots$ 
H15A H 0.52500 .02510 .56370 .053 Uiso 11 calc $R$. . H15B H 0.66790 .03750 .63830 .053 Uiso 11 calc R . . H15C H 0.57320 .06830 .55170 .053 Uiso 11 calc R . . C16 C 0.3593(3) $-0.01540(7) 0.7486(3) 0.0250(6)$ Uani $11 \mathrm{~d} \ldots$ H16A H $0.4089-0.00830 .68340 .030$ Uiso 11 calc R . . C17 C 0.4512(2) 0.18031(7) 0.4715(2) 0.0218(5) Uani $11 \mathrm{~d}$. . H17A H 0.49460 .20520 .50370 .026 Uiso 11 calc R . . C19 C 0.3878(3) 0.13413(7) 0.9993(2) 0.0272(6) Uani $11 \mathrm{~d} \ldots$ H19A H 0.42630 .11120 .96990 .041 Uiso 11 calc R . . H19B H 0.29510 .13020 .98630 .041 Uiso 11 calc $R$. . H19C H 0.42700 .13851 .09200 .041 Uiso 11 calc R . . C20 C -0.0109(3) 0.18185(7) 0.1558(2) 0.0270(6) Uani $11 \mathrm{~d}$. . H20A H 0.06080 .19470 .21640 .040 Uiso 11 calc R . . H20B H -0.0924 0.1930 0.1644 0.040 Uiso 11 calc R . . H20C H -0.00280 .18540 .06630 .040 Uiso 11 calc R . . C21 C -0.1003(3) 0.18834(9) 0.5389(3) 0.0368(7) Uani $11 \mathrm{~d} \ldots$ H21A H - 0.15230 .16900 .48210 .055 Uiso 11 calc R . . H21B H - 0.14090 .21370 .52000 .055 Uiso 11 calc R.. $\mathrm{H} 21 \mathrm{C}$ H -0.09400 .18160 .63020 .055 Uiso 11 calc R. . C22 C 0.5438(3) 0.15553(8) 0.4176(3) 0.0302(6) Uani $11 \mathrm{~d} \ldots$ H22A H 0.62110 .15030 .48690 .045 Uiso 11 calc R . . H22B H 0.56780 .16920 .34610 .045 Uiso 11 calc R. . H22C H 0.50190 .13110 .38510 .045 Uiso 11 calc R . . C23 C 0.4116(2) 0.16924(7) 0.9205(2) 0.0209(5) Uani $11 \mathrm{~d} \ldots$ H23A H 0.50660 .17320 .93790 .025 Uiso 11 calc R . . C24 C 0.1496(3) 0.03287(7) 0.4148(3) 0.0270(6) Uani $11 \mathrm{~d} \ldots$ H24A H 0.08040 .03490 .46010 .040 Uiso 11 calc R . . H24B H 0.23190 .02920 .47880 .040 Uiso 11 calc R . . H24C H 0.13310 .01090 .35490 .040 Uiso 11 calc R . . C25 C 0.4462(3) -0.03907(8) 0.8560(3) 0.0374(7) Uani $11 \mathrm{~d}$... H25A H $0.5216-0.02370 .89820 .056$ Uiso 11 calc R . . H25B H $0.4740-0.06240 .81830 .056$ Uiso 11 calc R . . H25C H $0.3988-0.04630 .92070 .056$ Uiso 11 calc R . . C26 C 0.1161(3) 0.21983(7) 0.6006(3) 0.0312(6) Uani $11 \mathrm{~d} \ldots$ H26A H 0.20140 .22050 .58240 .047 Uiso 11 calc R . . H26B H 0.12490 .21330 .69240 .047 Uiso 11 calc R . . H26C H 0.07520 .24510 .58210 .047 Uiso 11 calc R . . C27 C -0.0086(2) 0.13900 (7) $0.1873(2) 0.0209$ (5) Uani $11 \mathrm{~d} \ldots$ H27A H 0.07460 .12800 .17710 .025 Uiso 11 calc $R$. . C28 C 0.0817(2) 0.05578(7) 0.7492(3) 0.0250(6) Uani $11 \mathrm{~d} \ldots$ H28A H 0.08800 .02860 .71970 .030 Uiso 11 calc R . . C29 C 0.7329(2) 0.19725(8) 0.8571(3) 0.0302(6) Uani $11 \mathrm{~d}$. . H29A H 0.71100 .17090 .87690 .045 Uiso 11 calc $R$. . H29B H 0.72380 .21450 .92760 .045 Uiso 11 calc $R$. . $\mathrm{H} 29 \mathrm{C} \mathrm{H} 0.82190 .19800 .84890 .045$ Uiso 11 calc R . . C50 C 0.3528(3) 0.20538(7) 0.9662(3) 0.0280(6) Uani $11 \mathrm{~d} \ldots$ H50A H 0.36880 .22770 .91560 .042 Uiso 11 calc R . . H50B H 0.39230 .20981 .05890 .042 Uiso 11 calc R . H50C H 0.25990 .20180 .95340 .042 Uiso 11 calc R . . C51 C -0.1184(3) $0.11802(8) 0.0937(2) 0.0284(6)$ Uani $11 \mathrm{~d} \ldots$ H51 A H -0.1152 0.0906 0.1159 0.043 Uiso 11 calc R . . H51B H -0.1097 0.12120.0042 0.043 Uiso 11 calc R . . H51C H -0.2007 0.1289 0.1009 0.043 Uiso 11 calc R . .

loop

_atom_site_aniso_label 


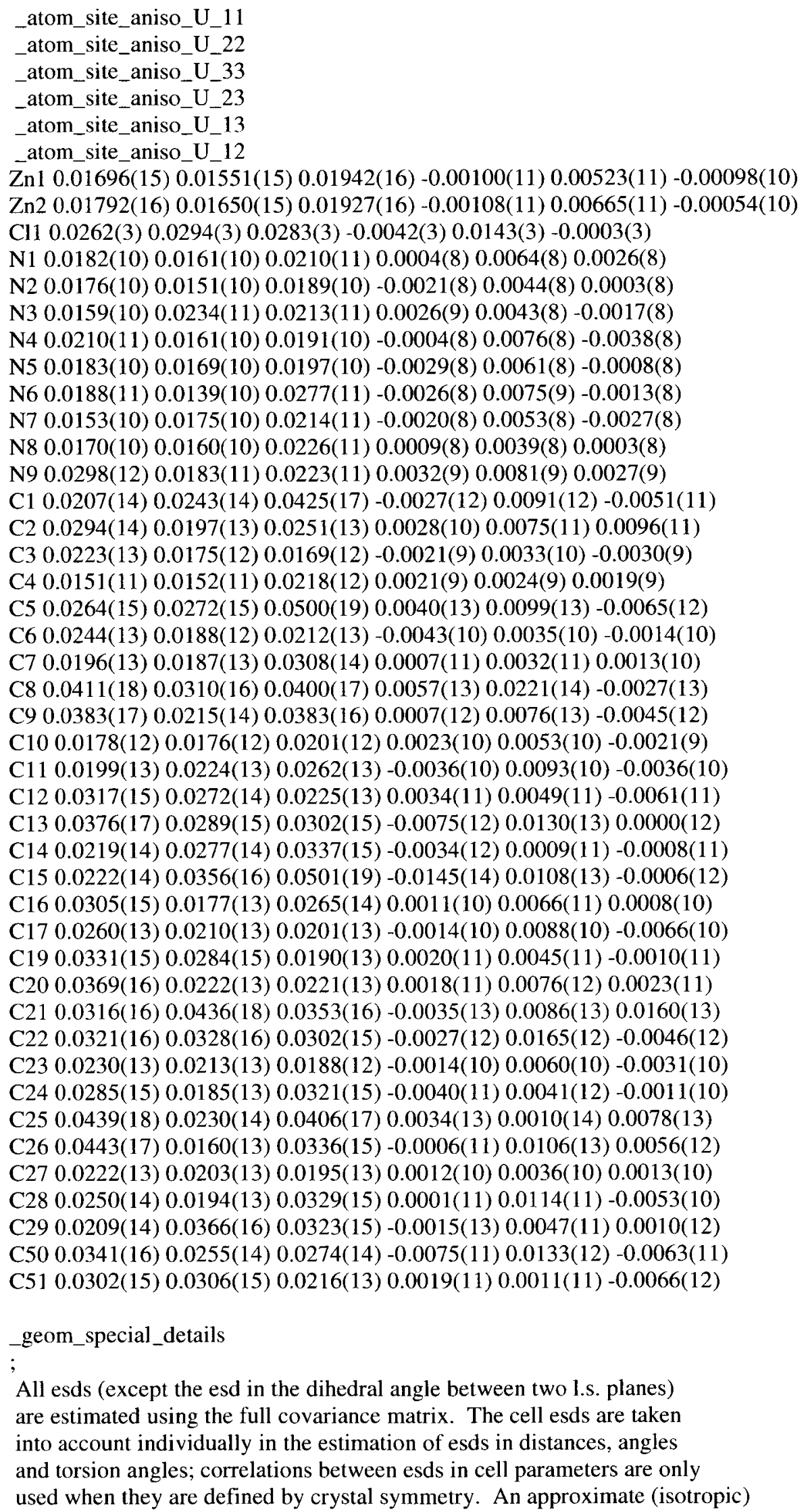


treatment of cell esds is used for estimating esds involving 1.s. planes.

;

loop_

_geom_bond_atom_site_label_1

_geom_bond_atom_site_label_2

_geom_bond_distance

_geom_bond_site_symmetry_2

_geom_bond_publ_flag

Zn1 N4 1.928(2) . ?

Zn1 N2 1.932(2).?

Zn1 N8 1.931(2). ?

Zn1 Zn2 2.7093(6).?

$\mathrm{Zn} 2 \mathrm{~N} 52.038(2)$.?

$\mathrm{Zn} 2 \mathrm{~N} 12.040(2)$. ?

$\mathrm{Zn} 2 \mathrm{~N} 72.054(2) . ?$

$\mathrm{Zn} 2 \mathrm{Cl1} 2.2876(8)$.?

N1 C10 1.338(3).?

N1 C2 1.490(3). ?

$\mathrm{N} 2 \mathrm{C} 10$ 1.334(3) . ?

N2 C6 1.468(3) . ?

N3 C10 1.385(3) . ?

N3 C27 1.472(3).?

N4 C4 1.336(3) . ?

N4 C17 1.481(3) . ?

N5 C4 1.347(3).?

N5 C23 1.485(3) . ?

N6 C4 1.384(3).?

N6 C1 1 1.470(3). ?

N7 C3 1.337(3). ?

N7 C28 1.485(3).?

N8 C3 1.333(3).?

N8 C7 1.468(3). ?

N9 C3 1.394(3). ?

N9 C16 1.471(3) . ?

C1 C28 1.522(4).?

C2 C21 1.521(4).?

C2 C26 1.524(4).?

C5 C11 1.521(4).?

C6 C13 1.519(4).?

C6 C24 1.531(3). ?

C7 C15 1.518(4) . ?

C7 C14 1.522(3). ?

C8 C28 1.537(4).?

C9 C16 1.519(4). ?

C11 C29 1.515(4). ?

$\mathrm{C} 12 \mathrm{C} 17$ 1.521(3).?

C16 C25 1.522(4).?

$\mathrm{C} 17 \mathrm{C} 22$ 1.525(4).?

$\mathrm{C} 19 \mathrm{C} 23$ 1.532(3).?

$\mathrm{C} 20 \mathrm{C} 27$ 1.522(3).?

C23 C50 1.534(3) . ?

C27 C51 1.524(3). ?

loop_

_geom_angle_atom_site_label_1 
_geom_angle_atom_site_label_2 _geom_angle_atom_site_label_3 _geom_angle

_geom_angle_site_symmetry_1 _geom_angle_site_symmetry_3 _geom_angle_publ_flag

N4 Zn1 N2 119.42(8) . . ?

N4 Zn1 N8 120.45(8) . . ?

N2 Zn1 N8 119.96(8) .. ?

N4 Zn1 Zn2 88.75(6) . . ?

$\mathrm{N} 2 \mathrm{Zn} 1 \mathrm{Zn} 288.84(6) \ldots$ ?

N8 Zn1 Zn2 88.29(6) . . ?

N5 Zn2 N1 110.22(8) ..?

N5 Zn2 N7 112.64(8) . . ?

N1 Zn2 N7 110.36(8) . ?

N5 Zn2 Cl1 108.22(6) . .?

N1 Zn2 Cl1 107.92(6)..?

N7 Zn2 Cl1 107.30(6) ..?

N5 Zn2 Zn1 72.46(6) .. ?

N1 Zn2 Zn1 71.93(6) .. ?

N7 Zn2 Zn1 72.17(5) .. ?

C11 Zn2 Zn1 179.30(2) . . ?

C10 N1 C2 117.0(2) ..?

C10 N1 Zn2 125.48(16) . .?

C2 N1 Zn2 117.32(15) ..?

C10 N2 C6 121.7(2) .. ?

C10 N2 Zn1 113.39(16) . . ?

C6 N2 Zn1 124.37(15) . . ?

C10 N3 C27 124.3(2) .. ?

C4 N4 C17 122.74(19) . . ?

C4 N4 Zn1 114.21(15)..?

C17 N4 Zn1 122.41(15) . . ?

C4 N5 C23 117.0(2) ..?

C4 N5 Zn2 125.12(16) .. ?

C23 N5 Zn2 117.50(15) .. ?

C4 N6 C11 124.1(2) . . ?

C3 N7 C28 117.7(2) ..?

C3 N7 Zn2 125.01(16) . . ?

C28 N7 Zn2 117.22(15) . . ?

C3 N8 C7 122.5(2) .. ?

C3 N8 Zn1 113.38(16) . . ?

C7 N8 Zn1 123.76(16) .. ?

C3 N9 C16 124.8(2) . . ?

N1 C2 C21 113.0(2) .. ?

N1 C2 C26 110.2(2)..?

C21 C2 C26 110.6(2) ..?

N8 C3 N7 119.4(2) . . ?

N8 C3 N9 120.2(2) .. ?

N7 C3 N9 120.4(2) . . ?

N4 C4 N5 119.0(2) .. ?

N4 C4 N6 120.6(2) .. ?

N5 C4 N6 120.4(2) . .?

N2 C6 C13 109.8(2) .. ?

N2 C6 C24 110.4(2)..?

C13 C6 C24 109.7(2) .. ?

N8 C7 C15 109.6(2) . . ? 
N8 C7 C14 111.2(2) . ?

C15 C7 C14 109.0(2) ..?

N2 C10 N1 119.2(2) ..?

N2 C10 N3 120.0(2) ..?

N1 C10 N3 120.7(2) .. ?

N6 C11 C29 111.9(2) . .?

N6 C11 C5 109.5(2)...?

C29 C11 C5 110.6(2)..?

N9 C16 C25 109.5(2) . .?

N9 C16 C9 111.5(2) ...?

C25 C16 C9 110.6(2) .. ?

N4 C17 C12 111.0(2) . .?

N4 C17 C22 108.9(2) . .?

C12 C17 C22 110.4(2) .. ?

N5 C23 C19 110.04(19) . .?

N5 C23 C50 112.8(2) ..?

C19 C23 C50 110.0(2) . . ?

N3 C27 C20 110.9(2) . . ?

N3 C27 C51 109.8(2) . . ?

C20 C27 C51 110.8(2) . . ?

N7 C28 C1 109.9(2) .. ?

N7 C28 C8 112.7(2) .. ?

C1 C28 C8 110.6(2) .. ?

loop

_geom_torsion_atom_site_label_1

_geom_torsion_atom_site_label_2

_geom_torsion_atom_site_label_3

_geom_torsion_atom_site_label_4

_geom_torsion

_geom_torsion_site_symmetry_1

_geom_torsion_site_symmetry_2

_geom_torsion_site_symmetry_3

_geom_torsion_site_symmetry_4

_geom_torsion_publ_flag

N4 Zn1 Zn2 N5 -31.88(8) ... ? ?

N2 Zn1 Zn2 N5 -151.35(8) ...? ?

N8 Zn1 Zn2 N5 88.64(8) ....?

N4 Zn1 Zn2 N1 87.09(8) ... . ?

$\mathrm{N} 2 \mathrm{Zn} 1 \mathrm{Zn} 2 \mathrm{~N} 1-32.37(8) \ldots$ ?

N8 Zn1 Zn2 N1 $-152.39(8) \ldots$ ?

N4 Zn1 Zn2 N7 $-153.60(8) \ldots$ ?

$\mathrm{N} 2 \mathrm{Zn} 1 \mathrm{Zn} 2 \mathrm{~N} 786.93(8) \ldots$ ?

N8 Zn1 Zn2 N7 -33.08(8) ... ?

N4 Zn1 Zn2 Cl1 165(2) ... ?

$\mathrm{N} 2 \mathrm{Zn} 1 \mathrm{Zn} 2 \mathrm{Cl} 145(2) \ldots$ ?

$\mathrm{N} 8 \mathrm{Zn} 1 \mathrm{Zn} 2 \mathrm{Cl} 1-75(2) \ldots$ ?

N5 Zn2 N1 C10 104.8(2) ... . ?

N7 Zn2 N1 C10 - 20.2(2) ....?

Cl1 Zn2 N1 C10-137.20(18) ....?

Zn1 Zn2 N1 C10 42.08(18) . . . ? ?

N5 Zn2 N1 C2 -80.32(18) ... ?

N7 Zn2 N1 C2 154.63(16) ....?

Cl1 Zn2 N1 C2 37.66(18) ....?

Zn1 Zn2 N1 C2 -143.06(17) ....?

N4 Zn1 N2 C10 -54.04(19) ... . ? 
N8 Zn1 N2 C10 121.22(17) ... . ?

Zn2 Zn1 N2 C10 33.86(16) .... ?

N4 Zn1 N2 C6 133.95(18) ... . ?

N8 Zn1 N2 C6 -50.8(2) ....?

Zn2 Zn1 N2 C6 -138.14(18).... ?

N2 Zn1 N4 C4 120.98(17) ... ?

N8 Zn1 N4 C4 -54.26(19) ... . ?

Zn2 Zn1 N4 C4 33.02(16) . . . ? ?

N2 Zn1 N4 C17 -50.1(2) ... ?

N8 Zn1 N4 C17 134.69(17).... ?

Zn2 Zn1 N4 C17-138.03(18) ... . ?

$\mathrm{N} 1 \mathrm{Zn} 2 \mathrm{~N} 5 \mathrm{C} 4-20.8(2) \ldots$ ?

N7 Zn2 N5 C4 102.93(19) . . . ?

Cl1 Zn2 N5 C4 -138.61(17) .... ?

Zn1 Zn2 N5 C4 41.60(17) ... . ?

N1 Zn2 N5 C23 152.02(15) ... ?

N7 Zn2 N5 C23 -84.24(17) ... . ?

C11 Zn2 N5 C23 34.22(17) ....?

Zn1 Zn2 N5 C23-145.57(17) ....?

N5 Zn2 N7 C3 -20.6(2) ....?

N1 Zn2 N7 C3 103.07(19) ....?

Cl1 Zn2 N7 C3 -139.58(18) ... . ?

Zn1 Zn2 N7 C3 40.91(18) ....?

N5 Zn2 N7 C28 155.43(16) ... . ?

N1 Zn2 N7 C28 -80.91(17) ... . ?

C11 Zn2 N7 C28 36.43(17) ....?

Zn1 Zn2 N7 C28 -143.07(17) ....?

N4 Zn1 N8 C3 123.98(17) ... . ?

N2 Zn1 N8 C3 -51.23(19) ... . ?

Zn2 Zn1 N8 C3 36.44(16) ... . ?

N4 Zn1 N8 C7 $-49.2(2) \ldots$ ?

N2 Zn1 N8 C7 135.61(18) ... ?

Zn2 Zn1 N8 C7 -136.72(18) ... . ?

C10 N1 C2 C21 93.9(3) ....?

Zn2 N1 C2 C21 -81.4(2) ...? ?

C10 N1 C2 C26-141.9(2) ....?

$\mathrm{Zn} 2 \mathrm{~N} 1 \mathrm{C} 2 \mathrm{C} 2642.8(3) \ldots$ ?

C7 N8 C3 N7 155.9(2) .... ?

Zn1 N8 C3 N7 -17.3(3) ....?

C7 N8 C3 N9 -24.3(3) ....?

Zn1 N8 C3 N9 162.48(17) ....?

C28 N7 C3 N8 156.7(2) ... . ?

Zn2 N7 C3 N8 -27.3(3) ....?

C28 N7 C3 N9-23.1(3)....?

Zn2 N7 C3 N9 152.89(17) ....?

C16 N9 C3 N8 -49.2(3)....?

C16 N9 C3 N7 130.7(2) ....?

C17 N4 C4 N5 158.2(2) ....?

Zn1 N4 C4 N5 -12.8(3) ... . ?

C17 N4 C4 N6 -20.3(3) ....?

Zn1 N4 C4 N6 168.71(17) ... . ?

C23 N5 C4 N4 156.3(2) ... . ?

Zn2 N5 C4 N4 -30.9(3) ... ?

C23 N5 C4 N6 -25.2(3).... ?

Zn2 N5 C4 N6 147.62(17) ... . ?

C11 N6 C4 N4 -52.3(3) ....? 
C11 N6 C4 N5 129.2(2) ...?

C10 N2 C6 C13 130.7(2) ... . ?

Zn1 N2 C6 C13 -57.9(3) ....?

C10 N2 C6 C24-108.3(3) ....?

Zn1 N2 C6 C24 63.1(3) .... ?

C3 N8 C7 C15 130.4(2) ... . ?

Zn1 N8 C7 C15 -57.1(3) ....?

C3 N8 C7 C14 -109.0(3) .... ?

Zn1 N8 C7 C14 63.5(3) ....?

C6 N2 C10 N1 158.6(2) ....?

Zn1 N2 C10 N1 -13.7(3) ... . ?

C6 N2 C10 N3 -20.4(3) ... ?

Zn1 N2 C10 N3 167.37(16) ....?

C2 N1 C10 N2 154.4(2) ....?

Zn2 N1 C10 N2 -30.7(3) ...? ?

C2 N1 C10 N3 -26.6(3) ... ?

Zn2 N1 C10 N3 148.25(17) ....?

C27 N3 C10 N2 -54.2(3) ... ? ?

C27 N3 C10 N1 126.8(2) ... ? ?

C4 N6 C11 C29 $-90.6(3) \ldots$ ?

C4 N6 C11 C5 146.4(2) ....?

C3 N9 C16 C25 144.1(2) ....?

C3 N9 C16 C9 $-93.2(3) \ldots$ ?

C4 N4 C17 C12 -110.1(3) ... . ?

Zn1 N4 C17 C12 60.2(3) ... . ?

C4 N4 C17 C22 128.2(2) ... . ?

Zn1 N4 C17 C22 -61.5(3) ...? ?

C4 N5 C23 C19-143.5(2)....?

Zn2 N5 C23 C19 43.1(2) ....?

C4 N5 C23 C50 93.2(3) ... ?

Zn2 N5 C23 C50 -80.2(2) ... ?

C10 N3 C27 C20 -91.9(3) ... ?

C10 N3 C27 C51 145.3(2) ...?

C3 N7 C28 C1 -143.6(2) ... ? ?

Zn2 N7 C28 C1 40.1(3) ...?

C3 N7 C28 C8 92.6(3)....?

Zn2 N7 C28 C8 -83.7(2) ...?

_diffrn_measured_fraction_theta_max 0.942

_diffrn_reflns_theta_full 25.00

_diffrn_measured_fraction_theta_full 0.999

_refine_diff_density_max 0.803

_refine_diff_density_min -0.562

_refine_diff_density_rms $\quad 0.086$ 


\section{A.7 Compound 11}

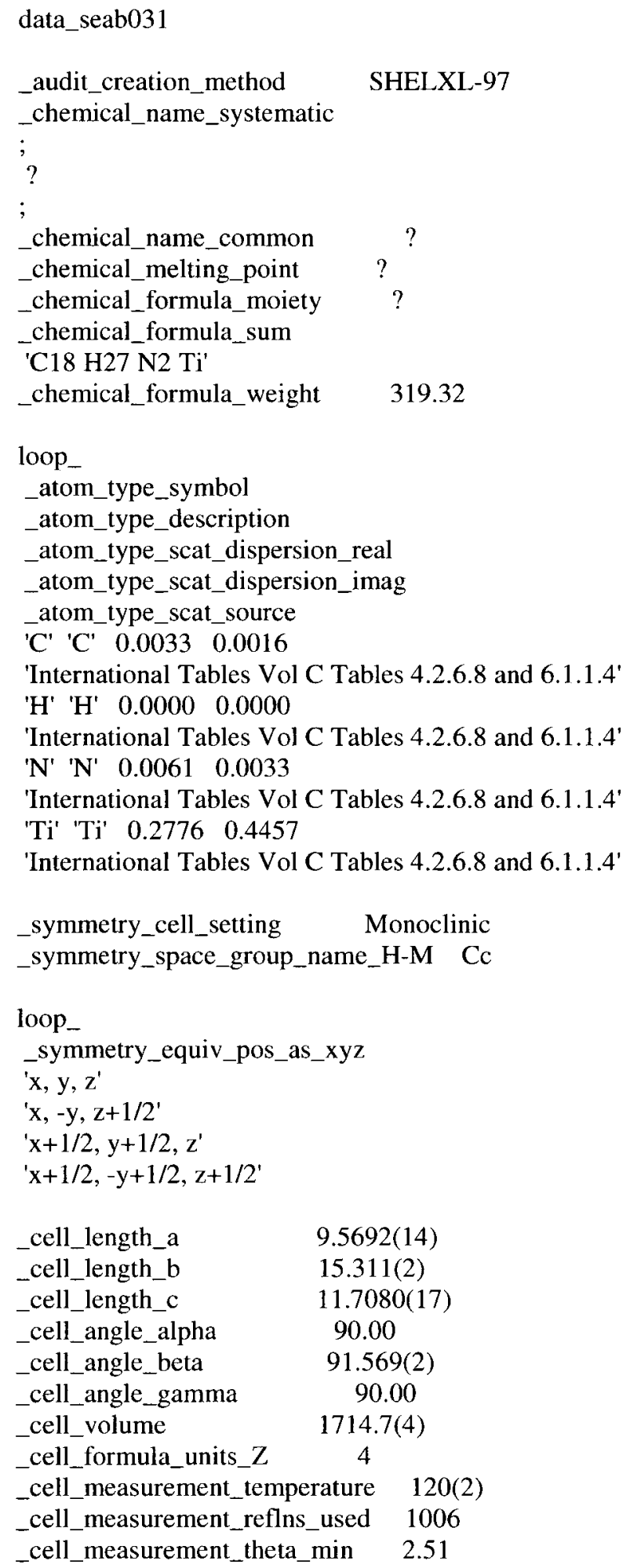


_cell_measurement_theta_max $\quad 22.10$

_exptl_crystal_description_block

_exptl_crystal_colour blue

_exptl_crystal_size_max $\quad 0.35$

_exptl_crystal_size_mid $\quad 0.28$

_exptl_crystal_size_min 0.18

_exptl_crystal_density_meas ?

_exptl_crystal_density_diffrn 1.237

_exptl_crystal_density_method 'not measured'

_exptl_crystal_F_000 684

_exptl_absorpt_coefficient_mu 0.495

_exptl_absorpt_correction_type multi-scan

_exptl_absorpt_correction_T_min 0.8450

_exptl_absorpt_correction_T_max 0.9153

_exptl_absorpt_process_details 'SADABS (Sheldrick, 2003)'

_exptl_special_details

;

Data collection is performed with four batch runs at

If $=0.00 \backslash \%$ (600 frames), at If $=90.001 \%$

(600 frames), at If $=180 \backslash \%$ (600 frames) and

at $\backslash f=270 \backslash \%$ (600 frames).

Frame width $=0.30 \backslash \&$ in $\backslash w$. Data is

merged, corrected for decay, and treated with

multi-scan absorption corrections.

;

_diffrn_ambient_temperature 120(2)

_diffrn_radiation_wavelength 0.71073

_diffrn_radiation_type MoKla

_diffrn_radiation_source_fine-focus sealed tube'

_diffrn_radiation_monochromator graphite

_diffrn_measurement_device_type 'Bruker AXS APEX diffractometer'

_diffrn_measurement_method Iw

_diffrn_detector_area_resol_mean 836.6

_diffrn_standards_number 0

_diffrn_standards_interval_count 0

_diffrn_standards_interval_time 0

_diffrn_standards_decay_\% 1

_diffrn_reflns_number 10432

_diffrn_reflns_av_R_equivalents 0.0431

_diffrn_reflns_av_sigmaI/netI 0.0607

_diffrn_reflns_limit_h_min -12

_diffrn_reflns_limit_h_max 12

_diffrn_reflns_limit_k_min $\quad-20$

_diffrn_reflns_limit_k_max 19

_diffrn_reflns_limit_1_min -15

_diffrn_reflns_limit___max 15

_diffrn_reflns_theta_min 2.51

_diffrn_reflns_theta_max 28.35

_reflns_number_total 4247

_reflns_number_gt 3822

_reflns_threshold_expression >2sigma(I)

_computing_data_collection 'SMART (Bruker, 2002)' 
_computing_cell_refinement

_computing_data_reduction

_computing_structure_solution

_computing_structure_refinement

_computing_molecular_graphics

_computing_publication_material

refine special details

$$
\text { ; }
$$

Refinement of $F^{\wedge} 2^{\wedge}$ against ALL reflections. The weighted $R$-factor $w R$ and goodness of fit $\mathrm{S}$ are based on $\mathrm{F}^{\wedge} 2^{\wedge}$, conventional $\mathrm{R}$-factors $\mathrm{R}$ are based on $F$, with $F$ set to zero for negative $F^{\wedge} 2^{\wedge}$. The threshold expression of $\mathrm{F}^{\wedge} 2^{\wedge}>2 \operatorname{sigma}\left(\mathrm{F}^{\wedge} 2^{\wedge}\right)$ is used only for calculating $\mathrm{R}$-factors $(\mathrm{gt}) \mathrm{etc}$. and is not relevant to the choice of reflections for refinement. R-factors based on $F^{\wedge} 2^{\wedge}$ are statistically about twice as large as those based on $F$, and $R$ factors based on ALL data will be even larger. H12a, H12b, and H12c were located from the diff. map and refined riding thermal parameters.

$$
\text { ; }
$$

_refine_ls_structure_factor_coef Fsqd

_refine_ls_matrix_type full

_refine_ls_weighting_scheme calc

_refine_ls_weighting_details

'calc $\mathrm{w}=1 /\left[\backslash \mathrm{s}^{\wedge} 2^{\wedge}\left(\mathrm{Fo}^{\wedge} 2^{\wedge}\right)+(0.0375 \mathrm{P})^{\wedge} 2^{\wedge}\right]$ where $\mathrm{P}=\left(\mathrm{Fo}^{\wedge} 2^{\wedge}+2 \mathrm{Fc}^{\wedge} 2^{\wedge}\right) / 3^{\prime}$

_atom_sites_solution_primary direct

_atom_sites_solution_secondary difmap

_atom_sites_solution_hydrogens geom

_refine_ls_hydrogen_treatment mixed

_refine_ls_extinction_method none

_refine_ls_extinction_coef ?

_refine_ls_abs_structure_details

'Flack H D (1983), Acta Cryst. A39, 876-881'

_refine_1s_abs_structure_Flack -0.04(2)

_refine_ls_number_reflns 4247

_refine_ls_number_parameters 203

_refine_1s_number_restraints 8

_refine_ls_R_factor_all $\quad 0.0477$

_refine_1s_R_factor_gt $\quad 0.0415$

_refine_ls_wR_factor_ref 0.0893

_refine_ls_wR_factor_gt 0.0860

_refine_ls_goodness_of_fit_ref 1.028

_refine_ls_restrained_S_all 1.028

_refine_ls_shift/su_max $\quad 0.000$

_refine_ls_shift/su_mean $\quad 0.000$

loop

_atom_site_label

_atom_site_type_symbol

_atom_site_fract_x

_atom_site_fract_y

_atom_site_fract_z

_atom_site_U_iso_or_equiv

_atom_site_adp_type

_atom_site_occupancy

_atom_site_symmetry_multiplicity

_atom_site_calc_flag 
_atom_site_refinement_flags

atom_site_disorder_assembly

atom_site_disorder_group

Ti Ti 0.84097(3) 0.18839(2) 0.72692(3) 0.01875(10) Uani $11 \mathrm{~d} \ldots$

N1 N 1.0451(2) 0.13108(13) 0.71861(17) 0.0232(4) Uani $11 \mathrm{~d} \ldots$

$\mathrm{N} 2 \mathrm{~N} 1.02055(18) 0.27253(12) 0.74286(16) 0.0203(4)$ Uani $11 \mathrm{~d} \ldots$

C1 C 0.8474(3) 0.2187(2) 0.9298(2) 0.0257(6) Uani $11 \mathrm{~d} \ldots$

H1A H 0.91310 .26010 .96980 .031 Uiso 11 calc R. .

C2 C 0.8682(3) 0.12904(19) 0.9179(2) 0.0269(6) Uani $11 \mathrm{~d}$. .

H2A H 0.95070 .09540 .94820 .032 Uiso 11 calc R . .

C3 C 0.7466(3) 0.09295(17) 0.8660(2) 0.0283(5) Uani $11 \mathrm{~d} \ldots$

H3A H 0.72720 .02930 .85520 .034 Uiso 11 calc R . .

C4 C 0.6505(3) 0.16057(17) 0.8476(2) 0.0301(6) Uani $11 \mathrm{~d}$. .

H4A H 0.55060 .15340 .82200 .036 Uiso 11 calc R . .

C5 C 0.7138(3) 0.23981(17) 0.8859(2) 0.0276(5) Uani $11 \mathrm{~d} \ldots$

H5A H 0.66650 .29780 .89190 .033 Uiso 11 calc R . .

C6 C 0.7872(3) 0.12549(19) 0.5438(2) 0.0293(6) Uani $11 \mathrm{~d}$. . .

H6A H 0.81460 .06590 .51760 .035 Uiso 11 calc $R$. .

C7 C 0.6581(3) 0.14895(17) 0.5892(2) 0.0296(5) Uani $11 \mathrm{~d} \ldots$

H7A H 0.57870 .10830 .60330 .036 Uiso 11 calc R . .

C8 C 0.6545(3) 0.24065(17) 0.6010(2) 0.0319(6) Uani $11 \mathrm{~d}$. .

H8A H 0.57220 .27610 .62420 .038 Uiso 11 calc R . .

C9 C 0.7798(3) 0.27350(19) 0.5612(2) 0.0351(6) Uani $11 \mathrm{~d} \ldots$

H9A H 0.80210 .33670 .55030 .042 Uiso 11 calc R . .

C10 C 0.8625(3) 0.2035(2) 0.5271(2) 0.0337(7) Uani $11 \mathrm{~d} \ldots$

H10A H 0.95260 .20840 .48620 .040 Uiso 11 calc R . .

C11 C 1.1104(2) 0.20702(15) 0.73368(19) 0.0229(5) Uani $11 \mathrm{~d} .$.

C12 C 1.2663(3) 0.21759(19) 0.7425(2) 0.0320(6) Uani $11 \mathrm{~d}$ D . .

H12A H 1.298(3) 0.2305(16) 0.6703(17) 0.048 Uiso $11 \mathrm{~d} \mathrm{D} \mathrm{.} \mathrm{.}$

H12B H 1.307(3) 0.1652(13) 0.759(2) 0.048 Uiso $11 \mathrm{~d} D$. .

$\mathrm{H} 12 \mathrm{C} \mathrm{H} 1.304(3) 0.2577(15) 0.7899$ (19) 0.048 Uiso $11 \mathrm{~d} \mathrm{D}$.

C13 C $1.1196(3) 0.04955(16) 0.7007(2) 0.0311(6)$ Uani $11 \mathrm{~d}$. . .

H13A H 1.20320 .04810 .75380 .037 Uiso 11 calc R .

C14 C 1.1697(3) 0.04229(18) 0.5779(2) 0.0429(7) Uani $11 \mathrm{~d}$. . .

H14A H 1.23220 .09120 .56180 .064 Uiso 11 calc R . .

H14B H 1.08900 .04380 .52460 .064 Uiso 11 calc R . .

H14C H $1.2202-0.01290 .56870 .064$ Uiso 11 calc R . .

C15 C 1.0258(3) $-0.02712(16) 0.7289(3) 0.0383$ (7) Uani $11 \mathrm{~d} \ldots$

H15A H $0.9953-0.02180 .80780 .057$ Uiso 11 calc R . .

H15B H $1.0777-0.08180 .72020 .057$ Uiso 11 calc R . .

H15C H $0.9439-0.02720 .67680 .057$ Uiso 11 calc R . .

C16 C 1.0649(3) 0.36334(16) 0.7571(2) 0.0261(5) Uani $11 \mathrm{~d}$. . .

H16A H 1.14670 .36460 .81210 .031 Uiso 11 calc $R$. .

C17 C 0.9480(3) 0.41673(16) 0.8075(2) 0.0319(6) Uani $11 \mathrm{~d}$. .

H17A H 0.92810 .39470 .88400 .048 Uiso 11 calc $R$.

H17B H 0.86380 .41180 .75830 .048 Uiso 11 calc R.

H17C H 0.97660 .47810 .81270 .048 Uiso 11 calc R. .

C18 C 1.1102(3) 0.40300(17) 0.6445(2) 0.0374(6) Uani $11 \mathrm{~d}$. .

H18A H 1.18450 .36720 .61260 .056 Uiso 11 calc R .

H18B H 1.14500 .46240 .65800 .056 Uiso 11 calc R. .

H18C H 1.03010 .40480 .59050 .056 Uiso 11 calc R. .

loop_

_atom_site_aniso_label

_atom_site_aniso_U_11

_atom_site_aniso_U_22 


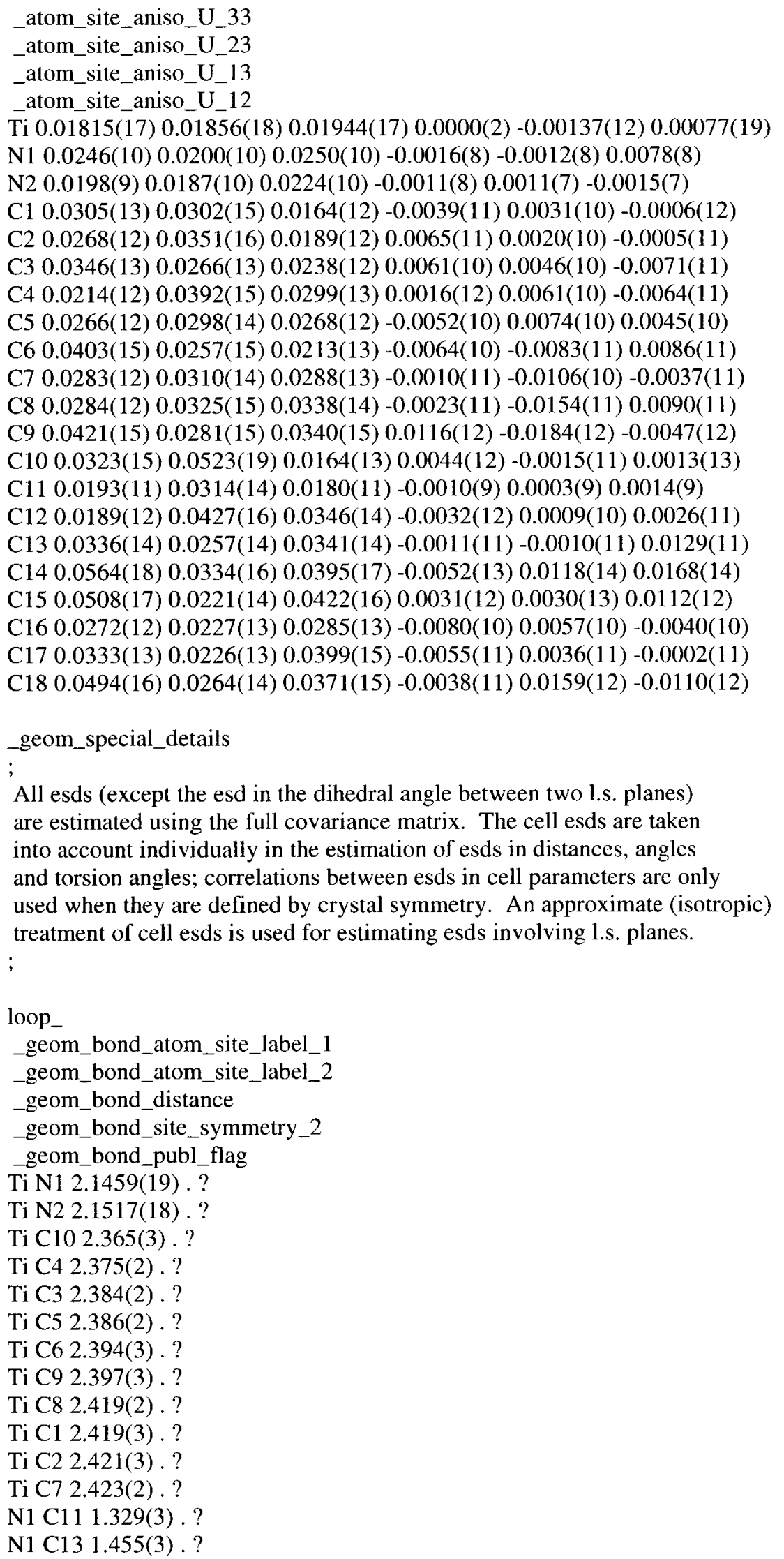


N2 C11 1.327(3) . ?

$\mathrm{N} 2 \mathrm{C} 16$ 1.462(3).?

C1 C2 1.395(4).?

C1 C5 1.402(4).?

C2 C3 1.411(4). ?

C3 C4 1.397(3). ?

C4 C5 1.423(4) . ?

C6 C7 1.405(4) ?

C6 C10 1.411(4) . ?

C7 C8 1.411(4) . ?

C8 C9 1.392(4) . ?

C9 C10 1.398(4).?

C11 C12 1.502(3) . ?

C13 C15 1.519(4). ?

C13 C14 1.532(4) . ?

C16 C17 1.517(3) . ?

C16 C18 1.526(3) . ?

loop_

_geom_angle_atom_site_label_1 _geom_angle_atom_site_label_2 _geom_angle_atom_site_label_3 _geom_angle _geom_angle_site_symmetry_1 _geom_angle_site_symmetry_3 _geom_angle_publ_flag

N1 Ti N2 61.51(7) . . ?

N1 Ti C10 83.74(9) .. ?

N2 Ti C10 86.35(9) . .?

N1 Ti C4 131.91(9) .. ?

N2 Ti C4 132.83(8) .. ?

C10 Ti C4 134.03(10) . . ?

N1 Ti C3 98.21(8) . .?

N2 Ti C3 128.65(8) ..?

C10 Ti C3 141.27(10) . ?

C4 Ti C3 34.14(8) . . ?

N1 Ti C5 130.90(8) . . ?

N2 Ti C5 99.09(8) . . ?

C10 Ti C5 143.12(10) .. ?

C4 Ti C5 34.79(9) . . ?

C3 Ti C5 57.20(9) . . ?

N1 Ti C6 88.20(8) . . ?

N2 Ti C6 118.05(9) .. ?

C10 Ti C6 34.48(10) . . ?

C4 Ti C6 108.13(9) . . ?

C3 Ti C6 106.79(10) . . ?

C5 Ti C6 136.90(9) . . ?

N1 Ti C9 112.83(9) . . ?

N2 Ti C9 85.49(8) . . ?

C10 Ti C9 34.13(10) . . ?

C4 Ti C9 113.88(9) . . ?

C3 Ti C9 142.89(9) .. ?

C5 Ti C9 109.51(10) .. ?

C6 Ti C9 56.75(10) . . ?

N1 Ti C8 139.87(9) . . ?

N2 Ti C8 115.38(8) . . ? 
C10 Ti C8 56.49(10) . . ?

C4 Ti C8 81.76(9)...?

C3 Ti C8 109.39(9) . . ?

C5 Ti C8 89.03(9) .. ?

C6 Ti C8 56.65(9)...?

C9 Ti C8 33.60(9) . . ?

N1 Ti C1 97.14(8) . . ?

N2 Ti C1 78.53(8) ..?

C10 Ti C1 162.11(9) .. ?

C4 Ti C1 56.61(9). . ?

C3 Ti C1 56.44(9) . . ?

C5 Ti C1 33.92(9) .. ?

C6 Ti C1 162.90(9) . . ?

C9 Ti C1 133.59(10) .. ?

C8 Ti C1 122.22(9) . . ?

$\mathrm{N} 1 \mathrm{TiC} 279.25(8) \ldots$ ?

$\mathrm{N} 2 \mathrm{Ti} \mathrm{C} 294.54(8) \ldots ?$

C10 Ti C2 160.05(10) . .?

C4 Ti C2 56.50(9) . . ?

C3 Ti C2 34.14(9) .. ?

C5 Ti C2 56.45(9) .. ?

C6 Ti C2 133.74(8) . . ?

C9 Ti C2 165.83(10) . . ?

C8 Ti C2 138.23(9) . . ?

C1 Ti C2 33.51(10) . . ?

N1 Ti C7 120.63(8) . . ?

$\mathrm{N} 2 \mathrm{Ti}$ C7 140.11(8) ..?

C10 Ti C7 56.43(10) . . ?

C4 Ti C7 78.42(9)..?

C3 Ti C7 91.23(9)..?

C5 Ti C7 103.13(9) . . ?

C6 Ti C7 33.90(9). . ?

C9 Ti C7 56.00(9) . . ?

C8 Ti C7 33.89(9)..?

C1 Ti C7 134.40(9) . . ?

C2 Ti C7 125.34(9) . . ?

C11 N1 C13 122.6(2) . .?

C11 N1 Ti 93.51(13)..?

C13 N1 Ti 143.81(17) . . ?

C11 N2 C16 122.79(19) . . ?

C11 N2 Ti 93.32(14). . ?

C16 N2 Ti 143.88(15) .. ?

C2 C1 C5 108.7(2) ..?

$\mathrm{C} 2 \mathrm{C} 1 \mathrm{Ti}$ 73.31(15) .. ?

C5 C1 Ti 71.72(15)...?

C1 C2 C3 108.1(2) .. ?

C1 C2 Ti 73.18(15) . . ?

C3 C2 Ti 71.48(15) . . ?

C4 C3 C2 107.9(2) .. ?

C4 C3 Ti 72.60(14) .. ?

C2 C3 Ti 74.37(14) .. ?

C3 C4 C5 108.1(2)..?

C3 C4 Ti 73.25(14) . . ?

C5 C4 Ti 73.00(13) . . ?

C1 C5 C4 107.2(2) .. ?

C1 C5 Ti 74.36(15) . .? 
C4 C5 Ti 72.22(13) . . ?

C7 C6 C10 107.1(2) . . ?

C7 C6 Ti 74.21(14) .. ?

C10 C6 Ti 71.66(16) .. ?

C6 C7 C8 108.4(2) .. ?

C6 C7 Ti 71.89(14) .. ?

C8 C7 Ti 72.89(13) . . ?

C9 C8 C7 107.7(2) . . ?

C9 C8 Ti 72.32(14) . . ?

C7 C8 Ti 73.22(13) .. ?

C8 C9 C10 108.5(2) . . ?

C8 C9 Ti 74.08(14) .. ?

C10 C9 Ti 71.71(16)...?

C9 C10 C6 108.3(3) . . ?

C9 C10 Ti 74.17(16) . . ?

C6 C10 Ti 73.85(16)...?

N1 C11 N2 111.64(19). . ?

N1 C11 C12 124.5(2) . .?

N2 C11 C12 123.9(2)..?

N1 C11 Ti 55.70(11) . .?

N2 C11 Ti 55.95(11) . .?

C12 C11 Ti 177.82(17) . . ?

N1 C13 C15 109.7(2) . . ?

$\mathrm{N} 1 \mathrm{C} 13 \mathrm{C} 14$ 111.4(2) . .?

C15 C13 C14 110.5(2) . . ?

N2 C16 C17 110.01(19) . . ?

N2 C16 C18 111.60(19) . .?

C17 C16 C18 110.6(2) . . ?

loop_

_geom_torsion_atom_site_label_1

_geom_torsion_atom_site_label_2

_geom_torsion_atom_site_label_3

_geom_torsion_atom_site_label_4

_geom_torsion

_geom_torsion_site_symmetry_1

_geom_torsion_site_symmetry_2

_geom_torsion_site_symmetry_3

_geom_torsion_site_symmetry_4

_geom_torsion_publ_flag

N2 Ti N1 C11 $0.72(13) \ldots$ ?

C10 Ti N1 C11 89.96(15) ....?

C4 Ti N1 C11 -122.79(15) . . . ? ?

C3 Ti N1 C11 -129.04(14) ....?

C5 Ti N1 C11 -75.84(17) ....?

C6 Ti N1 C11 124.25(15) ....?

C9 Ti N1 C11 71.73(15) ....?

C8 Ti N1 C11 97.20(17) .... ?

C1 Ti N1 C11 -72.05(15) ... . ?

C2 Ti N1 C11-100.51(15) ... . ?

C7 Ti N1 C11 134.61(14) . . . ? ?

N2 Ti N1 C13 -176.6(3) ....?

C10 Ti N1 C13 -87.3(3) ... . ?

C4 Ti N1 C13 59.9(3) ....?

C3 Ti N1 C13 53.7(3) .... ?

C5 Ti N1 C13 106.9(3) ... ? 
C6 Ti N1 C13 -53.1(3) ....?

C9 Ti N1 C13-105.6(3) .... ?

C8 Ti N1 C13-80.1(3) ... . ?

Cl Ti N1 C13 110.6(3) ... . ?

C2 Ti N1 C13 82.2(3) ... . ?

C7 Ti N1 C13 $-42.7(3) \ldots$ ?

$\mathrm{N} 1 \mathrm{Ti}$ N2 C1 $1-0.72(13) \ldots$ ?

C10 Ti N2 C11 $-85.58(15) \ldots$ ?

C4 Ti N2 C11 121.49(15) . . . ?

C3 Ti N2 C11 76.22(16) . . . ?

C5 Ti N2 C11 131.15(14) ... . ?

C6 Ti N2 C11 -71.48(15) .... ?

C9 Ti N2 C11 -119.78(15) ....?

C8 Ti N2 C11 -135.59(14) ... . ?

C1 Ti N2 C11 104.02(15) ... . ?

C2 Ti N2 C11 74.44(14) ... . ?

C7 Ti N2 C11 -105.48(16) .... ?

N1 Ti N2 C16 178.6(3) ....?

C10 Ti N2 C16 93.8(3) .... ?

C4 Ti N2 C16 -59.1(3) ... . ?

C3 Ti N2 C16-104.4(3) ... . ?

C5 Ti N2 C16 $-49.5(3) \ldots$ ?

C6 Ti N2 C16 107.9(3) ... . ?

C9 Ti N2 C16 59.6(3) ... . ?

C8 Ti N2 C16 43.8(3) ... . ?

C1 Ti N2 C16 -76.6(3) ....?

C2 Ti N2 C16-106.2(3) ....?

C7 Ti N2 C16 73.9(3) ... . ?

N1 Ti C1 C2 $-58.00(16) \ldots$ ?

$\mathrm{N} 2 \mathrm{Ti} \mathrm{C1} \mathrm{C2} \mathrm{-116.94(16) \ldots .} \mathrm{?}$

$\mathrm{C} 10 \mathrm{Ti} \mathrm{C1} \mathrm{C2}-149.7(3) \ldots$ ?

C4 Ti C1 C2 78.35(17) .... ?

C3 Ti C1 C2 37.14(15) ....?

C5 Ti C1 C2 116.9(2) ....?

C6 Ti C1 C2 49.4(4) ....?

C9 Ti C1 C2 170.75(15) .... ?

C8 Ti C1 C2 130.17(15) ....?

C7 Ti C1 C2 89.29(18) ....?

$\mathrm{N} 1 \mathrm{TiC} 1 \mathrm{C} 5-174.86(16) \ldots$ ?

N2 Ti C1 C5 126.20(17) ....?

C10 Ti C1 C5 93.4(4) ....?

C4 Ti Cl C5 $-38.51(16) \ldots$ ?

C3 Ti C1 C5 $-79.72(17) \ldots$ ?

C6 Ti C1 C5 -67.4(4).... ?

C9 Ti C1 C5 53.9(2) ... . ?

C8 Ti C1 C5 13.3(2) ....?

C2 Ti C1 C5-116.9(2) ... . ?

C7 Ti C1 C5 -27.6(2) .... ?

C5 C1 C2 C3 $0.0(3) \ldots$ ?

Ti C1 C2 C3 -63.40(18) . . . ?

C5 C1 C2 Ti 63.43(18)....?

N1 Ti C2 C1 121.07(16) ....?

$\mathrm{N} 2 \mathrm{Ti} \mathrm{C} 2 \mathrm{C} 161.22(16) \ldots$ ?

$\mathrm{C} 10 \mathrm{TiC} 2 \mathrm{C} 1$ 153.0(3)....?

C4 Ti C2 C1 -78.71(17) ... ?

C3 Ti C2 C1 -116.3(2) ... . ? 


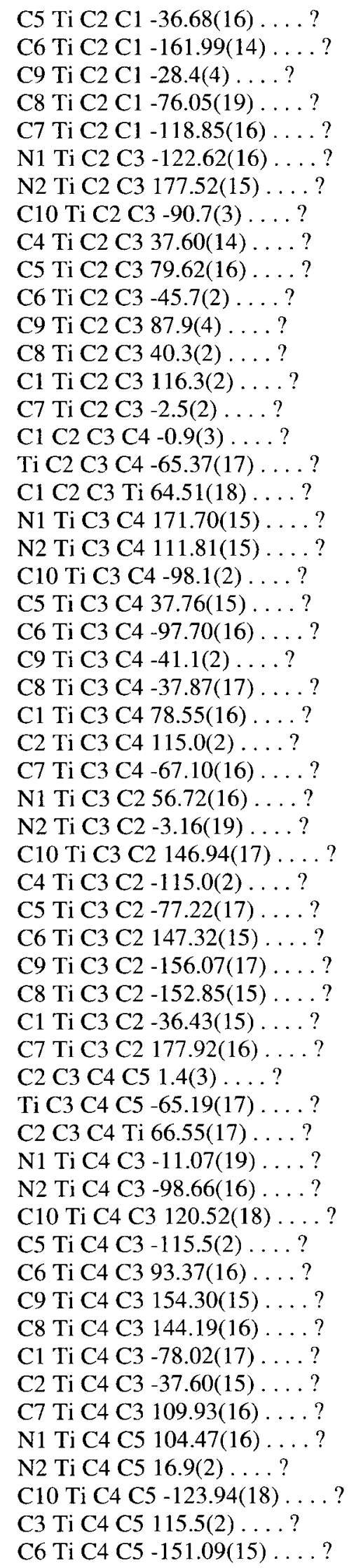




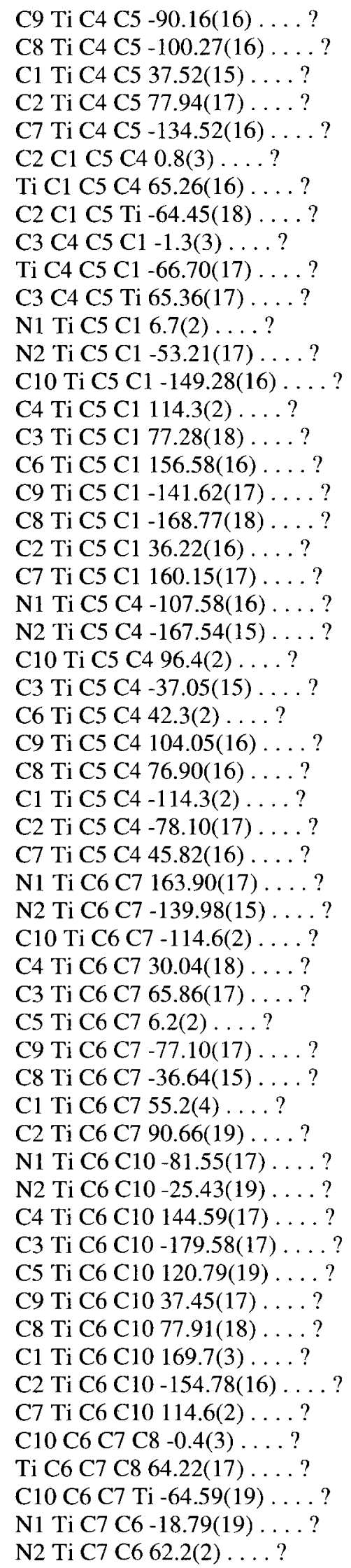


C10 Ti C7 C6 38.18(16) ... ?

C4 Ti C7 C6 -150.94(18) ....?

C3 Ti C7 C6-119.09(17) ....?

C5 Ti C7 C6 -175.63(17) ....?

C9 Ti C7 C6 79.52(19) .... ?

C8 Ti C7 C6 116.6(2)....?

C1 Ti C7 C6 -160.25(16) ....?

C2 Ti C7 C6 -117.66(15) ... . ?

N1 Ti C7 C8 $-135.40(15) \ldots$ ?

N2 Ti C7 C8 $-54.4(2) \ldots$ ?

C10 Ti C7 C8 - 78.43(18)....?

C4 Ti C7 C8 92.45(16).... ?

C3 Ti C7 C8 124.30(16) ....?

C5 Ti C7 C8 67.76(16) ... . ?

C6 Ti C7 C8 $-116.6(2) \ldots$ ?

C9 Ti C7 C8 $-37.09(16) \ldots$ ?

C1 Ti C7 C8 83.14(19) ....?

C2 Ti C7 C8 125.73(16) ....?

C6 C7 C8 C9 1.0(3) ....?

Ti C7 C8 C9 64.61(17) .... ?

C6 C7 C8 Ti $-63.57(17) \ldots$ ?

N1 Ti C8 C9 $-45.8(2) \ldots$ ?

N2 Ti C8 C9 29.39(19) ....?

C10 Ti C8 C9 $-37.11(17) \ldots$. . ?

C4 Ti C8 C9 163.14(18) .... ?

C3 Ti C8 C9 $-176.48(16) \ldots$. . ?

C5 Ti C8 C9 128.99(17) ....?

C6 Ti C8 C9-78.72(19) ... . ?

C1 Ti C8 C9 121.61(18) .... ?

C2 Ti C8 C9 160.90(17) .... ?

C7 Ti C8 C9 $-115.4(2) \ldots$ ?

N1 Ti C8 C7 69.6(2) ....?

$\mathrm{N} 2 \mathrm{Ti} \mathrm{C8} \mathrm{C7} \mathrm{144.76(14) \ldots ...?}$

C10 Ti C8 C7 78.26(18) ....?

C4 Ti C8 C7 $-81.48(16) \ldots$ ?

C3 Ti C8 C7 -61.11(17) ... . ?

C5 Ti C8 C7 -115.64(16) .... ?

C6 Ti C8 C7 36.65(15) . . . . ?

C9 Ti C8 C7 115.4(2) ....?

C1 Ti C8 C7 -123.01(16) ....?

C2 Ti C8 C7 -83.72(19) ... . ?

C7 C8 C9 C10-1.3(3) .... ?

Ti C8 C9 C10 63.90(19) ... . ?

C7 C8 C9 Ti -65.20(17) .... ?

N1 Ti C9 C8 149.93(15) ....?

N2 Ti C9 C8 $-153.59(17) \ldots$ ?

C10 Ti C9 C8 116.3(2) ....?

C4 Ti C9 C8 -18.29(19) ... . ?

C3 Ti C9 C8 5.5(3) ....?

C5 Ti C9 C8 -55.54(18) ....?

C6 Ti C9 C8 78.40(17) .... ?

C1 Ti C9 C8 -84.11(19) ....?

C2 Ti C9 C8 -62.9(4) ....?

C7 Ti C9 C8 37.42(15) ....?

N1 Ti C9 C10 33.67(19) ....?

N2 Ti C9 C10 90.14(18) ... . ? 


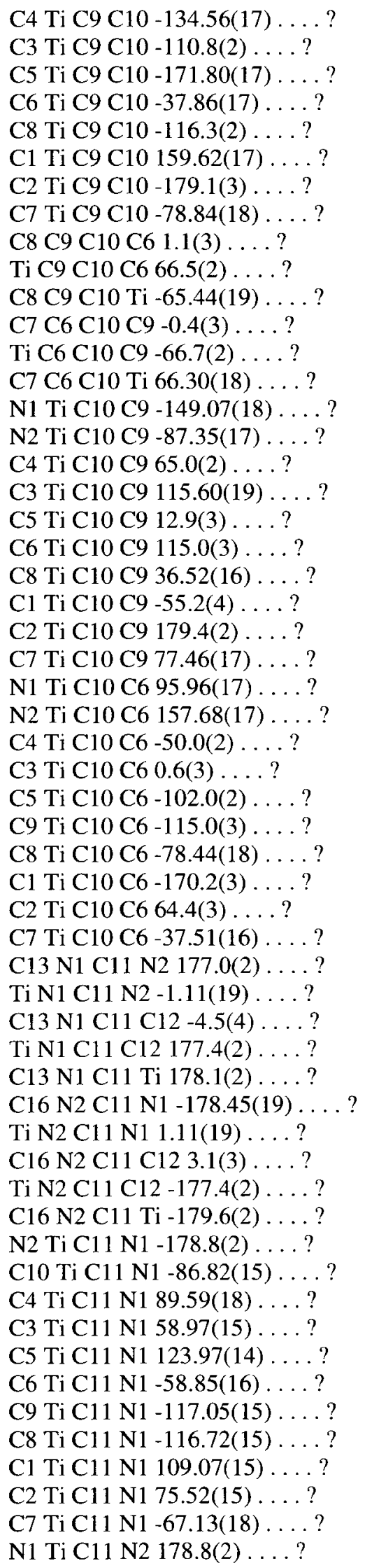


C10 Ti C11 N2 91.93(15) ... . ?

C4 Ti C11 N2 $-91.65(18) \ldots$ ?

C3 Ti C11 N2 -122.28(14)....?

C5 Ti C11 N2 -57.27(16) ....?

C6 Ti C11 N2 119.91(14)....?

C9 Ti C11 N2 61.71(15) ....?

C8 Ti C11 N2 62.03(17) ....?

C1 Ti C11 N2 -72.17(14) ... . ?

C2 Ti C11 N2 -105.73(14) ... . ?

C7 Ti C11 N2 111.62(16) ....?

N1 Ti C11 C12 -95(5) ....?

N2 Ti C11 C12 86(5) ....?

C10 Ti C11 C12 178(100) ... . ?

C4 Ti C11 C12 -5(5) ....?

C3 Ti C11 C12 -36(5) ....?

C5 Ti C11 C12 29(5) ... . ?

C6 Ti C11 C12 -154(5) ... . ?

C9 Ti C11 C12 148(5) ....?

C8 Ti C11 C12 148(5) ....?

C1 Ti C11 C12 14(5) ....?

C2 Ti C11 C12-19(5)....?

C7 Ti C11 C12-162(5) ....?

C11 N1 C13 C15 159.7(2) ... ?

Ti N1 C13 C15 -23.5(4) ....?

C11 N1 C13 C14 -77.7(3) ... . ?

Ti N1 C13 C14 99.1(3) ....?

C11 N2 C16 C17 -159.3(2) ... ?

Ti N2 C16 C17 21.4(4) ....?

C11 N2 C16 C18 77.6(3) ...? ?

Ti N2 C16 C18 -101.7(3) ...?

_diffrn_measured_fraction_theta_max 0.997

_diffrn_reflns_theta_full 25.00

_diffrn_measured_fraction_theta_full 1.000

_refine_diff_density_max 0.540

_refine_diff_density_min -0.199

_refine_diff_density_rms 0.055 


\section{A.8 Compound 15}

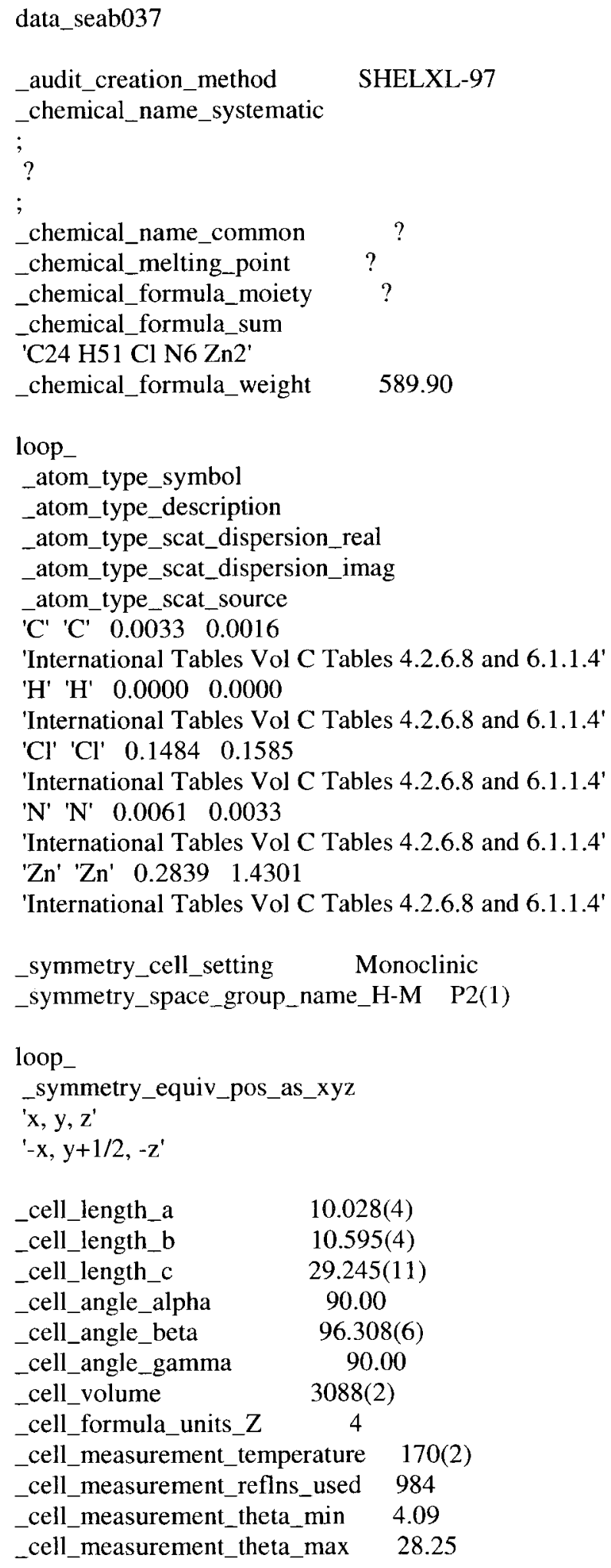




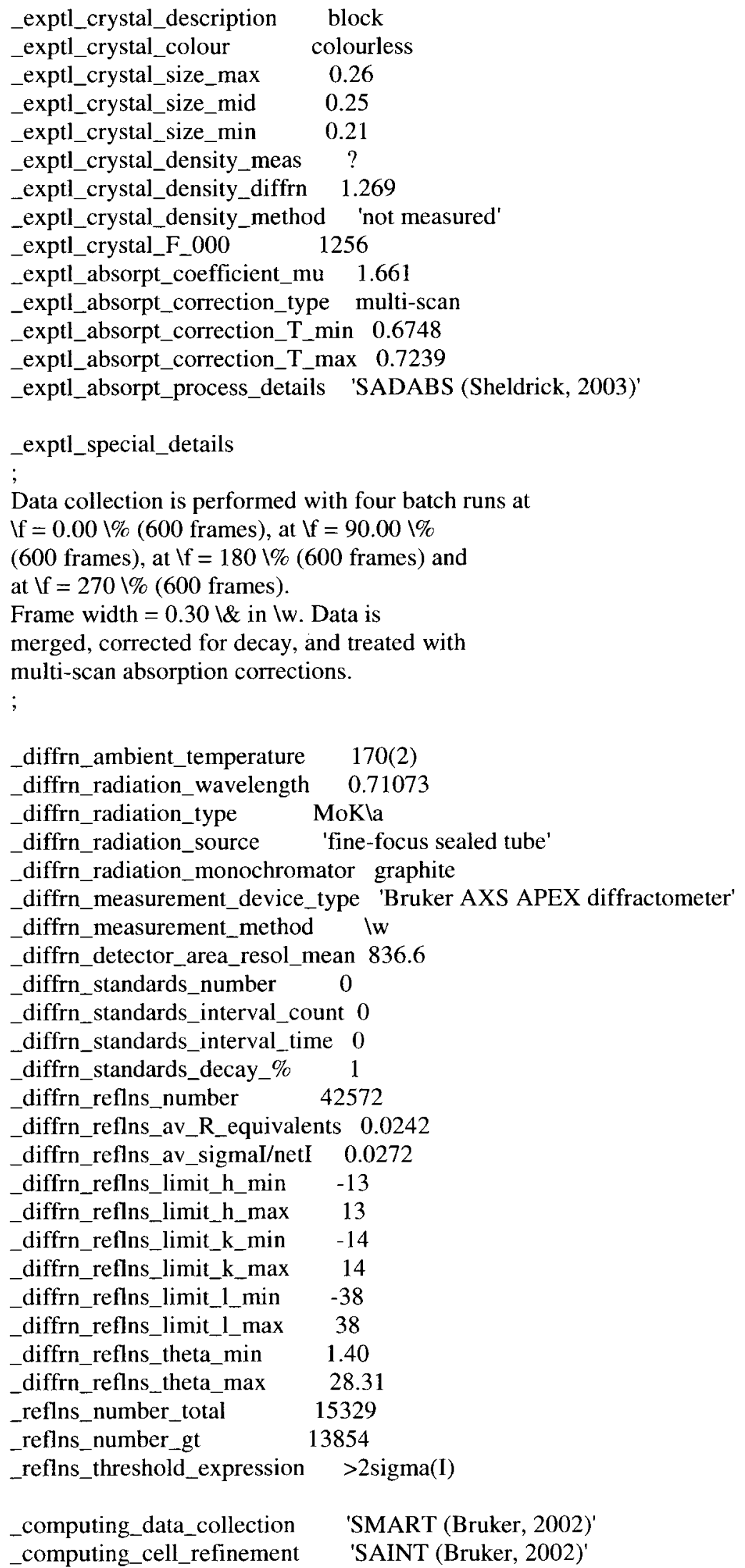




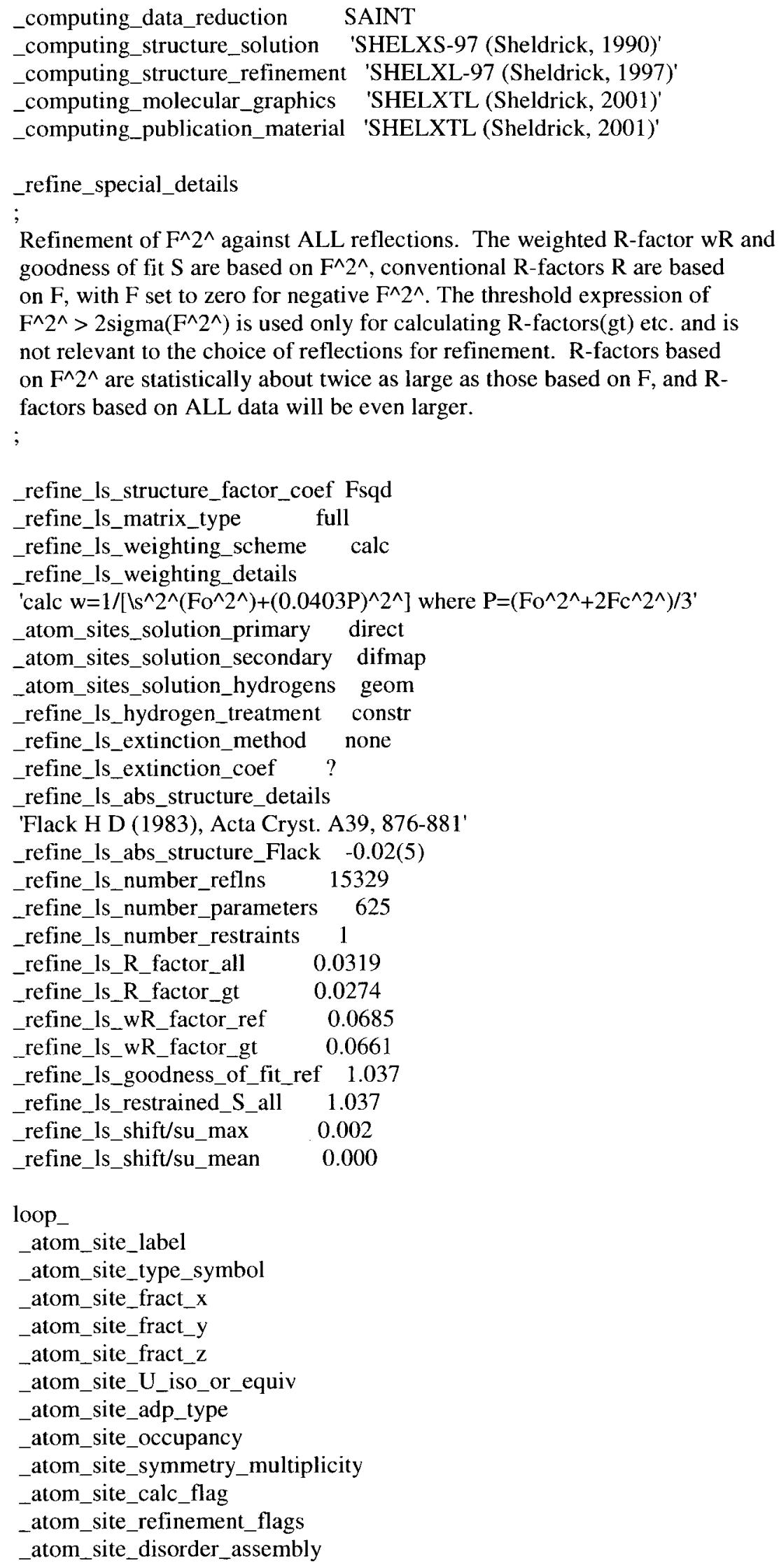


_atom_site_disorder_group

Zn1 Zn 0.13115(2) 0.697297(19) 0.174115(7) 0.02568(5) Uani $11 \mathrm{~d} \ldots$ $\mathrm{Zn} 2 \mathrm{Zn}$ 0.29597(2) 0.57083(2) 0.106773(7) 0.02827(5) Uani $11 \mathrm{~d} \ldots$

Zn3 Zn 0.90800(2) 0.191517(19) 0.323075(7) 0.02709(5) Uani $11 \mathrm{~d} \ldots$ $\mathrm{Zn} 4 \mathrm{Zn} 0.75263(2) 0.07252(2) 0.394870(7) 0.02838(5)$ Uani $11 \mathrm{~d} \ldots$ $\mathrm{Cl} 1 \mathrm{Cl}-0.07246(5) 0.72410(5) 0.19497(2) 0.04036(12)$ Uani $11 \mathrm{~d} \ldots$ $\mathrm{Cl} 2 \mathrm{Cl} 1.11265(5) 0.21949(5) 0.30271(2) 0.04202(12)$ Uani $11 \mathrm{~d} \ldots$ N1 N 0.22898(16) 0.83345(16) 0.14590(6) 0.0310(4) Uani $11 \mathrm{~d}$. . . $\mathrm{N} 2 \mathrm{~N} 0.41096(15) 0.70427$ (17) $0.13957(5) 0.0313(3)$ Uani $11 \mathrm{~d} \ldots$ $\mathrm{N} 3 \mathrm{~N} 0.25418(15) 0.59083(15) 0.21992(5) 0.0264(3)$ Uani $11 \mathrm{~d} \ldots$ N4 N 0.16967(16) 0.50857(14) 0.15211(5) 0.0260(3) Uani $11 \mathrm{~d} \ldots$ N5 N 0.35941(19) 0.43842(17) 0.06097(6) 0.0371(4) Uani $11 \mathrm{~d} \ldots$ N6 N 0.24493(19) 0.60992(18) 0.03908(6) 0.0383(4) Uani $11 \mathrm{~d} \ldots$ N7 N 0.80301(18) 0.32876(15) 0.34723(5) 0.0308(3) Uani $11 \mathrm{~d} \ldots$ N8 N 0.62922(15) 0.19609(18) 0.35975(6) 0.0339(3) Uani $11 \mathrm{~d} \ldots$ N9 N $0.78621(15) 0.07422(17) 0.28082(5) 0.0300$ (3) Uani $11 \mathrm{~d} \ldots$ $\mathrm{N} 10 \mathrm{~N} 0.87793(15) 0.00690(14) 0.34953(5) 0.0256(3)$ Uani $11 \mathrm{~d} \ldots$ $\mathrm{N} 11 \mathrm{~N} 0.79963(18) 0.12431(17) 0.46196(6) 0.0349(4)$ Uani $11 \mathrm{~d} \ldots$ N12 N 0.69943(19) -0.05661(18) 0.44361(6) 0.0384(4) Uani $11 \mathrm{~d} \ldots$ C1 C 0.1710(2) 0.9629(2) 0.14590(8) 0.0430(5) Uani $11 \mathrm{~d} \ldots$ H1A H 0.23181 .02090 .13090 .052 Uiso 11 calc R. . C2 C 0.0335(3) 0.9654(2) 0.11742(9) 0.0515(6) Uani $11 \mathrm{~d} \ldots$ H2A H 0.04320 .94000 .08570 .077 Uiso 11 calc R . . H2B H -0.00351 .05100 .11750 .077 Uiso 11 calc R . . H2C H -0.02710 .90690 .13080 .077 Uiso 11 calc R . C3 C 0.1622(3) 1.0102(2) 0.19445(9) 0.0536(7) Uani $11 \mathrm{~d} \ldots$ H3A H 0.25181 .00910 .21170 .080 Uiso 11 calc R . . H3B H 0.10200 .95550 .20970 .080 Uiso 11 calc $R$. . H3C H 0.12731 .09670 .19330 .080 Uiso 11 calc R . . C4 C 0.55756(19) 0.6820(2) 0.14562(8) 0.0403(5) Uani $11 \mathrm{~d}$... H4A H 0.60190 .75360 .16360 .048 Uiso 11 calc R . . C5 C 0.5855(2) 0.5604(3) 0.17291(8) 0.0473(6) Uani $11 \mathrm{~d} \ldots$ H5A H 0.55460 .56970 .20340 .071 Uiso 11 calc $R$. . H5B H 0.68200 .54310 .17630 .071 Uiso 11 calc $R$. . H5C H 0.53760 .49030 .15660 .071 Uiso 11 calc R . . C6 C 0.6132(2) 0.6751(3) 0.09920(9) 0.0580(7) Uani $11 \mathrm{~d} \ldots$ H6A H 0.59880 .75610 .08320 .087 Uiso 11 calc R. . H6B H 0.56700 .60810 .08050 .087 Uiso 11 calc R. . H6C H 0.70950 .65670 .10400 .087 Uiso 11 calc R . C7 C 0.3613(2) 0.8183(2) 0.14358(7) 0.0334(4) Uani $11 \mathrm{~d} \ldots$ C8 C $0.4517(3) 0.9340(2) 0.14455(9) 0.0507(6)$ Uani $11 \mathrm{~d} \ldots$ H8A H 0.54580 .90740 .14910 .076 Uiso 11 calc R . . H8B H 0.43280 .98950 .16980 .076 Uiso 11 calc R. . H8C H 0.43470 .97950 .11530 .076 Uiso 11 calc R . . C9 C 0.3355(2) 0.6006(2) 0.26463(7) $0.0338(4)$ Uani $11 \mathrm{~d} \ldots$ H9A H 0.41440 .54260 .26520 .041 Uiso 11 calc R. . C10 C 0.3847(3) 0.7357(2) 0.27053(8) 0.0507(6) Uani $11 \mathrm{~d}$. . . H10A H 0.44070 .75650 .24610 .076 Uiso 11 calc R . H10B H 0.43760 .74500 .30060 .076 Uiso 11 calc R. . H10C H 0.30760 .79300 .26870 .076 Uiso 11 calc R . . C11 C 0.2518(2) 0.5638(2) 0.30261(6) 0.0376(4) Uani $11 \mathrm{~d}$. . H11A H 0.22940 .47390 .30000 .056 Uiso 11 calc R . H11B H 0.16900 .61370 .29980 .056 Uiso 11 calc R . H11C H 0.30280 .58000 .33260 .056 Uiso 11 calc R . C12 C 0.0731(2) 0.40869(19) 0.13593(7) 0.0323(4) Uani $11 \mathrm{~d} \ldots$ H12A H 0.12370 .33070 .12930 .039 Uiso 11 calc R . . 
C13 C -0.0076(2) 0.4535(3) 0.09163(7) 0.0489(6) Uani $11 \mathrm{~d} \ldots$ H13A H 0.05290 .46670 .06790 .073 Uiso 11 calc $R$. . H13B H -0.05270 .53300 .09740 .073 Uiso 11 calc $R$. . H13C H -0.07470 .38960 .08110 .073 Uiso 11 calc R . . C14 C -0.0230(2) 0.3778(2) 0.17180(8) 0.0377(5) Uani $11 \mathrm{~d} \ldots$ H14A H 0.02870 .34830 .20020 .057 Uiso 11 calc R . . H14B H -0.08550 .31150 .15980 .057 Uiso 11 calc R . . H14C H -0.07340 .45370 .17830 .057 Uiso 11 calc R . . C15 C 0.24166(18) 0.48935(18) 0.19538(6) 0.0262(4) Uani $11 \mathrm{~d} \ldots$ C16 C 0.3018(2) 0.36301(19) 0.20951(8) 0.0367(5) Uani $11 \mathrm{~d} \ldots$ H16A H 0.29010 .30490 .18330 .055 Uiso 11 calc R . . H16B H 0.25690 .32870 .23490 .055 Uiso 11 calc R . . H16C H 0.39770 .37330 .21950 .055 Uiso 11 calc R . . C17 C 0.4188(2) 0.3142(2) 0.05422(8) 0.0447(5) Uani $11 \mathrm{~d} \ldots$ H17A H 0.46080 .31620 .02480 .054 Uiso 11 calc R . . C18 C 0.5271(3) 0.2860(3) 0.09291(11) 0.0720(9) Uani $11 \mathrm{~d} \ldots$ H18A H 0.59980 .34770 .09250 .108 Uiso 11 calc R . . H18B H 0.56240 .20090 .08900 .108 Uiso 11 calc R . . H18C H 0.48950 .29120 .12240 .108 Uiso 11 calc R . . C19 C 0.3135(3) 0.2113(3) 0.05070(12) 0.0753(9) Uani $11 \mathrm{~d}$... H19A H 0.24910 .22600 .02350 .113 Uiso 11 calc $R$. . H19B H 0.26640 .21210 .07830 .113 Uiso 11 calc R . . H19C H 0.35690 .12920 .04800 .113 Uiso 11 calc R . . C20 C 0.1864(2) 0.7102(2) 0.00850(7) 0.0456(5) Uani $11 \mathrm{~d}$. . H20A H $0.20020 .6884-0.02390 .055$ Uiso 11 calc R . . C21 C 0.2545(3) 0.8352(2) 0.02080(8) 0.0484(6) Uani $11 \mathrm{~d} \ldots$ H21 A H 0.35080 .82770 .01820 .073 Uiso 11 calc R . . H21B H 0.24100 .85790 .05250 .073 Uiso 11 calc R . . H21C H $0.21580 .9008-0.00030 .073$ Uiso 11 calc R . C22 C 0.0367(3) 0.7180(3) 0.01224(13) 0.0788(10) Uani $11 \mathrm{~d} \ldots$ H22A H -0.0071 $0.6407-0.00020 .118$ Uiso 11 calc R . . H22B H $-0.00110 .7910-0.00520 .118$ Uiso 11 calc $\mathrm{R}$. . $\mathrm{H} 22 \mathrm{C} \mathrm{H} 0.02160 .72720 .04460 .118$ Uiso 11 calc $\mathrm{R}$. . C23 C 0.3050(2) 0.5082(2) 0.02599(7) 0.0394(5) Uani $11 \mathrm{~d} \ldots$ C24 C 0.3100(3) 0.4732(3) -0.02411(8) 0.0578(7) Uani $11 \mathrm{~d} \ldots$ H24A H $0.23160 .5085-0.04270 .087$ Uiso 11 calc R. . H24B H $0.30960 .3811-0.02720 .087$ Uiso 11 calc R . . H24C H $0.39210 .5073-0.03470 .087$ Uiso 11 calc R . . C25 C 0.4843(2) 0.1676(2) 0.35728(9) 0.0467(6) Uani $11 \mathrm{~d}$. . H25A H 0.43480 .22700 .33490 .056 Uiso 11 calc R. . C26 C 0.4330(2) 0.1854(3) 0.40428(10) 0.0614(7) Uani $11 \mathrm{~d}$. . H26A H 0.44740 .27310 .41430 .092 Uiso 11 calc R . . H26B H 0.48180 .12880 .42670 .092 Uiso 11 calc R . . H26C H 0.33700 .16590 .40180 .092 Uiso 11 calc R . . C27 C 0.4603(2) 0.0336(2) 0.33969(10) 0.0615(8) Uani $11 \mathrm{~d} \ldots$ H27A H 0.49440 .02480 .30970 .092 Uiso 11 calc R . H27B H 0.36390 .01540 .33650 .092 Uiso 11 calc R. . H27C H $0.5073-0.02590 .36150 .092$ Uiso 11 calc R . . C28 C 0.8545(3) 0.4590(2) 0.34349(7) 0.0412(5) Uani $11 \mathrm{~d}$. . H28A H 0.78990 .51800 .35610 .049 Uiso 11 calc R . . C29 C 0.9899(3) 0.4724(2) 0.37233(8) 0.0494(6) Uani $11 \mathrm{~d} \ldots$ H29A H 0.98050 .45020 .40430 .074 Uiso 11 calc R . H29B H 1.02100 .55990 .37090 .074 Uiso 11 calc R. . H29C H 1.05510 .41590 .36030 .074 Uiso 11 calc R . . C30 C 0.8641(3) 0.4950(2) 0.29337(8) 0.0556(7) Uani $11 \mathrm{~d}$. . H30A H 0.77520 .48880 .27590 .083 Uiso 11 calc R . . 
H30B H 0.92620 .43750 .28010 .083 Uiso 11 calc $R$. . H30C H 0.89720 .58180 .29190 .083 Uiso 11 calc R . . C31 C 0.6724(2) 0.3094(2) 0.35036(7) 0.0332(4) Uani $11 \mathrm{~d}$. . C32 C 0.5750(3) 0.4196(2) 0.34387(10) 0.0542(7) Uani $11 \mathrm{~d}$. . H32A H 0.48390 .38750 .33540 .081 Uiso 11 calc $R$. . H32B H 0.60050 .47480 .31940 .081 Uiso 11 calc R . H32C H 0.57770 .46740 .37260 .081 Uiso 11 calc R . . C33 C 0.7003(2) 0.0733(2) 0.23658(6) 0.0377(4) Uani $11 \mathrm{~d} \ldots$ H33A H 0.63570 .00130 .23620 .045 Uiso 11 calc $R$. . C34 C 0.6226(3) 0.1970(3) 0.23227(9) 0.0737(10) Uani $11 \mathrm{~d} \ldots$ H34A H 0.56820 .20500 .25800 .110 Uiso 11 calc R . . H34B H 0.56380 .19790 .20320 .110 Uiso 11 calc R. . H34C H 0.68570 .26780 .23280 .110 Uiso 11 calc R . . C35 C 0.7866(2) 0.0578(2) 0.19768(7) 0.0398(5) Uani $11 \mathrm{~d} \ldots$ H35A H $0.8229-0.02810 .19810 .060$ Uiso 11 calc $R$. . H35B H 0.86070 .11860 .20140 .060 Uiso 11 calc $R$. . H35C H 0.73220 .07280 .16830 .060 Uiso 11 calc R . . C36 C 0.9815(2) $-0.08519(18) 0.36814(7) 0.0304(4)$ Uani $11 \mathrm{~d} \ldots$ H36A H $0.9362-0.16240 .37860 .036$ Uiso 11 calc R . . C37 C 1.0636(2) -0.0247(2) 0.40937(7) 0.0402(5) Uani $11 \mathrm{~d} \ldots$ H37A H $1.0048-0.00510 .43310 .060$ Uiso 11 calc R . H37B H 1.10500 .05320 .39960 .060 Uiso 11 calc R . . H37C H $1.1339-0.08340 .42190 .060$ Uiso 11 calc R . . C38 C 1.0738(2) -0.1229(2) 0.33188(8) 0.0376(5) Uani $11 \mathrm{~d}$. . H38A H $1.0207-0.16430 .30600 .056$ Uiso 11 calc $R$. . H38B H $1.1428-0.18110 .34560 .056$ Uiso 11 calc R . . H38C H $1.1166-0.04720 .32090 .056$ Uiso 11 calc R . . C39 C 0.80532(18) -0.02206(18) 0.30712(7) 0.0285(4) Uani $11 \mathrm{~d} \ldots$ C40 C 0.7534(2) -0.1530(2) 0.29625(8) 0.0388(5) Uani $11 \mathrm{~d} \ldots$. H40A H $0.6552-0.15270 .29410 .058$ Uiso 11 calc R . H40B H $0.7892-0.21090 .32070 .058$ Uiso 11 calc R. . H40C H $0.7821-0.18060 .26690 .058$ Uiso 11 calc R . . C41 C 0.8494(2) 0.2301(2) 0.49066(7) 0.0392(5) Uani 11 d . . H41 A H 0.82010 .21930 .52200 .047 Uiso 11 calc R . . C42 C $0.7911(3) 0.3522(2) 0.47003(8) 0.0460(6)$ Uani 11 d . . H42A H 0.69290 .34890 .46810 .069 Uiso 11 calc R . . H42B H 0.81850 .36330 .43910 .069 Uiso 11 calc R . H42C H 0.82400 .42330 .48950 .069 Uiso 11 calc R . . C43 C 1.0025(3) 0.2335(3) 0.49491(13) 0.0719(9) Uani $11 \mathrm{~d}$. . . H43A H 1.03840 .15570 .50960 .108 Uiso 11 calc R . . H43B H 1.03500 .30620 .51360 .108 Uiso 11 calc R . . H43C H 1.03240 .24060 .46420 .108 Uiso 11 calc R . . C44 C 0.6395(3) -0.1792(2) 0.45282(9) 0.0506(6) Uani $11 \mathrm{~d}$. . H44A H $0.6842-0.21160 .48280 .061$ Uiso 11 calc $R$. . C45 C 0.6649(3) -0.2720 (2) 0.41571(10) 0.0618(7) Uani $11 \mathrm{~d} \ldots$ H45A H $0.7617-0.28390 .41550 .093$ Uiso 11 calc R . H45B H $0.6265-0.23940 .38580 .093$ Uiso 11 calc R. . H45C H $0.6229-0.35300 .42170 .093$ Uiso 11 calc R . . C46 C 0.4910(3) -0.1674(3) 0.45681(14) 0.0904(12) Uani $11 \mathrm{~d}$. . H46A H $0.4759-0.09890 .47820 .136$ Uiso 11 calc R . . H46B H $0.4575-0.24690 .46830 .136$ Uiso 11 calc $R$. . H46C H $0.4434-0.14870 .42650 .136$ Uiso 11 calc R . . C47 C 0.7448(2) 0.0220(2) $0.47730(7) 0.0362(5)$ Uani $11 \mathrm{~d} \ldots$ C48 C 0.7355(3) -0.0046(2) 0.52773(8) 0.0505(6) Uani $11 \mathrm{~d} \ldots$ H48A H 0.81080 .03570 .54630 .076 Uiso 11 calc R . . H48B H $0.7386-0.09600 .53300 .076$ Uiso 11 calc $R$. . 
H48C H 0.65080 .02910 .53640 .076 Uiso 11 calc R . .

loop_
_atom_site_aniso_label
_atom_site_aniso_U_11
_atom_site_aniso_U_22
_atom_site_aniso_U_33
-atom_site_aniso_U_23
_atom_site_aniso_U_13
-atom_site_aniso_U_12

Zn1 0.02453(10) 0.02333(10) 0.02918(10) 0.00184(10) 0.00299(8) 0.00005(12)

Zn2 0.02737(11) $0.03061(11) 0.02762(10) 0.00192(10) 0.00661(8) 0.00057(12)$

Zn3 0.02767(11) 0.02391(10) 0.02943(10) $-0.00054(10) 0.00201(8) 0.00069(12)$

Zn4 0.02370(10) 0.02895(11) $0.03307(11)-0.00309(11) 0.00570(8)-0.00090(12)$

Cl1 0.0306(2) $0.0356(3) 0.0568(3) 0.0014(2) 0.0135(2) 0.0033(2)$

$\mathrm{Cl} 20.0362(3) 0.0368(3) 0.0552(3) 0.0043(2) 0.0147(2)-0.0038(2)$

$\mathrm{N} 10.0325(9) 0.0252(8) 0.0358(9) 0.0031(7) 0.0056(7)-0.0024(7)$

$\mathrm{N} 20.0232(7) 0.0347(9) 0.0362(8) 0.0038(8) 0.0036(6)-0.0047(7)$

$\mathrm{N} 30.0229(7) 0.0290(8) 0.0272(7) 0.0022(6) 0.0026(6)-0.0020(6)$

$\mathrm{N} 40.0263(8) 0.0247(8) 0.0273(8) 0.0015(6) 0.0051(6)-0.0023(6)$

N5 $0.0403(10) 0.0370(10) 0.0359(9) 0.0000(8) 0.0131(8) 0.0053(8)$

N6 0.0460(11) $0.0400(10) 0.0292(9) 0.0040(7) 0.0060(8) 0.0047(8)$

N7 0.0392(9) $0.0256(8) 0.0275(8)-0.0015(6) 0.0036(7) 0.0035(7)$

$\mathrm{N} 80.0217(7) 0.0369(9) 0.0419(9)-0.0084(9)-0.0013(6) 0.0051(8)$

N9 0.0247(8) 0.0334(8) 0.0313(8) -0.0074(8) -0.0002(6) 0.0040(7)

$\mathrm{N} 100.0221(8) 0.0247(8) 0.0300(8)-0.0008(6) 0.0038(6) 0.0018(6)$

$\mathrm{N} 110.0372(10) 0.0349(9) 0.0327(9)-0.0044(7) 0.0050(7)-0.0044(8)$

$\mathrm{N} 120.0379(10) 0.0354(9) 0.0447(10)-0.0017(8) 0.0164(8)-0.0074(8)$

C1 0.0481(14) 0.0252(10) 0.0577(14) 0.0079(10) 0.0154(11) 0.0009(9)

C2 $0.0551(16) 0.0471(14) 0.0535(14) 0.0163(12) 0.0117(12) 0.0216(12)$

C3 $0.0569(16) 0.0347(13) 0.0697(17)-0.0175(12) 0.0092(13)-0.0037(11)$

C4 0.0231(9) 0.0488(13) 0.0492(12) 0.0077(11) 0.0049(8) -0.0032(9)

C5 $0.0275(11) 0.0608(15) 0.0533(13) 0.0170(13) 0.0033(9) 0.0066(11)$

C6 0.0348(12) 0.080(2) 0.0622(15) 0.0208(15) 0.0207(11) 0.0006(13)

C7 0.0340(11) $0.0349(10) 0.0305(10) 0.0050(8)-0.0002(8)-0.0067(9)$

C8 0.0429(13) 0.0388(13) 0.0697(17) 0.0017(12) 0.0040(12) -0.0162(11)

C9 $0.0256(9) 0.0448(12) 0.0302(9) 0.0024(8)-0.0008(7)-0.0003(8)$

C10 0.0522(14) 0.0622(16) 0.0357(12) 0.0002(11) -0.0043(10)-0.0278(12)

C11 0.0422(11) 0.0394(11) 0.0317(9) 0.0009(9) 0.0061(8) 0.0013(10)

C12 0.0320(11) 0.0287(10) 0.0367(11) -0.0071(8) 0.0062(8) -0.0060(8)

C13 0.0441(13) 0.0647(16) 0.0363(12) -0.0019(11) -0.0033(10) -0.0215(12)

C14 0.0332(11) 0.0369(11) 0.0439(12) 0.0000(9) 0.0079(9) -0.0108(9)

C15 0.0208(8) 0.0270(9) 0.0319(9) 0.0068(7) 0.0069(7) 0.0025(7)

C16 0.0393(12) 0.0314(10) 0.0397(11) 0.0057(9) 0.0059(9) 0.0081(9)

C17 0.0475(14) 0.0428(12) 0.0464(13) -0.0032(11) 0.0163(11) 0.0071(11)

C18 0.070(2) 0.0563(18) 0.087(2) -0.0107(16) -0.0044(17) 0.0304(15)

C19 0.0622(18) 0.0422(16) 0.121(3) -0.0032(17) 0.0096(18) 0.0032(14)

C20 0.0581(14) 0.0474(14) 0.0304(10) 0.0079(10) 0.0002(9) 0.0054(12)

C21 0.0565(16) 0.0433(13) 0.0462(13) 0.0144(11) 0.0093(11) 0.0024(11)

C22 0.0483(16) 0.074(2) 0.107(3) 0.040(2) -0.0198(16) -0.0008(15)

C23 0.0452(13) 0.0430(12) 0.0320(11) -0.0010(9) 0.0135(9) $-0.0019(10)$

C24 0.080(2) 0.0615(17) 0.0338(12) -0.0034(12) 0.0164(12) 0.0085(15)

C25 0.0234(10) 0.0522(15) 0.0639(15) $-0.0186(12) 0.0018(10) 0.0038(9)$

C26 0.0280(11) 0.0746(18) 0.0847 (19) $-0.0278(17) 0.0194(11)-0.0050(13)$

C27 0.0267(12) 0.0623(17) 0.095(2) -0.0317(15) 0.0036(12) $-0.0085(11)$

C28 0.0591(15) 0.0259(10) 0.0408(12) $-0.0009(9) 0.0161(10) 0.0029(10)$ 


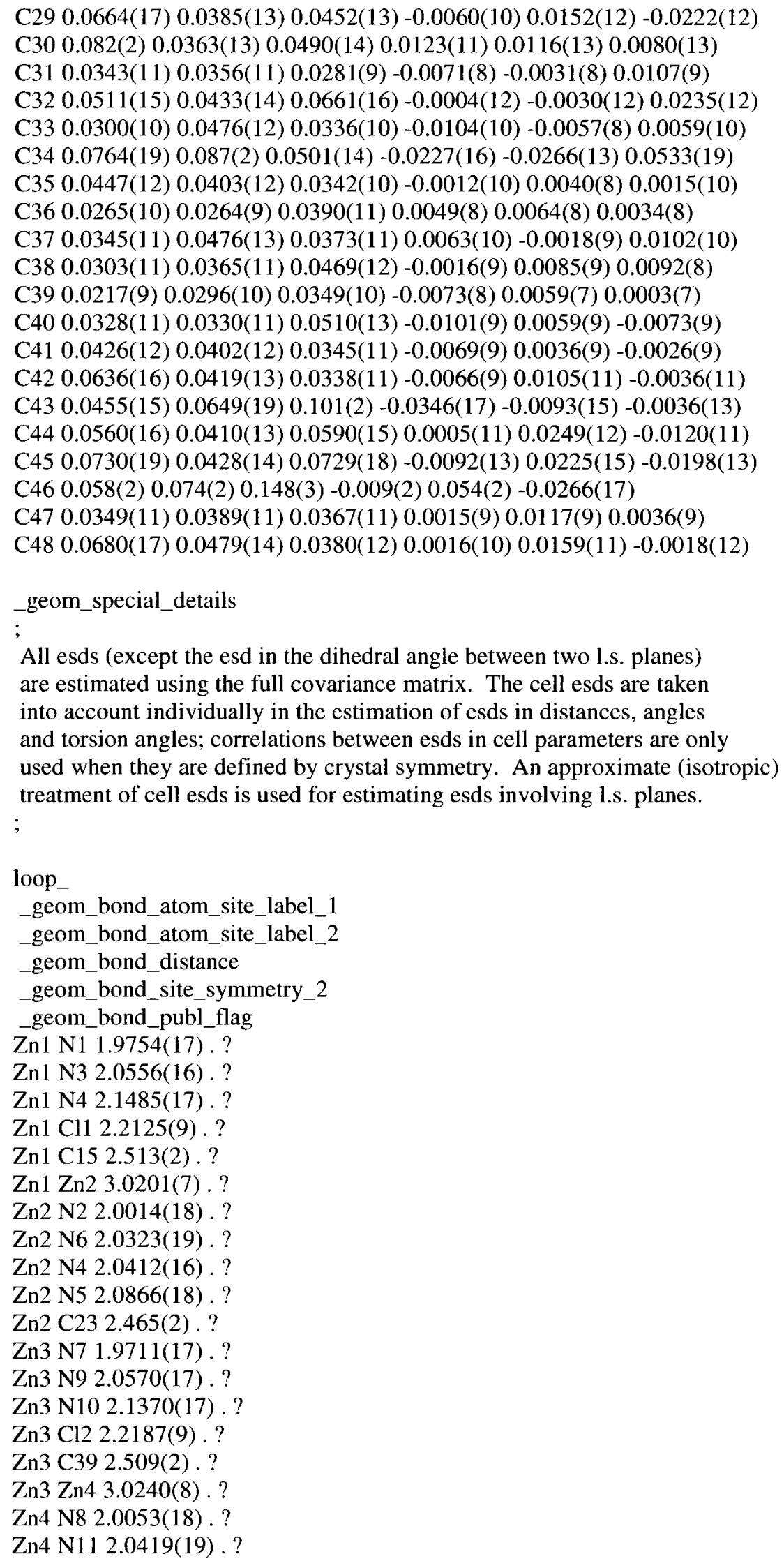


Zn4 N10 2.0461(16).? Zn4 N12 2.0870(19) .? $\mathrm{Zn} 4 \mathrm{C} 47$ 2.479(2) . ?

N1 C7 1.346(3) .?

N1 C1 1.490(3) . ?

N2 C7 1.317(3) . ?

N2 C4 1.480(3) . ?

N3 C15 1.291(2).?

N3 C9 1.467(2) .?

N4 C15 1.401(2). ?

N4 C12 1.477(2).?

N5 C23 1.329(3).?

N5 C17 1.467(3) . ?

N6 C23 1.312(3) . ?

N6 C20 1.469(3) . ?

N7 C31 1.339(3) .?

N7 C28 1.481(3).?

N8 C31 1.315(3).?

N8 C25 1.478(3).?

N9 C39 1.279(3). ?

N9 C33 1.474(2).?

N10 C39 1.402(2).?

N10 C36 1.484(2).?

N11 C47 1.317(3).?

N11 C41 1.456(3).?

N12 C47 1.331(3). ?

N12 C44 1.468(3). ?

C1 C3 1.517(3) . ?

C1 C2 1.530(4).?

C4 C5 1.525(3).?

C4 C6 1.525(3) . ?

C7 C8 1.523(3) . ?

C9 C11 1.515(3) . ?

C9 C10 1.518(3) . ?

C12 C13 1.526(3) .?

C12 C14 1.536(3).?

C15 C16 1.507(3) .?

C17 C18 1.510(4) .?

C17 C19 1.513(4).?

C20 C21 1.515(4) . ?

C20 C22 1.519(4).?

C23 C24 1.518(3) . ?

C25 C27 1.520(3) .?

C25 C26 1.532(3) . ?

C28 C29 1.524(4) . ?

C28 C30 1.528(3) . ?

C31 C32 1.521(3) . ?

C33 C35 1.512(3) . ?

C33 C34 1.523(3) . ?

C36 C37 1.525(3) . ?

C36 C38 1.535(3).?

C39 C40 1.503(3) . ?

C41 C42 1.517(3).?

C41 C43 1.527(4).?

C44 C45 1.507(4).?

C44 C46 1.512(4) .? 
C47 C48 1.514(3) . ?

loop_

_geom_angle_atom_site_label_1 _geom_angle_atom_site_label_2 _geom_angle_atom_site_label_3 _geom_angle _geom_angle_site_symmetry_1 _geom_angle_site_symmetry_3 _geom_angle_publ_flag

N1 Zn1 N3 112.51(7) . .?

N1 Zn1 N4 116.15(7) . . ?

N3 Zn1 N4 64.51(6) . . ?

N1 Zn1 Cl1 122.49(5) ..?

N3 Zn1 C11 113.38(5) .. ?

N4 Zn1 Cl1 113.81(4) ..?

N1 Zn1 C15 121.18(7) . . ?

N3 Zn1 C15 30.80(6) .. ?

N4 Zn1 C15 33.84(6) .. ?

Cl1 Zn1 C15 116.07(4) .. ?

N1 Zn1 Zn2 73.69(6) . . ?

N3 Zn1 Zn2 81.32(5) .. ?

N4 Zn1 Zn2 42.48(4) .. ?

Cl1 Zn1 Zn2 145.531(18) . . ?

C15 Zn1 Zn2 60.95(4) .. ?

N2 Zn2 N6 113.15(7) .. ?

N2 Zn2 N4 106.43(7) .. ?

N6 Zn2 N4 126.21(7)..?

N2 Zn2 N5 125.61(7)..?

N6 Zn2 N5 64.76(8) . . ?

N4 Zn2 N5 117.03(7) .. ?

$\mathrm{N} 2 \mathrm{Zn} 2 \mathrm{C} 23$ 124.71(7) . . ?

N6 Zn2 C23 32.13(8) .. ?

N4 Zn2 C23 128.78(7) . . ?

N5 Zn2 C23 32.64(7) . . ?

N2 Zn2 Zn1 72.65(5) .. ?

N6 Zn2 Zn1 116.58(6) . . ?

N4 Zn2 Zn1 45.31(5) .. ?

N5 Zn2 Zn1 160.76(5) . ?

C23 Zn2 Zn1 145.57(6) . . ?

N7 Zn3 N9 110.84(7) . . ?

N7 Zn3 N10 116.31(7) . . ?

N9 Zn3 N10 64.30(7) . . ?

N7 $\mathrm{Zn} 3 \mathrm{Cl} 2$ 122.95(6) ..?

N9 $\mathrm{Zn} 3 \mathrm{Cl} 2115.16(5) \ldots$ ?

N10 Zn3 Cl2 113.01(4) . . ?

N7 Zn3 C39 120.50(7) . . ?

N9 Zn3 C39 30.55(6) ...?

N10 Zn3 C39 33.93(6) .. ?

$\mathrm{Cl} 2$ Zn3 C39 116.32(4) .. ?

N7 Zn3 Zn4 73.89(5) .. ?

N9 Zn3 Zn4 81.26(5)...?

N10 Zn3 Zn4 42.53(4) . . ?

$\mathrm{Cl} 2 \mathrm{Zn} 3 \mathrm{Zn} 4$ 143.553(18) .. ?

C39 Zn3 Zn4 61.37(5) . . ?

N8 Zn4 N11 112.40(7) . . ? 
N8 Zn4 N10 106.16(7) . . ? N11 Zn4 N10 128.36(7) . . ? N8 Zn4 N12 126.03(8) . . ? N11 Zn4 N12 64.48(8) . . ? N10 Zn4 N12 116.17(7) .. ? N8 Zn4 C47 123.74(7) .. ? $\mathrm{N} 11 \mathrm{Zn} 4 \mathrm{C} 47$ 32.05(7) .. ? $\mathrm{N} 10 \mathrm{Zn} 4 \mathrm{C} 47$ 130.09(7) . . ? N12 Zn4 C47 32.48(7) .. ? N8 Zn4 Zn3 73.04(5) .. ? N11 Zn4 Zn3 118.23(5) . . ? N10 Zn4 Zn3 44.91(5) .. ? N12 Zn4 Zn3 159.62(5) .. ? C47 Zn4 Zn3 147.04(5) . . ? C7 N1 C1 119.82(18)..? C7 N1 Zn1 118.13(14) . . ? C1 N1 Zn1 117.42(13) .. ? C7 N2 C4 121.08(18) ..? C7 N2 Zn2 119.14(13) .. ? C4 N2 Zn2 117.19(15) .. ? C15 N3 C9 124.38(17) . . ? C15 N3 Zn1 94.59(11).. ? C9 N3 Zn1 141.03(13).. ? C15 N4 C12 116.10(15) . . ? C15 N4 Zn2 109.80(12) . ? C12 N4 Zn2 117.08(12) . .? C15 N4 Zn1 87.51(11)..? C12 N4 Zn1 129.02(13) . . ? Zn2 N4 Zn1 92.21(6)..?

C23 N5 C17 122.25(19) . .? C23 N5 Zn2 89.54(13) .. ? C17 N5 Zn2 147.83(15) . . ? C23 N6 C20 125.61(19) . . ? C23 N6 Zn2 92.41(14) .. ? C20 N6 Zn2 141.38(15) . . ? C31 N7 C28 119.97(18). . ? C31 N7 Zn3 118.44(14) . . ? C28 N7 Zn3 117.16(14) . . ? C31 N8 C25 121.38(18)..? C31 N8 Zn4 120.26(13) . . ? C25 N8 Zn4 116.08(16) . .? C39 N9 C33 123.87(19) . .? C39 N9 Zn3 94.63(12) .. ? C33 N9 Zn3 141.50(16) . . ? C39 N10 C36 117.08(15) . . ? C39 N10 Zn4 110.58(12) . ? C36 N10 Zn4 116.14(12) . ? C39 N10 Zn3 87.72(11) . ? C36 N10 Zn3 127.85(12) . ? Zn4 N10 Zn3 92.56(6) . . ? C47 N11 C41 124.58(19) . . ? C47 N11 Zn4 92.58(14) . .? C41 N11 Zn4 142.13(14) . . ? C47 N12 C44 122.07(19) . . ? C47 N12 Zn4 90.19(13) . . ? C44 N12 Zn4 147.74(16) . . ? 
N1 C1 C3 111.51(19) . . ?

N1 C1 C2 110.13(19) .. ?

$\mathrm{C} 3 \mathrm{C} 1 \mathrm{C} 2$ 111.3(2) .. ?

N2 C4 C5 108.67(17) .. ?

N2 C4 C6 110.89(18) .. ?

C5 C4 C6 111.2(2) .. ?

N2 C7 N1 119.94(19)...?

N2 C7 C8 120.6(2) . . ?

N1 C7 C8 119.4(2) .. ?

N3 C9 C11 109.67(16) . . ?

N3 C9 C10 108.03(17) . . ?

C11 C9 C10 111.02(19) . . ?

N4 C12 C13 108.48(17) . .?

N4 C12 C14 111.87(16) . . ?

C13 C12 C14 109.44(18) . . ?

N3 C15 N4 112.95(16) . . ?

N3 C15 C16 125.14(17) . . ?

N4 C15 C16 121.86(17) . . ?

N3 C15 Zn1 54.61(10) ..?

N4 C15 Zn1 58.65(9) .. ?

C16 C15 Zn1 177.00(14). . ?

N5 C17 C18 110.2(2) . . ?

N5 C17 C19 111.4(2) .. ?

C18 C17 C19 110.3(2) . . ?

N6 C20 C21 110.36(19) ..?

N6 C20 C22 109.1(2)...?

C21 C20 C22 111.1(2)..?

N6 C23 N5 113.27(19) ..?

N6 C23 C24 123.2(2)..?

N5 $\mathrm{C} 23 \mathrm{C} 24123.5(2) \ldots ?$

N6 C23 Zn2 55.46(11)..?

N5 C23 Zn2 57.83(11)..?

C24-C23 Zn2 178.52(18)..?

N8 C25 C27 109.00(19) . . ?

N8 C25 C26 110.89(19) ..?

C27 C25 C26 111.3(2)..?

N7 C28 C29 110.04(18) ..?

N7 C28 C30 111.27(18) . .?

C29 C28 C30 111.2(2) . ?

N8 C31 N7 120.10(18) . ?

N8 C31 C32 120.3(2) . .?

N7 C31 C32 119.6(2) .. ?

N9 C33 C35 109.46(16) . . ?

N9 C33 C34 108.17(17) . . ?

C35 C33 C34 111.2(2) ..?

N10 C36 C37 108.01(16) . . ?

N10 C36 C38 111.60(16) . . ?

C37 C36 C38 109.97(18) . ?

N9 C39 N10 112.73(17) . . ?

N9 C39 C40 125.68(19) ..?

N10 C39 C40 121.55(18) . . ?

N9 C39 Zn3 54.82(10) ..?

N10 C39 Zn3 58.34(9) . .?

C40 C39 Zn3 175.72(14) . . ?

N11 C41 C42 109.53(18) . ? ?

N11 C41 C43 110.06(19) . ? 
C42 C41 C43 110.7(2) . ?

N12 C44 C45 109.90(19) .. ?

N12 C44 C46 111.5(2)..?

C45 C44 C46 110.8(3)..?

N11 C47 N12 112.61(19). . ?

$\mathrm{N} 11 \mathrm{C} 47 \mathrm{C} 48$ 123.9(2) . ?

$\mathrm{N} 12$ C47 C48 123.5(2) . ?

N11 C47 Zn4 55.37(11). .?

N12 C47 Zn4 57.33(11) . ?

C48 C47 Zn4 177.55(17) . . ?

loop _geom_torsion_atom_site_label_1 _geom_torsion_atom_site_label_2 _geom_torsion_atom_site_label_3 _geom_torsion_atom_site_label_4 _geom_torsion _geom_torsion_site_symmetry_1 _geom_torsion_site_symmetry_2 _geom_torsion_site_symmetry_3 _geom_torsion_site_symmetry_4 _geom_torsion_publ_flag

N1 Zn1 Zn2 N2 41.52(7) . . . ? N3 Zn1 Zn2 N2 -75.11(7) ... ? N4 Zn1 Zn2 N2 -136.55(8) ... . ? Cl1 Zn1 Zn2 N2 165.75(6)... ? C15 Zn1 Zn2 N2 -99.71(7) ....? N1 Zn1 Zn2 N6 -66.19(8) ... ? ? N3 Zn1 Zn2 N6 177.19(7) ... . ? N4 Zn1 Zn2 N6 115.74(9) ....?

C11 Zn1 Zn2 N6 58.05(7) ....?

C15 Zn1 Zn2 N6 152.58(8) .... ?

N1 Zn1 Zn2 N4 178.07(8) ....?

$\mathrm{N} 3 \mathrm{Zn} 1 \mathrm{Zn} 2 \mathrm{~N} 461.45(8) \ldots$ ?

$\mathrm{Cl1} \mathrm{Zn} 1 \mathrm{Zn} 2 \mathrm{~N} 4$-57.69(7) ... . ?

C15 Zn1 Zn2 N4 36.84(8) ... ?

N1 Zn1 Zn2 N5 -155.43(17) ... . ?

N3 Zn1 Zn2 N5 87.94(16) ....?

N4 Zn1 Zn2 N5 26.49(17) ... . ?

Cl1 Zn1 Zn2 N5 -31.20(16) ... ? ?

C15 Zn1 Zn2 N5 63.34(16) ... . ?

N1 Zn1 Zn2 C23 -85.31(11)...?

N3 Zn1 Zn2 C23 158.06(10) ... ?

N4 Zn1 Zn2 C23 96.61(11)... . ?

Cl1 Zn1 Zn2 C23 38.92(10) ... . ?

C15 Zn1 Zn2 C23 133.45(11) ...?

N7 Zn3 Zn4 N8 40.10(7) ... ?

N9 Zn3 Zn4 N8 -74.68(7) ... ?

N10 Zn3 Zn4 N8 -135.90(8) ... . ?

$\mathrm{Cl} 2 \mathrm{Zn} 3 \mathrm{Zn} 4 \mathrm{~N} 8$ 164.28(6) ... ?

C39 Zn3 Zn4 N8 -99.34(7) ... ? ?

N7 Zn3 Zn4 N11 -66.66(8) ... . ?

N9 Zn3 Zn4 N11 178.56(8) ... . ?

N10 Zn3 Zn4 N11 117.34(9) . . . ?

$\mathrm{Cl} 2 \mathrm{Zn} 3 \mathrm{Zn} 4 \mathrm{~N} 11$ 57.52(7) ... ? ?

C39 Zn3 Zn4 N11 153.90(8) ... ? 
N7 Zn3 Zn4 N10 176.00(8) ... ? N9 Zn3 Zn4 N10 61.23(8) . . . ? Cl2 Zn3 Zn4 N10 -59.82(7) . . . ? C39 Zn3 Zn4 N10 36.56(8) .... ? N7 Zn3 Zn4 N12 -159.02(16) ....? N9 Zn3 Zn4 N12 86.21(16) ... ? ? N10 Zn3 Zn4 N12 24.98(17) ... ? $\mathrm{Cl} 2 \mathrm{Zn} 3 \mathrm{Zn} 4 \mathrm{~N} 12$-34.84(16) ... . ? C39 Zn3 Zn4 N12 61.54(16) . . . ? N7 Zn3 Zn4 C47 -86.56(11) ... . ? N9 Zn3 Zn4 C47 158.67(10) ... . ? $\mathrm{N} 10 \mathrm{Zn} 3 \mathrm{Zn} 4 \mathrm{C} 47$ 97.44(11)... . ? $\mathrm{Cl} 2 \mathrm{Zn} 3 \mathrm{Zn} 4 \mathrm{C} 47$ 37.62(10) ... . ? C39 Zn3 Zn4 C47 134.01(11)... . ? N3 Zn1 N1 C7 25.10(17) ....? N4 Zn1 N1 C7 -46.50(17) ... . ? Cl1 Zn1 N1 C7 165.74(13) ... . ? C15 Zn1 N1 C7 -8.17(18) .... ? Zn2 Zn1 N1 C7 -47.95(14) ... . ? N3 Zn1 N1 C1 -130.75(15) ... . ? N4 Zn1 N1 C1 157.64(14) . . . ? Cl1 Zn1 N1 C1 9.88(17) ...? ? C15 Zn1 N1 C1 -164.03(14)....? Zn2 Zn1 N1 C1 156.19(16) ....? N6 Zn2 N2 C7 64.25(16) ... . ? N4 Zn2 N2 C7 -78.50(16) . . . ? N5 Zn2 N2 C7 138.93(14) ... ? ? C23 Zn2 N2 C7 98.74(16) ... ? $\mathrm{Zn} 1 \mathrm{Zn} 2 \mathrm{~N} 2 \mathrm{C} 7-47.85(14) \ldots$ ? N6 Zn2 N2 C4 -97.73(15) ... ? N4 Zn2 N2 C4 119.52(14) ... ? N5 Zn2 N2 C4 -23.05(17) ... ? $\mathrm{C} 23 \mathrm{Zn} 2 \mathrm{~N} 2 \mathrm{C} 4-63.24(17) \ldots$ ? $\mathrm{Zn} 1 \mathrm{Zn} 2 \mathrm{~N} 2 \mathrm{C} 4$ 150.17(15) ... ? N1 Zn1 N3 C15 -113.54(12) ... . ? N4 Zn1 N3 C15 -4.22(10) ... ? Cl1 Zn1 N3 C15 102.11(11) ... ? Zn2 Zn1 N3 C15 -45.30(10) ... ? N1 Zn1 N3 C9 66.7(2) . . . ? N4 Zn1 N3 C9 176.0(2) ... ? Cl1 Zn1 N3 C9 -77.6(2) ... . ? C15 Zn1 N3 C9 -179.8(3) ... . ? Zn2 Zn1 N3 C9 134.94(19) ....? N2 Zn2 N4 C15 -44.96(14) ....? N6 Zn2 N4 C15 178.65(12) ... . ? N5 Zn2 N4 C15 101.35(13) ... ? ? C23 Zn2 N4 C15 137.95(13) ....? Zn1 Zn2 N4 C15 -88.15(12) ... . ? N2 Zn2 N4 C12 179.86(13) ....? N6 Zn2 N4 C12 43.47(16) ... . ? N5 Zn2 N4 C12 -33.83(16) ... . ? C23 Zn2 N4 C12 2.77(17) ... ? Zn1 Zn2 N4 C12 136.67(16) ... . ? N2 Zn2 N4 Zn1 43.19(8) ... ? ? N6 Zn2 N4 Zn1 -93.20(9) ... ? ? N5 Zn2 N4 Zn1 -170.50(6) ... . ? 
C23 Zn2 N4 Zn1 -133.90(8) ... ?

N1 Zn1 N4 C15 107.67(11)... . ?

N3 Zn1 N4 C15 3.88(10) ....?

Cl1 Zn1 N4 C15 -101.79(10) .... ?

Zn2 Zn1 N4 C15 109.73(12) ... . ?

N1 Zn1 N4 C12 -130.21(15) ... ? ?

N3 Zn1 N4 C12 125.99(17) ... . ?

Cl1 Zn1 N4 C12 20.32(16) ... ?

C15 Zn1 N4 C12 122.12(19) ... . ?

Zn2 Zn1 N4 C12 -128.15(18) ... ? ?

N1 Zn1 N4 Zn2 -2.06(9) ....?

N3 Zn1 N4 Zn2 -105.85(8) ... . ?

Cl1 Zn1 N4 Zn2 148.48(4) ....?

C15 Zn1 N4 Zn2 -109.73(12) . . . ?

N2 Zn2 N5 C23 -100.39(15) ....?

N6 Zn2 N5 C23 0.96(13) ....?

N4 Zn2 N5 C23 120.48(13) . . . ?

Zn1 Zn2 N5 C23 99.63(18) ....?

N2 Zn2 N5 C17 87.9(3) ... ?

N6 Zn2 N5 C17 -170.7(3) ... . ?

N4 Zn2 N5 C17 -51.2(3) ... . ?

C23 Zn2 N5 C17 -171.7(4) ... . ?

Zn1 Zn2 N5 C17 -72.0(4) ... ? ?

N2 Zn2 N6 C23 118.93(14) ... ?

N4 Zn2 N6 C23 -107.09(14) ... ?

N5 Zn2 N6 C23 -0.98(13) ... ?

Zn1 Zn2 N6 C23 -159.62(12) ... . ?

N2 Zn2 N6 C20 -51.7(3) .... ?

N4 Zn2 N6 C20 82.3(3) ....?

N5 Zn2 N6 C20 -171.6(3) ... . ?

C23 Zn2 N6 C20 -170.6(3) . . . . ?

Zn1 Zn2 N6 C20 29.8(3) ... . ?

N9 Zn3 N7 C31 25.48(16) . . . ?

N10 Zn3 N7 C31 -45.29(16) ... . ?

Cl2 Zn3 N7 C31 167.54(12) ... ?

C39 Zn3 N7 C31 -6.82(17) ... . ?

Zn4 Zn3 N7 C31 -48.31(14) ... . ?

N9 Zn3 N7 C28 -130.92(15) ... ?

N10 Zn3 N7 C28 158.31(13) ... ?

$\mathrm{Cl} 2 \mathrm{Zn} 3$ N7 C28 11.14(17) ... ?

C39 Zn3 N7 C28 -163.22(14) . . . ?

Zn4 Zn3 N7 C28 155.29(15) . . . ?

N11 Zn4 N8 C31 69.24(16) ... . ?

N10 Zn4 N8 C31 -75.67(16) ....?

N12 Zn4 N8 C31 143.20(15) ....?

C47 Zn4 N8 C31 103.43(16) ... . ?

Zn3 Zn4 N8 C31 -44.91(14) ... . ?

N11 Zn4 N8 C25 -93.88(15) ... . ?

N10 Zn4 N8 C25 121.21(15) ... ? ?

N12 Zn4 N8 C25 -19.93(18)....?

C47 Zn4 N8 C25 -59.70(17) ... . ?

Zn3 Zn4 N8 C25 151.97(15) .... ?

N7 Zn3 N9 C39-115.07(12) ... . ?

N10 Zn3 N9 C39 $-4.99(10) \ldots$ ?

Cl2 Zn3 N9 C39 99.68(11) ... . ?

Zn4 Zn3 N9 C39 -46.11(11) . . . . ? 
N7 Zn3 N9 C33 65.3(2) ... ?

N10 Zn3 N9 C33 175.4(2) . . . ?

Cl2 Zn3 N9 C33 -79.9(2) ... ? ?

C39 Zn3 N9 C33 -179.6(3) ... . ?

Zn4 Zn3 N9 C33 134.3(2) ... . ?

N8 Zn4 N10 C39 -44.66(14) ... . ?

N11 Zn4 N10 C39 178.01(12) ... . ?

N12 Zn4 N10 C39 100.90(13) ... . ?

C47 Zn4 N10 C39 136.32(13) ... . ?

Zn3 Zn4 N10 C39 -88.53(13) ... . ?

N8 Zn4 N10 C36 178.79(13) ....?

N11 Zn4 N10 C36 41.47(16) ....?

N12 Zn4 N10 C36 -35.64(15) ... . ?

C47 Zn4 N10 C36 -0.23(17) ... . ?

Zn3 Zn4 N10 C36 134.93(15) ... . ?

N8 Zn4 N10 Zn3 43.87(8) ... . ?

N11 Zn4 N10 Zn3 -93.46(8) ... ?

N12 Zn4 N10 Zn3 -170.57(6) ... . ?

C47 Zn4 N10 Zn3 -135.15(8) ... ?

N7 Zn3 N10 C39 106.22(11) ... ? ?

N9 Zn3 N10 C39 4.55(10) ...?

Cl2 Zn3 N10 C39-103.40(10) ... ?

Zn4 Zn3 N10 C39 110.51(12) ... . ?

N7 Zn3 N10 C36 -130.68(15) . . . ? ?

N9 Zn3 N10 C36 127.64(16) ....?

Cl2 Zn3 N10 C36 19.69(16) . . . ?

C39 Zn3 N10 C36 123.09(19) . . . . ?

Zn4 Zn3 N10 C36-126.40(17) .... ?

N7 Zn3 N10 Zn4 -4.29(8) ... ?

N9 Zn3 N10 Zn4 - 105.96(8) ... ? ?

C12 Zn3 N10 Zn4 146.09(4) ....?

C39 Zn3 N10 Zn4-110.51(12) ... . ?

N8 Zn4 N11 C47 118.29(13) ... ?

N10 Zn4 N11 C47 -106.47(14) . . . ?

N12 Zn4 N11 C47 -2.25(13) ... ?

Zn3 Zn4 N11 C47 -159.58(11) ... . ?

N8 Zn4 N11 C41 -51.3(3) ... ?

N10 Zn4 N11 C41 83.9(3) ... .?

N12 Zn4 N11 C41 -171.8(3) . . . ?

C47 Zn4 N11 C41 -169.6(3) ....?

Zn3 Zn4 N11 C41 30.8(3) ... . ?

N8 Zn4 N12 C47 -97.84(14) ... ?

$\mathrm{N} 11 \mathrm{Zn} 4 \mathrm{~N} 12 \mathrm{C} 47$ 2.23(13) ....?

N10 Zn4 N12 C47 124.34(13) ....?

Zn3 Zn4 N12 C47 104.94(17) ... . ?

N8 Zn4 N12 C44 81.0(3) ... ?

N11 Zn4 N12 C44 -179.0(3) ... ?

$\mathrm{N} 10 \mathrm{Zn} 4 \mathrm{~N} 12 \mathrm{C} 44-56.8(3) \ldots$ ?

C47 Zn4 N12 C44 178.8(4) ... . ?

Zn3 Zn4 N12 C44 -76.2(4) ... . ?

C7 N1 C1 C3 -94.5(2).... ?

Zn1 N1 C1 C3 61.0(2) ....?

C7 N1 C1 C2 141.5(2)....?

Zn1 N1 C1 C2 -63.1(2)....?

C7 N2 C4 C5 139.0(2)....?

Zn2 N2 C4 C5 -59.4(2) ... ? 
C7 N2 C4 C6 $-98.5(3) \ldots$ ?

$\mathrm{Zn} 2 \mathrm{~N} 2 \mathrm{C} 4 \mathrm{C} 663.1(2) \ldots$ ?

C4 N2 C7 N1 -168.48(18) ....?

Zn2 N2 C7 N1 30.3(2) ....?

C4 N2 C7 C8 12.9(3)....?

Zn2 N2 C7 C8 -148.35(17) ... . ?

C1 N1 C7 N2 -174.14(19) ... ?

Zn1 N1 C7 N2 30.6(2) ....?

C1 N1 C7 C8 4.5(3) ... ?

Zn1 N1 C7 C8 -150.77(17) ....?

C15 N3 C9 C11 -88.2(2) ... . ?

Zn1 N3 C9 C11 91.5(2) ...?

C15 N3 C9 C10 150.70(19) ....?

Zn1 N3 C9 C10 -29.6(3) .... ?

C15 N4 C12 C13 172.89(17) ... . ?

Zn2 N4 C12 C13 -54.7(2) ... ? ?

$\mathrm{Zn} 1 \mathrm{~N} 4 \mathrm{C} 12 \mathrm{C} 13$ 63.3(2) ... . ?

$\mathrm{C} 15 \mathrm{~N} 4 \mathrm{C} 12 \mathrm{C} 14$ 52.1(2) ....?

Zn2 N4 C12 C14 -175.54(13) ....?

Zn1 N4 C12 C14 -57.5(2) ....?

C9 N3 C15 N4 -173.84(16) ... . ?

$\mathrm{Zn} 1 \mathrm{~N} 3 \mathrm{C} 15 \mathrm{~N} 46.35(15) \ldots$. . ?

C9 N3 C15 C16 3.5(3) ....?

Zn1 N3 C15 C16 -176.34(17) ....?

C9 N3 C15 Zn1 179.8(2) ... ?

C12 N4 C15 N3-138.94(17) ...? ?

Zn2 N4 C15 N3 85.40(16) ... . ?

Zn1 N4 C15 N3 -6.06(15) ... . ?

C12 N4 C15 C16 43.7(2) ....?

$\mathrm{Zn} 2 \mathrm{~N} 4 \mathrm{C} 15 \mathrm{Cl} 6-92.01(18) \ldots$ ?

Zn1 N4 C15 C16 176.53(16) ... ? ?

C12 N4 C15 Zn1 -132.88(16) ....?

Zn2 N4 C15 Zn1 91.46(9) ... ? ?

N1 Zn1 C15 N3 81.88(13) ... . ?

N4 Zn1 C15 N3 173.15(17) ... . ?

C11 Zn1 C15 N3 -92.41(11)....?

Zn2 Zn1 C15 N3 126.50(12) ...? ?

N1 Zn1 C15 N4 -91.28(12) ....?

N3 Zn1 C15 N4 -173.15(17) ....?

Cl1 Zn1 C15 N4 94.44(10).... ?

Zn2 Zn1 C15 N4 -46.65(9) . . . . ?

N1 Zn1 C15 C16 168(3) ... . ?

N3 Zn1 C15 C16 86(3) .... ?

N4 Zn1 C15 C16-101(3) ... . ?

C11 Zn1 C15 C16 -6(3) ....?

Zn2 Zn1 C15 C16-147(3) ... . ?

C23 N5 C17 C18 152.3(2) ...?

Zn2 N5 C17 C18 -37.6(4) ... . ?

C23 N5 C17 C19-84.9(3) .... ?

Zn2 N5 C17 C19 85.3(4) ....?

C23 N6 C20 C21 -119.4(3) ... . ?

Zn2 N6 C20 C21 49.0(3) ... ?

C23 N6 C20 C22 118.3(3) ... . ?

Zn2 N6 C20 C22 -73.3(3) ... ? ?

C20 N6 C23 N5 174.3(2) ....?

Zn2 N6 C23 N5 1.5(2) ... ? 
C20 N6 C23 C24 -6.5(4) ... . ?

Zn2 N6 C23 C24 -179.3(2).... ?

C20 N6 C23 Zn2 172.8(3) ....?

C17 N5 C23 N6 173.3(2) ....?

Zn2 N5 C23 N6 -1.5(2) ....?

C17 N5 C23 C24 -5.9(4)....?

Zn2 N5 C23 C24 179.3(2) ....?

C17 N5 C23 Zn2 174.8(2) ... ?

N2 Zn2 C23 N6 -78.23(16) ... . ?

N4 Zn2 C23 N6 98.37(15) ....?

N5 Zn2 C23 N6 178.4(2) ... ?

Zn1 Zn2 C23 N6 33.43(19) ... ?

$\mathrm{N} 2 \mathrm{Zn} 2$ C23 N5 103.40(14) ... ? ?

N6 Zn2 C23 N5 -178.4(2) . . . ?

N4 Zn2 C23 N5 -79.99(16) ... . ?

$\mathrm{Zn} 1 \mathrm{Zn} 2 \mathrm{C} 23$ N5 -144.93(11) ... ?

N2 Zn2 C23 C24 -55(7) ... . ?

N6 Zn2 C23 C24 23(7) ... . ?

N4 Zn2 C23 C24 122(7) ... ?

N5 Zn2 C23 C24 -158(7) . . . ? ?

Zn1 Zn2 C23 C24 57(7) ....?

C31 N8 C25 C27 144.3(2) ... ?

Zn4 N8 C25 C27 -52.8(2) ... ?

C31 N8 C25 C26 -92.9(3) ... . ?

Zn4 N8 C25 C26 70.0(2) ....?

C31 N7 C28 C29 140.05(19) ....?

Zn3 N7 C28 C29-63.9(2) ... ?

C31 N7 C28 C30 -96.3(2) ... ?

Zn3 N7 C28 C30 59.8(2) ....?

C25 N8 C31 N7 -171.63(19)....?

Zn4 N8 C31 N7 26.1(2) ....?

C25 N8 C31 C32 9.5(3)...?

Zn4 N8 C31 C32 -152.70(17) ....?

C28 N7 C31 N8 -171.01(18)....?

Zn3 N7 C31 N8 33.3(2) ... ?

C28 N7 C31 C32 7.8(3) ...?

Zn3 N7 C31 C32 -147.88(17) ... . ?

C39 N9 C33 C35 -98.8(2) ... ? ?

Zn3 N9 C33 C35 80.8(2) ... . ?

C39 N9 C33 C34 139.9(2) ... ?

Zn3 N9 C33 C34 -40.5(3) ... ?

C39 N10 C36 C37 170.09(16) ... . ?

Zn4 N10 C36 C37 -56.23(18) ....?

Zn3 N10 C36 C37 60.2(2) ... . ?

C39 N10 C36 C38 49.1(2) ... . ?

Zn4 N10 C36 C38 -177.22(13) ... ? ?

Zn3 N10 C36 C38 -60.8(2) ... ?

C33 N9 C39 N10 -172.84(16) ... . ?

Zn3 N9 C39 N10 7.45(16) . . . ?

C33 N9 C39 C40 4.9(3) ...?

Zn3 N9 C39 C40 -174.78(17) ....?

C33 N9 C39 Zn3 179.7(2) ... . ?

C36 N10 C39 N9 -139.17(17) ... . ?

Zn4 N10 C39 N9 84.73(16) . . . ?

Zn3 N10 C39 N9 -7.15(15) . . . ?

C36 N10 C39 C40 43.0(2) ... ? 
Zn4 N10 C39 C40 -93.14(18) . . . ?

Zn3 N10 C39 C40 174.98(16) . . . ?

C36 N10 C39 Zn3 -132.02(16) . . . ?

Zn4 N10 C39 Zn3 91.89(9) ... . ?

N7 Zn3 C39 N9 79.28(13) ... ?

N10 Zn3 C39 N9 171.92(17) ... . ?

Cl2 Zn3 C39 N9 -95.44(11)... . ?

Zn4 Zn3 C39 N9 125.76(12) ... . ?

N7 Zn3 C39 N10 -92.64(11) ... ?

N9 Zn3 C39 N10 -171.92(17) ... ? ?

Cl2 Zn3 C39 N10 92.64(10) . . . ?

Zn4 Zn3 C39 N10 -46.16(9) . . . ?

N7 Zn3 C39 C40 177(100) . . . ? ?

N9 Zn3 C39 C40 98(2) ... . ?

N10 Zn3 C39 C40 -90(2) ... . ?

$\mathrm{Cl} 2 \mathrm{Zn} 3 \mathrm{C} 39 \mathrm{C} 403(2) \ldots$ ?

Zn4 Zn3 C39 C40 -136(2) ... . ?

C47 N11 C41 C42 -129.2(2) . . . ?

Zn4 N11 C41 C42 38.1(3) ... . ?

C47 N11 C41 C43 108.9(3) ....?

Zn4 N11 C41 C43 -83.8(3) ....?

C47 N12 C44 C45-149.9(2) ... ?

Zn4 N12 C44 C45 31.5(4) ....?

C47 N12 C44 C46 86.8(3) ... . ?

Zn4 N12 C44 C46 -91.8(3) ... . ?

C41 N11 C47 N12 175.7(2) ... . ?

Zn4 N11 C47 N12 3.46(19) ... . ?

C41 N11 C47 C48 -4.9(3) ... ?

Zn4 N11 C47 C48-177.2(2) . . . ?

C41 N11 C47 Zn4 172.3(2) ... ? ?

C44 N12 C47 N11 177.4(2) ....?

Zn4 N12 C47 N11 -3.38(19) . . . ?

C44 N12 C47 C48 -2.0(4) . . . ?

Zn4 N12 C47 C48 177.2(2) ... ?

C44 N12 C47 Zn4-179.3(2) ... ? ?

N8 Zn4 C47 N11 -78.26(15) ... ?

N10 Zn4 C47 N1 1 100.61(14) ... ?

N12 Zn4 C47 N11 176.2(2) ... ? ?

Zn3 Zn4 C47 N11 34.40(18) ... . ?

N8 Zn4 C47 N12 105.53(14) ... . ?

$\mathrm{N} 11 \mathrm{Zn} 4 \mathrm{C} 47 \mathrm{~N} 12-176.2(2) \ldots$ ?

N10 Zn4 C47 N12 -75.60(16) . . . ?

Zn3 Zn4 C47 N12 -141.81(12) ... . ?

N8 Zn4 C47 C48 -5(4)....?

N11 Zn4 C47 C48 74(4) ... . ?

N10 Zn4 C47 C48 174(4) ... . ?

N12 Zn4 C47 C48 -110(4) ....?

Zn3 Zn4 C47 C48 108(4) ... . ?

_diffrn_measured_fraction_theta_max 0.998

_diffrn_reflns_theta_full 25.00

_diffrn_measured_fraction_theta_full 0.999

_refine_diff_density_max 0.794

_refine_diff_density_min $\quad-0.264$

_refine_diff_density_rms 0.058 


\section{A.9 Compound 16}

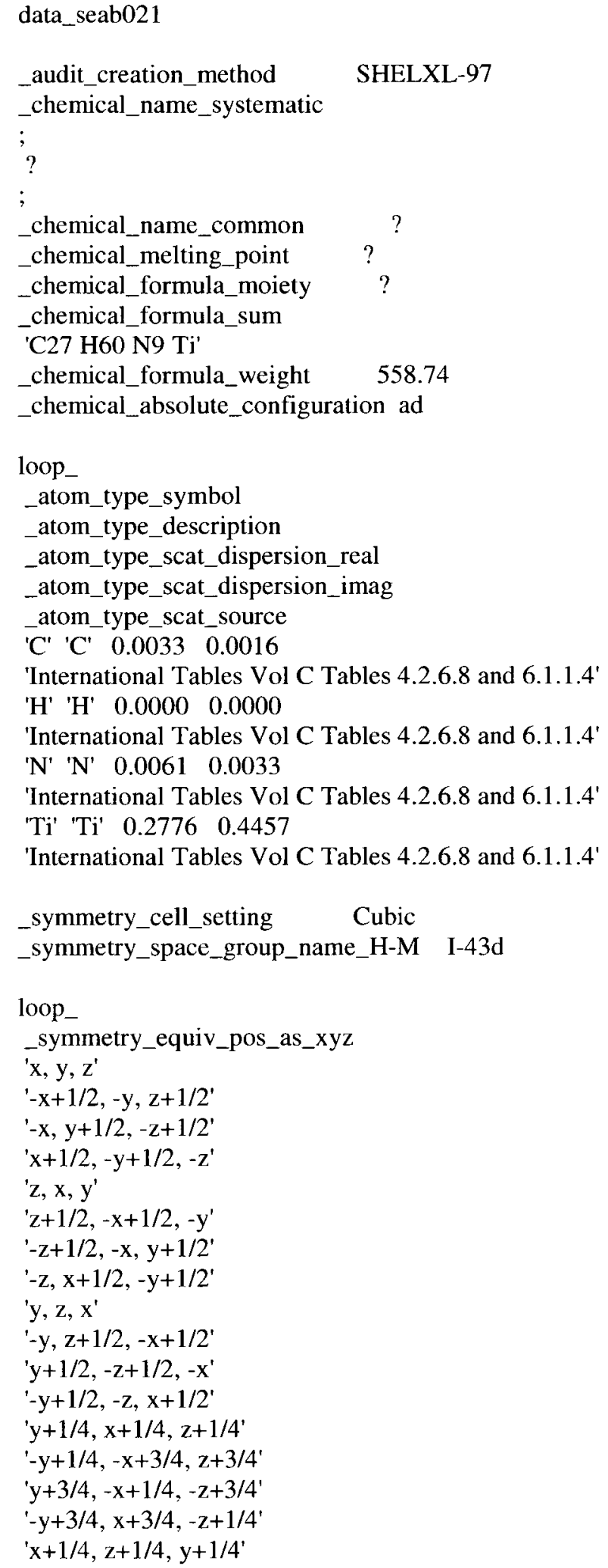


' $-\mathrm{x}+3 / 4, \mathrm{z}+3 / 4,-\mathrm{y}+1 / 4$ '

' $-x+1 / 4,-z+3 / 4, y+3 / 4$ '

' $x+3 / 4,-z+1 / 4,-y+3 / 4$ '

' $z+1 / 4, y+1 / 4, x+1 / 4$ '

' $z+3 / 4,-y+1 / 4,-x+3 / 4$ '

$'-z+3 / 4, y+3 / 4,-x+1 / 4$ '

' $-\mathrm{z}+1 / 4,-\mathrm{y}+3 / 4, \mathrm{x}+3 / 4$ '

$' x+1 / 2, y+1 / 2, z+1 / 2$ '

' $-\mathrm{x}+1,-\mathrm{y}+1 / 2, \mathrm{z}+1$ '

' $-\mathrm{x}+1 / 2, \mathrm{y}+1,-\mathrm{z}+1$ '

' $\mathrm{x}+1,-\mathrm{y}+1,-\mathrm{z}+1 / 2$ '

' $z+1 / 2, x+1 / 2, y+1 / 2$ '

' $\mathrm{z}+1,-\mathrm{x}+1,-\mathrm{y}+1 / 2$ '

$'-z+1,-x+1 / 2, y+1$ '

$'-z+1 / 2, x+1,-y+1$ '

' $y+1 / 2, z+1 / 2, x+1 / 2$ '

'-y+1/2, $z+1,-x+1$ '

' $\mathrm{y}+1,-\mathrm{z}+1,-\mathrm{x}+1 / 2$ '

' $-\mathrm{y}+1,-\mathrm{z}+1 / 2, \mathrm{x}+1$ '

'y+3/4, x+3/4, z+3/4'

$'-y+3 / 4,-x+5 / 4, z+5 / 4$ '

' $y+5 / 4,-x+3 / 4,-z+5 / 4$ '

$'-y+5 / 4, x+5 / 4,-z+3 / 4$ '

' $x+3 / 4, z+3 / 4, y+3 / 4 '$

$'-x+5 / 4, z+5 / 4,-y+3 / 4$ '

' $-\mathrm{x}+3 / 4,-\mathrm{z}+5 / 4, \mathrm{y}+5 / 4$ '

' $x+5 / 4,-z+3 / 4,-y+5 / 4$ '

' $z+3 / 4, y+3 / 4, x+3 / 4$ '

' $z+5 / 4,-y+3 / 4,-x+5 / 4$ '

$'-z+5 / 4, y+5 / 4,-x+3 / 4$ '

$'-z+3 / 4,-y+5 / 4, x+5 / 4$ '

_cell_length_a

_cell_length_b

_cell_length_c

_cell_angle_alpha

_cell_angle_beta

_cell_angle_gamma

_cell_volume

_cell_formula_units_Z

cell_measurement temperature

_cell_measurement_reflns_used

_cell_measurement_theta_min

_cell_measurement_theta_max

2.71

27.73

$\begin{array}{lc}\text { _exptl_crystal_description } & \text { block } \\ \text { _exptl_crystal_colour } & \text { green } \\ \text { _exptl_crystal_size_max } & 0.33 \\ \text { _exptl_crystal_size_mid } & 0.31 \\ \text { _exptl_crystal_size_min } & 0.16 \\ \text { _exptl_crystal_density_meas } & ? \\ \text { _exptl_crystal_density_diffrn } & 1.110 \\ \text { _exptl_crystal_density_method } & \text { 'not measured' } \\ \text { _exptl_crystal_F_000 } & 4912 \\ \text { _exptl_absorpt_coefficient_mu } & 0.285 \\ \text { _exptl_absorpt_correction_type } & \text { multi-scan }\end{array}$ 
_exptl_absorpt_correction_T_min 0.9128

_exptl_absorpt_correction_T_max 0.9550

_exptl_absorpt_process_details 'SADABS (Sheldrick, 2003)'

_exptl_special_details

Data collection is performed with four batch runs at

If $=0.00 \backslash \%$ (600 frames), at $\backslash \mathrm{f}=90.00 \backslash \%$

(600 frames), at If $=180 \backslash \%$ (600 frames) and

at $\backslash \mathrm{f}=270 \backslash \%$ (600 frames).

Frame width $=0.30 \backslash \&$ in Iw. Data is

merged, corrected for decay, and treated with

multi-scan absorption corrections.

;

_diffrn_ambient_temperature $120(2)$

_diffrn_radiation_wavelength $\quad 0.71073$

_diffrn_radiation_type MoKla

_diffrn_radiation_source 'fine-focus sealed tube'

_diffrn_radiation_monochromator graphite

_diffrn_measurement_device_type 'Bruker AXS APEX diffractometer'

_diffrn_measurement_method Iw

_diffrn_detector_area_resol_mean 836.6

_diffrn_standards_number 0

_diffrn_standards_interval_count 0

_diffrn_standards_interval_time 0

_diffrn_standards_decay_\% 1

_diffrn_reflns_number 56449

_diffrn_reflns_av_R_equivalents 0.0432

_diffrn_reflns_av_sigmaI/netI 0.0161

_diffrn_reflns_limit_h_min -31

_diffrn_reflns_limit_h_max 31

_diffrn_reflns_limit_k_min -31

_diffrn_reflns_limit_k_max 28

_diffrn_reflns_limit_l_min $\quad-30$

_diffrn_reflns_limit_l_max 31

_diffrn_reflns_theta_min $\quad 2.10$

_diffrn_reflns_theta_max 28.25

_reflns_number_total 2715

_reflns_number_gt 2598

_reflns_threshold_expression >2sigma(I)

_computing_data_collection 'SMART (Bruker, 2002)'

_computing_cell_refinement 'SAINT (Bruker, 2002)'

_computing_data_reduction SAINT

_computing_structure_solution 'SHELXS-97 (Sheldrick, 1990)'

_computing_structure_refinement 'SHELXL-97 (Sheldrick, 1997)'

_computing_molecular_graphics 'SHELXTL (Sheldrick, 2001)'

_computing_publication_material 'SHELXTL (Sheldrick, 2001)'

_refine_special_details

;

Refinement of $F^{\wedge} 2^{\wedge}$ against ALL reflections. The weighted $R$-factor $w R$ and goodness of fit $\mathrm{S}$ are based on $\mathrm{F}^{\wedge} 2^{\wedge}$, conventional $\mathrm{R}$-factors $\mathrm{R}$ are based on $F$, with $F$ set to zero for negative $\mathrm{F}^{\wedge} 2^{\wedge}$. The threshold expression of $\mathrm{F}^{\wedge} 2^{\wedge}>2 \operatorname{sigma}\left(\mathrm{F}^{\wedge} 2^{\wedge}\right)$ is used only for calculating R-factors(gt) etc. and is 
not relevant to the choice of reflections for refinement. R-factors based on $\mathrm{F}^{\wedge} 2^{\wedge}$ are statistically about twice as large as those based on $\mathrm{F}$, and Rfactors based on ALL data will be even larger.

;

_refine_ls_structure_factor_coef Fsqd

_refine_ls_matrix_type full

_refine_ls_weighting_scheme calc

_refine_ls_weighting_details

'calc $\mathrm{w}=1 /\left[\backslash \mathrm{s}^{\wedge} 2^{\wedge}\left(\mathrm{Fo}^{\wedge} 2^{\wedge}\right)+(0.0468 \mathrm{P})^{\wedge} 2^{\wedge}+8.2576 \mathrm{P}\right]$ where $\mathrm{P}=\left(\mathrm{Fo} \mathrm{o}^{\wedge} 2^{\wedge}+2 \mathrm{Fc}^{\wedge} 2^{\wedge}\right) / 3^{\prime}$

_atom_sites_solution_primary direct

_atom_sites_solution_secondary difmap

_atom_sites_solution_hydrogens geom

_refine_ls_hydrogen_treatment constr

_refine_ls_extinction_method none

_refine_ls_extinction_coef?

_refine_ls_abs_structure_details

'Flack H D (1983), Acta Cryst. A39, 876-881; 1250 Friedel pairs'

_refine_ls_abs_structure_Flack -0.03(2)

_refine_ls_number_reflns 2715

_refine_ls_number_parameters 118

_refine_ls_number_restraints 0

_refine_ls_R_factor_all $\quad 0.0327$

_refine_ls_R_factor_gt $\quad 0.0291$

_refine_ls_wR_factor_ref $\quad 0.0810$

_refine_ls_wR_factor_gt $\quad 0.0758$

_refine_ls_goodness_of_fit_ref 1.013

_refine_ls_restrained_S_all 1.013

_refine_ls_shift/su_max $\quad 0.000$

_refine_ls_shift/su_mean 0.000

loop_

_atom_site_label

_atom_site_type_symbol

_atom_site_fract_x

_atom_site_fract_y

atom_site_fract_z

_atom_site_U_iso_or_equiv

_atom_site_adp_type

_atom_site_occupancy

_atom_site_symmetry_multiplicity

_atom_site_calc_flag

_atom_site_refinement_flags

_atom_site_disorder_assembly

_atom_site_disorder_group

Ti Ti -0.009939(11) 0.490061(11) 0.009939(11) 0.01731(10) Uani $13 \mathrm{~d} \mathrm{~S}$. .

$\mathrm{N} 1 \mathrm{~N}-0.03900(5) 0.52530(5) 0.08778(5) 0.0196(2)$ Uani $11 \mathrm{~d} \ldots$

$\mathrm{N} 2 \mathrm{~N} 0.04305(5) 0.55062(5) 0.05088(5) 0.0199(2)$ Uani $11 \mathrm{~d} \ldots$

$\mathrm{N} 3 \mathrm{~N} 0.01421(6) 0.59443(5) 0.13873(5) 0.0255$ (3) Uani $11 \mathrm{~d} \ldots$

C1 C -0.09049(6) $0.53530(6) 0.12039$ (6) 0.0225 (3) Uani $11 \mathrm{~d} \ldots$

H1A H -0.08470 .56910 .14480 .027 Uiso 11 calc R .

C2 C -0.13992(6) 0.54651(7) 0.08069 (7) 0.0269 (3) Uani 11 d . .

H2A H -0.13280 .58110 .05930 .040 Uiso 11 calc R . .

H2B H -0.17460 .55080 .10270 .040 Uiso 11 calc R .

H2C H -0.14410 .51480 .05460 .040 Uiso 11 calc R .

C3 C -0.10473 (7) $0.48494(7) 0.15780(7) 0.0320(3)$ Uani $11 \mathrm{~d} \ldots$ 
H3A H - 0.07350 .47790 .18380 .048 Uiso 11 calc R . H3B H -0.1108 0.45160.13420.048 Uiso 11 calc R . $\mathrm{H} 3 \mathrm{C}$ H -0.13900 .49300 .17930 .048 Uiso 11 calc R . . C4 C 0.10190(6) 0.56924(6) 0.05395(6) 0.0217(3) Uani 11 d . . . H4A H 0.10860 .58650 .09180 .026 Uiso 11 calc R . . C5 C 0.11464(7) 0.61318(7) 0.00863(7) 0.0294(3) Uani 11 d . . . H5A H 0.08990 .64580 .01380 .044 Uiso 11 calc R . . H5B H $0.10820 .5967-0.02870 .044$ Uiso 11 calc R . H5C H 0.15400 .62510 .01170 .044 Uiso 11 calc R . . C6 C 0.14182(6) 0.51925(7) 0.04669(7) 0.0277(3) Uani $11 \mathrm{~d}$. . . H6A H 0.13580 .49220 .07730 .042 Uiso 11 calc R . H6B H 0.18090 .53260 .04760 .042 Uiso 11 calc R . H6C H 0.13440 .50090 .01050 .042 Uiso 11 calc R . C7 C 0.00692(6) 0.55729(6) 0.09320(6) 0.0193(3) Uani $11 \mathrm{~d}$. . C8 C 0.03591(7) 0.65086(7) 0.13072(7) 0.0280(3) Uani $11 \mathrm{~d}$. . H8A H 0.03180 .66170 .09110 .042 Uiso 11 calc $R$. . H8B H 0.07580 .65190 .14120 .042 Uiso 11 calc R . . H8C H 0.01480 .67720 .15440 .042 Uiso 11 calc R . . C9 C 0.01576(8) 0.57334(8) 0.19567(7) 0.0328(4) Uani 11 d . . H9A H -0.00610 .59830 .22020 .049 Uiso 11 calc R . . H9B H 0.05490 .57200 .20880 .049 Uiso 11 calc $R$. . H9C H -0.0004 0.5354 0.19670.049 Uiso 11 calc R . .

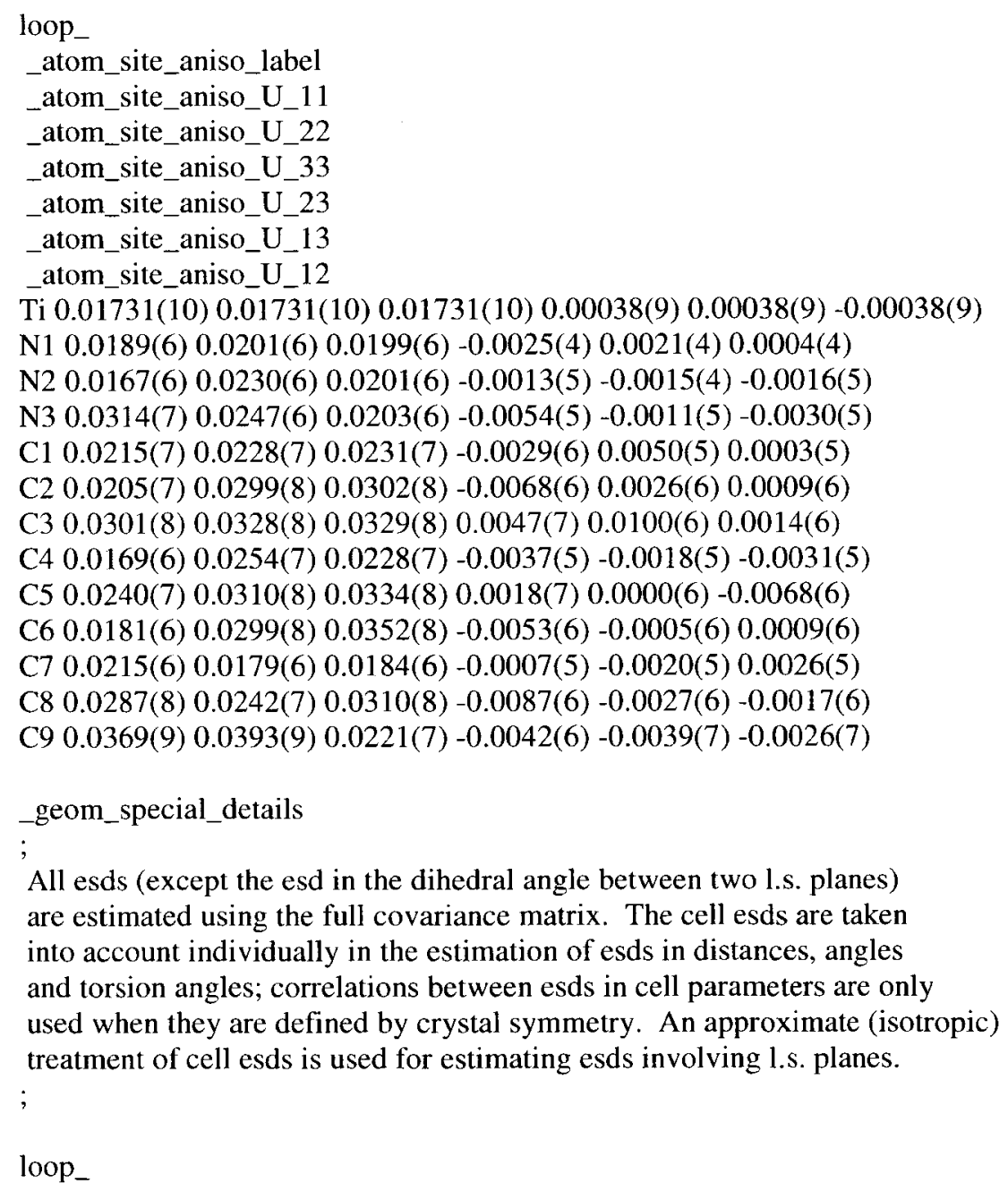

All esds (except the esd in the dihedral angle between two l.s. planes) are estimated using the full covariance matrix. The cell esds are taken into account individually in the estimation of esds in distances, angles and torsion angles; correlations between esds in cell parameters are only used when they are defined by crystal symmetry. An approximate (isotropic) treatment of cell esds is used for estimating esds involving 1.s. planes. ;

loop 
_geom_bond_atom_site_label_1 _geom_bond_atom_site_label_2 _geom_bond_distance _geom_bond_site_symmetry_2 _geom_bond_publ_flag

Ti N1 2.1424(12) . ?

Ti N1 2.1425(12) 8 ?

Ti N1 2.1425(12) 11_455 ?

Ti N2 2.1431(13) 8 ?

Ti N2 2.1432(13) 11_455?

Ti N2 2.1432(13) . ?

Ti C7 2.5717(14) 8 ?

Ti C7 2.5717(14) . ?

Ti C7 2.5717(14) 11_455 ?

N1 C7 1.335(2).?

N1 C1 1.4661(18). ?

N2 C7 1.3303(19) . ?

N2 C4 1.4672(18) , ?

N3 C7 1.4055(18) . ?

N3 C9 1.442(2) .?

$\mathrm{N} 3 \mathrm{C} 81.448(2)$.?

C1 C3 1.527(2).?

C1 C2 1.528(2). ?

C4 C6 1.528(2). ?

C4 C5 1.529(2).?

loop_

_geom_angle_atom_site_label_1 _geom_angle_atom_site_label_2 _geom_angle_atom_site_label_3 _geom_angle

_geom_angle_site_symmetry_1

_geom_angle_site_symmetry_3

_geom_angle_publ_flag

N1 Ti N1 100.64(4) . 8 ?

N1 Ti N1 100.65(4) . 11_455?

N1 Ti N1 100.65(4) 8 11_455?

N1 Ti N2 101.73(5) . 8 ?

N1 Ti N2 62.35(5) 88 ?

N1 Ti N2 154.06(5) 11_4558?

N1 Ti N2 154.06(5) . 11_455?

N1 Ti N2 101.73(5) 8 11_455?

N1 Ti N2 62.35(5) 11_455 11_455 ?

N2 Ti N2 100.18(4) 811_455?

N1 Ti N2 62.36(5) ..?

N1 Ti N2 154.06(5) 8 .?

N1 Ti N2 101.73(5) 11_455.?

N2 Ti N2 $100.18(4) 8 . ?$

N2 Ti N2 100.18(4) 11_455.?

N1 Ti C7 103.12(5) . 8 ?

N1 Ti C7 31.24(5) 88 ?

N1 Ti C7 129.35(5) 11_455 8 ?

N2 Ti C7 31.12(5) 88 ?

N2 Ti C7 102.81(4) 11_4558?

N2 Ti C7 128.92(5) . 8 ?

N1 Ti C7 31.24(5) . . ? 
N1 Ti C7 129.35(5) 8 .?

N1 Ti C7 103.12(5) 11_455.?

N2 Ti C7 102.81(4) 8 . ?

N2 Ti C7 128.91(5) 11_455.?

N2 Ti C7 31.12(5) . . ?

C7 Ti C7 119.999(1) 8 . ?

N1 Ti C7 129.35(5).11_455?

N1 Ti C7 103.12(5) 8 11_455 ?

N1 Ti C7 31.23(5) 11_455 11_455 ?

N2 Ti C7 128.92(5) 8 11_455?

N2 Ti C7 31.12(5) 11_455 11_455 ?

N2 Ti C7 102.81(4) . 11_455?

C7 Ti C7 120.0 8 11_455?

C7 Ti C7 120.0.11_455 ?

C7 N1 C1 122.53(12) .. ?

C7 N1 Ti 92.42(8)..?

C1 N1 Ti 141.92(10) . . ?

C7 N2 C4 122.72(12) . . ?

C7 N2 Ti 92.52(9) .. ?

C4 N2 Ti 141.58(10) . . ?

C7 N3 C9 120.41(13) .. ?

C7 N3 C8 121.55(13) . . ?

C9 N3 C8 115.81(13) .. ?

N1 C1 C3 111.40(12) . . ?

N1 C1 C2 110.04(12) . .?

C3 C1 C2 108.95(13) . . ?

$\mathrm{N} 2$ C4 C6 110.53(12) ..?

N2 C4 C5 111.05(12) . .?

C6 C4 C5 109.13(13) . . ?

N2 C7 N1 112.70(12). .?

N2 C7 N3 125.17(13) . . ?

N1 C7 N3 122.12(13) . . ?

N2 C7 Ti 56.36(7) . .?

N1 C7 Ti 56.34(7) . . ?

N3 C7 Ti 178.10(11) ..?

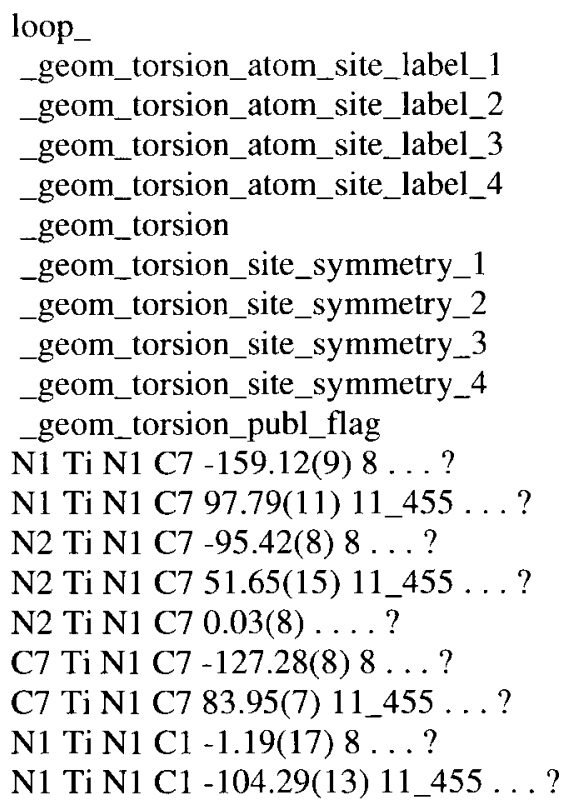


$\mathrm{N} 2$ Ti N1 C1 62.50(17) $8 \ldots$ ?

N2 Ti N1 C1 -150.43(15) 11_455 ...?

N2 Ti N1 C1 157.95(18) ....?

C7 Ti N1 C1 30.65(17) $8 \ldots$ ?

C7 Ti N1 C1 157.9(2) ...?

C7 Ti N1 C1 -118.12(16) 11_455 ...?

N1 Ti N2 C7 $-0.03(8) \ldots$ ?

N1 Ti N2 C7 53.10(15) $8 \ldots$ ?

N1 Ti N2 C7 -96.01(9) 11_455 ...?

N2 Ti N2 C7 97.97(11) $8 \ldots$ ?

N2 Ti N2 C7 -159.64(9) 11_455 . . ?

C7 Ti N2 C7 84.61(7) $8 \ldots$ ?

C7 Ti N2 C7 -127.98(8) 11_455 ...?

N1 Ti N2 C4 157.83(18) ... . ?

N1 Ti N2 C4 -149.05(15) $8 \ldots$ ?

N1 Ti N2 C4 61.84(16) 11_455 . . ?

N2 Ti N2 C4 -104.18(13) $8 \ldots$ ?

N2 Ti N2 C4 -1.78(17) 11_455 ...?

C7 Ti N2 C4 -117.54(15) $8 \ldots$ ?

C7 Ti N2 C4 157.9(2) ....?

C7 Ti N2 C4 29.88(17) 11_455 ...?

C7 N1 C1 C3 -118.45(16) ....?

Ti N1 C1 C3 88.00(19) ....?

C7 N1 C1 C2 120.60(14) ....?

Ti N1 C1 C2 -33.0(2) ...?

C7 N2 C4 C6 119.49(15) ....?

Ti N2 C4 C6 -33.9(2) ....?

C7 N2 C4 C5 -119.24(15) ....?

Ti N2 C4 C5 87.35(18) ....?

C4 N2 C7 N1 -163.79(13) ... ?

Ti N2 C7 N1 0.04(12) ....?

C4 N2 C7 N3 17.5(2) ...?

Ti N2 C7 N3 -178.64(12) ... . ?

C4 N2 C7 Ti $-163.83(15) \ldots$. . ?

C1 N1 C7 N2 -164.08(13)....?

Ti N1 C7 N2 -0.04(12) ....?

C1 N1 C7 N3 14.6(2) ....?

Ti N1 C7 N3 178.69(11) ....?

C1 N1 C7 Ti-164.04(16) .... ?

C9 N3 C7 N2 -120.55(16) ... ? ?

C8 N3 C7 N2 41.8(2) . . . ?

C9 N3 C7 N1 60.9(2) ... ?

C8 N3 C7 N1 -136.81(15) ....?

C9 N3 C7 Ti 96(3)....?

C8 N3 C7 Ti -102(3) ....?

N1 Ti C7 N2 179.96(13) ....?

$\mathrm{N} 1 \mathrm{Ti}$ C7 N2 $-153.10(8) 8 \ldots$ ?

N1 Ti C7 N2 91.01(9) 11_455 . . ?

$\mathrm{N} 2 \mathrm{Ti} \mathrm{C} 7 \mathrm{~N} 2-88.50(10) 8 \ldots$ ?

N2 Ti C7 N2 26.11(10) 11_455 ...?

C7 Ti C7 N2 -116.56(9) 8 ...?

C7 Ti C7 N2 62.56(11) 11_455 ...?

N1 Ti C7 N1 26.94(10) $8 \ldots$ ?

N1 Ti C7 N1 -88.94(10) 11_455 . . ?

$\mathrm{N} 2$ Ti C7 N1 91.54(9) $8 \ldots$ ?

N2 Ti C7 N1 -153.84(9) 11_455 . . ? 
N2 Ti C7 N1 -179.96(13) ... ?

C7 Ti C7 N1 63.48(11) $8 \ldots$ ?

C7 Ti C7 N1 -117.39(9) 11_455 . . ?

N1 TiC7 N3 -36(3) ...?

N1 Ti C7 N3 -9(3) $8 \ldots$ ?

N1 Ti C7 N3 -125(3) 11_455 ...?

N2 Ti C7 N3 56(3) $8 \ldots$ ?

N2 Ti C7 N3 170(3) 11_455 ...?

N2 Ti C7 N3 144(3) ....?

C7 Ti C7 N3 28(3) $8 \ldots$ ?

C7 Ti C7 N3 -153(3) 11_455 ...?

_diffrn_measured_fraction_theta_max 0.985

_diffrn_reflns_theta_full 25.00

_diffrn_measured_fraction_theta_full 1.000

_refine_diff_density_max 0.217

_refine_diff_density_min $\quad-0.133$

_refine_diff_density_rms 0.036 


\section{A.10 Compound 18}

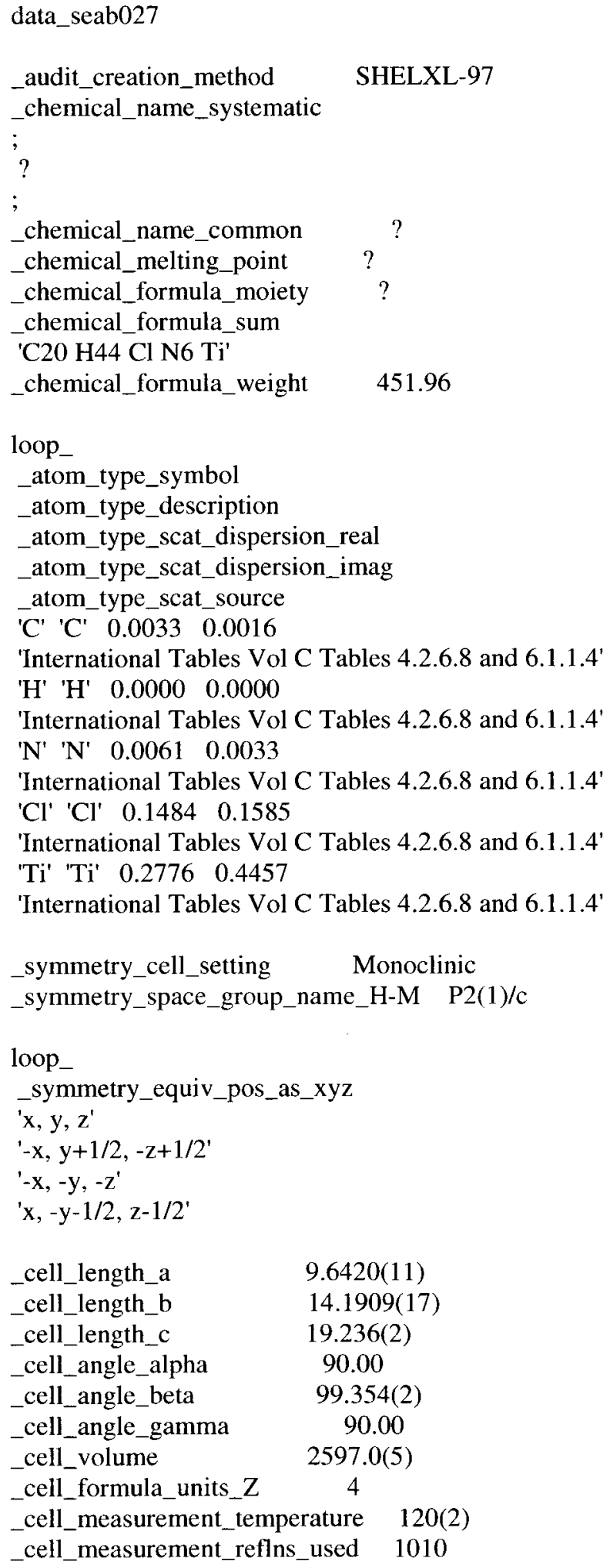




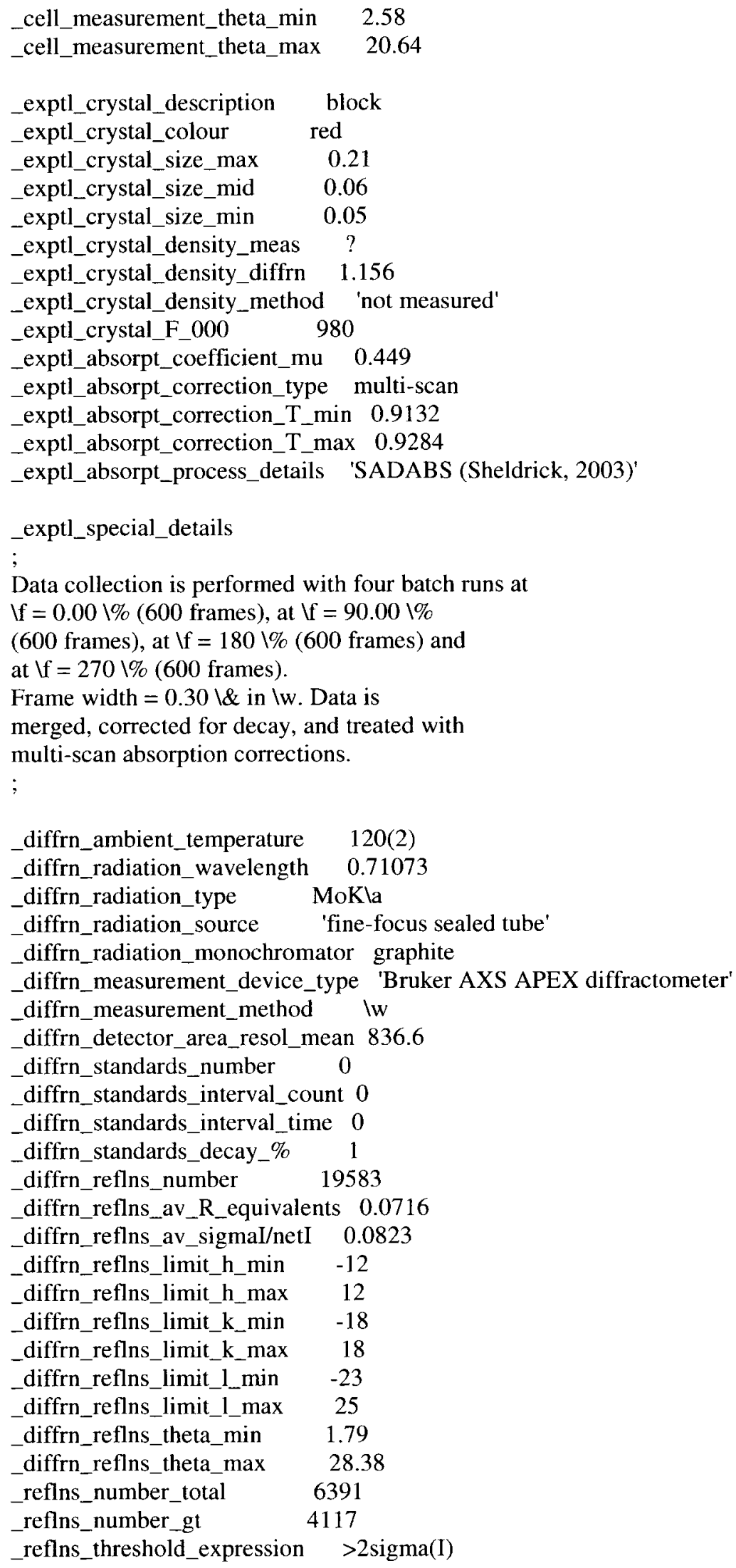


_computing_data_collection _computing_cell_refinement _computing_data_reduction _computing_structure_solution

_computing_structure_refinement 'SHELXL-97 (Sheldrick, 1997)'

_computing_molecular_graphics 'SHELXTL (Sheldrick, 2001)'

_computing_publication_material 'SHELXTL (Sheldrick, 2001)'

_refine_special_details

Refinement of $\mathrm{F}^{\wedge} 2^{\wedge}$ against $\mathrm{ALL}$ reflections. The weighted $\mathrm{R}$-factor $\mathrm{w} R$ and goodness of fit $S$ are based on $F^{\wedge} 2^{\wedge}$, conventional $R$-factors $R$ are based on $F$, with $F$ set to zero for negative $F^{\wedge} 2^{\wedge}$. The threshold expression of $\mathrm{F}^{\wedge} 2^{\wedge}>2 \operatorname{sigma}\left(\mathrm{F}^{\wedge} 2^{\wedge}\right)$ is used only for calculating $\mathrm{R}$-factors $(\mathrm{gt})$ etc. and is not relevant to the choice of reflections for refinement. $\mathrm{R}$-factors based on $\mathrm{F}^{\wedge} 2^{\wedge}$ are statistically about twice as large as those based on $F$, and $\mathrm{R}$ factors based on ALL data will be even larger.

$$
\text { ; }
$$

_refine_ls_structure_factor_coef Fsqd

_refine_ls_matrix_type full

_refine_ls_weighting_scheme calc

_refine_ls_weighting_details

'calc $\mathrm{w}=1 /\left[\backslash \mathrm{s}^{\wedge} 2^{\wedge}\left(\mathrm{Fo}^{\wedge} 2^{\wedge}\right)+(0.0500 \mathrm{P})^{\wedge} 2^{\wedge}\right]$ where $\mathrm{P}=\left(\mathrm{Fo}^{\wedge} 2^{\wedge}+2 \mathrm{Fc}^{\wedge} 2^{\wedge}\right) / 3^{\prime}$

_atom_sites_solution_primary direct

_atom_sites_solution_secondary difmap

_atom_sites_solution_hydrogens geom

_refine_ls_hydrogen_treatment constr

_refine_ls_extinction_method none

_refine_ls_extinction_coef ?

_refine_ls_number_reflns 6391

refine_ls_number_parameters 253

_refine_ls_number_restraints 0

_refine_ls_R_factor_all 0.1011

_refine_ls_R_factor_gt $\quad 0.0572$

_refine_ls_wR_factor_ref $\quad 0.1338$

_refine_ls_wR_factor_gt 0.1145

_refine_ls_goodness_of_fit_ref 1.050

_refine_ls_restrained_S_all 1.050

_refine_ls_shift/su_max 0.000

_refine_ls_shift/su_mean 0.000

loop_

_atom_site_label

_atom_site_type_symbol

_atom_site_fract_x

_atom_site_fract_y

_atom_site_fract_z

_atom_site_U_iso_or_equiv

_atom_site_adp_type

_atom_site_occupancy

_atom_site_symmetry_multiplicity

_atom_site_calc_flag

_atom_site_refinement_flags

_atom_site_disorder_assembly

_atom_site_disorder_group 
Ti Ti 0.23170(4) 0.49005(3) 0.24483(2) 0.01963 (13) Uani $11 \mathrm{~d} \ldots$ $\mathrm{Cl} \mathrm{Cl} 0.34960(8) 0.63119(5) 0.27596(4) 0.0399(2)$ Uani $11 \mathrm{~d}$. . .

N1 N 0.3139(2) 0.46085(14) 0.14986(11) 0.0220(5) Uani $11 \mathrm{~d} \ldots$ $\mathrm{N} 2 \mathrm{~N} 0.3229(2) 0.36131(14) 0.23960(11) 0.0213(5)$ Uani $11 \mathrm{~d} \ldots$ N3 N 0.4157(2) 0.30747(15) 0.13909(11) 0.0256(5) Uani $11 \mathrm{~d} \ldots$ H3A H 0.47310 .26880 .16550 .031 Uiso 11 calc R . .

$\mathrm{N} 4 \mathrm{~N} 0.0200(2) 0.48243(15) 0.21673(11) 0.0222(5)$ Uani $11 \mathrm{~d} \ldots$ N5 N 0.1169(2) 0.47661(14) 0.32927(11) 0.0209(5) Uani $11 \mathrm{~d} \ldots$ N6 N -0.1347(2) 0.45513(17) 0.29873(12) 0.0307(6) Uani $11 \mathrm{~d} \ldots$ H6A H -0.20480 .47550 .26730 .037 Uiso 11 calc R . .

C1 C 0.3527(2) 0.37558(18) 0.17325(13) 0.0212(5) Uani $11 \mathrm{~d} \ldots$ C2 C 0.3731(3) 0.50874(18) 0.09340(13) 0.0225(6) Uani $11 \mathrm{~d} \ldots$ H2A H 0.34590 .47270 .04860 .027 Uiso 11 calc R . . C3 C 0.5328(3) 0.51276(19) 0.11068(15) 0.0305(6) Uani $11 \mathrm{~d} \ldots$ H3B H 0.57050 .44860 .11690 .046 Uiso 11 calc $R$. . H3C H 0.56070 .54860 .15420 .046 Uiso 11 calc R . . H3D H 0.57010 .54360 .07200 .046 Uiso 11 calc R . . C4 C 0.3129(3) 0.60821(18) 0.08330(14) 0.0291(6) Uani $11 \mathrm{~d} \ldots$ H4A H 0.21030 .60490 .07160 .044 Uiso 11 calc R . . H4B H 0.35060 .63940 .04490 .044 Uiso 11 calc $R$. . H4C H 0.33930 .64430 .12690 .044 Uiso 11 calc R . . C5 C 0.3187 (3) 0.26566(18) 0.26840(14) 0.0284(6) Uani $11 \mathrm{~d} \ldots$ H5A H 0.40280 .23020 .25830 .034 Uiso 11 calc R . . C6 C 0.1873(4) 0.2134(2) 0.23485(16) 0.0488(9) Uani $11 \mathrm{~d}$. . . H6B H 0.18460 .21010 .18380 .073 Uiso 11 calc R . . H6C H 0.10390 .24700 .24490 .073 Uiso 11 calc R . H6D H 0.18840 .14950 .25420 .073 Uiso 11 calc $R$. . C7 C 0.3250(3) 0.2710(2) 0.34735(13) 0.0316(7) Uani $11 \mathrm{~d} \ldots$ H7A H 0.41070 .30420 .36840 .047 Uiso 11 calc $R$. . H7B H 0.32590 .20710 .36680 .047 Uiso 11 calc $R$. . H7C H 0.24260 .30500 .35800 .047 Uiso 11 calc R . . C8 C 0.3972(3) 0.29232(19) 0.06273(13) 0.0257(6) Uani $11 \mathrm{~d}$. . . H8A H 0.43300 .34900 .04030 .031 Uiso 11 calc $R$. . C9 C 0.2429(3) 0.2787(2) 0.03199(15) 0.0370(7) Uani $11 \mathrm{~d} \ldots$ H9A H 0.18950 .33460 .04180 .055 Uiso 11 calc $R$. . H9B H 0.20640 .22330 .05340 .055 Uiso 11 calc R . . H9C H $0.23330 .2695-0.01910 .055$ Uiso 11 calc $R$. . C10 C 0.4853(3) 0.2079(2) 0.04924(14) 0.0339(7) Uani $11 \mathrm{~d}$. . H10A H 0.58390 .21970 .06920 .051 Uiso 11 calc R. . H10B H $0.47700 .1975-0.00160 .051$ Uiso 11 calc R. . H10C H 0.45200 .15190 .07140 .051 Uiso 11 calc R . . C11 C - $0.0032(3) 0.47050(17) 0.28378(14) 0.0224(6)$ Uani $11 \mathrm{~d} \ldots$ C12 C -0.0911(3) 0.46757(19) 0.15627(13) 0.0260(6) Uani $11 \mathrm{~d} \ldots$ H12A H - 0.18010 .49520 .16760 .031 Uiso 11 calc R . .

C13 C -0.1162(3) 0.3635(2) 0.13934(15) 0.0384(7) Uani $11 \mathrm{~d} \ldots$ H13A H - 0.14140 .33110 .18060 .058 Uiso 11 calc R . . H13B H -0.0305 0.3355 0.12710 .058 Uiso 11 calc R . . H13C H -0.19310 .35690 .09950 .058 Uiso 11 calc R . . C14 C -0.0528(3) 0.5192(2) 0.09280(14) 0.0361(7) Uani $11 \mathrm{~d} \ldots$ H14A H -0.03690 .58600 .10440 .054 Uiso 11 calc R . H14B H -0.1298 0.51320.0530 0.054 Uiso 11 calc R. . H14C H 0.03290 .49180 .08010 .054 Uiso 11 calc R . . C15 C $0.1278(3) 0.49762(18) 0.40469(13) 0.0233(6)$ Uani $11 \mathrm{~d} \ldots$ H15A H 0.07740 .44760 .42740 .028 Uiso 11 calc R . .

C16 C 0.2820(3) 0.4973(2) 0.43780(14) 0.0297(6) Uani $11 \mathrm{~d} \ldots$ H16A H 0.32310 .43560 .43050 .045 Uiso 11 calc R . . 
H16B H 0.29040 .50970 .48840 .045 Uiso 11 calc $R$. . $\mathrm{H} 16 \mathrm{C}$ H 0.33200 .54630 .41590 .045 Uiso 11 calc R . . C17 C 0.0620(3) 0.5934(2) 0.41605(15) 0.0402(8) Uani $11 \mathrm{~d} \ldots$ H17A H -0.03740 .59290 .39470 .060 Uiso 11 calc R . . H17B H 0.11120 .64290 .39410 .060 Uiso 11 calc R . . H17C H 0.07020 .60590 .46670 .060 Uiso 11 calc $\mathrm{R}$. .

C18 C -0.1734(3) 0.4085(2) 0.36116(16) 0.0415(8) Uani $11 \mathrm{~d} \ldots$ H18A H -0.13590 .44680 .40370 .050 Uiso 11 calc R .

C19 C -0.1121(4) 0.3102(2) 0.37096(18) 0.0587(10) Uani $11 \mathrm{~d} \ldots$ H19A H - 0.00940 .31370 .37680 .088 Uiso 11 calc R . . H19B H - 0.14750 .27180 .32950 .088 Uiso 11 calc R . . H19C H -0.13980 .28140 .41290 .088 Uiso 11 calc R . . C20 C -0.3333(3) 0.4082(3) 0.35238(19) 0.0744(14) Uani $11 \mathrm{~d} \ldots$ H20A H -0.36830 .47290 .34600 .112 Uiso 11 calc R . . H20B H -0.36270 .38100 .39450 .112 Uiso 11 calc R . . $\mathrm{H} 20 \mathrm{C} \mathrm{H}-0.37160 .37050 .31100 .112$ Uiso 11 calc $\mathrm{R}$.

loop _atom_site_aniso_label
_atom_site_aniso_U_11
_atom_site_aniso_U_22
_atom_site_aniso_U_33
_atom_site_aniso_U_23
_atom_site_aniso_U_13
_atom_site_aniso_U_12 Ti 0.0182(2) $0.0203(2) 0.0203(2)-0.0009(2) 0.00273(18)-0.00082(18)$ $\mathrm{Cl} 0.0525(5) 0.0370(4) 0.0313(4)-0.0079(3) 0.0102(3)-0.0230(4)$ N1 $0.0210(11) 0.0229(11) 0.0222(12) 0.0035(9) 0.0038(9) 0.0035(9)$ $\mathrm{N} 20.0211(11) 0.0219(11) 0.0212(11) 0.0014(9) 0.0042(9) 0.0026(9)$ N3 0.0281(12) $0.0275(12) 0.0207(12) 0.0022(10) 0.0023(10) 0.0099(10)$ N4 0.0192(11) 0.0276(12) $0.0193(11)-0.0003(9) 0.0016(9)-0.0010(9)$ N5 0.0212(11) 0.0235(11) $0.0179(11)-0.0012(9) 0.0032(9)-0.0024(9)$ N6 0.0197(12) 0.0432(15) $0.0297(13) 0.0010(11) 0.0052(10)-0.0036(10)$ C1 0.0175(13) 0.0260(14) 0.0196(13) -0.0032(11) 0.0008(10) $-0.0006(10)$ C2 0.0245(13) $0.0261(14) 0.0175(13) 0.0016(11) 0.0048(10) 0.0011(11)$ C3 0.0282(15) 0.0308(16) 0.0340(16) 0.0031(13) 0.0091(12) -0.0005(12) C4 0.0322(15) $0.0262(15) 0.0301(16) 0.0058(12) 0.0086(12) 0.0032(12)$ C5 $0.0362(16) 0.0235(14) 0.0270(15) 0.0029(12) 0.0100(12) 0.0063(12)$ C6 0.070(2) 0.0377(19) 0.0368(19) 0.0063(15) 0.0020(16) -0.0217(17) C7 0.0390(17) 0.0314(16) 0.0253(16) 0.0046(12) 0.0078(13) 0.0047(13) C8 0.0329(15) 0.0254(14) 0.0184(14) 0.0005(11) 0.0025(11) 0.0053(11) C9 $0.0392(18) 0.0438(19) 0.0264(16)-0.0017(14) 0.0008(13) 0.0044(14)$ C10 0.0439(18) 0.0340(16) 0.0238(15) -0.0050(13) 0.0051(13) 0.0100(14) C11 0.0207(13) 0.0191(13) 0.0280(15) -0.0016(11) 0.0061(11) 0.0015(10) C12 0.0171(13) 0.0346(16) 0.0244(15) -0.0026(12) -0.0019(11) 0.0012(11) C13 0.0345(17) 0.0440(19) 0.0333(17) $-0.0086(15)-0.0045(13)-0.0050(14)$ C14 0.0288(16) 0.051(2) 0.0255(16) 0.0057(14) -0.0058(12)-0.0011(13) C15 0.0276(14) 0.0254(14) 0.0167(13) 0.0015(11) 0.0028(11) -0.0037(11) C16 0.0311(15) 0.0333(16) 0.0234(14) $-0.0009(12) 0.0001(12)-0.0024(12)$ C17 0.0487(19) 0.0389(18) 0.0311(17) -0.0107(14) 0.0006(14) 0.0103(15) C18 0.0314(17) 0.064(2) 0.0309(17) -0.0040(16) 0.0102(13) -0.0191(15) C19 0.077(3) 0.053(2) 0.046(2) 0.0044(18) 0.0099(19) -0.036(2) C20 0.0334(19) 0.146(4) 0.047(2) $-0.008(2) 0.0169(17)-0.037(2)$

_geom_special_details ; 
All esds (except the esd in the dihedral angle between two 1.s. planes) are estimated using the full covariance matrix. The cell esds are taken into account individually in the estimation of esds in distances, angles and torsion angles; correlations between esds in cell parameters are only used when they are defined by crystal symmetry. An approximate (isotropic) treatment of cell esds is used for estimating esds involving l.s. planes.

;

loop

_geom_bond_atom_site_label_1

_geom_bond_atom_site_label_2

_geom_bond_distance

_geom_bond_site_symmetry_2

_geom_bond_publ_flag

Ti N4 2.027(2) . ?

Ti N2 2.037(2). ?

Ti N5 2.117(2) .?

Ti N1 2.147(2) . ?

$\mathrm{Ti} \mathrm{Cl} 2.3326(8)$. ?

Ti C11 2.514(2) . ?

$\mathrm{Ti} \mathrm{Cl} 2.534(2)$. ?

N1 C1 1.323(3) . ?

N1 C2 1.473(3).?

$\mathrm{N} 2 \mathrm{C} 11.368(3)$.?

N2 C5 1.469(3) .?

$\mathrm{N} 3 \mathrm{C} 11.365(3)$. ?

N3 C8 1.466(3). ?

N4 C11 1.355(3).?

$\mathrm{N} 4 \mathrm{C} 12$ 1.463(3).?

N5 C1 $11.336(3) . ?$

N5 C15 1.468(3).?

N6 C11 1.362(3).?

N6 C18 1.472(3).?

$\mathrm{C} 2 \mathrm{C} 3$ 1.523(3).?

$\mathrm{C} 2 \mathrm{C} 4$ 1.527(4).?

C5 C7 1.512(3).?

C5 C6 1.518(4).?

C8 C10 1.516(3).?

C8 C9 1.521(4) . ?

C12 C14 1.520(4).?

C12 C13 1.524(4).?

C15 C16 1.519(3).?

C15 C17 1.531(4).?

C18 C19 1.515(5) . ?

C18 C20 1.523(4).?

loop_

_geom_angle_atom_site_label_1

_geom_angle_atom_site_label_2

_geom_angle_atom_site_label_3

geom_angle

_geom_angle_site_symmetry_1

_geom_angle_site_symmetry_3

geom_angle_publ_flag

N4 Ti N2 111.27(9) . . ?

N4 Ti N5 64.58(8) . . ? 
N2 Ti N5 103.93(8) . . ?

N4 Ti N1 104.94(8) .. ?

N2 Ti N1 64.07(8) . . ?

N5 Ti N1 161.21(8) . . ?

N4 Ti Cl 122.80(6) .. ?

$\mathrm{N} 2 \mathrm{Ti} \mathrm{Cl} \mathrm{125.91(6)} \mathrm{..} \mathrm{?}$

N5 $\mathrm{Ti} \mathrm{Cl} \mathrm{100.03(6)} \mathrm{..} \mathrm{?}$

$\mathrm{N} 1 \mathrm{Ti} \mathrm{Cl} \mathrm{98.76(6)..?}$

N4 Ti C11 32.53(8) . .?

N2 Ti C11 109.44(8) .. ?

N5 Ti C11 32.11(8) . .?

N1 Ti C11 135.04(8) . . ?

$\mathrm{Cl} \mathrm{Ti} \mathrm{C11} \mathrm{116.32(6)} \mathrm{..} \mathrm{?}$

N4 Ti C1 110.70(8) . . ?

N2 Ti C1 32.59(8) . . ?

N5 Ti C1 134.70(8) . . ?

N1 Ti C1 31.49(8) ..?

$\mathrm{Cl}$ Ti C1 116.22(6) .. ?

C11 Ti C1 127.45(8) .. ?

C1 N1 C2 123.4(2) . . ?

C1 N1 Ti 90.59(15) . .?

C2 N1 Ti 141.22(17) . . ?

C1 N2 C5 120.8(2) .. ?

C1 N2 Ti 94.08(15) . . ?

C5 N2 Ti 140.48(16) .. ?

C1 N3 C8 126.5(2) ..?

C11 N4 C12 121.7(2) . . ?

C11 N4 Ti 93.91(15) . . ?

C12 N4 Ti 142.66(17) . .?

C11 N5 C15 125.1(2).. ?

C11 N5 Ti 90.53(15). . ?

C15 N5 Ti 141.03(16) . .?

C11 N6 C18 127.8(2) . . ?

N1 C1 N3 127.4(2). .?

N1 C1 N2 111.2(2)..?

N3 C1 N2 121.4(2)..?

N1 C1 Ti 57.92(13) . . ?

N3 C1 Ti 174.59(19) . . ?

$\mathrm{N} 2 \mathrm{C} 1 \mathrm{Ti} 53.32(12) \ldots ?$

N1 C2 C3 110.8(2) . .?

N1 C2 C4 109.6(2)..?

C3 C2 C4 110.1(2) . . ?

N2 C5 C7 109.5(2)..?

N2 C5 C6 111.3(2)..?

C7 C5 C6 110.2(2) . . ?

N3 C8 C10 107.9(2) . . ?

N3 C8 C9 111.1(2) . . ?

C10 C8 C9 111.9(2) .. ?

N5 C11 N4 110.8(2) .. ?

N5 C11 N6 127.6(2) . . ?

N4 C11 N6 121.6(2) .. ?

N5 C11 Ti 57.37(12) . . ?

N4 C11 Ti 53.56(12) ..?

N6 C11 Ti 174.25(19) . .?

N4 C12 C14 109.1(2) . . ?

N4 C12 C13 112.4(2) . . ? 
C14 C12 C13 110.3(2) . ?

N5 C15 C16 108.8(2) . . ?

N5 C15 C17 110.9(2) .. ?

C16 C15 C17 110.1(2) . . ?

N6 C18 C19 111.7(3) . . ?

N6 C18 C20 107.3(3) .. ?

$\mathrm{C} 19 \mathrm{C} 18 \mathrm{C} 20$ 112.3(3) . . ?

loop_

_geom_torsion_atom_site_label_1

_geom_torsion_atom_site_label_2

_geom_torsion_atom_site_label_3

_geom_torsion_atom_site_label_4

_geom_torsion

_geom_torsion_site_symmetry_1

_geom_torsion_site_symmetry_2

_geom_torsion_site_symmetry_3

_geom_torsion_site_symmetry_4

_geom_torsion_publ_flag

N4 Ti N1 C1 -105.34(15) ....?

N2 Ti N1 C1 $1.38(14) \ldots$ ?

N5 Ti N1 C1 $-51.9(3) \ldots$ ?

$\mathrm{Cl}$ Ti N1 C1 127.18(14).... ?

C11 Ti N1 C1 $-90.72(17) \ldots$ ?

N4 Ti N1 C2 101.5(3) ....?

N2 Ti N1 C2 -151.7(3) ....?

N5 Ti N1 C2 $155.0(3) \ldots$ ?

Cl Ti N1 C2 -25.9(3) .... ?

C11 Ti N1 C2 116.1(2) ....?

C1 Ti N1 C2 -153.1(3) ....?

N4 Ti N2 C1 95.46(15) ....?

N5 Ti N2 C1 $163.24(14) \ldots$ ?

$\mathrm{N} 1 \mathrm{Ti}$ N2 C1 $-1.34(13) \ldots$ ?

$\mathrm{Cl}$ Ti N2 Cl $-83.11(15) \ldots$ ?

C11 Ti N2 C1 130.17(14) ....?

N4 Ti N2 C5 $-57.7(3) \ldots$ ?

N5 Ti N2 C5 10.1(3) ....?

N1 Ti N2 C5 $-154.5(3) \ldots$ ?

$\mathrm{Cl}$ Ti N2 C5 123.7(2) ....?

C11 Ti N2 C5 -23.0(3) ... . ?

C1 Ti N2 C5 -153.2(3) ... . ?

$\mathrm{N} 2 \mathrm{Ti}$ N4 C11 93.07(15) ... ?

N5 Ti N4 C11 -2.72(14) ... ?

N1 Ti N4 C11 160.63(14) ....?

$\mathrm{Cl}$ Ti N4 C11 -88.30(15) ....?

C1 Ti N4 C11 128.05(14) . . . ? ?

N2 Ti N4 C12 -70.3(3) ....?

N5 Ti N4 C12 -166.1(3) ... ?

N1 Ti N4 C12 -2.7(3) ....?

$\mathrm{Cl}$ Ti N4 C12 108.4(3) ....?

C11 Ti N4 C12 -163.3(4) ... . ?

C1 Ti N4 C12 -35.3(3) .... ?

N4 Ti N5 C11 2.75(14) ... . ?

N2 Ti N5 C1 $1-104.47(15) \ldots$ ?

N1 Ti N5 C11 $-56.5(3) \ldots$ ?

$\mathrm{Cl}$ Ti N5 C11 124.43(13) ... . ? 


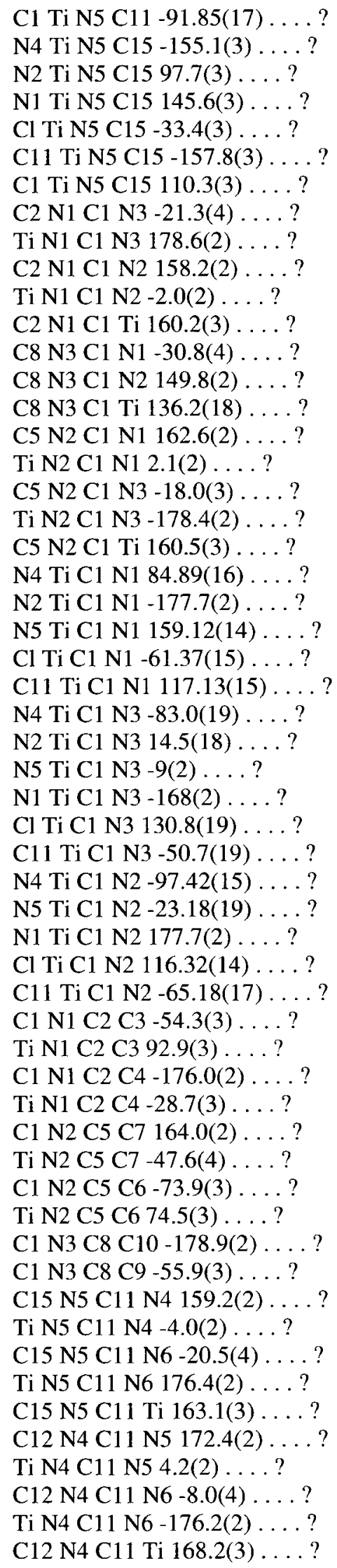


C18 N6 C11 N5 -24.4(4) ... . ?

C18 N6 C11 N4 156.0(3) ....?

C18 N6 C11 Ti 123.5(19) ....?

N4 Ti C1 1 N5 -175.4(2) ... . ?

N2 Ti C1 1 N5 85.29(15) . . . ?

N1 Ti C11 N5 157.66(14) ... . ?

Cl Ti C11 N5 -64.98(15) ... . ?

C1 Ti C11 N5 116.52(15) ....?

N2 Ti C1 1 N4 $-99.34(15) \ldots$ ?

N5 Ti C11 N4 175.4(2) . . . ?

N1 Ti C11 N4 -26.97(19) ....?

Cl Ti C11 N4 110.39(14) ... . ?

C1 Ti C11 N4 -68.11(17) .... ?

N4 Ti C11 N6 34.7(19) ... . ?

N2 Ti C11 N6 -64.7(19) . . . ?

N5 Ti C11 N6-150(2) ....?

N1 Ti C11 N6 8(2) ... ?

Cl Ti C11 N6 145.0(19) ... . ?

C1 Ti C11 N6-33(2) . . . ?

C11 N4 C12 C14 159.3(2) . . . ?

Ti N4 C12 C14 -40.4(4) . . . ?

C11 N4 C12 C13 -78.1(3).... ?

Ti N4 C12 C13 82.3(3) ... . ?

C11 N5 C15 C16 179.5(2) ... ?

Ti N5 C15 C16 -28.0(3) . . . . ?

C11 N5 C15 C17 -59.4(3) ... . ?

Ti N5 C15 C17 93.2(3) ... . ?

C11 N6 C18 C19-56.0(4) ....?

C11 N6 C18 C20-179.4(3) ....?

_diffrn_measured_fraction_theta_max 0.985

_diffrn_reflns_theta_full 25.00

_diffrn_measured_fraction_theta_full 0.998

_refine_diff_density_max 0.561

_refine_diff_density_min -0.392

_refine_diff_density_rms 0.077 


\section{A.11 Compound 19}

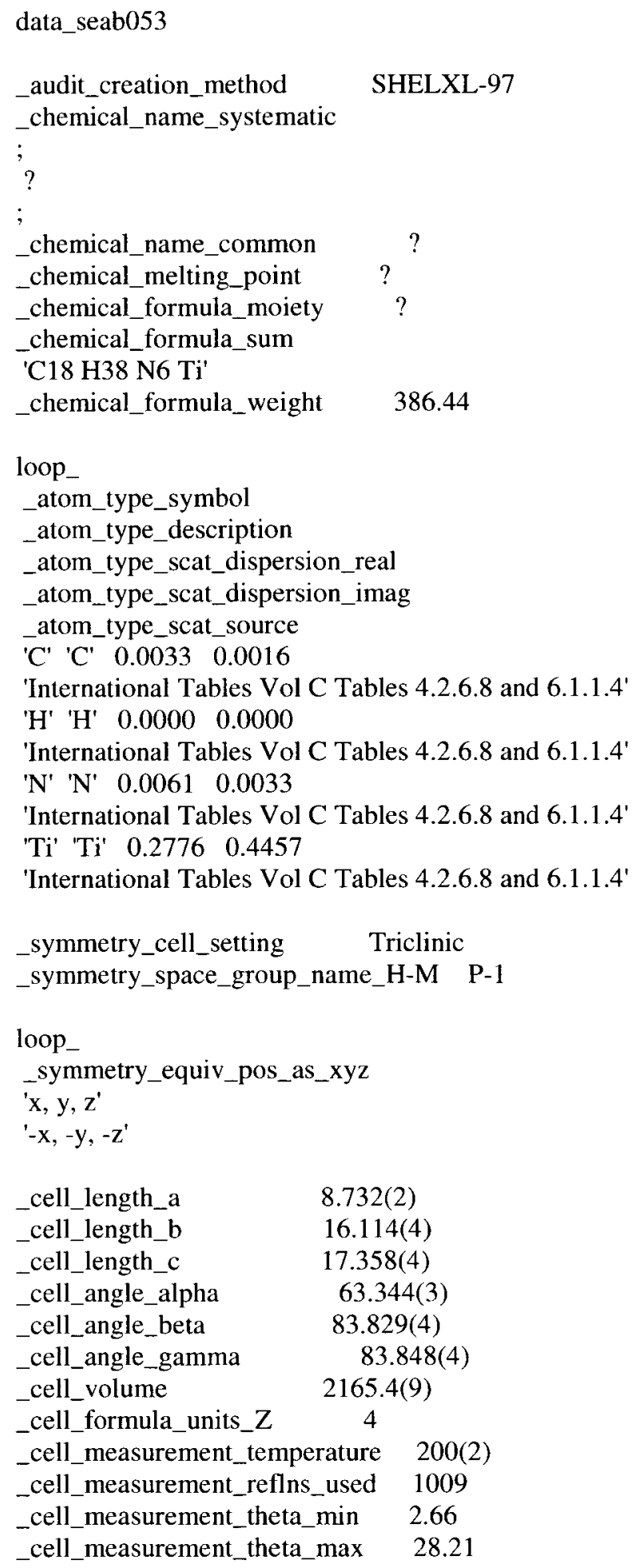




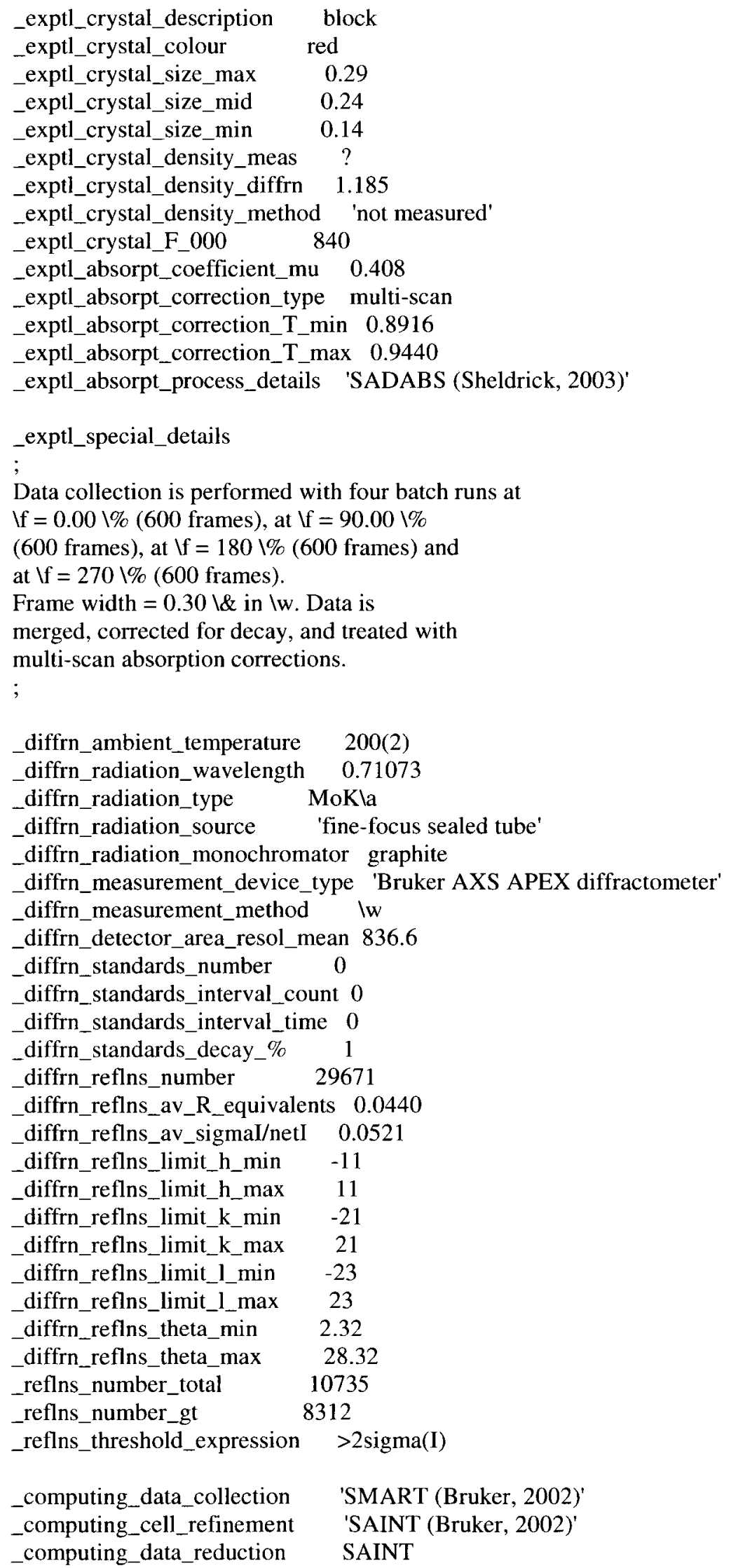


_computing_structure_solution 'SHELXS-97 (Sheldrick, 1990)'

_computing_structure_refinement 'SHELXL-97 (Sheldrick, 1997)'

_computing_molecular_graphics 'SHELXTL (Sheldrick, 2001)'

_computing_publication_material 'SHELXTL (Sheldrick, 2001)'

_refine_special_details

Refinement of $F^{\wedge} 2^{\wedge}$ against ALL reflections. The weighted $R$-factor $w R$ and goodness of fit $S$ are based on $\mathrm{F}^{\wedge} 2^{\wedge}$, conventional $\mathrm{R}$-factors $\mathrm{R}$ are based on $F$, with $F$ set to zero for negative $F^{\wedge} 2^{\wedge}$. The threshold expression of $\mathrm{F}^{\wedge} 2^{\wedge}>2 \operatorname{sigma}\left(\mathrm{F}^{\wedge} 2^{\wedge}\right)$ is used only for calculating $\mathrm{R}$-factors $(\mathrm{gt}) \mathrm{etc}$. and is not relevant to the choice of reflections for refinement. $R$-factors based on $\mathrm{F}^{\wedge} 2^{\wedge}$ are statistically about twice as large as those based on $\mathrm{F}$, and Rfactors based on ALL data will be even larger.

;

refine_ls_structure_factor_coef Fsqd

_refine_ls_matrix_type full

refine_ls_weighting_scheme calc

_refine_ls_weighting_details

'calc $\mathrm{w}=1 /\left[\backslash \mathrm{s}^{\wedge} 2^{\wedge}\left(\mathrm{Fo}^{\wedge} 2^{\wedge}\right)+(0.0574 \mathrm{P})^{\wedge} 2^{\wedge}+0.6356 \mathrm{P}\right]$ where $\mathrm{P}=\left(\mathrm{Fo}^{\wedge} 2^{\wedge}+2 \mathrm{Fc}^{\wedge} 2^{\wedge}\right) / 3^{\prime}$

_atom_sites_solution_primary direct

_atom_sites_solution_secondary difmap

_atom_sites_solution_hydrogens geom

_refine_ls_hydrogen_treatment mixed

_refine_ls_extinction_method none

_refine_ls_extinction_coef ?

_refine_ls_number_reflns 10735

_refine_ls_number_parameters 467

_refine_ls_number_restraints 0

_refine_ls_R_factor_all $\quad 0.0668$

_refine_ls_R_factor_gt 0.0491

_refine_ls_wR_factor_ref 0.1336

_refine_ls_wR_factor_gt 0.1216

_refine_ls_goodness_of_fit_ref 1.021

_refine_ls_restrained_S_all 1.021

_refine_ls_shift/su_max $\quad 0.001$

_refine_ls_shift/su_mean 0.000

loop

_atom_site_label

_atom_site_type_symbol

_atom_site_fract_x

_atom_site_fract_y

_atom_site_fract_z

_atom_site_U_iso_or_equiv

_atom_site_adp_type

_atom_site_occupancy

_atom_site_symmetry_multiplicity

_atom_site_calc_flag

_atom_site_refinement_flags

_atom_site_disorder_assembly

_atom_site_disorder_group

Ti1 Ti 0.02603(4) 0.23987(2) 1.04479(2) 0.02653(9) Uani $11 \mathrm{~d} .$.

Ti2 Ti 0.44975(4) 0.26547(2) 0.45959 (2) 0.02914 (9) Uani $11 \mathrm{~d}$. . .

N1 N $0.19602(18) 0.16623(12) 1.00304(11) 0.0322(4)$ Uani 11 d . . 
$\mathrm{N} 2 \mathrm{~N}-0.02205(18) 0.21075(11) 0.93368(10) 0.0303(3)$ Uani $11 \mathrm{~d} \ldots$ $\mathrm{N} 3 \mathrm{~N}-0.13520(19) 0.35191(11) 1.01960$ (11) $0.0328(4)$ Uani $11 \mathrm{~d} \ldots$ N4 N 0.08780(19) 0.37769(11) 0.94021 (10) 0.0307(3) Uani $11 \mathrm{~d} .$. N5 N -0.10957(19) 0.14682(12) $1.12208(11) 0.0336(4)$ Uani $11 \mathrm{~d} \ldots$ N6 N 0.1424(2) $0.24019(12) 1.13245(10) 0.0346(4)$ Uani $11 \mathrm{~d} \ldots$ $\mathrm{N} 7 \mathrm{~N} 0.3239(2) 0.15490(12) 0.48071(11) 0.0353(4)$ Uani $11 \mathrm{~d} \ldots$ N8 N 0.51412(19) 0.12523(12) 0.56739(10) 0.0327(4) Uani $11 \mathrm{~d} .$. N9 N 0.56916(19) 0.33737(12) $0.50660(11) 0.0347(4)$ Uani $11 \mathrm{~d} . \ldots$ N10 N 0.33395(18) 0.29474(11) 0.56752(10) 0.0302(3) Uani $11 \mathrm{~d} \ldots$ $\mathrm{N} 11 \mathrm{~N}$ 0.3204(2) 0.35969(12) 0.37668(11) 0.0368(4) Uani $11 \mathrm{~d} \ldots$ N12 N 0.6135(2) 0.26147(13) 0.37802(11) 0.0396(4) Uani $11 \mathrm{~d}$... C1 C 0.3432(2) 0.11361(16) 1.00679(15) 0.0403(5) Uani $11 \mathrm{~d} \ldots$ H1A H 0.34110 .05121 .05670 .048 Uiso 11 calc R . . H1B H 0.42790 .14671 .01190 .048 Uiso 11 calc R . . C2 C 0.3644(3) 0.10557(19) 0.92110(16) 0.0492(6) Uani $11 \mathrm{~d}$... H2A H 0.42660 .15560 .87710 .059 Uiso 11 calc $R$. . H2B H 0.41590 .04450 .92960 .059 Uiso 11 calc R . . C3 C 0.2004(3) 0.11549(16) 0.89400(14) 0.0409(5) Uani $11 \mathrm{~d} \ldots$ H3A H 0.19560 .15160 .83070 .049 Uiso 11 calc R . . H3B H 0.15920 .05400 .91280 .049 Uiso 11 calc R . . C4 C 0.1142(2) 0.16751(13) 0.94117(12) 0.0286(4) Uani $11 \mathrm{~d}$. . C5 C -0.1194(2) 0.21938(15) 0.86702(13) 0.0351(4) Uani $11 \mathrm{~d} \ldots$ H5A H - 0.05310 .23380 .81240 .042 Uiso 11 calc R . . C6 C -0.2406(3) 0.29985(17) 0.85090(17) 0.0511(6) Uani $11 \mathrm{~d} \ldots$ H6A H - 0.18930 .35770 .83210 .077 Uiso 11 calc R . . H6B H -0.30460 .28770 .90430 .077 Uiso 11 calc R . . H6C H -0.30590 .30590 .80590 .077 Uiso 11 calc R . . C7 C -0.1970(3) 0.12941(18) 0.89149(18) 0.0517(6) Uani $11 \mathrm{~d} \ldots$ H7A H - 0.11780 .07850 .90100 .078 Uiso 11 calc R . H7B H -0.25930 .13740 .84460 .078 Uiso 11 calc R . . H7C H -0.26370 .11470 .94450 .078 Uiso 11 calc R . . C8 C -0.2826(3) 0.39774(16) $1.03181(15) 0.0427(5)$ Uani $11 \mathrm{~d} \ldots$ H8A H - 0.28550 .40751 .08430 .051 Uiso 11 calc R . . H8B H -0.36900 .35991 .03750 .051 Uiso 11 calc R . . C9 C -0.2935(3) 0.49053(18) 0.95146(17) 0.0572(7) Uani $11 \mathrm{~d} \ldots$ H9A H -0.36240 .48780 .91100 .069 Uiso 11 calc R . . H9B H - 0.33460 .54100 .96720 .069 Uiso 11 calc R . . C10 C -0.1300(3) 0.50744(14) 0.91042(14) 0.0396(5) Uani $11 \mathrm{~d} \ldots$ H10A H - 0.12750 .52960 .84710 .047 Uiso 11 calc R . . H10B H - 0.08330 .55320 .92280 .047 Uiso 11 calc R . . C11 C -0.0489(2) 0.41183(13) 0.95398(12) 0.0299(4) Uani $11 \mathrm{~d} \ldots$ C12 C 0.1895(2) 0.43124(15) 0.86506(13) 0.0370(5) Uani $11 \mathrm{~d} \ldots$ H12A H 0.17920 .49770 .85500 .044 Uiso 11 calc $R$. . C13 C 0.3557(3) 0.39394(19) 0.88378(16) 0.0541(6) Uani $11 \mathrm{~d} \ldots$ H13A H 0.38320 .40000 .93420 .081 Uiso 11 calc $R$. . H13B H 0.42440 .42960 .83360 .081 Uiso 11 calc R. . H13C H 0.36670 .32820 .89560 .081 Uiso 11 calc R . . C14 C 0.1482(3) 0.42694(19) 0.78370(14) 0.0525(6) Uani $11 \mathrm{~d} \ldots$ H14A H 0.03960 .44840 .77350 .079 Uiso 11 calc $R$. . H14B H 0.16460 .36270 .79130 .079 Uiso 11 calc $R$. . $\mathrm{H} 14 \mathrm{C} \mathrm{H} 0.21380 .46700 .73410 .079$ Uiso 11 calc $\mathrm{R}$. . C15 C -0.0539(3) 0.06260(16) 1.19358(15) 0.0487(6) Uani $11 \mathrm{~d}$... H15A H -0.10840 .05791 .24760 .073 Uiso 11 calc R . H15B H 0.05710 .06441 .19650 .073 Uiso 11 calc R . . $\mathrm{H} 15 \mathrm{C} \mathrm{H}-0.07270 .00851 .18500 .073$ Uiso 11 calc $\mathrm{R}$. . C16 C -0.2723(2) 0.14581(17) 1.11389(15) 0.0446(5) Uani $11 \mathrm{~d} \ldots$ 
H16A H -0.2908 0.0901 1.10800 .067 Uiso 11 calc R . . H16B H -0.3050 0.2014 1.06270 .067 Uiso 11 calc R . . H16C H -0.33120 .14531 .16540 .067 Uiso 11 calc R . . C17 C 0.0712(3) 0.23340(19) 1.21447(15) 0.0535(6) Uani $11 \mathrm{~d} \ldots$ H17A H 0.09730 .28641 .22280 .080 Uiso 11 calc R . . H17B H 0.10950 .17531 .26150 .080 Uiso 11 calc R . . $\mathrm{H} 17 \mathrm{C} \mathrm{H}-0.04110 .23401 .21440 .080$ Uiso 11 calc $\mathrm{R}$. . C18 C 0.3092(3) 0.24034(18) 1.13036(16) 0.0478(6) Uani $11 \mathrm{~d} \ldots$ H18A H 0.33530 .28821 .14610 .072 Uiso 11 calc R . . H18B H 0.35390 .25371 .07210 .072 Uiso 11 calc $R$. . H18C H 0.35080 .17921 .17160 .072 Uiso 11 calc R . . C19 C 0.2052(3) 0.11000(17) 0.46283(16) 0.0472(6) Uani $11 \mathrm{~d} \ldots$ H19A H 0.23630 .10100 .41040 .057 Uiso 11 calc R . . H19B H 0.10600 .14810 .45410 .057 Uiso 11 calc $R$. . C20 C 0.1901(4) 0.0162(2) 0.54244(19) 0.0647(8) Uani $11 \mathrm{~d}$. . H20A H 0.10080 .01930 .58150 .078 Uiso 11 calc R. . H20B H $0.1762-0.03330 .52530 .078$ Uiso 11 calc R . C21 C 0.3402(3) -0.00293(15) 0.58641(15) 0.0428(5) Uani $11 \mathrm{~d} \ldots$ H21A H $0.3213-0.02840 .64990 .051$ Uiso 11 calc R . . H21B H $0.4124-0.04680 .57240 .051$ Uiso 11 calc R. . C22 C 0.4017(2) 0.09277(14) 0.54825(12) 0.0320(4) Uani $11 \mathrm{~d} \ldots$ C23 C 0.5994(3) 0.06745(15) 0.64380(13) 0.0402(5) Uani $11 \mathrm{~d} \ldots$ H23A H 0.60370 .00120 .65360 .048 Uiso 11 calc R . . C24 C 0.7634(3) 0.0983(2) 0.62786(18) 0.0644(8) Uani $11 \mathrm{~d}$. . H24A H 0.81160 .09540 .57540 .097 Uiso 11 calc R . . H24B H 0.82330 .05700 .67720 .097 Uiso 11 calc $R$. . H24C H 0.76090 .16230 .62070 .097 Uiso 11 calc R . . C25 C 0.5214(3) 0.0742(2) 0.72404(15) 0.0576(7) Uani $11 \mathrm{~d} \ldots$ H25A H 0.41620 .05380 .73410 .086 Uiso 11 calc R . H25B H 0.51740 .13880 .71540 .086 Uiso 11 calc R. . H25C H 0.58040 .03430 .77420 .086 Uiso 11 calc R . . C26 C 0.7044(3) 0.37632(19) 0.51595(18) 0.0515(6) Uani $11 \mathrm{~d} \ldots$ H26A H 0.73510 .42950 .46080 .062 Uiso 11 calc R . . H26B H 0.79200 .32870 .53280 .062 Uiso 11 calc R . . C27 C 0.6599(3) 0.4083(2) 0.5860(2) 0.0604(7) Uani $11 \mathrm{~d} \ldots$ H27A H 0.73860 .38460 .62930 .072 Uiso 11 calc R . . H27B H 0.65100 .47710 .56060 .072 Uiso 11 calc R . . C28 C 0.5054(3) 0.36925(19) 0.62767(17) 0.0496(6) Uani $11 \mathrm{~d}$... H28A H 0.51620 .31880 .68690 .059 Uiso 11 calc $R$. . H28B H 0.42950 .41840 .63010 .059 Uiso 11 calc R . . C29 C 0.4584(2) 0.33228(14) 0.56789(13) 0.0315(4) Uani $11 \mathrm{~d} \ldots$ C30 C 0.2044(2) 0.28551(14) 0.63070(13) 0.0333(4) Uani $11 \mathrm{~d}$... H30A H 0.24620 .27260 .68670 .040 Uiso 11 calc R . . C31 C 0.0988(3) 0.37467(16) 0.60215(16) 0.0443(5) Uani $11 \mathrm{~d}$... H31A H 0.15810 .42650 .59450 .066 Uiso 11 calc R . . H31B H 0.01410 .36650 .64630 .066 Uiso 11 calc R . . H31C H 0.05650 .38820 .54740 .066 Uiso 11 calc R . . C32 C 0.1139(3) 0.20351(16) 0.64483(15) 0.0423(5) Uani $11 \mathrm{~d} \ldots$ H32A H 0.18110 .14620 .66730 .063 Uiso 11 calc $R$. . H32B H 0.07660 .21360 .58980 .063 Uiso 11 calc $R$. . H32C H 0.02580 .19810 .68650 .063 Uiso 11 calc R . . C33 C 0.3785(3) 0.43779(16) 0.29973(15) 0.0516(6) Uani $11 \mathrm{~d}$... H33A H 0.33380 .49620 .29990 .077 Uiso 11 calc R . . H33B H 0.34970 .43430 .24830 .077 Uiso 11 calc R . . H33C H 0.49120 .43570 .29910 .077 Uiso 11 calc R . . C34 C 0.1530(3) $0.36470(19) 0.38340(16) 0.0526(6)$ Uani $11 \mathrm{~d} \ldots$ 
H34A H 0.11360 .42370 .38410 .079 Uiso 11 calc R . . H34B H 0.11660 .31270 .43690 .079 Uiso 11 calc $R$. . H34C H 0.11570 .36110 .33380 .079 Uiso 11 calc R . . C35 C 0.5845(3) 0.26158(19) 0.29702(15) 0.0550(6) Uani $11 \mathrm{~d} \ldots$ H35A H 0.64010 .20730 .29310 .083 Uiso 11 calc R . . H35B H 0.62040 .31860 .24860 .083 Uiso 11 calc R. . H35C H 0.47360 .25900 .29480 .083 Uiso 11 calc R . . C36 C 0.7781(3) 0.2610(2) 0.38452(18) 0.0572(7) Uani $11 \mathrm{~d} \ldots$ H36A H 0.83160 .20840 .37660 .086 Uiso 11 calc R . . H36B H 0.79640 .25490 .44160 .086 Uiso 11 calc R . . H36C H 0.81720 .31930 .33970 .086 Uiso 11 calc R . .

loop_
_atom_site_aniso_label
_atom_site_aniso_U_11
-atom_site_aniso_U_22
-atom_site_aniso_U_33
-atom_site_aniso_U_23
-atom_site_aniso_U_13
_atom_site_aniso_U_12

Ti1 $0.02423(17) 0.02909(18) 0.02420(17)-0.01035(14)-0.00216(12) 0.00059(13)$

Ti2 $0.02875(18) 0.03227(19) 0.02368(17)-0.00955(14)-0.00180(13)-0.00386(14)$

N1 $0.0264(8) 0.0371(9) 0.0338(9)-0.0170(7)-0.0061(7) 0.0060(7)$

$\mathrm{N} 20.0273(8) 0.0342(9) 0.0306(8)-0.0153(7)-0.0054(6) 0.0004(7)$

N3 $0.0296(8) 0.0338(9) 0.0323(8)-0.0134(7)-0.0009(7) 0.0027(7)$

N4 0.0312(8) 0.0296(8) $0.0289(8)-0.0109(7)-0.0009(6)-0.0029(6)$

N5 $0.0320(9) 0.0343(9) 0.0305(8)-0.0112(7)-0.0001(7)-0.0020(7)$

N6 $0.0353(9) 0.0398(9) 0.0285(8)-0.0144(7)-0.0060(7)-0.0011(7)$

N7 0.0347(9) $0.0395(9) 0.0337(9)-0.0167(8)-0.0048(7)-0.0056(7)$

N8 0.0329(9) 0.0323(9) 0.0295(8) $-0.0104(7)-0.0049(7)-0.0003(7)$

N9 $0.0258(8) 0.0393(9) 0.0397(9)-0.0178(8) 0.0000(7)-0.0063(7)$

$\mathrm{N} 100.0266(8) 0.0355(9) 0.0294(8)-0.0150(7)-0.0016(6)-0.0036(7)$

$\mathrm{N} 110.0389(10) 0.0376(9) 0.0295(8)-0.0102(7)-0.0072(7)-0.0012(7)$

$\mathrm{N} 120.0398(10) 0.0438(10) 0.0316(9)-0.0147(8) 0.0042(7)-0.0032(8)$

C1 0.0302(10) 0.0460(12) 0.0461(12) -0.0226(10) -0.0092(9) 0.0094(9)

C2 0.0351(12) 0.0644(16) 0.0566(15) -0.0377(13) -0.0044(10) 0.0136(11)

C3 0.0415(12) 0.0464(12) 0.0380(11) $-0.0237(10)-0.0048(9) 0.0094(10)$

C4 0.0282(9) 0.0288(9) 0.0275(9) $-0.0118(8)-0.0021(7) 0.0006(7)$

C5 $0.0322(10) 0.0439(12) 0.0307(10)-0.0176(9)-0.0072(8) 0.0005(9)$

C6 0.0477(14) $0.0518(14) 0.0535(14)-0.0212(12)-0.0253(11) 0.0110(11)$

C7 $0.0416(13) 0.0543(15) 0.0720(17)-0.0363(13)-0.0153(12)-0.0054(11)$

C8 0.0349(11) 0.0458(13) 0.0463(13) $-0.0222(11)-0.0002(9) 0.0073(9)$

C9 0.0529(15) 0.0526(15) 0.0504(14) $-0.0146(12)-0.0020(12) 0.0216(12)$

C10 0.0476(12) 0.0303(10) 0.0387(11) -0.0126(9) -0.0141(10) 0.0048(9)

C11 0.0335(10) 0.0296(9) 0.0297(9) $-0.0149(8)-0.0073(8)-0.0005(8)$

C12 0.0393(11) $0.0365(11) 0.0303(10)-0.0097(9) 0.0008(8)-0.0088(9)$

C13 0.0350(12) 0.0657(16) 0.0471(14) -0.0111(12) 0.0054(10) $-0.0157(11)$

C14 0.0571(15) $0.0664(17) 0.0316(11)-0.0196(11) 0.0046(10)-0.0115(13)$

C15 0.0517(14) 0.0406(12) 0.0414(12) $-0.0063(10)-0.0028(10)-0.0071(10)$

C16 0.0346(11) 0.0471(13) 0.0473(13) -0.0167(11) 0.0033(9) -0.0083(10)

C17 0.0682(17) 0.0636(16) 0.0352(12) $-0.0269(12)-0.0003(11)-0.0115(13)$

C18 0.0389(12) 0.0580(15) 0.0510(14) $-0.0253(12)-0.0149(10)-0.0043(11)$

C19 0.0463(13) $0.0537(14) 0.0496(14)-0.0272(12)-0.0096(11)-0.0097(11)$

C20 0.0727(19) 0.0587(17) 0.0678(18) $-0.0266(14)-0.0071(15)-0.0288(15)$

C21 0.0483(13) 0.0331(11) 0.0446(12) -0.0164(10) 0.0085(10)-0.0084(9)

C22 0.0340(10) 0.0316(10) 0.0294(10) -0.0139(8) 0.0038(8) -0.0021(8) 
C23 0.0437(12) 0.0356(11) 0.0331(11) -0.0081(9) -0.0106(9) 0.0060(9) C24 0.0405(14) 0.079(2) 0.0549(16) -0.0115(14) $-0.0157(12) 0.0035(13)$ C25 0.0670(17) 0.0657(17) 0.0324(12) -0.0156(12) -0.0085(11) 0.0039(14) C26 0.0316(11) 0.0592(15) 0.0743(18) -0.0381(14) 0.0027(11) -0.0132(10) C27 0.0427(14) 0.083(2) 0.0780(19) -0.0530(17) -0.0036(13) -0.0157(13) C28 0.0374(12) 0.0703(17) 0.0614(15) -0.0459(14) -0.0042(11) $-0.0088(11)$ C29 0.0304(10) 0.0315(10) 0.0325(10) -0.0139(8) -0.0050(8) -0.0006(8) C30 0.0299(10) 0.0413(11) 0.0304(10) -0.0173(9) 0.0006(8) $-0.0049(8)$ C31 0.0353(11) 0.0488(13) 0.0529(14) $-0.0272(11)-0.0005(10)-0.0001(10)$ C32 0.0389(12) 0.0464(13) 0.0416(12) $-0.0197(10) 0.0078(9)-0.0122(10)$ C33 0.0662(17) 0.0378(12) 0.0388(12) $-0.0059(10)-0.0058(11)-0.0026(11)$ C34 0.0457(14) 0.0611(16) 0.0439(13) -0.0162(12) -0.0146(11) 0.0043(12) C35 0.0711(18) 0.0572(16) 0.0387(13) $-0.0254(12) 0.0033(12) 0.0000(13)$ C36 0.0386(13) $0.0726(18) 0.0578(16)-0.0299(14) 0.0101(11)-0.0011(12)$

_geom_special_details

$$
\text { ; }
$$

All esds (except the esd in the dihedral angle between two 1.s. planes) are estimated using the full covariance matrix. The cell esds are taken into account individually in the estimation of esds in distances, angles and torsion angles; correlations between esds in cell parameters are only used when they are defined by crystal symmetry. An approximate (isotropic) treatment of cell esds is used for estimating esds involving 1.s. planes.

loop_

_geom_bond_atom_site_label_1

_geom_bond_atom_site_label_2

geom_bond_distance

_geom_bond_site_symmetry_2

_geom_bond_publ_flag

Til N5 1.9194(17) . ?

Til N6 1.9204(17) .?

Ti1 N1 2.0735(17) . ?

Ti1 N3 2.0766(17) . ?

Ti1 N4 2.2243(17) . ?

Ti1 N2 2.2682(17) . ?

Til C11 2.550(2) . ?

Ti1 C4 2.565(2) . ?

Ti2 N11 1.9167(17) .?

Ti2 N12 1.9185(18).?

Ti2 N7 2.0647(18) . ?

Ti2 N9 2.0941(18) . ?

Ti2 N10 2.2446(17) .?

Ti2 N8 2.2548(17). ?

Ti2 C22 2.561(2) . ?

Ti2 C29 2.562(2) . ?

N1 C4 1.344(2).?

$\mathrm{N} 1 \mathrm{C} 11.452(2)$. ?

$\mathrm{N} 2 \mathrm{C} 4$ 1.301(2) .?

$\mathrm{N} 2 \mathrm{C} 51.457(2)$. ?

N3 C11 1.335(3) . ?

N3 C8 1.457(3) . ?

N4 C11 1.304(3) . ?

$\mathrm{N} 4 \mathrm{Cl} 21.463(2)$. ?

N5 C16 1.445(3).? 
N5 C15 1.448(3) . ?

N6 C17 1.453(3) .?

N6 C18 1.453(3). ?

N7 C22 1.345(3). ?

N7 C19 1.458(3). ?

N8 C22 1.298(3). ?

N8 C23 1.462(3) . ?

N9 C29 1.339(3) . ?

N9 C26 1.452(3) . ?

N10 C29 1.301(2). ?

N10 C30 1.458(2). ?

N11 C34 1.450(3). ?

N11 C33 1.452(3).?

N12 C36 1.452(3). ?

N12 C35 1.454(3). ?

C1 C2 1.540(3).?

C2 C3 1.525(3). ?

C3 C4 1.513(3).?

C5 C6 1.525(3). ?

C5 C7 1.529(3).?

C8 C9 1.522(3) .?

C9 C10 1.521(3).?

C10 C11 1.511(3).?

C12 C13 1.520(3).?

C12 C14 1.527(3). ?

C19 C20 1.530(4) . ?

C20 C21 1.521(4).?

C21 C22 1.513(3).?

C23 C24 1.522(3). ?

C23 C25 1.527(3). ?

C26 C27 1.521(4).?

C27 C28 1.518(3) . ?

C28 C29 1.516(3).?

C30 C32 1.524(3). ?

C30 C31 1.528(3). ?

loop

_geom_angle_atom_site_label_1 _geom_angle_atom_site_label_2

_geom_angle_atom_site_label_3

_geom_angle

_geom_angle_site_symmetry_1

_geom_angle_site_symmetry_3

_geom_angle_publ_flag

N5 Til N6 96.25(8) . .?

N5 Ti1 N1 103.94(7) . . ?

N6 Ti1 N1 95.43(7) . . ?

N5 Ti1 N3 95.70(7) . .?

N6 Ti1 N3 103.60(7) . . ?

N1 Ti1 N3 150.93(7) . . ?

N5 Ti1 N4 156.19(7) . .?

N6 Til N4 97.52(7) . . ?

N1 Ti1 N4 94.00(7)..?

N3 Ti1 N4 62.17(6) . .?

N5 Til N2 90.79(7) . .?

N6 Ti1 N2 157.32(7) . . ? 
N1 Ti1 N2 61.91(6) . .?

N3 Til N2 97.09(6) . .?

N4 Til N2 83.89(6) ..?

N5 Til C11 126.43(7) . .?

N6 Til C1 1 103.44(7) . .?

N1 Til C11 122.67(7) . .?

N3 Til C11 31.47(6) . . ?

N4 Ti1 C11 30.73(6) . . ?

N2 Ti1 C1 $189.37(6) \ldots$ ?

N5 Til C4 98.22(7) . .?

N6 Ti1 C4 126.90(7). . ?

N1 Ti1 C4 31.47(6) .. ?

N3 Ti1 C4 125.19(6) . .?

N4 Til C4 88.89(6) ..?

N2 Ti1 C4 30.44(6) .. ?

C11 Ti1 C4 107.84(6) . .?

N11 Ti2 N12 96.35(8) .. ?

N11 Ti2 N7 96.22(8) . . ?

N12 Ti2 N7 103.07(8) .. ?

N11 Ti2 N9 104.67(8) .. ?

N12 Ti2 N9 95.16(8) . . ?

N7 Ti2 N9 150.50(7) . . ?

N11 Ti2 N10 92.12(7) . . ?

N12 Ti2 N10 156.93(7) . . ?

N7 Ti2 N10 97.27(7) . . ?

N9 Ti2 N10 61.88(6) ..?

N11 Ti2 N8 156.88(7) .. ?

N12 Ti2 N8 96.19(7) . .?

N7 Ti2 N8 61.98(7) . . ?

N9 Ti2 N8 93.44(7) ..?

N10 Ti2 N8 83.75(6) . . ?

N11 Ti2 C22 127.30(7) . . ?

N12 Ti2 C22 101.74(7) .. ?

N7 Ti2 C22 31.56(7) . ?

N9 Ti2 C22 122.13(7) ..?

$\mathrm{N} 10 \mathrm{Ti} 2 \mathrm{C} 22$ 89.90(6) .. ?

N8 Ti2 C22 30.43(6) .. ?

N11 Ti2 C29 100.91(7) . .?

N12 Ti2 C29 126.45(7) .. ?

N7 Ti2 C29 124.52(7) . . ?

N9 Ti2 C29 31.42(6)..?

N10 Ti2 C29 30.51(6) . .?

N8 Ti2 C29 87.02(7) ..?

C22 Ti2 C29 106.67(6) .. ?

C4 N1 C1 110.45(16) . . ?

C4 N1 Ti1 94.87(11). . ?

C1 N1 Ti1 154.56(14) .. ?

C4 N2 C5 120.70(17) . . ?

C4 N2 Ti1 87.49(12). .?

C5 N2 Ti1 151.78(13) . . ?

C11 N3 C8 110.54(16) . . ?

C11 N3 Til 94.24(12)..?

C8 N3 Til 155.18(14) .. ?

C11 N4 C12 121.42(17) .. ?

C11 N4 Ti1 88.59(12)..?

C12 N4 Ti1 148.46(14) ..? 
C16 N5 C15 111.27(18) . ?

C16 N5 Ti1 126.37(14) . . ?

C15 N5 Ti1 122.15(15) .. ?

C17 N6 C18 110.68(18) . . ?

C17 N6 Ti1 122.64(15) . . ?

C18 N6 Ti1 126.54(15).. ?

C22 N7 C19 110.26(18) . . ?

C22 N7 Ti2 95.01(13) . .?

C19 N7 Ti2 154.73(15) .. ?

C22 N8 C23 120.69(18) . ?

C22 N8 Ti2 87.94(12)..?

C23 N8 Ti2 150.61(14) .. ?

C29 N9 C26 1 10.64(18) . .?

C29 N9 Ti2 93.94(12)..?

C26 N9 Ti2 154.51(15) . . ?

C29 N10 C30 121.03(17) . . ?

C29 N10 Ti2 88.35(12) . . ?

C30 N10 Ti2 150.42(13) . . ?

C34 N11 C33 111.00(18) . . ?

C34 N11 Ti2 125.08(15) . . ?

C33 N11 Ti2 123.89(15)..?

C36 N12 C35 110.4(2) . . ?

C36 N12 Ti2 127.20(16) . . ?

C35 N12 Ti2 122.35(16) . . ?

N1 C1 C2 104.89(17) . . ?

C3 C2 C1 104.20(17) .. ?

C4 C3 C2 101.99(18) . . ?

N2 C4 N1 115.72(17) ..?

N2 C4 C3 132.24(18) . ?

N1 C4 C3 112.03(16). . ?

N2 C4 Ti1 62.07(10) . .?

N1 C4 Til 53.66(9) . .?

C3 C4 Ti1 165.61(14) . .?

N2 C5 C6 109.37(17) . . ?

N2 C5 C7 111.87(18) . .?

C6 C5 C7 110.32(19) . . ?

N3 C8 C9 $105.40(18) \ldots$ ?

C10 C9 C8 105.92(19) . . ?

C11 C10 C9 102.18(18) . . ?

N4 C11 N3 114.86(17). . ?

N4 C11 C10 132.49(19) . . ?

N3 C11 C10 112.64(18) . . ?

N4 C11 Ti1 60.67(10) . .?

N3 C11 Ti1 54.29(10) . ?

C10 C11 Ti1 166.65(15) . ?

N4 C12 C13 109.12(17) . ?

N4 C12 C14 111.84(18) . . ?

C13 C12 C14 109.9(2) . ?

N7 C19 C20 105.40(19) . . ?

C21 C20 C19 105.3(2) . ?

C22 C21 C20 102.36(19) .. ?

N8 C22 N7 115.04(18) ..?

N8 C22 C21 132.61(19) ..?

N7 C22 C21 112.34(18) . ? ?

N8 C22 Ti2 61.63(11)..?

N7 C22 Ti2 53.44(10) . .? 
C21 C22 Ti2 165.75(16) . . ? N8 C23 C24 109.08(18) .. ? N8 C23 C25 111.36(19) . . ? C24 C23 C25 110.0(2) . ? ? N9 C26 C27 106.54(19) . ? ? C28 C27 C26 106.31(19) . . ? $\mathrm{C} 29 \mathrm{C} 28 \mathrm{C} 27$ 102.82(19) . . ? N10 C29 N9 115.65(18) . .? N10 C29 C28 131.78(19) . . ? N9 C29 C28 112.53(18) .. ? N10 C29 Ti2 61.14(11) . . ? N9 C29 Ti2 54.64(10) .. ? C28 C29 Ti2 166.08(15) ..? N10 C30 C32 109.53(17) .. ? N10 C30 C31 111.52(17) . . ? C32 C30 C31 110.42(18) . . ?

loop_ _geom_torsion_atom_site_label_1 _geom_torsion_atom_site_label_2 _geom_torsion_atom_site_label_3 _geom_torsion_atom_site_label_4 _geom_torsion _geom_torsion_site_symmetry_1 _geom_torsion_site_symmetry_2 _geom_torsion_site_symmetry_3 _geom_torsion_site_symmetry_4 _geom_torsion_publ_flag

N5 Ti1 N1 C4 82.91(13) ....?

N6 Ti1 N1 C4 -179.25(12) ....?

N3 Ti1 N1 C4 $-48.2(2) \ldots$ ?

N4 Til N1 C4 -81.30(12)....?

N2 Ti1 N1 C4 $-0.40(11) \ldots$ ?

C11 Ti1 N1 C4 -69.48(14)...? ?

N5 Ti1 N1 C1 $-91.6(3) \ldots$ ?

N6 Ti1 N1 C1 6.2(4) ....?

N3 Ti1 N1 C1 137.3(3)....?

N4 Til N1 Cl 104.2(3) ....?

N2 Til N1 C1 $-174.9(4) \ldots$ ?

C11 Til N1 C1 116.0(3) ....?

C4 Til N1 C1 -174.5(4) ....?

N5 Ti1 N2 C4 -105.00(12)...?

N6 Til N2 C4 3.4(2) ....?

N1 Til N2 C4 0.41(11)....?

N3 Ti1 N2 C4 159.15(12) ....?

N4 Til N2 C4 98.26(12) ...?

C11 Ti1 N2 C4 128.57(12) ... . ?

N5 Ti1 N2 C5 77.6(3) ....?

N6 Ti1 N2 C5 -174.1(3) ....?

N1 Ti1 N2 C5 -177.0(3)....?

N3 Til N2 C5 -18.3(3) ... . ?

N4 Til N2 C5 -79.2(3) ... . ?

C11 Ti1 N2 C5 -48.9(3)....?

C4 Ti1 N2 C5 -177.4(3) ... . ?

N5 Til N3 C1 $1-168.54(12) \ldots$ ?

N6 Til N3 C11 93.61(12) . . . ? 


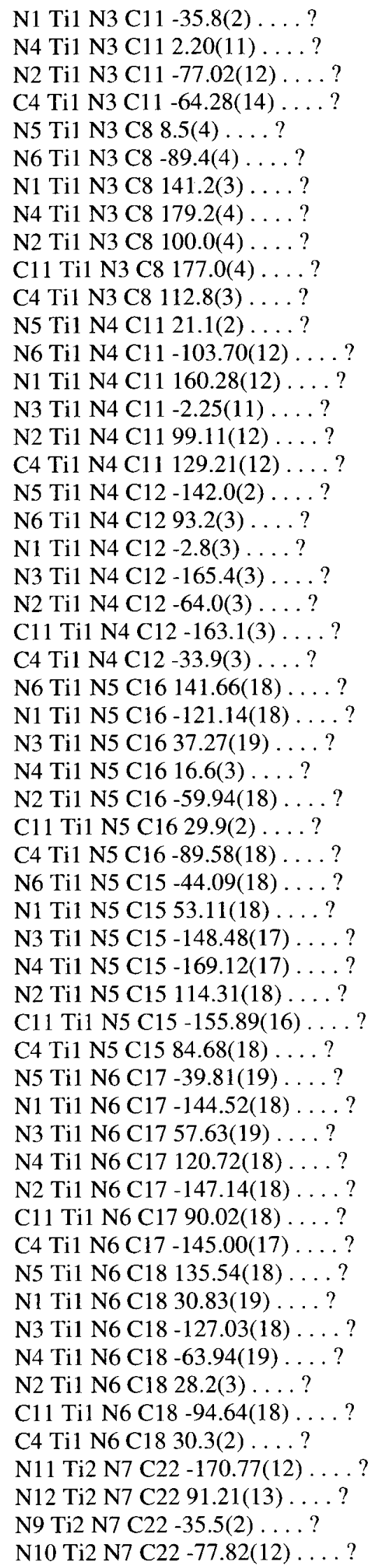


N8 Ti2 N7 C22 1.10(11) ...? C29 Ti2 N7 C22 -62.95(14) ...? ? N11 Ti2 N7 C19 10.5(4) ... ? N12 Ti2 N7 C19 -87.5(4) ....? N9 Ti2 N7 C19 145.8(3) ... ? ? N10 Ti2 N7 C19 103.5(4) ....? N8 Ti2 N7 C19 -177.6(4) ....? C22 Ti2 N7 C19-178.7(4) ....? C29 Ti2 N7 C19 118.3(4) ....?

N11 Ti2 N8 C22 19.8(2) ...? N12 Ti2 N8 C22 -102.67(13) ....? N7 Ti2 N8 C22 -1.14(11)....? N9 Ti2 N8 C22 $161.75(12) \ldots$ ? N10 Ti2 N8 C22 100.54(12) ....? C29 Ti2 N8 C22 130.98(12) ... ? ? N11 Ti2 N8 C23 -147.8(3) ... . ? N12 Ti2 N8 C23 89.7(3) ... . ? N7 Ti2 N8 C23 -168.7(3) ... ? N9 Ti2 N8 C23 $-5.8(3) \ldots$ ? N10 Ti2 N8 C23 -67.1(3)....? C22 Ti2 N8 C23 -167.6(3) ... . ? C29 Ti2 N8 C23 -36.6(3) ... . ? N11 Ti2 N9 C29 86:94(13) . . . ? N12 Ti2 N9 C29 -175.10(12) ... . ? N7 Ti2 N9 C29 $-46.7(2) \ldots$ ? N10 Ti2 N9 C29 2.48(11) ... . ? N8 Ti2 N9 C29 $-78.56(12) \ldots$ ? C22 Ti2 N9 C29 -67.76(14) .... ? N11 Ti2 N9 C26 -108.1(4) ... . ? N12 Ti2 N9 C26 -10.1(4) . . . ? N7 Ti2 N9 C26 118.2(4) ... ? N10 Ti2 N9 C26 167.4(4) ....? N8 Ti2 N9 C26 86.4(4) ....? C22 Ti2 N9 C26 97.2(4) ....? C29 Ti2 N9 C26 165.0(4) ... . ? N11 Ti2 N10 C29-108.06(13) ... . ? N12 Ti2 N10 C29 3.6(2)....? N7 Ti2 N10 C29 155.38(12) . . . ? N9 Ti2 N10 C29 $-2.55(11) \ldots$ ? N8 Ti2 N10 C29 94.75(12) ...? ? C22 Ti2 N10 C29 124.61(12) ... ? N11 Ti2 N10 C30 78.2(3) ....? N12 Ti2 N10 C30 -170.1(2).... ? N7 Ti2 N10 C30 -18.4(3) ....? N9 Ti2 N10 C30 -176.3(3) ... ? N8 Ti2 N10 C30 -79.0(3) ... ? C22 Ti2 N10 C30-49.1(3) ... ? ? C29 Ti2 N10 C30-173.7(3) ... . ? N12 Ti2 N11 C34 145.98(19) ... . ? N7 Ti2 N11 C34 42.0(2) ...? N9 Ti2 N11 C34 -116.97(19) ... . ? N10 Ti2 N11 C34 -55.52(19) ... ? N8 Ti2 N11 C34 23.5(3) ... . ? C22 Ti2 N11 C34 36.0(2) ....? C29 Ti2 N11 C34 -84.96(19) . . . ? N12 Ti2 N11 C33 -36.25(19) ....? 
N7 Ti2 N11 C33 -140.20(18) ....?

N9 Ti2 N11 C33 60.80(19) ... . ?

N10 Ti2 N11 C33 122.25(18) . . . ?

N8 Ti2 N11 C33 -158.74(18) ....?

C22 Ti2 N1 1 C33-146.26(17) ....?

C29 Ti2 N11 C33 92.81(18) ... . ?

N11 Ti2 N12 C36 134.0(2) ... . ?

N7 Ti2 N12 C36 -128.1(2) ....?

N9 Ti2 N12 C36 28.6(2) ... . ?

N10 Ti2 N12 C36 23.1(3) ... . ?

N8 Ti2 N12 C36 -65.5(2) ... ?

C22 Ti2 N12 C36 -95.8(2) ....?

C29 Ti2 N12 C36 25.4(2) ....?

N11 Ti2 N12 C35 $-43.89(19) \ldots$. ?

N7 Ti2 N12 C35 54.04(19) ....?

N9 Ti2 N12 C35 $-149.31(18) \ldots$ ?

N10 Ti2 N12 C35 -154.76(18) ... ?

N8 Ti2 N12 C35 116.65(18) ... . ?

C22 Ti2 N12 C35 86.34(18) ... ?

C29 Ti2 N12 C35-152.48(17) ... . ?

C4 N1 C1 C2 16.2(2) ....?

Ti1 N1 C1 C2 -169.6(3) ... . ?

N1 C1 C2 C3 -24.7(2) ....?

C1 C2 C3 C4 23.4(2) ... ?

C5 N2 C4 N1 177.97(17) ... ? ?

Ti1 N2 C4 N1 $-0.62(17) \ldots$ ?

C5 N2 C4 C3 $-3.3(3) \ldots$ ?

Ti1 N2 C4 C3 178.1(2) ....?

C5 N2 C4 Til 178.59(19) ... . ?

C1 N1 C4 N2 178.16(18)....?

Ti1 N1 C4 N2 $0.68(18) \ldots$ ?

C1 N1 C4 C3 $-0.8(2) \ldots$ ?

Ti1 N1 C4 C3 -178.29(14) ... . ?

C1 N1 C4 Til 177.48(19) ... . ?

C2 C3 C4 N2 166.3(2) ... ?

C2 C3 C4 N1 -14.9(2) ....?

C2 C3 C4 Ti1 -20.5(7) ....?

N5 Til C4 N2 77.38(12) ... . ?

N6 Ti1 C4 N2 $-178.37(11) \ldots$ ?

N1 Ti1 C4 N2 -179.30(19) ....?

N3 Til C4 N2 $-25.61(14) \ldots$ ?

N4 Til C4 N2 $-79.80(12) \ldots$ ?

C11 Til C4 N2 -55.22(12)....?

N5 Til C4 N1 -103.31(13)....?

N6 Til C4 N1 0.93(15) ....?

N3 Til C4 N1 153.70(12) ... ?

N4 Til C4 N1 99.50(12) ....?

N2 Til C4 N1 179.30(19) ... . ?

C11 Til C4 N1 124.09(12).... ?

N5 Til C4 C3 $-96.9(6) \ldots$ ?

N6 Til C4 C3 7.3(6) .... ?

N1 Til C4 C3 6.4(5) ....?

N3 Til C4 C3 160.1(6) ... . ?

N4 Til C4 C3 105.9(6) .... ?

N2 Til C4 C3 $-174.3(6) \ldots$ ?

C11 Til C4 C3 130.5(6) ... ? 


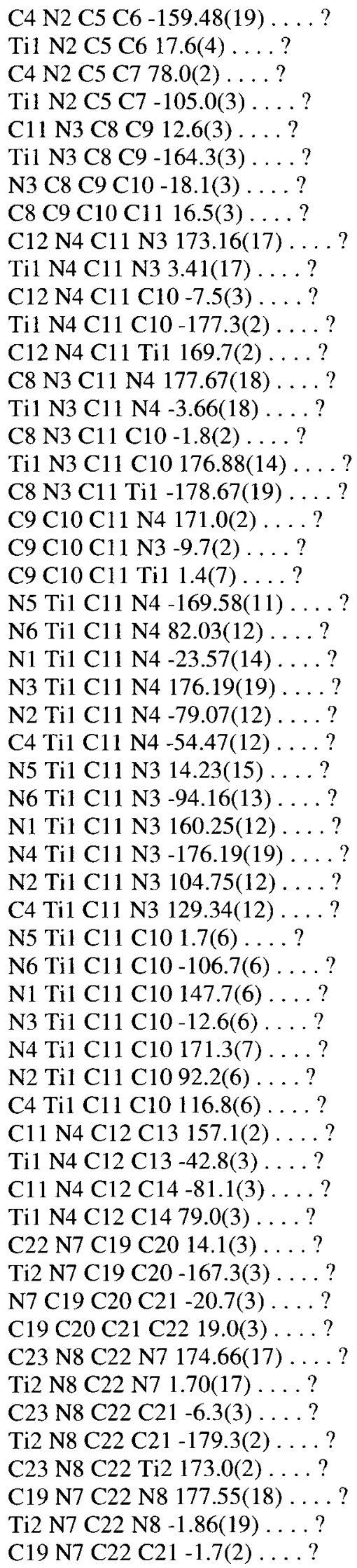


Ti2 N7 C22 C21 178.90(14) ....?

C19 N7 C22 Ti2 179.42(19) ....?

C20 C21 C22 N8 169.5(2) ....?

C20 C21 C22 N7-11.4(2) ... . ?

$\mathrm{C} 20 \mathrm{C} 21 \mathrm{C} 22 \mathrm{Ti} 2-7.8(7) \ldots$. ?

N1 1 Ti2 C22 N8 -170.35(12) ...?

N12 Ti2 C22 N8 82.17(13) ... . ?

N7 Ti2 C22 N8 178.08(19) ... . ?

N9 Ti2 C22 N8 -21.66(14) ...? ?

N10 Ti2 C22 N8 -77.76(12)....?

C29 Ti2 C22 N8 -51.91(13) ....?

N11 Ti2 C22 N7 11.56(15) ... . ?

N12 Ti2 C22 N7 -95.91(13) ....?

N9 Ti2 C22 N7 $160.25(12) \ldots$ ?

N10 Ti2 C22 N7 104.15(12) ... ?

N8 Ti2 C22 N7 -178.08(19) ... . ?

C29 Ti2 C22 N7 130.01(12)... ?

N11 Ti2 C22 C21 7.4(6) ...? ?

N12 Ti2 C22 C21 -100.0(6) ...? ?

N7 Ti2 C22 C21 -4.1(5) ... ?

N9 Ti2 C22 C21 156.1(6) ...?

N10 Ti2 C22 C21 100.0(6) ... ?

N8 Ti2 C22 C21 177.8(6) ....?

$\mathrm{C} 29 \mathrm{Ti} 2 \mathrm{C} 22 \mathrm{C} 21$ 125.9(6) ... ?

C22 N8 C23 C24 151.3(2) ... . ?

Ti2 N8 C23 C24 -43.2(4) ... ? ?

C22 N8 C23 C25 -87.1(3) ... ? ?

Ti2 N8 C23 C25 78.4(3) ... ?

C29 N9 C26 C27 -7.2(3) ... . ?

Ti2 N9 C26 C27 -171.1(3) ... . ?

N9 C26 C27 C28 10.7(3) ... . ?

C26 C27 C28 C29 -9.9(3) ... ?

C30 N10 C29 N9 -179.70(17) . . . ?

Ti2 N10 C29 N9 3.90(18) ... . ?

C30 N10 C29 C28 2.8(3) ....?

Ti2 N10 C29 C28 -173.6(2) ... ?

C30 N10 C29 Ti2 176.40(19) ... . ?

C26 N9 C29 N10-177.33(19) ... ? ?

Ti2 N9 C29 N10 $-4.19(19) \ldots$. . ?

C26 N9 C29 C28 0.7(3) ...?

Ti2 N9 C29 C28 173.80(16) . . . ?

C26 N9 C29 Ti2 -173.1(2) ....?

C27 C28 C29 N10-176.4(2) ... ?

C27 C28 C29 N9 6.1(3) ... ?

C27 C28 C29 Ti2 27.5(8) ... ? ?

N11 Ti2 C29 N10 75.36(13) ... ? ?

N12 Ti2 C29 N10 -178.24(12) . . . ?

N7 Ti2 C29 N10 -30.10(14) ... . ?

N9 Ti2 C29 N10 175.69(19) . . . ?

N8 Ti2 C29 N10 -82.74(12) ... . ?

C22 Ti2 C29 N10 -59.21(13)....?

N11 Ti2 C29 N9 -100.33(13) ... ? ?

N12 Ti2 C29 N9 6.07(15) . . . ?

N7 Ti2 C29 N9 154.21(12) ... ?

N10 Ti2 C29 N9 -175.69(19) . . . ?

N8 Ti2 C29 N9 $101.57(13) \ldots$ ? 
C22 Ti2 C29 N9 125.09(12) ... ?

N11 Ti2 C29 C28 -124.8(7) ... ?

N12 Ti2 C29 C28 -18.4(7) ... ?

N7 Ti2 C29 C28 129.7(7) ....?

N9 Ti2 C29 C28 -24.5(6) ... . ?

N10 Ti2 C29 C28 159.8(7) ... . ?

N8 Ti2 C29 C28 77.1(7) ...?

C22 Ti2 C29 C28 100.6(7) ... ?

C29 N10 C30 C32 -153.21(19) ....?

Ti2 N10 C30 C32 19.5(3) ....?

C29 N10 C30 C31 84.3(2) ... ? ?

Ti2 N10 C30 C31 -103.1(3) ....?

_diffrn_measured_fraction_theta_max 0.996

_diffrn_reflns_theta_full 25.00

_diffrn_measured_fraction_theta_full 1.000

_refine_diff_density_max 0.409

_refine_diff_density_min -0.251

_refine_diff_density_rms 0.055 


\section{A.12 Compound 22}

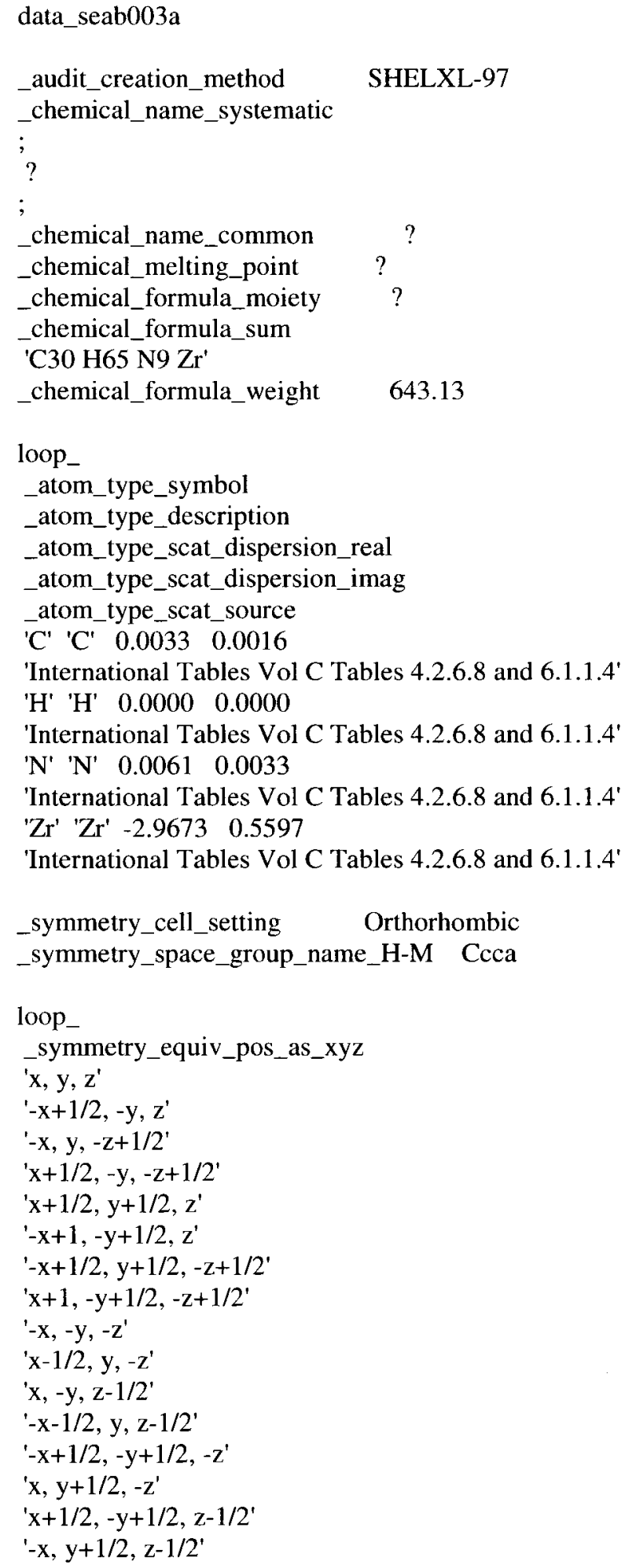




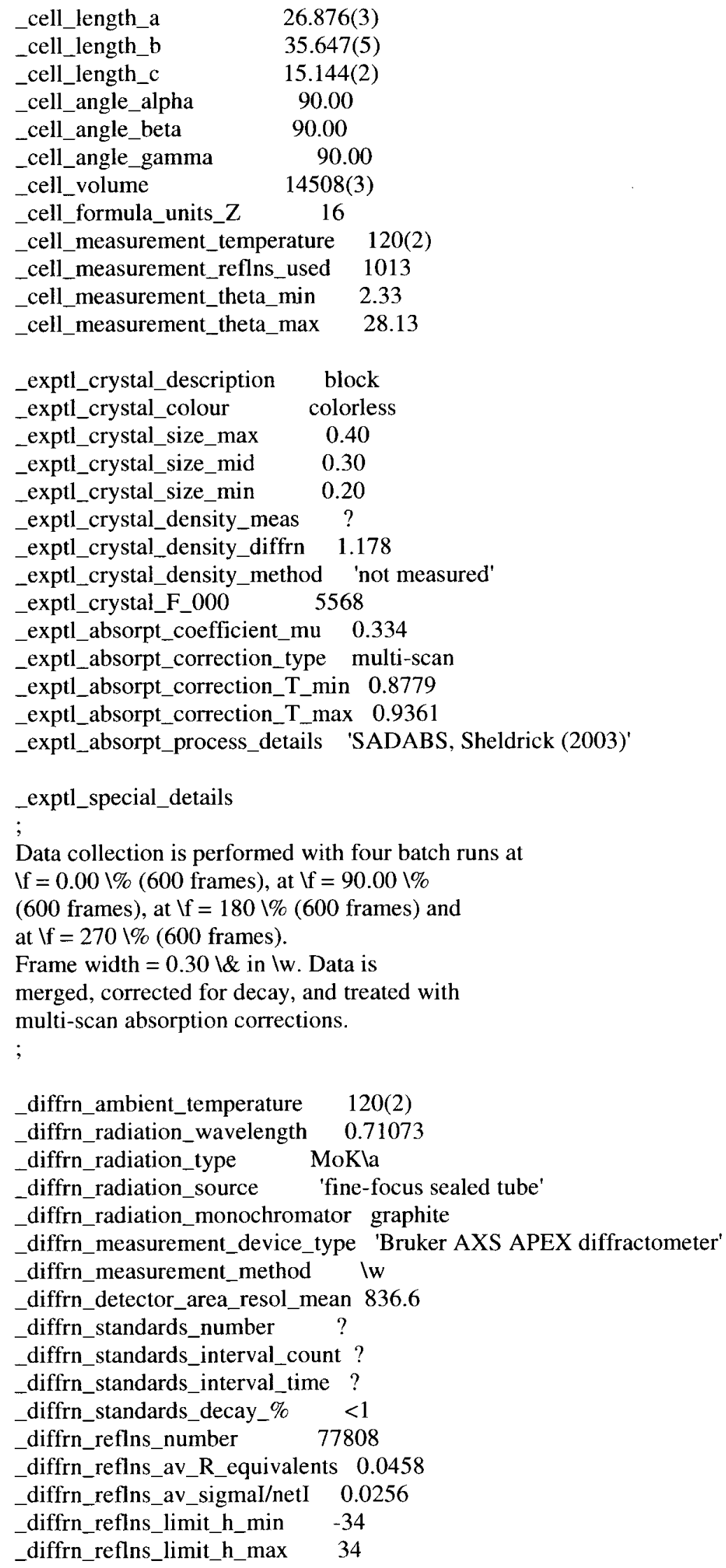




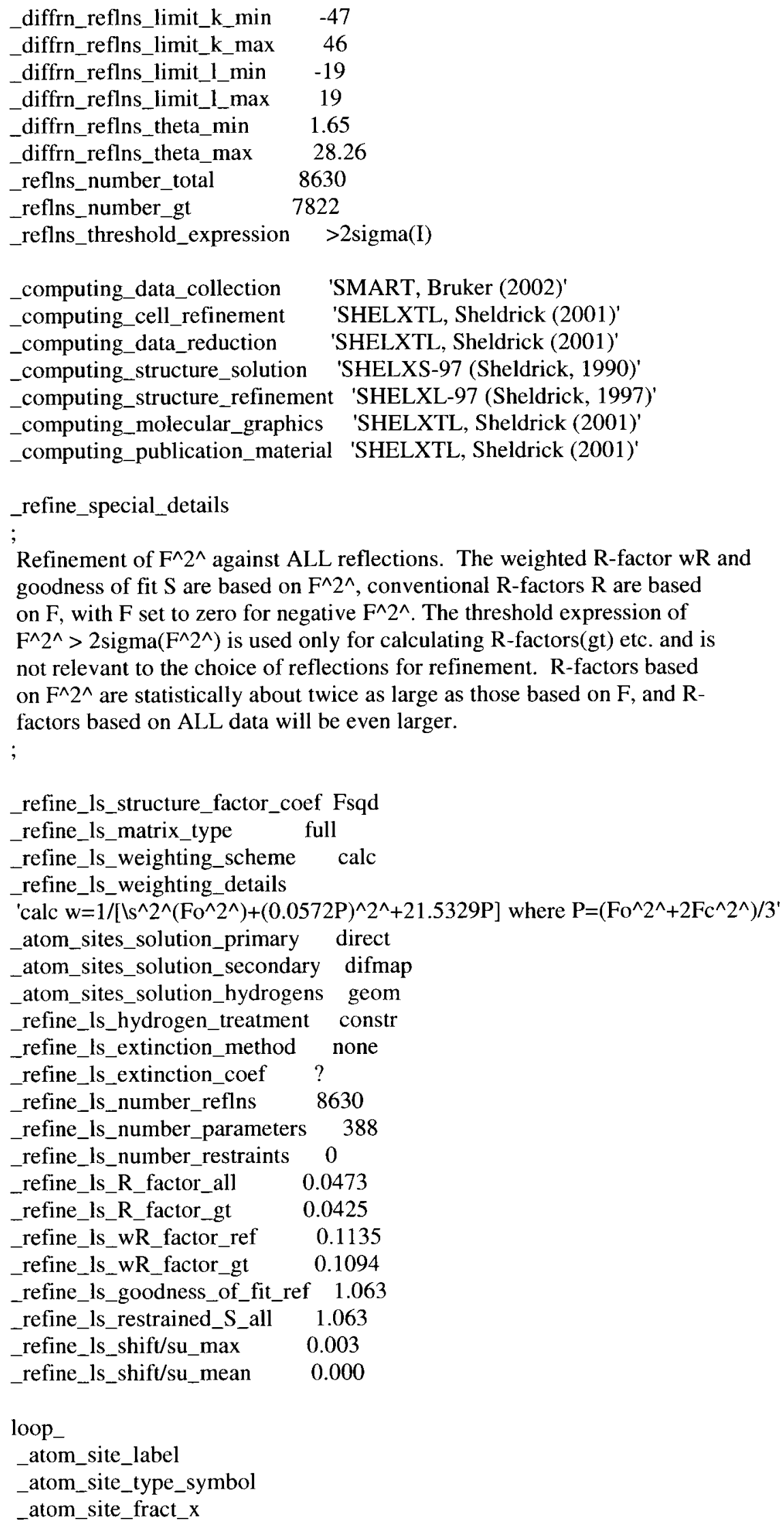




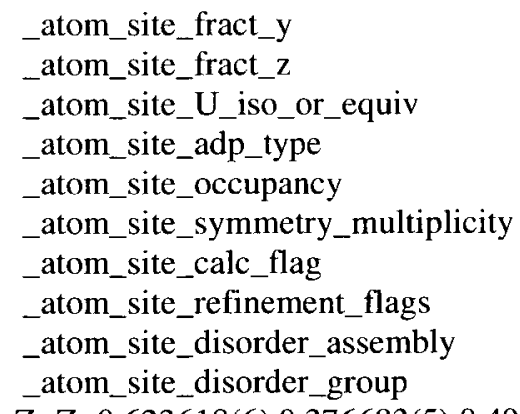

Zr Zr 0.623618(6) 0.376683(5) 0.491472(11) 0.01760(7) Uani $11 \mathrm{~d} \ldots$ N1 N 0.61787(5) 0.43306(4) 0.55186(9) 0.0176(3) Uani $11 \mathrm{~d}$. . . $\mathrm{N} 2 \mathrm{~N} 0.66947(5) 0.42339(4) 0.43764(9) 0.0163(3)$ Uani $11 \mathrm{~d} \ldots$ N3 N 0.65698(6) 0.48638(4) 0.48286(11) 0.0238(3) Uani $11 \mathrm{~d} \ldots$ H3D H 0.6768(13) 0.4928(10) 0.449(2) 0.029 Uiso $0.671 \mathrm{~d} \mathrm{P} \mathrm{.} \mathrm{.}$ N4 N 0.56345(5) 0.38263(4) 0.39683(9) 0.0177(3) Uani $11 \mathrm{~d}$. . . N5 N 0.61938(5) 0.33698(4) 0.38163(10) $0.0183(3)$ Uani $11 \mathrm{~d} \ldots$ N6 N 0.55814(6) 0.34757(5) 0.26462(10) 0.0291(4) Uani $11 \mathrm{~d} \ldots$ H6D H 0.5305(14) 0.3525(10) 0.261(2) 0.035 Uiso $0.671 \mathrm{~d}$ P . . N7 N 0.59714(6) 0.34515(4) 0.60654(10) 0.0244 (3) Uani $11 \mathrm{~d} \ldots$ $\mathrm{N} 8 \mathrm{~N} 0.67837(5) 0.34708(4) 0.57680(10) 0.0214(3)$ Uani $11 \mathrm{~d} \ldots$ N9 N $0.65718(8) 0.31879(5) 0.71184(11) 0.0358(4)$ Uani $11 \mathrm{~d} \ldots$ H9D H 0.6922(15) 0.3130(11) $0.723(3) 0.043$ Uiso $0.671 \mathrm{~d} \mathrm{P} \mathrm{.}$ C1 C 0.61309(7) 0.44906(5) 0.64108(11) 0.0235(4) Uani $11 \mathrm{~d} \ldots$ H1 H 0.60930 .47690 .63540 .028 Uiso 11 calc $\mathrm{R}$. . C2 C 0.56698(7) 0.43365(7) 0.68603(13) 0.0326(4) Uani $11 \mathrm{~d} \ldots$ H2A H 0.53740 .44060 .65180 .049 Uiso 11 calc $\mathrm{R}$. H2B H 0.56440 .44420 .74560 .049 Uiso 11 calc R . . H2C H 0.56930 .40630 .68970 .049 Uiso 11 calc R . . C3 C 0.66043(8) 0.44106(8) 0.69319(13) 0.0408(5) Uani $11 \mathrm{~d} \ldots$ H3A H 0.66530 .41390 .69780 .061 Uiso 11 calc R. . H3B H 0.65750 .45180 .75250 .061 Uiso 11 calc $R$. . H3C H 0.68900 .45230 .66280 .061 Uiso 11 calc R . C4 C 0.64852(6) 0.44935(5) 0.49176(11) 0.0174(3) Uani $11 \mathrm{~d} \ldots$ C5 C 0.62243(7) 0.51641(6) 0.50825(13) 0.0259(4) Uani $11 \mathrm{~d} \ldots$ H5 H 0.59160 .50480 .53300 .031 Uiso 11 calc $R$. . C6 C 0.60844(9) 0.53883(7) 0.42665(16) 0.0422(6) Uani $11 \mathrm{~d}$. . . H6A H 0.63830 .55070 .40200 .063 Uiso 11 calc R . . H6B H 0.58430 .55820 .44270 .063 Uiso 11 calc R . . H6C H 0.59370 .52210 .38250 .063 Uiso 11 calc R . . C7 C 0.64528(10) 0.54155(6) 0.57812(16) 0.0446(6) Uani $11 \mathrm{~d} \ldots$ H7A H 0.65490 .52640 .62930 .067 Uiso 11 calc $R$. . H7B H 0.62090 .56050 .59640 .067 Uiso 11 calc $R$. . H7C H 0.67480 .55400 .55380 .067 Uiso 11 calc R . . C8 C 0.69648(6) 0.43597(5) 0.35891(11) 0.0201(3) Uani $11 \mathrm{~d} \ldots$ H8 H 0.67860 .45800 .33330 .024 Uiso 11 calc $R$. . C9 C 0.74979(7) 0.44804(5) 0.38202(13) 0.0268(4) Uani $11 \mathrm{~d} \ldots$ H9A H 0.74910 .46490 .43300 .040 Uiso 11 calc R. . H9B H 0.76460 .46110 .33140 .040 Uiso 11 calc $R$. . H9C H 0.76970 .42580 .39630 .040 Uiso 11 calc R . . C10 C 0.69769(8) 0.40473(5) 0.28998(12) 0.0297(4) Uani $11 \mathrm{~d} \ldots$ H10A H 0.71390 .38250 .31510 .044 Uiso 11 calc R . . H10B H 0.71630 .41320 .23810 .044 Uiso 11 calc R . . H10C H 0.66360 .39840 .27250 .044 Uiso 11 calc R . . C11 C 0.53199(6) 0.41268(5) 0.36041(11) 0.0200 (3) Uani $11 \mathrm{~d} \ldots$ H1 1 H 0.50550 .40100 .32310 .024 Uiso 11 calc R. . 
C12 C 0.50694(7) 0.43406(6) 0.43525(13) 0.0291(4) Uani $11 \mathrm{~d} \ldots$ H12A H 0.48770 .41660 .47160 .044 Uiso 11 calc R. . H12B H 0.48470 .45310 .41060 .044 Uiso 11 calc R . . H12C H 0.53240 .44620 .47170 .044 Uiso 11 calc R . . C13 C 0.56244(7) 0.43944(5) 0.30249(13) 0.0268(4) Uani $11 \mathrm{~d}$. . H13A H 0.58860 .45110 .33810 .040 Uiso 11 calc R . . H13B H 0.54060 .45890 .27850 .040 Uiso 11 calc $R$. . H13C H 0.57760 .42540 .25380 .040 Uiso 11 calc R . . C14 C 0.57978(6) 0.35426(5) 0.34171(11) 0.0175(3) Uani $11 \mathrm{~d} \ldots$ C15 C 0.58045(7) 0.32789(5) 0.18970(11) 0.0228(4) Uani $11 \mathrm{~d} \ldots$ H15 H 0.61310 .31700 .20850 .027 Uiso 11 calc R . C16 C 0.58933(10) 0.35530(7) 0.11482(15) 0.0450(6) Uani $11 \mathrm{~d} \ldots$ H16A H 0.55750 .36600 .09570 .067 Uiso 11 calc R . . H16B H 0.60500 .34220 .06520 .067 Uiso 11 calc R . . H16C H 0.61130 .37550 .13510 .067 Uiso 11 calc R . . C17 C 0.54663(10) 0.29656(7) 0.15981(19) 0.0525(7) Uani $11 \mathrm{~d} \ldots$ H17A H 0.54350 .27800 .20710 .079 Uiso 11 calc R . . H17B H 0.56070 .28460 .10720 .079 Uiso 11 calc R . . H17C H 0.51370 .30680 .14570 .079 Uiso 11 calc R . . C18 C $0.63602(7) 0.29867(5) 0.36071(12) 0.0214(3)$ Uani $11 \mathrm{~d} \ldots$ H18 H 0.61350 .28800 .31450 .026 Uiso 11 calc $R$. . C19 C 0.68896(8) 0.29927(6) 0.32472(15) 0.0322(4) Uani $11 \mathrm{~d} \ldots$ H19A H 0.68980 .31380 .26980 .048 Uiso 11 calc R . . H19B H 0.69990 .27350 .31290 .048 Uiso 11 calc R . . H19C H 0.71110 .31080 .36830 .048 Uiso 11 calc R . . C20 C 0.63316(8) 0.27392(5) 0.44265(13) 0.0301(4) Uani $11 \mathrm{~d}$. . H20A H 0.65470 .28430 .48880 .045 Uiso 11 calc R . . H20B H 0.64420 .24850 .42780 .045 Uiso 11 calc R. . H20C H 0.59870 .27310 .46400 .045 Uiso 11 calc R . . C21 C 0.55085(7) 0.33069(6) 0.64501(13) 0.0304(4) Uani $11 \mathrm{~d} \ldots$ H21 H 0.54890 .33920 .70790 .036 Uiso 11 calc R . . C22 C 0.50696(8) 0.34735(8) 0.59477(15) 0.0433(6) Uani $11 \mathrm{~d} \ldots$ H22A H 0.50780 .37480 .59960 .065 Uiso 11 calc R . . H22B H 0.47580 .33790 .61990 .065 Uiso 11 calc R . . H22C H 0.50910 .34010 .53250 .065 Uiso 11 calc R . . C23 C 0.54848(10) 0.28788(7) $0.64320(16) 0.0461(6)$ Uani $11 \mathrm{~d} \ldots$ H23A H 0.54610 .27930 .58190 .069 Uiso 11 calc R. . H23B H 0.51920 .27940 .67620 .069 Uiso 11 calc R . . H23C H 0.57860 .27760 .67040 .069 Uiso 11 calc R . . C24 C 0.64329(7) 0.33619(5) 0.63636(12) 0.0237(4) Uani $11 \mathrm{~d} \ldots$ C25 C 0.73129(7) 0.34379(5) 0.59798(13) 0.0256(4) Uani $11 \mathrm{~d} \ldots$ $\mathrm{H} 25 \mathrm{H} 0.73600 .35050 .66160 .031$ Uiso 11 calc R . . C26 C 0.76047(8) 0.37149(6) 0.54205(16) 0.0363(5) Uani $11 \mathrm{~d} \ldots$ H26A H 0.75620 .36530 .47940 .054 Uiso 11 calc R . . H26B H 0.79580 .37010 .55760 .054 Uiso 11 calc R . . H26C H 0.74820 .39690 .55300 .054 Uiso 11 calc R. . C27 C 0.75125(8) 0.30403(6) 0.58326(15) 0.0351(5) Uani $11 \mathrm{~d} \ldots$ H27A H 0.73170 .28620 .61830 .053 Uiso 11 calc R. . H27B H 0.78620 .30290 .60150 .053 Uiso 11 calc R . . H27C H 0.74860 .29760 .52050 .053 Uiso 11 calc R. . C28 C 0.63215(8) 0.31844(6) 0.79704(13) 0.0335(4) Uani $11 \mathrm{~d} \ldots$ $\mathrm{H} 28 \mathrm{H} 0.59690 .31030 .78800 .040$ Uiso 11 calc R . C29 C 0.63199(10) 0.35697(7) 0.84028(15) 0.0436(6) Uani $11 \mathrm{~d} \ldots$ H29A H 0.66630 .36580 .84710 .065 Uiso 11 calc $R$. . H29B H 0.61610 .35530 .89840 .065 Uiso 11 calc R . . H29C H 0.61340 .37460 .80310 .065 Uiso 11 calc R. . 
C30 C 0.65827(9) 0.28969(7) 0.85521(14) 0.0415(5) Uani $11 \mathrm{~d} \ldots$ H30A H 0.65750 .26510 .82630 .062 Uiso 11 calc R . . H30B H 0.64120 .28810 .91230 .062 Uiso 11 calc $R$. . H30C H 0.69290 .29740 .86450 .062 Uiso 11 calc R . .

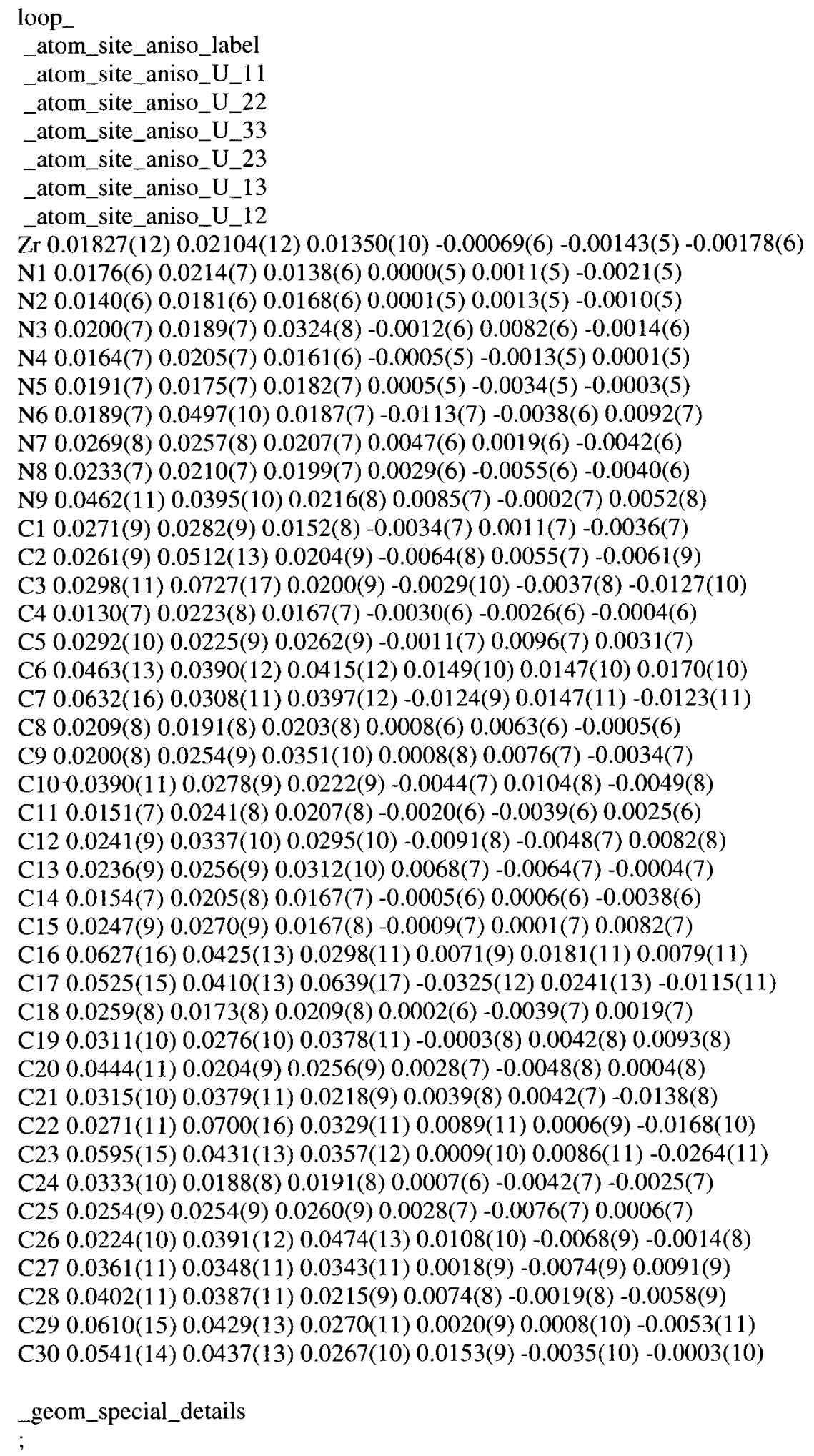


All esds (except the esd in the dihedral angle between two 1.s. planes) are estimated using the full covariance matrix. The cell esds are taken into account individually in the estimation of esds in distances, angles and torsion angles; correlations between esds in cell parameters are only used when they are defined by crystal symmetry. An approximate (isotropic) treatment of cell esds is used for estimating esds involving l.s. planes.

;

loop

_geom_bond_atom_site_label_1

_geom_bond_atom_site_label_2

_geom_bond_distance

_geom_bond_site_symmetry_2

_geom_bond_publ_flag

Zr N4 2.1711(14).?

Zr N5 2.1871(15).?

Zr N7 2.1925(15).?

Zr N1 2.2134(15).?

Zr N8 2.2246(15).?

Zr N2 2.2260(13).?

$\mathrm{Zr} \mathrm{C4} 2.6754(17)$. ?

Zr C14 2.6779(17) . ?

$\mathrm{Zr} \mathrm{C24} \mathrm{2.6790(18)} \mathrm{.} \mathrm{?}$

N1 C4 1.358(2). ?

N1 C1 1.472(2). ?

N2 C4 1.358(2). ?

N2 C8 1.466(2).?

N3 C4 1.346(2) . ?

N3 C5 1.469(2). ?

N4 C14 1.383(2) . ?

N4 C1 1 1.472(2). ?

N5 C14 1.370(2). ?

N5 C18 1.472(2) . ?

N6 C14 1.326(2) . ?

N6 C15 1.462(2). ?

N7 C24 1.358(2) . ?

N7 C21 1.467(2). ?

N8 C24 1.361(2).?

N8 C25 1.463(2). ?

N9 C24 1.353(2).?

N9 C28 1.455(3).?

C1 C2 1.517(3).?

C1 C3 1.524(3). ?

C5 C7 1.516(3).?

C5 C6 1.519(3).?

C8 C10 1.527(2).?

C8 C9 1.536(2).?

C11 C12 1.523(2). ?

C11 C13 1.533(2). ?

C15 C17 1.509(3) . ?

C15 C16 1.516(3) . ?

C18 C19 1.524(3) . ?

C18 C20 1.524(3).?

$\mathrm{C} 21 \mathrm{C} 22$ 1.524(3).?

C21 C23 1.527(3).?

C25 C26 1.519(3).? 
C25 C27 1.532(3). ?

C28 C30 1.523(3). ?

C28 C29 1.521(3). ?

loop

_geom_angle_atom_site_label_1

_geom_angle_atom_site_label_2

_geom_angle_atom_site_label_3

_geom_angle

_geom_angle_site_symmetry_1

_geom_angle_site_symmetry_3

_geom_angle_publ_flag

N4 Zr N5 61.47(5) . . ?

N4 Zr N7 109.44(6)..?

N5 Zr N7 104.81(6) . .?

N4 Zr N1 97.60(5) .. ?

N5 Zr N1 153.93(5) . . ?

N7 Zr N1 96.58(6) . . ?

N4 Zr N8 157.28(5) . . ?

N5 Zr N8 99.74(5) . . ?

N7 Zr N8 60.65(6) . . ?

N1 Zr N8 103.71(5) .. ?

N4 Zr N2 95.60(5) . . ?

N5 Zr N2 103.56(5) .. ?

N7 Zr N2 148.68(6) . . ?

N1 Zr N2 60.71(5) . . ?

N8 Zr N2 101.62(5) ..?

$\mathrm{N} 4 \mathrm{ZrC4} 95.33(5) \ldots$ ?

N5 Zr C4 129.86(5) . . ?

N7 Zr C4 125.20(5) ..?

N1 Zr C4 30.42(5) .. ?

$\mathrm{N} 8 \mathrm{Zr} \mathrm{C} 4$ 107.03(5) . . ?

N2 Zr C4 30.45(5) .. ?

N4 Zr C14 30.95(5) . . ?

N5 Zr C14 30.66(5) .. ?

N7 Zr C14 112.16(5) .. ?

N1 Zr C14 126.18(5) . . ?

N8 Zr C14 129.89(5) . . ?

$\mathrm{N} 2 \mathrm{ZrC} 14$ 99.02(5) . . ?

C4 Zr C14 113.61(5) . . ?

N4 Zr C24 137.75(6) . . ?

N5 Zr C24 106.53(6) . . ?

N7 Zr C24 30.33(6) . . ?

N1 Zr C24 99.47(5) . . ?

N8 Zr C24 30.47(6) . . ?

N2 Zr C24 126.42(5) . . ?

C4 Zr C24 118.10(5) .. ?

C14 Zr C24 128.29(5) .. ?

C4 N1 C1 120.16(14) .. ?

C4 N1 Zr 93.96(10) . . ?

C1 N1 Zr 137.48(12) . . ?

C4 N2 C8 119.17(14) . . ?

C4 N2 Zr 93.40(10) . . ?

C8 N2 Zr 143.20(11) . . ?

C4 N3 C5 125.59(15)..?

C14 N4 C11 119.23(14) . . ? 
C14 N4 Zr 95.21(10) . .? C11 N4 Zr 138.26(11) .. ? C14 N5 C18 123.93(14) . .? C14 N5 Zr 94.88(10) . . ? C18 N5 Zr 138.47(11) .. ? C14 N6 C15 126.12(15) . . ? C24 N7 C21 124.05(16) .. ? C24 N7 Zr 95.06(11)..? C21 N7 Zr 140.44(12) .. ? C24 N8 C25 120.35(15) .. ? C24 N8 Zr 93.55(11) .. ? C25 N8 Zr 143.96(12) .. ? C24 N9 C28 128.71(19) .. ? N1 C1 C2 110.05(15) . . ? N1 C1 C3 109.25(16) .. ? C2 C1 C3 112.44(16) . . ? N3 C4 N1 126.07(16)..? N3 C4 N2 122.53(15)..? N1 C4 N2 111.38(15)..? N3 C4 Zr 172.51(13) . .? N1 C4 Zr 55.62(9) .. ?

$\mathrm{N} 2 \mathrm{C} 4 \mathrm{Zr} 56.16(8) \ldots$ ? N3 C5 C7 110.94(17) . . ? N3 C5 C6 109.10(16) . . ? C7 C5 C6 110.9(2) .. ? N2 C8 C10 110.09(14) ..? N2 C8 C9 111.23(14) ..? C10 C8 C9 109.88(15) . . ? N4 C11 C12 109.84(14) . . ? N4 C11 C13 111.13(14) .. ? C12 C11 C13 110.53(16) ..? N6 C14 N5 130.41(16) . . ? N6 C14 N4 121.60(15)..? N5 C14 N4 107.99(14) ..? N6 C14 Zr 172.94(14) .. ? N5 C14 Zr 54.46(8) . . ? N4 C14 Zr 53.84(8) . . ? N6 C15 C17 109.91(16) . . ? N6 C15 C16 109.63(16) . .? C17 C15 C16 110.32(19) . . ? N5 C18 C19 110.34(15) . . ? N5 $\mathrm{C} 18 \mathrm{C} 20110.27(15) \ldots$ ? C19 C18 C20 110.27(16) . . ? N7 C21 C22 108.73(16) . . ? N7 C21 C23 112.28(18) ..? C22 C21 C23 110.37(19) . . ? N9 C24 N7 129.83(18) . .? N9 C24 N8 119.96(18) . .? N7 C24 N8 110.20(15) . . ? N9 C24 Zr 173.40(15) ...? N7 C24 Zr 54.61(9) .. ? N8 C24 Zr 55.97(9) . . ? N8 C25 C26 109.13(15) .. ? N8 C25 C27 112.49(16) . .? C26 C25 C27 109.84(18) . . ? N9 C28 C30 107.79(19) . . ? 
N9 C28 C29 112.04(18) . . ?

C30 C28 C29 111.08(19) . . ?

loop_

_geom_torsion_atom_site_label_1 _geom_torsion_atom_site_label_2

_geom_torsion_atom_site_label_3

_geom_torsion_atom_site_label_4

_geom_torsion

_geom_torsion_site_symmetry_1

_geom_torsion_site_symmetry_2

_geom_torsion_site_symmetry_3

_geom_torsion_site_symmetry_4

_geom_torsion_publ_flag

N4 Zr N1 C4 -87.59(10) . . . ?

N5 Zr N1 C4 -53.07(16) . . . ?

N7 Zr N1 C4 161.71(10) ... . ?

N8 Zr N1 C4 100.38(10) . . . ?

N2 Zr N1 C4 4.59(9) ... . ?

C14 Zr N1 C4 -74.60(11)... . ?

C24 Zr N1 C4 131.21(10) . . . ?

N4 Zr N1 C1 127.25(16) . . . ?

N5 Zr N1 C1 161.78(15) ... . ?

N7 Zr N1 C1 16.56(17) . . . ?

N8 Zr N1 C1 $-44.77(17) \ldots$. ?

N2 Zr N1 C1 -140.56(18) ....?

C4 Zr N1 C1 -145.2(2) . . . ?

C14 Zr N1 C1 140.25(15) . . . ?

C24 Zr N1 C1 -13.94(17).... ?

N4 Zr N2 C4 91.00(10) . . . ?

N5 Zr N2 C4 152.96(9) ... . ?

N7 Zr N2 C4 -52.58(15) ... . ?

N1 Zr N2 C4 -4.59(9) ... . ?

N8 Zr N2 C4 -103.91(10) ... ?

C14 Zr N2 C4 122.02(10) ... . ?

C24 Zr N2 C4 -84.26(11)....?

N4 Zr N2 C8 -62.42(18) ... . ?

N5 Zr N2 C8 $-0.46(19) \ldots$ ?

N7 Zr N2 C8 $154.00(16) \ldots$ ?

N1 Zr N2 C8 -158.01(19) ... . ?

N8 Zr N2 C8 102.67(18) ... ?

C4 Zr N2 C8 - 153.4(2) ... . ?

C14 Zr N2 C8 -31.41(18) ... . ?

C24 Zr N2 C8 122.32(17) . . . ?

N5 Zr N4 C14 -4.20(9) . . . ?

N7 Zr N4 C14 -100.90(10) ... . ?

N1 Zr N4 C14 159.33(10) ... . ?

N8 Zr N4 C14 -41.08(19) . . . . ?

N2 Zr N4 C14 98.20(10) . . . . ?

C4 Zr N4 C14 128.79(10) . . . . ?

C24 Zr N4 C14 -87.48(12) . . . . ?

N5 Zr N4 C11 -151.21(18) ... . ?

N7 Zr N4 C11 112.09(16) . . . ?

N1 Zr N4 C11 12.32(17) .... ?

N8 Zr N4 C11 171.91(15) . . . ?

N2 Zr N4 C11 -48.80(17) ... . ? 
$\mathrm{C} 4 \mathrm{Zr}$ N4 C11 -18.21(17) ... . ?

C14 Zr N4 C11 -147.0(2) ....?

$\mathrm{C} 24 \mathrm{Zr}$ N4 C11 125.51(16) ....?

N4 Zr N5 C14 4.24(9) ....?

N7 Zr N5 C14 108.60(10) ... . ?

N1 Zr N5 C14 -35.51(17) . . . ? ?

N8 Zr N5 C14 170.63(10) ... . ?

N2 Zr N5 C14 -84.80(10) ... ? ?

C4 Zr N5 C14 -67.33(11) ... ? ?

C24 Zr N5 C14 140.09(10) ... . ?

N4 Zr N5 C18 -156.04(19) ... . ?

N7 Zr N5 C18 -51.68(18) ... ? ?

N1 Zr N5 C18 164.21(15) ....?

N8 Zr N5 C18 10.35(18) ...? ?

N2 Zr N5 C18 114.92(17) ... ? ?

C4 Zr N5 C18 132.39(16) ... . ?

C14 Zr N5 C18 -160.3(2) .... ?

C24 Zr N5 C18 -20.19(18) . . . ? ?

N4 Zr N7 C24 162.00(10) ... . ?

N5 Zr N7 C24 97.50(11) ... . ?

$\mathrm{N} 1 \mathrm{Zr}$ N7 C24 $-97.53(11) \ldots$ ?

$\mathrm{N} 8 \mathrm{Zr}$ N7 C24 4.52(10) ... . ?

$\mathrm{N} 2 \mathrm{Zr}$ N7 C24 $-56.81(16) \ldots$ ?

C4 Zr N7 C24 -86.31(12)....?

C14 Zr N7 C24 128.96(10)....?

N4 Zr N7 C21 -9.8(2) ....?

N5 Zr N7 C21 -74.3(2) ....?

N1 Zr N7 C21 90.7(2) ....?

N8 Zr N7 C21 -167.3(2) ... ?

N2 Zr N7 C21 131.39(19) ... ?

C4 Zr N7 C21 101.9(2) ....?

$\mathrm{C} 14 \mathrm{Zr}$ N7 C21 -42.8(2)....?

C24 Zr N7 C21 -171.8(3).... ?

N4 Zr N8 C24 -73.77(18) ....?

N5 Zr N8 C24 -106.11(11)....?

N7 Zr N8 C24 -4.50(10) ... ? ?

N1 Zr N8 C24 85.39(11) ... . ?

N2 Zr N8 C24 $147.75(10) \ldots$. ?

C4 Zr N8 C24 116.78(10) ... . ?

$\mathrm{C} 14 \mathrm{Zr}$ N8 C24 -99.90(11).... ?

N4 Zr N8 C25 125.2(2) ... ?

N5 Zr N8 C25 92.9(2)....?

N7 Zr N8 C25 -165.5(2)....?

N1 Zr N8 C25 -75.6(2) ....?

$\mathrm{N} 2 \mathrm{Zr}$ N8 C25 -13.3(2)...? ?

C4 Zr N8 C25 -44.2(2)....?

C14 Zr N8 C25 99.1(2)....?

$\mathrm{C} 24 \mathrm{Zr}$ N8 C25-161.0(3) ... ? ?

C4 N1 C1 C2 163.55(16) ....?

Zr N1 C1 C2 -57.7(2) ...? ?

C4 N1 C1 C3 -72.5(2).... ?

$\mathrm{ZrN1} \mathrm{Cl} \mathrm{C} 3$ 66.2(2)....?

C5 N3 C4 N1 -26.2(3)....?

C5 N3 C4 N2 151.73(17) ... ?

C5 N3 C4 Zr 74.3(10) ....?

$\mathrm{C} 1 \mathrm{~N} 1 \mathrm{C} 4 \mathrm{~N} 3-35.5(2) \ldots$ ? 


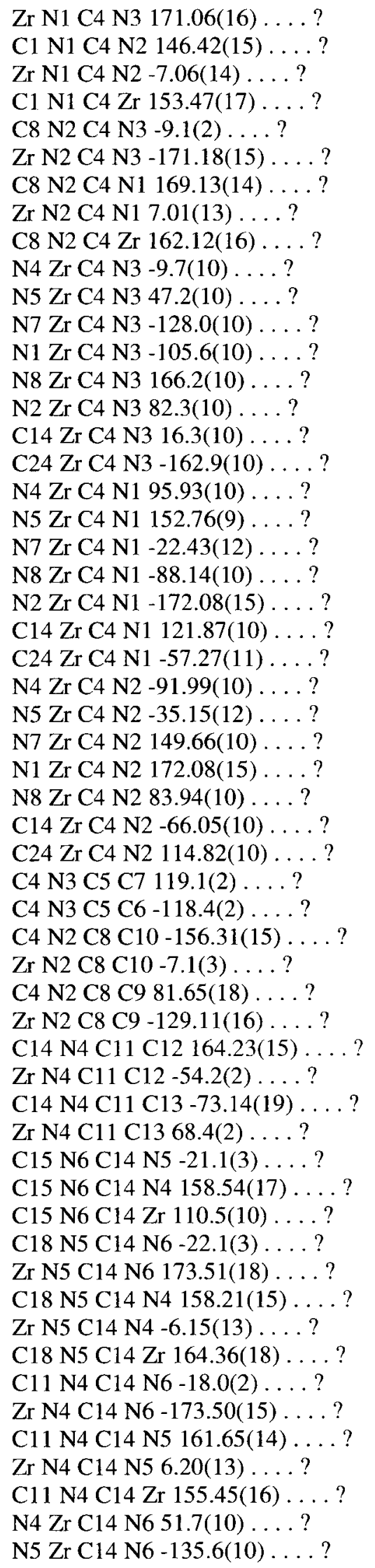


N7 Zr C14 N6 142.8(10) . . . ?

N1 Zr C14 N6 26.0(10) .... ?

N8 Zr C14 N6 -147.6(10) ....?

N2 Zr C14 N6 -34.2(10) ... ? ?

C4 Zr C14 N6 -6.2(10) .... ?

C24 Zr C14 N6 172.8(10) ....?

N4 Zr C14 N5 -172.75(15) ... ? ?

N7 Zr C14 N5 -81.62(11)....?

$\mathrm{N} 1 \mathrm{ZrC14}$ N5 161.56(9) ... . ?

$\mathrm{N} 8 \mathrm{Zr}$ C14 N5 -12.07(12) ....?

N2 Zr C14 N5 101.41(10) ... ?

C4 Zr C14 N5 129.37(10) ....?

C24 Zr C14 N5 -51.60(12) .... ?

N5 Zr C14 N4 172.75(15) ... ? ?

N7 Zr C14 N4 91.13(10) ... . ?

$\mathrm{N} 1 \mathrm{Zr}$ C14 N4 -25.69(12)....?

N8 Zr C14 N4 160.68(9) ... . ?

$\mathrm{N} 2 \mathrm{Zr}$ C14 N4 $-85.84(10) \ldots$ ?

$\mathrm{C} 4 \mathrm{ZrC14}$ N4 $-57.88(11) \ldots$ ?

C24 Zr C14 N4 121.15(10)....?

C14 N6 C15 C17 127.3(2) ... . ?

C14 N6 C15 C16-111.2(2) ....?

C14 N5 C18 C19 118.15(18) ... . ?

Zr N5 C18 C19 -85.8(2) ... ?

C14 N5 C18 C20 -119.79(18) ....?

Zr N5 C18 C20 36.3(2) ....?

C24 N7 C21 C22 179.29(18).... ?

Zr N7 C21 C22 -10.6(3) ... ?

C24 N7 C21 C23 -58.3(2)....?

$\mathrm{Zr}$ N7 C21 C23 111.8(2) ....?

C28 N9 C24 N7 -28.6(3) ....?

C28 N9 C24 N8 152.2(2) ....?

C28 N9 C24 Zr 101.7(13) ... . ?

C21 N7 C24 N9 -12.5(3)....?

Zr N7 C24 N9 173.83(19) ... . ?

C21 N7 C24 N8 166.83(17) ....?

Zr N7 C24 N8 -6.87(15) ... . ?

C21 N7 C24 Zr 173.7(2) ... . ?

C25 N8 C24 N9 -6.7(3) ....?

Zr N8 C24 N9 -173.86(16) ... . ?

C25 N8 C24 N7 173.96(15) ....?

Zr N8 C24 N7 6.76(15) ....?

C25 N8 C24 Zr 167.20(18) ....?

$\mathrm{N} 4 \mathrm{Zr}$ C24 N9 $-159.8(13) \ldots$ ?

N5 Zr C24 N9 134.7(13).... ?

N7 Zr C24 N9 -134.1(14)....?

N1 Zr C24 N9 -47.3(13) ....?

N8 Zr C24 N9 53.7(13) ....?

$\mathrm{N} 2 \mathrm{Zr}$ C24 N9 13.2(14)....?

$\mathrm{C} 4 \mathrm{Zr}$ C24 N9 $-21.7(13) \ldots$ ?

C14 Zr C24 N9 159.3(13) ... . ?

N4 Zr C24 N7 -25.69(14) ... ? ?

N5 Zr C24 N7 -91.21(11)... . ?

$\mathrm{N} 1 \mathrm{Zr}$ C24 N7 86.83(11)....?

N8 Zr C24 N7 -172.21(17) ... . ?

N2 Zr C24 N7 147.28(10) ... ? 
C4 Zr C24 N7 112.42(11) ... ?

C14 Zr C24 N7 -66.57(12) ... . ?

N4 Zr C24 N8 146.52(10) ... . ?

N5 Zr C24 N8 81.00(11) ... ?

N7 Zr C24 N8 172.21(17) ....?

$\mathrm{N} 1 \mathrm{Zr}$ C24 N8 -100.96(10)....?

$\mathrm{N} 2 \mathrm{Zr}$ C24 N8 $-40.51(12) \ldots$ ?

$\mathrm{C} 4 \mathrm{Zr} \mathrm{C} 24 \mathrm{~N} 8$-75.37(11)....?

C14 Zr C24 N8 105.64(11)... ?

C24 N8 C25 C26 -156.34(17) ....?

$\mathrm{Zr} \mathrm{N8} \mathrm{C} 25 \mathrm{C} 261.6(3) \ldots$ ?

C24 N8 C25 C27 81.5(2) ... . ?

$\mathrm{Zr} \mathrm{N8}$ C25 C27-120.6(2) ... . ?

C24 N9 C28 C30 170.8(2) ... . ?

C24 N9 C28 C29-66.7(3) ... ?

_diffrn_measured_fraction_theta_max 0.961

_diffrn_reflns_theta_full 25.00

_diffrn_measured_fraction_theta_full 1.000

_refine_diff_density_max 0.849

_refine_diff_density_min -0.356

_refine_diff_density_rms 0.068 